\title{
EFFECTS OF WASTE PLACEMENT PRACTICES ON THE ENGINEERING RESPONSE OF MUNICIPAL SOLID WASTE
}

\author{
A Thesis \\ presented to \\ the Faculty of California Polytechnic State University, \\ San Luis Obispo \\ In Partial Fulfillment \\ of the Requirements for the Degree \\ Master of Science in Civil and Environmental Engineering
}

by

Jason T. Cox

December 2013 
(C) 2013

Jason T. Cox

ALL RIGHTS RESERVED 


\section{COMMITTEE MEMBERSHIP}

TITLE:

Effects of Waste Placement Practices on the Engineering Response of Municipal Solid Waste

AUTHOR: $\quad$ Jason T. Cox

DATE SUBMITTED: December 2013

COMMITTEE CHAIR: James Hanson, Professor, Department of Civil and Environmental Engineering, California Polytechnic State University, San Luis Obispo

COMMITTEE MEMBER: Nazli Yesiller, Director, Global Waste Research Institute

COMMITTEE MEMBER: Samuel Vigil, Professor, Department of Civil and Environmental Engineering, California Polytechnic State University, San Luis Obispo 


\begin{abstract}
Effects of Waste Placement Practices on the Engineering Response of Municipal Solid Waste

Jason T. Cox

An extensive laboratory and field investigation was conducted at Santa Maria Regional Landfill (SMRL) in Santa Maria, California to determine the effects of waste placement practices on the engineering response of municipal solid waste (MSW). Laboratory and field testing was used to determine the engineering properties and monitor field response of MSW.
\end{abstract}

The specific gravity $\left(G_{s}\right)$ of manufactured MSW (MMSW), fresh MSW (FMSW), and old MSW (OMSW) was determined experimentally using a modified version of standard soil testing procedures. Effects of particle size, compactive effort, and degradation on the specific gravity of waste were evaluated. Specific gravity of manufactured waste samples increased with decreasing particle size, with compaction, and with increased degradation. The average specific gravity of uncompacted MMSW samples was 1.333, 1.374, and 1.424 for coarse, medium, and fine particle sizes, respectively. Specific gravity of coarse, medium, and fine MMSW samples compacted at dry of optimum ( $w_{d}=$ $30 \%)$ was determined to be $1.497,1.521$, and 1.552 , respectively and at wet of optimum $\left(w_{d}=90 \%\right)$ to be $1.500,1.542$, and 1.570 , respectively. The compacted and uncompacted specific gravity of fresh MSW was lower than manufactured and old MSW. The average $G_{s}$ of uncompacted and compacted fresh MSW was 1.072 and 1.208, respectively whereas old $M S W$ had $G_{s}$ of 2.201. 
Additional physical and engineering properties of MSW were determined for fresh and old wastes. A total of 8 magnetic extensometer settlement arrays and 4 thermocouple arrays were installed in old wastes. The settlement and temperature data were collected for an approximate duration of 1 year. In addition, laboratory experiments were conducted to determine the particle size distribution, organic content, and moisture content of fresh waste sampled from the active face of the landfill and from old waste sampled from different depths. The particle size distribution of OMSW was comparable to a well-graded coarsegrained soil. The average baseline moisture content of incoming MSW at SMRL was $42.7 \%$ (dry-weight basis). The average moisture content of residential MSW, commercial MSW, and self-delivered MSW were determined to be $57.7,46.3$, and $12.0 \%$, respectively. The organic content of fresh and old MSW was determined to be 77.2 and $23.5 \%$, respectively. Temperature increased over time due to heat generation of the waste mass. The temperature increased on average 3 to $6^{\circ} \mathrm{C}$ between the initial and final day of measurements for wastes that were 0.3 to 9 years old.

Fresh and old wastes at SMRL exhibited unique compression behavior. A majority of the waste was undergoing secondary compression characterized using a secondary compression ratio $\left(C_{\alpha}^{\prime}\right)$ ranging from 0.013 to 0.067 with an average of 0.030 . In addition, the fresh and old wastes exhibited recompression behavior. Fresh waste lifts were determined to be slightly overconsolidated such that the self-weight of the fresh waste was less than the preconsolidation stress. The old waste exhibited recompression behavior during loading and unloading of 
an earthen embankment. The modified recompression indices $\left(C_{r}^{\prime}\right)$ for fresh and old wastes were determined to be 0.076 and 0.012 , respectively. The initial compression ratio for old wastes $\left(C_{c, \text { old }}^{\prime}\right)$ was quantified for the old waste lifts to be between 0.069 and 0.332 .

Finally, meso- and full-scale field compaction experiments were conducted to determine the effects of systematic moisture addition prior to compaction on placement efficiency and compaction characteristics of MSW. Two $16 \times 46 \mathrm{~m}$ test plots were constructed for the meso-scale compaction tests. Approximately $890 \mathrm{kN}$ (100 tons) of residential MSW (RMSW) was placed into a test plot and compacted at target moisture contents of 55 (baseline as-received), $65,80,95$, and $110 \%$. Compaction curves generated for RMSW were bell shaped and similar to soil compaction curves. The maximum dry unit weight $\left(\gamma_{d \max }\right)$ and operational unit weight $\left(\gamma_{\text {oper-max }}\right)$ for the meso-scale compaction study were 8.5 and $13.3 \mathrm{kN} / \mathrm{m}^{3}$ with corresponding optimum moisture contents of $w_{\text {opt-dmax }}$ and $w_{\text {opt-oper }}, 78.5$ and $79.5 \%$, respectively. Moisture addition prior to compaction yielded beneficial waste placement results. An operational waste placement factor (OWPF) was defined as additional amount of waste that could be placed in one unit of volume. OWPF values were determined to be $1,1.33$, 1.66, 1.37, and 0.83 for RMSW compacted at target moisture contents of 55,65 , 85,90 , and $110 \%$, respectively.

The full scale compaction investigation was conducted in a similar manner to the meso-scale investigation. However, the compaction tests were conducted on the active face of the landfill and representative of the entire incoming daily 
waste stream. A daily average of $2940 \mathrm{kN}$ (330 tons) of MSW was placed and compacted at target moisture contents of 45 (baseline as-received), 65, 85, and 105\%. Compaction curves for the delivered MSW were bell shaped and similar to soil compaction curves. The maximum dry and operational unit weights for the full-scale test were 7.0 and $9.8 \mathrm{kN} / \mathrm{m}^{3}$, respectively corresponding to optimum moisture contents of $w_{\text {opt-dmax }}$ and $w_{\text {opt-oper }}, 76$ and $75.5 \%$, respectively. OWPFs were calculated to be $1,1.28,1.55$, and 0.80 for target moisture contents of $45,65,85$, and $105 \%$, respectively.

The spatial variability associated with moisture addition also was determined for the meso- and full-scale compaction tests and verified using test pits and spatial sampling of the surface of the active face. Particularly, the variations in degree of saturation $(S)$ and volumetric moisture content $(\theta)$ due to moisture addition were estimated. For waste compacted at target moisture contents of $55,65,80$, and $110 \%$ during the meso-scale tests, $S$ increased by $19,4.5,4.4$, and $4.3 \%$, respectively while $\theta$ increased by $28,7.7,8.1$, and $5.7 \%$, respectively. For the full scale compaction tests, $S$ increased by an average of $43 \%$ and $\theta$ increased by an average of $78 \%$. The average moisture content of waste at the surface after compaction at $45 \%$ moisture content (i.e., as-received) and at $80 \%$ moisture content (i.e., near optimum) were 34 and 133\%, respectively. The results of the investigation have environmental, operational, and financial implications such as extend the life of a landfill, ability to place more wastes in a unit landfill volume, and increasing $\theta$ to values above field capacity with moisture addition during compaction. 


\section{ACKNOWLEDGMENTS}

This study was funded by the City of Santa Maria and partially supported by the Global Waste Research Institute. I would like to thank Dr. Jim Hanson and Dr. Nazli Yesiller for their continued advice, guidance, and encouragement throughout the entire Master's program. I would especially like to thank Jeff Clarin for his continuous feedback, coordination of field experiments, and his willingness to improve the quality of the test program at all times. I would also like to thank the staff of Santa Maria Regional Landfill particularly Doug Shearer and Lance Llodes, for their cooperation and assistance during the test program. I would like to thank Dr. Sam Vigil for providing his time and serving on the thesis committee. I would also like to thank Taki Chrysovergis Michael Onen, Andy Flores, Derek Manheim, and Alex Sohn for their assistance with field instrumentation. Additionally, I would like to thank Danielle Noce for her assistance with laboratory and field testing. Finally, I would like to thank Lindsay Hoffman, Ryan Cox, and Laurene Cox for their support and encouragement throughout the entire process. 


\section{TABLE OF CONTENTS}

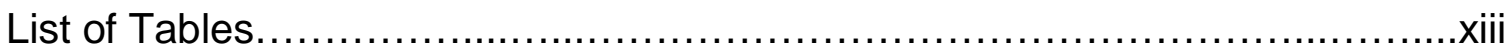

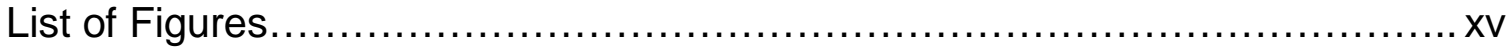

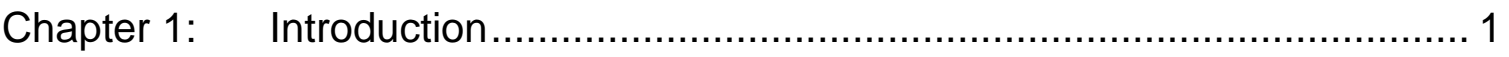

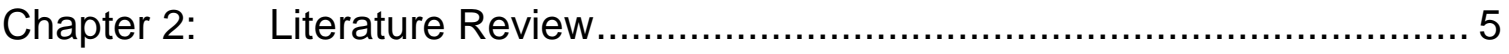

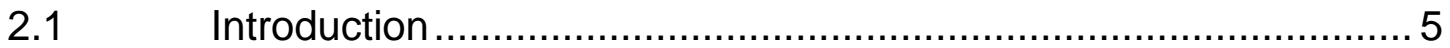

2.2 Waste Generation in the United States..................................... 5

2.3 Landfilling in the United States ........................................... 7

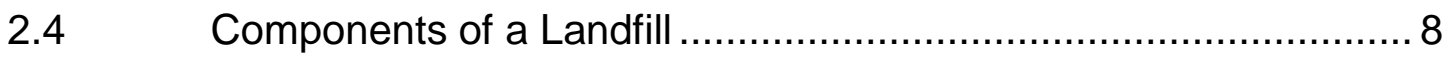

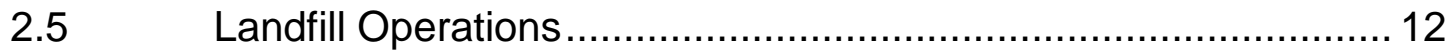

2.5 .1 Operating Schedule .......................................................... 13

2.5.2 Waste Placement Procedure ................................................ 13

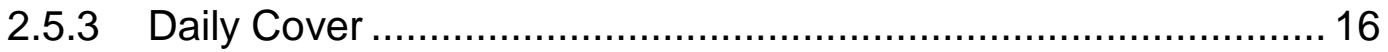

2.5.4 Equipment for Landfill Operations.......................................... 17

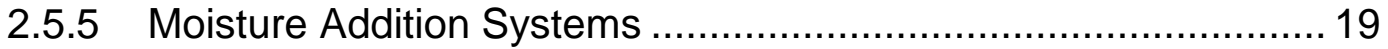

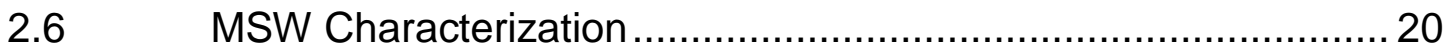

2.7 Fabric and Structure of MSW............................................... 24

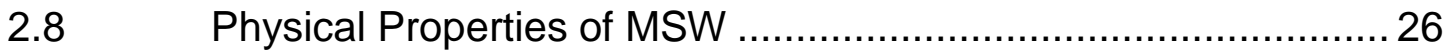

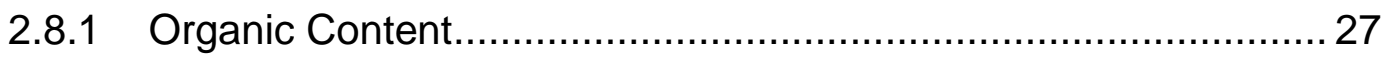

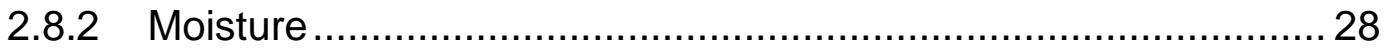

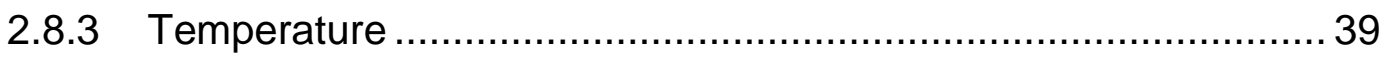

$2.9 \quad$ Specific Gravity ................................................................ 40 


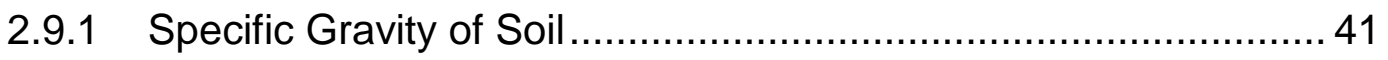

2.9.2 Specific Gravity of MSW ..................................................... 42

2.9.3 Relationship Between $G_{s}$ and Other Waste Properties............... 55

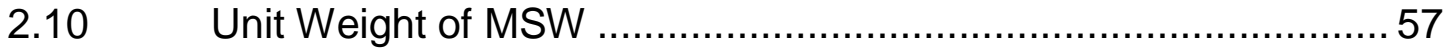

$2.11 \quad$ Settlement/Compressibility ................................................ 61

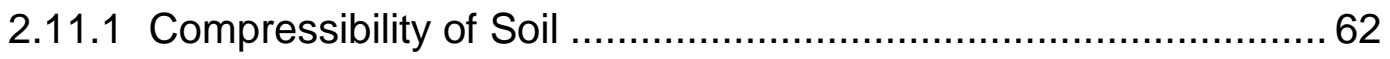

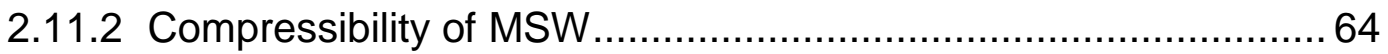

2.12 Hydraulic Conductivity and Shear Strength .............................. 90

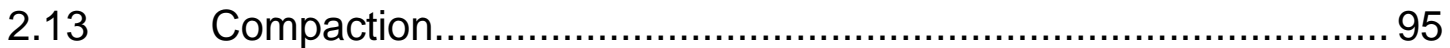

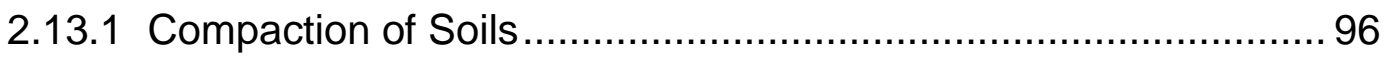

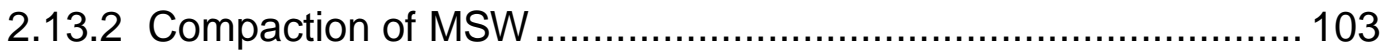

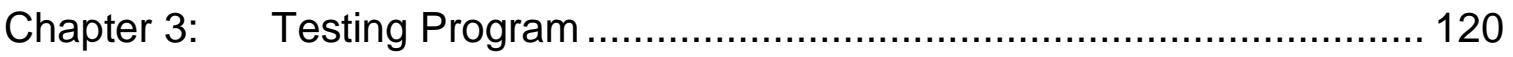

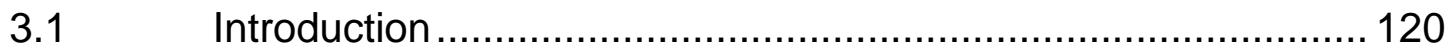

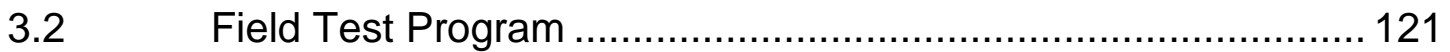

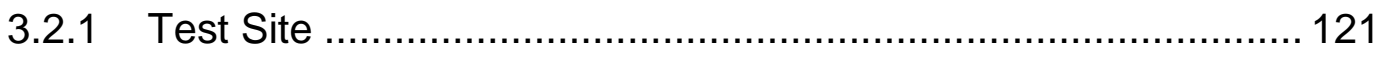

3.2.2 Waste Placement in Active Area (Cell 1) ............................... 126

3.2.3 Daily Operations and Baseline Conditions at SMRL ................ 127

3.2.4 Field Instrumentation and Monitoring.................................... 133

3.2.5 Meso-Scale Compaction Study ............................................ 150

3.2.6 Full-Scale Compaction Test.................................................... 162

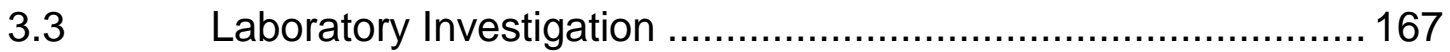

3.3.1 Determination of Specific Gravity of MSW ............................. 167

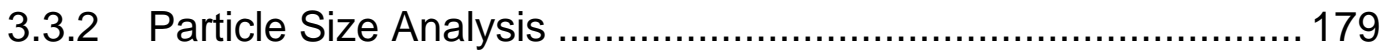


3.3.3 Organic Content (Loss on Ignition) ..................................... 181

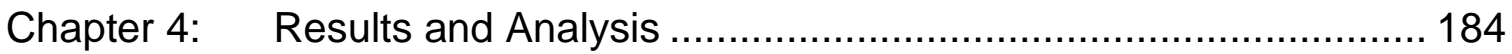

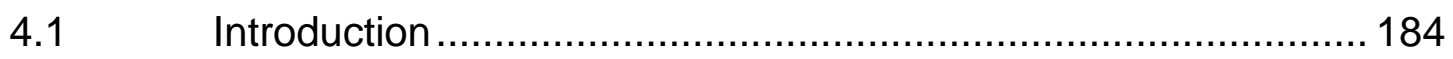

4.2 Particle Size Distribution ..................................................... 184

4.3 Baseline Moisture Conditions …........................................ 186

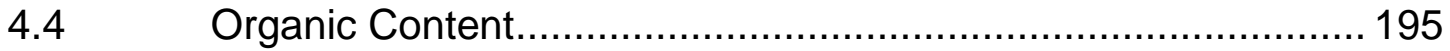

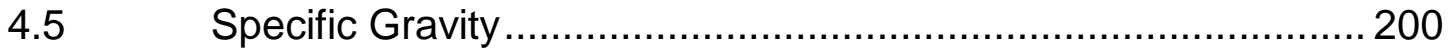

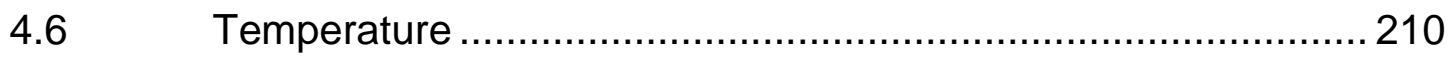

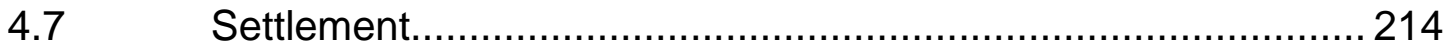

4.8 Field Compaction Investigation .............................................. 234

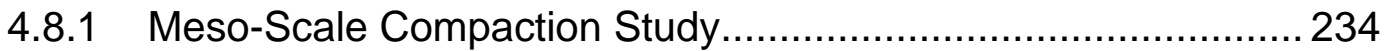

4.8.2 Full-Scale Compaction Study............................................... 247

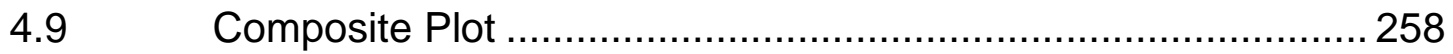

Chapter 5: Engineering Significance and Future Research...................... 267

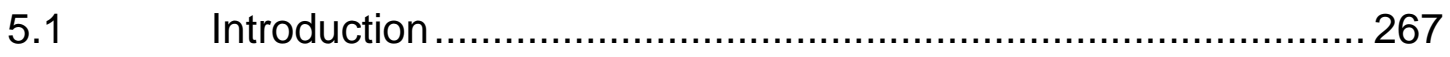

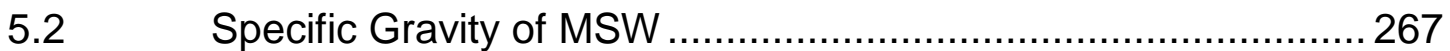

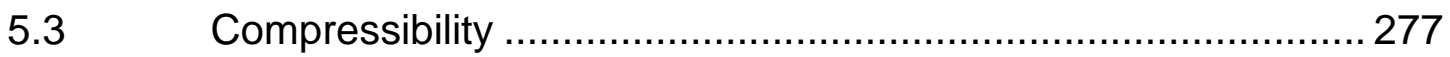

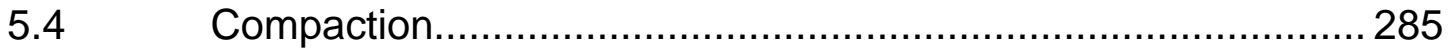

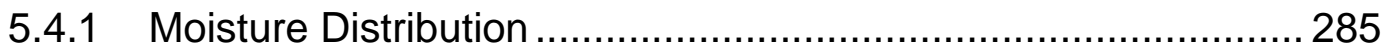

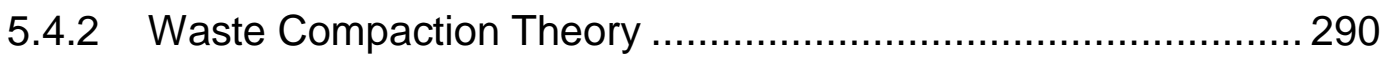

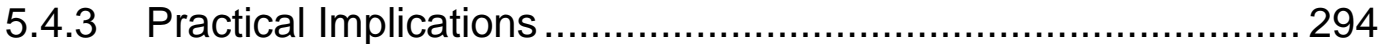

Chapter 6: Summary and Conclusions.................................................. 304

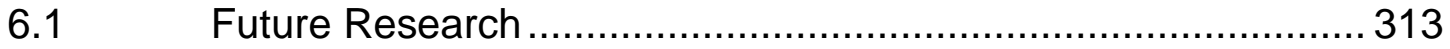


References

Appendix

333 


\section{List of Tables}

2.1 Breakdown of Individual MSW Constituents Disposed in U.S. Landfills .. 23

$2.2 G_{s}$ Values of MSW Reported in Literature............................................ 51

2.3 Methods for Determining Unit Weight of MSW ..................................... 58

$2.4 \quad$ Summary of MSW Compression Ratios.............................................. 73

2.5 Summary of Reported Strains Due to Mechanical Creep of MSW.......... 80

2.6 Comparison of the $C_{\propto M}^{\prime}$ and $C_{\propto B}^{\prime}$ Values for Both Conventional and Bioreactor Landfill Conditions ................................................................ 87

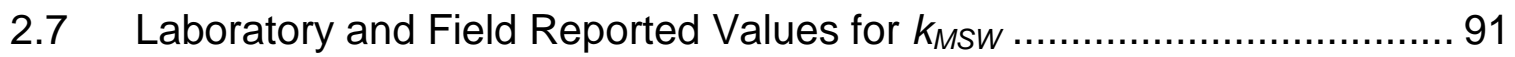

2.8 Reported $\emptyset^{\prime}$ and $c^{\prime}$ Values for MSW Shear Strength Characterization .... 95

2.9 Summary of Laboratory and Field Compaction Investigations............... 118

3.1 Description of the Four Distinct Sections at SMRL ............................ 123

3.2 MSW Placement Methods and Details at SMRL................................ 127

3.3 Onsite Equipment Used for Daily Operations at SMRL ….................. 128

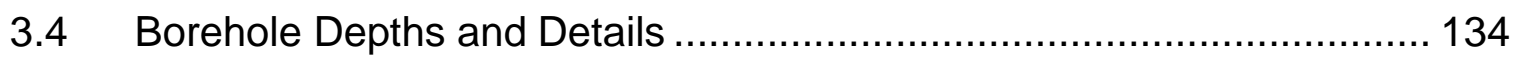

3.5 Moisture Addition Characteristics per Truckload of RMSW ................. 154

3.6 Meso-scale Compaction Study Schedule ........................................ 160

3.7 Full-Scale Compaction Study Schedule ............................................. 165

3.8 Overview of the Specific Gravity Experiments Conducted on MSW ...... 168

3.9 Properties of Manufactured MSW Specimens ................................... 171

3.10 Apparent Volume and Equivalent Diameter of Waste Constituents ....... 180

4.1 Particle Size Distribution Data for OMSW ......................................... 185

4.2 Moisture Content of OMSW Specimens ………................................ 189

4.3 Average Moisture Content of OMSW at Different Depths ..................... 193

4.4 Organic Content of FMSW Specimens ............................................. 196

4.5 Organic Content of OMSW Specimens.............................................. 197

4.6 Specific Gravity of Uncomapcted and Compacted FMSW................... 201

4.7 Specific Gravity for MMSW Specimens …….................................... 202

4.8 Particle Size Breakdown for MMSW Specimens …............................ 204

4.9 Measured Specific Gravity of OMSW Specimens ............................... 207

4.10 Summary of Changes in Waste Temperature Over Time .................... 211

4.11 Summary of Waste Strain Parameters and Data ................................ 222 
4.12 Embankment Unloading and Reloading Summary ........................... 226

$4.13 C_{c, \text { deg }}^{\prime}$ Values for the Bottom Lift of Boreholes 3, 6, and 7 .................. 227

4.14 Modified Recompression Index Properties of Fresh Waste Lifts............ 229

4.15 Compaction Data for Meso-scale Study........................................... 238

4.16 Volume Gain Due to Waste Penetration Effects ................................. 240

4.17 Summary of Meso-Scale Compaction Study ..................................... 242

4.18 Test Pit Measurements for Meso-Scale Compaction Study …............... 243

4.19 Moisture Characteristics of the Meso-Scale Compaction Study ............ 245

4.20 Full-Scale Compaction Study Data ................................................. 250

4.21 Summary of Field-Compaction Study …........................................ 253

4.22 Moisture Characteristics of the Full-Scale Compaction Study .............. 255

4.23 Spatial Moisture Content Results.................................................. 256

5.1 The Four Categories of Waste Constituents at MSW Landfills .............. 269

5.2 Reduction of Solids Volume due to Intraparticle Void Loss.................... 271

5.3 Reduction of Solids Volume of MMSW due to Intraparticle Void Loss... 273

5.4 Summary of Degree of Degradation and $\mathrm{G}_{\mathrm{S}}$ of MSW.......................... 275

5.5 $W C I$ and $C_{c}^{\prime}$ Values for Different Waste Placement Conditions .............. 279

5.6 Total Initial Compression with Varying Waste Placement Conditions .... 280

5.7 Long-Term Compression for Various Waste Placement Conditions ...... 282

5.8 Effects of Moisture Addition on Field Capacity for Meso-scale .............. 286

5.9 Effects of Moisture Addition on Field Capacity for Full-scale ................ 289

5.10 Additional Costs Associated with Systematic Moisture Addition ............ 298

5.11 Additional Revenue Associated with Systematic Moisture Addition....... 300

5.12 Settlement Induced Revenue Gain .................................................. 301

5.13 Comparison of Additional Costs and Revenues between Different Waste Placement Procedures and a Bioreactor Landfill ........................ 303 


\section{List of Figures}

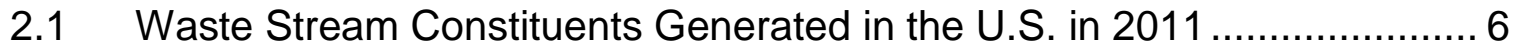

2.2 Percent of Waste Stream Discarded Into Landfills from 1960 to 2011 ...... 8

2.3 Typical Cross-section of a MSW Landfill............................................... 10

2.4 Example of Filling Procedure and the Subdivision of Cells at a Landfill... 14

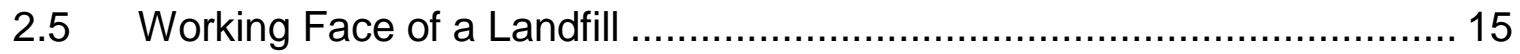

2.6 Vertical and Horizontal Orientation of Waste Placement at a Landfill ...... 16

2.7 Bulldozer with Trash Blade at a Landfill. ............................................. 18

$2.8 \quad$ Waste Compactor at a Landfill ........................................................ 19

2.9 Intraparticle Voids Present Within the Elemental Volume of Waste......... 25

2.10 Processes Affecting Moisture Distribution in MSW …........................... 36

2.11 Moisture Storage Tendency in a Landfill with Respect to Depth............. 37

2.12 Typical Relationship Between Temperature and Depth at a Landfill........ 40

2.13 Relationship Between $G_{s}$ and Compactive Effort................................. 56

2.14 Unit Weight Profiles for Conventional Landfills ..................................... 60

2.15 Five-Stage Compressibility Curve for MSW ...................................... 67

2.16 Secondary MSW Compression Versus Log-time for a Landfill .............. 77

2.17 Compaction Curve at Standard and Modified Effort................................ 97

2.18 Effect of Compaction on Soil Structure ….......................................... 99

2.19 Compaction Characteristics of Granular Soils .................................. 102

2.20 3D Schematic Plot of Waste Compaction .......................................... 105

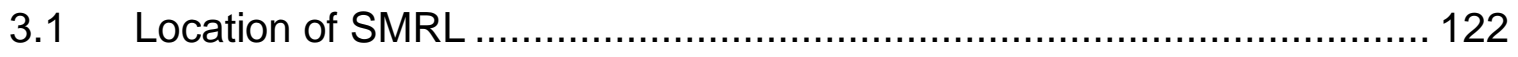

3.2 Site Plan for Santa Maria Regional Landfill........................................ 125

3.3 Typical Path of Compactor for a 16 x 46 m Sub-Cell of MSW .............. 129

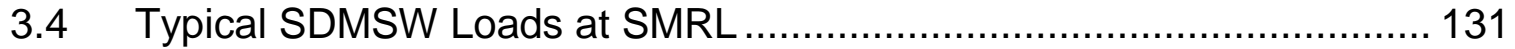

3.5 Convection Oven Used at SMRL to Dry Waste Samples..................... 132

3.6 Location of Boreholes at SMRL ........................................................ 135

3.7 Photographs of the Drilling and Sampling Procedures ….................... 136

3.8 Modification Process of the Magnetic Extensometer Ring .................... 140

3.9 The Settlement Array Installation Process ....................................... 141

3.10 Schematic of a Typical Settlement Array Inside a Borehole at SMRL ... 142

3.11 Typical Thermocouple Array Prior to Installation ................................. 143 
3.12 Installation of a Thermocouple Array Through the Embankment 144

3.13 Borehole Schematic for BH1 and BH2 ....................................... 146

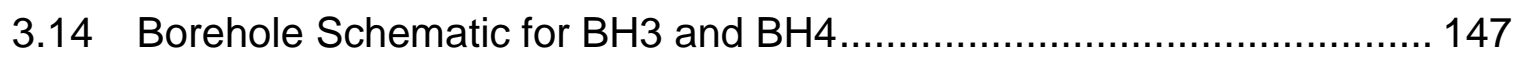

3.15 Borehole Schematic for BH5 and BH6 ......................................... 148

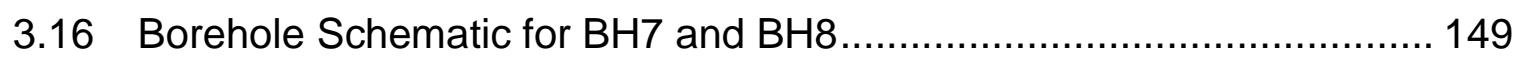

3.17 A Typical Load of RMSW at SMRL ............................................... 151

3.18 An Example of a Graded Test Plot ................................................... 152

3.19 Schematic of the Test Plot Layout .................................................. 152

3.20 Photographs of the General Waste Placement and Compaction Procedure of the Meso-Scale Compaction Study at SMRL .................. 157

3.21 Typical Test Pit for Moisture Verification............................................ 162

3.22 Grid Pattern of Spatial Moisture Distribution Sample Locations............. 166

3.23 Waste Constituents Prepared to Three Particle Size Fractions ............. 169

3.24 FMSW Sampled at the Active Face ............................................. 173

3.25 OMSW Obtained From Different Depths........................................ 174

3.26 Comparison of a Pycnometer and the Two Erlenmeyer Flasks ............. 175

3.27 The Specific Gravity Test Setup ...................................................... 177

3.28 Photographs of the Erlenmeyer Flasks Filled with Waste Only and with Waste-Water Mixture After Equilibrium ........................................ 178

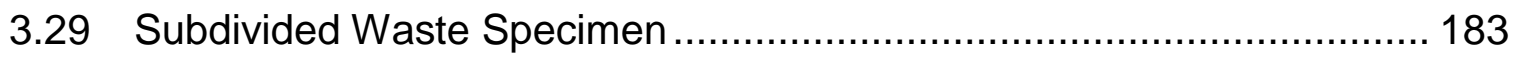

4.1 Particle Size Distribution of 3 OMSW Samples at Depth ..................... 185

4.2 Measured Moisture Content Histograms of FMSW .............................. 187

4.3 Measured Moisture Contents of FMSW ............................................. 188

$4.4 \quad$ Monthly Moisture Content of FMSW ……....................................... 189

4.5 Moisture Content of OMSW as a Function of Absolute and

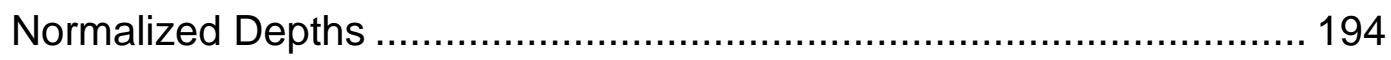

4.6 Measured Organic Content of FMSW and OMSW Specimens ............. 195

4.7 Organic Content as a Function of Absolute and Normalized Depths ..... 199

4.8 Comparison of Manufactured Waste $G_{s}$ for 3 Size Fractions................. 203

4.9 Relationship Between Specific Gravity and Equivalent Particle

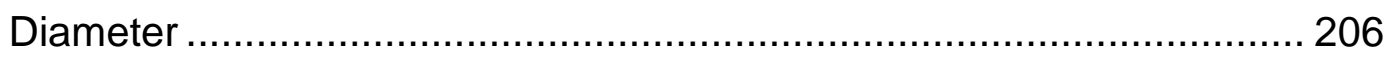

4.10 Specific Gravity of OMSW Specimens as a Function of Depth and Normalized Depths .... 209 


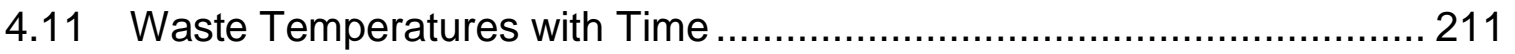

4.12 Temperature as a Function of Depth ............................................. 213

4.13 Vertical Waste Lift Strain of $\mathrm{BH} 1$ and $\mathrm{BH} 2$ as a Function of Time ......... 218

4.14 Vertical Waste Lift Strain of $\mathrm{BH} 3$ and $\mathrm{BH} 4$ as a Function of Time ........ 219

4.15 Vertical Waste Lift Strain of BH5 and BH6 as a Function of Time ........ 220

4.16 Vertical Waste Lift Strain of $\mathrm{BH} 7$ and $\mathrm{BH} 8$ as a Function of Time ......... 221

4.17 Embankment Schematic at Initial Placement and After Reloading ........ 225

4.18 Modified Recompression Index for Fresh MSW at SMRL ..................... 229

4.19 Assumed Creep Line For Lift I of BH6 .......................................... 231

4.20 Estimated Recompression Curve and $C_{r, \text { deg }}^{\prime}$ for Lift I of BH6 ................ 233

4.21 Compaction Curves from Meso-Scale Compaction Study .................... 236

4.22 Upper and Lower Limits of Dry Unit Weight for RMSW....................... 237

4.23 Compaction Curves for the Full-Scale Compaction Study .................... 252

4.24 Upper and Lower Limits of Dry Unit Weight for MSW ......................... 253

4.25 Spatial Moisture Distribution Index Map............................................ 258

4.26 Physical and Engineering Properties of MSW as a Function of

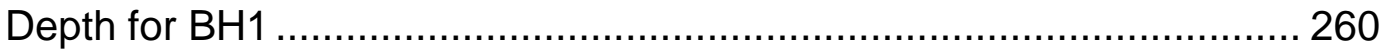

4.27 Physical and Engineering Properties of MSW as a Function of

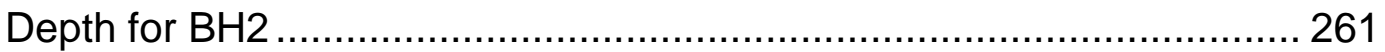

4.28 Physical and Engineering Properties of MSW as a Function of

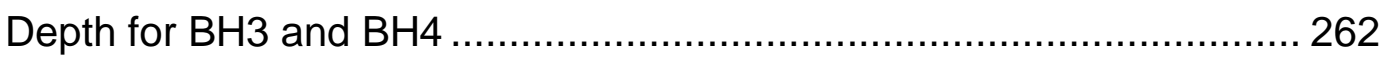

4.29 Physical and Engineering Properties of MSW as a Function of

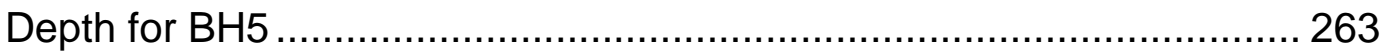

4.30 Physical and Engineering Properties of MSW as a Function of Depth for BH6....

4.31 Physical and Engineering Properties of MSW as a Function of

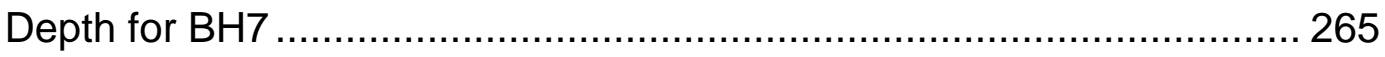

4.32 Physical and Engineering Properties of MSW as a Function of Depth for BH8

5.1 Relationship between DOD and Specific Gravity of MSW ................... 276

5.2 Dot Plot of Target and Measured $\theta$ for Meso-scale Compaction

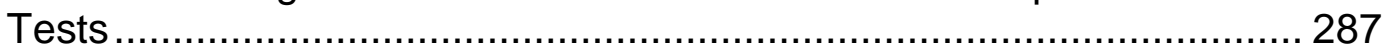

$5.3 \quad$ Compaction Plot with Variable ZAV ................................................. 293 


\section{Chapter 1: Introduction}

Disposal of MSW has become increasingly difficult of over the past several decades. Waste disposal rates have remained consistent while permitting and construction of new landfill sites have decreased due to scarcity of suitable sites, enhanced regulatory requirements, and citizen opposition to siting. The optimization of waste placement procedures and the physical and engineering properties of MSW are still not well understood.

In 2011, Americans generated approximately 2.22 billion kN (250 million tons) of municipal solid waste (MSW) (USEPA 2013a), which is equivalent to approximately $19.7 \mathrm{~N}$ (4.43 pounds) of MSW per person per day. After recycling and re-use, approximately 1.46 billion kN (164 million tons) of MSW is discarded into landfills around the United States. In spite of rigorous efforts towards waste reduction, the percentage of MSW discarded in landfills over the past several years continued to remain consistent. In addition, the number of operational landfills has decreased steadily over the past several decades.

Implementation of a more environmentally conscientious solid waste management strategy set forth by the USEPA (i.e., priorities established for source reduction of waste, recycling and recovery of waste, and combustion with energy recovery), difficulties associated with permitting and locating sites for new landfills, and the trend of average landfill size increasing have resulted in the need for optimizing waste placement procedures and maximizing landfill capacity. It is necessary to gain a better understanding of the physical and engineering properties of municipal solid waste in order to improve waste 
placement efficiency and prolong the life of landfills. In addition, an improved understanding of waste properties would allow for safer and more environmentally sound landfills, both during operation and post closure. The physical and engineering properties of waste can be difficult to determine and standardize due to the heterogeneous nature of the waste and variability in waste composition between landfill sites. Furthermore, waste placement procedures and compaction of wastes at landfills have improved over the past several decades. However, the placement efficiency of waste has seemingly remained consistent in recent years.

An extensive laboratory and field test program was conducted at Santa Maria Regional Landfill (SMRL) in Santa Maria, CA to assess the effects of moisture addition on placement efficiency and further develop an understanding of the physical and engineering properties as a function of waste placement conditions. In particular, laboratory experiments were conducted on manufactured, fresh, and old MSW to determine the specific gravity of MSW and the effects of particle size, compaction, and degradation on the specific gravity of waste. Specific gravity is an important property used for weight-volume phase relationship calculations. Specific gravity of MSW has not been thoroughly evaluated up to this point. Several researchers have conducted supplemental specific gravity tests (e.g., Hettiarachchi 2005; Breitmeyer 2011; Reddy et al. 2011) or determined the specific gravity of MSW through backcalculation (e.g., Hanson et al. 2010a). However, the effects of particle size, compaction, and degradation on the specific gravity of waste have not been addressed. 
Particle size distribution, moisture content, organic content, and temperature of fresh and old MSW obtained from SMRL also were evaluated in order to characterize the waste and expand upon the available data on the physical properties of MSW. The compressibility of waste has been characterized using limited field data, data from laboratory compression tests, and results generated from settlement modeling. Monitoring and evaluation of the compression response of individual fresh and old waste lifts has yet to be addressed. A total of 8 magnet extensometer settlement arrays were installed at SMRL with magnetic extensometer rings (MERs) deployed at waste lift interfaces. The compression response of individual fresh and old waste lifts was monitored for approximately 1 year. Better understanding of the compression response of waste can result in more accurate settlement predictions and landfill storage capacity requirement calculations.

Improving waste placement efficiency and maximizing as-placed density of waste will result in significant environmental and financial benefits. Some laboratory and field compaction studies have been conducted in recent years to determine the compaction characteristics of waste (e.g., Gabr and Valero 1995; Itoh 2005; Von Stockhausen 2007; Wong 2009). Von Stockhausen (2007) and Wong (2009) determined that moisture addition prior to compaction can increase waste placement efficiency and improve the as-placed unit weight of waste however, the representativeness of the tests were limited. A meso- and full-scale compaction test program was implemented at SMRL to determine the effects of systematic moisture addition on placement efficiency and as-placed density of 
MSW. Moisture addition was incorporated into the daily waste placement operations to provide representative landfill conditions.

In this thesis, an initial review of waste generation and landfilling in the U.S., landfill components and operations, MSW characterization and waste structure, physical properties of MSW, unit weight of MSW, and the engineering properties of MSW is presented in Chapter 2. This is followed by description of the test methods and procedures used within this test program (Chapter 3). Test results and discussion are presented in Chapter 4. The engineering significance of the test results is discussed with both quantitative and qualitative analysis in Chapter 5. Finally, conclusions are drawn and suggestions for future work are made in Chapter 6. 


\section{Chapter 2: Literature Review}

\subsection{Introduction}

This section provides a summary of information available in literature related to MSW landfills, physical and engineering properties of MSW, and waste placement procedures at MSW landfills. First, the current state of waste generation and landfilling in the United States is summarized. Next, the components and operation procedures of landfills are presented. Following, a summary of the information regarding waste characterization and waste structure is presented. The coverage of organic content, moisture, temperature, and specific gravity of MSW in the literature is then summarized. Next, the engineering properties of MSW (i.e., compressibility, hydraulic conductivity, and shear strength) are summarized. Lastly, the compaction characteristics and procedures of MSW at landfills are presented.

\subsection{Waste Generation in the United States}

According to the United States Environmental Protection Agency (USEPA 2013a), MSW "consists of everyday items such as product packaging, grass clippings, furniture, clothing, bottles, food scraps, newspapers, appliances, and batteries." The percentage breakdown of the distinct categories of MSW generated in the United States in 2011 is presented in Figure 2.1. 


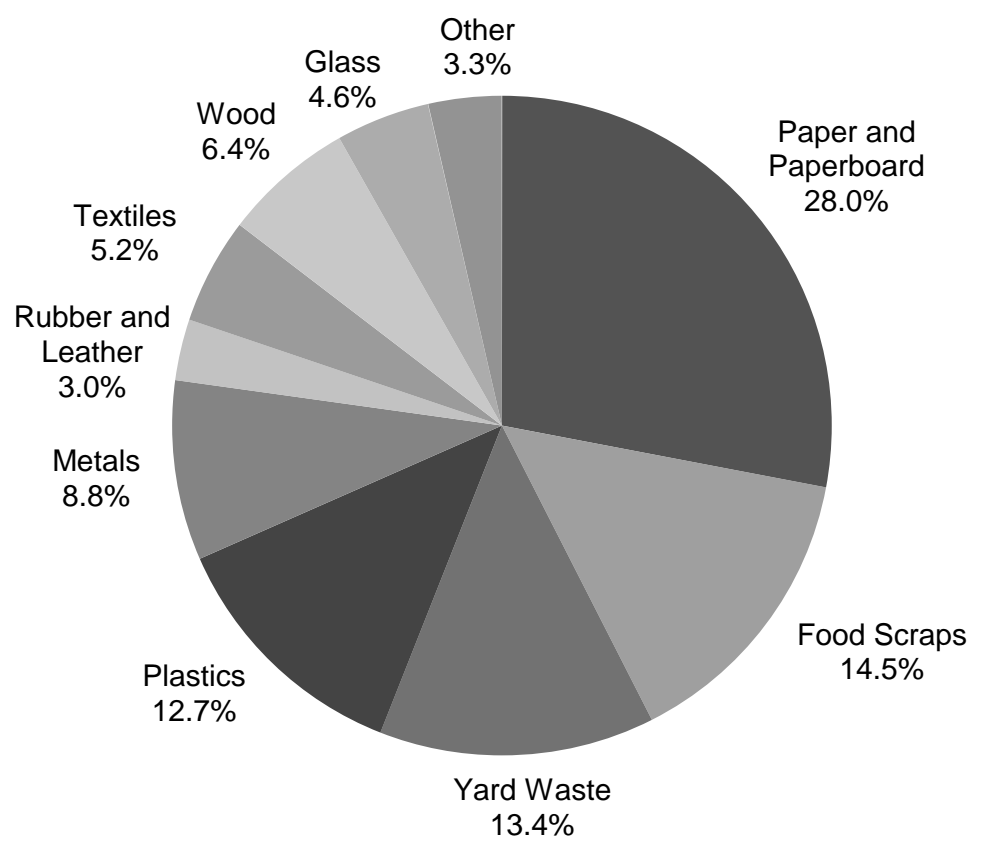

Figure 2.1. Waste Stream Constituents Generated in the U.S. in 2011. (USEPA 2013a).

In 2011, approximately 2.22 billion kN (250 million tons) of municipal solid waste (MSW) were generated in the United States (USEPA 2013a), which is equivalent to approximately $19.7 \mathrm{~N}$ (4.43 pounds) of MSW per person per day. Both the total and per capita generation of MSW in the United States have increased steadily from 1960 [when 788 million kN (88 million tons) of MSW per year and approximately $12 \mathrm{~N}$ (2.68 pounds) of MSW per person per day were being generated] to 2007 [when 2.28 billion kN (256 million tons) of MSW per year and approximately $20.8 \mathrm{~N}$ (4.66 pounds) of MSW per person per day were being generated]. Since 2007, both the total and per capita generation of MSW in the United States have decreased to 2.23 billion kN (250 million tons) per year and approximately $19.6 \mathrm{~N}$ (4.40 pounds) per person per day (USEPA 2013a). The state of the economy has a strong impact on generation of waste and during 
times of economic decline, waste generation decreases as was the case in the United States from 2007 to 2011. Although, the generation of MSW decreased from 2007 to 2011, the percentage of the MSW discarded in landfills (postrecycling and recovery) remained consistent at approximately 54\% (USEPA 2013a).

\subsection{Landfilling in the United States}

Landfills are the most widely-used method for handling and disposing of municipal solid waste in the United States (Qian et al. 2002). As of 2009, a reported 1,908 landfills were operational in the United States. This represents a significant decrease in the number of operational landfills since 1960 when a reported 7,924 landfills were operational (USEPA 2013a). The decrease in number of landfills over time can be explained by implementation of a more environmentally conscious solid waste management strategy set forth by the USEPA (i.e., priorities established for source reduction of waste, recycling and recovery of waste, and combustion with energy recovery), difficulties associated with permitting and locating sites for new landfills, and the trend of average landfill size increasing. The long-term performance of these facilities is becoming increasingly important due to the stringent regulations in place to ensure the safety of the areas surrounding landfills from contamination.

In spite of rigorous efforts towards waste reduction, the percentage of MSW discarded in landfills over the past several years has remained relatively constant at 54\%. From 1960 to 2000 the percentage of waste discarded in landfills decreased from 93.6 to $57.5 \%$ but since 2000 that percentage has 
leveled out at about $54 \%$ with discarded rates varying between 57.6 and $53.6 \%$ (USEPA 2013a). Figure 2.2 demonstrates the trend of discarded MSW into landfills.

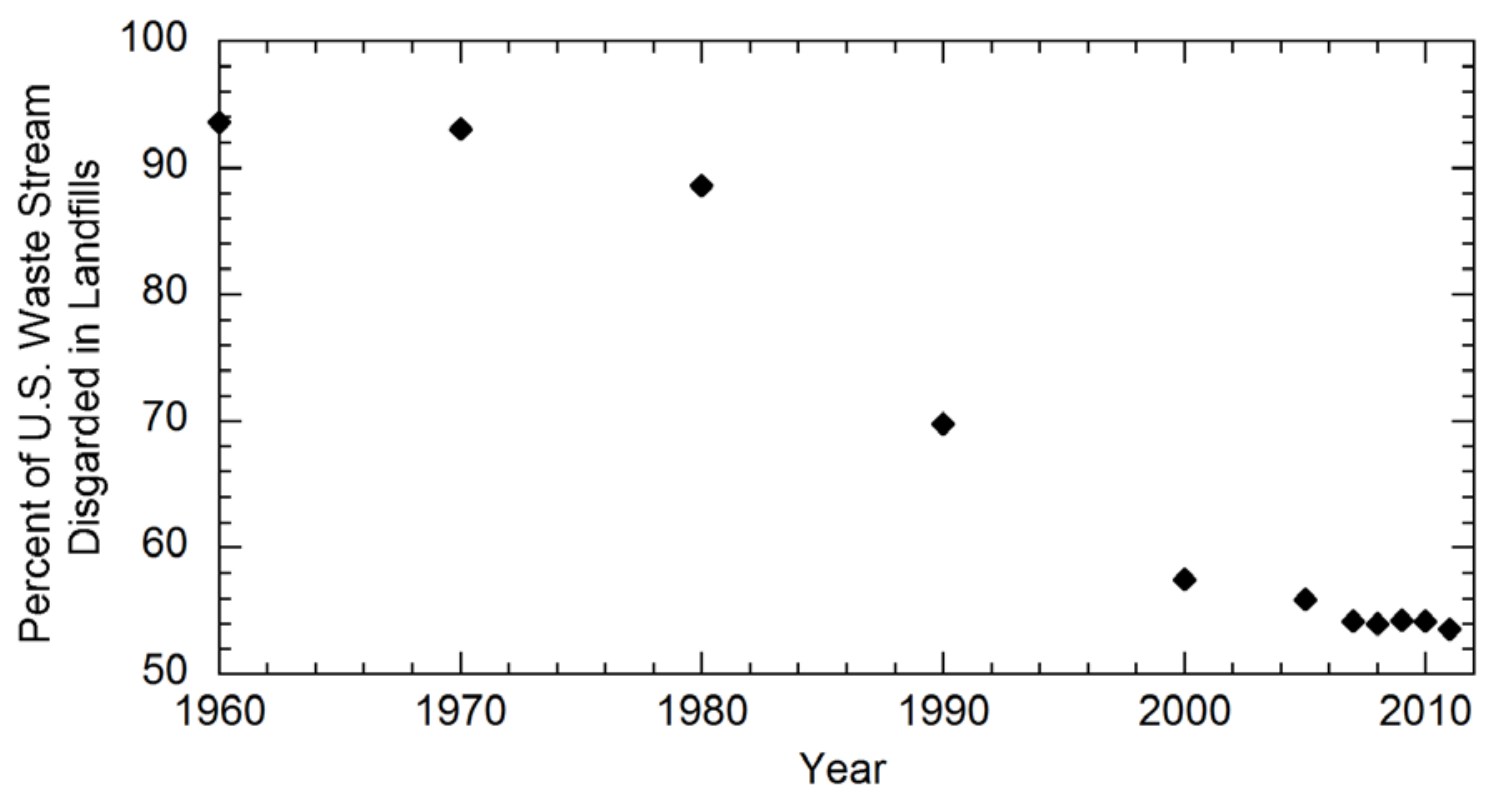

Figure 2.2. Percent of Waste Stream Discarded in Landfills From 1960 to 2011 (Summarized data from USEPA 2013a).

The trend indicates further waste diversion from landfills is becoming increasingly difficult and that the need for landfilling MSW will continue for the long term, most likely in the form of expansion. As exiting landfills expand to accommodate new wastes, the operation, monitoring, and maintenance of landfill performance becomes increasingly critical and more complex.

\subsection{Components of a Landfill}

The most important performance requirement of a landfill is that it does not pollute or degrade the surrounding environment (Qian et al. 2002). Wellplanned siting and proper design, construction, and operation of a landfill greatly 
reduces the risk of catastrophic failures. A properly designed and constructed landfill consists of an envelope that encapsulates the waste, prevents leachate from entering into the environment, limits rainfall infiltration, and allows for management of gas generation (Qian et al. 2002). The two components of the envelope are the bottom liner and top cover, both of which are complex systems with several layers comprised of geosynthetics, gas and leachate collection pipes, low permeability soils for containment, and high permeability materials for drainage. A typical example for the liner system, leachate collection and removal system, gas collection and control system, and final cover system are presented in Figure 2.3.

The liner system isolates the waste and serves as a barrier against leachate and gas contamination into the surrounding environment. The liner system is placed on the bottom and base side slopes of a landfill and generally contains multiple drainage and low-permeability layers. The low-permeability layers can consist of compacted clay liners (CCLs), geomembranes, geosynthetic clay liners (GCLs), and/or combinations of these while the drainage layers typically consist of permeable soils (i.e., sand or gravel) or a geosynthetic drainage materials (i.e., geotextile and geonet or geocomposite). 


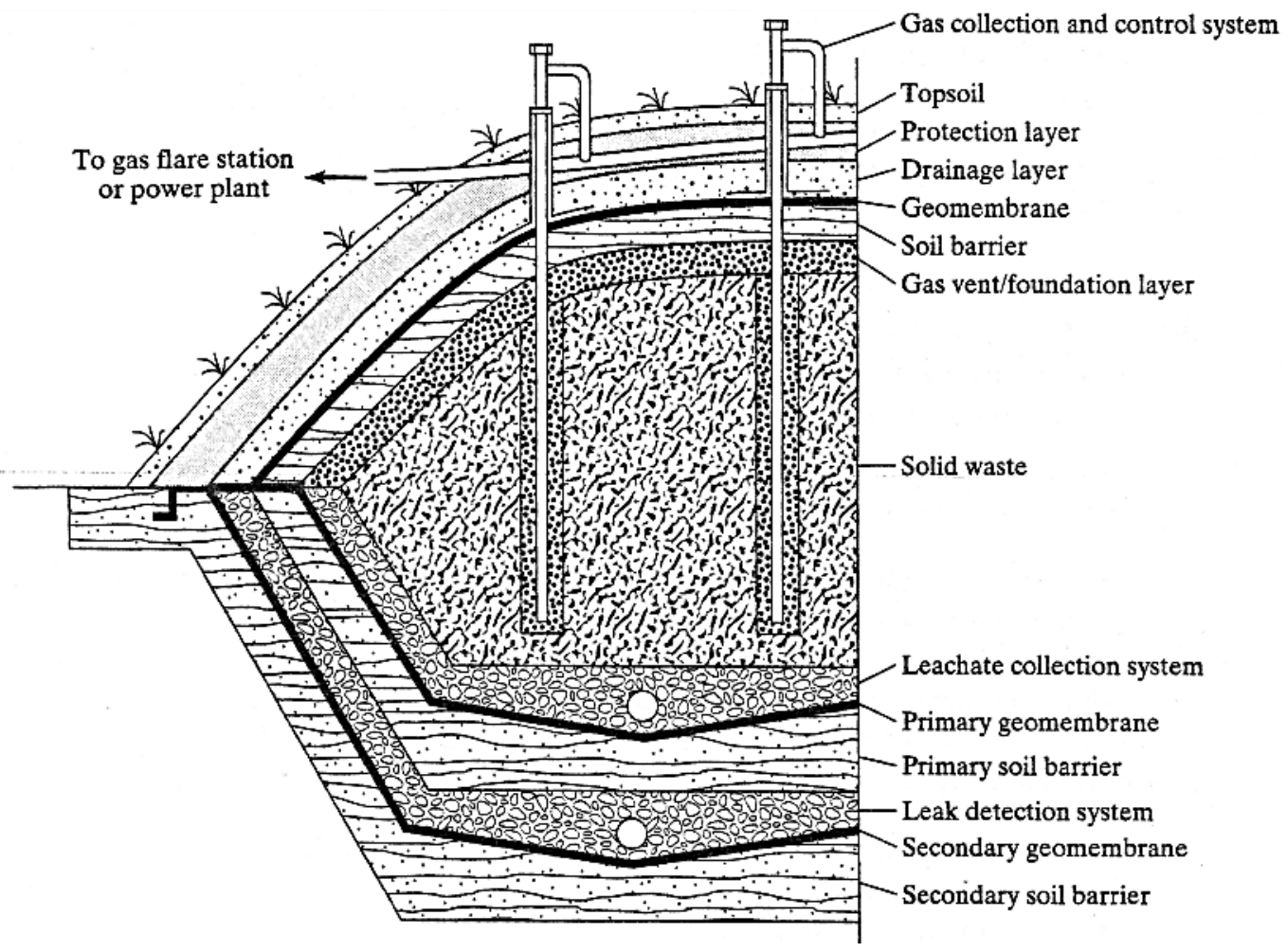

Figure 2.3. Typical Cross-section of a MSW Landfill (Qian et al. 2002).

The USEPA (2004) requires composite liner systems (both clay and geosynthetic layers) and a leachate collection and removal system for all MSW landfills however, double composite liners with both primary and secondary leachate collection systems also have been used (Qian et al. 2002). Furthermore, regulations dictate that the hydraulic conductivity of the barrier not to exceed $1 \times 10^{-7} \mathrm{~cm} / \mathrm{sec}$ (USEPA 2004).

The leachate control, collection, and removal system functions to transport the leachate at the bottom of the landfill to a treatment facility or to a recirculation system depending on the liquid management strategy (Qian et al. 2002). The requirement for maximum allowable head of $30 \mathrm{~cm}$ on the liner system is in place to minimize the advective flow (i.e., leakage) through the system. 
Municipal solid waste produces large quantities of greenhouse gases such as methane and carbon dioxide during decomposition. If not properly managed, these gasses have the potential to escape into the atmosphere, migrate vertically and/or laterally into the surrounding soil, or to combust. MSW landfills are currently the third-largest source of anthropogenic methane emissions in the United States, accounting for approximately $17 \%$ of these emissions (USEPA 2013b). A gas collection and control system must be in place to manage emissions and prevent unexpected combustion at the landfill. Gas collection systems generally consist of a series of collection wells and a blower/flare or vacuum system. The gas collection systems direct the landfill gas to a central point where it can be processed and treated depending upon the ultimate use for the gas. Once the gas is collected at the central point it can either be flared off, used to generate electricity, replace fossil fuels in industrial and manufacturing operations, or upgraded to pipeline-quality gas where the gas may be used directly or processed into an alternative vehicle fuel (USEPA 2013b).

The cover system is the final component of the landfill containment system and constitutes the barrier between the atmosphere and the waste in the landfill. The cover system at a landfill is used to prevent infiltration of precipitation, to minimize soil erosion, and to prevent emissions from escaping the landfill into the atmosphere. In general, the final cover system for a landfill is a multicomponent system that includes an erosion control layer, a protection layer, a drainage layer, a hydraulic barrier layer, a gas vent layer, and a foundation layer (Qian et al. 2002). The regulations regarding allowable permeability and construction 
requirements of the final cover system are defined in Title 40 of the Resource Conservation and Recovery Act (RCRA) (USEPA 2013c).

Landfills are permitted for a specific volume of airspace that can be filled with waste. The time period during which waste is placed is referred to as the operational life of a landfill. Once the operational life of a landfill is complete, the landfill must close and final closure procedures must begin within 30 days. After beginning final closure procedures all closure activities must be completed within 180 days (USEPA 2013d). The USEPA also requires maintaining and monitoring the final cover system, leachate collection system, groundwater monitoring system, and methane gas monitoring system for a period of 30 years after the final closure date of a landfill (USEPA 2013d). The post-closure care activities are the responsibility of the landfill owner and/or operator.

\subsection{Landfill Operations}

It is important to have a working plan in-place for carrying out daily landfill operations including: maintaining an operating schedule (i.e. tonnage records, billing, traffic patterns, communication, unloading sequences, etc.); coordinating filling procedures; daily (intermediate) cover requirements; and equipment requirements (Tchobanoglous and Kreith 2002). Specific operational practices employed vary among landfills. For example, the size and type of equipment used can vary depending on the waste acceptance rate at a landfill. Landfill operating schedule, waste placement methods, daily cover, equipment for landfill operations, and moisture addition systems are described in the following sections. 


\subsubsection{Operating Schedule}

Several factors must be considered when maintaining an efficient landfill operating schedule. The site manager must have a working knowledge of tonnage records, arrival sequences for collection vehicles, traffic patterns at the site, peak placement hours, climatic effects, and commercial and public access (Tchobanoglous et al. 1993). For example, high-wind conditions can hinder waste placement by blowing papers and other waste constituents around and if it is not possible to control the blowing trash the site manager may have to temporarily close the landfill or create a wind-blockade.

\subsubsection{Waste Placement Procedure}

Typical waste acceptance rates at landfills can range between 4,500 kN (500 U.S. tons) and 63,000 kN (10,000 U.S. tons) per day (Cal Recycle 2013). Even with differing operational requirements, landfills across the United States generally employ similar waste placement practices. The specific method of placement however, will depend on the characteristics of the site such as available cover material, the topography, and the local hydrology and geology (Tchobanoglous and Kreith 2002). The entire footprint of a landfill is typically

divided into cells which are strategically laid out prior to the landfill becoming operational. Individual cells are commonly constructed and filled with waste at separate times. The size of each cell is a function of the expected size of the landfill and the predetermined number of cells needed at the landfill. An active cell receives the incoming wastes during the current operational placement 
period. A schematic plan view of a landfill with multiple cells and a filling procedure is presented in Figure 2.4.

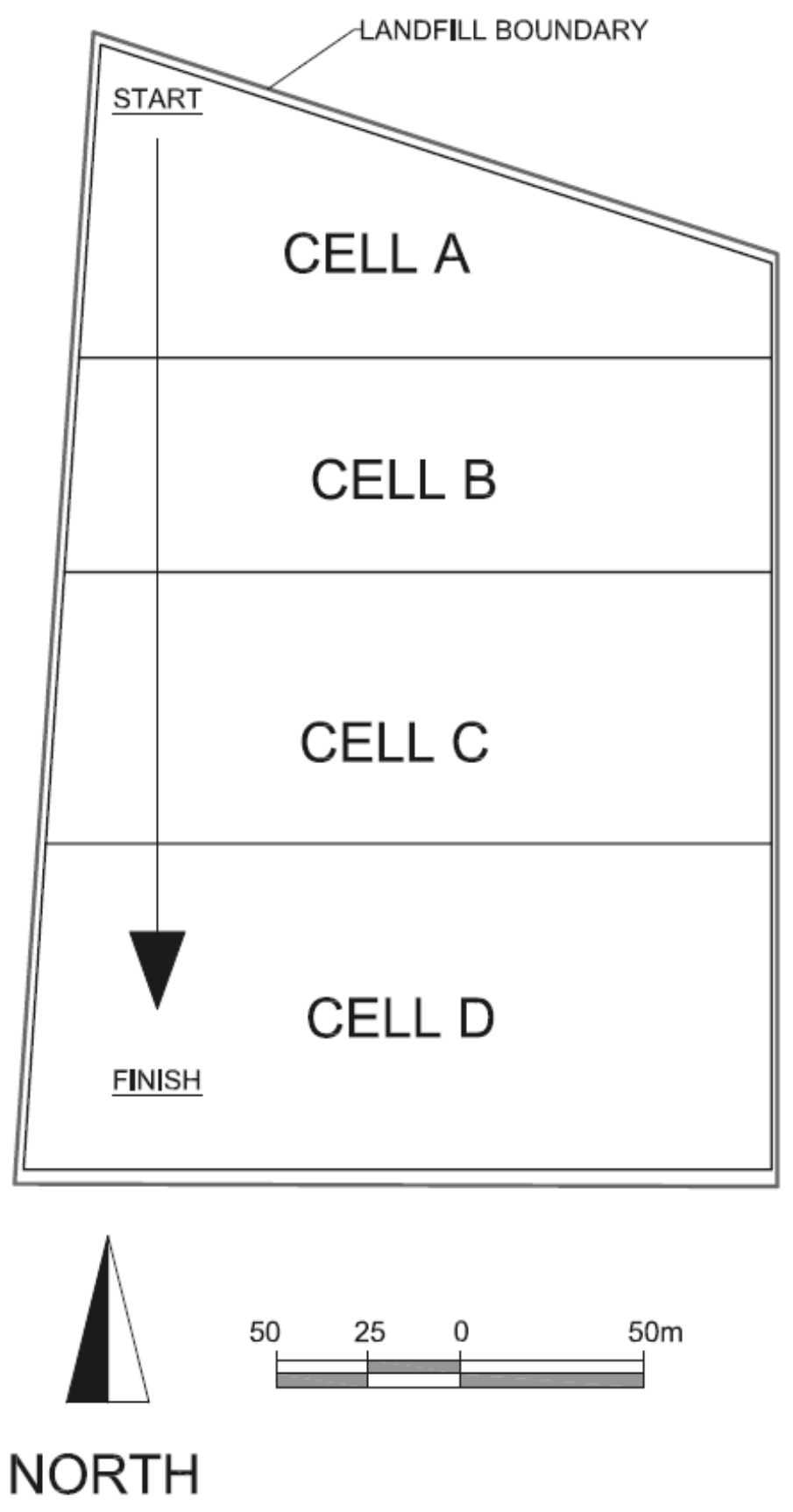

Figure 2.4. Example of Filling Procedure and the Subdivision of Cells at a Landfill. 
The working face or active face of a landfill is the location where waste is actively being placed. The size of the working face depends on incoming waste tonnage, but commonly covers an area on the order of $1,400 \mathrm{~m}^{2}\left(15,000 \mathrm{ft}^{2}\right)$. When a truckload of MSW arrives at the active cell, the MSW is unloaded and spread over the working face using a bulldozer in a series of thin layers (approximately $30-60 \mathrm{~cm}$ in thickness) and is then compacted by heavy waste compactors. A photograph of compactors on a working face of a landfill is presented in Figure 2.5 .

Each cell is filled in a series of lifts which are comprised of several layers that are placed throughout the day. A waste lift is placed with either a vertical or horizontal orientation although vertical lift placement is more common. A vertical lift typically measures approximately $2.5 \mathrm{~m}$ thick and a horizontal lift measures approximately $3 \mathrm{~m}$ thick. A schematic of both orientations of daily lift placement at a landfill is presented in Figure 2.6. At the conclusion of each day, a layer of daily cover is placed over the waste.

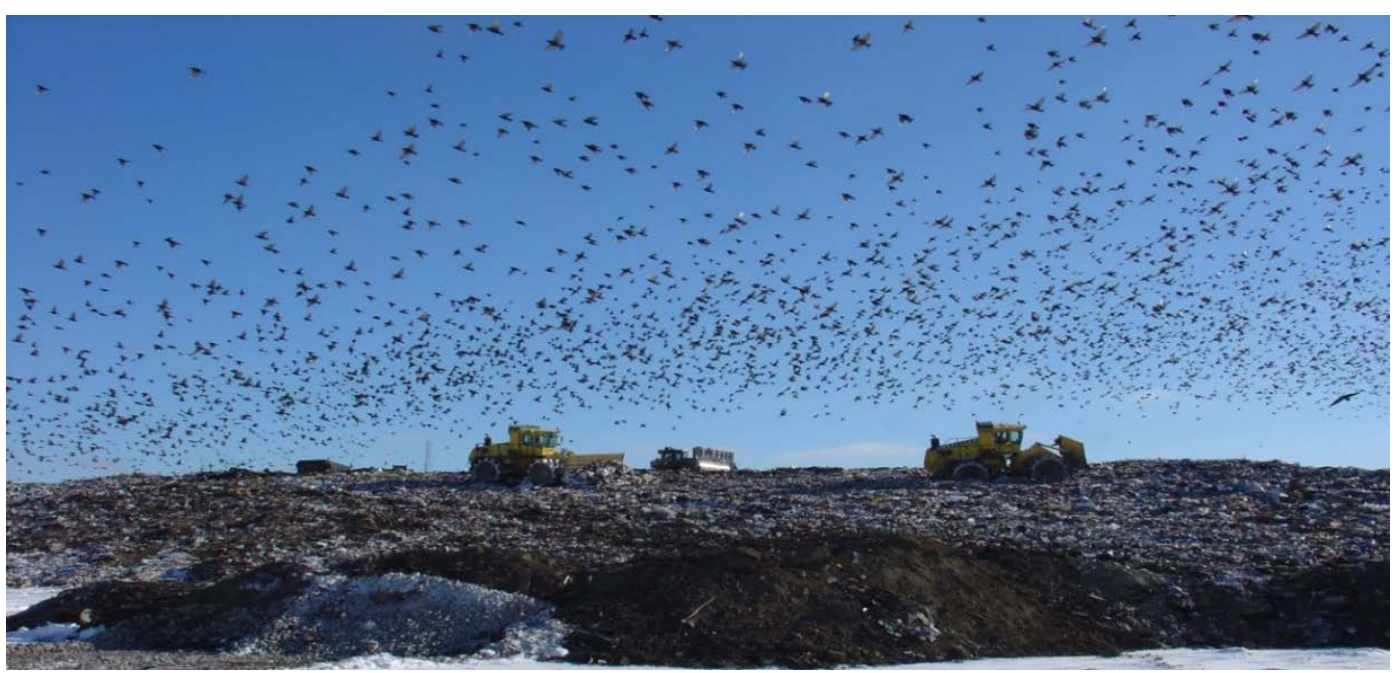

Figure 2.5. Working Face of a Landfill (Von Stockhausen 2007). 


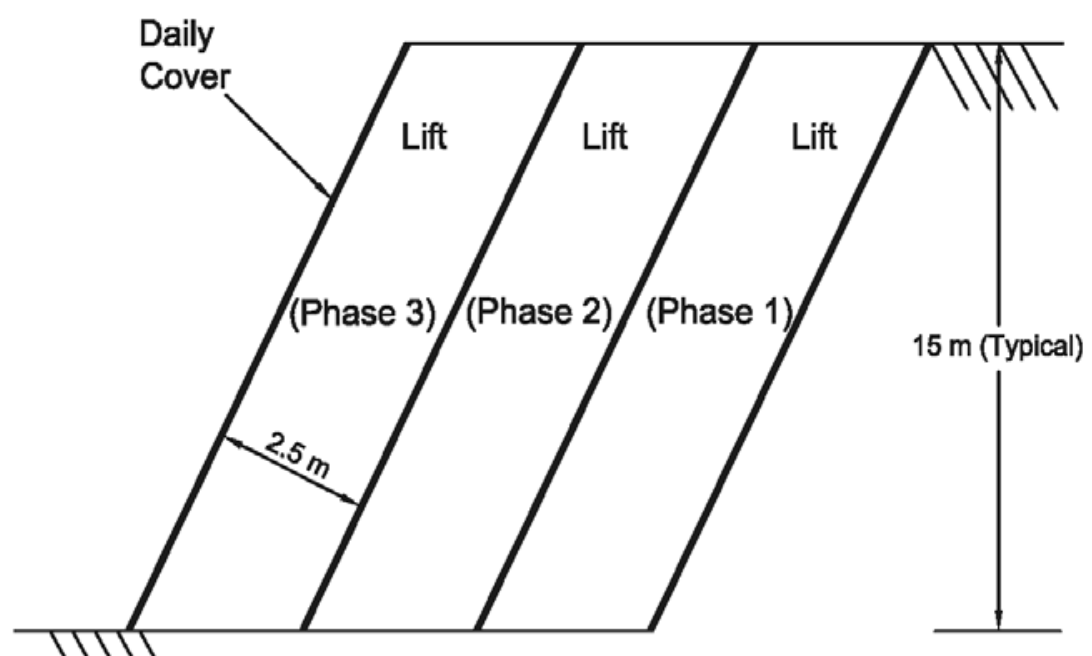

VERTICAL LIFT

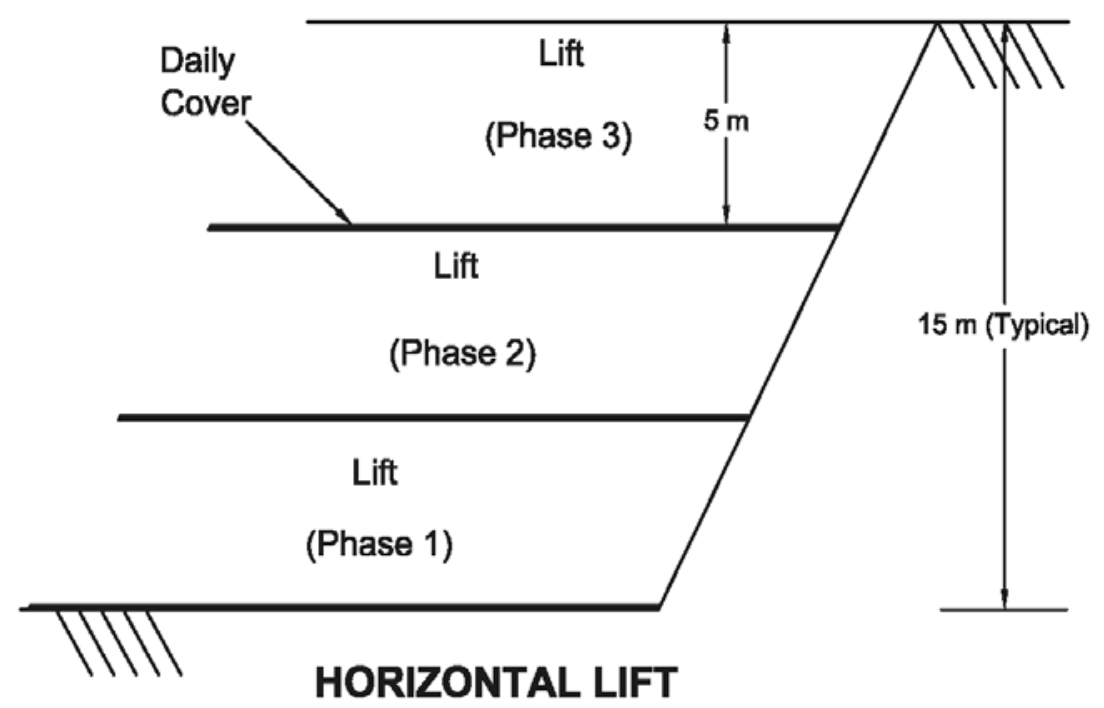

Figure 2.6. Vertical and Horizontal Orientation of Waste Placement at a Landfill.

\subsubsection{Daily Cover}

A layer of daily cover is placed over the active face at the end of each day and is required to be a minimum of $150 \mathrm{~mm}$ thick layer of soil or an alternative material that provides equivalent performance to soil (USEPA 2005). Daily cover 
can consist of native soil or other appropriate material such as compost, shredded tire chips, construction materials, or geosynthetics. Historically, daily cover was used to prevent rats, flies, and other disease vectors from entering or exiting the landfill (Tchobanoglous and Kreith 2002). Daily landfill cover is now primarily used to control the blowing of waste materials, control scavenging, reduce odors, and control the entry of runoff into the landfill during operation. At the beginning of each day, the daily cover from the previous day can either be removed or left in place with waste placement continuing on top of the daily cover.

\subsubsection{Equipment for Landfill Operations}

Typical equipment used at landfills includes waste compactors, bulldozers, excavators, scrapers, water trucks, and roll-off trucks. The bulldozers, excavators, and roll-off trucks are used for delivery and placement of the waste. The scrapers are used to transport and place daily cover and water trucks are often used to maintain site conditions (i.e., dust control). The bulldozer is used for pushing and/or spreading the waste onto the active face of the landfill (Figure 2.7). 


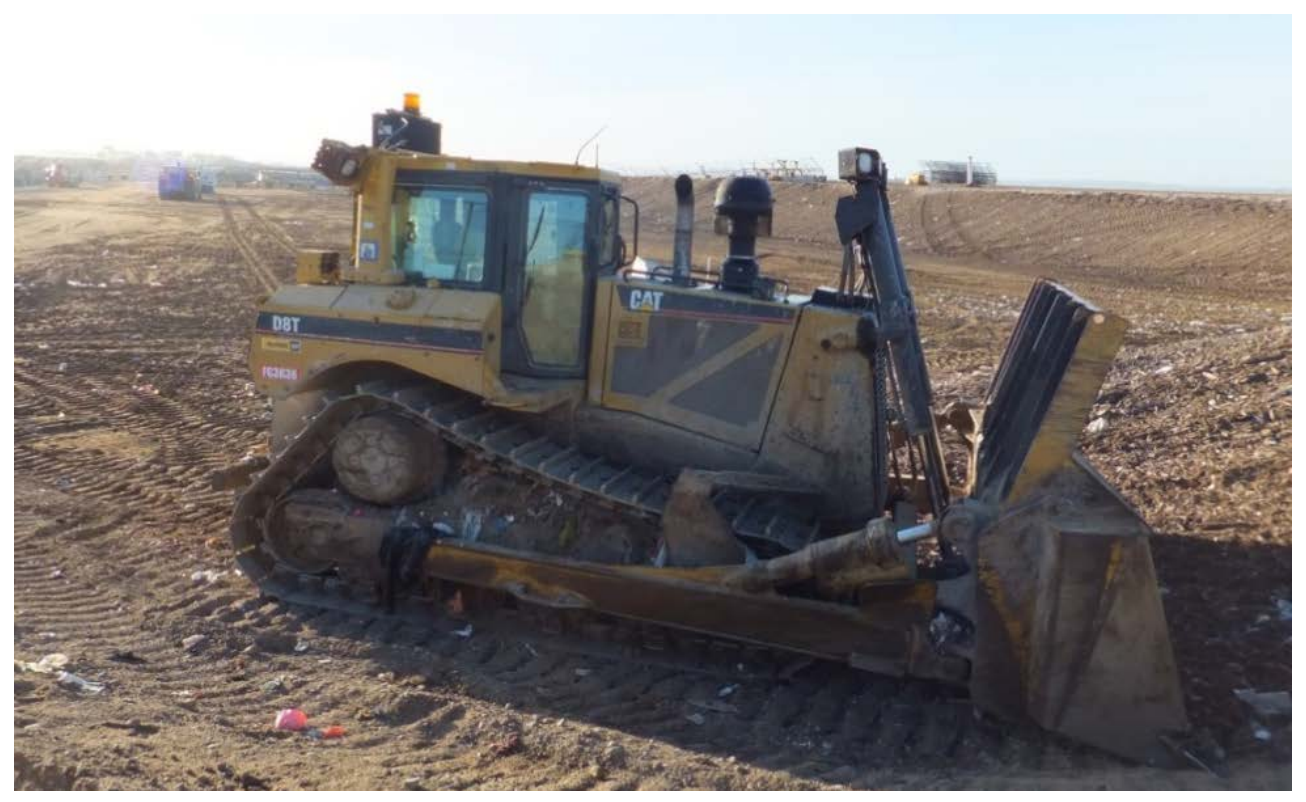

Figure 2.7. Bulldozer with Trash Blade at a Landfill.

The waste compactor is the most critical piece of equipment at a landfill site. The compactor is used for spreading the waste on the working face and primarily for, through a series of passes, densifying the waste. Modern compactors, such as the equipment manufactured by BOMAG and Caterpillar, can weigh over $543 \mathrm{kN}(120,000 \mathrm{lbs})$ and generate a significant amount of compactive energy (Figure 2.8). Waste compactors are specifically designed to work using the same general concepts that are used by pad foot rollers for soil compaction. However, the teeth that protrude outward from the drum are typically larger on waste compactors and in general, waste compactors weigh more than the compactors used for soil compaction (which typically weigh $205 \mathrm{kN}$ $[46,000 \mathrm{lbs}])$. 


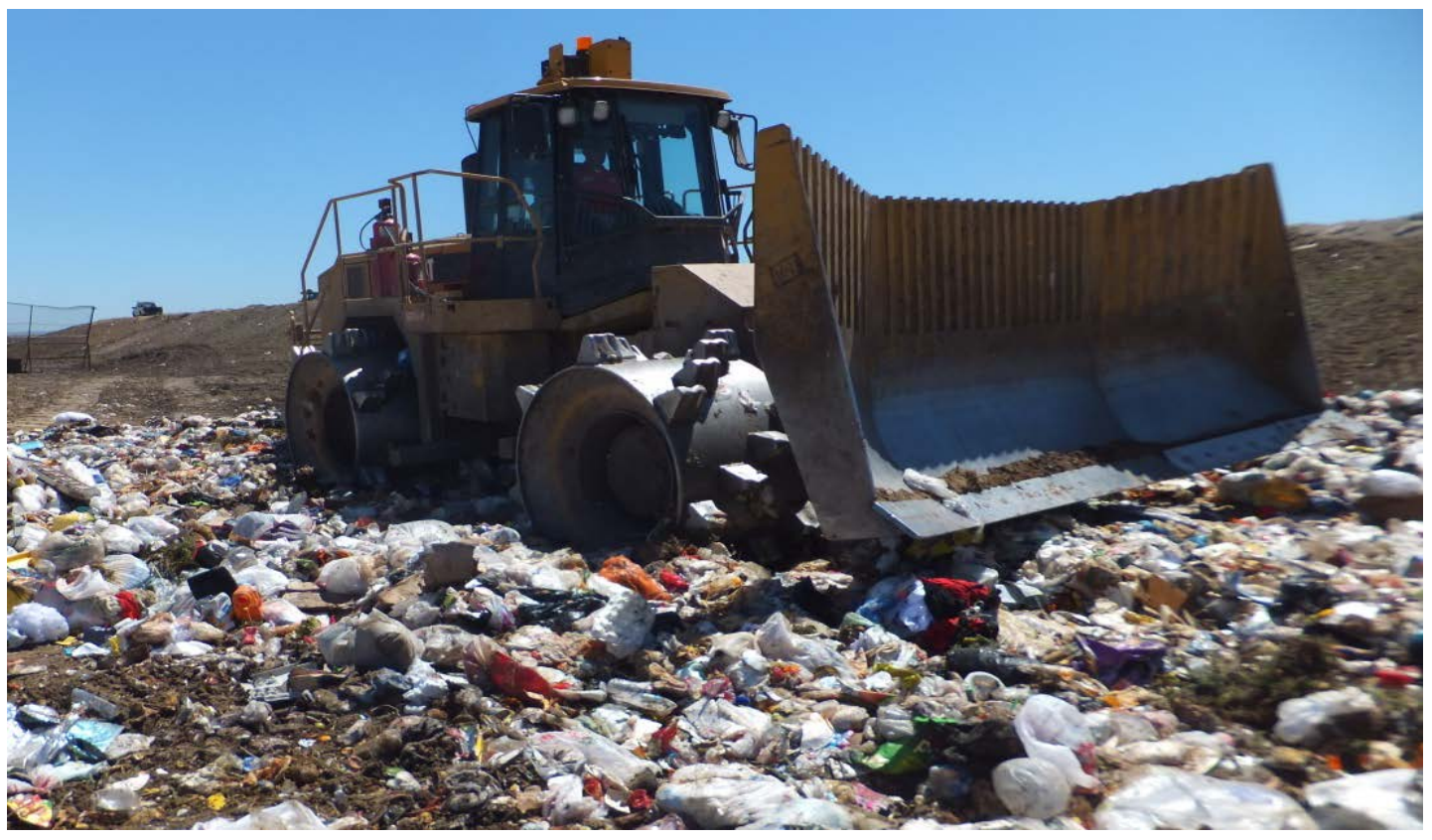

Figure 2.8. Waste Compactor at a Landfill.

The drum varies between approximately 1.2 and $1.6 \mathrm{~m}$ in diameter and has extruding teeth running along the outside. The teeth typically are approximately $20 \mathrm{~cm}$ long and provide kneading and cutting motions that help to chop, shred, and break-up waste particles while simultaneously reorienting the waste particles into a tighter, interlocking matrix with less void space.

\subsubsection{Moisture Addition Systems}

The addition of moisture to MSW in the form of leachate or water is used to optimize the moisture content of the waste and in turn enhance biodegradation and stabilization processes (e.g., Warith et al. 2005; Benson et al. 2007; Sethi et al. 2013). The current and most commonly utilized methods of moisture addition at MSW landfills include vertical injection wells (VW) and horizontal trenches (HT) (Haydar and Khire 2005). Prewetting of the waste and irrigation spraying also has been implemented at landfill sites for many years (Reinhart and 
Townsend 1998). A permeable drainage blanket (PB) is a more recent method of leachate recirculation as presented by Khire and Haydar (2003), Haydar and Khire (2006), and Haydar and Khire (2007).

Each method of moisture addition has advantages and disadvantages. The environmental and economic benefits of moisture addition systems at MSW landfills are well documented (Reinhart and Townsend 1998; Pohland and Kim 1999) and include: 1 ) a reduction in the leachate treatment and disposal costs (in cases of leachate recirculation); 2) accelerated decomposition and settlement of waste resulting in airspace gain; 3) an increase in the rate of gas production; 4) improvement in the quality of recirculated leachate; and 5) potential reduction in the postclosure care period and associated maintenance costs.

\subsection{MSW Characterization}

The characterization of MSW is necessary to describe the constituents of a given waste stream and determine the engineering response of MSW (e.g., hydraulic conductivity, shear strength, compaction, and compressibility) at a landfill. A waste characterization framework should have two elements: a classification system for waste components and a description of the constituents of the waste mass (Dixon and Langer 2006). In this section, a brief review of the existing characterization/classification systems are presented along with a description and breakdown of the typical MSW constituents received at landfills in the United States. 
Several researchers have developed classification systems to characterize MSW and collect relative information about waste with respect to its geotechnical properties (e.g., Landva and Clark 1990; Grisolia et al. 1995; Dixon and Langer 2006; Zekkos et al. 2010). Landva and Clark (1990) divided the waste constituents into organic and inorganic materials. Organic materials include both putrescible waste (i.e., "readily" biodegradable waste) and nonputrescible waste (i.e., "slowly" biodegradable material). Inorganic wastes include both degradable materials (i.e, metals that are corrodible to a degree) and nondegradable (i.e., inert) wastes. Grisolia et al. (1995) characterized MSW in a similar manner to Landva and Clark (1990) and divided waste into three classes: 1 ) inert stable materials; 2 ) highly deformable materials; and 3) readily biodegradable materials.

More recently, Dixon and Langer (2006) and Zekkos et al. (2010) developed comprehensive characterization systems that optimize the collection of physical information that has been shown to have an impact on the mechanical properties of MSW. Dixon and Langer (2006) suggested that waste classification schemes should consist of terms that are both brief and meaningful, have reasonably easy to measure parameters, and have groups that represent waste materials by similar engineering properties. Dixon and Langer (2006) stated that selection of appropriate groups required that the waste materials are considered in their initial state (i.e., as-delivered and uncompacted) because engineering properties, shape, and size of components will change as a result of placement conditions (i.e., compaction), overburden stresses, and in the long- 
term, degradation processes. Thus, the classification system allowed for waste components to change groups over time due as a result of the described processes (Dixon and Langer 2006). To establish the proposed classification scheme, Dixon and Langer (2006) suggested that the following information be gathered as the waste is delivered to the landfill, following compaction of the waste, and periodically over time: percentage composition of waste constituents, component shape, size distribution, material engineering properties (e.g., shear, compressive and tensile strength), and the state of degradation.

Zekkos et al. (2010) designed a four phase system to capture the characteristics of MSW that may have a major influence on its mechanical properties. The proper utilization of the phased characterization system requires that the following data be collected and procedures be followed during each phase: 1) waste origin, landfill operational procedures, climatic conditions, and waste age; 2) visual observation, geophysical exploration, and in-situ unit weight tests; 3) separation of waste constituents into large ( $>20 \mathrm{~mm})$ and small $(<20$ $\mathrm{mm}$ ) groups, state of degradation, and more detailed visual characterization; and 4) organic content determination, moisture content determination, and sieve analysis (Zekkos et al. 2010).

Common categories of waste components include: paper/cardboard, plastics, food waste, metals, rubber, and glass (Jessberger et al. 1995). In the United States, the USEPA employs a classification system for the annual waste stream which is broken down into individual waste constituent categories on a weight basis. The USEPA (2013a) makes specific adjustments to the production 
data for each waste material and category including imports, exports, and diversions. The difference between the amount produced and the amount recycled (which is directly quantified) is determined as the amount that is landfilled on an annual basis. The weight based percentage breakdowns of individual waste constituents disposed in landfills in 2009 and 2011 are presented in Table 2.1.

Table 2.1. Breakdown of Individual MSW Constituents

Disposed in U.S. Landfills (USEPA 2010; USEPA 2013a)

\begin{tabular}{|c|c|c|c|c|}
\hline \multirow{2}{*}{ Material Type } & \multicolumn{2}{|c|}{$\begin{array}{c}\text { Weight Discarded in } \\
\text { Landfill (million tons) }\end{array}$} & \multicolumn{2}{c|}{$\begin{array}{c}\text { Percentage of Total } \\
\text { Discarded Waste }\end{array}$} \\
\cline { 2 - 5 } & $\mathbf{2 0 0 9}$ & $\mathbf{2 0 1 1}$ & $\mathbf{2 0 0 9}$ & $\mathbf{2 0 1 1}$ \\
\hline $\begin{array}{c}\text { Paperl } \\
\text { Paperboard }\end{array}$ & 25.93 & 24.12 & 16.0 & 14.8 \\
\hline Glass & 8.78 & 8.30 & 5.4 & 5.1 \\
\hline Steel & 10.55 & 11.07 & 6.5 & 6.8 \\
\hline Aluminum & 2.75 & 2.75 & 1.7 & 1.7 \\
\hline Other Metals & 0.60 & 0.62 & 0.40 & 0.40 \\
\hline Plastics & 27.93 & 29.19 & 17.3 & 17.9 \\
\hline $\begin{array}{c}\text { Rubber and } \\
\text { Leather }\end{array}$ & 6.04 & 6.18 & 3.7 & 3.8 \\
\hline Textiles & 10.97 & 11.09 & 6.8 & 6.8 \\
\hline Wood & 13.39 & 13.70 & 8.3 & 8.4 \\
\hline Other Materials & 3.40 & 3.31 & 2.1 & 2.0 \\
\hline Food & 32.75 & 34.91 & 21.3 & 21.3 \\
\hline $\begin{array}{c}\text { Yard } \\
\text { Trimmings }\end{array}$ & 11.73 & 14.41 & 8.2 & 8.8 \\
\hline $\begin{array}{c}\text { Miscellaneous } \\
\text { Inorganics }\end{array}$ & 3.69 & 3.87 & 2.4 & 2.4 \\
\hline Total & 161.88 & 163.52 & 100 & 100 \\
\hline
\end{tabular}

The difference between the amount and percentage of individual MSW component discards from 2009 to 2011 is minimal and is an indicator of consistent waste stream characteristics over the past several years. Physical characterization/classification of MSW is important to better understand the 
physical and engineering properties of waste, such as those being investigated in this test program.

\subsection{Fabric and Structure of MSW}

The term fabric refers to the particles, particle groups, and pore spaces within a given soil mass (Mitchell and Soga 2005). However, the same definition of fabric can be applied to MSW. Similarly, the structure of a soil represents the combined effects of the fabric, composition, and interparticle forces within a given soil mass (Mitchell and Soga 2005), a term that can also be applied to MSW. Engineering properties of a given waste mass are dependent upon the composition, size and shape, and orientation of waste constituents as well as the interactions and responses of the individual constituents to physical and mechanical changes over time. In this section, the fabric and structure of MSW are described.

The individual constituents of MSW and void spaces within a given waste matrix that make up the fabric of MSW are unique in that they vary with time. For example, waste constituents can be classified as inert, deformable, or degradable (e.g., Landva and Clark 1990; Grisolia et al. 1995) materials and the relative quantity of each type of constituent at a given location in a landfill can change significantly over small periods of time. Furthermore, the fabric of MSW contains interparticle voids (i.e., void space between individual waste constituents) which can vary spatially as well depending on the composition of the waste in a given location. The presence of bulky constituents such as furniture or appliances creates large interparticle voids in the surrounding area. 
Another characteristic of the fabric that is unique to MSW is the presence of intraparticle voids within almost all individual waste constituents disposed in landfills. In an undisturbed or natural state, individual waste constituents such as paper, cardboard, textiles, glass, rubber, food, wood, yard trimmings, and some plastics contain inaccessible voids (filled with liquid or gas) that are trapped within the boundaries of the constituent itself (e.g., Landva and Clark 1990; Beaven and Powrie 1996; Hudson et al. 2004; Zhang et al. 2010). However, in a landfill environment, the individual waste constituents are constantly undergoing physical and mechanical changes such that the intraparticle voids may become accessible. Hudson et al. (2004) developed a schematic (Figure 2.9) to highlight the types of intraparticle voids that are present within the elemental volume of waste. Additionally, intraparticle voids can also be present in sealed containers, bottles, and cans such that a large pore filled with liquid and/or gas is trapped within the sealed item.

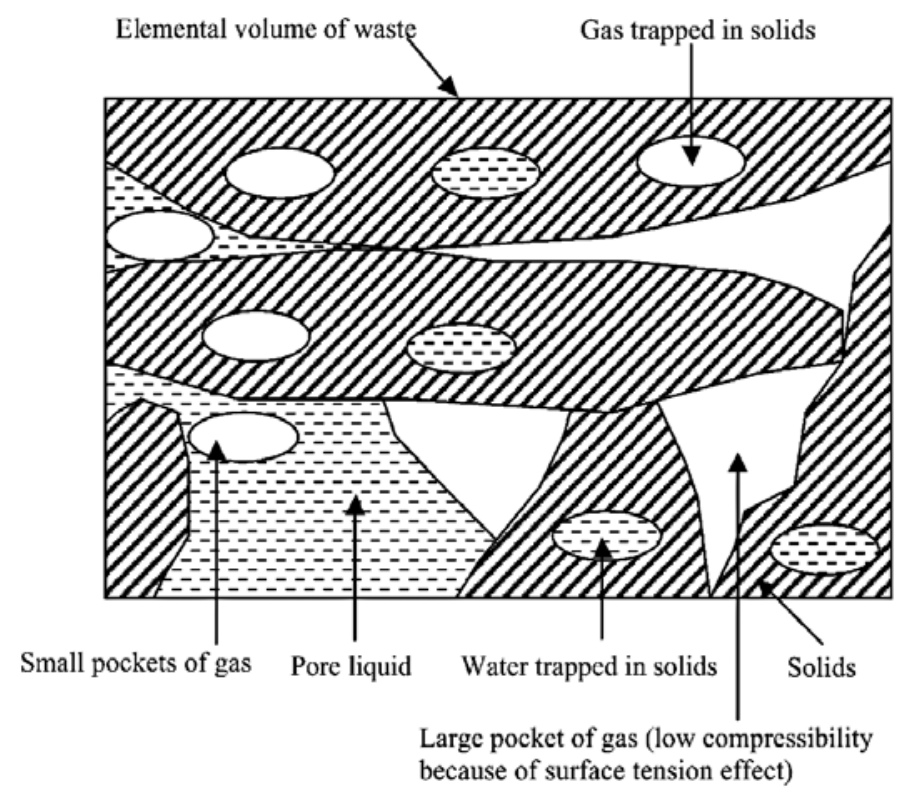

Figure 2.9. Intraparticle Voids Present Within the Elemental Volume of Waste (Hudson et al. 2004). 
The structure of MSW is best described as the response of the MSW fabric to the physical (i.e., degradation, climate) and mechanical (i.e., applied stress) variations over time. Several mechanisms contribute to the spatial and temporal variations in the structure of MSW including: saturation of individual waste constituents from excess moisture (i.e., precipitation, leachate recirculation) (Olivier and Gourc 2007), removal of solids through degradation processes, reduction of interparticle voids due to applied stresses and reorientation of particles (Hudson et al. 2004), deformation of solids due to applied stresses (e.g., Landva and Clark 1990; Beaven and Powrie 1996; Hudson et al. 2004), expulsion of liquid and gas from intraparticle pores in deformable degradable constituents due to applied stresses (Powrie and Beaven 1999; Hudson et al. 2004), intraparticle void reduction due to applied stresses and/or degradation of solids within an individual waste constituent (McDougall and Pyrah 2004). These physical and mechanical mechanisms result in a reduction of both the interparticle and intraparticle voids over time (Zhang et al. 2010).

\subsection{Physical Properties of MSW}

The physical properties of MSW, namely organic content, moisture conditions, and temperature, affect the engineering response of wastes in landfill systems. In this section, the physical properties of MSW and their influence on the engineering properties of waste are described in detail. 


\subsubsection{Organic Content}

Organic constituents (i.e., biodegradable materials) most commonly found in MSW include paper, cardboard, yard trimmings, wood, and food waste. The organic content of MSW is one of the most important physical properties of MSW because it has been demonstrated to influence other physical and mechanical properties of MSW including methane potential (Barlaz et al. 1989; Eleazer et al. 1997; Demirbas 2006), temperature (Yesiller et al. 2011), absorption capacity (Zornberg et al. 1999), unit weight (Kavazanjian 2006; Gomes and Lopes 2012); hydraulic conductivity (Beaven and Powrie 1996; Reddy et al. 2011; Wu et al. 2012), shear strength (Hossain et al. 2009; Reddy et al. 2009a; Reddy et al. 2011) and compressibility (e.g., Sowers 1973; Hossain et al. 2003; Reddy et al. 2009a; Bareither et al. 2012a; Zhao et al. 2012).

The amount of organic material present in fresh MSW at a landfill is influenced by several factors including geographical location of the landfill, seasonal variations, and the incoming waste stream variation (i.e., percentages of residential waste, commercial waste, agricultural waste, etc.). In general, organic material accounts for more than $50 \%$ (by weight) of the total MSW disposed of in landfills (Barlaz et al. 1990; Demirbas 2006). For example, in 2009 and 2011 approximately 53.8 and $53.3 \%$ of the total amount MSW discarded into U.S. landfills was organic material, respectively (USEPA 2010; USEPA 2013a).

Organic content can either be determined by incineration at high temperatures $\left(440-600^{\circ} \mathrm{C}\right)$ or by chemical oxidation. Incineration at high 
temperatures (or loss on ignition) can be used to determine the total organic matter content, usually designated as volatile solids (VS), total volatile solids (TVS) or ash content, whereas chemical oxidation can be used to determine the major biodegradable polymers in MSW (i.e., lignin, cellulose, and hemicellulose) (Gomes and Lopes 2012). Chemical oxidation is typically performed with various strong oxidizing agents in which samples of MSW are soaked for several hours to allow the acids to breakdown the polymers and carbohydrates (Kelly et al. 2006; Gomes and Lopes 2012). Both procedures are useful for characterizing the organic components of MSW however, loss on ignition (LOI) is a more general approach and used in this test program.

\subsubsection{Moisture}

Moisture in municipal solid waste affects both mechanical and biochemical processes in waste. Moisture provides an aqueous environment that facilitates the transport of nutrients and microbes, dilutes the concentration of inhibitors, and enhances the substrate access for microorganisms thus improving gas generation (El-Fadel and Al-Rashed 1998; Warith et al. 2005; Kulkarni and Reddy 2012). Furthermore, moisture affects the placement and compaction of MSW (Von Stockhausen 2007; Wong 2009) as well as the stability (i.e., shear strength) of the waste (Wong 2009). Moisture effects on compaction and waste placement are described in more detail in Section 2.12. Moisture content can be

expressed either gravimetrically or volumetrically (Equations 2.1-2.3). For this investigation, the term "moisture content" refers to the gravimetric moisture content of MSW on a dry mass basis unless otherwise stated. 
The optimum moisture content range for waste decomposition is 40 to 70\% (Guerin et al. 2004). The moisture distribution characteristics and amount of moisture in landfills are important parameters for landfill operators because moisture is considered to be the key factor for the degradation processes of MSW (Barlaz et al. 1989; El-Fadel and Al-Rashed 1998; Kazimoglu et al. 2005; Warith et al. 2005; Benson et al. 2007; Reddy et al. 2009a,b; Staub et al. 2010a). Consequently, landfill integrity and long-term performance are affected by the moisture properties of MSW (e.g., Beaven and Powrie 1996; Guerin et al. 2004; Imhoff et al. 2007; Kulkarni and Reddy 2012). In general, fresh MSW will contain some water but will not be fully saturated (Powrie and Beaven 1999). The sources of moisture in a landfill include precipitation/infiltration of storm water or systematic moisture addition (i.e., prewetting and/or leachate recirculation) (Imhoff et al. 2007). In this section, moisture properties of MSW including: moisture content, field capacity and absorptive capacity, and moisture distribution, are discussed in detail.

\section{Moisture Content}

Moisture content in landfills is highly dependent on several interrelated factors, including waste composition, weather conditions, landfill operating procedures, presence of leachate and/or gas collection systems, and closure sequence of the landfill (Zornberg et al. 1999). Due to the heterogeneity of MSW, it is common that the moisture content of waste vary significantly with location and depth. For example, a sample of waste at a given location and depth in a landfill may contain saturated or partially saturated intraparticle voids and dry 
interparticle voids, but a short distance away at the same depth, the waste composition may be entirely different and contain dry intraparticle voids and saturated interparticle voids (Landva and Clark 1990).

The gravimetric moisture content can be defined on a dry $\left(w_{d}\right)$ or wet $\left(w_{w}\right)$ mass basis. The dry mass based gravimetric moisture content is defined as the ratio of the mass of water to the mass of dry solids. The wet mass based gravimetric moisture content is defined as the ratio of the mass of water to the total mass of water and solids. The volumetric moisture content of MSW $(\theta)$ is defined as the ratio of the volume of moisture to the total volume of air, water, and solids. The three definitions of moisture content of MSW are presented in Equations (2.1-2.3):

$$
\begin{gathered}
w_{d}=\frac{M_{w}}{M_{s}} \\
w_{w}=\frac{M_{w}}{M_{t}} \\
\theta=\frac{V_{w}}{V_{t}}
\end{gathered}
$$

Where:

$$
\begin{aligned}
M_{w} & =\text { mass of moisture } \\
M_{s} & =\text { mass of solids } \\
M_{t} & =\text { total mass } \\
V_{w} & =\text { volume of moisture } \\
V_{t} & =\text { total volume }
\end{aligned}
$$

The type of moisture content (i.e., gravimetric or volumetric) that is reported in literature varies significantly. Development of relationships between 
gravimetric and volumetric moisture contents are required through weight-volume phase relation calculations to establish a framework for evaluating the results from the different studies (Zornberg et al. 1999; Imhoff et al. 2007). Numerous studies have reported the gravimetric moisture content of MSW (fresh and old) at landfills directly (e.g., Gabr and Valero 1995; Wall and Zeiss 1995; Beaven and Powrie 1996; Powrie and Beaven 1999; Zornberg et al. 1999; Gawande et al. 2003; Hettiarachchi 2005; Kelly et al. 2006; Reddy et al. 2009b; Staub et al. 2009; Staub et al. 2010a; Breitmeyer 2011; Bareither et al. 2012b; Gomes and Lopes 2012) and a wide range of values between 7 and $150 \%$ have been reported. High moisture contents (above 200\%) have been reported for a landfill in a tropical area with heavy rainfall (Marques et al. 2003). The distribution of moisture in a landfill, the degradation characteristics of MSW, and the effectiveness of leachate recirculation systems are all dependent on the accurate determination of the moisture content of MSW (Shihada et al. 2013).

The standard method to determine the moisture content of a MSW sample is similar to the thermogravimetric method used for soils (ASTM D2216), which consists of oven drying a given mass of the material at $110^{\circ} \mathrm{C}$ for 24 hours (ASTM 2010a). The main difference between the thermogravimetric method used for soils and MSW is the temperature at which a sample is oven dried. For example, Gabr and Valero (1995) suggested that the temperature should be $60^{\circ} \mathrm{C}$ to prevent the loss of volatiles while Zornberg et al. (1999) suggested oven drying at a temperature of $85^{\circ} \mathrm{C}$. Furthermore, Reddy et al. (2009a) oven dried MSW samples at several different temperatures for different durations of time 
and determined that oven drying at $60^{\circ} \mathrm{C}$ for 24 hours yielded the same results as oven drying at $105^{\circ} \mathrm{C}$ for 24 hours.

The thermogravimetric method is the only available direct method for determination of MSW moisture content and is both time consuming and destructive (Shihada et al. 2013). Nondestructive methods including: neutron probe (NP), electrical resistance sensors (ERS), electromagnetic techniques (EM) (i.e., time domain reflectometry and transmissivity, TDR and TDT), electrical resisitivity tomography (ERT), and partitioning gas tracer test (PGTT), have been implemented to determine the moisture content and moisture movement in MSW (e.g., Gawande et al. 2003; Imhoff et al. 2003; Imhoff et al. 2007; Carpenter et al. 2008; Staub et al. 2009; Staub et al. 2010b; Shihada et al. 2013).

After placement and compaction of MSW, the moisture content of the waste may increase through absorption of additional moisture (e.g., precipitation, leachate recirculation) by some components of the waste such as paper, cardboard and textiles or redistribution of moisture within the waste mass due to release from previously occluded voids. In practice it is very difficult to determine whether an increase in the overall water content is due to true absorption or to fluid trapped in non-drainable voids (Beaven and Powrie 1996). Knowledge of moisture movement through waste and moisture distribution properties of waste is necessary to prevent negative environmental effects (i.e., groundwater contamination) and ensure effective landfill operations (i.e., leachate collection and recirculation) (Stoltz et al. 2012). 


\section{Field Capacity, Absorptive Capacity, and Moisture Distribution}

Field capacity of waste is the quantity of water per unit volume that can be held within the waste against the force of gravity (Zornberg et al. 1999). Consequently, free liquid will be generated when the amount of moisture within the waste exceeds the field capacity (Beaven and Powrie 1996; Zornberg et al. 1999). Field capacity for soil was originally defined as "the amount of water held in the soil after the excess gravitational water has drained away and after the rate of downward movement of water has materially decreased" by Veihmeyer and Hendrickson (1931). Field capacity is a critical moisture retention property of MSW because it can be used to estimate leachate generation quantities at a landfill (Zornberg et al. 1999; Kazimoglu et al. 2005). Field capacity can be expressed using either volumetric or gravimetric relationships however, volumetric field capacity is more commonly reported (Beaven and Powrie 1996; Zornberg et al. 1999; Orta de Velasquez 2003; Breitmeyer 2011; Stoltz et al. 2012) and therefore will be defined as such in this test program unless otherwise stated.

Aside from field capacity, the absorptive capacity of MSW is another important moisture retention property. The absorptive capacity is defined as the difference between the initial volumetric water content and the field capacity of MSW (Beaven and Powrie 1996; Reinhart and Townsend 1998; Zornberg et al. 1999; Kazimoglu et al. 2005). Paper, cardboard, wood, and textiles are the individual waste components with the most absorptive potential and thus, tend to absorb moisture (to an extent) and increase the overall moisture content of the 
waste mass (Beaven 2000). Hentrich et al. (1979) reported that shredding of waste increases the absorptive capacity of waste while Zornberg et al. (1999) postulated that absorptive capacity decreases with increasing compression.

Limited laboratory- and field-scale studies have been conducted to determine the field capacity of waste and reported values range between 40 and 70\% (Beaven and Powrie 1996; Zornberg et al. 1999; Orta de Velasquez et al. 2003; Staub et al. 2009; Breitmeyer 2011; Stoltz et al. 2010; Stoltz et al. 2012). Field capacity was indicated to be a function of waste composition, age, density, and porosity (Beaven and Powrie 1996; Reinhart and Townsend 1998). For example, Holmes (1983) reported findings from analysis of samples obtained from nineteen landfills. Field capacity was observed to decline with age due to the degradation of organic materials that contribute most to the absorptive capacity of waste and field capacity also decreased with increasing density due to the collapse of pore spaces available to moisture migration and retention. Furthermore, field capacity was observed to decrease with increasing landfill depth due to the subsequent increase of overburden stresses in the lower layers of waste (Tchobanoglous et al. 1993 and Reinhart and Townsend 1998). Fungaroli and Steiner (1979), developed a relationship between field capacity and total unit weight of the waste (Equation 2.4). This relationship was later verified by Zornberg et al. (1999) through laboratory and field experiments on waste obtained at different depths from a landfill in California, United States.

$$
\theta_{F C}=21.7 \ln \left(\gamma_{t}\right)-5.4
$$

Where: 
$\theta_{F C}=$ volumetric field capacity of MSW (\%)

$\gamma_{t}=$ total unit weight of MSW $\left(\mathrm{kN} / \mathrm{m}^{3}\right)$

Uneven moisture distribution is a natural consequence of unsaturated flow, however in landfills this effect is pronounced by the heterogeneity of municipal solid waste (Reinhart and Townsend 1998; Catley et al. 2008). Moisture distribution is affected by the mechanisms of leachate movement through a given waste mass. Uniform distribution of moisture in landfills is virtually non-existent as the heterogeneity of waste leads to channeling and preferential flow of the downward movement of leachate. Furthermore, gas production can block flow paths and low permeability materials within the waste mass such as plastic bags can result in ponding of leachate (Reinhart and Townsend 1998). The processes affecting leachate movement through a landfill and ultimately affecting the distribution of moisture are summarized in Figure 2.10.

Zornberg et al. (1999) suggested that isolated liquid zones may exist because of localized disposal of liquid wastes and/or the use of relatively low permeable soils as daily cover. In addition, Zornberg et al. (1999) described the distribution of moisture in a landfill as a function of three mechanisms: 1) moisture within the intraparticle voids of the waste constituents; 2) moisture held in the interparticle voids between waste constituents by capillary forces; and 3) ponding of moisture due to low permeable layers within a given waste mass. 


\section{Landfill Surface}

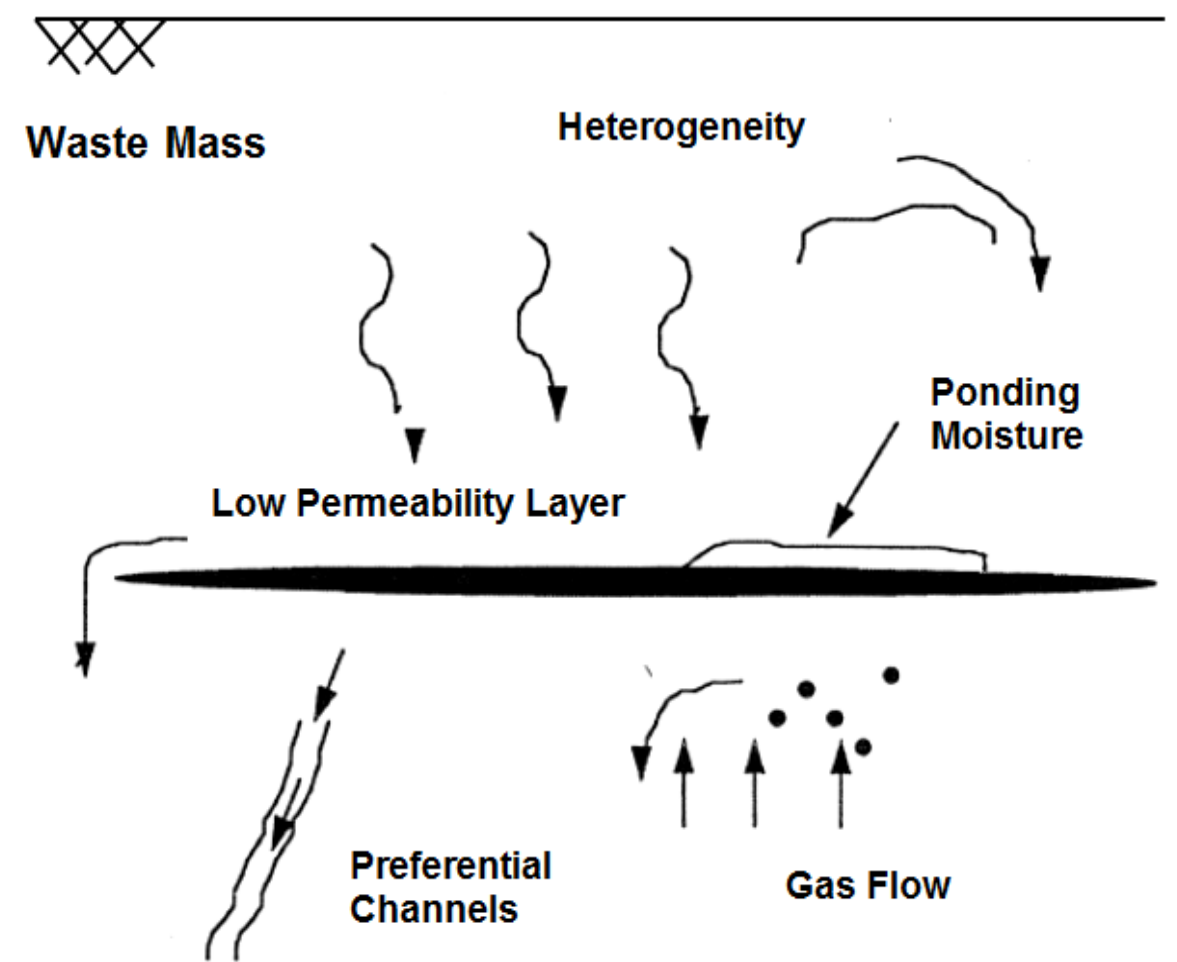

Figure 2.10. Processes Affecting Moisture Distribution in MSW (Adapted from Reinhart and Townsend 1998).

The complexity of the moisture distribution mechanisms is further defined by the modeling of moisture movement through waste and the development of the moisture retention curve (MRC). Kazimoglu et al. (2005) described moisture retention as a being a function of hydraulic boundary conditions and the age of the waste. Specifically, Kazimoglu et al. (2005) suggested that for MSW placed at a uniform incoming volumetric moisture content, moisture will redistribute towards the equilibrium moisture profile and may result in both drainage and absorption. That is, waste placed near the bottom of the landfill will have a higher equilibrium volumetric moisture content potential and will therefore absorb moisture as opposed to waste placed near the surface of the landfill which will have a lower equilibrium volumetric moisture content potential and will therefore 
tend to expel moisture. The concept of MRC in landfills is illustrated in Figure 2.11.

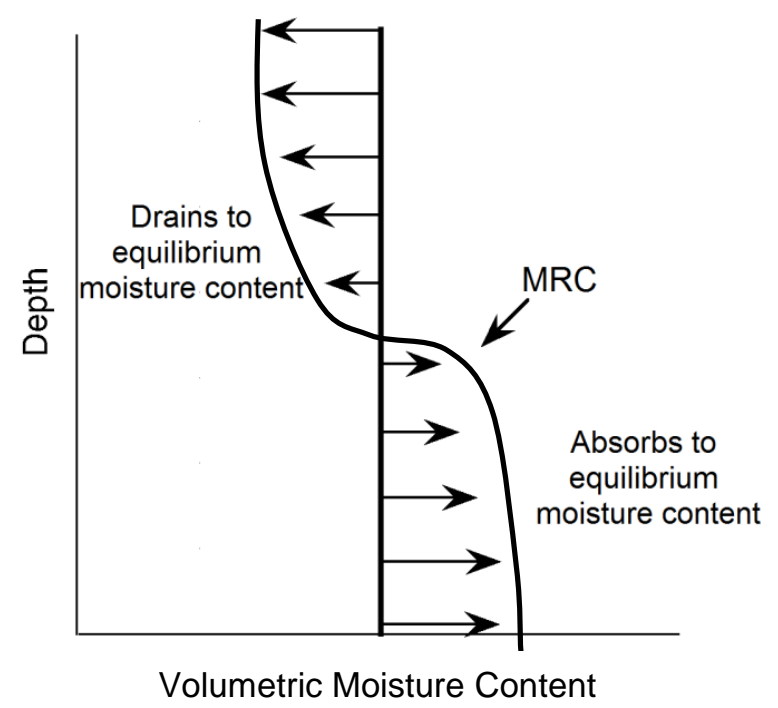

Figure 2.11. Moisture Storage Tendency in a Landfill with Respect to Depth (Adapted from Kazimoglu et al. 2005).

This concept correlates strongly to results obtained Breitmeyer (2011); Stoltz et al. (2012); and Wu et al. (2012). Breitmeyer (2011) determined that moisture retention capacity was influenced by matric suction and that waste at greater depths is subjected to lower matric suction and consequently retains a larger volume of liquid. In addition, Stoltz et al. (2012) further supported the MRC and indicated that competing mechanisms influenced the moisture retention properties of waste. First, compression influenced the volumetric moisture content of waste. The maximum measured volumetric moisture content (i.e., when suction equals zero) of waste specimens decreased as the dry density increased (i.e. greater depths) resulting in a reduction of the quantity of pores available to hold liquid (Stoltz et al. 2012). Next, the volumetric field capacity was observed to increase with increasing dry density at a given matric suction value 
which was attributed to the increase in capillary forces within the reduced pores at higher densities. Therefore, more moisture was absorbed into the waste at greater depths. The increase in capillary forces between MSW particles at greater depths due to reduced pore sizes was also observed by Wu et al. (2012). Wu et al. (2012) reported the volumetric field capacity of waste increased with increasing depth (i.e., increasing compressive stresses and levels of degradation) and postulated that hydraulic properties waste at greater depths behave similar to silt loams.

Moisture distribution within landfills, particularly bioreactor landfills, has been the focus of many numerical modeling, laboratory, and field studies over the past several years (e.g., Li and Zeiss 2001; Kazimoglu et al. 2005; Grellier et al. 2006; Capelo and De Castro 2007; Marcoux et al. 2007; Catley et al. 2008; Staub et al. 2009; Kadambala et al. 2011; Stoltz et al. 2012). Kulkarni and Reddy (2012) provided an extensive literature review of previous studies that have investigated moisture distribution (e.g., field capacity, absorption, moisture retention, flow characteristics) in landfills. Kulkarni and Reddy (2012) suggested that although the results from the studies have provided the industry with a better understanding of moisture distribution within landfills, many challenges still exist to accurately measure the moisture characteristics of MSW. In particular, the heterogeneity of MSW and the ability to uniformly distribute moisture throughout the waste mass are the two most challenging issues yet to overcome (Kulkarni and Reddy 2012). Furthermore, modeling and measuring moisture retention 
capabilities of intraparticle void spaces within MSW are needed to fully understand the moisture properties of waste (Stoltz et al. 2012).

\subsubsection{Temperature}

Heat is generated in a landfill as the organic constituents of MSW biodegrade. Factors such as depth of waste, rate of filling, climatic conditions, waste properties, and particularly waste moisture content have been determined to affect waste temperature (e.g., Rowe 1998, Yesiller et al. 2005, and Hanson et al. 2010b; Wang et al. 2012). Temperature affects bacterial growth and chemical reactions within a landfill including the solubility of many chemicals (Sethi et al. 2013).

Maximum temperatures occur at middle depths of the landfill and have been reported to occur approximately between 1 and 10 years upon placement of waste. In general, waste temperatures near the surface are similar to seasonal air temperatures, near the base of the landfill temperatures are slightly elevated, and in the center of the landfill temperatures are significantly higher than those near the surface and base of the landfill (Yesiller et al. 2005). The distribution and range of waste temperatures with depth is illustrated by the curvilinear relationship presented in Figure 2.12. 


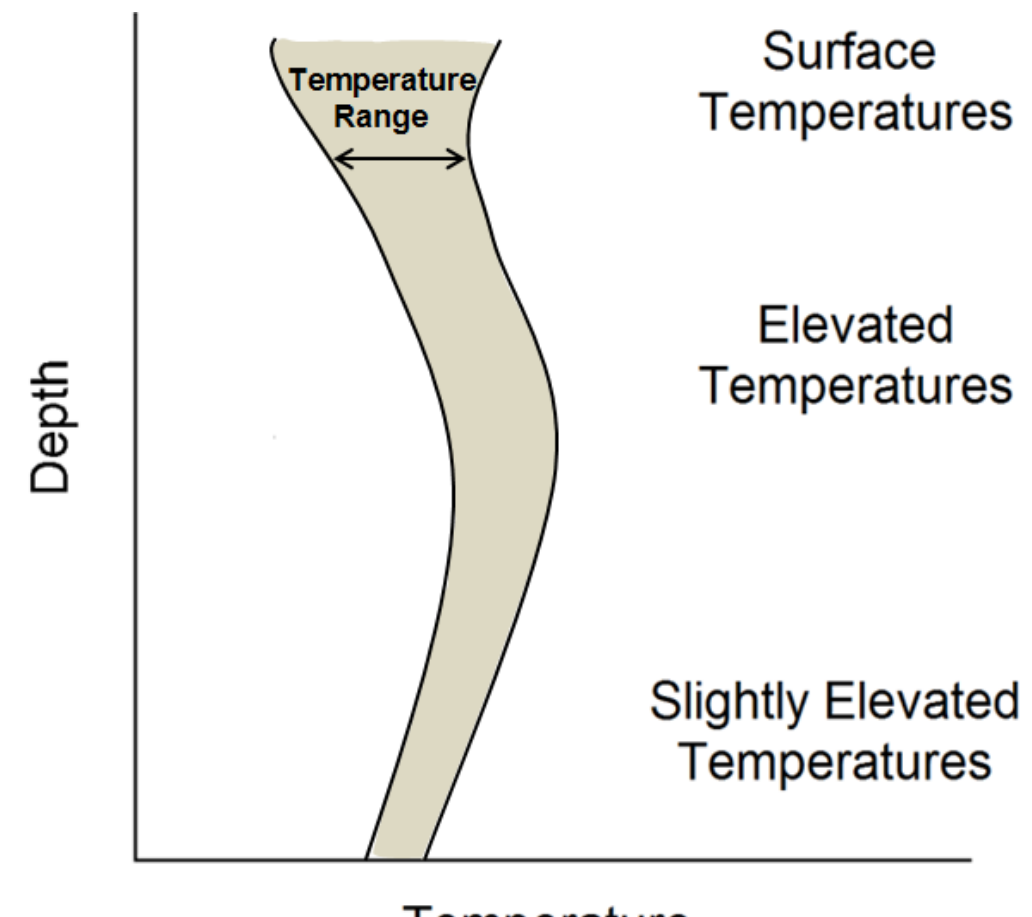

Temperature

Figure 2.12. Typical Relationship between Temperature and Depth at a Landfill (Based on Yesiller et al.2005 and Hanson et al. 2010b)

Several studies presented in the literature suggested a correlation exists between optimal temperature and elevated waste degradation and gas production to an extent (Rees 1980; Hartz et al. 1982; Mata-Alvarez and Martinez-Viturtia 1986; Blakey et al. 1997; Yesiller et al. 2011; Wang et al. 2012).

\subsection{Specific Gravity}

Specific gravity is broadly defined as the ratio of the density of a substance to the density of a standard reference substance. Specific gravity is used in geotechnical and geoenvironmental engineering in calculation of basic phase (i.e., weight-volume) relations such as void ratio, porosity, volumetric water content, and degree of saturation. In this section the specific gravity of soils are reviewed followed by a detailed summary of the reported methods for 
determining specific gravity of MSW. Lastly, the relationship between specific gravity and physical and engineering properties are described.

\subsubsection{Specific Gravity of Soil}

Several different specific gravities can be defined for engineering calculation however, for geotechnical engineering purposes, only bulk specific gravity $\left(G_{m}\right)$, specific gravity of solids $\left(G_{s}\right)$, and specific gravity of water $\left(G_{w}\right)$ are of interest (Holtz et al. 2011). The specific gravity of water is generally assumed to be 1.0 for temperature ranges between 0 and $40^{\circ} \mathrm{C}$ (Holtz et al. 2011). $G_{m}$ and $G_{s}$ are important properties for soils and $G_{s}$ is particularly important because it can be used to determine other fundamental properties of soil (e.g., degree of saturation, void ratio) through phase relationship calculations. The definition of specific gravity of solids used for soils is "the ratio of the mass of a unit volume of soil solids to the mass of the same volume of gas-free distilled water at $20^{\circ} \mathrm{C}$ " (ASTM D854) and $G_{s}$ is calculated as:

$$
G_{s}=\frac{\rho_{s}}{\rho_{w}}
$$

Where:

$$
\begin{aligned}
& G_{s}=\text { specific gravity of soil solids } \\
& \rho_{s}=\text { density of soil solids } \\
& \rho_{w}=\text { density of water at } 20^{\circ} \mathrm{C}
\end{aligned}
$$

Typical values for most inorganic soils range from 2.60 to 2.80 (Means and Parcher 1951), whereas organic soils have specific gravities less than 2.0 (Coduto et al. 2010). 


\subsubsection{Specific Gravity of MSW}

Limited data on specific gravity of MSW has been presented in the literature. $G_{s}$ of MSW is analogous to the definition used for soils and is an important property that can be used in MSW phase relationship analyses. Testing for waste specific gravity is complicated by several factors including: large particle sizes; heterogeneous mixture of particles (size, shape, and material composition); relative specific gravity of individual particles with respect to water; complex particle microstructure; and potential interaction with water.

In general, limited information is available on experimental determination of specific gravity of MSW. The ASTM standard method for determination of $G_{s}$ of soils, D854, is based on water pycnometry and has been used by Gabr and Valero (1995); Hettiarachchi (2005); Entenmann and Wendt (2007); Reddy et al. (2009a,b); Reddy et al. (2011); Breitmeyer (2011); and Wu et al. (2012) to determine specific gravity of MSW. Other methods such as back calculation analysis and weighted average analysis of individual waste constituents have been used to determine the particle density and specific gravity of MSW (Landva and Clark 1990; Powrie and Beaven 1999; Beaven 2000; Olivier and Gourc 2007; Hanson et al. 2010a; Stoltz et al. 2010). In this section, the details and results of the studies conducted to experimentally determine the specific gravity of MSW are described. Then, the back calculation analyses of MSW particle density and specific gravity that have been reported in literature are presented. Lastly, the reported weighted average analyses of individual waste constituents used to determine the particle density or specific gravity of MSW are described. 
Specific gravity tests were conducted by Gabr and Valero (1995) on 15- to 30-year-old waste recovered during boring procedures (i.e., drill cuttings) at a landfill in Pennsylvania, United States. The waste sampled during the drilling operations had a maximum particle size of $9.5 \mathrm{~mm}$ (Gabr and Valero 1995). Five of the waste specimens used for $G_{s}$ tests contained particles that were representative of the entire grain-size distribution while the other five specimens had a maximum particle size of $0.075 \mathrm{~mm}$ (No. 200 Sieve). The mass of the specimens used for the testing procedure were not reported. Average $G_{s}$ values of 2.0 and 2.4 were reported for the specimens representative of the entire grainsize curve and representative of only the finer fraction, respectively (Gabr and Valero 1995). Hettiarachchi (2005) conducted specific gravity tests on three 100 g specimens of a manufactured MSW sample with particle sizes less than $5 \mathrm{~mm}$. The manufactured MSW was prepared using the individual constituent weightbased percentages provided by USEPA.

Hettiarachchi (2005) used two separate mixing techniques for the specific gravity tests in order to produce a representative, yet fairly homogeneous mixture of waste. The $100 \mathrm{~g}$ waste specimen for Test 1 was prepared by weighing the individual waste constituents and preparing the mixture, while the waste specimens for Tests 2 and 3 were sampled from a large batch of uniformly mixed, manufactured MSW. The $G_{s}$ was determined to be 1.65 for Test 1 and 1.59 and 1.67 for Tests 2 and 3, respectively. Water pycnometry was used to test mechanically and biologically pre-treated waste by Entenmann and Wendt (2007). Limited information was provided regarding the testing procedures and 
sample preparation of the MSW used in this specific gravity test program. However, the $G_{s}$ was determined to be between 1.6 and 1.65 which is comparable to the results obtained by Hettiarachchi (2005).

Penmethsa (2007) conducted specific gravity tests on laboratory degraded MSW (maximum particle size of $50 \mathrm{~mm}$ ) obtained from a transfer station in Texas, United States. The waste from the transfer station was not entirely representative of typical MSW disposed of in landfills as it was only comprised of paper, textiles, food, plastic, and soil. Laboratory bioreactors were constructed and filled with the MSW obtained from the transfer station. The MSW was allowed to degrade in the biologically enhanced environment of the bioreactors and then sampled at different stages of degradation, designated as Phase 1, Phase 2, Phase 3, and Phase 4 (Penmethsa 2007). A total of 16 specific gravity tests were performed in accordance with ASTM standards D854 (ASTM 2010b) and D5057 (ASTM 2010c). Twelve tests were conducted on bulk MSW samples (3 at each phase of degradation) using ASTM D5057 and four tests were performed on MSW particles that passed the No. 200 sieve at each phase of degradation using ASTM D854 (Penmethsa 2007).

ASTM D5057 is the standard test method for determining the apparent specific gravity (ASG) and bulk density of waste and the "precision and bias of the test has not been determined due to the variability of the sample matrix" (ASTM 2010c). Thus, the reported values of ASG of MSW are difficult to compare to actual reported $G_{s}$ values that were determined using standard or modified water pyncometry methods. Neverthless, the ASG and $G_{s}$ were reported 
to decrease with increasing levels of degradation and the trends were attributed to the increase in percentage of plastic which has a relatively low specific gravity and decrease in percentage of paper with decomposition (Penmethsa 2007). The 3 ASG values determined for bulk waste samples at each phase of degradation were averaged and determined to be $1.07,0.95,0.91$, and 0.91 for Phase 1 , Phase 2, Phase 3, and Phase 4, respectively. Similarly, the $G_{s}$ values for MSW samples with particles finer than No. 200 were determined to be 1.65, 1.54, 1.52, and 1.48 for Phase 1, Phase 2, Phase 3, Phase 4, respectively (Penmethsa 2007).

$G_{s}$ was determined on shredded fresh (from active face) and old (1.5 years) wastes from a MSW landfill in the U.S in accordance with ASTM D854. Reddy et al. (2009a) prepared the fresh and old waste samples such that the maximum particle size was approximately $40 \mathrm{~mm}$. The measured specific gravities were 0.85 and 0.97 for fresh and old wastes, respectively (Reddy et al. 2009a,b). Reddy et al. (2009b) noted that the maximum size and size distribution of the MSW particles should be taken into account when laboratory results are interpreted or compared due to the significant difference between their results and the Gs values reported by Hettiarachchi (2005). Reddy et al. (2011) performed specific gravity tests on fresh and degraded manufactured MSW. The level of degradation was rated from a low to high degree of degradation (DOD) and was determined using a relationship between the initial and final organic content of the tested MSW specimens. In all, one fresh and four degraded waste specimens were tested. 
The $G_{s}$ was determined to be 1.09 for the fresh manufactured waste, whereas the $G_{s}$ was determined to be $2.05,2.26,2.30$, and 2.47 for the four specimens that were tested at increasing levels of degradation from 1-4. Tests were conducted on waste samples obtained from shallow, middle, and deep layers of a MSW landfill in China by Wu et al. (2012). The particle size distributions of the waste samples from the three layers in the landfill indicated that 50 to $65 \%$ of the particle sizes were larger than $4.75 \mathrm{~mm}$. Limited details were provided and sample size was not given. The $G_{s}$ was reported to be 1.51 , 1.88, and 2.14 for shallow, middle, and deep layers of the waste mass, respectively (Wu et al. 2012).

A modified version of ASTM D854 was used by Breitmeyer (2011) on MSW specimens with particle sizes less than $25 \mathrm{~mm}$ and masses between 300 and $450 \mathrm{~g}$. Tests were conducted using a two-chambered vessel (75-mm diameter by 300-mm tall) separated by a steel, perforated disk, which prevented floating of low specific gravity particles. The $G_{s}$ was determined to be 1.34 for shredded and recombined relatively fresh (3-4 month old) wastes obtained from an MSW landfill. The $G_{s}$ was determined to be $1.65,1.80$, and 1.90 for shredded and recombined relatively fresh wastes obtained from the same MSW landfill that had undergone low, medium, and high levels of degradation, respectively in laboratory reactors (Breitmeyer 2011). Additionally, specific gravity was determined to be 1.84 for shredded and recombined waste that had undergone 1097 days of enhanced degradation in a large-scale $(8.2 \mathrm{~m}$ height, $2.4 \mathrm{~m}$ diameter) lysimeter test program (Breitmeyer 2011). 
Stoltz et al. (2010) determined solid density of waste for specimens obtained from incoming wastes at a MSW landfill in France (mixture of household and non-hazardous industrial waste). The solid density was calculated using measurements obtained from compression tests in a specially designed oedopermeameter operated in a manner similar to a gas pycnometer for determination of waste gas content. The solid density was reported for 10 separate tests and ranged between 1.572 and $1.697 \mathrm{Mg} / \mathrm{m}^{3}$ with an average value of $1.65 \mathrm{Mg} / \mathrm{m}^{3}$ (Stoltz et al. 2010). In addition, Stoltz et al. (2010) compared the solid density values obtained from the modified gas pyncnometer tests and provided an estimate of solid density as $1.37 \mathrm{Mg} / \mathrm{m}^{3}$ based on a weighted average of individual waste constituent densities obtained from the literature. The discrepancy between the estimated (1.37) and the experimental (1.65) value was explained with uncertainties in obtaining representative composition of the tested wastes and potential approximations involved in the constituent component data provided in the literature (Stoltz et al. 2010).

In addition to experimentally obtained waste particle densities and Gs values, Powrie and Beaven (1999) and Beaven (2000), determined the particle density of waste through back calculation methods. Powrie and Beaven (1999) and Beaven (2000) back calculated particle densities of MSW using data obtained from 1-D compression tests. Both Powrie and Beaven (1999) and Beaven (2000) observed an increase in average particle density with increasing average stress and concluded that such a relationship was not surprising considering the deformable and compressible nature of individual waste 
components. Powrie and Beaven calculated that the particle density increased from 0.876 to $1.303 \mathrm{Mg} / \mathrm{m}^{3}$ with an increase in average stress from 34 to $463 \mathrm{kPa}$ and associated increase in waste dry density from 0.39 to $0.71 \mathrm{Mg} / \mathrm{m}^{3}$. A similar analysis was made by Beaven (2000) for pulverized waste, where the particle density increased from 0.59 to $0.93 \mathrm{Mg} / \mathrm{m}^{3}$ with an increase in average stress from 35 to $486 \mathrm{kPa}$. Hanson et al. (2010a) suggested that specific gravity and unit weight increased with increasing compactive effort.

Hanson et al. (2010a) determined the specific gravity of MSW through back calculation methods. $A G_{s}$ value of 1.6 was back calculated using laboratory compaction curves generated using $4 \mathrm{X}$ modified effort. This calculation was based on an assumed degree of saturation (S) of $85 \%$ calculated from the modified effort compaction curve at the optimum moisture content and maximum dry unit weight data point. Specifically, Hanson et al. (2010a) determined 85\% degree of saturation by assuming Gs of 1.4 for the modified effort compaction data (i.e., maximum dry density and optimum moisture content) and then applied the same degree of saturation along line of optimums (LOO) to the $4 \mathrm{X}$ modified effort compaction curve. Furthermore, Hanson et al. (2010a) estimated a $G_{s}$ value of 1.55 for $4 X$ modified effort using data provided by Hudson et al. (2004), for variable waste particle densities obtained from waste compression tests.

Particle densities for MSW constituent components or overall MSW also have been provided in the literature and in general, these data were obtained using indirect methods and not through direct measurements. Weighted average particle density (Landva and Clark 1990; Olivier and Gourc 2007; Stoltz et al. 
2010a) and specific gravity (Wong 2009) values for MSW were determined using the individual waste constituent densities or specific gravities (Landva and Clark 1990; Olivier and Gourc 2007; Wong 2009; Stoltz et al. 2010). Particle densities for select waste constituents were provided by Landva and Clark (1990) based on a combination of approaches: data obtained from literature, densities determined using mass/volume measurements, densities determined using assumed $G_{s}$ values, and entirely assumed values. The data reported by Landva and Clark (1990) were $1.0 \mathrm{Mg} / \mathrm{m}^{3}$ for food waste; $0.3 \mathrm{Mg} / \mathrm{m}^{3}$ for garden waste; $0.4 \mathrm{Mg} / \mathrm{m}^{3}$ for paper; $1.1 \mathrm{Mg} / \mathrm{m}^{3}$ for plastic and rubber; $0.3 \mathrm{Mg} / \mathrm{m}^{3}$ for textiles; $0.45 \mathrm{Mg} / \mathrm{m}^{3}$ for wood; $6.0 \mathrm{Mg} / \mathrm{m}^{3}$ for metal; $2.9 \mathrm{Mg} / \mathrm{m}^{3}$ for glass and ceramics; and $1.8 \mathrm{Mg} / \mathrm{m}^{3}$ for ash, rock, and soil. Landva and Clark (1990) did not provide a weighted average value for the solid density of MSW. However, a weighted average solid density value of $1.18 \mathrm{Mg} / \mathrm{m}^{3}$ can be determined by applying the data provided by Landva and Clark (1990) to the weight-based percentage breakdown of constituents discarded into U.S. landfills in 1990 (USEPA 2013a).

Olivier and Gourc (2007) reported a waste solid density of $1.03 \mathrm{Mg} / \mathrm{m}^{3}$ for a manufactured waste sample. The calculation was based on individual waste constituent densities and the waste density was calculated by averaging the density of individual solid constituents determined using the mass of the solids (including any bound water) and the volume of the solids for a given material. This method was determined to yield an underestimate of the actual waste solid density due to difficulties in testing procedures (Olivier and Gourc 2007). A weighted average $G_{s}$ value of 1.4 was reported by Wong (2009) which was 
based on individual constituent specific gravities that coincided with percentage MSW constituent breakdowns provided by USEPA "2007 Facts and Figures." The individual MSW constituent specific gravity values were determined through experimentation and literature research.

A summary of the $G_{s}$ values determined using experimental test programs, back calculation analysis, and constituent weighted average analysis in the literature is provided in Table 2.2. 
Table 2.2. $G_{s}$ Values of MSW Reported in Literature

\begin{tabular}{|c|c|c|c|c|}
\hline Method & Material & Details & $\begin{array}{l}\mathbf{G}_{s} \text { (Unit less) or } \\
\text { Particle Density }\end{array}$ & Reference \\
\hline Weighted Average & $\begin{array}{c}\text { Unprocessed } \\
\text { Waste }\end{array}$ & $\begin{array}{l}\text { - Individual waste constituent densities obtained } \\
\text { from literature, mass/volume measurements, } \\
\text { assumed } G_{s} \text { values, and entirely assumed values } \\
\text { - Weighted average determined using USEPA's } \\
\text { "Materials Discarded in The Municipal Waste } \\
\text { Stream" (USEPA 2013a) in } 1990\end{array}$ & $1.18 \mathrm{Mg} / \mathrm{m}^{3}$ & $\begin{array}{l}\text { Landva } \\
\text { and Clark } \\
\quad(1990)\end{array}$ \\
\hline $\begin{array}{l}\text { Experimental } \\
\text { (ASTM D854) }\end{array}$ & $\begin{array}{c}\text { Old Shredded } \\
\text { Waste }\end{array}$ & $\begin{array}{l}\text { - Samples obtained from different depths during a } \\
\text { drilling operation at a landfill in U.S. } \\
\text { - Max. particle size was } 9.5 \mathrm{~mm} \\
\text { - Specimens representative of both the full grain- } \\
\text { size distribution and of the fine fraction were tested }\end{array}$ & $\begin{array}{l}2.0 \\
\text { (Full Grain-Size) } \\
\\
2.4 \\
\text { (Fines Only) }\end{array}$ & $\begin{array}{c}\text { Gabr and } \\
\text { Valero (1995) }\end{array}$ \\
\hline Back Calculation & $\begin{array}{l}\text { Unprocessed } \\
\text { Fresh MSW }\end{array}$ & $\begin{array}{l}\text { - Fresh household waste obtained from UK landfill } \\
\text { - Compression tests conducted in large cell ( } 3 \mathrm{~m} \\
\text { height } \times 2 \mathrm{~m} \text { diameter) at stresses ranging } \\
\text { between } 34 \text { to } 463 \mathrm{kPa}\end{array}$ & $\begin{array}{c}0.876-1.303 \\
\mathrm{Mg} / \mathrm{m}^{3}\end{array}$ & $\begin{array}{l}\text { Powrie } \\
\text { and Beaven } \\
\quad(1999)\end{array}$ \\
\hline Back Calculation & $\begin{array}{l}\text { Fresh } \\
\text { Shredded } \\
\text { MSW }\end{array}$ & $\begin{array}{l}\text { - Fresh household waste obtained from UK landfill } \\
\text { - Compression tests conducted in large cell ( } 3 \mathrm{~m} \\
\text { height } \times 2 \mathrm{~m} \text { diameter) at stresses ranging } \\
\text { between } 35 \text { to } 486 \mathrm{kPa} \\
\text { - Max. particle size was } 160 \mathrm{~mm}\end{array}$ & $0.59-0.93 \mathrm{Mg} / \mathrm{m}^{3}$ & $\begin{array}{c}\text { Beaven } \\
(2000)\end{array}$ \\
\hline $\begin{array}{l}\text { Experimental } \\
\text { (ASTM D854) }\end{array}$ & $\begin{array}{c}\text { Manufactured } \\
\text { Waste }\end{array}$ & $\begin{array}{l}\text { - Waste specimens generated using constituent } \\
\text { composition provided by USEPA } \\
\text { - } 100 \mathrm{~g} \text { specimens } \\
\text { - Max. Particle sizes less than } 5 \mathrm{~mm}\end{array}$ & $\begin{array}{l}1.65 \text { (Test } 1) \\
1.59 \text { (Test 2) } \\
1.67(\text { Test } 3) \\
\text { (Avg. } 1.64)\end{array}$ & $\begin{array}{l}\text { Hettiarachchi } \\
\text { (2005) }\end{array}$ \\
\hline
\end{tabular}


Table 2.2. $G_{s}$ Values of MSW Reported in Literature (Cont.)

\begin{tabular}{|c|c|c|c|c|}
\hline Method & Material & Details & $\begin{array}{l}G_{s} \text { (Unit less) or } \\
\text { Particle Density }\end{array}$ & Reference \\
\hline $\begin{array}{c}\text { Experimental (Water } \\
\text { Pycnometry) }\end{array}$ & $\begin{array}{l}\text { Mechanically } \\
\text { and Biologically } \\
\text { Pre-Treated } \\
\text { Waste }\end{array}$ & $\begin{array}{l}\text { Waste samples obtained prior to disposal from a } \\
\text { German landfill and then mechanically and } \\
\text { biologically treated }\end{array}$ & $1.6-1.65$ & $\begin{array}{l}\text { Entenmann } \\
\text { and Wendt } \\
\quad(2007)\end{array}$ \\
\hline $\begin{array}{l}\text { Experimental } \\
\text { (ASTM D854 and } \\
\text { D5057) }\end{array}$ & $\begin{array}{l}\text { Laboratory } \\
\text { Degraded } \\
\text { Waste }\end{array}$ & $\begin{array}{l}\text { - Samples obtained from transfer station in U.S. } \\
\text { - MSW comprised only of paper, plastic, food, textile, } \\
\text { and soil } \\
\text { - Both bulk samples (max. particle size } 50 \mathrm{~mm} \text { ) and } \\
\text { finer particle samples (max. particle size } 0.075 \mathrm{~mm} \text { ) } \\
\text { tested } \\
\text { - Apparent specific gravity (ASG) determined for bulk } \\
\text { samples; } G_{s} \text { determined for finer particle samples } \\
\text { - Samples tested at four stages of degradation: Phase } \\
\text { 1, Phase } 2, \text { Phase } 3 \text {, and Phase } 4\end{array}$ & $\begin{array}{l}\text { ASG } \\
1.07 \text { (Phase 1) } \\
0.95 \text { (Phase 2) } \\
0.91 \text { (Phase 3) } \\
0.91 \text { (Phase 4) } \\
\qquad G_{s} \\
1.65 \text { (Phase 1) } \\
1.54 \text { (Phase 2) } \\
1.52 \text { (Phase 3) } \\
1.46 \text { (Phase 4) }\end{array}$ & $\begin{array}{l}\text { Penmethsa } \\
(2007)\end{array}$ \\
\hline Weighted Average & $\begin{array}{l}\text { Unprocessed } \\
\text { Fresh Waste }\end{array}$ & $\begin{array}{l}\text { - Calculation was based on individual waste } \\
\text { constituent densities } \\
\text { - Solid constituent densities determined using the } \\
\text { mass of the solids (including any bound water) and } \\
\text { the volume of the solids for a given material }\end{array}$ & $1.03 \mathrm{Mg} / \mathrm{m}^{3}$ & $\begin{array}{l}\text { Olivier and } \\
\text { Gourc (2007) }\end{array}$ \\
\hline $\begin{array}{l}\text { Experimental } \\
\text { (ASTM D854) }\end{array}$ & $\begin{array}{c}\text { Fresh Shredded } \\
\text { Waste }\end{array}$ & $\begin{array}{l}\text { - Samples obtained from active face of a landfill in U.S. } \\
\text { - Sample collection prior or post compaction } \\
\text { not reported } \\
\text { - Max. particle size was } 40 \mathrm{~mm}\end{array}$ & 0.85 & $\begin{array}{l}\text { Reddy et al. } \\
\text { (2009a) }\end{array}$ \\
\hline $\begin{array}{l}\text { Experimental } \\
\text { (ASTM D854) }\end{array}$ & $\begin{array}{c}\text { Old Shredded } \\
\text { Waste }\end{array}$ & $\begin{array}{l}\text { - Samples obtained from } 20 \mathrm{~m} \text { depth at landfill in U.S. } \\
\text { - Waste age was } 1.5 \text { years } \\
\text { - Max. particle size was } 40 \mathrm{~mm}\end{array}$ & 0.97 & $\begin{array}{l}\text { Reddy et al. } \\
\text { (2009a) }\end{array}$ \\
\hline
\end{tabular}


Table 2.2. $G_{s}$ Values of MSW Reported in Literature (Cont.)

\begin{tabular}{|c|c|c|c|c|}
\hline Method & Material & Details & $\begin{array}{l}G_{s} \text { (Unit less) or } \\
\text { Particle Density }\end{array}$ & Reference \\
\hline Weighted Average & $\begin{array}{l}\text { Unprocessed } \\
\text { Waste }\end{array}$ & $\begin{array}{l}\text { - Individual waste constituent } G_{s} \text { values obtained } \\
\text { from literature research and experimentation, } \\
\text { - Weighted average determined using USEPA's } \\
\text { "Materials Discarded in The Municipal Waste } \\
\text { Stream" (USEPA 2013a) in } 2007\end{array}$ & 1.4 & $\begin{array}{l}\text { Wong } \\
\text { (2009) }\end{array}$ \\
\hline Back Calculation & $\begin{array}{l}\text { Fresh } \\
\text { Manufactured } \\
\text { Waste }\end{array}$ & $\begin{array}{l}\text { - Analyzed increasing compactive effort and } G_{s} \\
\text { - Manufactured waste based on USEPA individual } \\
\text { MSW constituent breakdown }\end{array}$ & $\begin{array}{l}1.6 \\
1.55 \\
\text { (Estimated using } \\
\text { Hudson et al. } \\
\text { 2004 data) } \\
\end{array}$ & $\begin{array}{l}\text { Hanson et al. } \\
\text { (2010a) }\end{array}$ \\
\hline $\begin{array}{l}\text { Experimental } \\
\text { (Oedopermeameter- } \\
\text { Modified Gas } \\
\text { Pycnometry) }\end{array}$ & $\begin{array}{l}\text { Fresh Shredded } \\
\text { Waste }\end{array}$ & $\begin{array}{l}\text { - Samples obtained prior to disposal from a French } \\
\text { landfill } \\
\text { - Incoming waste was a mixture of household and } \\
\text { non-hazardous industrial wastes } \\
\text { - Conducted } 10 \text { compression tests at stresses } \\
\text { ranging from } 20 \text { to } 300 \mathrm{kPa} \\
\text { - Max. particle size was } 70 \mathrm{~mm}\end{array}$ & $\begin{array}{l}1.572-1.697 \\
\mathrm{Mg} / \mathrm{m}^{3} \\
\text { (Avg. } 1.65)\end{array}$ & $\begin{array}{l}\text { Stoltz et al. } \\
(2010 a)\end{array}$ \\
\hline Weighted Average & $\begin{array}{l}\text { Unprocessed } \\
\text { Fresh Waste }\end{array}$ & $\begin{array}{l}\text { - Estimated solid density based on a weighted } \\
\text { average of individual constituent densities } \\
\text { obtained from the literature }\end{array}$ & $1.37 \mathrm{Mg} / \mathrm{m}^{3}$ & $\begin{array}{l}\text { Stoltz et al. } \\
\text { (2010a) }\end{array}$ \\
\hline
\end{tabular}


Table 2.2. $G_{s}$ Values of MSW Reported in Literature (Cont.)

\begin{tabular}{|c|c|c|c|c|}
\hline Method & Material & Details & $\begin{array}{l}G_{s} \text { (Unit less) or } \\
\text { Particle Density }\end{array}$ & Reference \\
\hline $\begin{array}{c}\text { Experimental } \\
\text { (Modified ASTM D854) }\end{array}$ & $\begin{array}{l}\text { Relatively } \\
\text { Fresh Waste }\end{array}$ & $\begin{array}{l}\text { - Shredded and recombined relatively fresh (3-4 } \\
\text { month old) wastes obtained from a landfill } \\
\text { - Max. particle size was } 25 \mathrm{~mm}\end{array}$ & 1.34 & $\begin{array}{l}\text { Breitmeyer } \\
\quad(2011)\end{array}$ \\
\hline $\begin{array}{c}\text { Experimental } \\
\text { (Modified ASTM D854) }\end{array}$ & $\begin{array}{l}\text { Laboratory } \\
\text { Degraded } \\
\text { Waste }\end{array}$ & $\begin{array}{l}\text { - Same waste as above after low (L), medium (M), } \\
\text { and high (H) degradation in the laboratory and } \\
\text { after degradation for } 1097 \text { days in a biologically } \\
\text { enhanced lysimeter (BEL) } \\
\text { - Max. particle size was } 25 \mathrm{~mm}\end{array}$ & $\begin{array}{c}1.65(\mathrm{~L}) \\
1.80(\mathrm{M}) \\
1.90(\mathrm{H}) \\
1.84(\mathrm{BEL})\end{array}$ & $\begin{array}{l}\text { Breitmeyer } \\
\quad(2011)\end{array}$ \\
\hline $\begin{array}{l}\text { Experimental } \\
\text { (ASTM D854) }\end{array}$ & $\begin{array}{l}\text { Undegraded } \\
\text { Manufactured } \\
\text { Waste }\end{array}$ & $\begin{array}{l}\text { - U.S. representative waste stream } \\
\text { - Max. particle size was } 40 \mathrm{~mm}\end{array}$ & 1.09 & $\begin{array}{l}\text { Reddy et al. } \\
\text { (2011) }\end{array}$ \\
\hline $\begin{array}{l}\text { Experimental } \\
\text { (ASTM D854) }\end{array}$ & $\begin{array}{l}\text { Degraded } \\
\text { Manufactured } \\
\text { Waste }\end{array}$ & $\begin{array}{l}\text { - U.S. representative waste stream } \\
\text { - Max. particle size was } 40 \mathrm{~mm} \\
\text { - Tested at } 4 \text { levels of degradation }\end{array}$ & $\begin{array}{l}2.05 \text { (Level 1) } \\
2.26 \text { (Level 2) } \\
2.30 \text { (Level 3) } \\
2.47 \text { (Level 4) }\end{array}$ & $\begin{array}{l}\text { Reddy et al. } \\
\text { (2011) }\end{array}$ \\
\hline Experimental & Old Waste & $\begin{array}{l}\text { - Wastes obtained from shallow (S), middle (M), and } \\
\text { deep (D) layers from a landfill in China }\end{array}$ & $\begin{array}{l}1.51(\mathrm{~S}) \\
1.88(\mathrm{M}) \\
2.14(\mathrm{D})\end{array}$ & $\begin{array}{l}\text { Wu et al. } \\
\text { (2012) }\end{array}$ \\
\hline
\end{tabular}




\subsubsection{Relationship Between $G_{s}$ and Other Waste Properties}

The specific gravity of MSW has been demonstrated to increase with an increasing level of decomposition (i.e., increasing depth or decreasing organic fraction) (Breitmeyer 2011; Reddy et al. 2011; Wu et al. 2012). As lighter organic matter is broken down and consumed by microbes during degradation stages of MSW, the heavier inorganic materials remain and therefore result in elevated $G_{s}$

values (Wu et al. 2012). Bareither et al. (2012a) expanded on this concept and presented a linear relationship between the $G_{s}$ values of MSW degraded to low, medium, and high levels reported by Breitmeyer (2011) and the methane yield from the corresponding laboratory bioreactors (Equation 2.5).

$$
G_{s}=\left(0.183 * C_{4} \text { Yield }\right)+1.55
$$

Where:

$\mathrm{CH}_{4}$ Yield $=$ methane yield for degraded waste $\left(\mathrm{L}-\mathrm{CH}_{4} / \mathrm{kg}\right.$-dry mass $)$

However, the results provided by Penmethsa (2007) demonstrated an opposite trend. Penmethsa (2007) suggested that the lower $G_{s}$ values at higher stages of degradation were attributed to the presence of higher quantities of lighter materials, such as plastics. The materials tested by Penmethsa (2007) were obtained from a transfer station and were not entirely representative of typical MSW.

Variations in particle density and specific gravity of wastes due to applied stress have been reported by Powrie and Beaven (1999); Beaven (2000); and Hanson et al. (2010a). These investigations did not include direct measurement of particle density or specific gravity, but back calculation of the parameters using 
data obtained in 1-D compression test programs on fresh waste. Hanson et al. (2010a) postulated that the unit weight and specific gravity of waste solids increased with compactive effort to explain sharp increases in the dry unit weight of wastes with relatively low change in moisture content in laboratory and field compaction tests. Unlike soils, the zero air voids (ZAV) curve for wastes was not unique and a composite zero air voids curve ( $\left.Z A V_{\text {composite }}\right)$ corresponding to progressively increasing $G_{s}$ was proposed for MSW (Figure 2.13). The new $Z A V_{\text {composite }}$ was positioned parallel to the line of optimums to describe the equivalent degrees of saturation at the peak of the compaction curves (Hanson et al. 2010a).

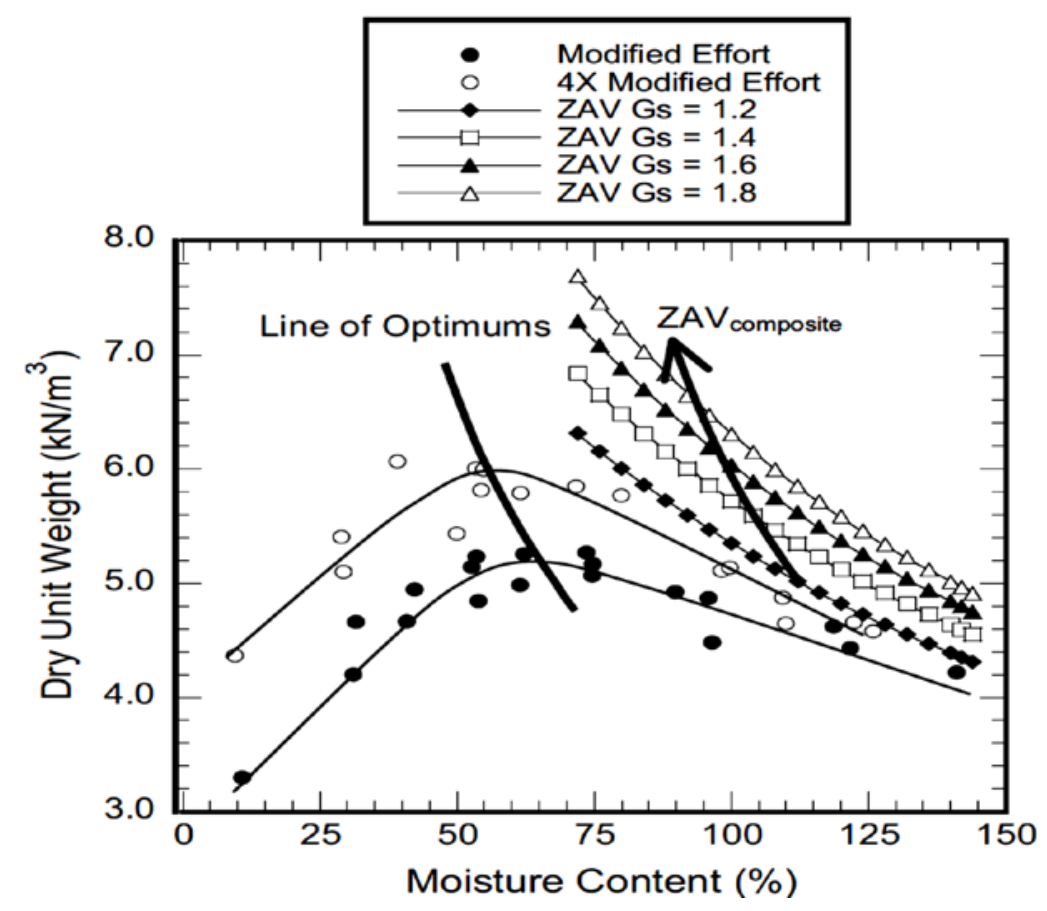

Figure 2.13. Relationship Between $G_{s}$ and Compactive Effort (Hanson et al. 2010a)

Systematic analysis of particle size effects on $G_{s}$ of MSW has not been provided in the literature. However, such data were provided for other materials 
including volcanic rocks (Wesley 2001 and Tamari et al. 2005) and an industrial byproduct (Millspaugh et al. 2010). The $G_{s}$ of volcanic scoria increased from 1.20 to 2.34 when the particle size decreased from $15 \mathrm{~mm}$ to less than $74 \mu \mathrm{m}$ (Wesley 2001) and the $G_{s}$ of volcanic scoria increased from 2.55 to 2.79 when the particle size decreased from $4.75 \mathrm{~mm}$ to $35 \mu \mathrm{m}$ (Tamari et al. 2005). Millspaugh et al. (2010) measured similar trends for chromium ore processing residue. The $G_{s}$ increased from 3.146 to 3.355 and 2.711 to 2.720 for two types of ore residue when the ore material was ground to a nominal particle size of $80 \mu \mathrm{m}$ (unground particle sizes were not provided). Presence of closed intraparticle voids and opening of these voids to the atmosphere during particle size reduction were indicated to be the mechanism for increased $G_{s}$. Visual evidence of intraparticle voids and presence of secondary porosity determined by SEM were provided for the chromium ore by Tinjum et al. (2008).

\subsection{Unit Weight of MSW}

The unit weight of municipal solid waste is a necessary parameter for engineering analyses of landfills (Zekkos et al. 2006). MSW unit weight is required for analysis and evaluation of static and dynamic slope stability, liner integrity, settlement prediction, structural integrity of pipe systems, capacity of geosynthetic drainage systems, and landfill capacity (Dixon and Jones 2005; Zekkos et al. 2005; Zekkos et al. 2006; Kavazanjian 2006). Variation in reported MSW unit weight values between landfill sites in significant, which is attributed to differences in waste composition, waste placement conditions (e.g, compaction procedures, incoming moisture content, daily cover material), and confining 
stresses (Dixon and Jones 2005; Zekkos et al. 2006). Zekkos (2005) compiled data from 37 different landfills and reported a range of in-situ unit weight values of MSW between 3 and $20 \mathrm{kN} / \mathrm{m}^{3}$. Qian et al. (2002) reported a similar range (3.1 to $13.2 \mathrm{kN} / \mathrm{m}^{3}$ ) of average unit weights reported in the literature.

Three methods can be used to determine the unit weight of MSW (Zekkos 2005; Zekkos et al. 2005; Zekkos et al. 2006) and are presented in Table 2.3.

Table 2.3. Methods for Determining Unit Weight of MSW

\begin{tabular}{|c|c|c|}
\hline Method & Description & Limitation \\
\hline $\begin{array}{c}\text { Surveys and } \\
\text { Site Records }\end{array}$ & $\begin{array}{c}\text { Landfill records provide total weight } \\
\text { of waste landfilled and surveys } \\
\text { allow for volumes of the in place } \\
\text { materials to be estimated }\end{array}$ & $\begin{array}{c}\text { Provides a good estimation of } \\
\text { the average unit weight but } \\
\text { does not provide a means of } \\
\text { assessing the unit weight as it } \\
\text { relates to confining stress (i.e. } \\
\text { depth) }\end{array}$ \\
\hline $\begin{array}{c}\text { Undisturbed } \\
\text { Sampling }\end{array}$ & $\begin{array}{c}\text { Unit weight can be determined on } \\
\text { intact (undisturbed) samples of } \\
\text { waste obtained via drilling } \\
\text { operations }\end{array}$ & $\begin{array}{c}\text { Nearly impossible to obtain an } \\
\text { intact and representative } \\
\text { sample of MSW using existing } \\
\text { drilling and sampling methods }\end{array}$ \\
$\begin{array}{c}\text { In-Situ, } \\
\text { Large-Scale }\end{array}$ & $\begin{array}{c}\text { Mimics the ASTM standard sand- } \\
\text { cone density test but on a larger } \\
\text { scale. Test pits are excavated and } \\
\text { backfilled using a material with a } \\
\text { known unit weight (e.g., uniform } \\
\text { gravel) }\end{array}$ & $\begin{array}{c}\text { Labor intensive and material } \\
\text { costs could be expensive } \\
\text { depending on the size and } \\
\text { quantity of tests pits } \\
\text { excavated. }\end{array}$ \\
$\begin{array}{c}\text { Can be difficult to obtain limit of } \\
\text { excavation (Von Stockhausen } \\
\text { 2007) }\end{array}$ \\
\hline
\end{tabular}

Zekkos et al. (2005) and Zekkos et al. (2006) recommended that in-situ unit weight measurements obtained through large-scale sampling be used whenever possible due to the reliability of the procedure. However, at great depths in-situ unit weight testing is not practical and therefore Zekkos et al. (2006) suggested that large diameter large-diameter bucket auger borehole 
(minimum diameter of $760 \mathrm{~mm}$ ) be used to estimate the MSW unit weight at depth. The unit weight of MSW is determined by measuring the weight of the waste extracted during the drilling and dividing that value by the volume of the borehole created by the bucket auger.

Unit weight of MSW can be presented in three ways: 1) dry unit weight $\left(\gamma_{d}\right)$; 2) total or wet unit weight $\left(\gamma_{t}\right)$; and 3) operational unit weight $\left(\gamma_{o p e r}\right)$. The definitions of the dry and total unit weights are equivalent to those used in geotechnical engineering analysis. The operational unit weight is a more recent concept that was first reported by Hanson et al. (2010a) as a means to estimate the disposal volume available at a landfill for incoming wastes while neglecting moisture addition (e.g., leachate recirculation). Hanson et al. (2010a) highlighted that the weight of incoming wastes is critical for landfill operations as financial determinations are made based on the tipping fees charged for the wastes by weight upon entry to the landfill. The three distinct unit weights for waste are defined in Equations (2.6 - 2.8).

$$
\begin{aligned}
\gamma_{d} & =\frac{\text { Weight of Solids }}{\text { Total Compacted Volume }} \\
\gamma_{\text {oper }} & =\frac{\text { Weight of Incoming Waste }}{\text { Total Compacted Volume }} \\
\gamma_{t} & =\frac{\text { Weight of Incoming Waste+Addional Water (if used) }}{\text { Total Compacted Volume }}
\end{aligned}
$$

Based on reported initial in-place densities of MSW at modern landfills and the waste compressibility values reported by Fasset et al. (1994), a unit weight profile with respect to depth was developed by Kavazanjian et al. (1995) to assist 
with the seismic analysis of landfills. The profile has since been further developed (Kavazanjian 2001) and correlates well with more recent studies (Zekkos et al. 2006). Zekkos et al. (2005) obtained results from in-situ unit weight tests conducted at six different landfills. Zekkos et al. (2005) concluded that individual landfills, where consistent waste collection and placement practices are implemented over time, have characteristic unit weight versus depth profiles that are related to an initial unit weight value. In general, unit weights of MSW tend to increase with increasing depth and compaction effort (Kavazanjian et al. 1995; Kavazanjian et al. 2001; Zekkos et al. 2005; Kavazanjian 2006) Zekkos et al. 2006 developed a group of unit weight profiles (Figure 2.14) that is considered reasonable for conventional landfills (i.e., at moisture contents less than field capacity).

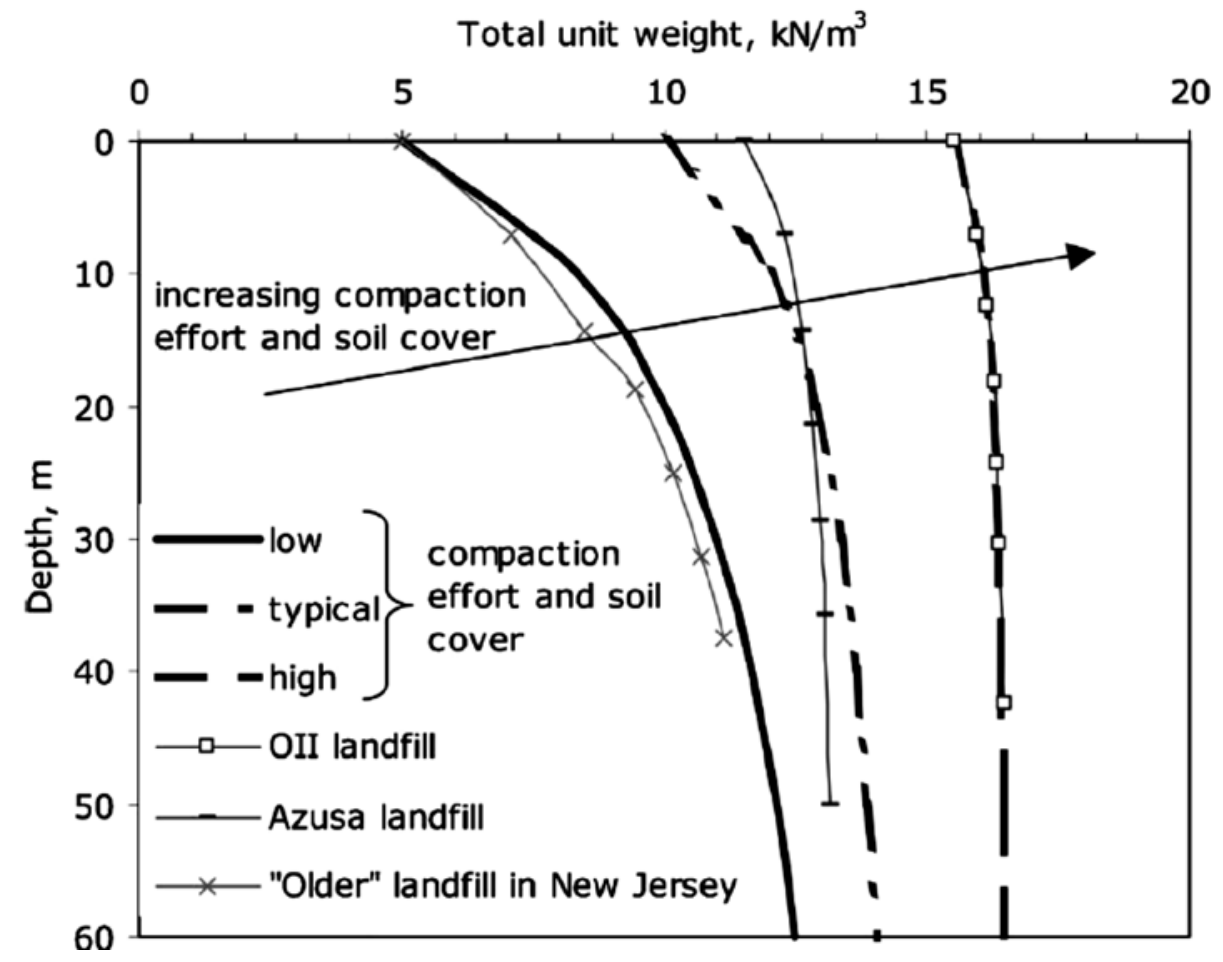

Figure 2.14. Unit Weight Profiles for Conventional Landfills (Zekkos et al. 2006) 
The unit weight profiles are a reasonable method for performing reliable engineering analyses of a landfill provided that waste properties and landfill operations (i.e., waste composition and placement procedures) remain consistent over time (Zekkos et al. 2006). However, Kavazanjian (2006) alluded to limitations of the existing MSW unit weight data presented in the literature. To date, the effects of waste degradation on the unit weight of waste has yet to be fully understood or documented. Furthermore, the unit weight profiles presented in Zekkos et al. (2006) are only applicable to conventional landfills. Kavazanjian (2006), therefore suggested that both waste degradation effects and liquid addition should be considered when performing engineering analyses on bioreactor landfills.

\subsection{Settlement/Compressibility}

Compressibility or change in volume of a material, results from the application of a load or overburden stress. The vertical strains or deformations and associated compressibility response time and magnitude that occur upon vertical loading of geomaterials, vary depending on the type of material characteristics. In this section, the settlement mechanisms for soils are briefly discussed to provide a framework for evaluating MSW compressibility. This is followed by an investigation and review of municipal solid waste settlement including the various mechanisms of MSW settlement as well as the methods and relevant models used to predict MSW settlement. 


\subsubsection{Compressibility of Soil}

The mechanics of soil compressibility have been studied in depth and are relatively well understood (Terzaghi and Peck 1948; Salgado 2006; Holtz et al. 2011). Soil settlement is generally analyzed one-dimensionally and results from the application of a load, which is most commonly generated in the form of a constructed building or an earthen structure. The vertical deformation of a soil due to loading is difficult to quantify because of the complex response of soil to the loading. Most soils have a nonlinear stress-strain relationship, a timedependent response to loading, elastic and plastic response when loaded and unloaded, and are non-conservative materials (i.e., have a memory as a result of stress history) (Holtz et al. 2011). In this section, the mechanisms of soil compressibility are discussed.

The total amount of settlement of a soil occurs as the sum of three mechanisms: elastic compression (immediate), consolidation (time-dependent), and creep or secondary compression (long-term). Elastic settlement occurs in an undrained state, prior to dissipation of excess pore pressures due to loading and when the soil stiffness is at its maximum (Lambe and Whitman 1969; Mitchell and Soga 2005). Elastic settlement of soil is a function of initial void ratio, applied stress, stress history of the soil, and undrained or drained Young's Modulus, $E_{u}$

or $E_{d}$ (drained Young's Modulus is used for granular soils due to their relatively high hydraulic conductivity). During the elastic compression phase, the voids within the soil matrix are reduced and soil particles shift into a tighter packing arrangement. Although the elastic response of soil that occurs immediately after 
the application of a load is not truly elastic, it is usually estimated as such using elastic theory for convenience purposes (Holtz et al. 2011).

Consolidation is the next sequential mechanism of soil compressibility and is time-dependent. Consolidation occurs as water trapped within the voids of the soil is discharged by an applied static load. Consolidation is more prominent in fine-grained soils, as compared to granular soils, due to lower hydraulic conductivity and slower rates of pore pressure dissipation in fine-grained soils. The magnitude of consolidation of the soil is directly related to the quantity stress (or loading) applied to the soil. The rate of consolidation settlement is directly proportional to the rate of pore pressure dissipation (Holtz et al. 2011).

Secondary compression, or creep, of soil is continuation of the volume change that starts during the consolidation process. However creep occurs at a much slower rate and after all of the excess pore pressure has dissipated. According to Holtz et al. (2011), the secondary settlement of soils result from compression of the bonds between individual particles and domains, as well as other rearrangement of particle structure under constant effective stress. Secondary compression is time-dependent and particularly problematic in organic soils such as peat.

Theories for compressibility of soils have been applied to MSW. From a phenomenological standpoint, MSW settlement is similar to peat settlement with both characterized by high compositional variability, high natural water content, high initial void ratio, high compressibility, and large settlements (Edil and den Haan 1994; Mesri et al. 1997). 


\subsubsection{Compressibility of MSW}

The compressibility characteristics of MSW are significantly more complex than those of soil compressibility due to the heterogeneity of the physical properties of MSW. Distinct considerations regarding waste mechanics must be taken into account when quantifying settlement. The mechanics of MSW settlement share similarities with the theories of soil mechanics but have unique and discrete differences. Municipal solid waste compression is commonly apportioned into different phases corresponding to different mechanisms. Historically, soil mechanics-based models and/or empirical and rheologic models that use basic soil mechanics principles, have been used to estimate waste settlement (Sowers 1973; Yen and Scanlon 1975; Rao et al. 1977; Oweis and Khera 1986; Morris and Woods 1990; Edil et al. 1990; Bjarngard and Edgers 1990; Fasset et al. 1994; Park and Lee 1997; Ling et al. 1998; El-Fadel and AlRashed 1998). However, in recent years, more advanced, composite models that account for long term settlements due to biochemical degradation have been utilized to quantify waste settlement (Park et al. 2002; Marques et al. 2003; Liu et al. 2006; Hettiarachchi et al. 2009; Babu et al. 2010a; Gourc et al. 2010; Chen et al. 2010a; Krase et al. 2011; Chen et al. 2012). In this section, the mechanisms of waste settlement are described followed by a summary of relevant models used to predict MSW compression.

The magnitude and rate at which MSW settles depends primarily on initial density of the waste, waste composition, applied stress and stress history, and environmental conditions such as the native climate and as-received moisture 
content of the waste (El-Fadel and Khoury 2000). MSW settlement is attributed to three physical and biochemical mechanisms: initial mechanical compression, mechanical creep and raveling, and physico-chemical and biological degradation (Sowers 1973; Yen and Scanlon 1975; Bjarngard and Edgers 1990; Edil et al. 1990; Edgers et al. 1992; El-Fadel and Khoury 2000; Marques et al. 2003). All of these mechanisms occur in both conventional and bioreactor landfills (Sharma and De 2007; Bareither et al. 2010). The total settlement of municipal solid waste can be quantified through a summation of the three compressibility mechanisms (Equation 2.9).

$$
S_{t}=S_{i}+S_{m c}+S_{b c}
$$

Where:

$$
\begin{aligned}
S_{t} & =\text { total settlement } \\
S_{i} & =\text { initial compression } \\
S_{m c} & =\text { compression due to mechanical creep } \\
S_{b c} & =\text { compression due to biological and chemical degradation }
\end{aligned}
$$

The behavior of municipal solid waste as it settles is best described in five stages (Grisolia and Napoleoni 1995). The five-stages of compressibility for MSW (Figure 2.15) coincide with the three mechanisms of waste settlement and include: instantaneous, mechanical compression and reduction of macro-voids (Stage I); primary mechanical compression and continuous movement of waste particles into void spaces (Stage II); secondary mechanical compression (creep) and initial degradation of organic materials (Stage III); decomposition of organic matter and tertiary mechanical compression (Stage IV); residual deformation due 
to applied load and degradation (Stage V). Stages I and II correspond to the initial compression mechanism, stage III and a fraction of stage IV correspond to the mechanical creep mechanism, and stage IV corresponds to the biochemical compression. Long-term, residual creep deformations occur during stage $\mathrm{V}$ but are minimal compared to the deformations due to the other mechanisms of MSW compression. 


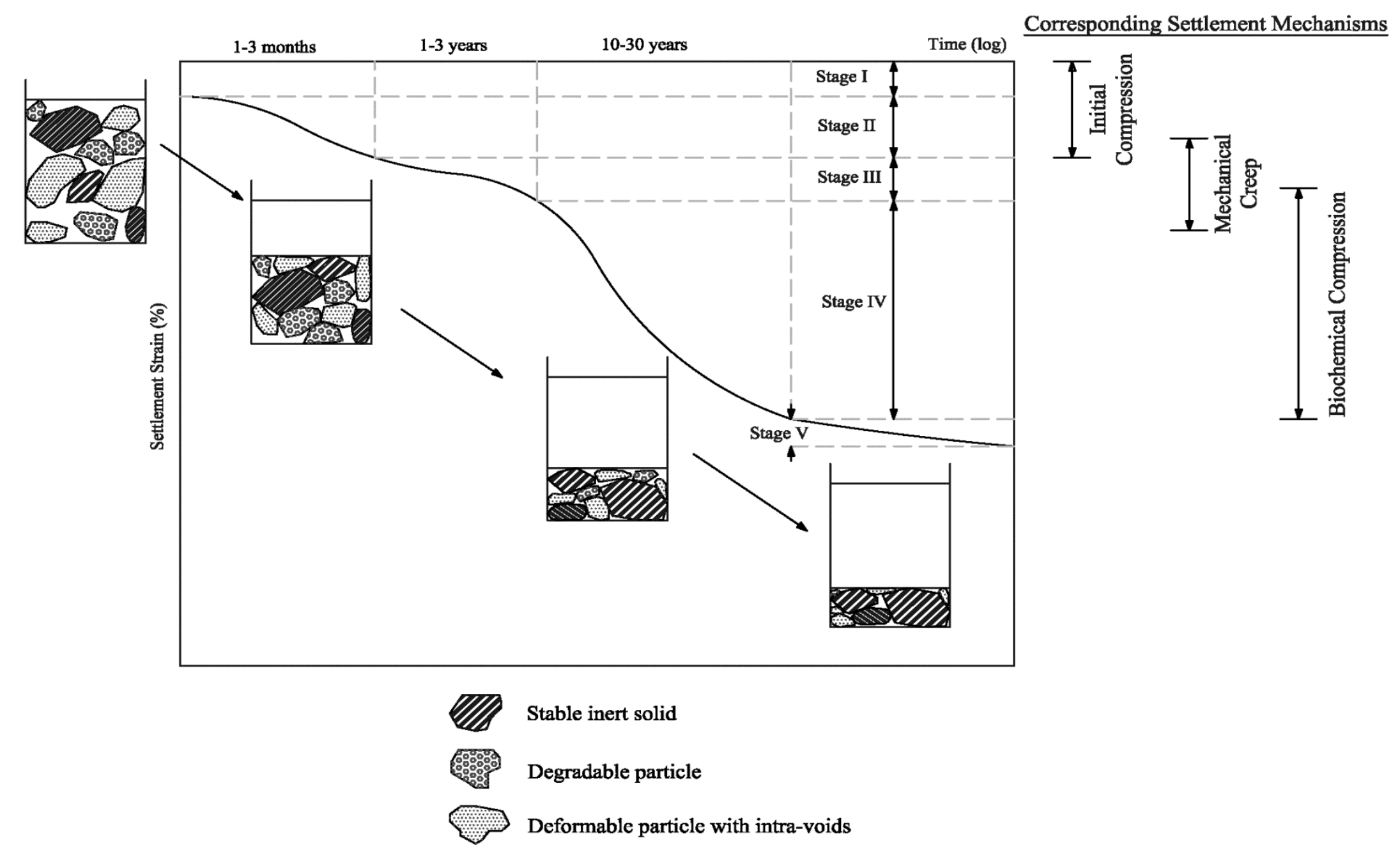

Figure 2.15. Five-Stage Compressibility Curve for MSW (Adapted from Grisolia and Napoleoni 1995). 


\section{Initial Compression}

Initial compression of MSW occurs due to the reduction of void spaces within the waste mass and deformation of particles from mechanical loading (e.g., self-weight or a surcharge). In relation to traditional soil mechanics principles, initial compression of MSW is the combination of instantaneous settlement and consolidation and generally takes place within the first two months upon application of a load (Sowers 1973; Morris and Woods 1990; Edil et al. 1990; Edgers et al. 1992; Fasset et al. 1994; El-Fadel and Khoury 2000). According to Wall and Zeiss (1995), the instantaneous settlement of waste is comparable to foundation settlements of coarse-grained soils and of partially saturated fine-grained soils. Wall and Zeiss (1995) indicated that since waste has permeability in the range of clean sand and gravels and experiences an immediate settlement under load, the instantaneous compression should be accounted for using elastic theory used to estimate instantaneous settlement in soils (Holtz et al. 2011):

$$
S_{\text {instant }}=\frac{\Delta \sigma * H_{O}}{E_{S}}
$$

Where:

$$
\begin{aligned}
S_{\text {instant }} & =\text { instantaneous settlement } \\
H_{o} & =\text { initial thickness of waste } \\
E_{S} & =\text { modulus of elasticity } \\
\Delta \sigma & =\text { stress increment applied to waste }
\end{aligned}
$$


However, modern landfills commonly incorporate good compaction of the waste upon placement which eliminates a majority of the instantaneous elastic response experienced by the waste and therefore the instantaneous settlement is generally neglected when calculating the initial compression of MSW. The initial compression phase of MSW is predominantly controlled by mechanical deformations that are similar to the consolidation of soils. The term initial compression is used for wastes in lieu of the combined mechanisms of instantaneous settlement and consolidation to better distinguish between soil mechanics and waste mechanics (Bareither et. al 2012a). Unlike low permeability soils, little to no porewater pressure build-up occurs during initial compression of waste. This can be attributed to the relatively high permeability of MSW as well as the design of a modern landfill which enables liquids to drain freely and allow for the waste mass to remain in an unsaturated state.

The initial settlement phase of waste, first reported by Sowers (1973) and later by several others (Oweis and Khera 1986; Morris and Woods 1990; Bjarngard and Edgers 1990; Fasset et al. 1994; Marques et al. 2003), is defined as:

$$
S_{i}=H \cdot C_{c}^{\prime} \cdot \log \frac{\sigma_{v o}^{\prime}+\Delta \sigma_{v}^{\prime}}{\sigma_{v o}^{\prime}}
$$

Where:

$$
\begin{aligned}
H & =\text { thickness of a given waste lift } \\
C_{c}^{\prime} & =\text { compression ratio } \\
\sigma_{v o}^{\prime} & =\text { initial vertical effective stress at midpoint of layer } \\
\Delta \sigma_{v}^{\prime} & =\text { induced change in vertical effective stress at midpoint of layer }
\end{aligned}
$$


The initial compressive strain of MSW typically ranges between 10 and $15 \%$ but can be as high as $25 \%$ depending on the waste composition, induced load, climate conditions, and placement procedures (e.g., compactive effort). A breadth of initial compression strains have been reported in both laboratory and field-scale studies (Oweis and Khera 1986; Bjarngard and Edgers 1990; Wall and Zeiss 1995; Hossain et al. 2003; Olivier and Gourc 2007; Hossain and Gabr 2009; Chen et al. 2010b; Bareither et al. 2012a-c). Settlement data compiled from several landfills yielded initial compression strains of 5 to $11 \%$ of the original thickness of the waste mass (Oweis and Khera 1986; Bjarngard and Edgers 1990), whereas laboratory-controlled compression tests resulted in initial compression strains ranging from 15 to 45\% (Wall and Zeiss 1995; Olivier and Gourc 2007; Bareither et al. 2012a-b). The MSW samples tested in the laboratory included enhanced manufactured waste (i.e., an environment with biodegradation promoted), fresh MSW samples from a landfill, and older, and degraded samples from a landfill. The larger strains (greater than 30\%) were attributed to active biodegradation coupled with increasing vertical stress (Hossain and Gabr 2009; Bareither et al. 2012a).

Analogous to the strain-based modified compression index in soil mechanics, the compression ratio for waste, $C_{c}^{\prime}$, is the most widely used parameter to predict the initial compression of MSW. The compression ratio for MSW is a function of waste composition (Sowers 1973; Kavazanjian et al. 1999; Hossain et al. 2003; Chen et al. 2009; Bareither et al. 2012a), waste particle size/density (Landva et al. 2000; Chen et al. 2009; Stoltz et al. 2010; Bareither et 
al. 2012a), and moisture content (Vilar and Carvalho 2004; Reddy et al. 2009a; Bareither et al. 2012a). Recently, Bareither et al. (2012a) investigated the influence of scale, stress, waste segregation, and waste decomposition effects on $C_{c}^{\prime}$ as compared to previous laboratory and field-scale compressibility experiments. The results of the study coupled with data from previous experiments, yielded a predictive tool that relates $C_{c}^{\prime}$ to waste composition and material properties:

$$
C_{c}^{\prime}=0.26+0.058 \cdot \log (W C I)
$$

Where:

$$
W C I=\text { waste compressibility index (dimensionless) }
$$

The $\mathrm{WCl}$ was developed because no single waste characteristic was found to consistently influence $C_{c}^{\prime}$. Bareither et al. (2012a) determined that $C_{c}^{\prime}$ was sensitive to $w_{d}, \gamma_{d}$, and the percent of biodegradable organic waste (i.e., the sum of the percent of paper, cardboard, food waste, and yard waste on a dry mass basis). These variables were combined into the dimensionless waste compressibility index $(W C l)$, which is defined as:

$$
W C I=w_{d} \cdot\left(\frac{\gamma_{w}}{\gamma_{d}}\right) \cdot\left(\frac{O W}{100-O W}\right)
$$

Where:

$$
\begin{aligned}
w_{d} & =\text { moisture content } \\
\gamma_{w} & =\text { unit weight of water } \\
\gamma_{d} & =\text { dry unit weight of waste } \\
O W & =\text { percent of biodegradable organic waste }
\end{aligned}
$$


Furthermore, Bareither et al. (2012a) stated that no correlation exists between MSW compression ratio and stress with two caveats: 1) $C_{c}^{\prime}$ should be evaluated in a broad stress range (e.g. 20-300 kPa), and 2) sustained loading coupled with waste decomposition decreases $C_{c}^{\prime}$ values as a result of removal of compressible organic solids and stiffening of the waste matrix. In general, researchers have reported comparable values for $C_{c}^{\prime}$ using different testing methods. MSW compression ratios obtained from various laboratory- and field-scale testing programs are summarized in Table 2.4.

In addition, Chen et al. (2010a) suggested another approach for evaluating $C_{c}^{\prime}$ such that the initial mechanical compression of fresh and degraded wastes respond differently to vertical loading (i.e., overburden stresses). Chen et al. (2010a) defined the initial compression ratio of fresh MSW as $C_{c}^{\prime}$ and the initial compression ratio of degraded MSW as $C_{c \infty}^{\prime}$. Differentiating between the initial compression of fresh and degraded wastes is applicable for varying operational procedures at a given landfill. Landfill operators may choose to construct a waste lift and let it sit for a number of years before placing another lift of overlying waste. On the contrary, a freshly placed waste lift may be overlaid with another waste lift within a few days. Consequently, Chen et al. (2010a) suggested that the initial compression of the fresh waste lift will be higher than the initial compression of the degraded waste lifts. 
Table 2.4. Summary of MSW Compression Ratios

\begin{tabular}{|c|c|c|c|}
\hline Waste Description & $\begin{array}{c}\text { Test Methods } \\
\end{array}$ & $C_{c}^{\prime}$ & Reference \\
\hline N/A & $\begin{array}{l}\text { 1000-mm- to } 2000-m m \text {-diameter cell } \\
\text { compression tests }\end{array}$ & $0.10-0.41$ & Sowers (1973) \\
\hline N/A & N/A & $0.15-0.33$ & Zoino $(1974)^{a}$ \\
\hline $\mathrm{N} / \mathrm{A}$ & N/A & $0.25-0.30$ & Converse $(1975)^{a}$ \\
\hline N/A & $\mathrm{N} / \mathrm{A}$ & 0.10 & Rao et al. (1977) ${ }^{a}$ \\
\hline $\begin{array}{l}\text { As-placed waste at a landfill in the } \\
\text { United States }\end{array}$ & $\begin{array}{l}\text { Test cells installed at landfill to monitor } \\
\text { settlement }\end{array}$ & $0.08-0.22$ & Oweis and Khera (1986) \\
\hline Samples recovered from a landfill & $\begin{array}{l}\text { 200-mm- and 470-mm-diameter cell } \\
\text { compression tests }\end{array}$ & $0.20-0.50$ & Landva and Clark (1990) \\
\hline $\begin{array}{l}\text { Waste obtained from the active face } \\
\text { of a landfill in England }\end{array}$ & $\begin{array}{l}\text { 2000-mm-diameter cell compression } \\
\text { tests }\end{array}$ & $0.18-0.39$ & $\begin{array}{l}\text { Beaven and Powrie } \\
(1995)^{c}\end{array}$ \\
\hline $\begin{array}{l}\text { 5- to } 15 \text {-year-old samples from a } \\
\text { landfill in Taiwan }\end{array}$ & $\begin{array}{l}\text { 305-mm-diameter cell compression } \\
\text { tests }\end{array}$ & 0.25 & Chen and Lee $(1995)^{b}$ \\
\hline $\begin{array}{l}\text { 15- to } 30 \text {-year-old samples from a } \\
\text { landfill in the United States }\end{array}$ & $\begin{array}{l}\text { 64-mm-diameter cell compression } \\
\text { tests }\end{array}$ & $0.15-0.22$ & $\begin{array}{l}\text { Gabr and Valero } \\
\text { (1995) }\end{array}$ \\
\hline $\begin{array}{l}\text { As-placed waste at a landfill in the } \\
\text { United States }\end{array}$ & $\begin{array}{l}\text { Settlement plates installed to monitor } \\
\text { settlement }\end{array}$ & 0.16 & $\begin{array}{l}\text { Stulgis et al. } \\
\text { (1995) }\end{array}$ \\
\hline $\begin{array}{l}\text { As-placed waste at a landfill in } \\
\text { China }\end{array}$ & $\begin{array}{l}\text { Test cells installed at landfill to monitor } \\
\text { settlement }\end{array}$ & $0.21-0.25$ & $\begin{array}{l}\text { Wall and Zeiss } \\
\text { (1995) }\end{array}$ \\
\hline $\begin{array}{l}\text { Processed waste and 2- to 5-year- } \\
\text { old samples from landfill in Canada }\end{array}$ & $\begin{array}{l}\text { 600-mm-diameter cell compression } \\
\text { tests }\end{array}$ & $0.19-0.24$ & $\begin{array}{l}\text { Landva et al. } \\
\qquad(2000)\end{array}$ \\
\hline Manufactured waste samples & $\begin{array}{l}\text { 64-mm-diameter cell compression } \\
\text { tests }\end{array}$ & $0.16-0.37$ & $\begin{array}{l}\text { Hossain et al. } \\
\text { (2003) }\end{array}$ \\
\hline Fresh MSW from a landfill in Brazil & $\begin{array}{l}\text { Multi-regression analysis based on } \\
\text { measured settlement data }\end{array}$ & 0.11 & Marques et al. $(2003)^{c}$ \\
\hline
\end{tabular}


Table 2.4. Summary of MSW Compression Ratios (Cont'd)

\begin{tabular}{|c|c|c|c|}
\hline Waste Description & Test Methods & $C_{c}^{\prime}$ & Reference \\
\hline $\begin{array}{l}\text { 15-year-old samples from a landfill in } \\
\text { Brazil }\end{array}$ & $\begin{array}{l}\text { 365-mm-diameter cell compression } \\
\text { tests }\end{array}$ & $0.18-0.23$ & Vilar and Carvalho (2004) \\
\hline $\begin{array}{l}\text { 10-year-old samples from a landfill in } \\
\text { the United States }\end{array}$ & $\begin{array}{l}\text { 64-mm- and } 712-\mathrm{mm} \text {-diameter cell } \\
\text { compression tests }\end{array}$ & $0.13-0.26$ & Durmusoglu et al. (2006) \\
\hline Laboratory-prepared waste samples & $\begin{array}{l}\text { 1000-mm-diameter cell compression } \\
\text { tests }\end{array}$ & $0.22-0.27$ & Gourc and Olivier (2007) \\
\hline $\begin{array}{l}\text { 1-month to } 10 \text {-year-old samples from a } \\
\text { landfill in China }\end{array}$ & $\begin{array}{l}\text { 84-mm- and 98-mm-diameter cell } \\
\text { compression tests }\end{array}$ & $0.10-0.30$ & $\begin{array}{l}\text { Chen et al. } \\
(2009)\end{array}$ \\
\hline $\begin{array}{l}1.5 \text { year-old samples obtained from a } \\
\text { landfill in the United States and } \\
\text { subjected to leachate recirculation }\end{array}$ & 64-mm-diameter cell compression tests & $0.19-0.24$ & $\begin{array}{l}\text { Reddy et al. } \\
\quad(2009 a)\end{array}$ \\
\hline $\begin{array}{l}\text { Waste obtained from active face of a } \\
\text { landfill in the United States }\end{array}$ & 64-mm-diameter cell compression tests & $0.24-0.33$ & $\begin{array}{l}\text { Reddy et al. } \\
\text { (2009b) }\end{array}$ \\
\hline $\begin{array}{l}\text { Prepared waste to simulate typical } \\
\text { MSW composition in United States }\end{array}$ & 64-mm-diameter cell compression tests & $0.16-0.31$ & $\begin{array}{l}\text { Reddy et al. } \\
\quad(2009 c)\end{array}$ \\
\hline $\begin{array}{l}\text { Prepared waste to simulate typical } \\
\text { MSW composition in China }\end{array}$ & $\begin{array}{l}\text { 190-mm-diameter cell compression } \\
\text { tests }\end{array}$ & $0.20-0.32$ & $\begin{array}{l}\text { Chen et al. } \\
(2010 a)\end{array}$ \\
\hline $\begin{array}{l}\text { Waste recovered from a landfill in } \\
\text { France }\end{array}$ & $\begin{array}{l}\text { 270-mm-diameter cell compression } \\
\text { tests }\end{array}$ & $0.27-0.37$ & $\begin{array}{l}\text { Stoltz et al. } \\
(2010 \mathrm{a})\end{array}$ \\
\hline $\begin{array}{l}\text { In-situ and prepared 3- to 4-month-old } \\
\text { waste samples from a landfill in the } \\
\text { United States }\end{array}$ & 64-mm-diameter cell compression tests & $0.22-0.28$ & $\begin{array}{l}\text { Bareither et al. } \\
\qquad(2012 a)\end{array}$ \\
\hline
\end{tabular}

N/A - Information not available

${ }^{a}$ As reported in Oweis and Khera (1986)

${ }^{\mathrm{b}}$ As reported in Bareither et al. (2012a)

${ }^{\mathrm{c}}$ Based on analysis of data gathered from 20 settlement instruments 
As the initial compression phase concludes, MSW settlement transitions into the secondary compression phases comprised of mechanical creep and biochemical degradation-induced settlements which, are described in the following sections.

\section{Mechanical Creep}

The compression of waste due to mechanical creep is best described as the time-dependent reduction of interparticle voids within the waste matrix and intraparticle voids within individual waste constituents due to the application of a vertical load. The reduction/elimination of the interparticle voids within the waste matrix is attributed to raveling, or reorientation and migration of finer waste particles into large macro pores that are formed by the bridging of bulky items such as furniture, appliances, etc. (Sowers 1973; Bjarngard and Edgers 1990; Edil et al. 1990). The reduction of intraparticle voids within individual waste particles is less documented and virtually impossible to quantify, especially on the field-scale. However, Zhang et al. (2010) decoupled and quantified interparticle and intraparticle void volume reduction through back calculation of one-dimensional compression data reported by Powrie and Beaven (1999). Zhang et al. (2010) concluded that the interparticle void volume change during compression was approximately double the amount of intraparticle void volume change. It has yet to be proven at what time the reduction of intraparticle voids occurs. A general scenario at a landfill provides insight to the influence of intraparticle void reduction on the mechanical creep compression of MSW: If a glass or plastic container remains intact long enough to get crushed during the 
creep/raveling compression phase, the void space inside the container is eliminated. This amount of intraparticle void reduction is significantly less than the collapse of a larger interparticle void space within the waste matrix (e.g., bridging due to a desk or table).

The size of the waste constituents also can affect the total amount of MSW creep settlement as reported by Gourc et al. (2010). Small, shredded waste particles were hypothesized to undergo less mechanical creep most likely credited to a decrease in interparticle void reduction potential (i.e., less raveling potential) (Gourc et al. 2010). However, this phenomenon has limited application at modern, fully-operational landfills as shredding and/or sorting are not common practices, particularly in the U.S.

Sowers (1973) was the first to present a model for secondary compression of waste in landfills. The model was based on data collected from several fullscale municipal landfills and the equation presented is a modification of Buisman's theory for secondary compression of soils (Buisman 1936). The theory assumes that the secondary portion of the settlement curve is linear with respect to the logarithm of time. A limitation of Sowers (1973) secondary compression model is lack of distinguishing between mechanical creep and biochemical compression. A distinction between mechanical creep and biochemical compression can be difficult to incorporate due to the overlapping of the two mechanisms during the progression of the MSW compression stages defined by Grisolia and Napoleoni (1995) (Figure 2.15). Nevertheless, this distinction was first addressed by Bjarngard and Edgers (1990) through an 
investigation of settlement data from 24 different landfills. A distinct transition between mechanical creep and settlement due to biochemical degradation was identified (Figure 2.16) and later verified via modeling, case-studies, and laboratory- and field-scale experiments (Edgers et al. 1992; Lamothe and Edgers 1994; Wall and Zeiss 1995; Park and Lee 1997; El-Fadel and Khoury 2000; Marques et al. 2003; Hossain et al. 2003; Oweis 2006; Sharma and De 2007; Benson et al. 2007; Olivier and Gourc 2007; Bareither et al. 2010; Babu et al. 2010a; Gourc et al. 2010; Bareither et al. 2012a-c; Bareither et al. 2013).

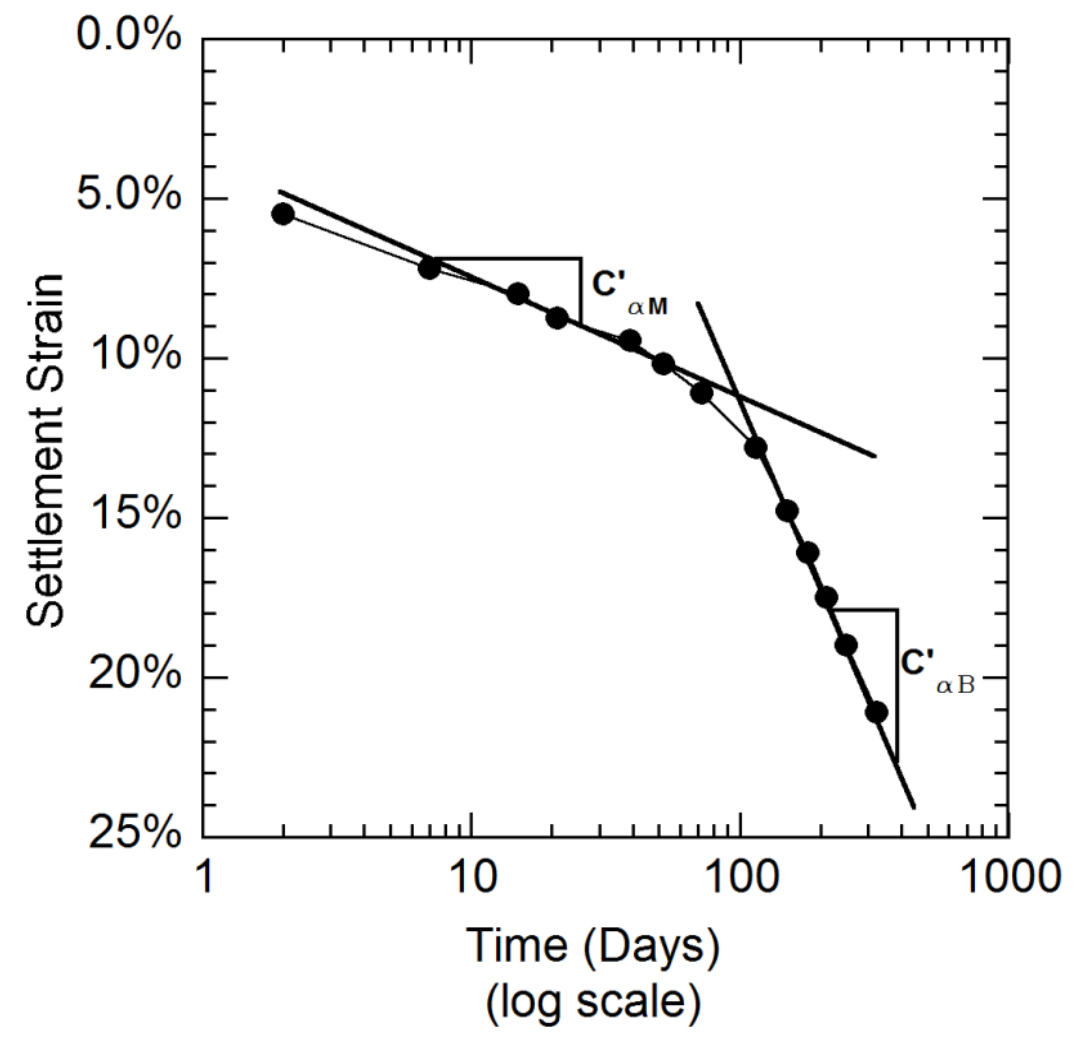

Figure 2.16. Secondary MSW Compression Versus Log-time for a Landfill (Redrawn from Bjarngard and Edgers 1990).

The distinct transition from mechanical creep to biochemical compression has been linked to the onset of methane production and acid removal (Olivier 
and Gourc 2007; Ivanova et al. 2008; Gourc et al. 2010). Furthermore, Bareither et al. (2013) noted that the transition from mechanical creep to biochemical compression was initiated with the onset of leachate dosing in a bioreactor experiment and estimated the transition time as the elapsed time for occurrence of peak leachate COD.

The mechanical creep portion of MSW compressibility presented by Bjarngard and Edgers (1990), allows for calculation of the settlement of MSW due to raveling and mechanical distortion of the waste particles using Equation 2.14:

$$
S_{m c}=H_{i} \cdot C_{\alpha M}^{\prime} \cdot \log \left(\frac{t_{m c}}{t_{i}}\right)
$$

Where:

$$
\begin{aligned}
H_{i} & =\text { thickness of the waste lift after initial compression } \\
C_{\alpha M}^{\prime} & =\text { mechanical creep compression ratio } \\
t_{m c} & =\text { duration of the mechanical creep phase } \\
t_{i} & =\text { duration of the initial compression phase }
\end{aligned}
$$

The mechanical creep compression ratio is a strain-based parameter represented by different nomenclature in various models however, the meaning of each is identical. A broad range of values for $C_{\alpha M}^{\prime}$ have been provided by researchers but are generally reported within the same order of magnitude. In a recent investigation, Bareither et al. (2013) determined that a strong correlation existed between $C_{\alpha M}^{\prime}$ and $\mathrm{WCl}$ and indicated that larger $C_{\alpha M}^{\prime}$ values correspond with higher $w_{d}$, lower $\gamma_{d}$, and/or higher organic waste content, regardless of 
waste type, test scale, or stress level. The mechanical creep compression ratio is often reported in comparison with the biochemical compression ratio. Therefore, the mechanical creep compression ratios presented in literature are compiled together with the biochemical compression ratios in Table 2.6 in the "Biochemical Compression" section.

On a field-scale, the majority of the reported MSW settlements associated with mechanical creep typically occurred 6 months to 2 years after the end of initial compression (Bjarngard and Edgers 1990; Edgers et al. 1992; Park et al. 2007). On the contrary, the duration of mechanical creep in laboratory-controlled environments (i.e., ideal conditions for biodegradation) has been observed to be significantly less and on the order of days to months (Lamothe and Edgers 1994; Olivier and Gourc 2007; Gourc et al. 2010; Bareither et al. 2012b,c). This behavior is explained by Bareither et al. (2008) and Chen et al. (2010b) as a moisture-induced softening of the waste structure leading to enhanced mechanical creep rates and potential onset of tertiary creep effects. Moisture is uniformly distributed throughout the waste mass in the laboratory and provides ideal moisture-induced softening as compared to field conditions. In addition to existing mechanical creep settlements during the active filling of a landfill, research suggests that mechanical creep continues in the long term including post-closure (Oweis 2006; Sharma and De 2007; Chen et al. 2010a; Bareither et al. 2013).

Coduto and Huitric (1990) postulated that long-term secondary compression of MSW due to mechanical creep and degradation effects can 
account for up to $25 \%$ of the total MSW thickness. Strain values this high were indicated to be likely overestimates even for bioreactor landfills where leachate was recirculated to promote waste degradation processes and softening of the waste occurs (Oweis 2006). Creep strains of waste reported in the literature for conventional and bioreactor landfill conditions are fairly consistent regardless of the testing method, but tend to be slightly higher in simulated bioreactor environments (Table 2.5).

Table 2.5. Summary of Reported Strains Due to Mechanical Creep of MSW.

\begin{tabular}{|c|c|c|c|c|}
\hline $\begin{array}{l}\text { State } \\
\text { of } \\
\text { MSW }\end{array}$ & Reference & $\begin{array}{l}\text { Test } \\
\text { Scale }\end{array}$ & $\begin{array}{c}\text { Mechanical } \\
\text { Creep Strain } \\
(\%)\end{array}$ & $\begin{array}{c}\text { Fraction of the Total } \\
\text { Secondary } \\
\text { Compression Strain } \\
(\%)\end{array}$ \\
\hline \multirow{7}{*}{ 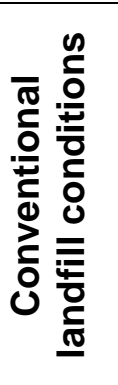 } & $\begin{array}{l}\text { Bjarngard and Edgers } \\
(1990)^{\mathrm{a}}\end{array}$ & Field & 4 & 33 \\
\hline & Marques (2001) & Field & $7.5-9$ & $14-26$ \\
\hline & Hossain et al. (2003) & Lab & $2-5$ & $10-18$ \\
\hline & Park et al. $(2007)^{\mathrm{c}}$ & Field & $6-9$ & $30-45$ \\
\hline & Bareither et al. (2010) & Field & $2-4$ & $30-40$ \\
\hline & Liu et al. (2011) & Lab & 9 & 12 \\
\hline & Chen et al. (2012) & Field & 3 & 23 \\
\hline \multirow{8}{*}{ 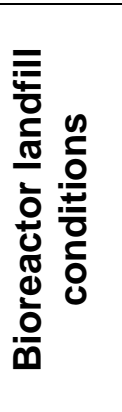 } & $\begin{array}{l}\text { Lamothe and Edgers } \\
\text { (1994) }\end{array}$ & Lab & 8-15 & $40-60$ \\
\hline & Hossain et al. (2003) & Lab & $1-4$ & $10-22$ \\
\hline & Olivier and Gourc (2007) & Lab & 9 & 37 \\
\hline & Park et. al $(2007)^{c}$ & Field & 9 & 26 \\
\hline & Ivanova et al. (2008) & Lab & 14 & $18-28$ \\
\hline & Bareither et al. (2010) & Field & 4 & 25 \\
\hline & ${\text { Gourc et al. }(2010)^{d}}^{d}$ & Field & $1-10$ & $13-55$ \\
\hline & Bareither et al. (2012b) & Field & $3-5$ & $20-25$ \\
\hline
\end{tabular}

${ }^{a}$ Average values from 24 case studies

${ }^{\mathrm{b}}$ Marques (2001) as reported by Babu et al. (2010b)

${ }^{\mathrm{c}}$ Estimated long-term settlement using data from several landfill sites

${ }^{d}$ Validated large-scale compression experiments using composite secondary compression model

Mechanical creep-induced settlements of MSW have been reported to occur throughout the duration of the filling process of a landfill as well as several 
years beyond closure (Oweis 2006). The chemical and biological degradation of MSW account for the majority of the observed/measured settlement in a landfill after a certain length of time.

\section{Biochemical Compression}

The final phase of MSW compression is attributed to the physico-chemical and biological degradation of the organic constituents in waste such as food, paper/cardboard, wood, and yard trimmings. Coduto and Huitric (1990) suggested that biochemical compression can account for 18 to $24 \%$ of the original thickness of a landfill and El-Fadel and Al-Rashed (1998) stated that biochemical compression strains could theoretically reach $40 \%$. As the organic matter in MSW decomposes and breaks down into simpler compounds by way of aerobic and anaerobic processes (El-Fadel and Al-Rashed 1998), gas, primarily composed of methane and carbon dioxide, is generated. Along with gas generation, a reduction of solid mass and weakening of the waste structure occurs, resulting in large biochemical settlements (Wall and Zeiss 1995; Oweis and Khera 1998; Marques et al. 2003; Oweis 2006; Benson et al. 2007; Bareither 2010). The settlement of MSW due to biochemical degradation begins approximately 1-3 years after placement of waste, can continue for many years (e.g. 10-50 years) following closure of a landfill, and can have a detrimental effect on the integrity of final cover systems (Sharma and De 2007; Ivanova et al. 2008).

MSW decomposition is a microbial mediated process that occurs in a series of sequential phases (Bareither 2010). Each phase of waste 
decomposition has distinct leachate chemistry and biogas characteristics that can be linked to physical and biochemical compression processes (Hossain et al. 2003; Ivanova et al. 2008; Gourc et al. 2010). First, oxygen trapped in the void spaces of MSW is depleted as the organic materials react with the oxygen to form carbon dioxide, water, and other byproducts such as bacterial cells (ElFadel and Al-Rashed 1998). This depletion of oxygen signifies the transition into long-term anaerobic microbial processes (Barlaz et al. 1989; Park and Lee 1997; El-Fadel and Al-Rashed1998; Bareither 2010).

The anaerobic decomposition of MSW begins with acidogenesis where some of the cellulose and hemicellulose is hydrolyzed to soluble molecules (e.g., amino acids and sugars). The amino acids, sugars, and other soluble molecules are then converted into volatile fatty acids, carbon dioxide, and hydrogen (Barlaz et al. 1989; El-Fadel and Al-Rashed 1998; Bareither 2010). As the fatty acids accumulate, $\mathrm{pH}$ decreases, acid concentration and chemical oxygen demand increase, and methane generation begins; marking the transition from acidogenesis to methanogenesis (Barlaz et al. 1989; Pohland and Kim 1999). The methanogenesis phase of waste degradation is characterized by a rapid increase in the rate of methane production to some maximum value due to an increase in the population of methanogen microbes (Barlaz et al. 1989). As methogenesis progresses, acids are consumed by methanogenic microorganisms, leachate $\mathrm{pH}$ increases, and methane production begins to transition into a decelerating phase (Barlaz et al. 1989; Bareither 2010). 
Temporal transitions in methanogenic activity as well as the duration of methanogenesis can be linked to transitions in leachate $\mathrm{pH}$, chemical oxygen demand, and oxidation-reduction potential (Bareither et al. 2013). The decomposition rate of organic solids peaks during the latter half of the methanogenesis phase corresponding to the potentially large, long-term biochemical settlements (Swati and Joseph 2008; Bareither 2010). Wall and Zeiss (1995) demonstrated that in the short term (i.e., 225 days), there is not a significant increase in biochemical compression under enhanced degradation conditions.

The extent to which biodegradation influences waste compressibility depends on several biochemical parameters including the amount and nature of organic matter, moisture content, microbial populations, temperature, and $\mathrm{pH}$ (Edgers et al. 1992; El-Fadel and Al-Rashed 1998; Mehta et al. 2002, McDougall 2007). The site-by-site variability of these factors can make it difficult to accurately quantify the amount of settlement solely attributed to biochemical degradation of MSW. To date, several researchers have attempted to quantify biochemical compression through modeling and/or laboratory- and field-scale test programs (e.g., Edgers et al. 1992; Lamothe and Edgers 1994; Wall and Zeiss 1995; Park and Lee 1997; Marques et al. 2003; Benson et al. 2007; Ivanova et al. 2008; Bareither et al. 2010; Bareither et al. 2013).

Bjarngard and Edgers (1990) subdivided the secondary compression of MSW into two sub-phases that correlate with the mechanical creep compression and biochemical compression phases of MSW. Bjarngard and Edgers (1990) 
characterized the biochemical sub-phase using a secondary compression ratio, $C_{\alpha 2}^{\prime}$. Although Bjarngard and Edgers (1990) did not identify the secondary compression ratio as a decomposition-induced parameter, the values obtained from the test program correspond well with more recent laboratory and field studies that identify the secondary compression ratio as a biochemical compression ratio $\left(C_{\alpha B}^{\prime}\right)$ (e.g., Lamothe and Edgers 1994; Park et al. 2002; Hossain and Gabr 2005; Olivier and Gourc 2007; Bareither 2010; Bareither et al. 2012b). Edgers et al. (1992) were the first to model biologically-induced settlements and expressed biochemical compression as a function of the activity of microorganisms. Later, Park and Lee (1997), Marques et al. (2003) and Hossain and Gabr (2005) proposed settlement models that incorporated timedependent biodegradation of waste. Modeling biochemical compression as a function of the solid-to-gas conversion of waste and gas generation due to MSW decomposition is another common approach (Durmusoglu et al. 2005; Oweis 2006; Liu et al. 2006; Machado et al. 2008; Gourc et al. 2010).

In addition to modeling biochemical compression of MSW, researchers have conducted laboratory- and field-scale compression tests that compare longterm secondary settlements in both conventional and bioreactor landfill conditions (Lamothe and Edgers 1994; Wall and Zeiss 1995; Hossain et al. 2003; Benson et al. 2007; Olivier and Gourc 2007; Ivanova et al. 2008; Swati and Joseph 2008; Bareither et al. 2008; Hossain et al. 2009; Bareither et al. 2010; Bareither et al. 2012b,c). The purposes of these studies were to examine the influence of physical and biochemical parameters on waste degradation, to 
quantify the amount of settlement attributed solely to biochemical degradation of MSW, and to examine the effects of leachate recirculation and/or moisture addition on the biochemical degradation of MSW. The data from the test programs indicated that the level of waste degradation (i.e., low, medium, high), age of the waste, and the physical characteristics of the waste (e.g., moisture content, temperature, organic content, etc.), were directly related to the amount of biochemical compression of MSW that occurred. Also, the rate at which biochemical compression occurs is affected by leachate recirculation and/or moisture addition. Wall and Zeiss (1995) stated that the enhancement of biological processes in a landfill will trigger an increase in waste stabilization and rate of settlement. Bareither et al. (2010) confirmed the increasing rate of biochemical settlement in bioreactor landfill conditions. They reported that the settlement rate attributed to biochemical degradation of MSW in field-scale bioreactor landfill conditions was 1.6 times larger than the rate in conventional landfill conditions.

Biochemical compression strains of MSW reported in the literature for conventional landfill conditions range from 2 to $10 \%$ (Rao et al. 1977; Park et al. 2002; Hossain et al. 2003; Benson et al. 2007; Ivanova et al. 2008; Swati and Joseph 2008; Bareither et al. 2010; Bareither et al. 2012b,c) and the strains reported from bioreactor landfill conditions range from 6 to 23\% (Lamothe and Edgers 1994; Hossain et al. 2003; Benson et al. 2007; Ivanova et al. 2008; Swati and Joseph 2008; Bareither et al. 2010; Bareither et al. 2012b,c). 
Parameterization is the governing factor of every biochemical compression model. For example, Hettiarachchi et al. (2009) highlighted that the biochemical decay rate as well as the secondary compression ratio were the most sensitive parameters when assessing settlements. Furthermore, El-Fadel and Khoury (2000) stated that settlement models incorporating biodegradation require determination of bacterial degradation expressions with respect to kinetic coefficients, which can be a difficult task due to the variation and inability to fully measure environmental conditions. The ability to accurately parameterize MSW settlement characteristics creates a strong correlation to laboratory- and fieldscale settlement data and a more effective model (Bareither 2010).

Several parameters were used to characterize the biochemical compression of MSW in numerous proposed models in literature and include: the strain-based biochemical compression ratio $\left(C_{\alpha B}^{\prime}\right)$ (Bjarngard and Edgers 1990; Lamothe and Edgers 1994; Wall and Zeiss 1995; Hossain et al. 2003; Benson et al. 2007; Olivier and Gourc 2007; Sharma and De 2007; Ivanova et al. 2008; Bareither 2010; Bareither et al. 2010; Bareither et al. 2012b), biochemical strain potential $\left(E_{D G}\right)$ (Park and Lee 1997; Marques et al. 2003), rate constant for biological decomposition (d) (Park and Lee 1997; Marques et al. 2003; Liu et al. 2006; Oweis 2006; Hettiarachchi et al. 2009; Bareither et al. 2013), and the gas generation rate constant $(\lambda)$ (Durmusoglu et al. 2005; Machado et al. 2008; Gourc et al. 2010).

$C_{\alpha B}^{\prime}$ is the most widely-used and reported parameter in literature in comparison to the other biochemical compression parameters (Bjarngard and 
Edgers 1990; Lamothe and Edgers 1994; Wall and Zeiss 1995; Hossain et al. 2003; Benson et al. 2007; Olivier and Gourc 2007; Sharma and De 2007; Ivanova et al. 2008; Bareither 2010; Bareither et al. 2010; Bareither et al. 2012b). The data from experimental test programs suggests that the biochemical compression ratios for bioreactor landfill conditions are generally higher than those in conventional landfill conditions. This can be attributed to the increased rate of biochemical compression present in the biologically enhanced environment of a bioreactor landfill. The biochemical compression ratios for bioreactor landfill conditions and conventional landfill conditions that are reported in the literature are presented in Table 2.6 in comparison to the mechanical creep compression ratios.

Table 2.6. Comparison of the $C_{\alpha M}^{\prime}$ and $C_{\alpha B}^{\prime}$ Values for Both Conventional and Bioreactor Landfill Conditions.

\begin{tabular}{|c|c|c|c|c|c|}
\hline \multirow{2}{*}{ Reference } & \multirow{2}{*}{ Test Scale } & \multicolumn{2}{|c|}{$\begin{array}{c}\text { Conventional } \\
\text { Landfill Conditions }\end{array}$} & \multicolumn{2}{|c|}{$\begin{array}{c}\text { Bioreactor Landfil } \\
\text { Conditions }\end{array}$} \\
\hline & & $C_{\alpha M}^{\prime}$ & $C_{\alpha B}^{\prime}$ & $C_{\alpha M}^{\prime}$ & $C_{\alpha B}^{\prime}$ \\
\hline Rao et. al (1977) & Field & 0.016 & 0.080 & - & - \\
\hline $\begin{array}{l}\text { Bjarngard and } \\
\text { Edgers (1990) }\end{array}$ & Field & 0.019 & 0.125 & - & - \\
\hline $\begin{array}{l}\text { Gandolla et al. } \\
\quad(1992)^{\mathrm{a}}\end{array}$ & Field & - & - & 0.063 & 0.340 \\
\hline $\begin{array}{l}\text { Lamothe and } \\
\text { Edgers (1994) }\end{array}$ & Laboratory & $\begin{array}{l}0.017- \\
0.028\end{array}$ & $\begin{array}{l}0.056- \\
0.120\end{array}$ & $\begin{array}{l}0.026- \\
0.028\end{array}$ & $\begin{array}{l}0.112- \\
0.190\end{array}$ \\
\hline $\begin{array}{l}\text { Wall and Zeiss } \\
(1995)\end{array}$ & Field & $\begin{array}{l}0.037- \\
0.049\end{array}$ & - & $\begin{array}{l}0.033- \\
0.056\end{array}$ & - \\
\hline Lee et al. (1995) & Field & 0.063 & 0.149 & - & - \\
\hline
\end{tabular}


Table 2.6. Comparison of the $C_{\alpha M}^{\prime}$ and $C_{\alpha B}^{\prime}$ Values for Both Conventional and Bioreactor Landfill Conditions (Cont'd).

\begin{tabular}{|c|c|c|c|c|c|}
\hline \multirow[t]{2}{*}{ Reference } & \multirow[t]{2}{*}{ Test Scale } & \multicolumn{2}{|c|}{$\begin{array}{c}\text { Conventional } \\
\text { Landfill Conditions }\end{array}$} & \multicolumn{2}{|c|}{$\begin{array}{l}\text { Bioreactor Landfill } \\
\text { Conditions }\end{array}$} \\
\hline & & $C_{\alpha M}^{\prime}$ & $C_{\alpha B}^{\prime}$ & $C_{\alpha M}^{\prime}$ & $C_{\alpha B}^{\prime}$ \\
\hline $\begin{array}{l}\text { Hossain et al. } \\
\qquad(2003)\end{array}$ & Laboratory & - & - & $\begin{array}{l}0.020- \\
0.030\end{array}$ & 0.190 \\
\hline $\begin{array}{l}\text { Benson et al. } \\
\quad(2007)\end{array}$ & Field & 0.029 & - & 0.026 & 0.280 \\
\hline $\begin{array}{l}\text { Sharma and De } \\
(2007)\end{array}$ & Field & $\begin{array}{l}0.014- \\
0.060\end{array}$ & - & - & $\begin{array}{l}0.100- \\
0.340\end{array}$ \\
\hline $\begin{array}{l}\text { Olivier and Gourc } \\
\qquad(2007)\end{array}$ & Laboratory & - & - & 0.046 & 0.35 \\
\hline $\begin{array}{l}\text { Ivanova et al. } \\
\qquad(2008)\end{array}$ & Laboratory & - & - & $\begin{array}{l}0.044- \\
0.054\end{array}$ & $\begin{array}{l}0.130- \\
0.190\end{array}$ \\
\hline $\begin{array}{l}\text { Hossain et al. } \\
\text { (2009) }\end{array}$ & Laboratory & $\begin{array}{l}0.030- \\
0.040\end{array}$ & - & - & - \\
\hline Bareither $(2010)^{C}$ & Field & - & - & $\begin{array}{l}0.045- \\
0.068\end{array}$ & $\begin{array}{l}0.200- \\
0.240\end{array}$ \\
\hline Bareither (2010) ${ }^{c}$ & Laboratory & - & - & $\begin{array}{l}0.021- \\
0.052\end{array}$ & $\begin{array}{l}0.060- \\
0.400\end{array}$ \\
\hline $\begin{array}{l}\text { Bareither et al. } \\
\qquad(2010)\end{array}$ & Field & 0.041 & 0.180 & $\begin{array}{l}0.032- \\
0.049\end{array}$ & $\begin{array}{l}0.17- \\
0.34\end{array}$ \\
\hline Gourc et al. (2010) & Laboratory & - & - & $\begin{array}{l}0.020- \\
0.100\end{array}$ & - \\
\hline $\begin{array}{l}\text { Bareither et al. } \\
\quad(2012 b)\end{array}$ & Laboratory & $\begin{array}{l}0.036- \\
0.048\end{array}$ & - & $\begin{array}{l}0.026- \\
0.035\end{array}$ & $\begin{array}{l}0.360- \\
0.420\end{array}$ \\
\hline
\end{tabular}

Note: The symbol "-“" represents unreported data

${ }^{a}$ As reported by Park et al. (2002)

${ }^{\mathrm{b}}$ As reported by Bareither et al. (2012b)

${ }^{\mathrm{c}}$ Both laboratory- and field-scale tests were conducted 
The average value for $C_{\alpha M}^{\prime}$ in both conventional and bioreactor landfill conditions is 0.035. $C_{\alpha B}^{\prime}$ has been demonstrated to be directly related to enhanced biological conditions such that an increase in biological activity will result in an increase in biochemical compression (e.g., Bareither et al. 2013). Consequently, the average values of $C_{\alpha B}^{\prime}$ for conventional and bioreactor landfill conditions are 0.118 and 0.215 , respectively.

\section{$\underline{\text { Relevant Approaches for Modeling MSW Compression }}$}

Numerous models have been proposed to predict the settlement of MSW (e.g., Sowers 1973; Bjarngard and Edgers 1990; Edil et al. 1990; Park and Lee 1997; Ling et al. 1998; Marques et al. 2003; Babu et al. 2010b). The older models, namely, Sowers (1973); Bjarngard and Edgers (1990); and Edil et al. (1990), are less relevant as compared to several more recent models due to improvements of modeling techniques in recent years. Several composite models have been proposed in recent years that incorporate all three mechanisms (Marques et al. 2003 and Babu et al. 2010b). Both models incorporated the incremental lift thickness and number of lifts placed at landfill which allowed for a more accurate prediction of settlement at any given time.

Hettiarachci et al. (2005) proposed a 2-phase model that incorporates the mechanical and biodegradation settlements of MSW. A unique aspect of the model is the incorporation of specific gravity in the biodegradation component (Hettiarachchi et al. 2005). Durmusolglu et al. (2005) and Liu et al. (2011) proposed models that incorporate gas composition and production over time as the MSW degrades. 


\subsection{Hydraulic Conductivity and Shear Strength}

Hydraulic conductivity and shear strength are two of the most important engineering properties of MSW that need to be accurately characterized when designing a landfill. The knowledge of the basic behavior and likely ranges of shear strength and hydraulic conductivity are necessary for several design considerations including: waste slope stability, shallow slope liner stability, steep slope liner stability, and leachate/gas well integrity (Dixon et al. 2005). In this section hydraulic conductivity and shear strength of MSW are described in some detail. In addition, testing procedures and previously reported values of waste hydraulic conductivity and shear strength are provided.

Hydraulic conductivity $(k)$ is an engineering property that describes how fluid flows through a material (Holtz et al. 2011). The hydraulic conductivity of waste is typically in line with the hydraulic conductivity of coarse-grained soils (i.e., sands) due to large pore spaces within the waste mass. MSW hydraulic conductivity $\left(k_{M S W}\right)$ is an important parameter for landfill design that influences movement of moisture within the waste mass. In addition, $k_{M S w}$ affects leachate pressure distributions in the waste body and hence the magnitude and distribution of effective stresses and shear strength (Dixon and Jones 2005). The heterogeneous nature and placement dependent particle structure of MSW, result in reported hydraulic conductivities varying over several orders of magnitude. Several laboratory and field experiments have been conducted to determine the hydraulic conductivity of MSW. A summary of the hydraulic conductivity values reported in literature for MSW is provided in Table 2.7. 
Table 2.7. Laboratory and Field Reported Values for $k_{M S W}$

\begin{tabular}{|c|c|c|c|}
\hline Test & $\begin{array}{c}\text { Waste } \\
\text { Description }\end{array}$ & $k_{M S W}(\mathrm{~cm} / \mathrm{s})$ & Reference \\
\hline Field & $\begin{array}{l}\text { As-placed MSW at a } \\
\text { landfill in the U.S. }\end{array}$ & $1.0 \times 10^{-3}$ to $2.6 \times 10^{-2}$ & $\begin{array}{l}\text { Landva and Clark } \\
\text { (1986) }\end{array}$ \\
\hline Field & $\begin{array}{l}\text { As-placed MSW at a } \\
\text { landfill in the U.S. }\end{array}$ & $1.6 \times 10^{-4}$ to $1.0 \times 10^{-3}$ & $\begin{array}{l}\text { Oweis et al. } \\
\text { (1990) }\end{array}$ \\
\hline Laboratory & Manufactured MSW & $4.7 \times 10^{-5}$ to $9.6 \times 10^{-2}$ & $\begin{array}{c}\text { Chen and } \\
\text { Chynoweth (1995) }\end{array}$ \\
\hline Laboratory & $\begin{array}{l}\text { Old MSW recovered } \\
\text { from a landfill in the } \\
\text { U.S. }\end{array}$ & $1.0 \times 10^{-5}$ to $1.0 \times 10^{-3}$ & $\begin{array}{l}\text { Gabr and Valero } \\
(1995)\end{array}$ \\
\hline Laboratory & $\begin{array}{l}\text { Fresh MSW obtained } \\
\text { from active face of a } \\
\text { landfill in England }\end{array}$ & $3.7 \times 10^{-8}$ to $1.5 \times 10^{-4}$ & $\begin{array}{c}\text { Powrie and Beaven } \\
\text { (1999) }\end{array}$ \\
\hline Laboratory & $\begin{array}{l}\text { Old MSW recovered } \\
\text { from a landfill in the } \\
\text { U.S. }\end{array}$ & $4.7 \times 10^{-6}$ to $1.2 \times 10^{-2}$ & $\begin{array}{l}\text { Durmusoglu et al. } \\
\qquad(2006)\end{array}$ \\
\hline Field & $\begin{array}{l}\text { As-placed MSW at a } \\
\text { landfill in the U.S. }\end{array}$ & $7.4 \times 10^{-6}$ to $6.1 \times 10^{-5}$ & $\begin{array}{l}\text { Jain et al. } \\
(2006)\end{array}$ \\
\hline Laboratory & $\begin{array}{c}\text { Laboratory degraded } \\
\text { waste obtained from a } \\
\text { transfer station in the } \\
\text { U.S. } \\
\end{array}$ & $8.0 \times 10^{-4}$ to $1.0 \times 10^{-2}$ & $\begin{array}{l}\text { Penmenthsa } \\
\quad(2007)\end{array}$ \\
\hline Laboratory & $\begin{array}{l}\text { Laboratory degraded } \\
\text { manufactured waste }\end{array}$ & $1.0 \times 10^{-4}$ to $1.0 \times 10^{-2}$ & $\begin{array}{l}\text { Olivier and Gourc } \\
\text { (2007) }\end{array}$ \\
\hline Laboratory & $\begin{array}{c}\text { Laboratory degraded } \\
\text { waste obtained from a } \\
\text { transfer station in the } \\
\text { U.S. }\end{array}$ & $1.3 \times 10^{-3}$ to $8.8 \times 10^{-3}$ & $\begin{array}{l}\text { Hossain et al. } \\
\text { (2008) }\end{array}$ \\
\hline Laboratory & $\begin{array}{l}\text { Shredded fresh and old } \\
\text { MSW obtained from a } \\
\text { landfill in the U.S. }\end{array}$ & $7.8 \times 10^{-5}$ to $2.0 \times 10^{-1}$ & $\begin{array}{l}\text { Reddy et al. } \\
\text { (2009d) }\end{array}$ \\
\hline Laboratory & $\begin{array}{l}\text { Shredded, old MSW } \\
\text { obtained from a French } \\
\text { landfill }\end{array}$ & $4.6 \times 10^{-4}$ to $7.4 \times 10^{-3}$ & $\begin{array}{l}\text { Staub et al. } \\
\quad 2009\end{array}$ \\
\hline Laboratory & $\begin{array}{l}\text { Processed, fresh (F) } \\
\text { and degraded (D) MSW } \\
\text { obtained from a landfill } \\
\text { in the U.S. }\end{array}$ & $\begin{array}{c}4.6 \times 10^{-7} \text { to } 7.0 \times 10^{-3}(\mathrm{~F}) \\
2.0 \times 10^{-4} \text { to } 1 \times 10^{2}(\mathrm{D})\end{array}$ & Breitmeyer (2011) \\
\hline Field & $\begin{array}{l}\text { Excavated MSW from a } \\
\text { landfill in the U.S. }\end{array}$ & $\begin{array}{l}6.8 \times 10^{-4} \text { to } 7.7 \times 10^{-1}(\mathrm{~F}) \\
3.1 \times 10^{-2} \text { to } 3.4 \times 10^{0}(\mathrm{D})\end{array}$ & Breitmeyer (2011) \\
\hline
\end{tabular}


Table 2.7. Laboratory and Field Reported Values for $k_{M S W}$ (Cont'd)

\begin{tabular}{|c|c|c|c|}
\hline Test & $\begin{array}{c}\text { Waste } \\
\text { Description }\end{array}$ & $\boldsymbol{k}_{\text {MSW }}(\mathbf{c m} / \mathbf{s})$ & Reference \\
\hline Laboratory & $\begin{array}{c}\text { Fresh and degraded } \\
\text { manufactured waste }\end{array}$ & $1.0 \times 10-8$ to $1.0 \times 10-3$ & $\begin{array}{c}\text { Reddy et al. } \\
(2011)\end{array}$ \\
\hline Field & $\begin{array}{c}\text { Excavated MSW from a } \\
\text { landfill in the U.S. }\end{array}$ & $2.0 \times 10-5$ to $4.0 \times 10-3$ & $\begin{array}{c}\text { Bareither et al. } \\
(2012 \mathrm{c})\end{array}$ \\
\hline
\end{tabular}

The hydraulic conductivity of MSW has been shown to vary significantly depending on the waste composition, compaction, entrapped gas within the waste, and overburden stress (Chen and Chynoweth 1995; Powrie and Beaven 1999; Powrie et al. 2005; Jain et al. 2006; Durmusoglu et al. 2006; Reddy et al. 2009d; Staub et al. 2009; Breitmeyer 2011; Reddy et al. 2011). In addition, spatial and temporal variations in $k_{M S W}$ have been reported as a function of the extent of degradation due to the significant change in the composition and size distribution of waste components as degradation processes progress (Penmethsa 2007; Hossain et al. 2008; Reddy et al. 2009d). Furthermore, Dixon and Jones (2005) postulated that placement and compaction of waste in layers and the use of daily cover soil (often relatively low $k$ ) resulted in a waste mass structure containing preferential horizontal flow paths and hence higher $k$ in the horizontal direction. The horizontal flow paths were attributed to low $k$ barriers created by horizontal orientation of MSW particles such as paper and plastics and the low $k$ daily cover material (Dixon and Jones 2005). The preferential horizontal flow of moisture and leachate seeps onto temporary waste slopes had been observed in many landfills (Dixon and Jones 2005). Such moisture 
movements could potentially produce zones of low shear strength and ultimately, slope failures.

Shear strength is defined as the ultimate or maximum shear stress $(\tau)$ a material can withstand and is characterized by the internal angle of friction and cohesion of the material (Holtz et al. 2011). Shear stress in soils is best described by the Mohr-Coulomb failure criterion (Holtz et al. 2011):

$$
\tau=\sigma \tan \phi+c
$$

Where:

$$
\begin{aligned}
& \sigma=\text { effective stress } \\
& \phi=\text { internal angle of friction } \\
& c=\text { cohesion }
\end{aligned}
$$

The shear strength of MSW is a critical engineering property for static and seismic stability analyses at landfills (Bray et al. 2009). Similar to the shear strength of soils, MSW shear strength is typically described using the MohrCoulomb criteria (Dixon and Jones 2005; Zekkos 2005). In addition, the shear strength characteristics (i.e., $\phi$ and $c$ ) of MSW are similar to those of soil such that the shear strength is primarily stress dependent (i.e., frictional) particularly at higher confining stresses. Also, waste has significant strength at low confining stresses (i.e., high cohesive strength) due to the fibrous constituents of the waste (Dixon and Jones 2005; Bray et al. 2009).

Numerous laboratory (e.g., simple shear, direct shear, triaxial) and field (e.g., CPT, SPT, in-situ direct shear) tests have been conducted to characterize 
MSW shear strength however, large variability exists in reported values for $\phi$ and c (e.g., Landva and Clark 1990; Singh and Murphy 1990; Gabr and Valero 1995; Grisolia et al. 1995; Kavazanjian et al. 2001; Zekkos 2005; Bray et al. 2009; Reddy et al. 2009a,b; Gomes et al. 2013). The variability in the reported MSW shear strength parameters is presented in Table 2.8. The obstacles to evaluating the shear strength parameters of MSW include the heterogeneous nature of waste, degree of degradation (i.e., age of waste), collecting and testing a representative waste sample due to the bulkiness of some waste constituents, and the use of different testing devices that induce discrepancies in the stressstrain-strength response of MSW (Bray et al. 2009; Gomes et al. 2013).

In addition, degradation processes have been determined to directly affect the shear strength of waste (Singh and Murphy 1990; Gabr et al. 2007). Results from laboratory shear strength testing indicated that the friction angle of refuse decreased with decomposition from 32 to $24^{\circ}$ (Gabr et al. 2007). Gabr et al. (2007) observed that degraded waste samples contained higher plastics content which resulted in reduction of friction angles. The physical and mechanical evolution of MSW over time due to degradation processes needs to be considered when evaluating shear strength parameters for stability analyses. Furthermore, Singh and Murphy (1990) suggested that averaging $c$ and $\phi$ values for variable stages of degraded MSW, will inaccurately characterize the shear strength parameters of that particular waste sample. 
Table 2.8. Reported $\phi$ and $c$ Values for MSW Shear Strength Characterization

\begin{tabular}{|c|c|c|}
\hline Reference & $\boldsymbol{c ~ ( k P a )}$ & $\boldsymbol{\phi}$ (degrees) \\
\hline Landva and Clark (1990) & 23 & 24 \\
\hline Gabr and Valero (1995) & 0 to 28 & 20 to 39 \\
\hline Kavazanjian et al. (2001) & 16 to 30 & 33 to 59 \\
\hline Bray et al. (2009) & 15 & 36 \\
\hline Reddy et al. (2009a) & $\begin{array}{c}12 \text { to } 63 \\
(41)\end{array}$ & $\begin{array}{c}31 \text { to } 35 \\
(33)\end{array}$ \\
\hline Reddy et al. (2009b) & $\begin{array}{c}31 \text { to } 64 \\
(43)\end{array}$ & $\begin{array}{c}26 \text { to } 30 \\
\text { (29) }\end{array}$ \\
\hline Campi and Boscov (2011) & 5 to 30 & 5 to 30 \\
\hline Gomes et al. (2013) & $\begin{array}{c}0 \text { to } 72 \\
\text { (23) }\end{array}$ & $\begin{array}{c}14 \text { to } 50 \\
\text { (33) }\end{array}$ \\
\hline
\end{tabular}

Note: Values in parentheses are averages of the reported data ${ }^{\mathrm{a}}$ Recommended values

\subsection{Compaction}

Compaction is a mechanical procedure used to stabilize and in general, improve the engineering properties (i.e., shear strength, compressibility, and hydraulic conductivity) of a geomaterial through densification. Compaction is particularly important when a given geomaterial is used as an engineering material (e.g., embankment/earthen structure, foundation material, etc.). Mechanical energy can be applied to a material using static, vibratory, dynamic, or kneading compaction techniques (Holtz et al. 2011). The theories, mechanisms and procedures related to the compaction of both fine-grained and coarse-grained soils are discussed in this section followed by a description of the mechanisms and characteristics of municipal solid waste compaction. 


\subsubsection{Compaction of Soils}

Enhancing the engineering properties of soil through densification is the overall objective of compaction. Compaction as applied to soils, can reduce or prevent detrimental settlements, increase soil strength, improve slope stability, improve the bearing capacity of pavement subgrades, decrease hydraulic conductivity, and control volume changes in fine-grained soils (i.e., shrink/swell and freeze/thaw mechanisms) (Lambe 1958b; Seed and Chan 1959; Holtz et al. 2011).

The fundamentals of compaction of fine-grained soils were first introduced by Proctor (1933) through the development of the standard laboratory compaction test. Proctor (1933) postulated that compaction was a function of four parameters: 1) dry density; 2) water content; 3) compactive effort, 4) soil type (e.g., gradation, presence of clay minerals). The standard and modified laboratory compaction tests are described in current ASTM standards D698 and D1557, respectively (ASTM 2012a,b). In both standards, a compactive effort (measure of mechanical energy) is applied to a soil mass. The applied standard effort is $600 \mathrm{kN}-\mathrm{m} / \mathrm{m}^{3}$ (ASTM 2012a) whereas the applied modified effort is 2700 $\mathrm{kN}-\mathrm{m} / \mathrm{m}^{3}$ (ASTM 2012b). The compaction test is repeated at multiple moisture contents with moisture contents plotted against corresponding dry unit weights to generate compaction curves. A compaction curve is unique for a given soil type, method of compaction, and (constant) compactive effort (Holtz et al. 2011). A typical compaction curve of a fine-grained soil that has been compacted at standard and modified efforts is presented in Figure 2.17. 


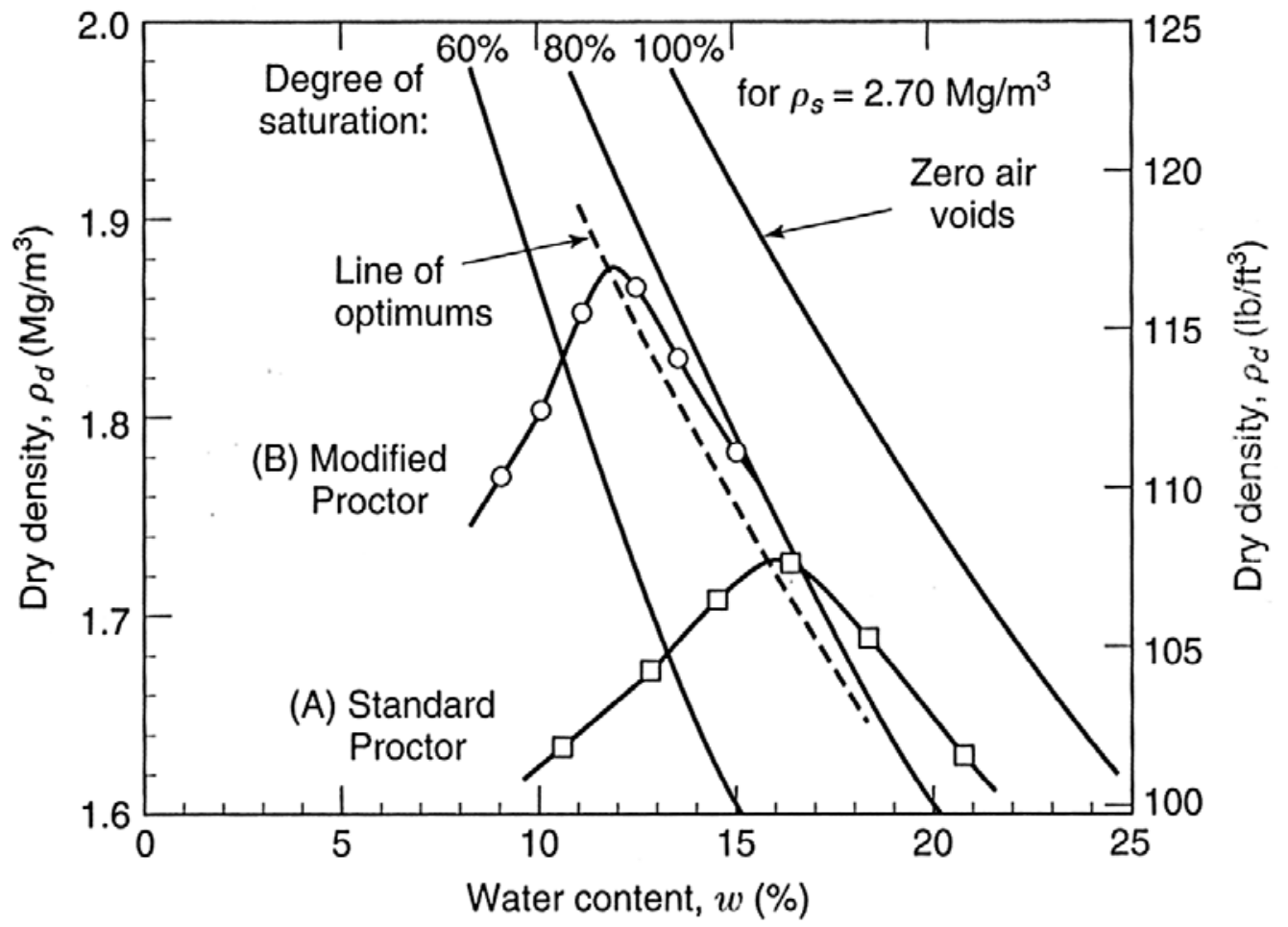

Figure 2.17. Compaction Curve at Standard and Modified Effort (Holtz et al. 2011)

The peak of each curve represents the maximum dry density that can be obtained for a specific compactive effort and method of compaction however, it does not necessarily reflect the maximum dry density than can be obtained in the field (Holtz et al. 2011). The moisture content that corresponds with a given maximum dry density is often referred to as the optimum moisture content. The zero air voids (ZAV) curve and line of optimums (LOO) are characteristics of the compaction curve that describe the degree of saturation (S) for a given soil (Figure 2.17). In particular, the ZAV curve represents 100\% saturation and regardless of the compactive effort and the addition of water, a soil does not become completely saturated (Holtz et al. 2011). The LOO is the line or curve drawn through the peak points of the compaction curves for the same soil compacted using different compactive efforts. 
The engineering properties of fine-grained soils are directly affected by the state of compaction. The moisture content at which compaction is performed has major implications upon the strength and hydraulic conductivity of fine-grained soils. For example, soils compacted dry of optimum have an increased hydraulic conductivity, more capacity for swelling, and decreased capacity for shrinkage whereas, soils compacted wet of optimum generally have a lower hydraulic conductivity, less capacity for swelling, and more capacity for shrinkage (Holtz et al. 2011).

Lambe (1958a) stated that soil particles under any state of stress, require a certain amount of moisture for development of the diffuse double layer. That is, at low moisture contents soil particles tend to flocculate and have a lower degree of particle orientation and lower density. As the moisture content is increased to the optimum level, the soil fabric becomes more oriented as the particles become more "lubricated" with thicker diffuse double layer and are able to slide pass one another into a more dense orientation (Lambe 1958a). However, as noted by Lambe (1958a), the dense orientation of soil particles begin to disperse as the moisture content of a fine-grained soil is increased to wet of optimum conditions. Figure 2.18 illustrates the effects of increasing moisture content and compactive effort on the structure and arrangement of fine-grained soil particles. 


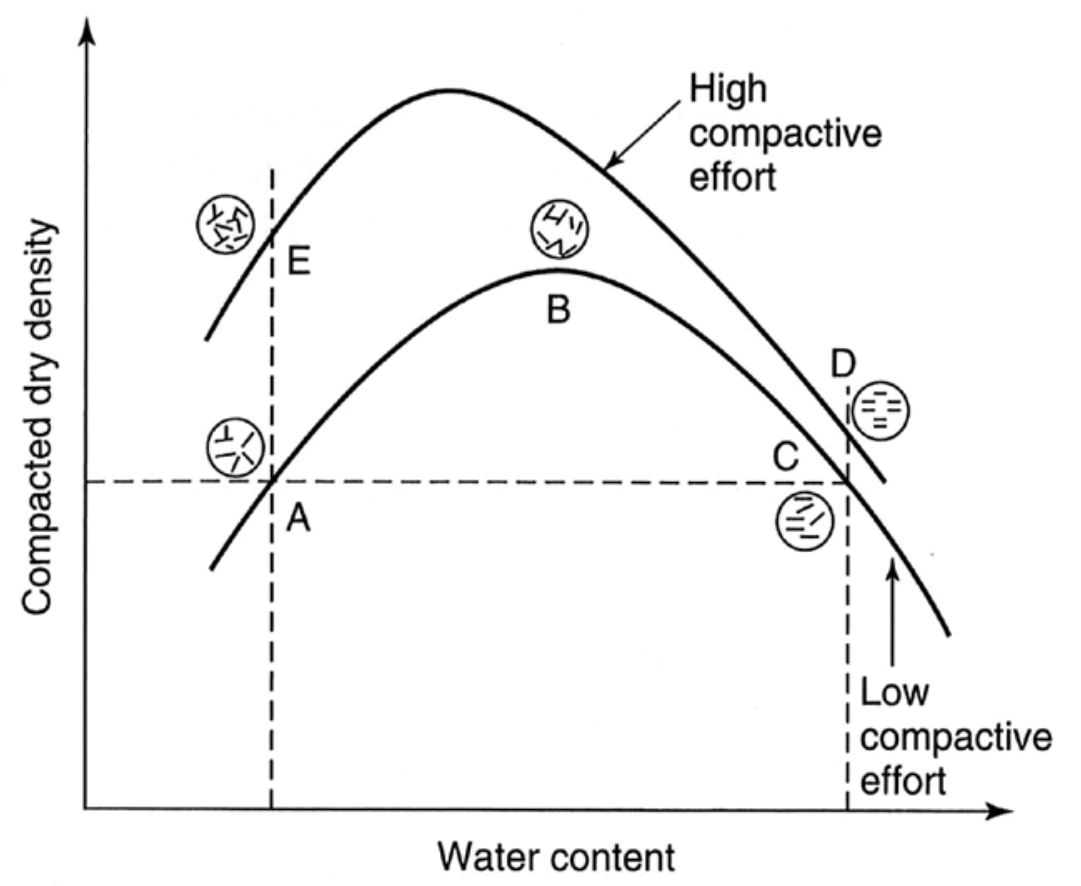

Figure 2.18. Effect of Compaction on Soil Structure (From Lambe 1958a as reported by Holtz et al. 2011)

An increase in the compactive effort on the same soil at dry of optimum results in a tighter packing arrangement of the soil particles and thus, a more dense soil mass. The same effect occurs when a soil is compacted wet of optimum but the increase in compacted density is not nearly as prominent (Holtz et al. 2011). This phenomenon is explained by the water deficiency of dry of optimum fine-grained soils, namely clayey soils. A fine-grained soil is more sensitive to change when it is compacted dry of optimum than compacted at wet of optimum (Lambe 1958a; Holtz et al. 2011).

Both Lambe (1958b) and Seed and Chan (1959) described ways in which the engineering behavior of clays are affected by compaction. In particular, Lambe (1958b) summarized the permeability, compressibility, and strength behavior of clays compacted at dry and wet of optimum. Lambe (1958b) 
indicated that clays compacted dry of optimum are more permeable than clays compacted wet of optimum. Lambe (1958b) also stated that clays are more compressible at low pressure levels when compacted wet of optimum and more compressible at high pressure levels when compacted dry of optimum. Furthermore, both the drained and undrained as-molded strengths of a clay are generally high when compacted dry of optimum (Lambe 1958b). Seed and Chan (1959) suggested that different methods of compaction tend to produce similar characteristics for clays compacted dry of optimum at a given density and moisture content but produce different characteristics for clays compacted wet of optimum. In addition, Seed and Chan (1959) suggested that particle orientation and shrinkage tend to decrease, while strength at low strains tends to increase with the following order of compaction types: kneading, impact, vibratory, and static.

Aside from the particle orientation theory described by Lambe (1958a), another theory was developed by Olsen (1962) that described the influence of compaction characteristics on the behavior of fine-grained soil particles. Olsen (1962) postulated that clods of fine-grained soil (i.e., clay) particles may be broken down by the mechanical energy applied during compaction. At low moisture contents, the clods are held together in a flocculated arrangement via capillary action. As the moisture content increases toward optimum, the capillary forces decrease and allow for the breakdown of the flocculated structures into a more consistent configuration (Olsen 1962). When a fine-grained soil is compacted at wet of optimum, the additional water prevents the soil particles 
from packing as tightly into clods due to the replacement of solids volume with water volume (Proctor 1933).

There is a significant difference between the response of coarse-grained (granular) soils and fine-grained soils to compaction. Unlike fine-grained soils, coarse-grained soils exhibit distinct maximum and minimum density limits which are determined by their classification and grain-size characteristics including: 1) median grain size $\left.\left(D_{50}\right) ; 2\right)$ range of grain sizes $\left(C_{r}\right)$; and 3$)$ the shape of the grain size curve (Burmister 1963; Burmister 1964). The granular soil particles have no inherent cohesion such that a coarse-grained soil can easily rearrange from a looser to a denser configuration through vibratory compaction methods (Holtz et al. 2011).

D' Appolonia et al. (1969) presented an important concept of the fundamentals of granular soil compaction during the investigation of field compaction (i.e., number of passes) and lift thickness of sand in relation to a zone of influence. D' Appolonia et al. (1969) summarized four important aspects of the field compaction of sand using vibratory rollers: 1) compaction of in-situ granular deposits was not effective for achieving high densities at depths greater than $1.5 \mathrm{~m}$ (Figure 2.19a); 2) the compacted density at any given depth increased with the number of passes however, after approximately 5 passes, a large increase in the number of passes was required to achieve a significant increase in density (Figure 2.19b); 3) a given lift should be placed at a height that matches the depth at which maximum density can be achieved in order to avoid loose layers trapped near the interfaces of sand layers or overcompaction of near 
surface layers; and 4) vibratory compaction of granular soil created a lateral and vertical zone of influence in which the maximum dynamic stresses applied to the soil by the roller occur directly beneath the roller and are less significant further away from the roller (Figure 2.19c).

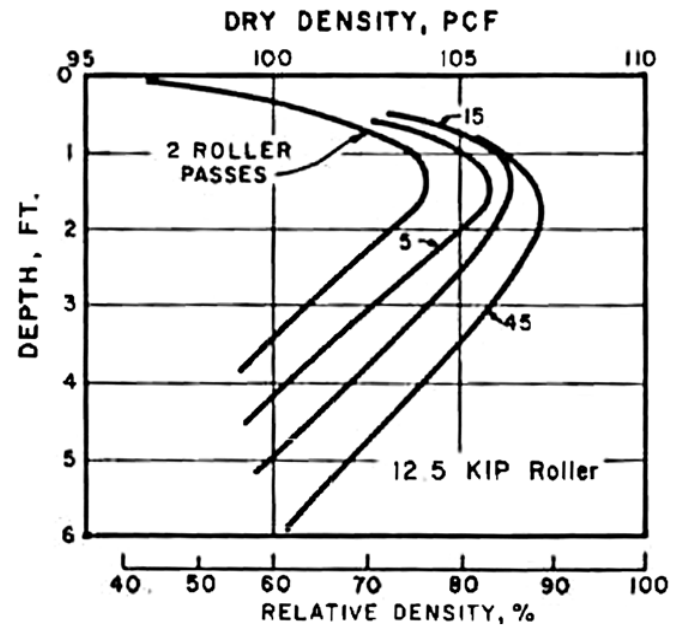

a
RELATIVE DENSITY, $\%$

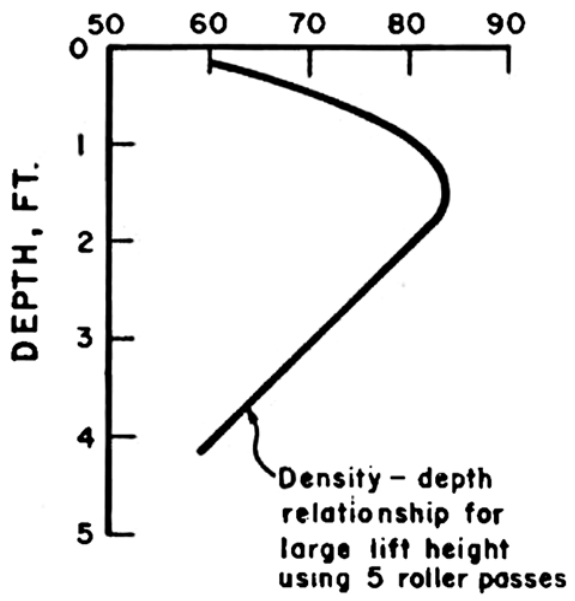

LEGENO

Moximum omplitude vertical stross, PS।

- - - Minimum vortlcal stress = 0

-.- Maximum vertical accoloration, g'v

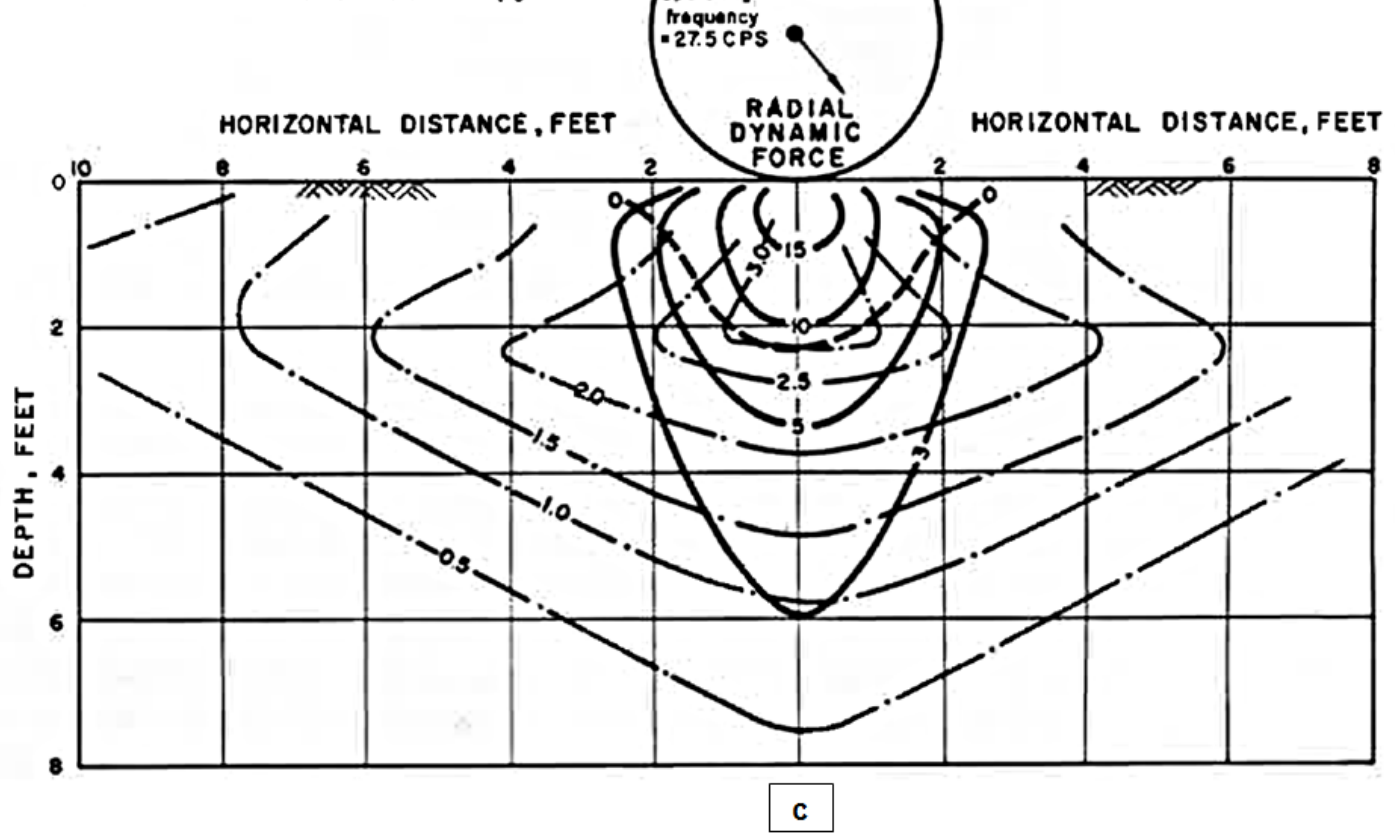

Figure 2.19. Compaction Characteristics of Granular Soils

(D' Appolonia et al. 1969) 
The concept of relative compaction (Lee and Singh 1971) as applied to granular and fine-grained soils is important for writing compaction specifications, controlling the placement of fills, evaluating engineering properties, and for developing engineering judgment as to the performance of the fill. Relative compaction is defined as the ratio of the field dry density, $\rho_{d, \text { field }}$, to the laboratory maximum dry density, $\rho_{d, \max }$.

The compaction characteristics for soils are well established in comparison to municipal solid waste. However, the theories and mechanisms related to soil compaction can be applied to waste compaction.

\subsubsection{Compaction of MSW}

In comparison to soils, the characteristics and mechanisms of waste compaction are less defined, due in large part to the variability in the composition and engineering properties of MSW. Parameters that affect the compaction characteristics of waste include: type and size of the compactor, design and orientation of the compactor wheel teeth, compactor operator experience, lift thickness, compactive effort, composition of the waste, and climatic conditions (Surprenant and Lemke 1994; Collins 2001; Marques et al. 2002; Hanson et al. 2010a). The short-term density and placement efficiency of MSW at a landfill is predominantly controlled by the compaction methods employed.

Similar to the relationship between total unit weight and moisture content of compacted soils (Johnson and Sallberg 1960), a specific relationship exists between total unit weight, moisture content and densification of the solids for 
compacted MSW (Hanson et al. 2010a). For soils, a linear increase in total unit weight results from addition of water weight and a nonlinear increase from compaction results from improved particle packing efficiency at increasing moisture contents. At high moisture contents (specifically, wet of optimum), solids are replaced with water which results in a decrease in unit weight with further increases in moisture content (Johnson and Sallberg 1960). For waste, the variation of total unit weight with moisture content is generally similar to that for soils. However, the decrease in $\gamma_{t}$ at high $w$ for wastes is not as prominent as that for soils because the relative difference between unit weight of water and unit weight of solids is lower for wastes than for soils (Hanson et al. 2010a). The two-dimensional plot of moisture content versus total unit weight developed by Johnson and Sallberg (1960) is sufficient for soils compacted at variable efforts. However, a third axis is required for wastes to include the variation in $\gamma_{t}$ due to the increase of $G_{s}$ of the solids with compactive effort, which typically does not apply to soils (Hanson et al. 2010a). The three-dimensional (3D) schematic plot of highlighting the relationship between total unit weight, moisture content, and compactive effort for MSW is presented in Figure 2.20. 


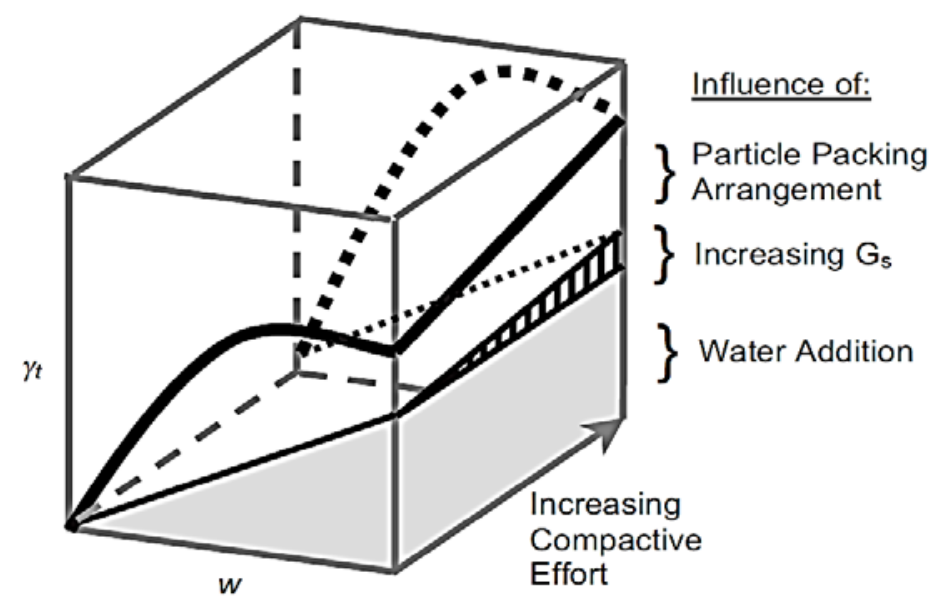

Figure 2.20. 3D Schematic Plot of Waste Compaction (Hanson et al. 2010a)

The three-dimensional (3D) plot allows for representative depiction of the results of waste compaction tests at variable compactive efforts. If this $3 D$ plot were produced for soil compaction, it would have a similar appearance with the exception that the triangular wedge associated with increasing Gs would not be present (Hanson et al. 2010a).

In general, the compaction equipment used at landfills on MSW is larger, heavier, and has larger compactor teeth than the equipment used for soil compaction. The compactor teeth are especially important for waste compaction because they produce kneading and cutting motions that help to chop, shred, and break-up waste particles while simultaneously reorienting the waste particles into a tighter, interlocking matrix with less void space. The compactive effort is related to the number of passes with the compactor in the field and the number of drops with the hammer in the laboratory. Marques et al. (2002), Von Stockhausen (2007), and Wong (2009) demonstrated that increasing the effort 
during the compaction of MSW will result in an increase in the overall density of the waste for a given moisture content (i.e., upward shift of compaction curve).

The compaction curves generated for MSW have less prominent peaks than those generated from soils and represent a wider range of moisture contents. In addition, the maximum dry density and optimum moisture content of laboratory and field compacted MSW generally differ significantly in comparison to soil. Reported values for maximum dry density $\left(\gamma_{d, \max }\right)$ and optimum moisture content $\left(w_{\text {opt }}\right)$ of laboratory compacted MSW range from 4.1 to $9.3 \mathrm{kN} / \mathrm{m}^{3}$ and 10 to $80 \%$, respectively (Harris 1979; Gabr and Valero 1995; Hettiarachchi 2005; Itoh 2005; Reddy 2009b; Hanson et al. 2010a). Maximum dry density and optimum moisture content of field compacted MSW ranged from 6.2 to 10.2 $\mathrm{kN} / \mathrm{m}^{3}$ and 30 to $80 \%$, respectively (Collins 2001; Hanson et al. 2010a).

In comparison to the physical and other engineering properties of MSW, limited studies have been conducted on the compaction characteristics of MSW (Harker and Juds 1976; Ham et al. 1978; Harris 1979; Surprenant and Lemke 1994; Gabr and Valero 1995; Collins 2001; Marques et al. 2002; Hettiarachchi 2005; Itoh et al. 2005; Fakher 2006; Von Stockhausen 2007; Reddy et al. 2009b; Wong 2009; Wang et al. 2012). A laboratory investigation was performed by Harker and Juds (1976) to investigate the effectiveness of roller compaction on individual waste constituents (e.g., glass bottles, aluminum cans, various metal containers). Significant volume reduction and high compaction efficiency was reported for each of the tested waste materials (Harker and Juds 1976). However, the data reported from the study is severely limited for current waste 
placement practices because organic wastes were neglected from the investigation and the response of an independent waste constituent to compaction does not represent the response of the heterogeneous waste mass in a landfill.

Ham et al. (1978) investigated the density of milled and unprocessed waste in both the laboratory and the field. Effects of vibration, particle size (i.e., milled vs. unprocessed), and applied pressure on the density of waste were reported and then related to the practical applications of waste compaction processes at a landfill. The laboratory-scale compaction tests involved placement and compaction of residential MSW in a $0.6 \times 0.6 \times 0.9 \mathrm{~m}$ rectangular cell (Ham et al. 1978). Approximately $4.5 \mathrm{kN}$ of unprocessed residential MSW and $4.5 \mathrm{kN}$ of milled residential MSW with an average moisture content of $45 \%$ was used for a total of 10 tests. Five tests were conducted on unprocessed residential MSW and 5 tests were conducted on milled residential MSW. In addition, vibrations were generated during 4 of the 5 tests conducted on both the unprocessed and milled residential MSW to simulate the compaction of waste using a vibratory compactor (Ham et al. 1978). Compactive effort was simulated by compressive forces applied using a steel plate attached to a compression machine.

Ham et al. (1978) demonstrated that the density of the compacted milled waste was approximately $20 \%$ higher than the density of compacted unprocessed waste for a given compactive effort. In addition, vibrations during compaction resulted in increased densities over the entire pressure range for both milled and unprocessed waste but the percentage increase due to vibration 
was less significant at higher pressures for each type of waste (Ham et al. 1978). The applicability of the results from the laboratory compaction tests to modern compaction operations is limited due to the use of significantly heavier kneading compactors as opposed to vibratory rollers.

Field-scale compaction tests were also conducted by Ham et al. (1978). First, a total of 13 test cells $(12 \times 30 \times 1.7 \mathrm{~m})$ were constructed and A D7 Caterpillar bulldozer was used to compact incoming MSW in the field. Eight cells were filled with milled MSW and 5 cells were filled with unprocessed MSW in a series of 3 sub lifts. Each waste lift was spread and then compacted using the bulldozer. The moisture content of the compacted MSW ranged between 20 and $45 \%$. The weight of milled waste used for the 8 cells varied between 4220 and $7510 \mathrm{kN}$ and the weight of the unprocessed waste used for the 5 cells varied between 4880 and $12960 \mathrm{kN}$ The compactive effort (i.e., number of passes) was not reported however, Ham et al. (1978) reported that the milled waste was $13 \%$ more dense than the unprocessed waste after compaction.

The final field-scale compaction tests were conducted on unprocessed and milled fresh MSW. A total of 3 tests pits ( 1 for unprocessed and 2 for milled) were excavated and filled with approximately $10,500 \mathrm{kN}$ of waste. Upon placement into the test pit, the waste was compacted at an average moisture content of $50 \%$ using a steel wheeled tractor for an average of 21 hours (Ham et al. 1978). A maximum dry unit weight of $5.1 \mathrm{kN} / \mathrm{m}^{3}$ was reported for milled waste with a moisture content of $53 \%$ as compared to a maximum dry unit weight of 4.2 $\mathrm{kN} / \mathrm{m}^{3}$ for unprocessed waste at a moisture content of 38\% (Ham et al. 1978). 
Similar to the laboratory compaction data provided by Ham et al. (1978), the field compaction data is limited due to the use of smaller compaction machinery (i.e., bulldozers and tractors). However, the results of the milled waste compaction tests most likely simulated the kneading and shredding of the waste caused by the teeth of modern waste compactors.

Standard effort laboratory tests were conducted on waste obtained from a landfill in England (Harris 1979). The compaction tests yielded an average maximum dry unit weight of $7.1 \mathrm{kN} / \mathrm{m}^{3}$ and an optimum moisture content of $58 \%$. Harris (1979) suggested that the moisture content of incoming fresh waste typically varied as a function of weather conditions and that the addition of moisture during compaction would aid in waste placement efficiency and maximize landfill volume.

Surprenant and Lemke (1994) performed a field compaction study at a landfill in Illinois, United States. The purpose of the study was to investigate the factors affecting compaction of MSW including: size of compactor, lift thickness, and number of passes (Surprenant and Lemke 1994). A $12.4 \times 21.7 \mathrm{~m}$ test plot with a capacity to hold approximately $17,800 \mathrm{kN}$ (2000 tons) of MSW was constructed for the compaction study. The incoming waste was composed of "pure" MSW (i.e., free of construction and demolition (C \& D) waste and sludge) and no cover soil was used during the testing (Surprenant and Lemke 1994). The data obtained from the investigation highlighted that a $14 \%$ increase in density was achieved using a heavier compactor and a $25 \%$ increase in density was achieved using $0.3 \mathrm{~m}$ lifts as compared to $0.8 \mathrm{~m}$ lifts. In addition, a majority of the 
densification of the waste was achieved within four passes but a 3 and $9 \%$ increase in density was achieved with four additional passes on lift heights of 0.3 and $0.8 \mathrm{~m}$, respectively (Surprenant and Lemke 1994).

Standard effort compaction (ASTM D698) tests were performed by Gabr and Valero (1995) on 15 to 30 year old municipal solid waste recovered from drilling operations (i.e., drill cuttings). The maximum particle size of the waste obtained was determined to be $9.5 \mathrm{~mm}$. Due to the disturbance during auger drilling and subsequent sample reconstitution, the in-situ unit weight of the waste could not be determined. A maximum dry unit weight of $9.3 \mathrm{kN} / \mathrm{m}^{3}$ was achieved at a moisture content of $31 \%$. Saturation of the sample occurred at approximately $70 \%$ moisture content and a unit weight of $8 \mathrm{kN} / \mathrm{m}^{3}$. At $31 \%$ moisture content, a theoretical maximum dry unit weight of $12 \mathrm{kN} / \mathrm{m}^{3}$ was estimated from the zero air voids curve.

A field-scale compaction study was conducted at a landfill in Germany by Collins (2001). The goal of the study was to determine the most effective treatment and compaction procedure to reach maximum waste densities (Collins 2001). The MSW used for the compaction test was processed and treated prior to compaction where large quantities of waste were placed into multiple large mixing drums with capacities of $295 \mathrm{kN}$ (33 tons) and then allowed to degrade for time periods ranging between 3 and 13 months. A small portion of the processed waste was compacted following the mixing and degradation while the remaining larger portion was further processed using a sieve. The sieving resulted in a maximum particle size of $60 \mathrm{~mm}$ with $70 \%$ of the particles less than $8 \mathrm{~mm}$ in size 
(Collins 2001). Both the unsieved and sieved waste was placed and compacted at maximum lift heights of $0.3 \mathrm{~m}$. A medium sized compactor was used for the compaction on the unsieved waste while a small, medium, and large sized compactor was used on the sieved waste. Collins (2001) reported maximum dry unit weights of $8.4,12.4$, and $15.3 \mathrm{kN} / \mathrm{m}^{3}$ for the sieved waste using small, medium, and large sized compactors, respectively. The maximum dry unit weight for the unsieved waste using the medium size compactor was determined to be $10.2 \mathrm{kN} / \mathrm{m}^{3}$ (Collins 2001). The field compaction tests conducted by Collins (2001) were not typical testing procedures for determining the compaction characteristics of waste such that a compaction curve was not generated.

Marques et al. (2002) evaluated the compaction of MSW at a Brazilian landfill. The field compaction tests were carried out using two different types of compaction equipment namely, a compaction roller and a bulldozer. Lift thickness, compactive effort (i.e., number of passes), and slope of compaction angle were the parameters assessed during the compaction investigation (Marques et al. 2002). The results indicated that the dry unit weight of waste decreased with increasing moisture content independent of the compactor type, lift thickness, or the compactive effort.

The standard proctor compaction test (ASTM D698) was used to evaluate the compaction characteristics of manufactured waste by Hettiarachchi (2005). Test were performed at different moisture contents on fresh manufactured waste as well as on reconstituted manufactured waste (i.e., samples had been used for previous experiments). The two samples of reconstituted waste had been used 
23 and 43 times prior to the compaction investigation (Hettiarachchi 2005). The maximum particle size of all of the manufactured samples was $5 \mathrm{~mm} . \gamma_{d, \max }$ values for fresh, moderately reused (23 times), and highly reused (43 times) waste samples were reported to be $5.15,5.69$, and $5.98 \mathrm{kN} / \mathrm{m}^{3}$, respectively (Hettiarachchi 2005). The corresponding $w_{\text {opt }}$ values were reported as 62,70 , and $80 \%$ (Hettiarachchi 2005).

Itoh (2005) conducted low effort $\left(550 \mathrm{~kJ} / \mathrm{m}^{3}\right.$ in comparison to $600 \mathrm{~kJ} / \mathrm{m}^{3}$ for standard effort) compaction tests on a select waste mixture primarily composed of vinyl and plastics with some glass, ceramics, organics, and fibrous materials. The waste samples were obtained from a landfill in Tokyo, Japan and had a maximum particle size of $5 \mathrm{~mm}$ (Itoh 2005). For low effort compaction, Itoh (2005) reported a maximum dry unit weight of $5.9 \mathrm{kN} / \mathrm{m}^{3}$ at $20 \%$ moisture content. Higher effort tests $\left(2,500 \mathrm{~kJ} / \mathrm{m}^{3}\right.$ compared to $2,700 \mathrm{~kJ} / \mathrm{m}^{3}$ for modified effort) resulted in a maximum dry unit weight of $7.8 \mathrm{kN} / \mathrm{m}^{3}$ at $10 \%$ moisture content.

A laboratory- and field-scale experiment on the compaction of fresh waste was conducted at a landfill in Iran to determine a practical maximum unit weight of fresh MSW at natural moisture content and a relative compaction value for fresh MSW (Fahker 2006). A $550 \mathrm{~mm}$ diameter steel mold was filled to a $600 \mathrm{~mm}$ height. Three compaction experiments were conducted using in accordance with the modified effort compaction tests (ASTM D1557). The procedures were slightly modified such that the waste was placed in 5,6 , and 7 lifts and then compacted at efforts of 56, 60, and 70 blows per lift, respectively (Fahker 2006). 
A practical maximum total unit weight of $6.9 \mathrm{kN} / \mathrm{m}^{3}$ was reported by Fahker (2006) and corresponded to placement of 7 lifts, 60 blows per lift, and a compactive energy of $5600 \mathrm{~kJ} / \mathrm{m}^{3}$ (2x modified effort). The moisture content of the tested MSW was not reported.

The field portion of the experiment involved placement and compaction of the fresh waste using a D6 bulldozer at different compactive efforts. The waste lifts were placed at heights of $0.4 \mathrm{~m}$ and compaction was performed using 2, 4, 6, and 8 passes of the bulldozer. The in-situ unit weight of the MSW was determined at each compactive effort using the excavation and replacement method described by Zekkos et al. 2005 and Zekkos et al. 2006. Fahker (2006) defined the relative compaction for MSW as the quotient of the field unit weight (after compaction) and the practical maximum unit weight (from laboratory) and determined that $99.5 \%$ of the compaction is reached after 3 passes using the D6 bulldozer. Fahker (2006) suggested that the relative compaction of MSW could be used to determine the maximum number of passes needed to achieve the maximum compacted density. The representativeness of modified effort for field waste compaction was not evaluated.

Laboratory and field investigations were conducted by Von Stockhausen (2007) to determine the influence of moisture content and mechanical effort on the compacted unit weight of MSW. For the laboratory compaction experiments, manufactured waste was prepared using the waste constituent breakdown provided in the 2006 USEPA Facts and Figures (Von Stockhausen 2007). The maximum particle size of the waste constituents was $100 \mathrm{~mm}$. Modified proctor 
tests (ASTM D1557) were performed on manufactured MSW samples prepared in $150 \mathrm{~mm}$ diameter molds at 7 different moisture contents varying from 6.4 to 152\%. (Von Stockhausen 2007). The compaction curve generated from the laboratory compaction experiment yielded a maximum dry unit weight of 5.6 $\mathrm{kN} / \mathrm{m}^{3}$ at an optimum moisture content of $42 \%$ (Von Stockhausen 2007).

A field compaction study also was conducted at a landfill in Michigan, United States to determine the influence of operational conditions, climate conditions, and moisture content on the unit weight of waste. Several compaction tests were conducted on field test plots that had approximate areas of $200 \mathrm{~m}^{2}$ and specimen sizes of approximately $355 \mathrm{kN}$ (40 tons) of fresh incoming MSW. GPS surveying was used to determine the compacted volumes of waste at low and high efforts and in conjunction with different amounts of moisture addition prior to compaction. In all, 6 low effort and 4 high effort field compaction tests were conducted at different moisture contents (i.e., different levels of moisture addition). From field tests, Von Stockhausen (2007) reported a maximum dry unit weight of $6.2 \mathrm{kN} / \mathrm{m}^{3}$ at an optimum moisture content of $70.5 \%$ for the low effort tests and a maximum dry unit weight of $8.2 \mathrm{kN} / \mathrm{m}^{3}$ at an optimum moisture content of $79.5 \%$ for the high effort tests. These values were compared to the baseline (i.e., non-wetted) compacted dry unit weight of the incoming waste which was determined to be $4.8 \mathrm{kN} / \mathrm{m}^{3}$ at a moisture content of approximately 30\% (Von Stockhausen 2007).

The workability of MSW (i.e., amount of rebound after compaction) was determined to be related to the moisture content of MSW and increased 
workability (i.e., less rebound after compaction) of MSW was indicated by higher operational unit weights and an increased normalized effort (Von Stockhausen 2007). In addition, a moisture content range of between $40 \%$ and $100 \%$ was determined to correspond to samples that required less time to compact and, therefore, received more productive passes with the compactor (Von Stockhausen 2007).

Reddy et al. (2009b) conducted standard effort laboratory compaction tests on waste samples obtained from a landfill in California, United States. Samples were screened to ensure that the maximum particle size did not exceed $40 \mathrm{~mm}$. Reddy et al. (2009b) reported an optimum moisture content of $70 \%$ and a maximum dry unit weight of $4.12 \mathrm{kN} / \mathrm{m}^{3}$ for samples compacted using the standard compaction method. Data obtained from the tests performed by Reddy et al. (2009b) were compared to the data obtained by Hettiarachchi (2005). The differences in maximum dry unit weight and moisture content between the studies were attributed to differences in maximum waste component size and well as component size distribution.

Wong (2009) performed laboratory compaction tests on manufactured MSW to determine the moisture content-dry unit weight relationship for the MSW. Tests were performed in a 150-mm-diameter compaction mold with a mechanically raised, automatic compactor. Four sets of compaction tests were completed on manufactured waste samples with maximum particle size of 50 $\mathrm{mm}$ : two with conventional hydration (termed pre-wetted) at modified Proctor compactive effort (modified); two with conventional hydration at four times 
modified Proctor compactive effort (4X modified compactive effort), two with nonpre-wetted hydration at modified compactive effort; and two with non-pre-wetted hydration at $4 \mathrm{X}$ modified compactive effort (Wong 2009).

Conventional hydrated samples were brought to target moisture contents immediately after sample mixing and allowed to hydrate for 16 to 24 hours prior to compaction. The non-pre-wetted samples were mixed, brought to $30 \%$ moisture content (i.e., field conditions at a landfill), allowed to hydrate for 16 to 24 hours, and then brought to the target moisture contents immediately prior to compaction testing (within 5 minutes). The pre-wetted samples were prepared to simulate soaking of the waste in the field prior to compaction and evaluate the differences, if any, between soaking and non-soaking MSW in the field prior to compaction (Wong 2009). In addition, Wong (2009) noted that the $4 \mathrm{X}$ modified effort was employed to simulate the compactive effort in the field.

For the modified compaction tests, a maximum dry unit weight of 5.1 $\mathrm{kN} / \mathrm{m}^{3}$ was determined at a moisture content of $66 \%$ while a maximum dry unit weight of $5.9 \mathrm{kN} / \mathrm{m}^{3}$ and optimum moisture content of $56 \%$ was determined for the manufactured MSW compacted at $4 \mathrm{X}$ modified effort (Wong 2009). No significant differences in compaction characteristics were identified between samples that were hydrated in the conventional versus the non-pre-wet manner and therefore, the results obtained were treated as a uniform set of data for a given compactive effort (Wong 2009).

Wang et al. (2012) recently investigated the compaction characteristics of MSW at a landfill in China. The purpose of the experiments was to determine the 
optimum compacted density of MSW at a landfill that had never utilized compaction procedures prior to the experiment. Compactive effort and lift thickness were the parameters investigated in this experiment (Wang et al. 2012). It was determined that a lift thickness of $0.6 \mathrm{~m}$ combined with 3 passes using a BOMAG kneading compactor yielded optimum compacted densities. Wang et al. (2012) estimated that a maximum compacted unit weight of 8.8 $\mathrm{kN} / \mathrm{m}^{3}$ could be achieved on incoming wastes with moisture contents between 50 and $65 \%$.

There is a wide range of laboratory and field compaction data that has been reported in the literature. A summary of the methods and results of the comparable compaction studies (i.e., comparable testing procedures) presented in the literature are provided in Table 2.9. 
Table 2.9. Summary of Laboratory and Field Compaction Investigations

\begin{tabular}{|c|c|c|c|c|}
\hline Method & Details & $\begin{array}{c}\gamma_{d, \max } \\
\left(\mathrm{kN} / \mathrm{m}^{3}\right)\end{array}$ & $\begin{array}{l}W_{\text {opt }} \\
(\%)\end{array}$ & Reference \\
\hline $\begin{array}{c}\text { Laboratory } \\
\text { (Standard Effort) }\end{array}$ & - MSW obtained from a landfill in England & 7.1 & 58 & $\begin{array}{l}\text { Harris } \\
(1979)\end{array}$ \\
\hline $\begin{array}{l}\text { Laboratory } \\
\text { (ASTM D698) }\end{array}$ & $\begin{array}{l}\text { - } 15 \text { to } 30 \text { year-old MSW obtained from a landfill in } \\
\text { the U.S. } \\
\text { - Samples recovered from drilling procedure } \\
\text { - Max. particle size of } 9.5 \mathrm{~mm}\end{array}$ & 9.3 & 31 & $\begin{array}{c}\text { Gabr and Valero } \\
\text { (1995) }\end{array}$ \\
\hline Field & $\begin{array}{l}\text { - } \text { Processed and pre-treated MSW } \\
\text { - Test plots of unsieved and sieved processed and } \\
\text { pre-treated waste } \\
\text { - Maximum particle size of } 60 \mathrm{~mm} \text { with } 70 \% \text { of } \\
\text { particles < } 8 \mathrm{~mm} \\
\text { - Three compactor sizes: small (S), medium (M), } \\
\text { and large (L) were used }\end{array}$ & $\begin{array}{l}\text { Sieved MSW: } \\
8.4(\mathrm{~S}) \\
12.4(\mathrm{M}) \\
15.3(\mathrm{~L}) \\
\\
\text { Unsieved MSW: } \\
10.2(\mathrm{M})\end{array}$ & 30 & $\begin{array}{l}\text { Collins } \\
(2001)\end{array}$ \\
\hline $\begin{array}{c}\text { Laboratory } \\
\text { (ASTM D698) }\end{array}$ & $\begin{array}{l}\text { - Manufactured MSW } \\
\text { - Max. particle size of } 5 \mathrm{~mm} \\
\text { - } \text { Fresh (F), moderately reused (MR), and highly } \\
\text { reused (HR) samples were tested }\end{array}$ & $\begin{array}{l}5.15(\mathrm{~F}) \\
5.69(\mathrm{MR}) \\
5.98(\mathrm{HR})\end{array}$ & $\begin{array}{l}62(\mathrm{~F}) \\
70(\mathrm{MR}) \\
80(\mathrm{HR})\end{array}$ & $\begin{array}{l}\text { Hettiarachchi } \\
\text { (2005) }\end{array}$ \\
\hline $\begin{array}{l}\text { Laboratory } \\
\text { (Low and High } \\
\text { Effort) }\end{array}$ & $\begin{array}{l}\text { - MSW obtained from a landfill in Japan } \\
\text { - Max. particle size of } 5 \mathrm{~mm} \\
\text { - Both low (LE) and high (HE) effort tests were } \\
\text { conducted }\end{array}$ & $\begin{array}{l}5.9(\mathrm{LE}) \\
7.8(\mathrm{HE})\end{array}$ & $\begin{array}{l}20 \text { (LE) } \\
10(\mathrm{HE})\end{array}$ & $\begin{array}{l}\text { Itoh } \\
(2005)\end{array}$ \\
\hline
\end{tabular}


Table 2.9. Summary of Laboratory and Field Compaction Investigations (Cont'd)

\begin{tabular}{|c|c|c|c|c|}
\hline Method & Details & $\begin{array}{c}\gamma_{d, \max } \\
\left(\mathrm{kN} / \mathrm{m}^{3}\right)\end{array}$ & $\begin{array}{l}W_{\text {opt }} \\
(\%)\end{array}$ & Reference \\
\hline $\begin{array}{c}\text { Laboratory } \\
\text { (ASTM D1557) }\end{array}$ & $\begin{array}{l}\text { - Manufactured MSW } \\
\text { - Max. particle size of } 100 \mathrm{~mm} \\
\text { - Moisture content varied between } 6 \text { and } 152 \%\end{array}$ & 5.6 & 42 & $\begin{array}{l}\text { Von } \\
\text { Stockhausen } \\
(2007)\end{array}$ \\
\hline Field & $\begin{array}{l}\text { - Fresh incoming MSW at a landfill in U.S. } \\
\text { - Both low effort (LE) and high effort (HE) tests } \\
\text { were implemented } \\
\text { - Test plots with } 200 \mathrm{~m}^{2} \text { area and approximately } \\
335 \mathrm{kN}(40 \text { tons) were used } \\
\text { - Moisture added to test plots prior to } \\
\text { compaction }\end{array}$ & $\begin{array}{l}5.7(\mathrm{LE}) \\
8.2(\mathrm{HE})\end{array}$ & $\begin{array}{l}70.5 \text { (LE) } \\
79.5(\mathrm{HE})\end{array}$ & $\begin{array}{l}\text { Von } \\
\text { Stockhausen } \\
\text { (2007) }\end{array}$ \\
\hline $\begin{array}{l}\text { Laboratory } \\
\text { (ASTM D698) }\end{array}$ & $\begin{array}{l}\text { - Fresh waste samples obtained from U.S. } \\
\text { landfill } \\
\text { - Max. particle size of } 40 \mathrm{~mm}\end{array}$ & 4.1 & 70 & $\begin{array}{l}\text { Reddy et al. } \\
\text { (2009b) }\end{array}$ \\
\hline $\begin{array}{l}\text { Laboratory } \\
\text { (ASTM D1557 } \\
\text { and Modified } \\
\text { ASTM D1577) }\end{array}$ & $\begin{array}{l}\text { - Manufactured MSW } \\
\text { - Modified effort (Mod) and } 4 \text { X modified effort } \\
\text { (4X Mod) tests were conducted } \\
\text { - Max. particle size of } 50 \mathrm{~mm}\end{array}$ & $\begin{array}{c}5.1 \text { (Mod) } \\
5.9 \text { (4X Mod) }\end{array}$ & $\begin{array}{c}66 \text { (Mod) } \\
56 \text { (4X Mod) }\end{array}$ & $\begin{array}{l}\text { Wong } \\
(2009)\end{array}$ \\
\hline
\end{tabular}




\section{Chapter 3: Testing Program}

\subsection{Introduction}

A field investigation coupled with a laboratory investigation was conducted to determine the effects of waste placement practices on the engineering response of municipal solid waste. The tests were conducted at the Santa Maria Regional Landfill (SMRL) in Santa Maria, California, United States. In particular, a meso-scale test plot compaction test program was conducted to analyze baseline operational compaction procedures and the effect of moisture addition on compaction characteristics of residential MSW. In addition, a full-scale (i.e., entire waste stream) compaction test program was conducted to determine the compaction characteristics and operational procedures necessary for optimization of waste placement. Furthermore, the physical and engineering properties of fresh and partially degraded MSW were determined including: temperature, moisture content, organic content, and settlement. Fresh and degraded waste samples were obtained from SMRL. Lastly, specific gravity of manufactured, fresh, and partially degraded municipal solid waste was investigated in the laboratory to determine the influence of particle size, age, and compaction procedures on the phase (i.e., weight-volume) relations of MSW. This test program was conducted over a 2-year time span beginning in September 2011 and ending in September 2013. 


\subsection{Field Test Program}

A field investigation was conducted for this test program to determine compaction characteristics and optimum placement procedures at an active MSW landfill that employs typical operational procedures used in the U.S. The field investigation included meso-scale and full-scale compaction studies at SMRL. The meso-scale compaction experiment included construction of several test pads, placement of residential only waste, and compaction of the waste with and without moisture addition. The full-scale compaction experiment was executed in a similar manner to the test plot compaction experiment however, the compaction study utilized the active face of the landfill and included the entire daily incoming waste stream at SMRL. Physical and engineering properties also were determined using data collected from field instrumentation.

\subsubsection{Test Site}

Santa Maria Regional Landfill is located in Santa Maria, California which is located approximately 430 kilometers south of San Francisco, CA and 260 kilometers north of Los Angeles, CA (Figure 3.1). 


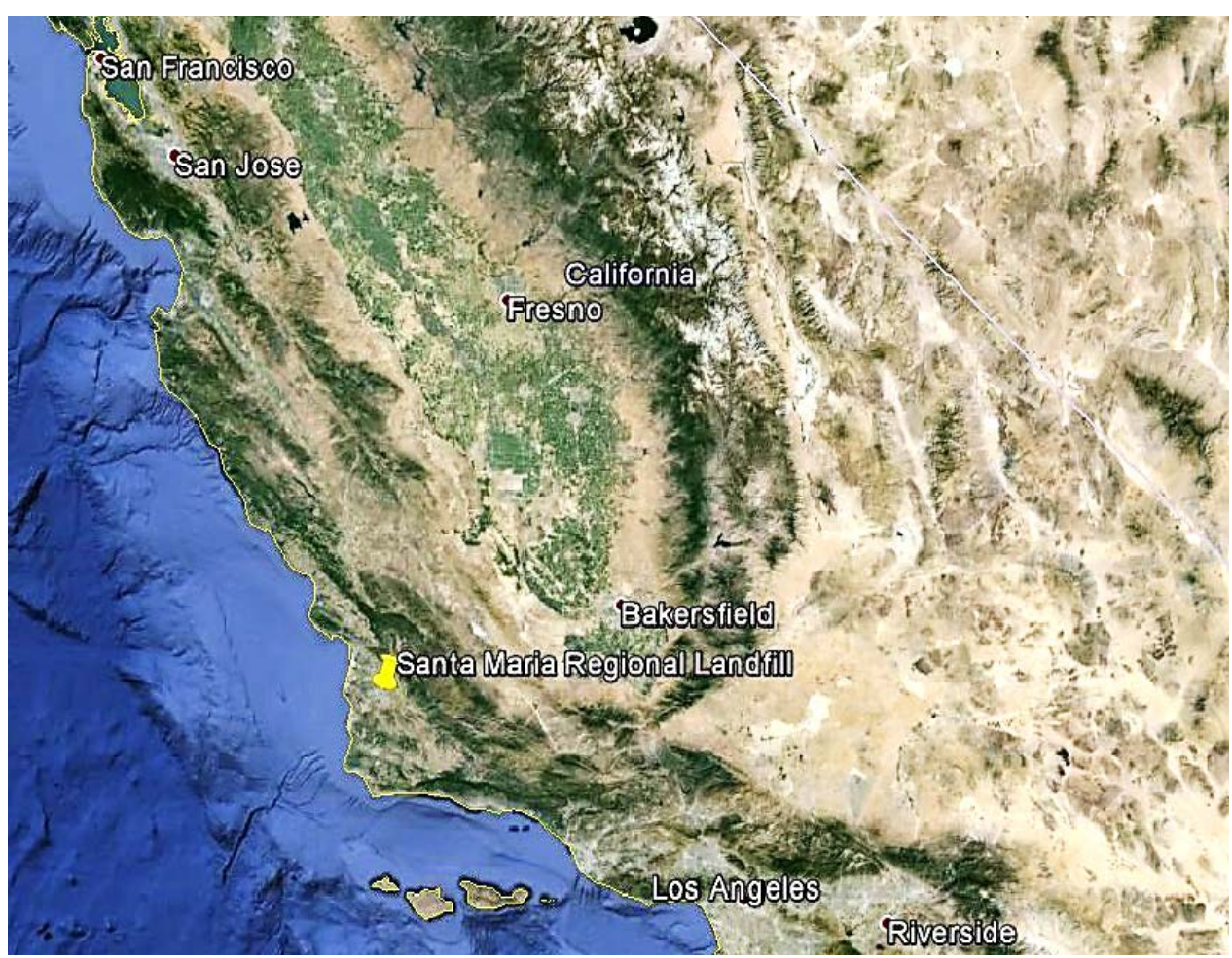

Figure 3.1. Location of SMRL (Google Earth 2013).

SMRL has been in operation since the 1950s and is owned and operated by the City of Santa Maria. The landfill is classified as a Class III disposal facility, permitted to accept nonhazardous solid wastes in accordance with waste classification regulations in 27 CCR, Sections 20220 and 20230 (Clarin 2013). The SMRL accepts residential, commercial, construction and demolition (C\&D), industrial, and agricultural wastes as part of the MSW operations. The facility also accepts materials that follow special waste handling procedures, which include non-friable asbestos waste, treated medical waste, household hazardous waste $(\mathrm{HHW})$, electronic waste (E-Waste), cathode-ray tubes, universal wastes, used whole tires, used oil, and treated wood waste. In addition, SMRL accepts Non-Hazardous Hydrocarbon Impacted Soils (NHIS) which are generated from oil well sumps and material from excavation of well sites. 
The facility consists of a total area of 115 hectacres and the current permitted disposal area footprint is approximately 100 hectacres. Landfill disposal operations are currently being conducted in the Active Area (lined Cell 1 area). Once disposal operations are completed in the Cell 1 area footprint, the City of Santa Maria will move operations to a new landfill site or construct a lined Cell 2 in the southeastern portion of the landfill. The four distinct areas of SMRL are described in Table 3.1

Table 3.1. Description of the Four Distinct Sections at SMRL.

\begin{tabular}{|c|c|c|}
\hline $\begin{array}{l}\text { Distinct } \\
\text { Section of } \\
\text { SMRL }\end{array}$ & $\begin{array}{c}\text { Area in } \\
\text { Hectares } \\
\text { and } \\
\text { (Acres) }\end{array}$ & Description \\
\hline $\begin{array}{c}\text { Inactive } \\
\text { Area }\end{array}$ & $\begin{array}{c}28 \\
(68)\end{array}$ & $\begin{array}{l}\text { - Landfilled in the } 1950 \text { s and } 1960 \text { s } \\
\text { - Contains predominantly burn ash and small amounts } \\
\text { of MSW } \\
\text { - Unlined and no leachate collection and removal } \\
\text { system }\end{array}$ \\
\hline $\begin{array}{c}\text { Closed/Active } \\
\text { Area }\end{array}$ & $\begin{array}{c}48 \\
(118)\end{array}$ & $\begin{array}{l}\text { - Closed for disposal of non-hazardous MSW since } \\
\text { November } 30,2002 \\
\text { - Since late 2002, portions of this area have received } \\
\text { non-hazardous hydrocarbon impacted soils (NHIS) } \\
\text { materials } \\
\text { - Unlined beneath MSW fill; however, a LLDPE liner } \\
\text { was placed over MSW fill prior to placement of NHIS }\end{array}$ \\
\hline $\begin{array}{c}\text { Active Area } \\
\text { (Cell 1) }\end{array}$ & $\begin{array}{c}15 \\
(38)\end{array}$ & $\begin{array}{l}\text { - Current active area for disposal of non-hazardous } \\
\text { MSW } \\
\text { - Cell } 1 \text { is lined and has a leachate collection and } \\
\text { removal system } \\
\text { - Filling procedures started in November } 2002 \text { and are } \\
\text { scheduled to be completed in May } 2022\end{array}$ \\
\hline $\begin{array}{c}\text { Proposed } \\
\text { Active Area } \\
\text { (Cell 2) }\end{array}$ & $\begin{array}{c}10 \\
(25)\end{array}$ & $\begin{array}{l}\text { - Proposed active area for disposal of non-hazardous } \\
\text { MSW } \\
\text { - Currently utilized for material storage and recycling } \\
\text { purposes } \\
\text { - Use of Cell } 2 \text { as a disposal area will be implemented if } \\
\text { an offsite landfill is not constructed by the time Cell } 1 \\
\text { is filled }\end{array}$ \\
\hline
\end{tabular}


Figure 3.2 provides an aerial photograph of the site layout including the Inactive Area, Closed/Active Area, and Active Area (Cell 1 and Cell 2), along with the scalehouse, flare station, administration building, recycling area, Household Hazardous Waste (HHW) Collection Facility, and the dedicated onsite research area used during this investigation. 


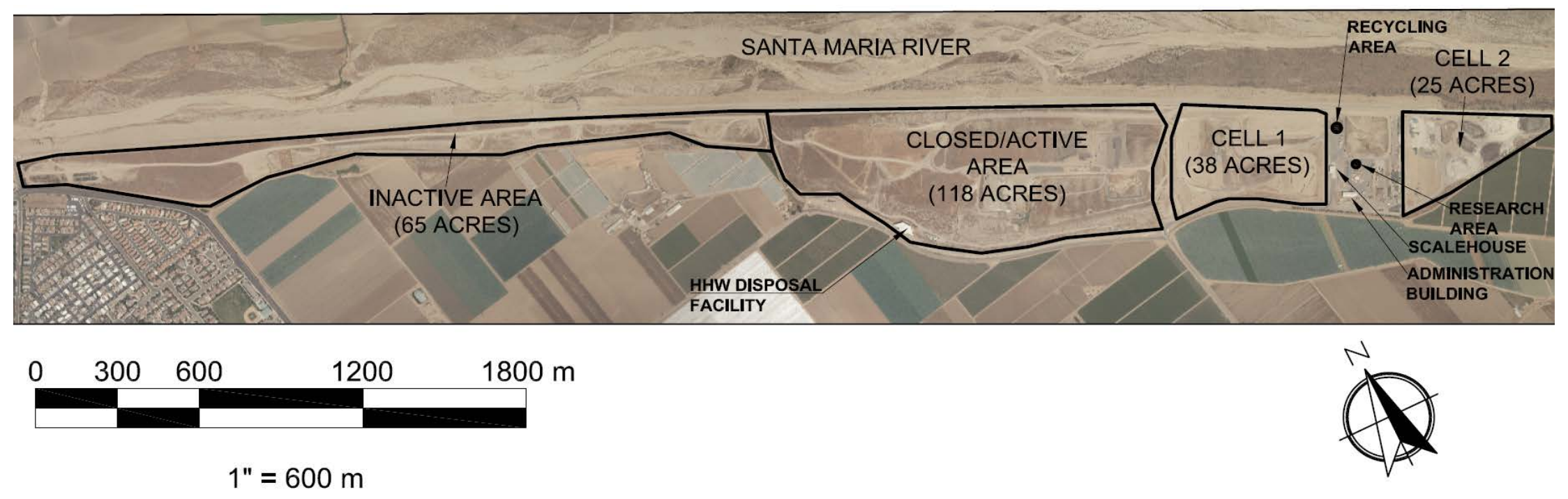

Figure 3.2. Site Plan for Santa Maria Regional Landfill. 
The permitted disposal area (100 hectacres) at SMRL has a capacity of 10.7 million $\mathrm{m}^{3}$ (14.0 million $\left.\mathrm{yd}^{3}\right)$ which includes the intermediate and daily cover but not the final cover. The annual waste disposal rate at the site is approximately $700,000 \mathrm{kN}$ (78,000 tons) with an approximate daily disposal rate of $2,800 \mathrm{kN}$ (315 tons). As of August 2012, the remaining air space available for disposal of MSW and intermediate daily cover was approximately 2.4 million $\mathrm{m}^{3}$ (3.1 million $\mathrm{yd}^{3}$ ) (SWT Engineering 2012a).

\subsubsection{Waste Placement in Active Area (Cell 1)}

Cell 1 was designed and constructed to comply with Subtitle D regulations contained in $40 \mathrm{CFR}$ and $27 \mathrm{CCR}$. Cell 1 has been the active waste disposal area since November 2002. Waste placement and site records were not well maintained between November 2002 and July 2006. However, good records are available for the period since July 2006 (Clarin 2013). Waste was initially placed as a $9.3 \mathrm{~m}$ (30 ft.) lift over the entire 38 acre footprint of Cell 1 from November 2002 to August 3, 2007. Then MSW was placed in predetermined sub-cells with approximate dimensions of $16 \mathrm{~m}(50 \mathrm{ft}) \times 46 \mathrm{~m}(150 \mathrm{ft})$. Waste was placed in each sub-cell to a height of approximately $5 \mathrm{~m}$ (15 ft) and typically over a 10-15 day period (Clarin 2013).

Placement of MSW in $16 \times 46 \times 5 \mathrm{~m}$ sub-cells has continued to the present day and will be utilized until closure. According to Clarin (2013), waste placement at SMRL will consist of a total of 5 lifts, 4 of which are or will include the use of numerous sub-cells. As of September 2013, Lift II is $90 \%$ complete 
(i.e., covers $90 \%$ of the active area footprint) and Lift III is approximately $65 \%$ complete. The details of each lift are provided in Table 3.2.

Table 3.2. MSW Placement Methods and Details at SMRL.

\begin{tabular}{|c|c|l|c|}
\hline Lift & $\begin{array}{c}\text { Height } \\
(\mathbf{m})^{\mathbf{a}}\end{array}$ & \multicolumn{1}{|c|}{ Details } & Completion (\%) \\
\hline I & 9.3 & $\begin{array}{l}\text { - Started in November 2002 and completed } \\
\text { on August 3, 2007 }\end{array}$ & 100 \\
\hline II & 4.6 & $\begin{array}{l}\text { - Started on August 3, 2007 and currently } \\
\text { being completed } \\
\text { - Lift height adjusted to 4.6 m } \\
\text { - Placement of waste in sub-cells } \\
\text { implemented }\end{array}$ & 90 \\
\hline III & 4.6 & $\begin{array}{l}\text { - Started on October 10, 2010 and } \\
\text { currently being completed }\end{array}$ & 65 \\
\hline IV & 4.6 & $\begin{array}{l}\text { - Yet to be started } \\
\text { - Yet to be started } \\
\text { - Final proposed lift }\end{array}$ & 0 \\
\hline V & 4.6 & 0 \\
\hline
\end{tabular}

${ }^{a}$ Lift heights exclude the intermediate cover soil used in between lifts

SMRL uses alternate daily cover (ADC) and tarps to cover the active face in between days of operation. The ADC is generally comprised of wood chips and is only used on the slopes of active face. The tarps are rolled out at the end of each day over the active face until a sub-cell is completed. Once a sub-cell has been

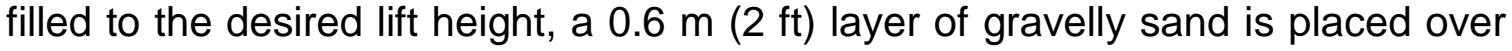
the top and serves as the intermediate cover. The gravelly sand is obtained from the Santa Maria River bed adjacent to the landfill and typically stockpiled in different areas of the site.

\subsubsection{Daily Operations and Baseline Conditions at SMRL}

Daily operations and baseline waste placement procedures at Santa Maria Regional Landfill were determined using site records, daily tonnage records, 
aerial surveys, and climate data. The onsite equipment used for daily operations at SMRL is summarized in Table 3.3.

Table 3.3. Onsite Equipment Used for Daily Operations at SMRL.

\begin{tabular}{|c|c|c|}
\hline Model & Description & Quantity \\
\hline Caterpillar 826D & $\begin{array}{c}\text { Kneading Waste } \\
\text { Compactor }\end{array}$ & 2 \\
\hline Caterpillar D8T & Bulldozer & 2 \\
\hline Caterpillar 627 & Scraper & 1 \\
\hline Caterpillar CS56 & $\begin{array}{c}2.2 \text { m Drum Vibratory Soil } \\
\text { Compactor }\end{array}$ & 1 \\
\hline International & $\begin{array}{c}15,140 \text { L (4000 gallon) } \\
\text { Water Truck }\end{array}$ & 1 \\
\hline Tarp-o-Matic $®$ & $\begin{array}{c}12.4 \text { m (40 ft.) } \\
\text { Automated Tarp Machine }\end{array}$ & 3 \\
\hline
\end{tabular}

Incoming MSW is unloaded from the waste trucks and then pushed onto and spread over the active face (i.e., sub-cells) using the Caterpillar D8T bulldozer. The waste is then compacted using the Caterpillar 826D compactor. The compactor operators adjust the number of passes based on their own judgment. All of the compactor operators have been working at the landfill for several years and therefore have a good understanding of when the maximum density is achieved. The compaction procedure based on operator judgment leads to a varying degree of number of passes any given day at SMRL. Although the number of passes vary from day to day depending on the compactor operator, the path of compaction is consistent and standardized at SMRL. For a given $15.5 \times 46.4 \mathrm{~m}$ sub-cell, the operator will drive over the entire area of the sub-cell (i.e., coverage) a total of 3 times (Figure 3.3). For example, the compactor operator will make a number of passes over the waste moving in one direction (e.g., north to south) then change the direction (e.g., east to west) of the 
compactor. The operator will finish the compaction by repeating the original direction (e.g., north to south). The compaction path and number of coverages per sub-cell footprint were carefully controlled for both the test plot and full-scale compaction studies of this investigation.

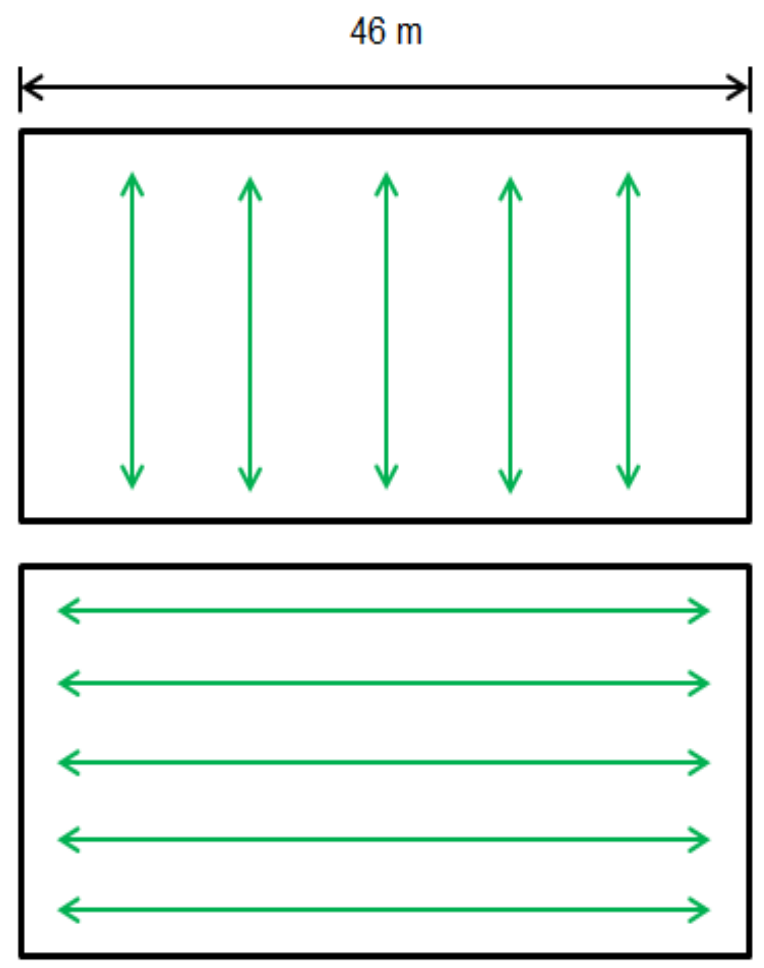

$16 \mathrm{~m}$

1st Coverage of Sub-Cell Footprint

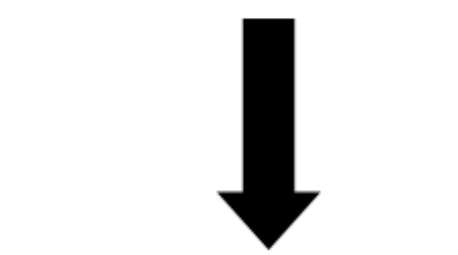

2nd Coverage of Sub-Cell Footprint

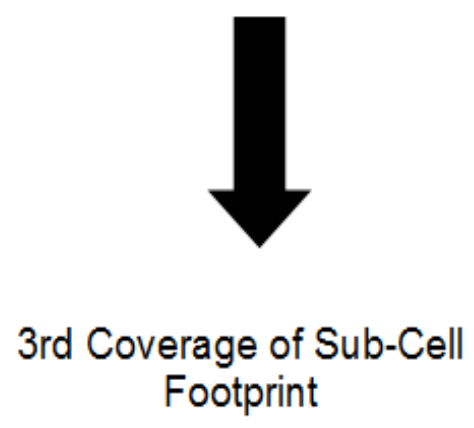

3rd Coverage of Sub-Cell Footprint

Figure 3.3. Typical Path of Compactor for a $16 \times 46 \mathrm{~m}$ Sub-Cell of MSW.

The baseline average compacted operational unit weight achieved at SMRL from November 2002 to August 2012 was determined as the quotient of 
the weight of the waste accepted and the volume of space filled by the waste over a given period of time. The weight of the waste was obtained using the daily tonnage records that were recorded at the scalehouse. The volume of the waste was calculated based on annual aerial surveys.

The baseline composition of MSW at SMRL is divided into three categories that include: residential waste (RMSW), commercial waste (CMSW), and self-delivered waste (SDMSW). Self-delivered waste includes the waste that is delivered by individual customers as opposed to the waste delivered to the landfill by the SMRL MSW trucks. The self-delivered waste accounts for a moderate portion of the overall incoming waste stream at the landfill and varies significantly from load to load. A typical example of SDMSW at the landfill which commonly includes bulky items, such as furniture, is presented in Figure 3.4.

The average moisture content of incoming MSW was determined by ovendrying samples obtained immediately after being delivered by the waste trucks and directly from the active face. Samples of residential, commercial, and selfdelivered waste were collected in metal trays and placed into a convection oven (Figure 3.5) located in a designated area at SMRL. The samples were oven dried at $75^{\circ} \mathrm{C}$ for approximately 24 hours to ensure all of the moisture was removed from the sample. The samples were not oven dried at $105^{\circ} \mathrm{C}$ (temperature used for determination of moisture content of soils) because particular materials became charred and previous research suggests that lower temperatures can be used to obtain the same outcome as oven drying at $105^{\circ} \mathrm{C}$ (e.g. Reddy et al. 2009a; Gomes and Lopes 2012). The percent by mass of each waste category 
(i.e., residential, commercial, and self-delivered) was determined using the tonnage records which was then used to calculate an average moisture content by means of a weighted average. The moisture content of residential, commercial, and self-delivered wastes was determined for wet and dry seasons.
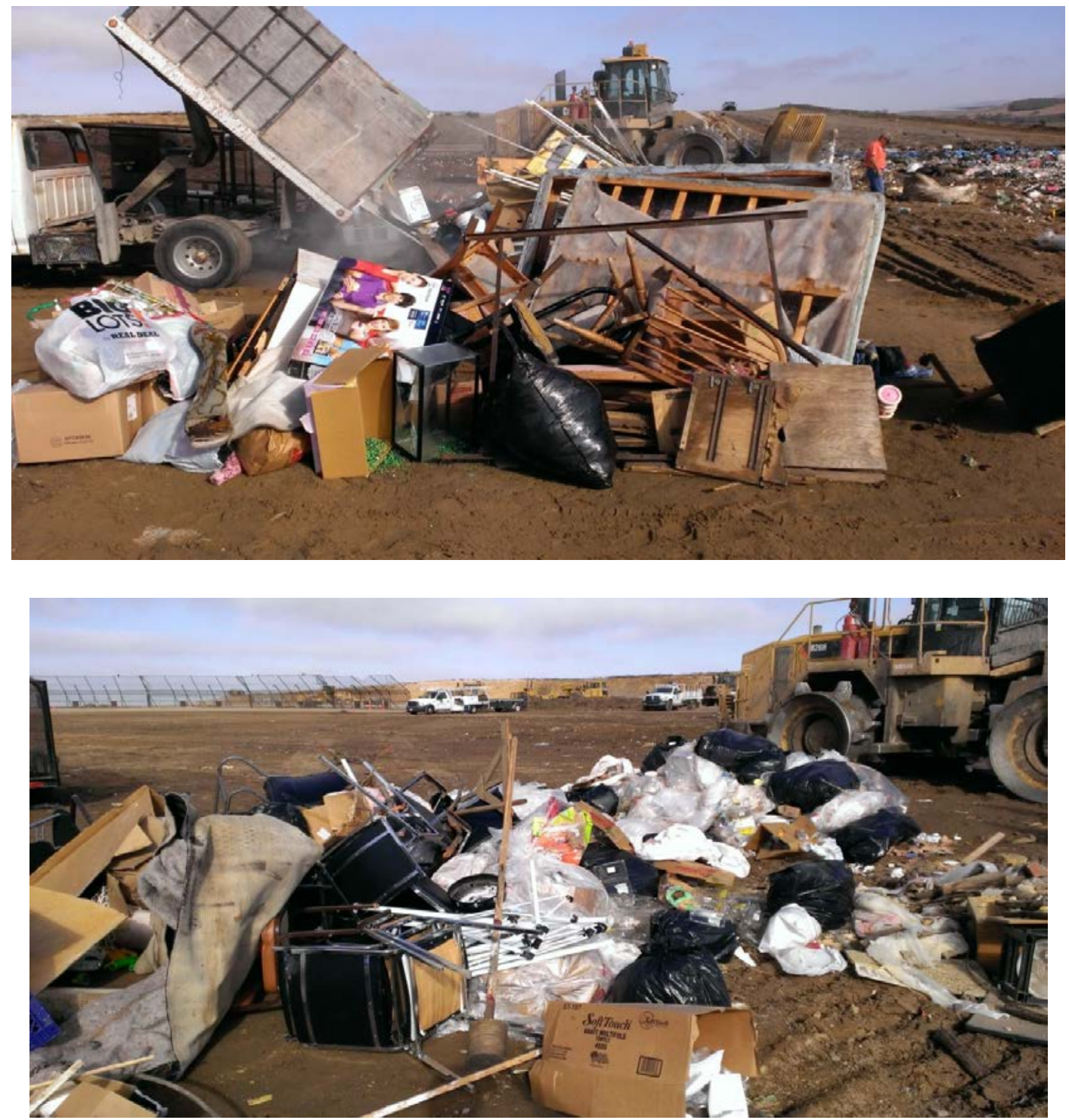

Figure 3.4. Typical SDMSW Loads at SMRL. 


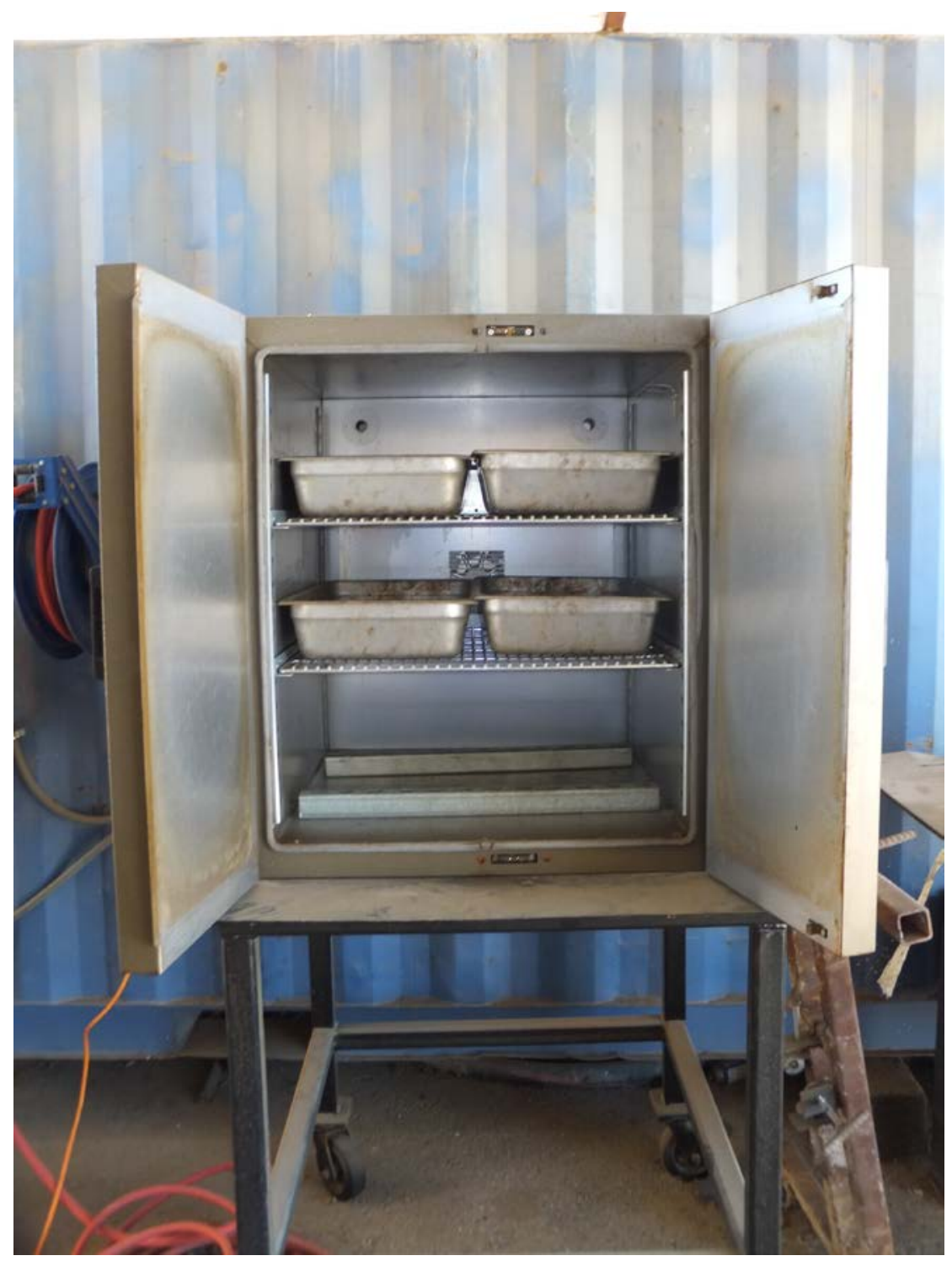

Figure 3.5. Convection Oven Used at SMRL to Dry Waste Samples.

The baseline climate conditions for Santa Maria Regional Landfill were determined using climate data obtained from a nearby National Oceanic and Atmospheric Administration (NOAA) weather station. Climate conditions for this investigation were differentiated by wet and dry seasons. The typical wet season in Santa Maria spanned from October to May while the typical dry season spanned from June to September. The climate conditions were initially analyzed with the intent to investigate the influence of climate changes (i.e., wet season 
versus dry season) on waste placement procedures. However, minimal amounts of precipitation occurred during this investigation and therefore a wet and dry season could not be established for waste placement comparison purposes.

\subsubsection{Field Instrumentation and Monitoring}

Temperature and settlement monitoring systems were installed at several locations within Cell 1. The instruments were installed in a total of eight boreholes during two separate drilling events that occurred approximately 1 month apart. Data obtained from the settlement and thermocouple arrays were used to characterize the engineering and physical properties of the MSW at SMRL. Schematic layouts of the instrumentation in each borehole are presented at the end of this section.

\section{Drilling and Sampling Procedures}

A total of 8 boreholes $(\mathrm{BH})$ were installed at several locations within Cell 1 by SG Drilling Company. Four of the boreholes were installed on October 15, 2012 and the remaining four were installed on November 21, 2012. The location of each borehole was established based on three factors: 1) the number of underlying lifts or, layers of waste; 2) the climate conditions in which the top lift of waste was placed (i.e., wet or dry); and 3) the age of the MSW within the top lift. The locations of the boreholes within Cell 1 are presented in Figure 3.6.

The 8 boreholes were installed in order to house the temperature and settlement systems for obtaining data on different waste placement conditions. The target depth of each borehole was established using the surface and liner elevations. Six of the boreholes were installed in waste layers only whereas, two 
of the boreholes were installed through an overlying embankment and several layers of underlying waste. The embankment had a height of approximately 7.1 $\mathrm{m}$, a basal area of approximately $3650 \mathrm{~m}^{2}$, and a volume of approximately $19,000 \mathrm{~m}^{3}$. The unit weight of the embankment material was determined using a nuclear density gauge. To avoid risk of drilling through the bottom liner system a $3.1 \mathrm{~m}$ (10 ft.) buffer from the liner was used during determination of borehole depths. Table 3.4 summarizes the depths of each borehole as well as the details of each borehole (i.e., date installed, number of underlying layers, and climate conditions during placement of top lift). The lift information provided in Table 3.4 follows from the lift data provided in section 3.2.2.

Table 3.4. Borehole Depths and Details

\begin{tabular}{|c|c|c|c|c|}
\hline Borehole & $\begin{array}{l}\text { Depth } \\
\text { (m) }\end{array}$ & $\begin{array}{c}\text { Date } \\
\text { Installed }\end{array}$ & Underlying Layers & $\begin{array}{c}\text { Climate } \\
\text { Conditions of } \\
\text { Top Waste Layer }\end{array}$ \\
\hline $\mathrm{BH} 1$ & 14.6 & $\begin{array}{c}\text { Oct. 15, } \\
2012\end{array}$ & $\begin{array}{l}\text { Lift III (Top) } \\
\text { Lift II (Middle) } \\
\text { Lift I (Bottom) }\end{array}$ & Dry \\
\hline $\mathrm{BH} 2$ & 13.9 & $\begin{array}{c}\text { Oct. 15, } \\
2012\end{array}$ & $\begin{array}{l}\text { Lift III (Top) } \\
\text { Lift II (Middle) } \\
\text { Lift I (Bottom) }\end{array}$ & Wet \\
\hline $\mathrm{BH} 3$ & 9.7 & $\begin{array}{l}\text { Oct. 15, } \\
2012\end{array}$ & $\begin{array}{l}\text { Lift II (Top) } \\
\text { Lift I (Bottom) }\end{array}$ & Dry \\
\hline $\mathrm{BH} 4$ & 9.5 & $\begin{array}{l}\text { Oct. 15, } \\
2012\end{array}$ & $\begin{array}{c}\text { Lift II (Top) } \\
\text { Lift I (Bottom) }\end{array}$ & Wet \\
\hline BH5 & 22.3 & $\begin{array}{c}\text { Nov. 21, } \\
2012\end{array}$ & $\begin{array}{c}\text { Embankment (Top) } \\
\text { Lift III (Top) } \\
\text { Lift II (Middle) } \\
\text { Lift I (Bottom) }\end{array}$ & Dry \\
\hline $\mathrm{BH} 6$ & 22.2 & $\begin{array}{c}\text { Nov. 21, } \\
2012\end{array}$ & $\begin{array}{c}\text { Embankment (Top) } \\
\text { Lift III (Top) } \\
\text { Lift II (Middle) } \\
\text { Lift I (Bottom) } \\
\end{array}$ & Wet \\
\hline $\mathrm{BH} 7$ & 4.2 & $\begin{array}{l}\text { Nov. 21, } \\
2012\end{array}$ & Lift I & Dry \\
\hline $\mathrm{BH} 8$ & 3.6 & $\begin{array}{l}\text { Nov. 21, } \\
2012 \\
\end{array}$ & Lift I & Wet \\
\hline
\end{tabular}



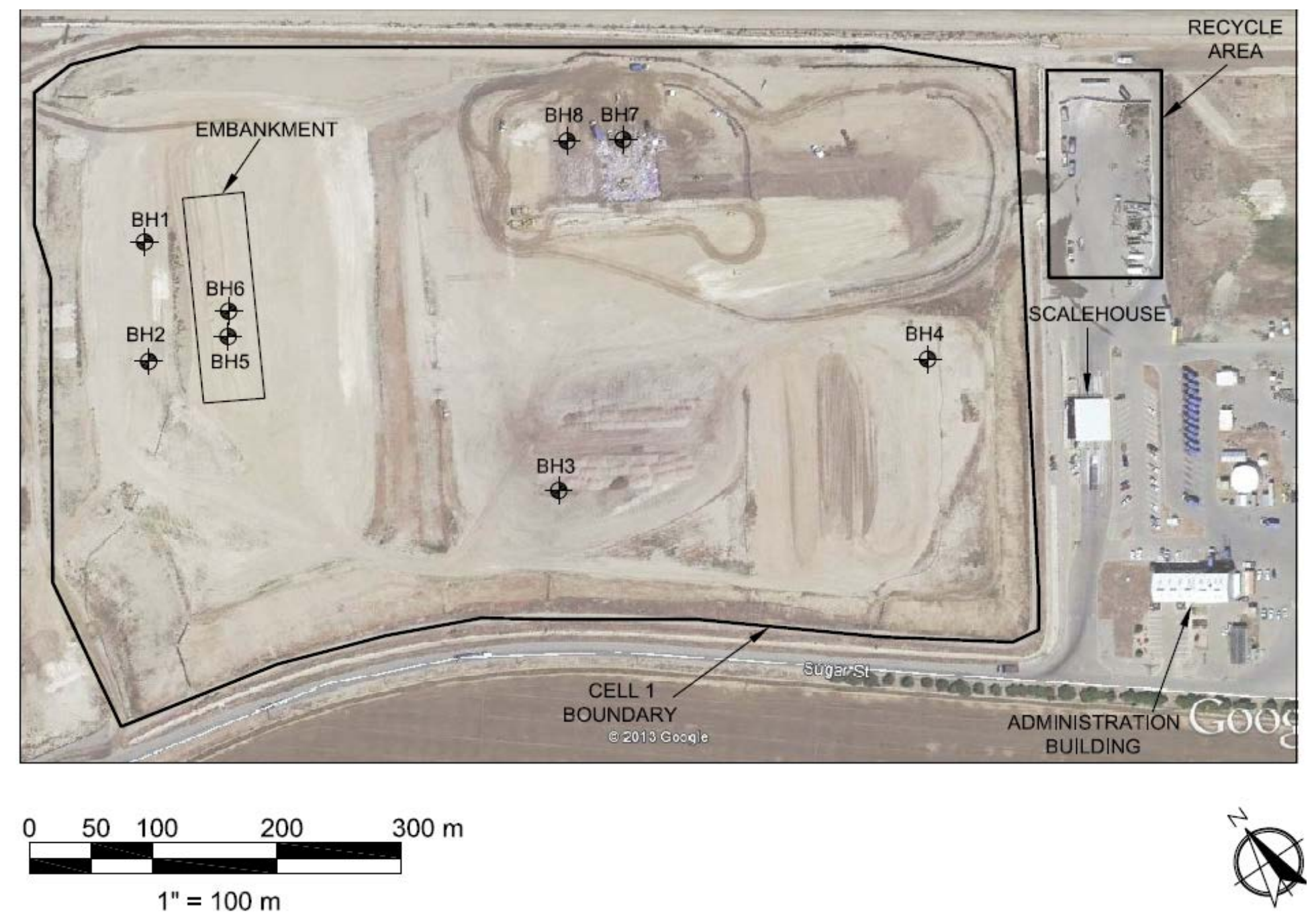

Figure 3.6. Location of Boreholes at SMRL. 
A hollow stem auger (Figure 3.7a) was used for drilling and produced a $203 \mathrm{~mm}$ (8 in.) diameter borehole. The samples obtained from each borehole, collected from drilling cuttings at the surface, were bagged in $3.8 \mathrm{~L}$ (1 gallon) "zip" (nonbrand) bags (Figure 3.7b) and labeled (Figure 3.7c). The waste samples obtained at different depths were then analyzed in the laboratory and described in detail in Section 3.3.

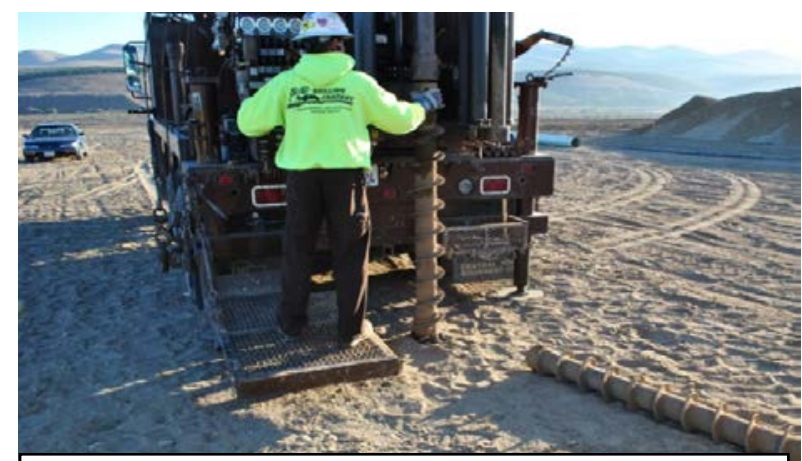

a) Hollow Stem Auger Drilling Through MSW
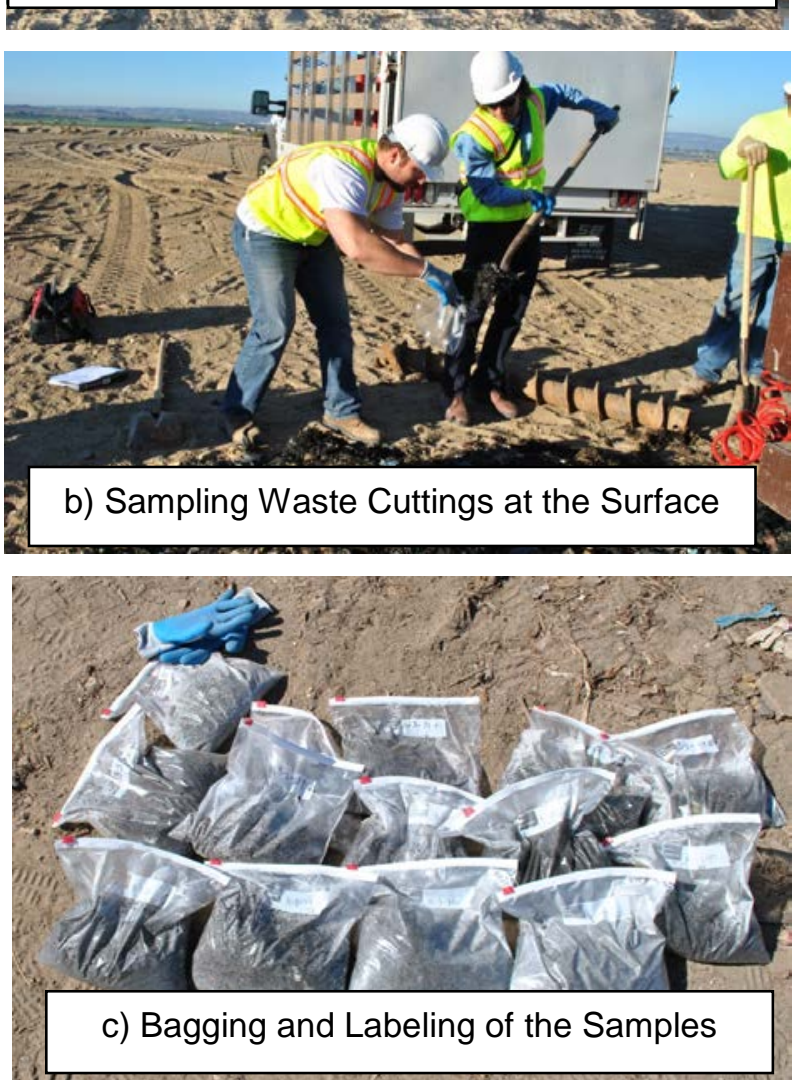

Figure 3.7. Photographs of the Drilling and Sampling Procedures. 


\section{Settlement Arrays}

A total of 8 magnetic extensometer settlement systems (settlement arrays) manufactured by RST Instruments Ltd. were installed at SMRL to monitor the settlement of MSW. The RST magnetic settlement system is typically used for soil applications but was modified to function as a MSW settlement monitoring system for this test program. The major components of the magnetic extensometer system include: $25 \mathrm{~mm}$ (1 in.) PVC pipes with threaded joints, magnetic extensometer rings (MERs), settlement plates, and a magnetic probe.

The installation process of the settlement arrays (SA) was comprised of several steps. A preliminary settlement analysis was used to determine the location (i.e., depth) at which each magnetic extensometer ring for a given settlement array needed to be installed at to obtain data from the existing waste layer interface locations. First, average unit weights of each waste lift were determined using aerial surveys and tonnage data and the ages of each waste lift were determined using waste placement records. Next, the overburden stresses on each waste lift were calculated using the known approximate lift heights and average unit weight of the corresponding waste lift. The total settlement of each waste lift was calculated using the methods provided by Sowers (1973) and Bjarngard and Edgers (1990). The assumptions used for the analysis included: 1) initial settlement occurred within the first 30 days of waste placement; 2) mechanical creep occurred within the first 100 days following the initial settlement; 3) a less favorable environment for decomposition of MSW (i.e., dry conditions) was present at SMRL; and 4) the intermediate cover and 
embankment material had a unit weight of $18.9 \mathrm{kN} / \mathrm{m}^{3}$. The last step of the preliminary settlement analysis was the interpretation of the calculated total settlement and the use of engineering judgment to select the most representative placement locations to monitor a given waste lift.

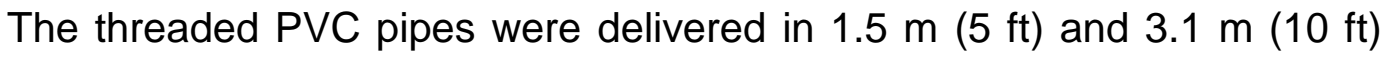
sections. The next step of the installation process was to attach the MERs to the desired locations along given PVC pipe sections prior to placement into the borehole. However, when deployed, the diameter of the MER legs measured to be approximately $203 \mathrm{~mm}$ which was equivalent to the diameter of the drilled borehole. Thus, if the MERs were attached to the PVC pipes as manufactured and deployed within the borehole, the MER legs may not have sufficiently sprung out and lock into the borehole walls as intended. In order to address this issue, the MER legs were detached from the ring magnet and preconditioned (bent manually) to provide a longer extension distance (i.e., diameter) when deployed. After the MER legs were modified and reassembled, the modified MERs were attached to the PVC pipes. Zip-ties, duct tape, and electrical tape were needed to reattach the MER legs to the PVC pipes due to the development of increased tension forces within each leg. Photographs of the modification process of the MERs are presented in Figure 3.8.

Upon completion of the modification process, the PVC pipes were then transported to their respective boreholes' locations. Next, construction twine was attached to the deployment rods of each modified MER and used to release the MER legs into the borehole walls. For the boreholes that were drilled through 
only waste (6 out of 8 ), the settlement arrays were installed directly into the open borehole. In contrast, the hollow stem auger was left in the ground during the installation of the 2 settlement arrays that were placed through the embankment and the underlying MSW in order to prevent the collapse of the sandy material of the embankment back into the borehole. Each settlement array was installed by lowering the initial PVC section into the borehole, attaching the subsequent PVC pipe section, and then continuing to lower and attach PVC pipe sections until the entire settlement array was placed in the borehole. Photographs of the installation process in an open borehole and in a borehole with the hollow stem auger are presented in Figure 3.9a and 3.9b, respectively. 

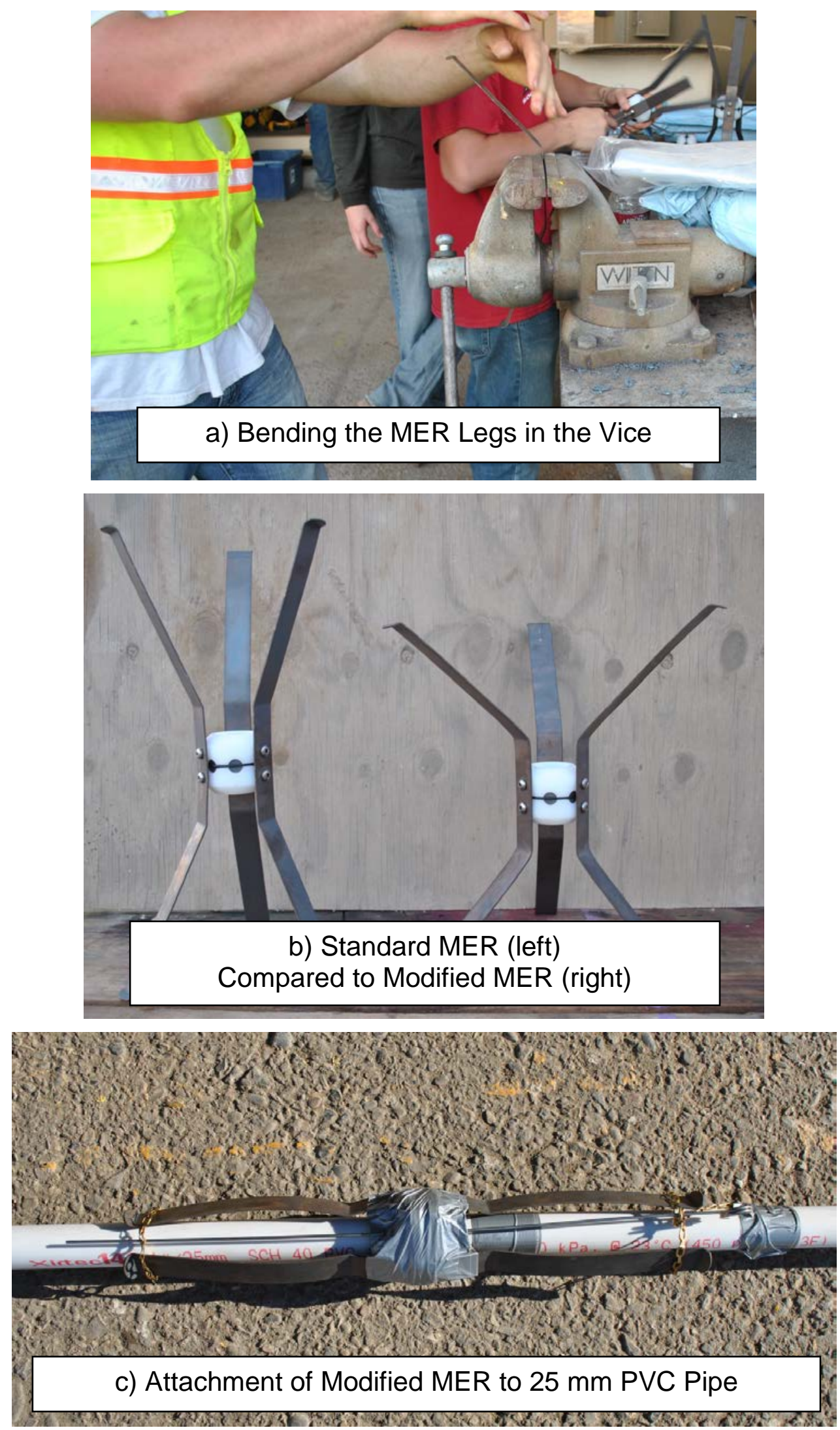

Figure 3.8. Modification Process of the Magnetic Extensometer Ring. 

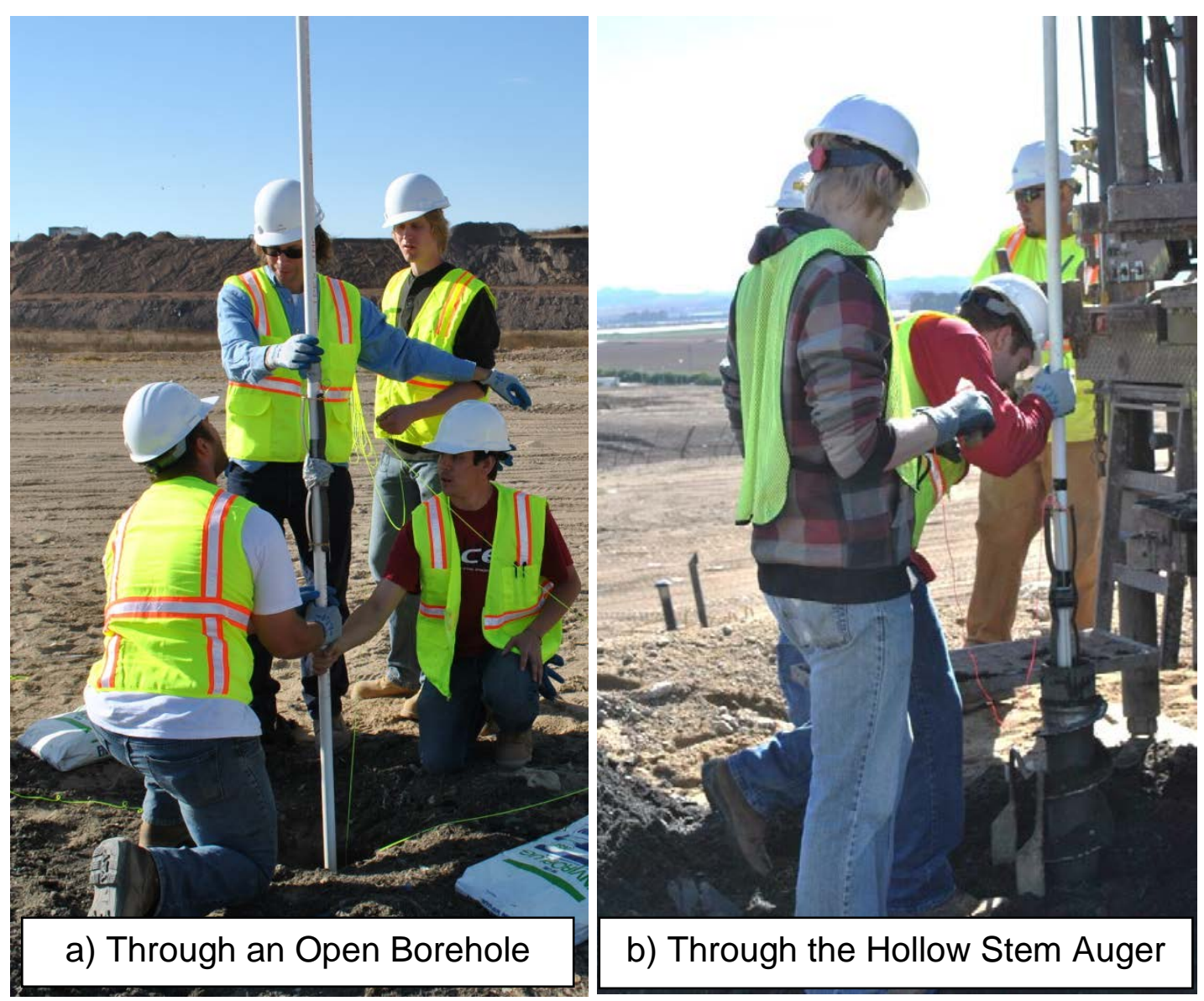

Figure 3.9. The Settlement Array Installation Process.

Next, the construction string attached to the deployment rod of the MER was pulled upward and the MER legs were deployed into the borehole walls (i.e., waste). This process was performed for each MER within a given borehole, where the deepest MER was deployed first and the shallowest MER was deployed last. The borehole was then backfilled with a select mixture of MSW borehole cuttings and intermediate cover material up to a height approximately $0.6 \mathrm{~m}$ below the original surface. The remaining $0.6 \mathrm{~m}$ was capped with a bentonite slurry to prevent the migration of landfill gases to the surface. Finally, a settlement plate was placed on the surface of the backfilled boreholes with the 
exception of the boreholes drilled through the embankment. A schematic of a typical settlement array installation is presented in Figure 3.10.

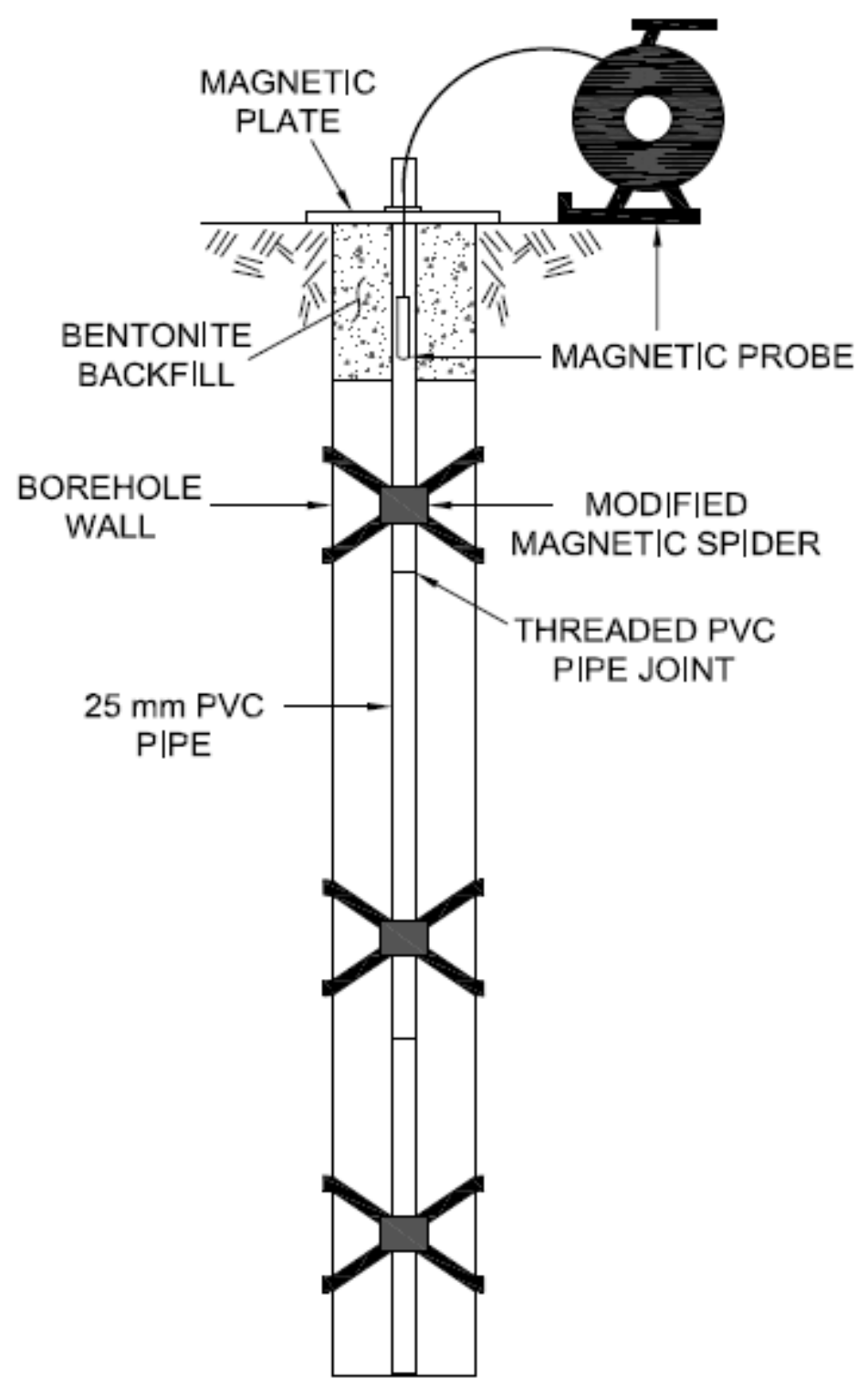

Figure 3.10. Schematic of a Typical Settlement Array Inside a Borehole at SMRL. After the installation of the settlement arrays, the surveyor employed at SMRL determined the elevations of the top of the PVC pipe sections that were above the ground surface at each borehole location. This elevation was used to provide absolute baseline elevations for the settlement system. The settlement arrays were designed to allow for vertical extension through the additional future 
waste lifts and continued monitoring of settlement up to and beyond closure of the landfill.

\section{Thermocouple Arrays}

Thermocouple arrays were installed in 4 of the boreholes at SMRL to monitor the temperature of the MSW. The thermocouple arrays (TA) were constructed using flexible PVC tubing as a protective conduit and Type K thermocouple wire. Each thermocouple array contained 2 PVC tubes and 12 thermocouple wires (6 in each tube) and was approximately $30 \mathrm{~m}(100 \mathrm{ft})$ in length. Soldered thermocouple junctions were located at $2 \mathrm{~m}$ spacing from the bottom end of the array. Figure 3.11 shows an example of a typical constructed thermocouple array prior to installation. Extra length was provided for future vertical extension and continued monitoring of temperature.

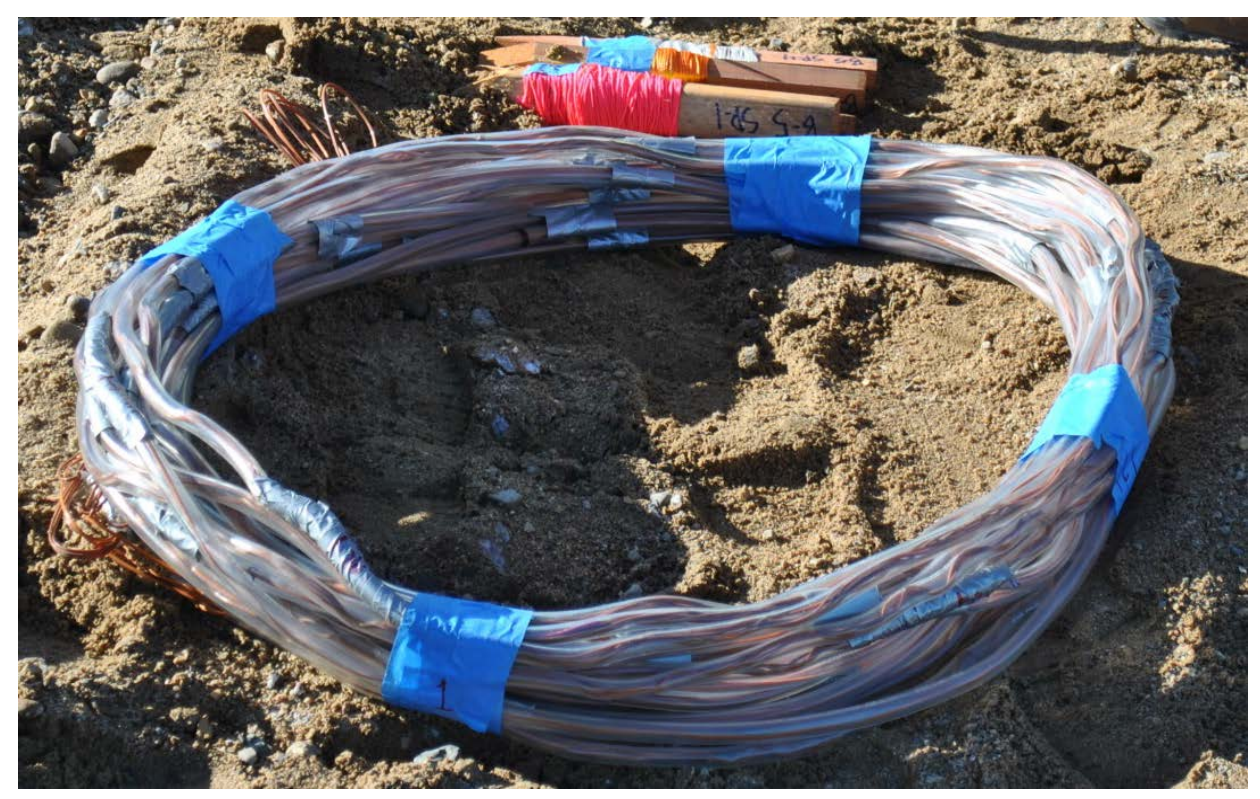

Figure 3.11. Typical Thermocouple Array Prior to Installation. 
The thermocouple arrays were installed during the second drilling operation at SMRL and were placed into the same boreholes as the settlement arrays. However, the thermocouple arrays were installed after the settlement arrays were in place and the MERs had been deployed. A piece of rebar was attached to the bottom end of each array in order to facilitate placement of the array in each borehole. Similar to the settlement arrays, 2 of the thermocouple arrays were installed through the embankment and therefore were installed through the hollow stem auger. As the hollow stem auger was removed from the ground the thermocouple arrays were pulled through the bottom end of the auger (Figure 3.12).

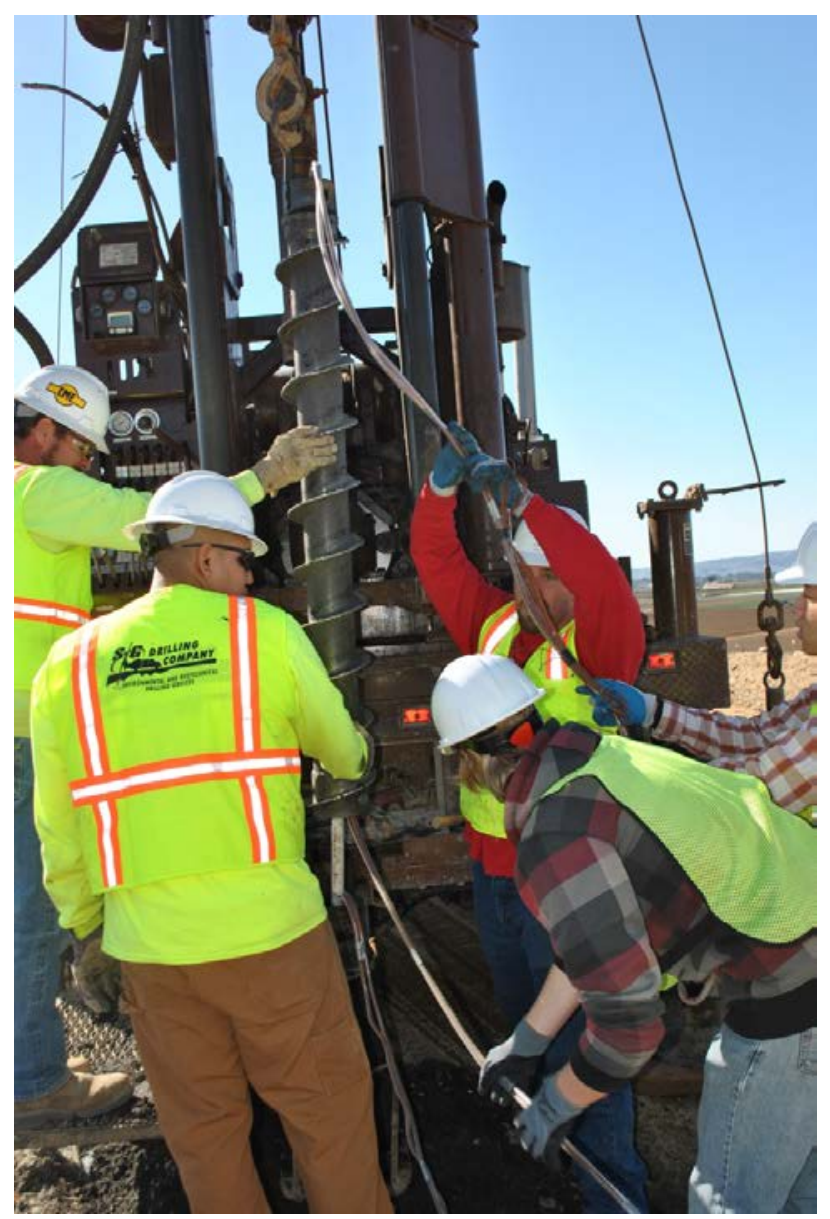

Figure 3.12. Installation of a Thermocouple Array Through the Embankment. 
After the thermocouple arrays were placed into the ground, thermocouple wire connectors were attached to the exposed ends of the thermocouple wires so that the temperature could be monitored using a digital thermometer. During the initial weeks of temperature data collection, the excess thermocouple tubing (i.e., the tubing above the ground surface) was exposed to the open environment and slight cracking of the PVC tubing was observed. Therefore, the excess tubing was placed in a container to preserve the integrity of the thermocouple array system.

\section{Borehole Schematics}

The schematic layout of each borehole is presented in Figures 3.13 through 3.16. The waste properties (i.e., waste age, as-placed unit weight, and lift height) of each borehole also are presented in the following figures. Waste Layers represent the distance between a set of MERs or settlement plates, or . between a MER and a settlement plate. On the contrary, Waste Lifts correspond to the waste lifts constructed at Santa Maria Regional Landfill. For this investigation the settlement characteristics of the waste lifts were analyzed. 


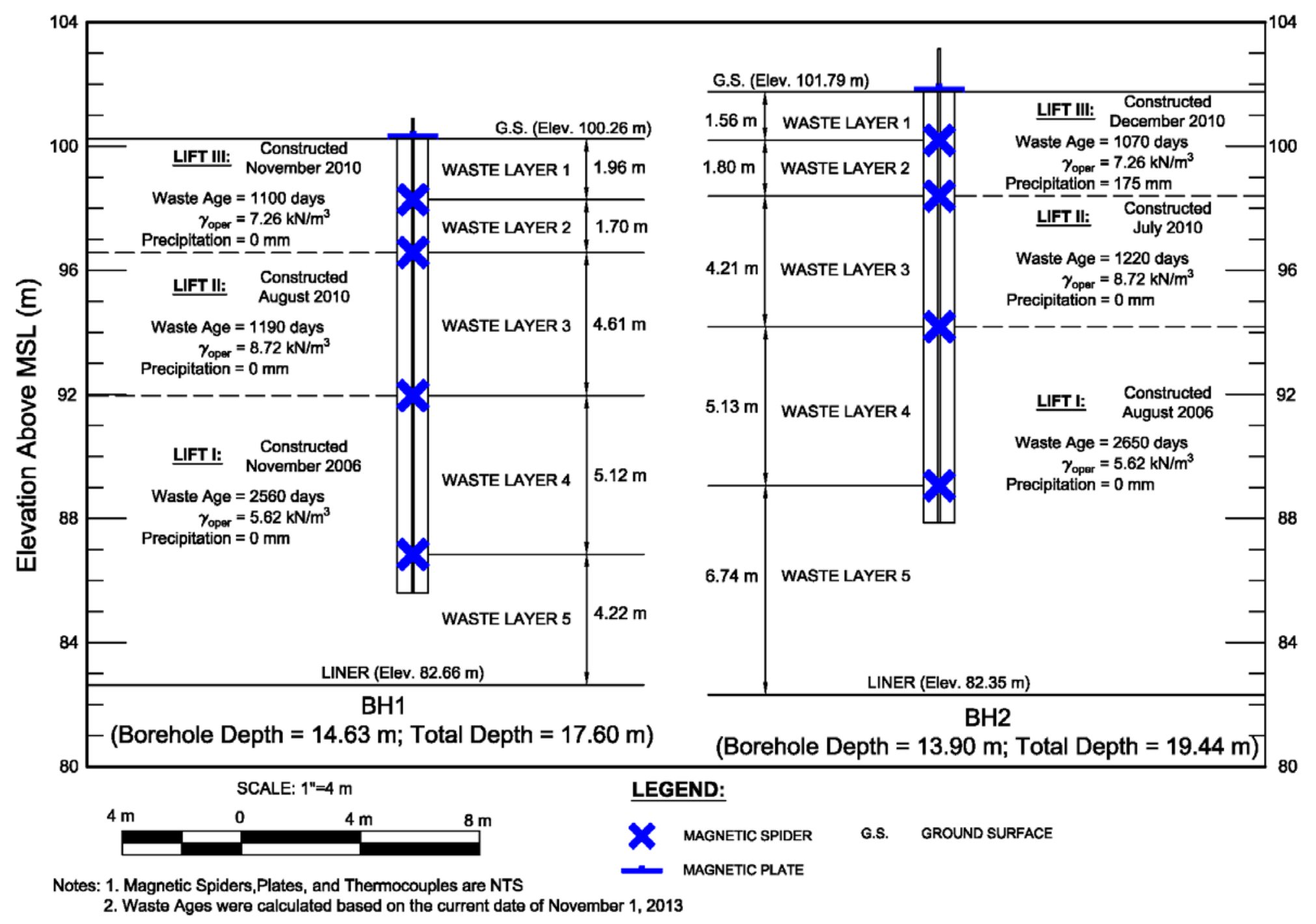

Figure 3.13. Borehole Schematic for $\mathrm{BH} 1$ and $\mathrm{BH}$. 


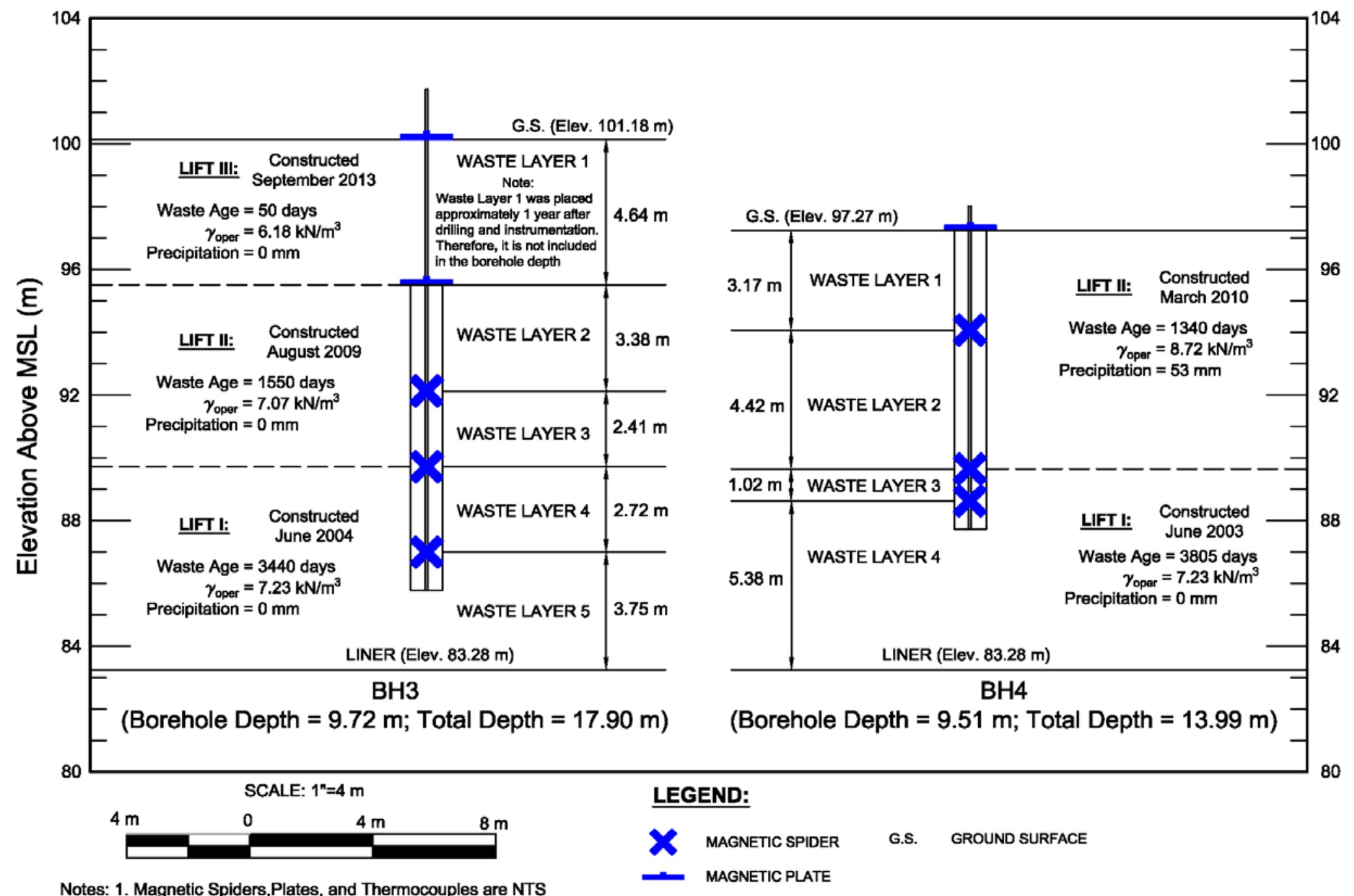

Notes: 1. Magnetic Spiders,Plates, and Thermocouples are NTS

2. Waste Ages were calculated based on the current date of November 1, 2013

Figure 3.14. Borehole Schematic for BH3 and BH4. 


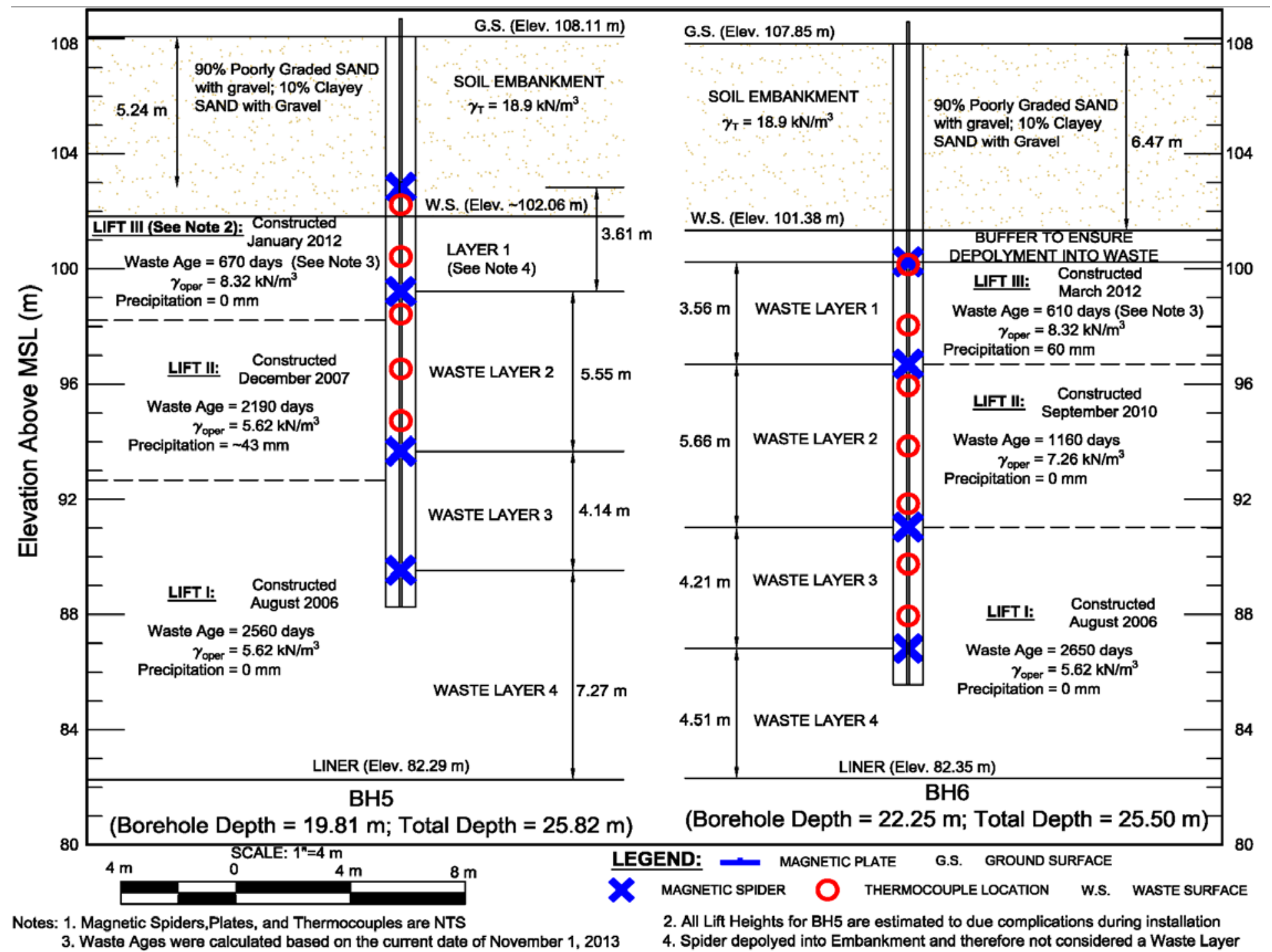

Figure 3.15. Borehole Schematic for BH5 and BH6. 


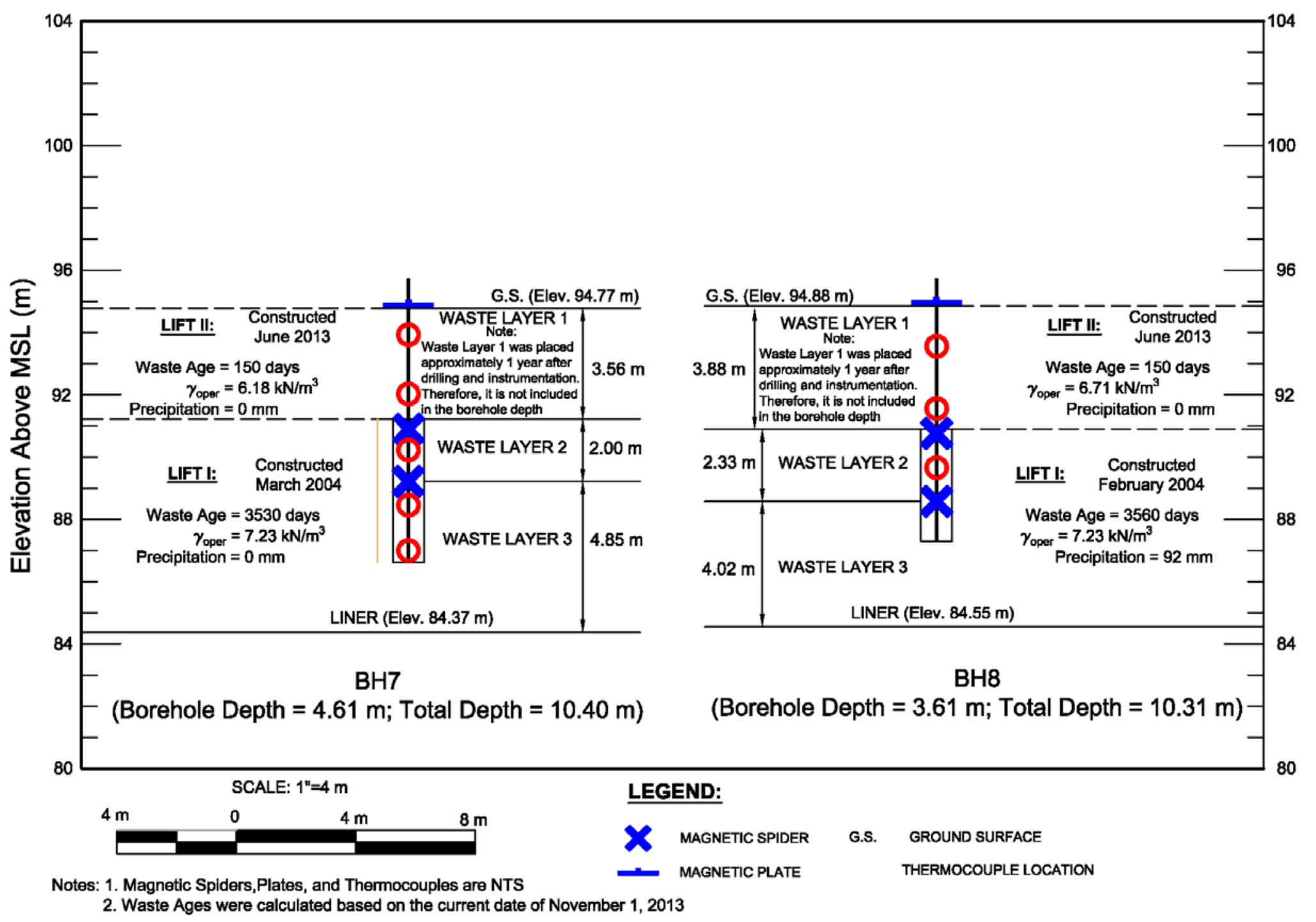

Figure 3.16. Borehole Schematic for $\mathrm{BH} 7$ and $\mathrm{BH}$. 


\subsubsection{Meso-Scale Compaction Study}

A meso-scale compaction study was conducted at SMRL to determine baseline operational compaction procedures and the effect of moisture addition on compaction characteristics of residential MSW. The details and procedures of the meso-scale compaction study are described in the following sections.

\section{Waste Composition}

The use of residential MSW (RMSW) (i.e., exclusively household or curbside MSW) for the meso-scale compaction study provided a controlled waste placement environment. Specifically, the residential MSW trucks could be easily tracked, the average moisture content of as-received RMSW had been well established through sampling prior to the compaction study, and the composition of each residential MSW load was relatively consistent. As-received waste is defined as the waste delivered by SMRL's waste trucks or individual customers and placed into the landfill without the addition of moisture.

RMSW consisted of several waste constituents. The most commonly observed waste constituents in individual loads of RMSW were food and yard waste, plastic garbage bags, plastic bottles and containers, glass bottles and containers, and paper and cardboard materials. Other miscellaneous waste items such as diapers, shoes, and textiles were occasionally present in RMSW loads delivered to the landfill. During the sampling of RMSW, it was estimated through observations that approximately $70 \%$ of the incoming residential waste was composed of food and yard waste, plastic garbage bags, and plastic containers. A photograph of a typical RMSW load at SMRL is presented in Figure 3.17. 


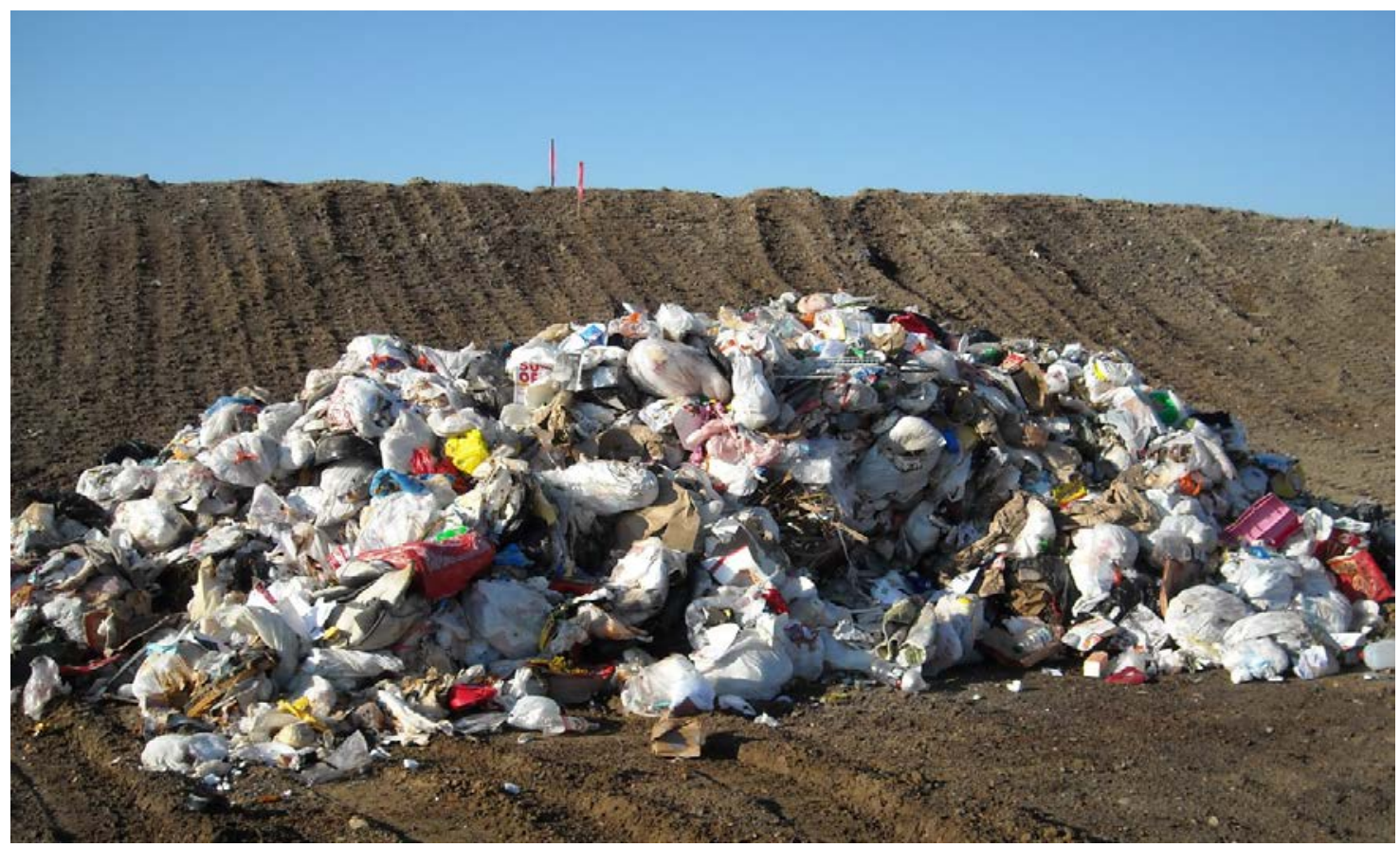

Figure 3.17. A Typical Load of RMSW at SMRL.

\section{Construction and Layout of the Test Plots}

The meso-scale analysis was conducted using test plots (TP) constructed in Cell 1 in close proximity to the active face in order to maintain efficient daily landfill operations. A total of 2 test plots were constructed. Each test plot was approximately $31 \mathrm{~m}$ in length, $11 \mathrm{~m}$ in width, and covered a footprint of approximately $341 \mathrm{~m}^{2}$. First, a bulldozer was used to remove the top $0.5 \mathrm{~m}$ of the intermediate cover soil and create a flat base for the test plots. Then, each test plot was divided in half using survey stakes and spray paint. The halved test plots were defined as test pads for this study. An example of a graded test plot is presented in Figure 3.18.

The first test plot constructed for the compaction study (TP1) was subdivided into Test Pad A and Test Pad B. Once TP1 was filled to completion a 
second test plot (TP2) was constructed adjacent to TP1. TP2 was then subdivided into Test Pad C and Test Pad D. A schematic layout of the 2 test plots constructed for the meso-scale compaction study, a spatial reference to the active filling location at the time of the study, and the nearby borehole locations are provided in Figure 3.19.

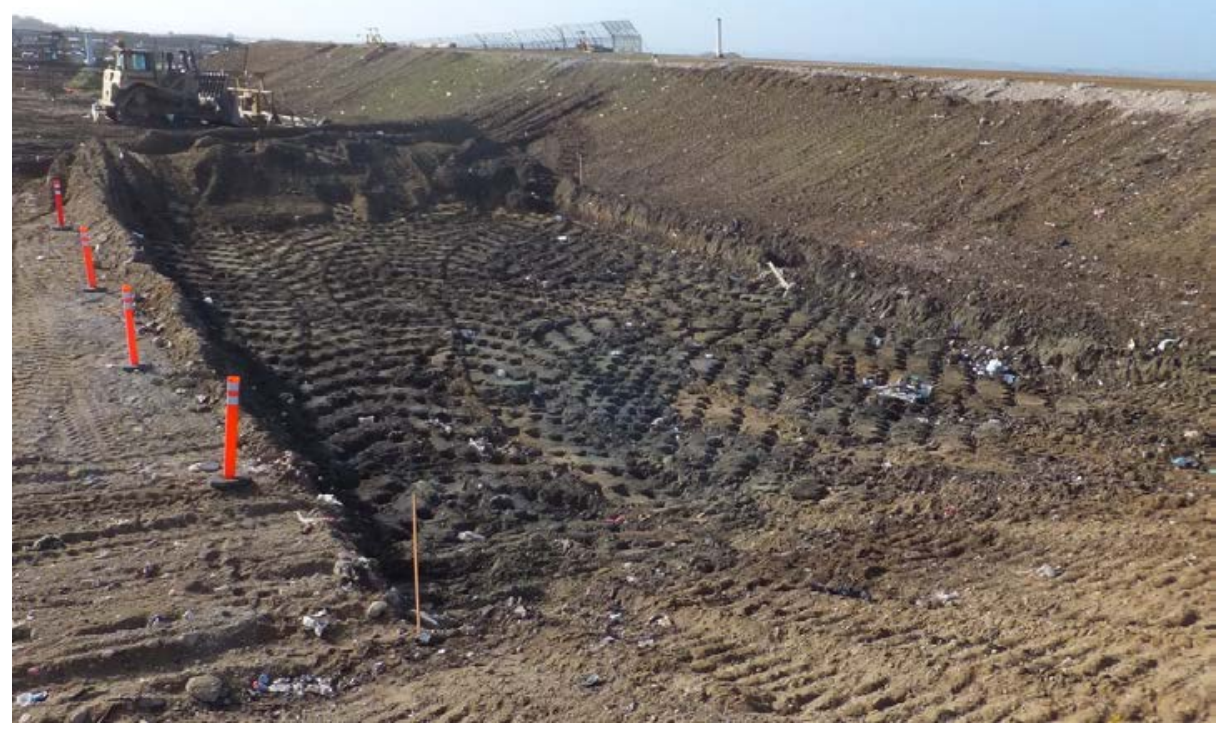

Figure 3.18. An Example of a Graded Test Plot.

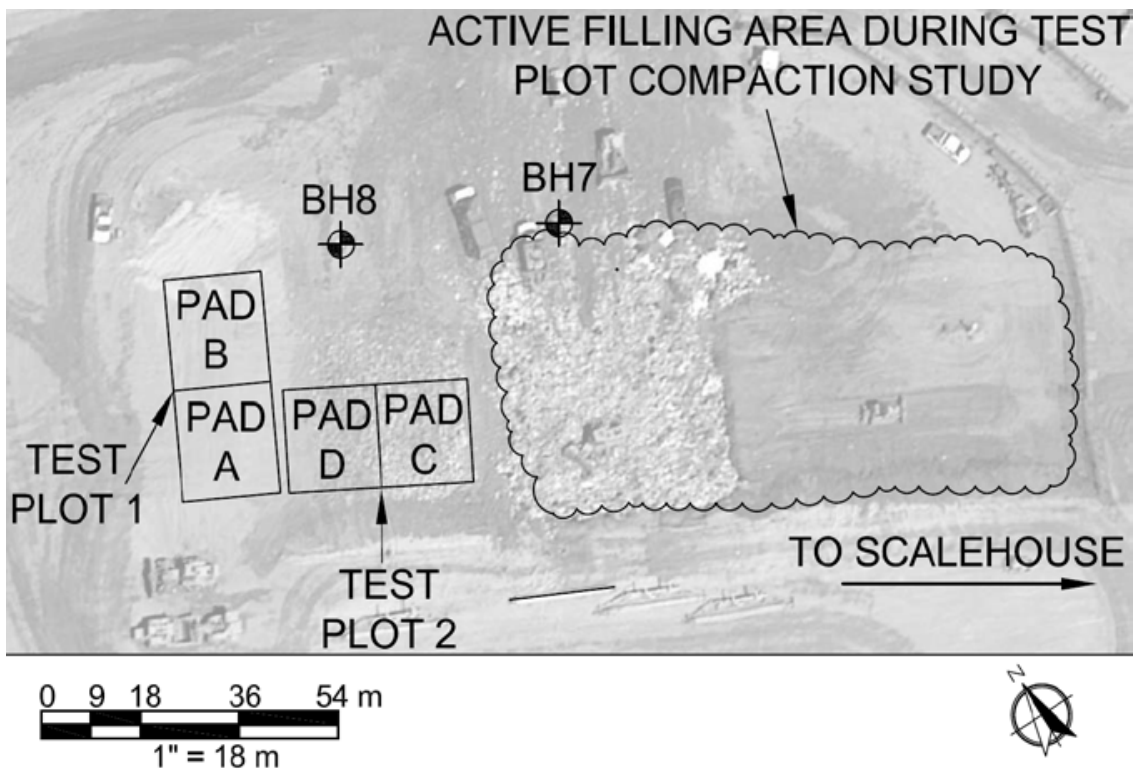

Figure 3.19. Schematic of the Test Plot Layout. 


\section{Meso-scale Compaction Study Procedures}

The meso-scale compaction study consisted of 3 distinct phases of waste placement and compaction procedures. Each phase was carried out in a similar manner such that a general procedure for waste placement and compaction was applied to given test pad during each phase. However, the moisture addition characteristics and waste placement methods were different for each phase. Baseline compaction procedures were established during the first (Phase 1) and second (Phase 2) phases.

Prior to the commencement of the meso-scale compaction study, preliminary analyses were made to establish the characteristics of the incoming RMSW and determine the waste placement procedures for the study. First, the amount of waste to be used per day for the study was determined to be 10-12 truckloads (approximately $890 \mathrm{kN}$ ) based on tonnage records. The estimated daily quantity of incoming RMSW was divided between the 2 test pads of a given test plot such that each test pad would receive approximately $450 \mathrm{kN}$ (50 tons) of RMSW per day.

Next, target moisture contents of $65,80,95$, and $110 \%$ were selected for the compaction study based on the measured baseline moisture content of $55 \%$ for as-received RMSW. The target moisture contents were chosen in order to generate a compaction curve similar to the curves generated in laboratory compaction tests (Hanson et al. 2010a). The total amount of additional moisture that needed to be added per day to achieve each target moisture content was then calculated using the average incoming moisture content of as-received 
RMSW and the assumed total weight $(450 \mathrm{kN})$ of RMSW to be delivered and placed in a test pad on a given day. This calculated total amount of additional moisture to obtain a specific target moisture content was then refined to a per truckload basis. Specifically, it was estimated that one waste truck would deliver on average, $89 \mathrm{kN}$ (10 tons) of RMSW per trip. Combining the average weight of RMSW per truckload, the total amount of moisture needed reach a specific moisture content per truckload, and the measured pumping rate $(1145 \mathrm{~L} / \mathrm{min})$ of the onsite water truck at 1700 RPM, a pump time per truckload was determined. Table 3.5 summarizes the total amount of additional moisture for a given target moisture content and the pump time per truckload used for the meso-scale compaction study.

Table 3.5. Moisture Addition Characteristics per Truckload of RMSW

\begin{tabular}{|c|c|c|}
\hline $\begin{array}{c}\text { Target Moisture } \\
\text { Content (\%) }\end{array}$ & $\begin{array}{c}\text { Total Additional } \\
\text { Moisture (L) }\end{array}$ & $\begin{array}{c}\text { Pump Time } \\
\text { (Seconds) }\end{array}$ \\
\hline $55^{\mathrm{a}}$ & 0 & 0 \\
\hline 65 & 149 & 29 \\
\hline 80 & 372 & 74 \\
\hline 95 & 595 & 118 \\
\hline 110 & 819 & 162 \\
\hline
\end{tabular}

${ }^{\mathrm{a}}$ Measured baseline moisture content of RMSW

After the moisture addition characteristics were determined, the baseline waste placement and compaction procedures used throughout the entire mesoscale compaction study were established. On the first day of the compaction test plot study, the compactor operator was allowed to apply the necessary number of passes to a given test pad such that maximum compaction was achieved based on his interpretation and judgment. The number of passes established on the first day was used as the baseline compactive effort for the duration of the test plot 
study. The baseline compactive effort was determined to be 8 passes per coverage (Figure 3.3) of the test pad footprint, which is equivalent to 24 total passes per test pad.

The general procedures of waste placement and compaction used for the meso-scale compaction study at SMRL are described in the following steps and corresponding photographs (Figure 3.20):

1. A truckload of RMSW was delivered to a given test pad (Figure 3.20a)

2. Up to 3 truckloads were allowed to be delivered per test pad before being pushed onto the test pad

3. The Caterpillar D8T Bulldozer was used to push the truckload(s) of RMSW onto the test pad and spread the RSMW evenly across the footprint of the test pad (Figure 3.20b)

4. Moisture was added to a test pad(s) using a turret nozzle to achieve a target moisture content if applicable (Figure 3.20)

5. The RMSW that was spread over the test pad footprint by the bulldozer was compacted using the Caterpillar 826D per the baseline compactive effort (Figure 3.20d) 
6. A GPS survey of the test pad footprint was conducted at the end of each day to determine the incremental volume of waste placed during that day.

7. The placement and compaction of RMSW of a given test plot was repeated until a final height of approximately $4.6 \mathrm{~m}$ (i.e., the typical lift height used at SMRL) was reached at which time the test plot was covered with a layer of intermediate cover soil.
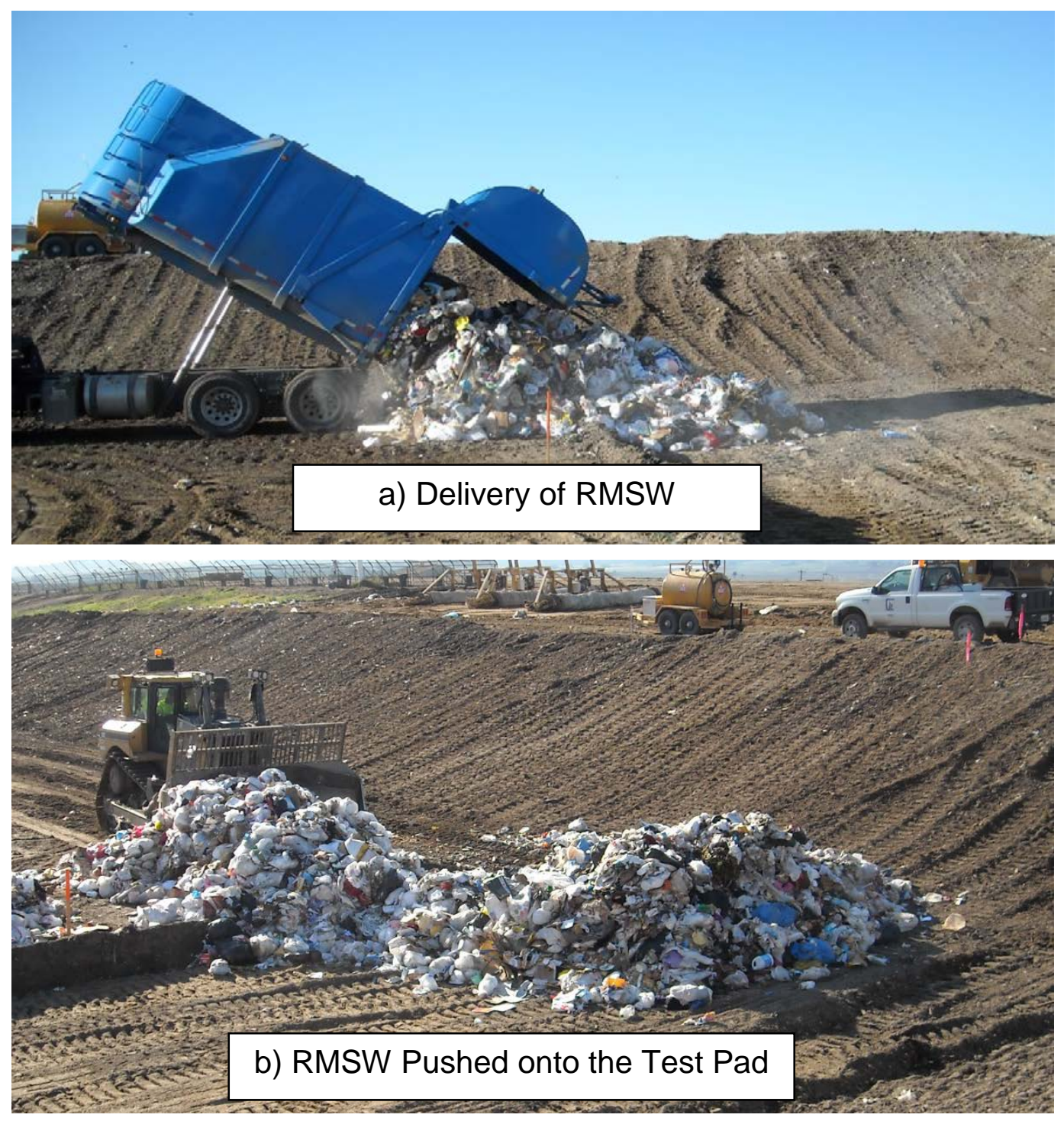

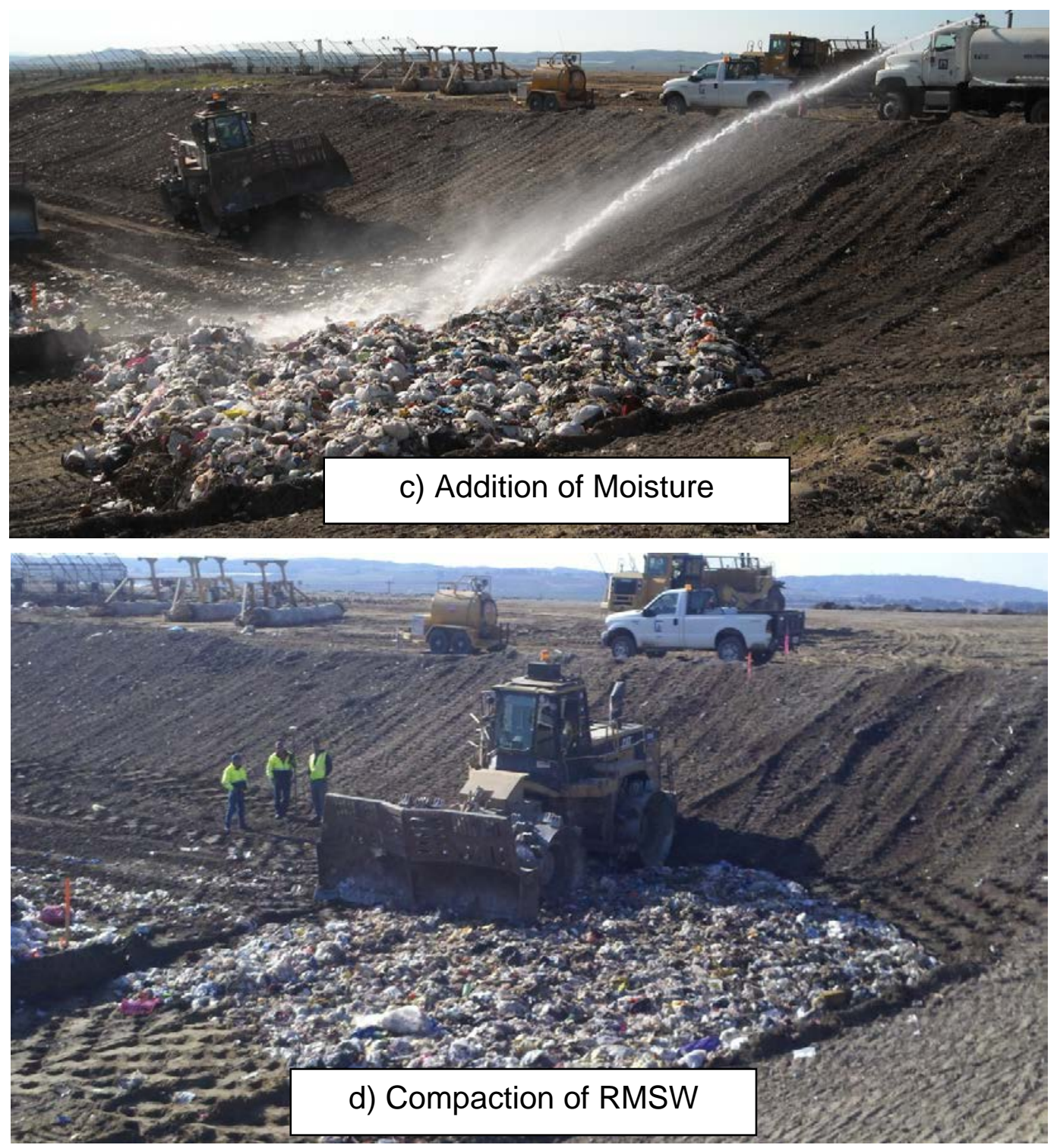

Figure 3.20. Photographs of the General Waste Placement and Compaction Procedure of the Meso-Scale Compaction Study at SMRL

Each phase of the meso-scale compaction study followed a similar general procedure but included variations in moisture addition characteristics and waste placement methods. During Phase 1, Test Plot 1(Test Pads A and B), was partially filled with RMSW. Test Pads A and B were filled simultaneously with Test Pad A designated as the moisture addition side and Test Pad B designated as the control side (i.e., as-received wastes). The original moisture addition 
schedule for the test plot study consisted of obtaining a target moisture content of $65 \%$ for 3 consecutive days, progressing to an $80 \%$ target moisture content for 3 consecutive days, then moving on to a target moisture content of $95 \%$ for 3 consecutive days, and finishing the test plot with 1 day of compacting the RMSW at moisture content of $110 \%$ to avoid oversaturation and poor compaction. However, the test plot study was shut down for 1 day after compacting the waste in Test Pad A at a moisture content of $65 \%$ for 3 consecutive days and at $80 \%$ for 2 consecutive days due to overheating of the compactor and bulldozer. Phase 1 resumed the following day and the final day of compacting at $80 \%$ moisture content was performed. Due to the operational complications experienced during the first 6 days of RMSW placement and compaction, the meso-scale compaction study was postponed for a short period of time while the waste placement methods were reevaluated. This marked the completion of Phase 1 at which point Test Plot 1 had reached a height of approximately $2.2 \mathrm{~m}$, or half of the final lift height.

Phase 2 was initiated approximately 3 weeks after the completion of Phase 1. The test pad designation of Phase 2 was identical to that of Phase 1. Namely, Test Pad A was designated as the moisture addition side and Test Pad B was designated as the control side. Furthermore, the placement and compaction of as-received RMSW in Test Pad B was continued during Phase 2. However, the waste placement methods of RMSW in Test Pad A were altered slightly for Phase 2 to avoid further operational complications. An alternating waste placement procedure of 2 days as-received followed by 1 day of moisture 
addition was implemented during Phase 2. For example, the first 2 days consisted of the placement and compaction of as-received RMSW (i.e., no moisture addition) in both test pads. On the third day, moisture was added to the residential waste in Test Pad A prior to compaction, whereas, the residential waste in Test Pad B was compacted at the as-received state. The "2-to-1" placement procedure was repeated twice (i.e., 6 days) followed by a final day of waste placement and compaction at the as-received moisture content in both Test Pad A and B at which point the final fill height was reached and a $0.6 \mathrm{~m}$ layer of intermediate cover soil was placed on top of the waste. The targeted moisture content for the 2 days of moisture addition during Phase 2 was 65\%.

Phase 3 consisted of the construction of Test Plot 2 and placement of waste into Test Pads C and D. The major difference between Phase 3 and Phase 2 was the implementation of the "2-to-1" placement procedure for both Test Pads C and D (i.e., moisture addition every third day). Test Pad C was designated as the $95 \%$ target moisture side and Test Pad D was designated as the $80 \%$ target moisture content side. The "2-to-1" placement procedure was repeated a total of 3 times during Phase 3 . The RMSW was compacted at 80 and 95\% target moisture contents during the first two cycles of the "2-to-1" placement procedure. The targeted moisture content of third cycle of the "2-to-1" placement procedure was $110 \%$ and was implemented for Test Pads C and D. A summary of the test plot compaction schedule including the test pad designations and the target moisture contents for each phase is provided in Table 3.6. 
Table 3.6. Meso-scale Compaction Study Schedule

\begin{tabular}{|c|c|c|c|}
\hline \multirow{2}{*}{ Phase } & \multirow{2}{*}{ Day } & \multicolumn{2}{|c|}{ Target Moisture Content (\%) } \\
\hline & & Test Pad A & Test Pad B \\
\hline \multirow{6}{*}{$1 \mathrm{~A}$} & 1 & 65 & 55 \\
\hline & 2 & 65 & 55 \\
\hline & 3 & 65 & 55 \\
\hline & 4 & 80 & 55 \\
\hline & 5 & $80^{\mathrm{a}}$ & $55^{a}$ \\
\hline & 6 & 80 & 55 \\
\hline \multirow{7}{*}{ 1B } & 1 & 55 & 55 \\
\hline & 2 & 55 & 55 \\
\hline & 3 & 65 & 55 \\
\hline & 4 & 55 & 55 \\
\hline & 5 & 55 & 55 \\
\hline & 6 & 65 & 55 \\
\hline & 7 & 55 & 55 \\
\hline \multirow{10}{*}{$1 C$} & & Test Pad C & Test Pad D \\
\hline & 1 & 55 & 55 \\
\hline & 2 & 55 & 55 \\
\hline & 3 & 95 & 80 \\
\hline & 4 & 55 & 55 \\
\hline & 5 & 55 & 55 \\
\hline & 6 & 95 & 80 \\
\hline & 7 & 55 & 55 \\
\hline & 8 & 55 & 55 \\
\hline & 9 & 110 & 110 \\
\hline
\end{tabular}

Note: Bold and italicized values represent days of moisture addition

${ }^{a}$ Meso-scale compaction study was postponed for 2 days

The total and operational unit weights of the compacted RMSW were determined for each day of waste placement during the entire meso-scale compaction study. The weight of RMSW placed per day in a given test pad was determined using scalehouse records and the daily volumes of RMSW for a given test pad were calculated using the daily GPS survey data which was analyzed with Trimble ${ }^{\circledR}$ Business Center software. 


\section{Verification of Moisture Distribution Characteristics}

In order to verify the moisture addition techniques and moisture distribution characteristics of the meso-scale compaction study, several RMSW samples were obtained from the test pads and oven dried in the onsite oven approximately 12-15 hours after a day of moisture addition. A bulldozer was used to excavate large test pits which reached depths of approximately $1.3 \mathrm{~m}$ ( $4.5 \mathrm{ft}$.) Each test pit included 3 days of residential waste placement and compaction (i.e., 3 layers of RMSW). Next, 4 samples were obtained for each test pit beginning with sampling waste from the surface and obtaining samples at $0.45 \mathrm{~m}$ depth intervals up to a depth of approximately $1.3 \mathrm{~m}$ (4.5 ft). Lastly, the samples were placed in the oven and dried for approximately 24 hours at $75^{\circ} \mathrm{C}$. A photograph and schematic of a typical test pit are presented in Figure 3.21a and 3.21b.

A total of 3 test pits were excavated during the meso-scale compaction study: Once during Phase 1, following a day when waste was placed and compacted at $80 \%$ moisture content, once during Phase 2, following a day when waste was placed and compacted at $65 \%$ moisture content, and once during Phase 3 , following a day when waste was placed and compacted at $110 \%$. The specimen mass ranged between approximately 2.6 and $5.7 \mathrm{~kg}$. RMSW also was sampled from the surface on as-received and moisture addition days, periodically throughout the meso-scale compaction study. 

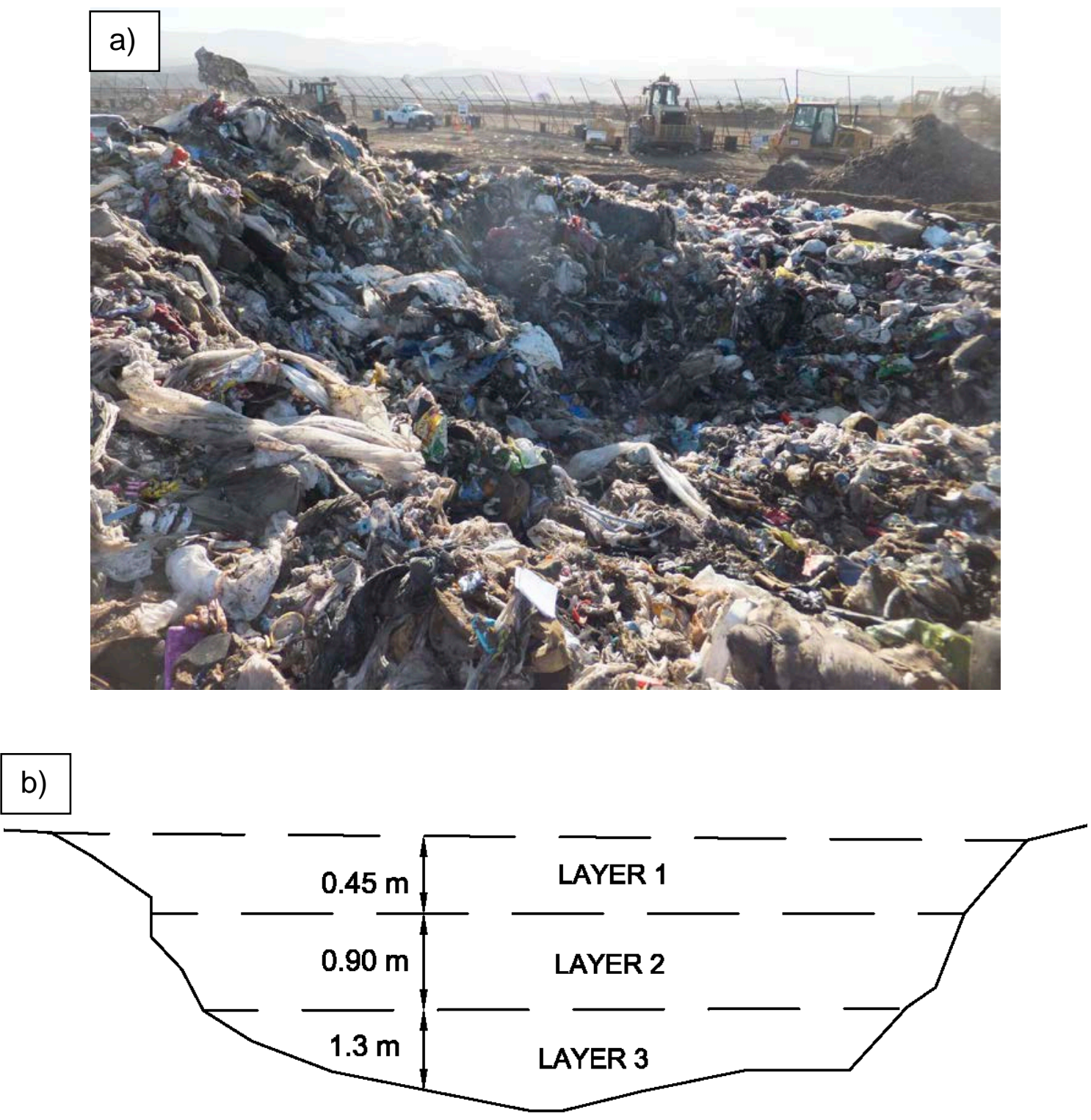

Figure 3.21. Typical Test Pit for Moisture Verification.

\subsubsection{Full-Scale Compaction Test}

After completion of the meso-scale compaction study, a full-scale compaction test was conducted to determine the compaction characteristics of MSW and the effects of moisture addition on the normal daily waste placement procedures at SMRL. This test program is described in the following sections. 


\section{Waste Composition, Waste Placement, and Compaction Procedures}

The waste used during the full-scale compaction study was the normal daily MSW delivered to the landfill and placed in the active filling area (i.e., active face). The incoming MSW at SMRL that was placed at the active face was comprised of residential, commercial, and self-delivered waste. The active face was represented by a $16 \times 46 \mathrm{~m}$ sub-cell with a height of approximately $5 \mathrm{~m}$. Waste placement and compaction procedures implemented for the full-scale compaction study were similar to the procedures implemented for the meso-scale compaction study.

A preliminary analysis was conducted prior to commencement of the fullscale compaction study. First, the daily average weight of MSW disposed at SMRL was determined to be approximately $2940 \mathrm{kN}$ (330 tons) and was calculated using scalehouse records. This value excluded the daily average weight of waste disposed in the landfill on Sundays because the landfill was not open on Sundays over the duration of the compaction study. Next, the weighted average moisture content (i.e., as-received moisture content), determined through sampling of fresh waste from the active face, was used to define the target moisture contents used for the full-scale tests and the amount of water needed to obtain the target moisture contents (i.e., moisture addition characteristics). Consequently, the 4 target moisture contents selected for the full-scale compaction were 45 (as-received moisture content), 65, 85, and 105\%. The amount of water needed to achieve the target moisture contents of 65,85 , and $105 \%$ was estimated to be $45,000 \mathrm{~L}(12,000$ gallons), $91,000 \mathrm{~L}(24,000$ 
gallons), and 136,000 L (36,000 gallons), respectively. Lastly, the baseline compaction characteristics (i.e., total, operational, and dry unit weight) of the asreceived MSW were determined using daily scalehouse records and daily GPS surveys.

The general waste placement procedures implemented for the full-scale compaction study were similar to the normal daily waste placement operations at SMRL. Specifically, incoming MSW was unloaded in front of the active face, pushed onto the active face footprint using the bulldozer and then spread out using the compactor. The MSW was then compacted until the compactor operator determined maximum density was achieved (i.e., 5-8 passes per coverage (Figure 3.3), or $15-24$ total passes). When applicable, moisture was added to the MSW prior to compaction via the turret nozzle of the water truck. The process was repeated several times throughout a given day.

In addition, the "2-to-1" placement method was implemented for the fullscale compaction study with the exception that 4 days of as-received wastes were placed prior to the $105 \%$ target moisture content waste placement day. The 65,85 , and $105 \%$ moisture contents were targeted to occur over 2,4 , and 1 testing days, respectively. The full-scale compaction study schedule is provided in Table 3.7. Lastly, a GPS survey of the active face was conducted at the end of each day to determine the incremental volume of waste placed during that day. 
Table 3.7. Full-Scale Compaction Study Schedule.

\begin{tabular}{|c|c|c|}
\hline Day & Day of the Week & $\begin{array}{c}\text { Target Moisture } \\
\text { Content (\%) }\end{array}$ \\
\hline 1 & Friday & 45 \\
\hline 2 & Saturday & 45 \\
\hline 3 & Monday & 65 \\
\hline 4 & Tuesday & 45 \\
\hline 5 & Wednesday & 45 \\
\hline 6 & Thursday & 65 \\
\hline 7 & Friday & 45 \\
\hline 8 & Saturday & 45 \\
\hline 9 & Monday & 85 \\
\hline 10 & Tuesday & 45 \\
\hline 11 & Wednesday & 45 \\
\hline 12 & Thursday & 85 \\
\hline 13 & Friday & 45 \\
\hline 14 & Saturday & 45 \\
\hline 15 & Monday & 85 \\
\hline 16 & Tuesday & 45 \\
\hline 17 & Wednesday & 45 \\
\hline 18 & Thursday & 85 \\
\hline 19 & Friday & 45 \\
\hline 20 & Saturday & 45 \\
\hline 21 & Monday & 45 \\
\hline 22 & Tuesday & 45 \\
\hline 23 & Wednesday & 105 \\
\hline
\end{tabular}

\section{Verification of Moisture Distribution Characteristics}

The moisture addition techniques and moisture distribution characteristics of the full-scale compaction study were verified through excavated test pits and a detailed spatial moisture distribution analysis. The test pits were excavated approximately 12-15 hours after waste was placed and compacted at a target moisture content of $85 \%$ and MSW was sampled using similar methods of the meso-scale compaction study. A total of 2 test pits were excavated to a depth of approximately $1.2 \mathrm{~m}$ and samples were obtained from the surface and at depths of 0.6 and $1.2 \mathrm{~m}$. A total of 6 samples ( 2 per depth) were collected from each test 
pit, and then oven dried for 24 hours at $75^{\circ} \mathrm{C}$. The sample mass ranged from approximately $1-2.5 \mathrm{~kg}$.

In addition to the test pits, a highly detailed spatial moisture distribution analysis was conducted during the full-scale compaction study. The spatial moisture distribution characteristics were analyzed for MSW compacted at the as-received moisture content and for MSW compacted at 85\%. 50 MSW samples were obtained from the surface of the active face at the end of a day of waste placement and compaction at the as-received and $85 \%$ target moisture contents (i.e., 100 total samples). MSW was sampled in a grid pattern (Figure 3.22) and each sample location was determined using GPS survey. The average mass for as-received and 85\% target moisture content specimens was 1.16 and $1.86 \mathrm{~kg}$, respectively.

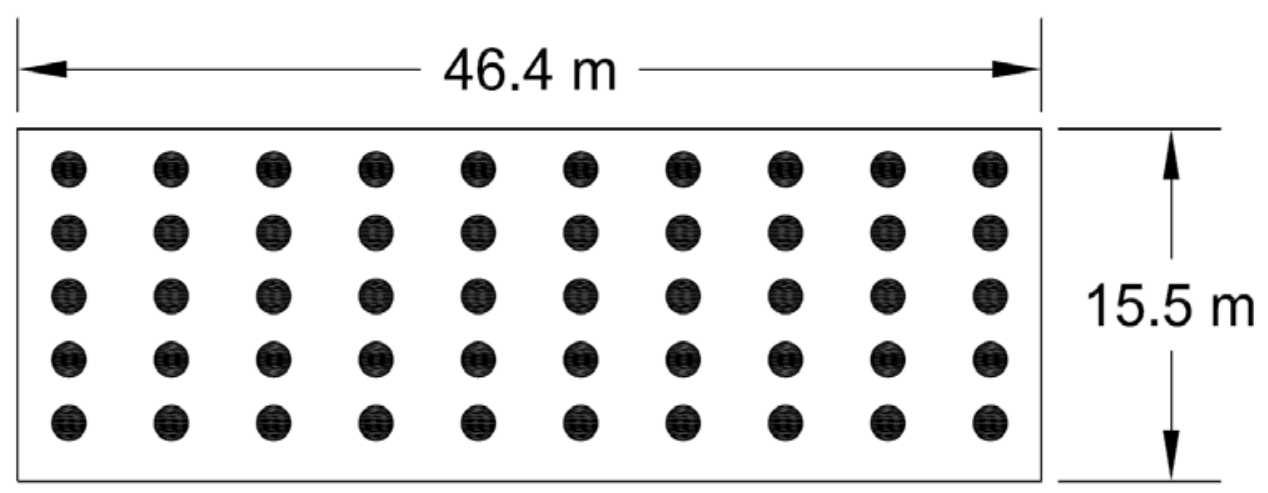

Figure 3.22. Grid Pattern of Spatial Moisture Distribution Sample Locations.

The samples were sealed in bags, labeled, and then oven dried for 24 hours at $75^{\circ} \mathrm{C}$. After the moisture contents were calculated, the survey data and moisture content data was imported to ArcGIS and a spatial moisture distribution map was developed for the as-received and $85 \%$ moisture content conditions. 


\subsection{Laboratory Investigation}

A laboratory investigation was conducted for this test program to determine the specific gravity, particle size distribution, and organic content of MSW. The experiments included sample preparation and specific gravity tests on MSW with different characteristics/conditioning. Particle size distribution and organic content analyses also were conducted on MSW samples with varied characteristics.

\subsubsection{Determination of Specific Gravity of MSW}

The specific gravity of MSW was determined using a modified version of the ASTM Standard D854 - "Standard Test Methods for Specific Gravity of Soil Solids by Water Pycnometer" (ASTM 2010b). A total of three categories of tests were conducted to determine the range of $G_{s}$ for MSW and the factors that affect $G_{s}$. Category I tests were conducted on manufactured wastes to investigate the factors that affect specific gravity without the influence of compositional variability between test specimens. The manufactured waste specimens had variable particle sizes and compacted under variable conditions. Category II tests were conducted on fresh MSW samples obtained from Santa Maria Regional Landfill (SMRL) located in Santa Maria, California. The samples were collected immediately before and after compaction at the landfill. Category III tests included testing of old wastes (waste ages between 0.7 and 6 years) obtained at depth from the landfill to determine the evolution of $G_{s}$ over time. A summary of the $G_{s}$ test study is presented in Table 3.8. 
Table 3.8. Overview of the Specific Gravity Experiments Conducted on MSW

\begin{tabular}{|c|c|c|c|}
\hline Category & Waste Type & Experimental Variables & $\begin{array}{c}\text { Number of } \\
\text { Tests }\end{array}$ \\
\hline I & Manufactured MSW & $\begin{array}{c}\text { Particle size and Stages } \\
\text { of Compaction }\end{array}$ & 12 \\
\hline II & Fresh MSW from SMRL & Stages of Compaction & 10 \\
\hline III & Old MSW from SMRL & $\begin{array}{c}\text { Level of Degradation (i.e., } \\
\text { Waste Age/Depth) }\end{array}$ & 18 \\
\hline
\end{tabular}

\section{$\underline{\text { Test Materials, Sample Collection, and Preparation }}$}

Manufactured MSW (MMSW) specimens (Category I) were prepared based on the waste constituent percentage breakdown reported by the USEPA (2013a). In addition, the MMSW specimens were prepared and tested at three different particle sizes designated as coarse, medium, and fine. A photograph of the individual waste constituents (Figure 3.23) displays the distinction between the three particle sizes for each waste constituent. Specimens were manufactured by first cutting and crushing the specific materials to the desired sizes that corresponded to the coarse, medium, and fine particle fractions. Then the individual waste components were weighed out to the corresponding USEPA percentage. Finally, the constituents were placed in a large bowl and thoroughly mixed by hand. The mixed constituents represented the as-prepared MMSW. The moisture content of the as-prepared MMSW specimens was determined using a weighted average by mass of the individual waste constituents. The moisture contents of paper, cardboard, wood, rubber, leather, yard trimmings, textiles, and miscellaneous inorganics were individually determined using ASTM D2216 - "Standard Test Methods for Laboratory Determination of Water 
(Moisture) Content of Soil and Rock by Mass," and the remaining inert waste constituents (e.g., steel) were assumed to have a moisture content of zero.

\begin{tabular}{|c|c|c|c|c|}
\hline \multicolumn{5}{|c|}{ MANUFACTURED MUNICIPAL SOLID WASTE } \\
\hline MATERIAL & \% WEIGHT & COARSE & MEDIUM & FINE \\
\hline PAPER & 12.94 & & & \\
\hline CARDBOARD & 3.22 & & & \\
\hline GLASS & 5.46 & & & \\
\hline STEEL & 6.46 & & & \\
\hline ALUMINUM & 1.68 & & & \\
\hline $\begin{array}{l}\text { OTHER METALS } \\
\text { (TIN) }\end{array}$ & 0.37 & & & \\
\hline HDPE & 13.5 & & & \\
\hline LDPE & 3.72 & & & \\
\hline RUBBER & 3.30 & & & \\
\hline LEATHER & 0.66 & & & \\
\hline TEXTILE & 6.73 & & & \\
\hline WOOD & 8.46 & & & \\
\hline $\begin{array}{l}\text { OTHER } \\
\text { (CONCRETE) }\end{array}$ & 2.12 & & & \\
\hline FOOD & 20.78 & & & \\
\hline $\begin{array}{c}\text { YARD } \\
\text { TRIMMINGS }\end{array}$ & 8.26 & & & \\
\hline $\begin{array}{l}\text { MISCELLANEOUS } \\
\text { INORGANIC }\end{array}$ & 2.37 & & & \\
\hline
\end{tabular}

Figure 3.23. Waste Constituents Prepared to Three Particle Size Fractions. 
A predetermined amount of moisture was added (using a spray bottle) to the specimens that were compacted at the dry and wet of optimum moisture content. These specimens were then mixed in the same large bowl by hand. Dry and wet of optimum moisture contents were determined to be 30 and $90 \%$, respectively using laboratory waste compaction curves associated with $4 \mathrm{X}$ modified compaction effort that were generated by Wong (2009). Both the dry and wet of optimum moisture contents corresponded with a dry unit weight of 5.3 $\mathrm{kN} / \mathrm{m}^{3}$.

The maximum particle sizes of the coarse, medium, and fine specimens were approximately 50.8, 25.4, and $12.7 \mathrm{~mm}$, respectively. However, the size of each individual constituent varied depending on the shape (i.e., polygonal vs. spherical vs. cylindrical) and type of the constituent. A summary of the type and percentage of the waste constituents used for the MMSW specimens is provided in Table 3.9. The dimensions of each waste constituent at the 3 particle sizes and the specific gravity values of the individual waste constituents which were reported by Wong (2009) are presented in Table 3.9 as well.

The target mass of each MMSW specimen (pre-moisture addition) for $G_{s}$ testing was $100 \mathrm{~g}$. Constituents such as paper, cardboard, trash bag coupons, and leaves are lightweight and consume a significant amount of the volume within the testing apparatus (i.e., Erlenmeyer flask). Therefore, specimens were prepared to a mass of approximately $100 \mathrm{~g}$ in order to fit the entire specimen within the testing apparatus. 
Table 3.9. Properties of Manufactured MSW Specimens

\begin{tabular}{|c|c|c|c|c|c|c|}
\hline \multirow{2}{*}{$\begin{array}{c}\text { Waste } \\
\text { Specimen } \\
\text { Constituent }\end{array}$} & \multirow{2}{*}{ Description } & \multirow{2}{*}{$\begin{array}{l}\text { Weight } \\
\text { Fraction } \\
(\%)\end{array}$} & \multirow{2}{*}{$\mathbf{G}_{s}$} & \multicolumn{3}{|c|}{ Particle Size (mm) } \\
\hline & & & & Coarse & Medium & Fine \\
\hline Paper & $\begin{array}{l}\text { printer paper } \\
\text { coupons }\end{array}$ & 13 & 1.53 & $50.8 \times 50.8$ & $\begin{array}{c}25.4 x \\
25.4\end{array}$ & $12.7 \times 12.7$ \\
\hline Cardboard & $\begin{array}{l}\text { cardboard } \\
\text { coupons }\end{array}$ & 3 & 1.53 & $50.8 \times 50.8$ & $\begin{array}{l}25.4 x \\
25.4\end{array}$ & $12.7 \times 12.7$ \\
\hline Food & $\begin{array}{l}\text { chopped and } \\
\text { crushed dog } \\
\text { food biscuits }\end{array}$ & 21 & 1.22 & $38.1 \times 25.4$ & $\begin{array}{c}12.7 x \\
12.7\end{array}$ & $\begin{array}{c}\text { Passes No. } \\
4 \text { Sieve }\end{array}$ \\
\hline HDPE & $\begin{array}{l}\text { milk carton } \\
\text { coupons and } \\
\text { HDPE chips }\end{array}$ & 13 & 0.95 & $25.4 \times 25.4$ & $\begin{array}{c}12.7 x \\
12.7\end{array}$ & $\begin{array}{c}\text { Passes No. } \\
4 \text { Sieve }\end{array}$ \\
\hline LDPE & $\begin{array}{l}\text { trash bag } \\
\text { coupons }\end{array}$ & 4 & 0.92 & $50.8 \times 50.8$ & $\begin{array}{c}25.4 x \\
25.4\end{array}$ & $6.35 \times 6.35$ \\
\hline $\begin{array}{c}\text { Yard } \\
\text { Trimmings }\end{array}$ & $\begin{array}{l}\text { chopped } \\
\text { leaves and } \\
\text { shredded } \\
\text { grass }\end{array}$ & 8 & 0.94 & $\begin{array}{l}50.8 \times 25.4 \\
\text { leaves }\end{array}$ & $\begin{array}{c}19.05 \mathrm{x} \\
19.05 \\
\text { leaves }\end{array}$ & $\begin{array}{c}\text { Passes No. } \\
4 \text { Sieve }\end{array}$ \\
\hline Wood & $\begin{array}{l}\text { wood blocks } \\
\text { and wood } \\
\text { shavings }\end{array}$ & 8 & 1.53 & $\begin{array}{c}25.4 \times 19.05 \\
\times 12.7\end{array}$ & $\begin{array}{c}12.7 x \\
12.7 x \\
6.35 \\
\end{array}$ & $\begin{array}{c}\text { Passes No. } \\
8 \text { Sieve }\end{array}$ \\
\hline Steel & $\begin{array}{l}\text { chopped } \\
\text { nails }\end{array}$ & 6.5 & 7.86 & $\begin{array}{c}38.1 \text { length } \\
x \\
\text { 3.3 diameter }\end{array}$ & $\begin{array}{c}19.05 \\
\text { length } \mathrm{x} \\
3.3 \\
\text { diameter }\end{array}$ & $\begin{array}{c}6.35 \text { length } \\
x \\
3.3 \text { diameter }\end{array}$ \\
\hline Aluminum & $\begin{array}{c}\text { aluminum } \\
\text { can coupons } \\
\text { and shavings }\end{array}$ & 2 & 2.7 & $25.4 \times 25.4$ & $\begin{array}{c}12.7 x \\
12.7\end{array}$ & $\begin{array}{c}\text { Passes No. } \\
4 \text { Sieve }\end{array}$ \\
\hline Other Metals & $\begin{array}{l}\text { scrap metal } \\
\text { coupons }\end{array}$ & 0.5 & 2.7 & $\begin{array}{c}19.05 x \\
19.05\end{array}$ & $\begin{array}{c}12.7 x \\
12.7\end{array}$ & $6.35 \times 6.35$ \\
\hline Glass & $\begin{array}{c}\text { crushed } \\
\text { glass bottles }\end{array}$ & 5 & 2.6 & $12.7 \times 12.7$ & $\begin{array}{l}6.35 x \\
6.35\end{array}$ & $\begin{array}{c}\text { Passes No. } \\
4 \text { Sieve }\end{array}$ \\
\hline Textile & $\begin{array}{l}\text { textile } \\
\text { coupons }\end{array}$ & 7 & 1.27 & $50.8 \times 50.8$ & $\begin{array}{l}25.4 x \\
25.4\end{array}$ & $12.7 \times 12.7$ \\
\hline Rubber & $\begin{array}{l}\text { shoe rubber } \\
\text { coupons and } \\
\text { shredded tire }\end{array}$ & 3.4 & 1.1 & $\begin{array}{c}19.05 \times \\
19.05 \times 3.18\end{array}$ & $\begin{array}{l}6.35 x \\
6.35\end{array}$ & $\begin{array}{c}\text { Passes No. } \\
4 \text { Sieve }\end{array}$ \\
\hline Leather & $\begin{array}{l}\text { shoe leather } \\
\text { coupons }\end{array}$ & 0.7 & 0.86 & $\begin{array}{l}19.05 x \\
19.05\end{array}$ & $\begin{array}{c}12.7 x \\
12.7\end{array}$ & $\begin{array}{c}3.175 x \\
3.175\end{array}$ \\
\hline $\begin{array}{l}\text { Inorganic } \\
\text { Waste }\end{array}$ & soils & 3 & 2.65 & $\begin{array}{c}12.7 \\
\text { diameter }\end{array}$ & $\begin{array}{l}\text { Retained } \\
\text { on No. } 8\end{array}$ & $\begin{array}{l}\text { Passes No. } \\
200 \text { Sieve }\end{array}$ \\
\hline Other & $\begin{array}{l}\text { crushed } \\
\text { concrete } \\
\text { fragments }\end{array}$ & 2 & 2.6 & $\begin{array}{c}19.05 x \\
19.05\end{array}$ & $\begin{array}{c}12.7 x \\
6.35\end{array}$ & $\begin{array}{c}\text { Passes No. } \\
4 \text { Sieve }\end{array}$ \\
\hline
\end{tabular}


Fresh MSW bulk samples (Category II) were collected in $340 \mathrm{~L}$ (90 gallon) containers from the active face of SMRL. The fresh MSW (FMSW) bulk samples were collected at three different field conditions: 1) uncompacted at as-received moisture content; 2) compacted at as-received moisture content; and 3) compacted at optimum moisture content. The as-received bulk samples were obtained upon disposal before and after compaction and were assumed to have a moisture content of approximately $45 \%$. The optimum moisture content bulk samples were obtained after spraying and compaction of the waste for which the target moisture content was $85 \%$. However, the measured moisture contents were slightly different and were determined to be 37 and $75 \%$ for the as-received and optimum moisture conditions, respectively.

The bulk samples obtained at each field condition weighed approximately $10 \mathrm{~kg}$ and were representative of the MSW received by SMRL with the exception of bulky items such as furniture and appliances. A portion of bulk samples of FMSW were then separated and placed into $3.8 \mathrm{~L}$ ( 1 gallon) sealed bags. The maximum particle size of the FMSW specimens was approximately between 50 and $75 \mathrm{~mm}$ and the mass of the specimens varied between nominally 135 and $335 \mathrm{~g}$. Next, the remaining portion of the bulk samples was placed into the oven for moisture content analysis. A photograph of the FMSW sampled at the active face at SMRL is presented in Figure 3.24. 


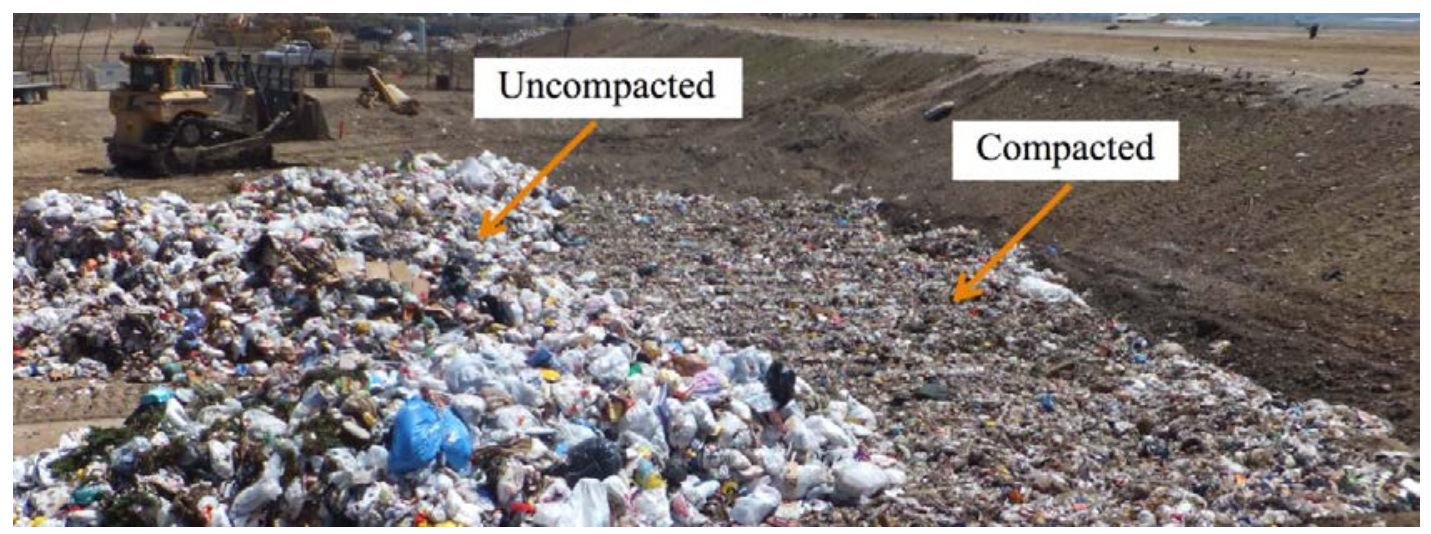

Figure 3.24. FMSW Sampled at the Active Face.

Old MSW specimens (Category III) were obtained from different depths at SMRL. Examples of the waste obtained from shallow and great depths are presented in Figure $3.25 \mathrm{a}$ and $3.25 \mathrm{~b}$, respectively. The old MSW (OMSW) specimens were collected from the drill cuttings of different boreholes associated with the field instrumentation procedures. The specimens were then bagged in 3.8 L (1 gallon) sealed bags. A portion of each specimen was transported back to the laboratory for $G_{s}$ testing while the other portion of each specimen was oven dried to determine the moisture content. The maximum particle size of the OMSW specimens was approximately $25 \mathrm{~mm}$ and the mass of the specimens varied between nominally 145 and $345 \mathrm{~g}$. 

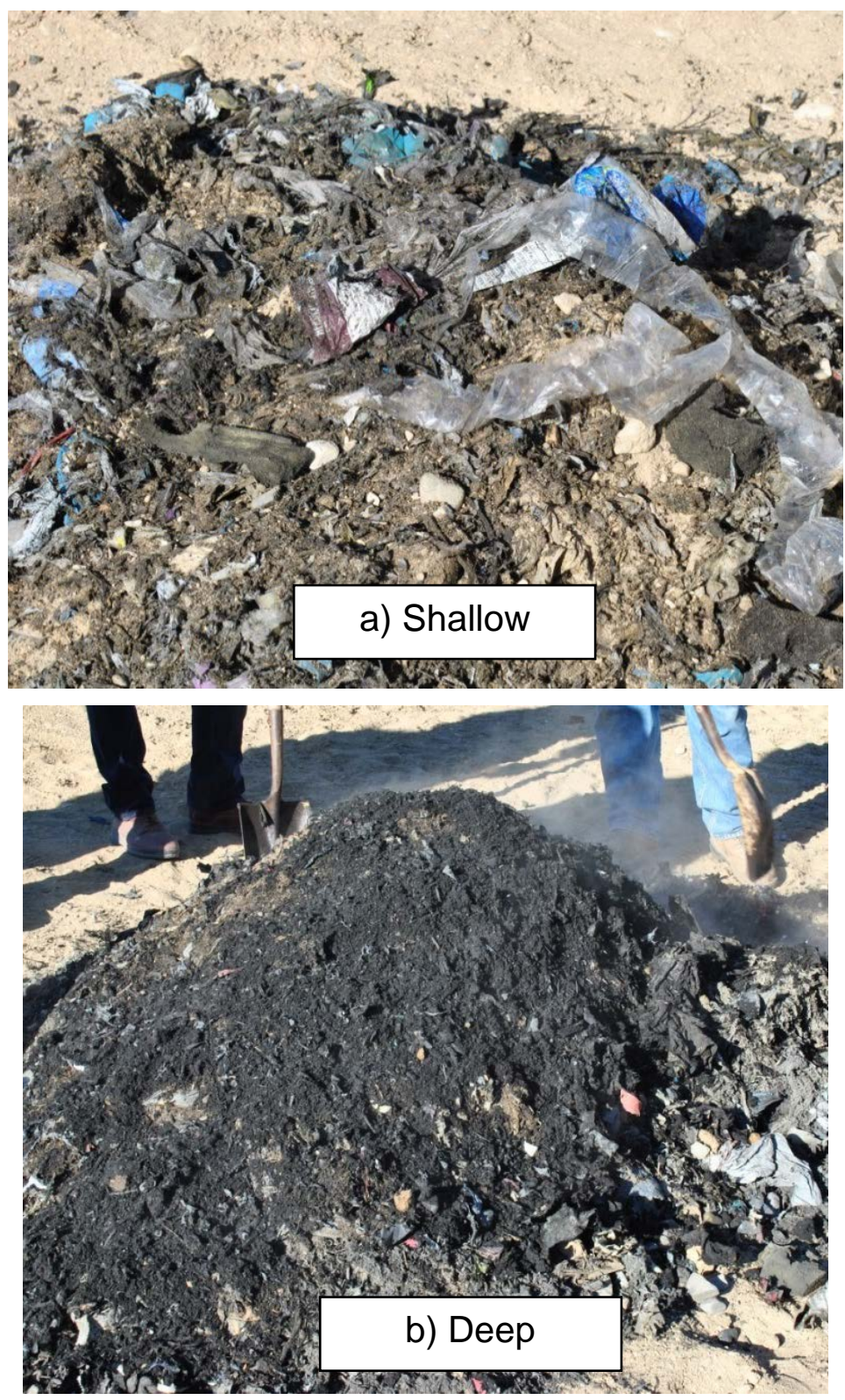

Figure 3.25. OMSW Obtained From Different Depths.

\section{$\underline{\text { Test Equipment }}$}

Laboratory specific gravity tests were conducted using water pycnometry generally following the procedures used for soil testing (ASTM D854). The standard soil testing procedure was adapted and modified for testing MSW. The tests were conducted using two types of Erlenmeyer flasks with volumes of 2000 
$\mathrm{ml}$ to accommodate the relatively large particle sizes of MSW in comparison to typical soils (Figure 3.26). The Erlenmeyer flask used for MMSW and OMSW specimens had an opening (i.e., mouth) of approximately $50 \mathrm{~mm}$ diameter whereas the Erlenmeyer flask used for the FMSW specimens had an opening of approximately $75 \mathrm{~mm}$ diameter. A shake table and vacuum pump also were used during the testing procedure in order to remove trapped air within the sample.

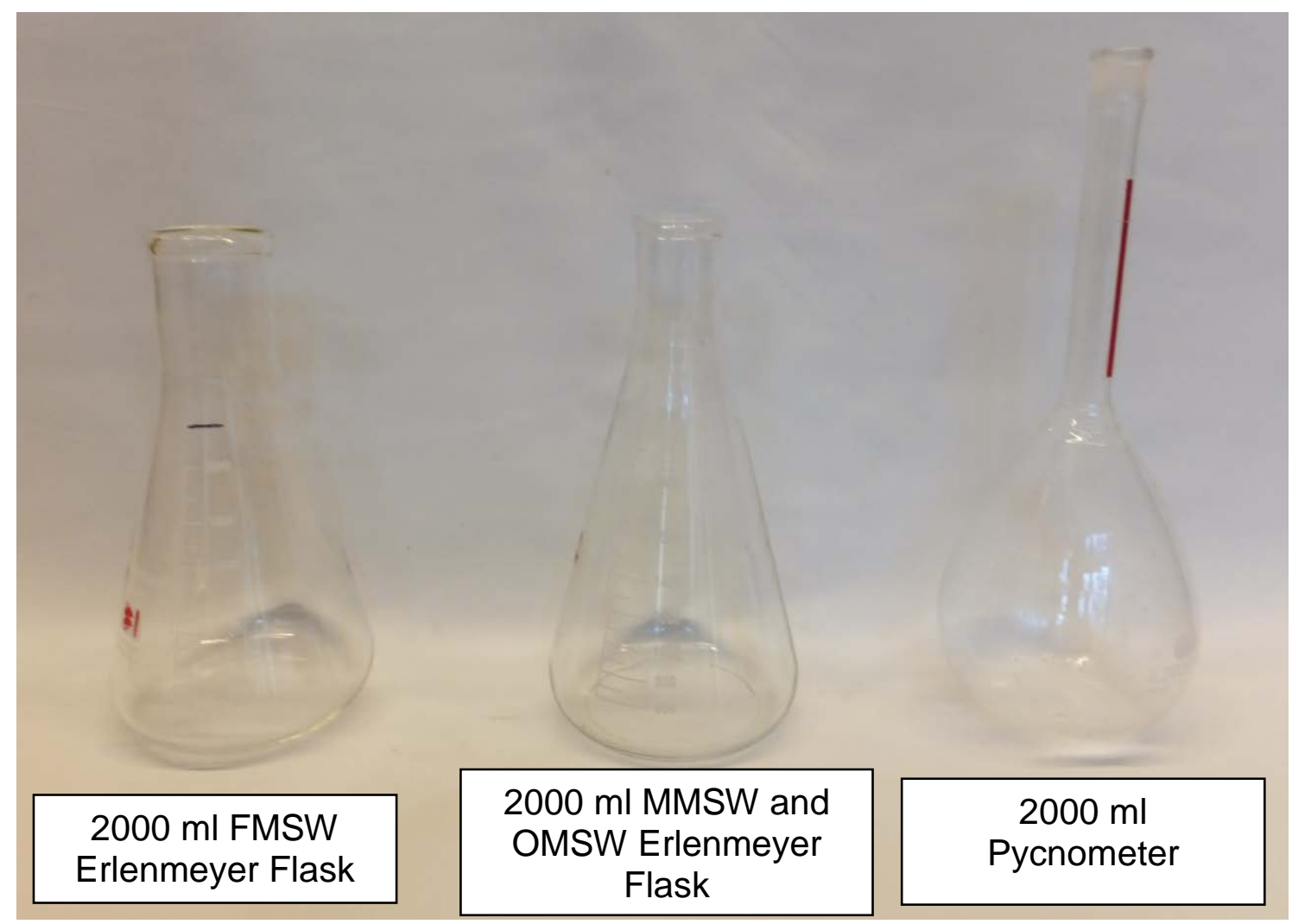

Figure 3.26. Comparison of a Pycnometer and the Two Erlenmeyer Flasks.

\section{$\underline{\text { Testing Procedure }}$}

The procedure outlined by ASTM D854 was generally used for the determination of specific gravity of MSW. First, deionized water was desired for approximately 20 minutes. Pre-weighed MSW specimens were concurrently prepared and added to the Erlenmeyer flask. All three types of the MSW 
specimens were added to the Erlenmeyer flask in the same manner. However, prior to the addition of the MMSW to the Erlenmeyer flask, the coarse, medium, and fine sized manufactured MSW specimens were prepared as either uncompacted (i.e., as-prepared), compacted dry of optimum ( $30 \%$ moisture content), or compacted wet of optimum (90\% moisture content) conditions. The as-prepared MMSW specimens were added to the Erlenmeyer flask after uniformly mixing the waste constituents in a bowl. The dry and wet of optimum MMSW specimens were compacted using the $4 \mathrm{X}$ modified procedure of ASTM D1557 as described by Wong (2009). These specimens were placed in the 152 $\mathrm{mm}$ proctor mold in 4 lifts and subjected to a total of 93 blows evenly distributed between each lift (equivalent to $4 \mathrm{X}$ modified effort). The compacted MMSW specimens were then placed into the Erlenmeyer flask and weighed.

Next, the Erlenmeyer flask (MSW specimen included) was filled with the desired, deionized water to a 2/3 full level. The waste and water filled flask was then placed on a shake table and connected to a vacuum pump for approximately 1 hour to remove entrapped air within the waste-water mixture (Figure 3.27). After the entrapped air had been removed, the remaining $1 / 3$ of flask was filled with desired, deionized water and the full flask was placed into a temperature controlled container and allowed to reach equilibrium (approximately 8 hours). The temperature of the water inside the flask was measured and the waste-water filled Erlenmeyer flask was weighed and weight recorded after reaching equilibrium. Photographs of the MMSW, FMSW, and OMSW in the Erlenmeyer flask prior to the addition of water and after reaching equilibrium are 
presented in Figure 3.28. Lastly, the specific gravity of each specimen was determined using the formulas provided in ASTM D854.

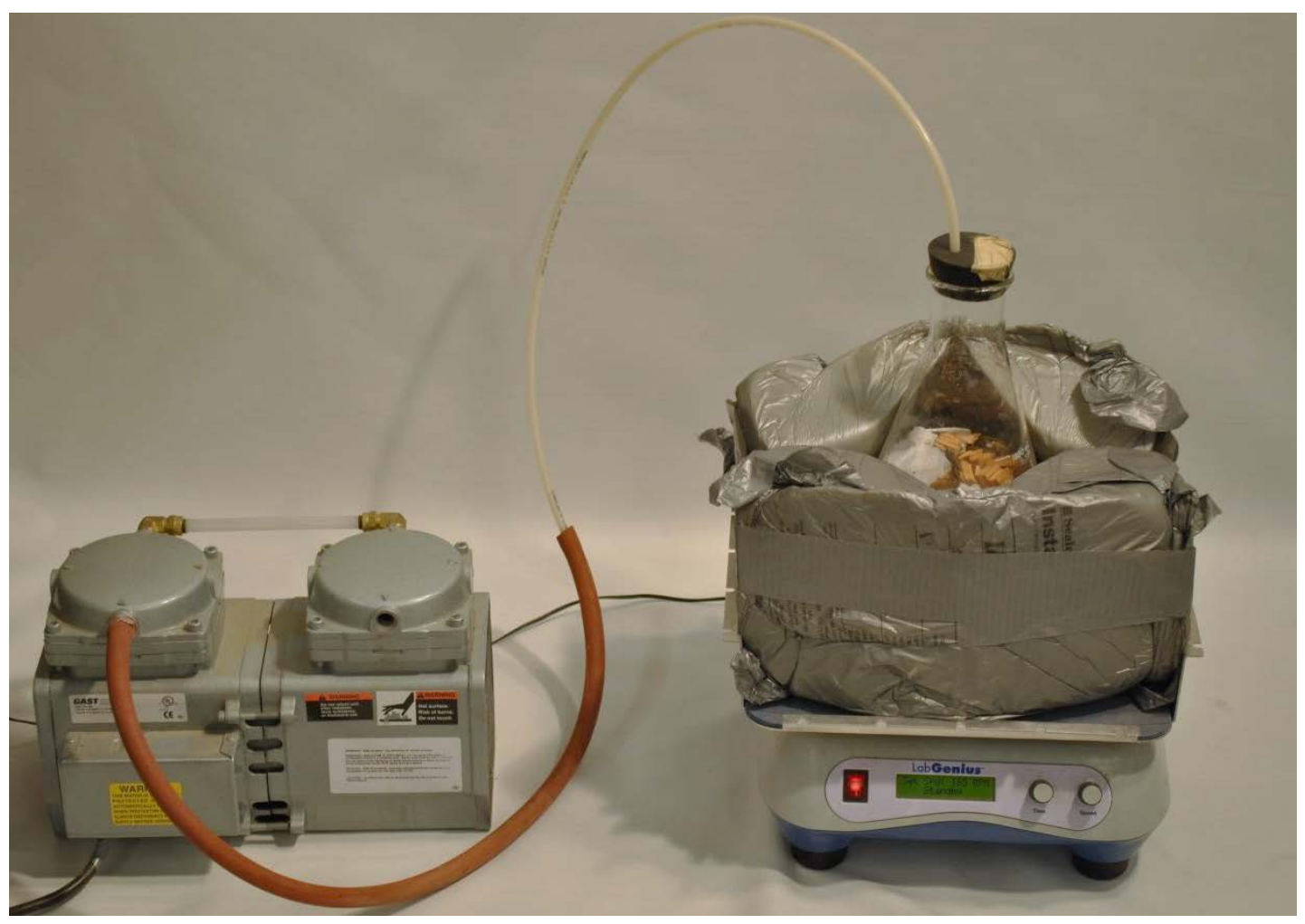

Figure 3.27. The Specific Gravity Test Setup. 

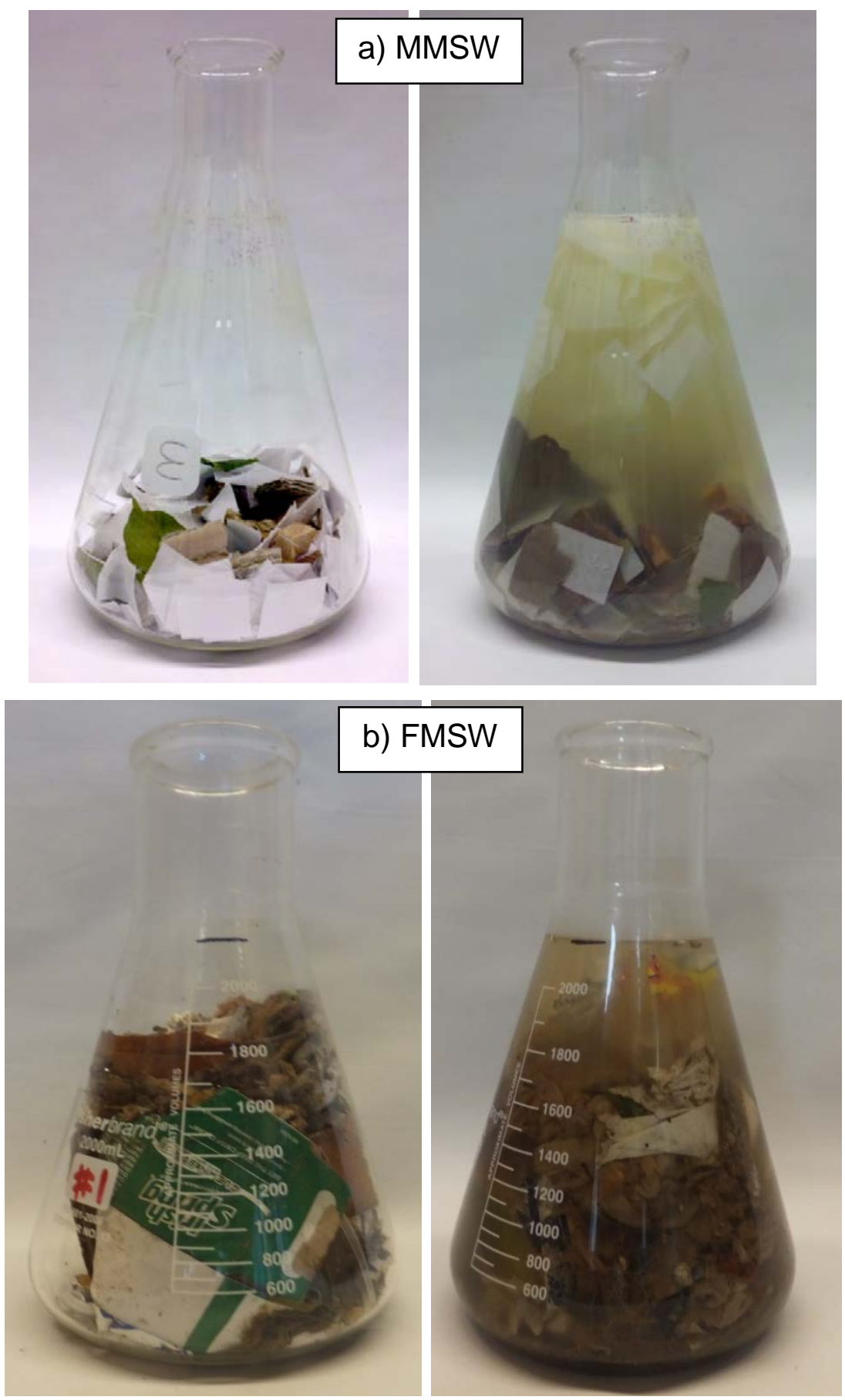


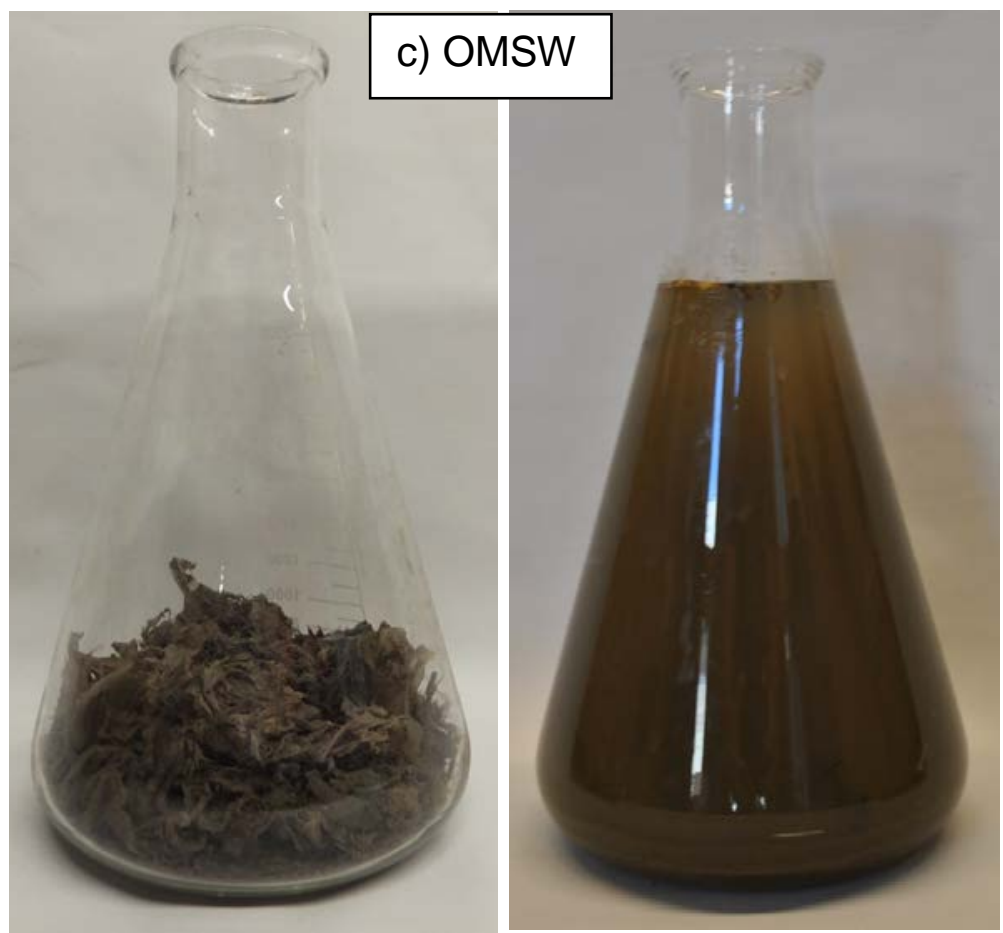

Figure 3.28. Photographs of the Erlenmeyer Flasks Filled with Waste Only (left-side) and with Waste-Water Mixture After Equilibrium (right-side).

\subsubsection{Particle Size Analysis}

A full sieve analysis was not suitable to accurately determine the particle distribution of the MMSW specimens and therefore an equivalent particle diameter was calculated for the manufactured wastes in each size fraction. Several particles were measured for each waste constituent and size fraction. For non-spherical components (e.g., paper, food, plastics, textile, rubber and leather), an apparent volume was calculated using the measured length, width, and thickness of a particle. Then, an equivalent diameter $\left(d_{e q}\right)$ for the particle was back calculated from this volume. For relatively rounded particles such as fine wood, fine aluminum, and fine glass, particle diameter was directly measured using a pair of calipers. The equivalent particle diameters for each size fraction were determined using a weighted average of the constituent components. A 
summary of the calculated apparent volumes and equivalent diameters of each waste constituent are presented in Table 3.10.

Table 3.10. Apparent Volume and Equivalent Diameter of Waste Constituents.

\begin{tabular}{|l|c|c|c|c|c|c|}
\hline \multirow{2}{*}{$\begin{array}{c}\text { Waste } \\
\text { Constituent }\end{array}$} & \multicolumn{3}{c|}{$\begin{array}{c}\text { Apparent Volume } \\
\left(\mathbf{m m}^{\mathbf{3}} \mathbf{)}\right.\end{array}$} & \multicolumn{3}{c|}{$\begin{array}{c}\text { Equivalent Diameter } \\
\text { (mm) }\end{array}$} \\
\cline { 2 - 7 } & Coarse & Medium & Fine & Coarse & Medium & Fine \\
\hline Paper & 243 & 61 & 15 & 7.74 & 4.87 & 3.07 \\
\hline Cardboard & 2143 & 947 & 640 & 16.00 & 12.19 & 10.69 \\
\hline Glass & 600 & 225 & - & 10.46 & 7.55 & 2.19 \\
\hline Steel & 330 & 165 & 55 & 8.57 & 6.80 & 4.72 \\
\hline Aluminum & 69 & 17 & - & 5.09 & 3.21 & 1.76 \\
\hline Other Metals & 69 & 17 & 4 & 5.09 & 3.21 & 2.02 \\
\hline HDPE & 595 & 149 & 17 & 10.44 & 6.57 & 3.17 \\
\hline LDPE & 59 & 15 & 1 & 4.83 & 3.04 & 1.21 \\
\hline Rubber & 3073 & 1024 & 136 & 18.04 & 12.51 & 6.39 \\
\hline Leather & 929 & 232 & 15 & 12.11 & 7.63 & 3.03 \\
\hline Textile & 516 & 129 & 32 & 9.95 & 6.27 & 3.95 \\
\hline Wood & 6145 & 1024 & - & 22.73 & 12.51 & 1.18 \\
\hline Other & 944 & 225 & - & 12.17 & 7.55 & 3.64 \\
\hline Food & 9400 & 1367 & 380 & 26.18 & 13.77 & 8.99 \\
\hline Yard Trimmings & 336 & 98 & 3 & 8.63 & 5.72 & 1.73 \\
\hline Soil & 227 & - & - & 7.57 & 3.23 & 0.07 \\
\hline
\end{tabular}

In addition, the effects of compaction on the particle sizes of MMSW were analyzed using a simplified version of ASTM D6913 - "Standard Test Methods for Particle-Size Distribution (Gradation) of Soils Using Sieve Analysis" (ASTM 2009). First, three MMSW specimens (one at each stage of compaction) were weighed to approximately $100 \mathrm{~g}$. Next, the specimens were oven dried at $105^{\circ} \mathrm{C}$ to prevent wet waste constituents from sticking to the sieves during the testing. The oven dried specimens were then placed into a small stack of sieves that consisted of a 12.7 and $9.5 \mathrm{~mm}$ sieve and a pan. Lastly, the sieve stack was placed in a mechanical sieve shaker and allowed to shake for approximately 15 
minutes. The percent passing and percent retained on each sieve was then determined.

A sieve analysis (ASTM D6193) also was performed on OMSW to determine the particle size distribution of three old waste specimens obtained from different depths. Two samples were obtained from borehole $2(\mathrm{BH} 2)$ at depths of 6.5 and $13.9 \mathrm{~m}$ and the third sample was obtained from borehole (BH5) at a depth of $3.7 \mathrm{~m}$. The OMSW specimens were then dried at $75^{\circ} \mathrm{C}$ for 24 hours in the oven located at SMRL and then transported to the laboratory. A particle size analysis was performed on the 3 specimens using a stack of the following sieve sizes: $25.4 \mathrm{~mm}, 19.1 \mathrm{~mm}, 12.7 \mathrm{~mm}, 9.5 \mathrm{~mm}$, No. 4, No. 10, No. 20, No. 40, No. 60 , No. 100 , and No. 200. The specimens were weighed prior to and after 15 minutes of mechanical shaking to determine the percent passing and percent retained.

\subsubsection{Organic Content (Loss on Ignition)}

The organic content or loss on ignition of OMSW and FMSW specimens were determined in the laboratory using the methods described by ASTM D2974 - "Standard Test Methods for Moisture, Ash, and Organic Matter of Peat and Other Organic Soils" (ASTM 2007). A total of 15 old waste specimens were obtained from different depths ranging from 0.1 to $14 \mathrm{~m}$ and boreholes $(\mathrm{BH} 1$, $\mathrm{BH} 2, \mathrm{BH} 5$, and $\mathrm{BH} 6)$ during the drilling operations. The specimens weighed between 300 and $800 \mathrm{~g}$.

A total of 5 fresh waste specimens were collected from the active face of SMRL in 3.8 L (1 gallon) "zip" (non-brand) bags and weighed between 300 and 
$500 \mathrm{~g}$. Both the old and fresh waste specimens were oven dried at $75^{\circ} \mathrm{C}$ for 24 hours using the oven located at SMRL. Next the specimens were transported back to the laboratory and subdivided into smaller portions. Each of the 20 waste specimens (15 OMSW and 5 FMSW) were subdivided into 3 smaller subspecimens and weighed in order to get a better representation of the organic content of each specimen. The 3 sub-specimens were then placed into porcelain bowls and weighed prior to placement in the muffle furnace. Next, the waste-filled porcelain bowls were placed in the muffle furnace for 3 hours at a temperature of approximately $450^{\circ} \mathrm{C}$. The porcelain bowls were then transferred to a desiccator and allowed to cool to room temperature. Upon reaching room temperature (approximately 30 minutes) the waste-filled porcelain bowls were re-weighed. Next, the organic content of the sub-specimens was determined using the formula provided in ASTM D2974 (Equation 3.1).

$$
O C=100-\left(\frac{m_{a s h * 100}}{m_{d}}\right)
$$

Where:

$$
\begin{aligned}
O C & =\text { organic content of waste specimen } \\
m_{d} & =\text { mass of the oven-dried waste specimen }\left(\text { post } 110^{\circ} \mathrm{C} \text { or } 75^{\circ} \mathrm{C}\right. \text { ) } \\
m_{a s h} & \left.=\text { mass of the ashed waste specimen (post } 450^{\circ} \mathrm{C}\right)
\end{aligned}
$$

Finally, the organic content of each waste specimen was determined by averaging the organic content of the 3 corresponding smaller samples of waste. A photograph of a waste specimen subdivided into 3 smaller sub-specimens as well as a comparison of the waste specimen prior to and after placement in the muffle furnace is displayed in Figure 3.29. 

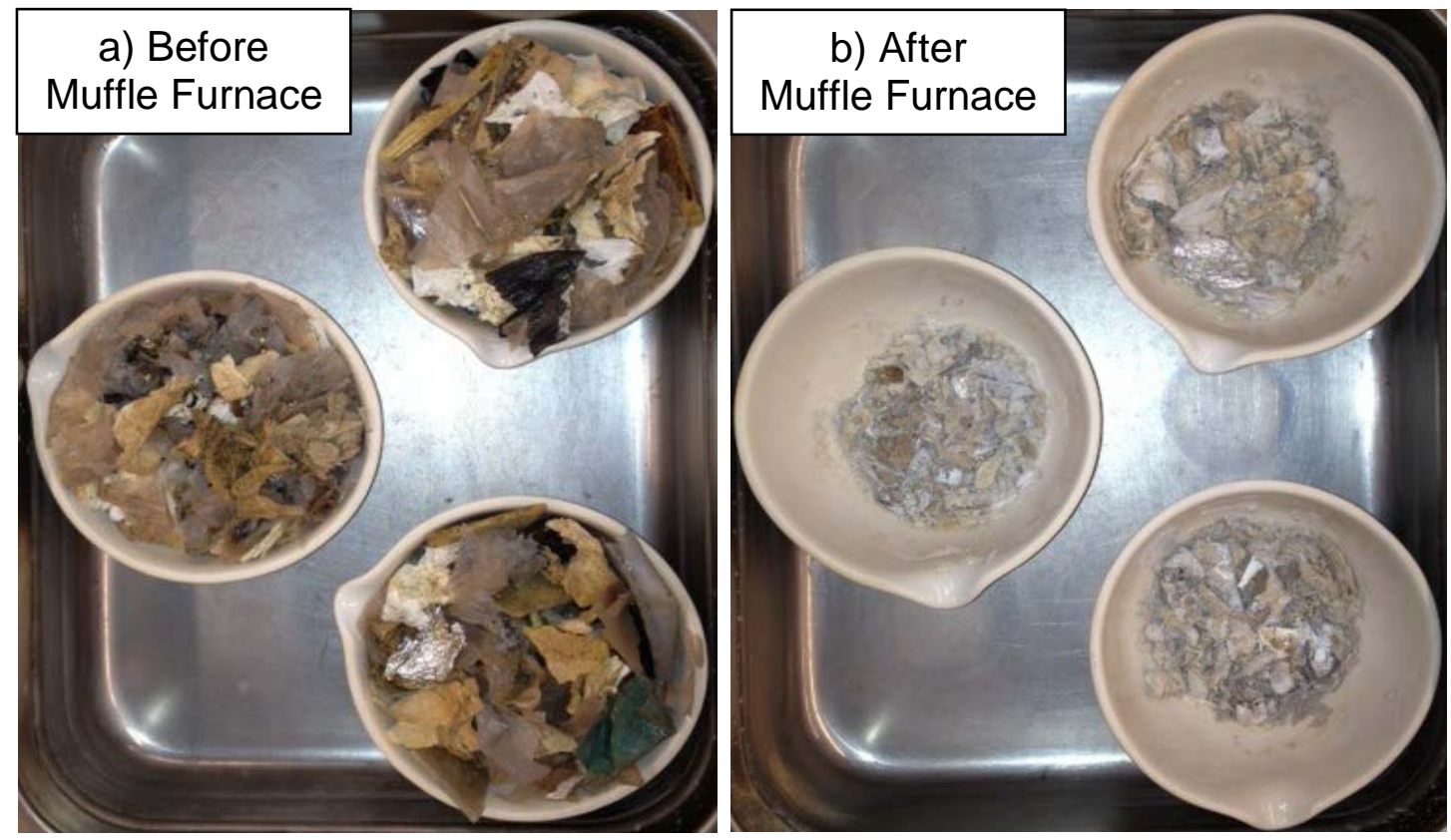

Figure 3.29. Subdivided Waste Specimen. 


\section{Chapter 4: Results and Analysis}

\subsection{Introduction}

Results from the laboratory and field test program are presented in this chapter. First, the results of the analysis of the physical and engineering properties of various types of MSW are summarized. The results of the particle size distribution, moisture content, organic content, specific gravity, temperature, and settlement analyses are presented first. Next, the results of the meso-scale compaction investigation are summarized. Finally, full-scale compaction investigation results and analysis are presented.

\subsection{Particle Size Distribution}

Particle size distribution of the old waste was determined using the borehole cuttings obtained from $\mathrm{BH} 2$ at depths of 6.4 and $13.7 \mathrm{~m}$ and from $\mathrm{BH} 5$ at a depth of $11.5 \mathrm{~m}$ (Figure 4.1). The particle size varied between 0.075 and $25.4 \mathrm{~mm}$ with a generally well-graded distribution. The average coefficient of uniformity $\left(C_{u}\right)$ was approximately 11 and the average coefficient of curvature $\left(C_{c}\right)$ was approximately 0.5 . The percent passing for the OMSW samples is summarized in Table 4.1. 
Table 4.1. Particle Size Distribution Data for OMSW.

\begin{tabular}{|c|c|c|c|c|}
\hline \multirow{2}{*}{$\begin{array}{c}\text { Sieve } \\
\text { Designation }\end{array}$} & Sieve & \multicolumn{3}{|c|}{ Percent Passing (\%) } \\
\cline { 3 - 5 } Size (mm) & BH2 (6.5 m) & BH2 (13.9 m) & BH5 (11.5 m) \\
\hline $25.0 \mathrm{~mm}(1 ")$ & 25.40 & - & - & 100 \\
\hline $19.5 \mathrm{~mm}(3 / 4 ")$ & 19.05 & 100 & 100 & 91.7 \\
\hline $12.5 \mathrm{~mm}(1 / 2 ")$ & 12.70 & 84.1 & 79.5 & 88.2 \\
\hline $9.5 \mathrm{~mm}\left(3 / 8^{\prime \prime}\right)$ & 9.525 & 78.5 & 76.0 & 79.6 \\
\hline No. 4 & 4.75 & 70.7 & 62.7 & 69.3 \\
\hline No. 10 & 2.00 & 60.9 & 53.8 & 55.1 \\
\hline No. 20 & 0.85 & 41.5 & 39.4 & 44.5 \\
\hline No. 40 & 0.425 & 19.0 & 24.1 & 24.8 \\
\hline No. 60 & 0.25 & 7.8 & 12.3 & 8.6 \\
\hline No. 100 & 0.15 & 3.1 & 5.0 & 4.0 \\
\hline No. 200 & 0.075 & 1.3 & 1.7 & 1.4 \\
\hline
\end{tabular}

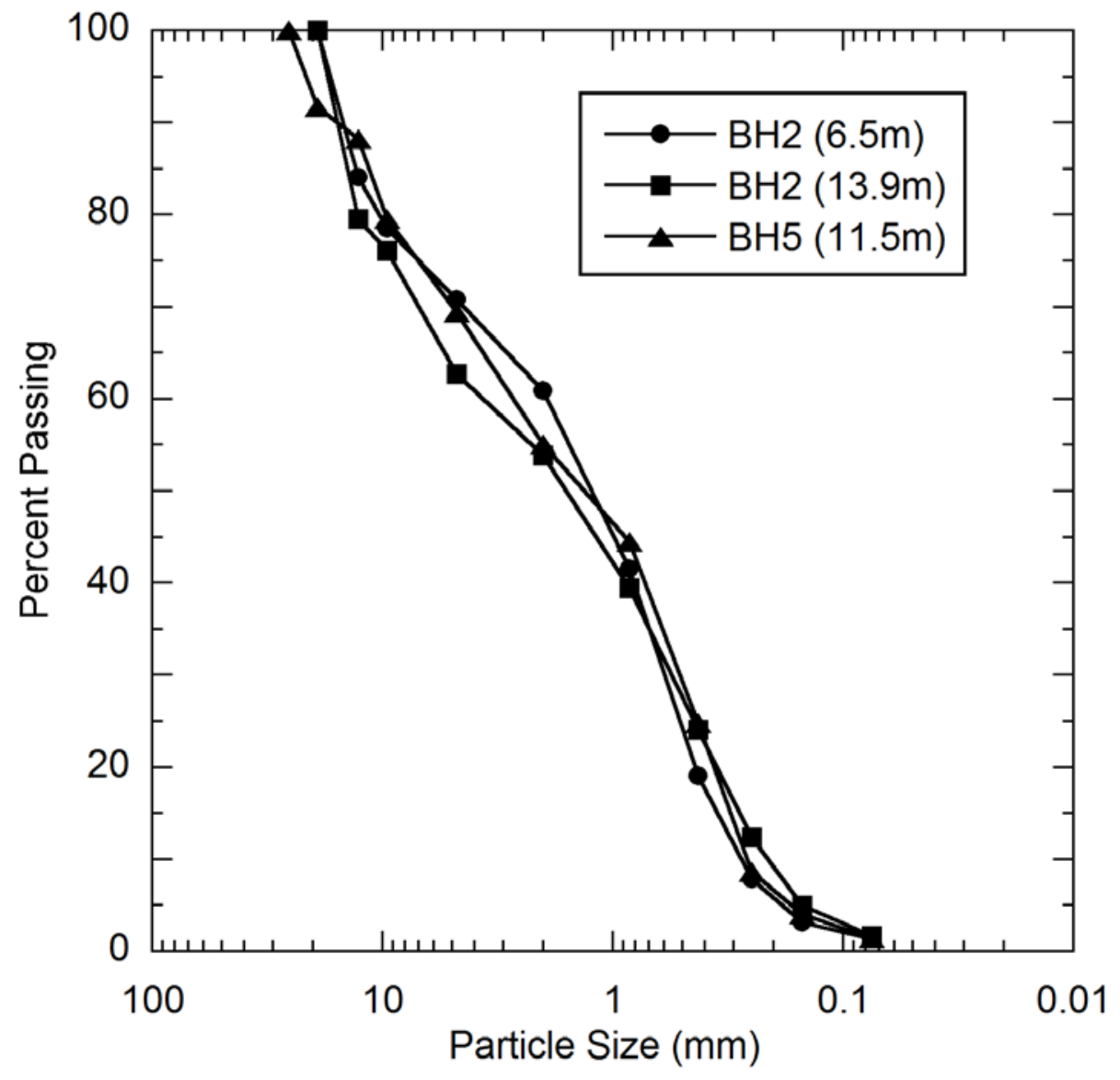

Figure 4.1. Particle Size Distribution of 3 OMSW Samples at Depth.

Significant differences in particle size distribution were not present between the tested samples from the 3 depths. The uniformity of particle size distribution 
between the 3 samples was most likely attributed to the disturbance (e.g., shredding and cutting) of the waste caused by the hollow stem auger during drilling. The particle size distribution curves for the tested OMSW samples were similar to particle size analysis data provided by Reddy et al. (2009a), Machado et al. (2010), and Gomes and Lopes (2012).

\subsection{Baseline Moisture Conditions}

The weighted-average baseline moisture content of tested specimens of incoming FMSW (comprised of residential, commercial, and self-delivered wastes) was $42.7 \%$. The residential, commercial, and self-delivered fresh waste represented approximately 38,39 , and $23 \%$ (by mass), of the entire incoming waste stream, respectively. The average moisture content of tested specimens of individual residential, commercial, and self-delivered FMSW were 57.7, 46.3, and 12.0\%, respectively. Residential MSW specimens were further analyzed and the moisture content of the residential specimens delivered during the wet and dry season were measured to determine if a seasonal discrepancy existed. The average moisture contents of tested specimens of residential MSW delivered during the wet and dry seasons were 56.2 and $58.5 \%$, respectively. It should be noted that a historically low amount of precipitation occurred over the duration of the test program. The baseline moisture content distributions of the tested residential (wet season), residential (dry season), commercial, and self-delivered waste specimens are presented in a series of histograms (Figure 4.2) and then presented as an entire set on a single histogram (Figure 4.3). 

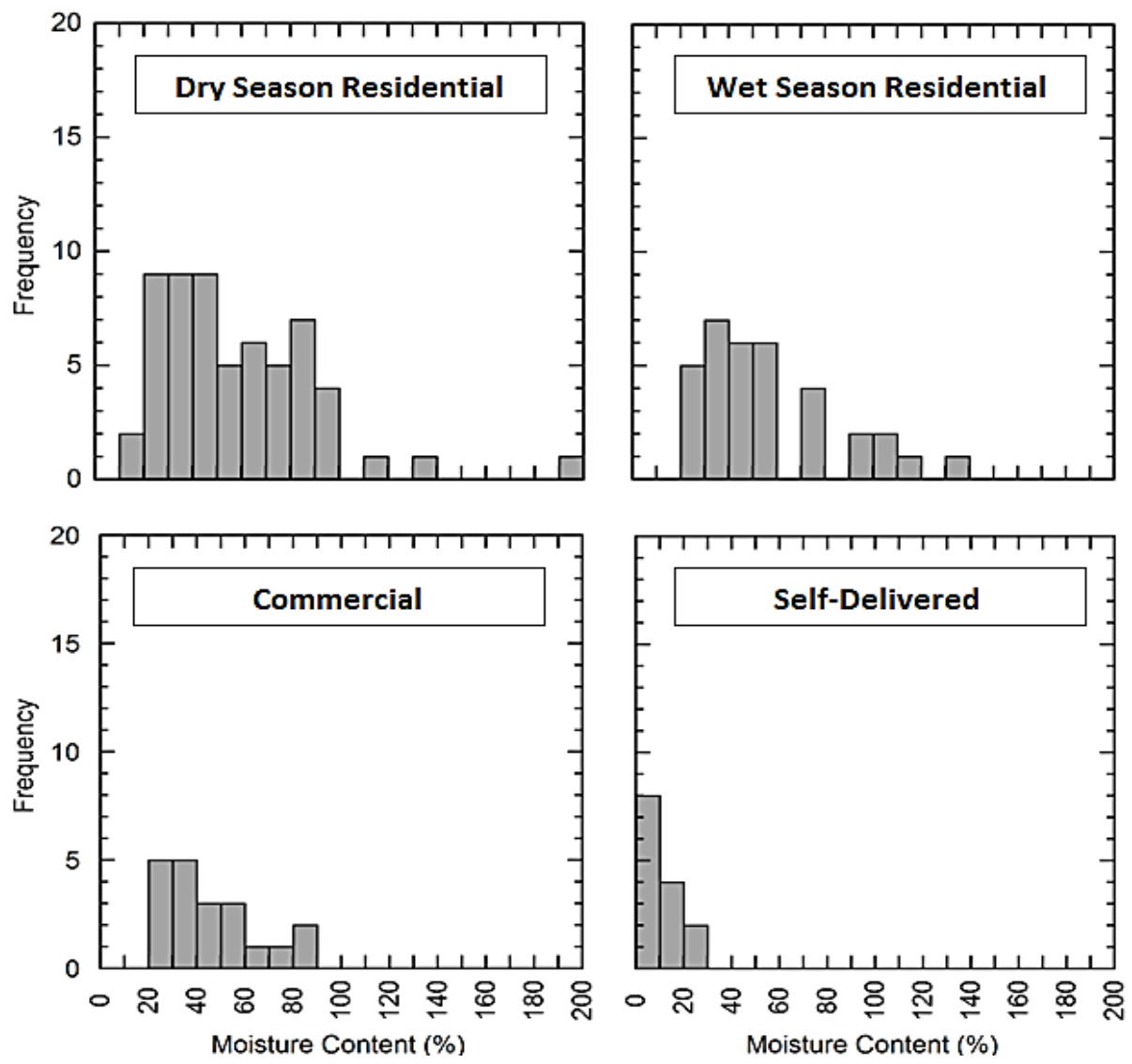

Figure 4.2. Measured Moisture Content Histograms of FMSW. 


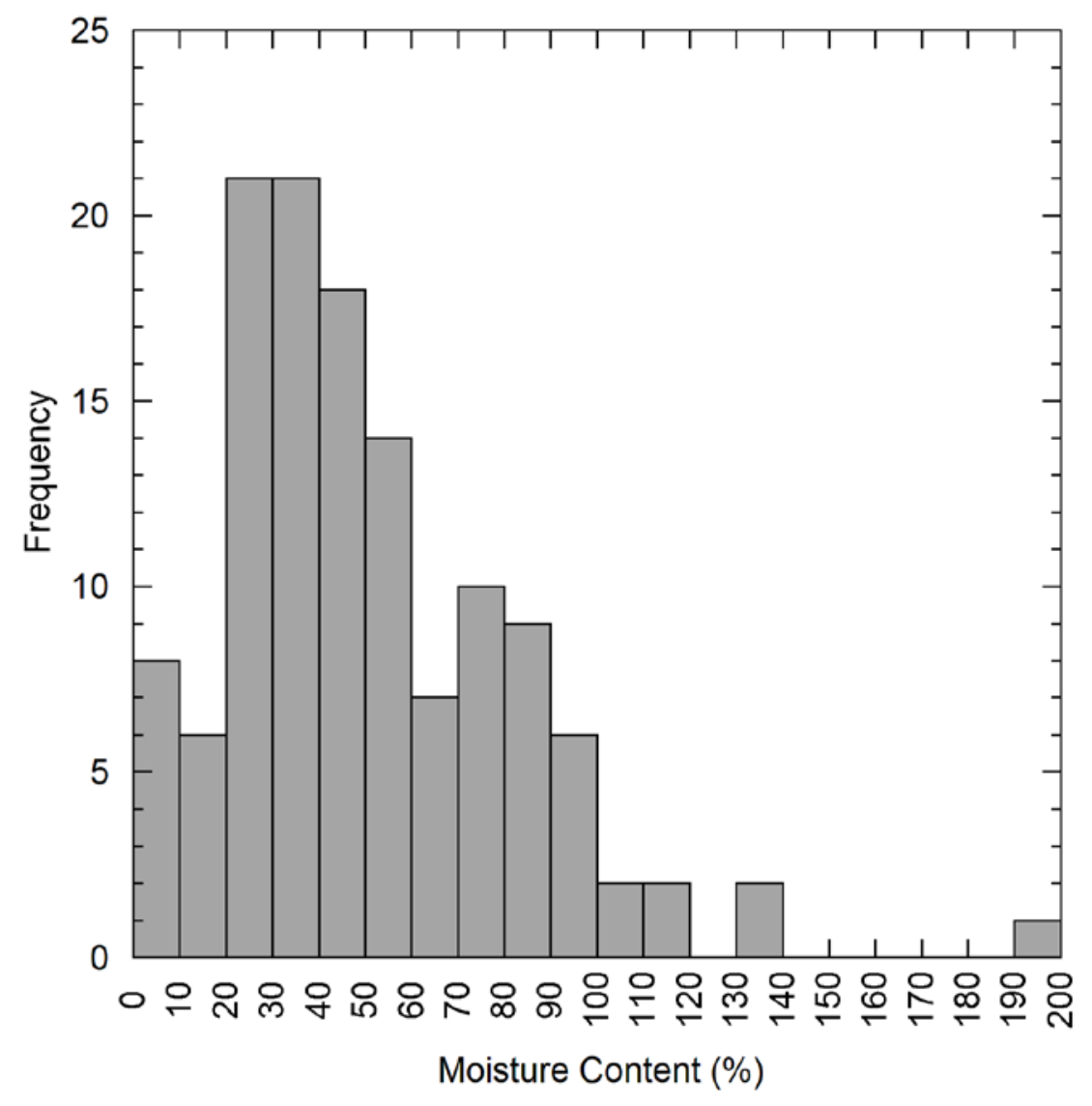

Figure 4.3. Measured Moisture Contents of FMSW.

In addition, the tested FMSW specimens were analyzed on a monthly basis to differentiate between seasonal placement conditions (i.e., wet and dry seasons). In general, the average monthly moisture content remained consistent for both the wet (October to April) and the dry (May to September) seasons. A peak monthly moisture content of $46.3 \%$ was determined for June and attributed to the increased disposal of fruits (e.g., strawberries, melons, etc.) harvested during late spring/early summer. The average monthly moisture contents of FMSW are presented in Figure 4.4. 


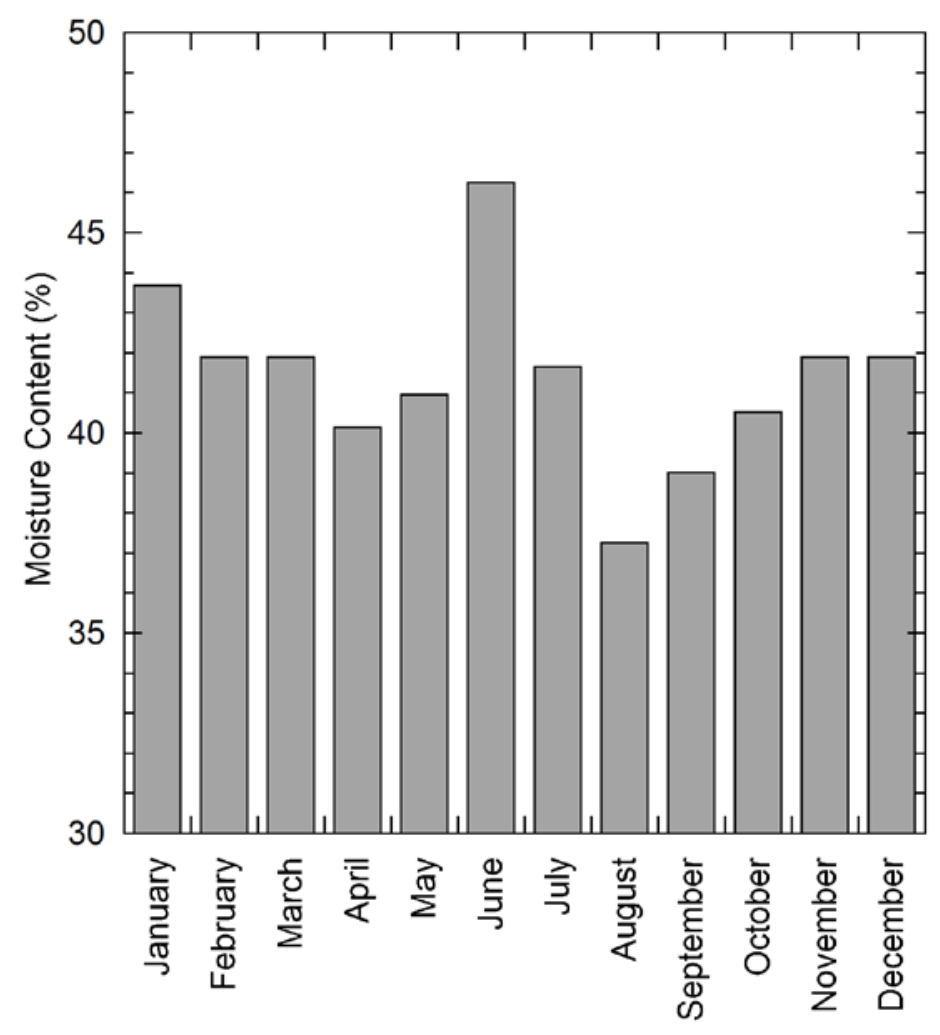

Figure 4.4. Monthly Moisture Content of FMSW.

For OMSW (Category III) specimens, the moisture content varied as a function of depth. The measured moisture content data of the OMSW specimens obtained at different depths from each of the 8 boreholes are summarized in Table 4.2. The mass of measured specimens ranged between 200 and $2700 \mathrm{~g}$ with an average mass of approximately $900 \mathrm{~g}$.

Table 4.2. Moisture Content of OMSW Specimens.

\begin{tabular}{|c|c|c|c|c|}
\hline Borehole & $\begin{array}{c}\text { Depth } \\
\text { (m) }\end{array}$ & $\begin{array}{c}\text { Normalized } \\
\text { Depth }\end{array}$ & $\begin{array}{c}\text { Specimen } \\
\text { Mass (g) }\end{array}$ & $\begin{array}{c}\text { Moisture } \\
\text { Content } \\
(\mathbf{\%})\end{array}$ \\
\hline \multirow{4}{*}{ BH1 } & 0.6 & 0.03 & 876 & 12.5 \\
\cline { 2 - 5 } & 1.2 & 0.07 & 771 & 26.1 \\
\cline { 2 - 5 } & 1.8 & 0.10 & 517 & 17.5 \\
\cline { 2 - 5 } & 3.4 & 0.19 & 619 & 32.0 \\
\cline { 2 - 5 } & 4.0 & 0.23 & 326 & 34.6 \\
\cline { 2 - 5 } & 5.2 & 0.29 & 444 & 22.9 \\
\cline { 2 - 5 } & 6.1 & 0.35 & 500 & 29.6 \\
\hline
\end{tabular}


Table 4.2. Moisture Content of OMSW Specimens Obtained from SMRL (Cont'd).

\begin{tabular}{|c|c|c|c|c|}
\hline Borehole & $\begin{array}{l}\text { Depth } \\
\text { (m) }\end{array}$ & $\begin{array}{l}\text { Normalized } \\
\text { Depth }\end{array}$ & $\begin{array}{l}\text { Specimen } \\
\text { Mass (g) }\end{array}$ & $\begin{array}{c}\text { Moisture } \\
\text { Content } \\
\text { (\%) }\end{array}$ \\
\hline \multirow{9}{*}{$\mathrm{BH} 1$} & 6.7 & 0.38 & 398 & 33.8 \\
\hline & 7.6 & 0.43 & 503 & 17.9 \\
\hline & 8.2 & 0.47 & 323 & 28.8 \\
\hline & 9.4 & 0.54 & 286 & 19.3 \\
\hline & 10.7 & 0.61 & 799 & 25.6 \\
\hline & 12.2 & 0.69 & 756 & 28.1 \\
\hline & 12.8 & 0.73 & 255 & 32.4 \\
\hline & 13.4 & 0.76 & 225 & 27.5 \\
\hline & 14.0 & 0.80 & 362 & 38.4 \\
\hline \multirow{24}{*}{$\mathrm{BH} 2$} & 0.6 & 0.03 & 202 & 11.6 \\
\hline & 1.2 & 0.06 & 1106 & 17.1 \\
\hline & 1.8 & 0.09 & 1055 & 23.1 \\
\hline & 2.1 & 0.11 & 697 & 29.6 \\
\hline & 2.4 & 0.13 & 560 & 29.1 \\
\hline & 3.0 & 0.16 & 776 & 33.0 \\
\hline & 3.7 & 0.19 & 485 & 19.9 \\
\hline & 4.3 & 0.22 & 898 & 35.0 \\
\hline & 4.9 & 0.25 & 514 & 21.7 \\
\hline & 5.2 & 0.27 & 830 & 24.0 \\
\hline & 5.8 & 0.30 & 571 & 7.2 \\
\hline & 6.4 & 0.33 & 573 & 18.3 \\
\hline & 7.3 & 0.38 & 605 & 10.8 \\
\hline & 7.6 & 0.39 & 434 & 14.4 \\
\hline & 8.2 & 0.42 & 1146 & 12.0 \\
\hline & 9.8 & 0.50 & 447 & 14.6 \\
\hline & 10.1 & 0.52 & 1078 & 11.7 \\
\hline & 10.4 & 0.53 & 1420 & 16.8 \\
\hline & 11.0 & 0.56 & 830 & 28.2 \\
\hline & 11.6 & 0.60 & 1105 & 22.4 \\
\hline & 11.9 & 0.61 & 1177 & 17.1 \\
\hline & 12.2 & 0.63 & 1027 & 16.0 \\
\hline & 13.7 & 0.71 & 710 & 26.2 \\
\hline & 14.0 & 0.72 & 513 & 30.4 \\
\hline \multirow{11}{*}{$\mathrm{BH} 3$} & 0.6 & 0.03 & 697 & 13.7 \\
\hline & 1.2 & 0.07 & 507 & 38.2 \\
\hline & 2.1 & 0.12 & 207 & 18.2 \\
\hline & 3.4 & 0.19 & 425 & 41.3 \\
\hline & 4.3 & 0.24 & 1222 & 31.8 \\
\hline & 4.9 & 0.27 & 387 & 42.0 \\
\hline & 5.8 & 0.32 & 663 & 28.0 \\
\hline & 6.7 & 0.37 & 342 & 9.2 \\
\hline & 7.0 & 0.39 & 265 & 8.2 \\
\hline & 7.3 & 0.41 & 306 & 11.1 \\
\hline & 7.9 & 0.44 & 274 & 8.7 \\
\hline
\end{tabular}


Table 4.2. Moisture Content of OMSW Specimens Obtained from SMRL (Cont'd).

\begin{tabular}{|c|c|c|c|c|}
\hline Borehole & $\begin{array}{l}\text { Depth } \\
(\mathrm{m})\end{array}$ & $\begin{array}{l}\text { Normalized } \\
\text { Depth }\end{array}$ & $\begin{array}{l}\text { Specimen } \\
\text { Mass (g) }\end{array}$ & $\begin{array}{c}\text { Moisture } \\
\text { Content } \\
(\%)\end{array}$ \\
\hline \multirow{3}{*}{$\mathrm{BH} 3$} & 8.5 & 0.48 & 1226 & 22.9 \\
\hline & 9.1 & 0.51 & 1885 & 26.2 \\
\hline & 9.4 & 0.53 & 1073 & 25.1 \\
\hline \multirow{13}{*}{$\mathrm{BH} 4$} & 1.2 & 0.09 & 1443 & 26.0 \\
\hline & 1.8 & 0.13 & 1148 & 41.0 \\
\hline & 2.1 & 0.15 & 948 & 48.6 \\
\hline & 2.7 & 0.20 & 743 & 36.9 \\
\hline & 3.7 & 0.26 & 432 & 31.5 \\
\hline & 4.9 & 0.35 & 444 & 37.2 \\
\hline & 5.5 & 0.39 & 492 & 51.0 \\
\hline & 6.4 & 0.46 & 319 & 46.4 \\
\hline & 7.0 & 0.50 & 709 & 39.0 \\
\hline & 7.6 & 0.54 & 671 & 28.8 \\
\hline & 8.2 & 0.59 & 625 & 22.0 \\
\hline & 8.5 & 0.61 & 738 & 12.6 \\
\hline & 9.1 & 0.65 & 460 & 15.4 \\
\hline \multirow{19}{*}{$\mathrm{BH} 5$} & 1.4 & 0.07 & 2402 & 6.3 \\
\hline & 2.0 & 0.10 & 2724 & 7.9 \\
\hline & 2.9 & 0.15 & 1928 & 5.4 \\
\hline & 3.5 & 0.18 & 1515 & 26.3 \\
\hline & 4.2 & 0.21 & 773 & 11.5 \\
\hline & 5.1 & 0.26 & 786 & 10.4 \\
\hline & 5.7 & 0.29 & 1638 & 12.6 \\
\hline & 6.6 & 0.33 & 770 & 21.0 \\
\hline & 7.5 & 0.38 & 1162 & 18.3 \\
\hline & 8.1 & 0.41 & 647 & 15.2 \\
\hline & 8.7 & 0.44 & 653 & 18.8 \\
\hline & 9.6 & 0.49 & 1269 & 22.5 \\
\hline & 10.6 & 0.53 & 871 & 34.6 \\
\hline & 10.9 & 0.55 & 1559 & 45.4 \\
\hline & 12.1 & 0.61 & 1236 & 44.5 \\
\hline & 12.7 & 0.64 & 844 & 22.5 \\
\hline & 13.6 & 0.69 & 691 & 48.6 \\
\hline & 14.2 & 0.72 & 639 & 51.0 \\
\hline & 14.8 & 0.75 & 699 & 51.2 \\
\hline \multirow{9}{*}{ BH6 } & 0.5 & 0.03 & 762 & 8.1 \\
\hline & 2.0 & 0.11 & 1592 & 7.4 \\
\hline & 2.9 & 0.15 & 918 & 10.2 \\
\hline & 4.2 & 0.22 & 1213 & 9.2 \\
\hline & 5.1 & 0.27 & 940 & 11.4 \\
\hline & 6.0 & 0.31 & 679 & 15.0 \\
\hline & 6.6 & 0.35 & 1140 & 14.8 \\
\hline & 7.5 & 0.39 & 798 & 14.5 \\
\hline & 8.1 & 0.43 & 915 & 18.1 \\
\hline
\end{tabular}


Table 4.2. Moisture Content of OMSW Specimens Obtained from SMRL (Cont'd).

\begin{tabular}{|c|c|c|c|c|}
\hline Borehole & $\begin{array}{c}\text { Depth } \\
(\mathrm{m})\end{array}$ & $\begin{array}{c}\text { Normalized } \\
\text { Depth }\end{array}$ & $\begin{array}{c}\text { Specimen } \\
\text { Mass }(\mathrm{g})\end{array}$ & $\begin{array}{c}\text { Moisture } \\
\text { Content } \\
(\%)\end{array}$ \\
\hline \multirow{5}{*}{ BH6 } & 9.3 & 0.49 & 426 & 30.0 \\
\cline { 2 - 5 } & 10.3 & 0.54 & 933 & 33.8 \\
\cline { 2 - 5 } & 11.2 & 0.59 & 749 & 28.5 \\
\cline { 2 - 5 } & 12.1 & 0.63 & 479 & 45.4 \\
\cline { 2 - 5 } & 12.7 & 0.67 & 961 & 42.0 \\
\cline { 2 - 5 } & 13.6 & 0.71 & 644 & 55.9 \\
\cline { 2 - 5 } & 14.2 & 0.75 & 450 & 47.1 \\
\cline { 2 - 5 } & 14.8 & 0.78 & 1225 & 38.9 \\
\hline \multirow{5}{*}{ BH7 } & 0.3 & 0.04 & 618 & 3.5 \\
\cline { 2 - 5 } & 1.2 & 0.18 & 339 & 5.6 \\
\cline { 2 - 5 } & 1.5 & 0.22 & 2018 & 13.9 \\
\cline { 2 - 5 } & 1.8 & 0.27 & 1467 & 12.5 \\
\cline { 2 - 5 } & 2.1 & 0.31 & 657 & 20.6 \\
\cline { 2 - 5 } & 2.4 & 0.36 & 1513 & 25.9 \\
\cline { 2 - 5 } & 3.0 & 0.44 & 1077 & 37.4 \\
\cline { 2 - 5 } & 3.7 & 0.53 & 1156 & 40.0 \\
\cline { 2 - 5 } & 4.0 & 0.58 & 580 & 21.7 \\
\hline \multirow{4}{*}{ BH8 } & 4.3 & 0.62 & 731 & 31.2 \\
\cline { 2 - 5 } & 0.6 & 0.10 & 1036 & 4.8 \\
\cline { 2 - 5 } & 1.2 & 0.19 & 631 & 10.0 \\
\cline { 2 - 5 } & 1.5 & 0.24 & 1182 & 9.7 \\
\hline & 1.8 & 0.29 & 2182 & 19.3 \\
\cline { 2 - 5 } & 2.1 & 0.34 & 1658 & 16.6 \\
\cline { 2 - 5 } & 3.0 & 0.48 & 1577 & 12.7 \\
\hline & 3.7 & 0.58 & 1473 & 12.2 \\
\hline
\end{tabular}

In general, the moisture content slightly increased with increasing depth for each of the boreholes (approximately 1.75 percentage points $/ \mathrm{m}$ ). The increasing moisture content with increasing depth was attributed to downward movement of moisture due to gravity and due to lower hydraulic conductivity of the waste $\left(k_{M S W}\right)$ at greater depths caused by consolidation. The measured moisture contents as a function of depth and normalized depth are presented in Figure 4.5. For normalized depths, the value of 0 represents the waste surface and the value of 1 represents the depth of the liner. 
In addition, the average moisture contents of the OMSW obtained at shallow, middle, and great depths are presented in Table 4.3. Shallow, middle, and great depths represent the top, middle, and bottom $33 \%$ of the entire waste mass for a given borehole, respectively

Table 4.3. Average Moisture Content of OMSW at Different Depths

\begin{tabular}{|c|c|c|}
\hline Depth & Description & $\begin{array}{c}\text { Average Moisture } \\
\text { Content } \\
\text { (\%) }\end{array}$ \\
\hline Shallow & $\begin{array}{c}\text { Waste obtained from top 33\% of entire } \\
\text { waste mass for a given borehole }\end{array}$ & 19.4 \\
\hline Middle & $\begin{array}{c}\text { Waste obtained from middle 33\% of } \\
\text { entire waste mass for a given borehole }\end{array}$ & 25.6 \\
\hline Great & $\begin{array}{c}\text { Waste obtained from bottom 33\% of } \\
\text { entire waste mass for a given borehole }\end{array}$ & 30.8 \\
\hline
\end{tabular}



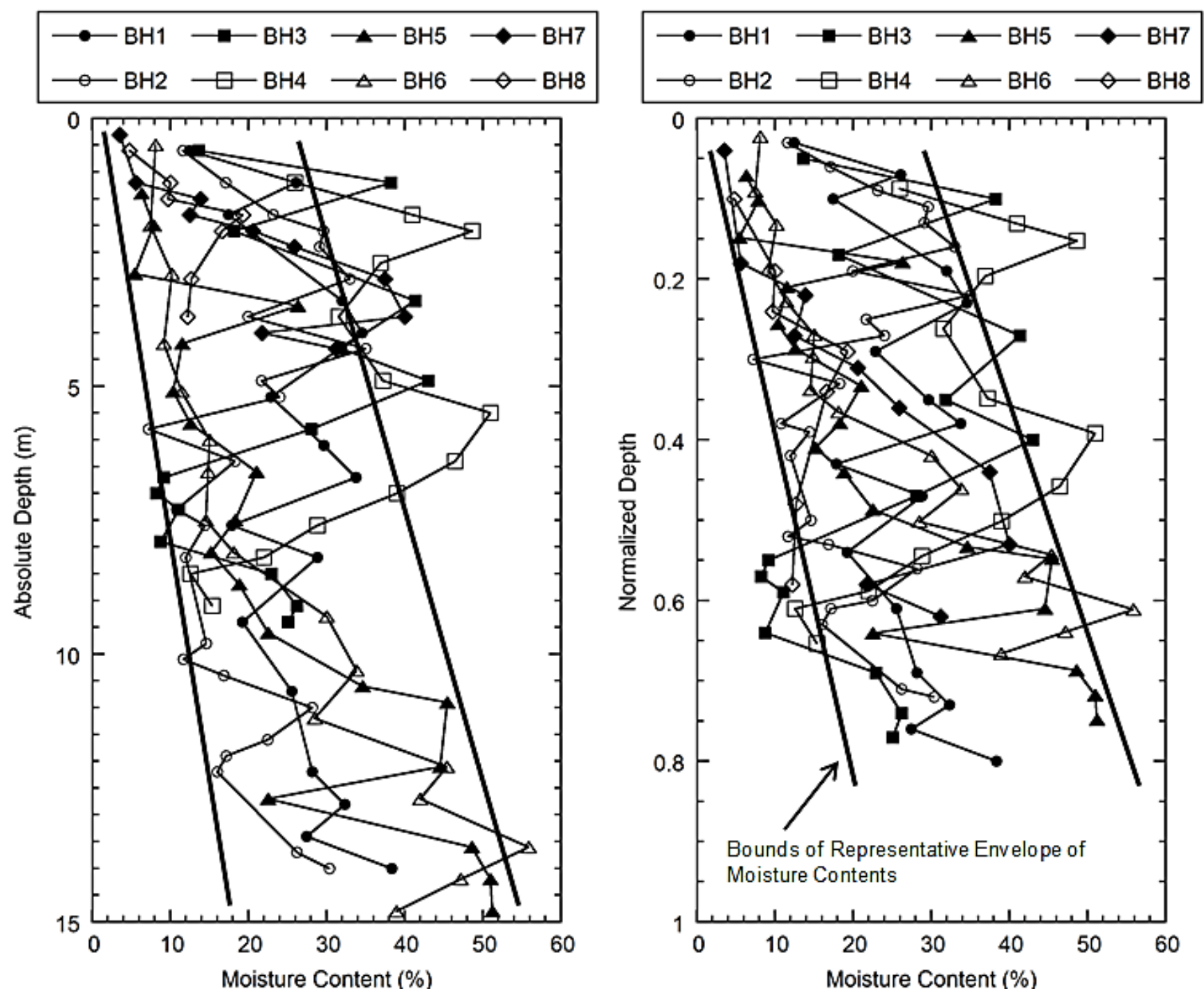

Figure 4.5. Moisture Content of OMSW as a Function of Absolute and Normalized Depths. 


\subsection{Organic Content}

In general, the measured organic content of fresh (Category II) MSW specimens was higher than the measured organic content of old (Category III) MSW specimens. The average organic content of FMSW was determined to be $77.2 \%$ as compared to an average organic content of $23.5 \%$ for OMSW specimens. A histogram of the measured organic content for fresh and old MSW specimens is presented in Figure 4.6.

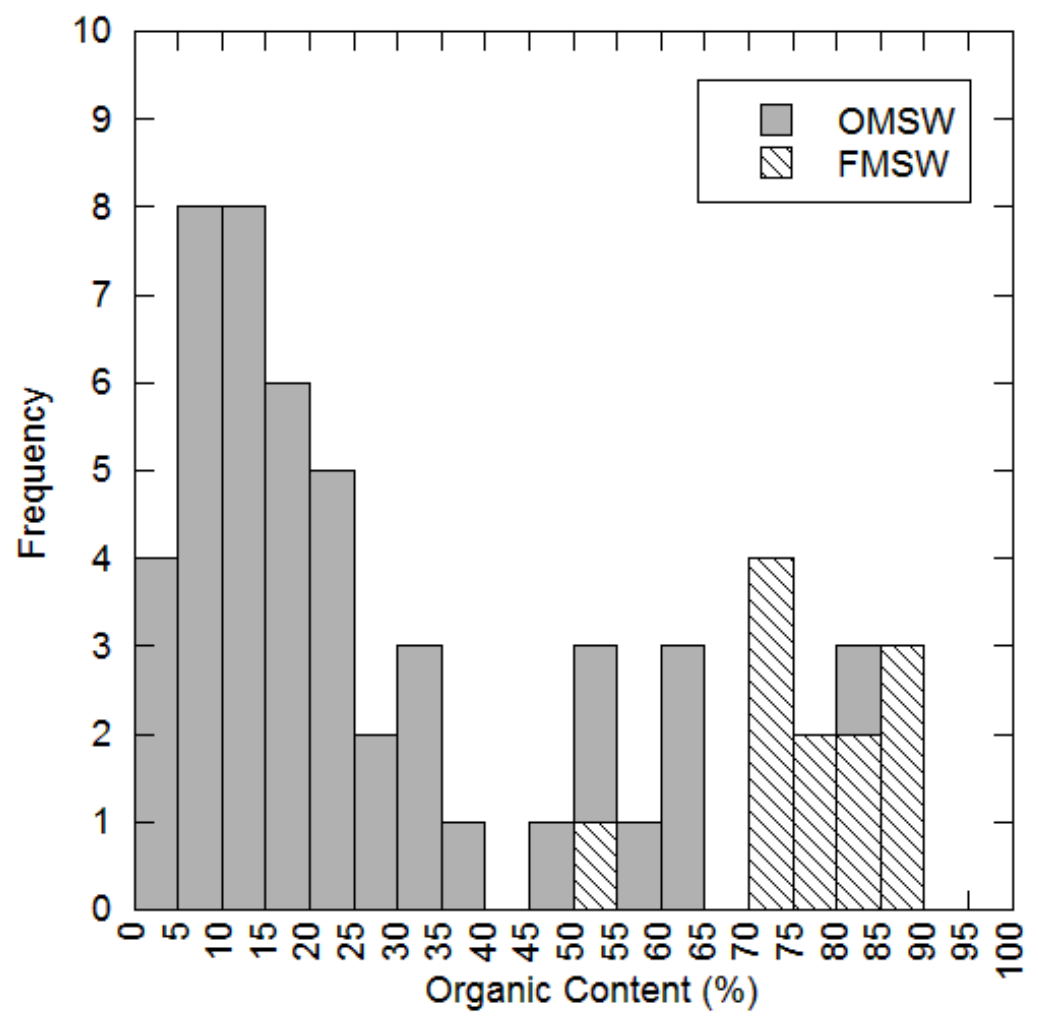

Figure 4.6. Measured Organic Content of FMSW and OMSW Specimens.

The measured organic content of FMSW specimens ranged between 68.1 and $86.2 \%$. The resulting values are similar to reported organic content values of FMSW obtained from landfills in other investigations (Kelly et al. 2006; Machado et al. 2010). The mass of the tested sub-specimens (i.e., amount placed in the 
crucible) ranged between 17 and $53 \mathrm{~g}$ and had a maximum particle size of approximately $20 \mathrm{~mm}$. A summary of the measured organic content of FMSW specimens is presented in Table 4.4

Table 4.4. Organic Content of FMSW Specimens

\begin{tabular}{|c|c|c|c|}
\hline Specimen & $\begin{array}{l}\text { Sub-Specimen } \\
\text { Mass (g) }\end{array}$ & $\begin{array}{c}\text { Organic Content } \\
\text { (\%) }\end{array}$ & $\begin{array}{l}\text { Average Organic } \\
\text { Content (\%) }\end{array}$ \\
\hline \multirow{3}{*}{1} & 35.47 & 84.6 & \multirow{3}{*}{78.8} \\
\hline & 26.49 & 77.7 & \\
\hline & 41.83 & 74.0 & \\
\hline \multirow{3}{*}{2} & 41.72 & 74.4 & \multirow{3}{*}{68.1} \\
\hline & 32.38 & 78.8 & \\
\hline & 53.51 & 51.0 & \\
\hline \multirow{3}{*}{3} & 22.56 & 70.6 & \multirow{3}{*}{75.9} \\
\hline & 22.66 & 72.1 & \\
\hline & 17.07 & 85.2 & \\
\hline \multirow{3}{*}{4} & 29.05 & 86.4 & \multirow{3}{*}{86.2} \\
\hline & 18.61 & 87.8 & \\
\hline & 20.31 & 84.5 & \\
\hline
\end{tabular}

The measured organic content of OMSW ranged between 3.0 and $66.1 \%$ which was a significantly wider range of values as compared to the organic content of FMSM specimens. The mass of the tested OMSW sub-specimens ranged between 15 and $225 \mathrm{~g}$ and the maximum particle size specimens was of the OMSW approximately $20 \mathrm{~mm}$. A summary of the measured organic content, depth, and mass of each specimen is provided in Table 4.5 
Table 4.5. Organic Content of OMSW Specimens.

\begin{tabular}{|c|c|c|c|c|}
\hline Borehole & Depth (m) & $\begin{array}{c}\text { Sub-Specimen } \\
\text { Mass (g) }\end{array}$ & $\begin{array}{c}\text { Organic } \\
\text { Content (\%) }\end{array}$ & $\begin{array}{l}\text { Average Organic } \\
\text { Content (\%) }\end{array}$ \\
\hline \multirow{9}{*}{$\mathrm{BH} 1$} & \multirow{3}{*}{1.9} & 36.75 & 29.0 & \multirow{3}{*}{19.4} \\
\hline & & 55.59 & 18.3 & \\
\hline & & 98.70 & 11.0 & \\
\hline & \multirow{3}{*}{6.2} & 15.48 & 36.4 & \multirow{3}{*}{48.5} \\
\hline & & 21.00 & 48.0 & \\
\hline & & 20.89 & 61.0 & \\
\hline & \multirow{3}{*}{14.2} & 32.52 & 60.2 & \multirow{3}{*}{56.2} \\
\hline & & 36.21 & 57.1 & \\
\hline & & 22.40 & 51.4 & \\
\hline \multirow{9}{*}{$\mathrm{BH} 2$} & \multirow{3}{*}{1.5} & 102.68 & 15.4 & \multirow{3}{*}{15.2} \\
\hline & & 118.25 & 13.9 & \\
\hline & & 83.13 & 16.2 & \\
\hline & \multirow{3}{*}{6.5} & 87.02 & 12.0 & \multirow{3}{*}{10.8} \\
\hline & & 134.47 & 9.9 & \\
\hline & & 100.81 & 10.5 & \\
\hline & \multirow{3}{*}{13.9} & 57.92 & 34.9 & \multirow{3}{*}{29.7} \\
\hline & & 53.07 & 23.3 & \\
\hline & & 49.58 & 30.8 & \\
\hline \multirow{15}{*}{ BH5 } & \multirow{3}{*}{2.5} & 127.63 & 9.2 & \multirow{3}{*}{8.8} \\
\hline & & 147.89 & 6.7 & \\
\hline & & 111.34 & 10.5 & \\
\hline & \multirow{3}{*}{5.3} & 82.78 & 11.7 & \multirow{3}{*}{11.6} \\
\hline & & 107.08 & 9.9 & \\
\hline & & 105.35 & 13.3 & \\
\hline & \multirow{3}{*}{7.7} & 58.53 & 32.0 & \multirow{3}{*}{24.5} \\
\hline & & 66.90 & 19.8 & \\
\hline & & 68.99 & 21.6 & \\
\hline & \multirow{3}{*}{9.3} & 61.41 & 63.5 & \multirow{3}{*}{66.1} \\
\hline & & 62.26 & 53.4 & \\
\hline & & 102.33 & 81.4 & \\
\hline & \multirow{3}{*}{12.1} & 80.93 & 10.4 & \\
\hline & & 134.15 & 15.5 & 15.9 \\
\hline & & 80.57 & 21.9 & \\
\hline & & 199.67 & 2.4 & \\
\hline & 0.1 & 209.48 & 2.5 & 3.0 \\
\hline & & 224.32 & 4.2 & \\
\hline & & 136.66 & 7.9 & 67 \\
\hline & 4.3 & 153.13 & 4.7 & 0.1 \\
\hline & & 122.76 & 7.5 & \\
\hline BHb & & 62.58 & 21.8 & 132 \\
\hline & 7.2 & 98.57 & 9.3 & 13.3 \\
\hline & & 86.11 & 9.0 & \\
\hline & & 66.20 & 26.1 & \\
\hline & 12.1 & 64.81 & 24.6 & 22.6 \\
\hline & & 82.62 & 17.1 & \\
\hline
\end{tabular}


In general, a strong trend does not exist between organic content and depth and can be attributed to the variability of MSW during sampling. The measured organic content of OMSW as a function of depth and normalized depths is presented in Figure 4.7. 

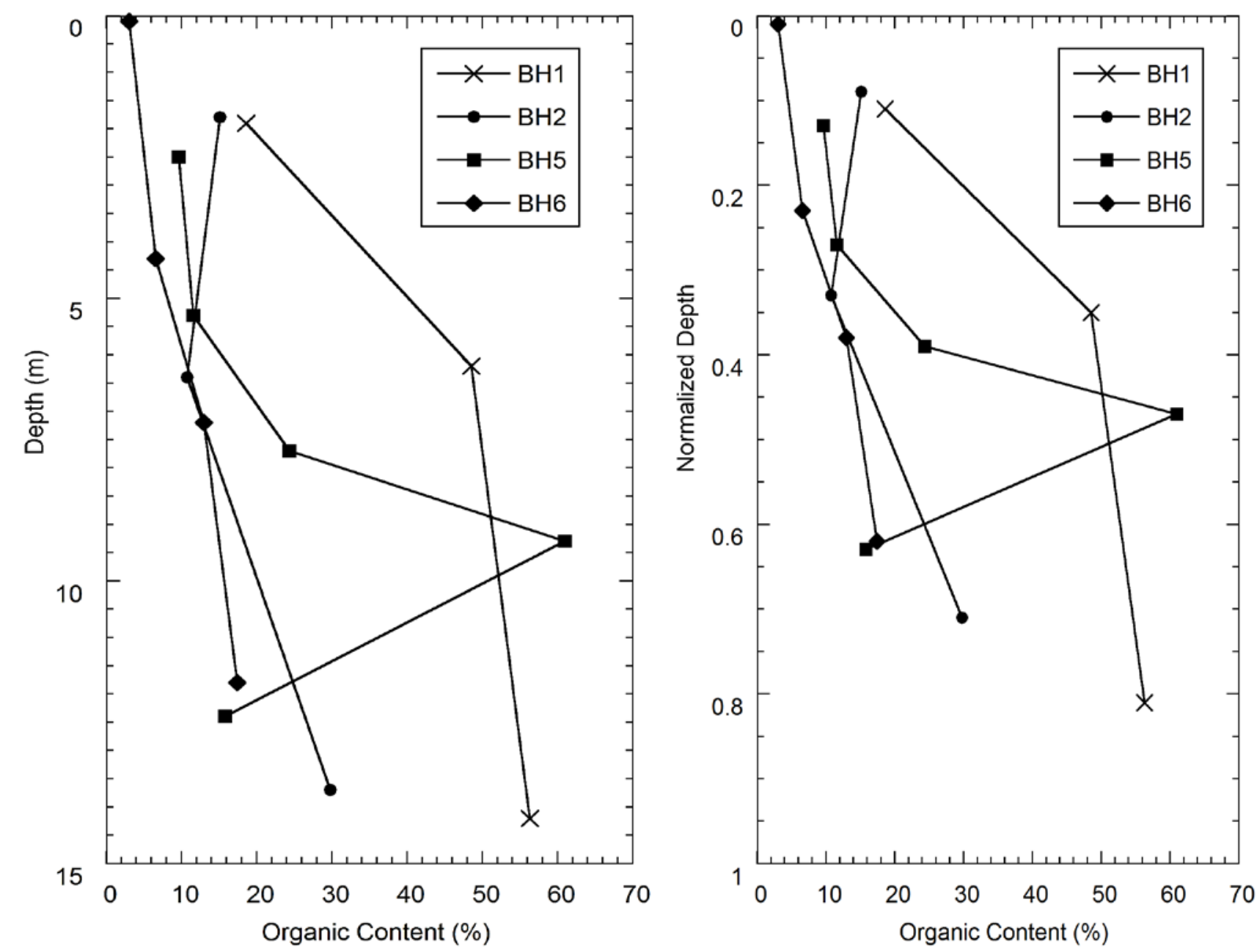

Figure 4.7. Organic Content as a Function of Absolute and Normalized Depths. 


\subsection{Specific Gravity}

The specific gravity of manufactured (Category I), fresh (Category II), and old (Category III) municipal solid waste was determined in the laboratory. For Category II fresh wastes, the measured specific gravity ranged from 0.741 to 1.388. The average specific gravity values of fresh MSW compacted in the field at dry of optimum (average $w_{d}=37 \%$ ) and compacted in the field near optimum (average $w_{d}=75 \%$ ) were 1.259 and 1.172 , respectively. The effects of moisture addition to the waste (i.e., dry of optimum vs. near optimum conditions) on specific gravity could not be assessed based on the results of the $G_{s}$ testing. Therefore, the specific gravity values of FMSW compacted at dry of optimum and near optimum moisture conditions were averaged and described as compacted FMSW herein.

The average specific gravity values of uncompacted (i.e., as-received) and compacted FMSW were 1.072 and 1.208, respectively, which correlates to $12.7 \%$ increase in $G_{s}$ after compaction of the waste. The crushing, bending, and shredding of waste particles during compaction resulted in a general decrease in particle sizes. The maximum particle size of the tested FMSW specimens was approximately 50 to $75 \mathrm{~mm}$ and the mass of the specimens used in the $G_{s}$ tests varied between nominally 135 and $335 \mathrm{~g}$. The measured $G_{s}$ values of FMSW specimens are provided in Table 4.6. Specific gravity values less than 1 are indicative of fresh waste specimens containing a significant amount of lightweight materials (e.g., plastics) resulting in a reduced solid density of the entire waste specimen. The increase in $G_{s}$ of FMSW after compaction was likely attributed to 
the reduction and/or exposure of previously occluded intraparticle voids that were originally closed to the outside.

Table 4.6. Specific Gravity of Uncompacted and Compacted FMSW

\begin{tabular}{|c|c|c|c|c|}
\hline Specimen & $\begin{array}{l}\text { Mass } \\
\text { (g) }\end{array}$ & $\begin{array}{c}G_{s} \\
\left(20^{\circ} \mathrm{C}\right)\end{array}$ & $\begin{array}{c}\text { Average } \\
\mathbf{G}_{s}\end{array}$ & Description of MSW \\
\hline 1 & 335.08 & 0.803 & \multirow{5}{*}{1.072} & \multirow{5}{*}{$\begin{array}{l}\text { Uncompacted; As-Received } \\
\text { Moisture Content } \\
\text { (Target 45\%; Measured 33\%) }\end{array}$} \\
\hline 2 & 324.92 & 1.248 & & \\
\hline 3 & 186.69 & 1.388 & & \\
\hline 4 & 184.04 & 1.178 & & \\
\hline 5 & 261.03 & 0.741 & & \\
\hline 6 & 186.09 & 1.254 & \multirow{5}{*}{1.258} & \multirow{5}{*}{$\begin{array}{c}\text { Compacted in Field; As-Received } \\
\text { Moisture Content } \\
\text { (Target 45\%; Measured 37\%) }\end{array}$} \\
\hline 7 & 135.76 & 1.178 & & \\
\hline 8 & 205.18 & 1.343 & & \\
\hline 9 & 173.13 & 1.147 & & \\
\hline 10 & 253.20 & 1.370 & & \\
\hline 11 & 245.28 & 0.819 & \multirow{5}{*}{1.156} & \multirow{5}{*}{$\begin{array}{c}\text { Compacted in Field; Optimum } \\
\text { Moisture Content } \\
\text { (Target 75\%; Measured 73\%) }\end{array}$} \\
\hline 12 & 256.24 & 1.359 & & \\
\hline 13 & 191.32 & 1.206 & & \\
\hline 14 & 174.69 & 1.244 & & \\
\hline 15 & 197.98 & 1.154 & & \\
\hline
\end{tabular}

The measured specific gravity for manufactured waste specimens ranged from 1.326 to 1.570 . The average specific gravity values were $1.377,1.523$, and 1.538 for as-prepared (i.e., uncompacted), compacted at the dry of optimum moisture content, and compacted at the wet of optimum moisture content specimens, respectively. The experimentally determined $G_{s}$ (1.377) for the uncompacted manufactured waste specimens was similar to the $G_{s}$ value of 1.336 calculated by Yesiller et al. (2013) using the weighted average of the individual specific gravity values of the waste constituents, indicating that the water pycnometry analysis was effective for the determination of the specific gravity. The $G_{s}$ values of the tested MMSW specimens are summarized in Table 
4.7 along with specimen mass and the calculated equivalent diameters (Section 3.3.1).

For a given specimen the specific gravity of the manufactured wastes increased with decreasing waste particle size (Table 4.7 and Figure 4.8). As the specimen size decreased from coarse $\left(d_{e q}=14.2 \mathrm{~mm}\right)$ to fine $\left(d_{e q}=4.4 \mathrm{~mm}\right)$ the $G_{s}$ of wastes increased by an amount between 0.055 and 0.103 . The increases were higher for the uncompacted specimens (0.080 and 0.103) than the compacted specimens (0.055 and 0.070). The increases in $G_{s}$ with decreasing particle size were attributed to potential exposure of occluded intraparticle voids that were originally closed to the outside. Waste constituents that likely contained inaccessible pores included organic particles such as food, wood, and yard waste as well as rubber, leather, and cardboard components. The presence of the occluded voids was observed visually with naked eye for the some waste constituents (e.g., the dog biscuits) used in the test program.

Table 4.7. Specific Gravity for MMSW Specimens

\begin{tabular}{|c|c|c|c|c|c|c|}
\hline $\begin{array}{l}\text { Specimen } \\
\text { Condition }\end{array}$ & $\begin{array}{l}\text { Specimen } \\
\text { Number }\end{array}$ & $\begin{array}{l}\text { Mass } \\
(\mathrm{g})\end{array}$ & $\begin{array}{l}\text { Particle } \\
\text { Size }\end{array}$ & $\underset{(\mathrm{mm})}{d_{e q}}$ & $\begin{array}{c}G_{s} \\
\left(20^{\circ} \mathrm{C}\right)\end{array}$ & $\begin{array}{c}\text { Average } \\
\mathbf{G}_{s}\end{array}$ \\
\hline \multirow{6}{*}{$\begin{array}{l}\text { As-prepared } \\
\text { (Uncompacted) }\end{array}$} & 1 & 103.6 & Coarse & 14.2 & 1.339 & \multirow{2}{*}{1.333} \\
\hline & 2 & 100.1 & Coarse & 14.2 & 1.326 & \\
\hline & 3 & 100.5 & Medium & 8.5 & 1.376 & \multirow{2}{*}{1.374} \\
\hline & 4 & 100.3 & Medium & 8.5 & 1.372 & \\
\hline & 5 & 99.5 & Fine & 4.4 & 1.419 & \multirow{2}{*}{1.424} \\
\hline & 6 & 100.1 & Fine & 4.4 & 1.429 & \\
\hline \multirow{3}{*}{$\begin{array}{l}\text { Compacted - Dry } \\
\text { of Optimum } \\
\text { (30\% Moisture } \\
\text { Content) }\end{array}$} & 7 & 100.1 & Coarse & 14.2 & 1.497 & - \\
\hline & 8 & 100.1 & Medium & 8.5 & 1.521 & - \\
\hline & 9 & 100.0 & Fine & 4.4 & 1.552 & - \\
\hline \multirow{3}{*}{$\begin{array}{l}\text { Compacted - Wet } \\
\text { of Optimum } \\
\text { (90\% Moisture } \\
\text { Content) }\end{array}$} & 10 & 100.1 & Coarse & 14.2 & 1.500 & - \\
\hline & 11 & 100.1 & Medium & 8.5 & 1.542 & - \\
\hline & 12 & 100.0 & Fine & 4.4 & 1.570 & - \\
\hline
\end{tabular}




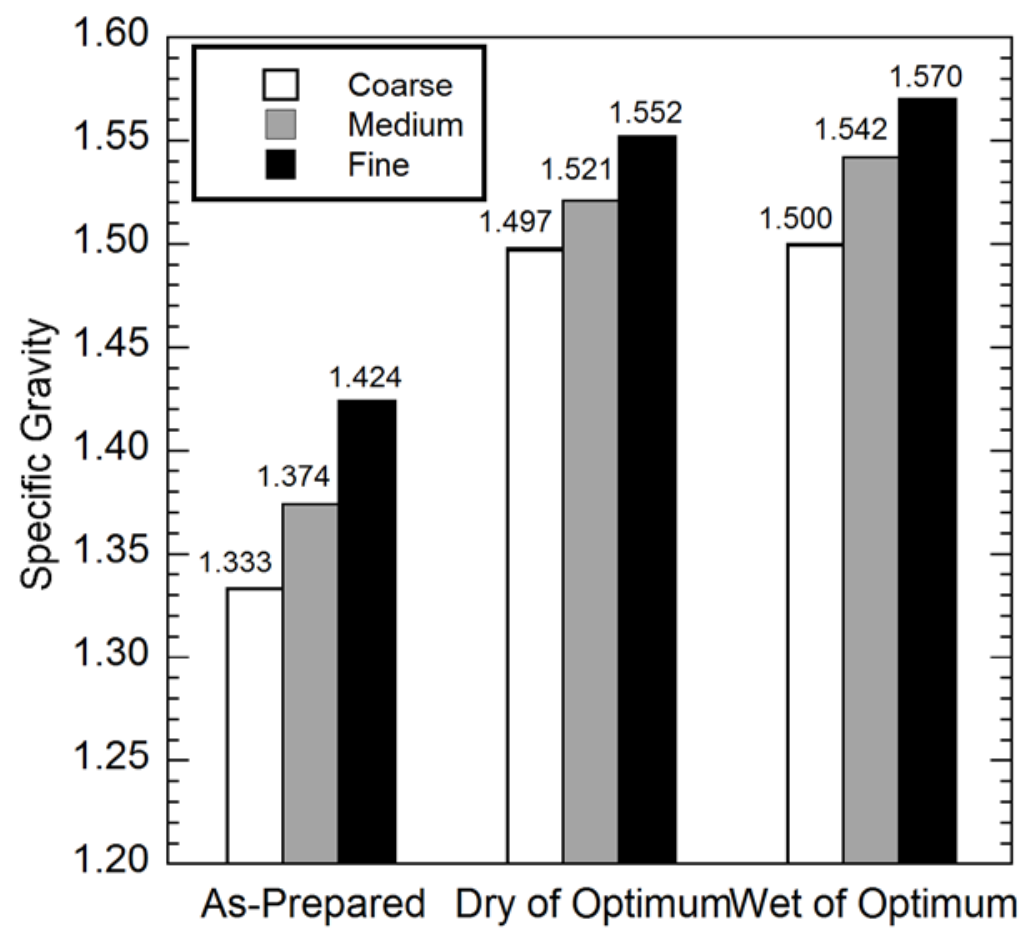

Figure 4.8. Comparison of Manufactured Waste $G_{s}$ for 3 Size Fractions.

Systematic analysis of particle size effects on Gs of MSW was not presented in the literature. However, data were provided for other materials such as volcanic rocks (Wesley 2001 and Tamari et al. 2005) and an industrial byproduct (Millspaugh et al. 2010). The specific gravity of volcanic scoria increased from 1.20 to 2.34 when the particle size decreased from $15 \mathrm{~mm}$ to $<74$ $\mu \mathrm{m}$ (Wesley 2001) and from 2.55 to 2.79 when the particle size decreased from $4.75 \mathrm{~mm}$ to $35 \mu \mathrm{m}$ (Tamari et al. 2005). For chromium ore processing residue, the $G_{s}$ increased from 3.146 to 3.355 and 2.711 to 2.720 for two types of ore residue when the ore was ground to a nominal particle size of $80 \mu \mathrm{m}$ (unground particle sizes were not provided) (Millspaugh et al. 2010). Presence of closed intraparticle voids and exposure of these voids due to particle size reduction were indicated to be the mechanism for increased $G_{s}$. Visual SEM evidence of 
intraparticle voids and secondary porosity was provided for the chromium ore by Tinjum et al. (2008).

Similar to the measured $G_{s}$ of fresh MSW, the specific gravity of manufactured wastes also increased due to compaction (Table 4.7). For the MMSW specimens, the $G_{s}$ increased by 0.146 and 0.161 for dry of optimum moisture content and wet of optimum moisture content specimens, respectively compared to the as-prepared uncompacted specimens (Table 4.7). The changes in particle size of the coarse manufactured waste samples due to compaction were quantified using a sieving analysis (Table 4.8). The distribution of the particle sizes changed as the quantity of fine particles in the manufactured wastes increased due to compaction. For manufactured wastes, the particle sizes of the specimens compacted at the dry and wet of optimum moisture content were generally similar (Table 4.8) and in line with this trend, the specific gravity values of the compacted specimens were similar (1.523 and 1.538 for dry and wet of optimum moisture contents, respectively) irrespective of the compaction moisture content in MMSW tests. The average specific gravity for the compacted wastes was 1.530 in these tests.

Table 4.8. Particle Size Breakdown for MMSW Specimens

\begin{tabular}{|c|c|c|}
\hline $\begin{array}{c}\text { Sample } \\
\text { Description }\end{array}$ & $\begin{array}{c}\text { Passing 12.7 mm } \\
\text { Sieve (\%) }\end{array}$ & $\begin{array}{c}\text { Passing 9.5 mm } \\
\text { Sieve (\%) }\end{array}$ \\
\hline Uncompacted & 16 & 9 \\
\hline $\begin{array}{c}\text { Compacted Dry } \\
\text { of Optimum }\end{array}$ & 38 & 38 \\
\hline $\begin{array}{c}\text { Compacted Wet } \\
\text { of Optimum }\end{array}$ & 38 & 34 \\
\hline
\end{tabular}


The $G_{s}$ data for the as-prepared, compacted dry of optimum and compacted wet of optimum MMSW specimens were analyzed as a function of equivalent particle diameter. In addition, the as-prepared specimens and compacted specimens were individually averaged and analyzed as a function of equivalent diameter. The relationships were linear for the range of equivalent particle diameters included in the analysis and are presented in Figure 4.9a and 4.9b. Based on the manufactured waste tests, particle size had more significant influence on the specific gravity of wastes than the compaction moisture content. 


\begin{tabular}{|lll|}
\hline - As-Prepared & $\mathrm{G}_{\mathrm{s}}=1.4591-0.00912 \mathrm{~d}_{\text {eq }}$ & $\mathrm{R}^{2}=0.97658$ \\
$\begin{array}{l}\text { Compacted } \\
\text { Dry of Optimum } \\
\text { Moisture Content }\end{array}$ & $\mathrm{G}_{\mathrm{s}}=1.5729-0.005504 \mathrm{~d}_{\mathrm{eq}}$ & $\mathrm{R}^{2}=0.97139$ \\
- $\begin{array}{l}\text { Compacted } \\
\text { Wet of Optimum } \\
\text { Moisture Content }\end{array}$ & $\mathrm{G}_{\mathrm{s}}=1.6015-0.007134 \mathrm{~d}_{\mathrm{eq}}$ & $\mathrm{R}^{2}=0.99966$ \\
\hline
\end{tabular}

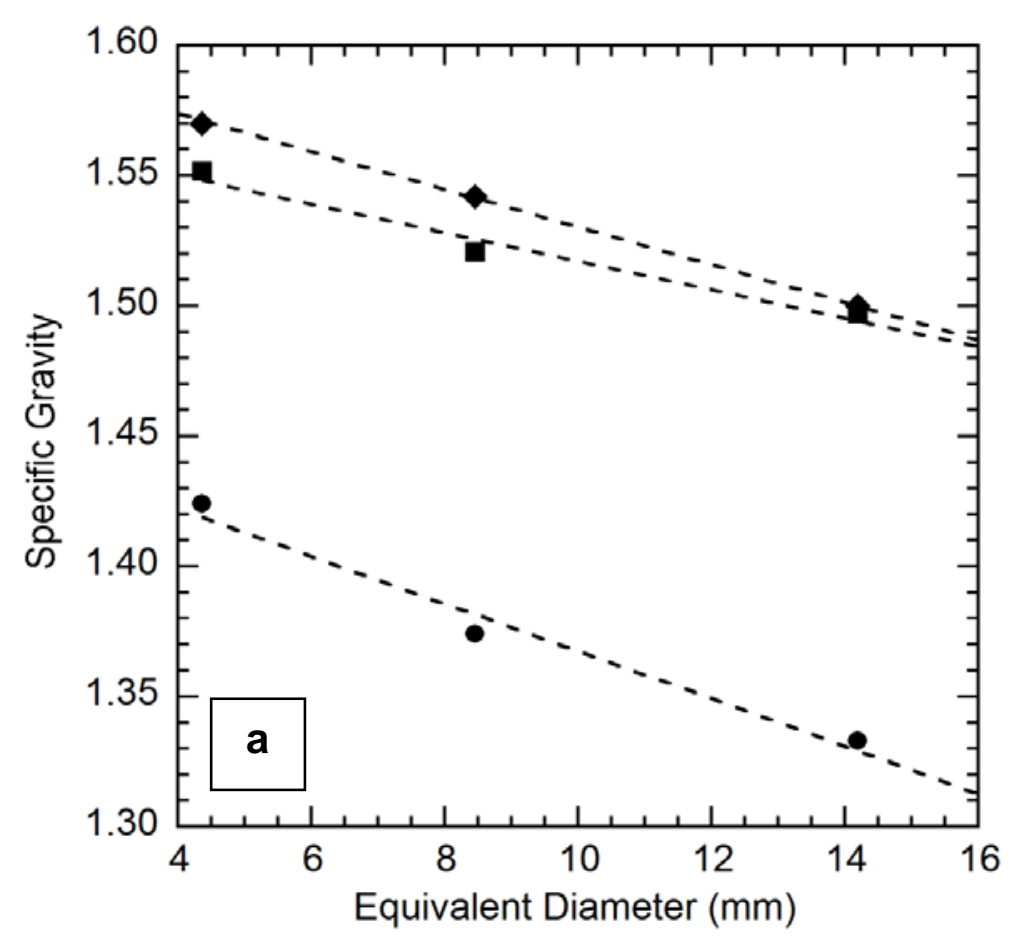

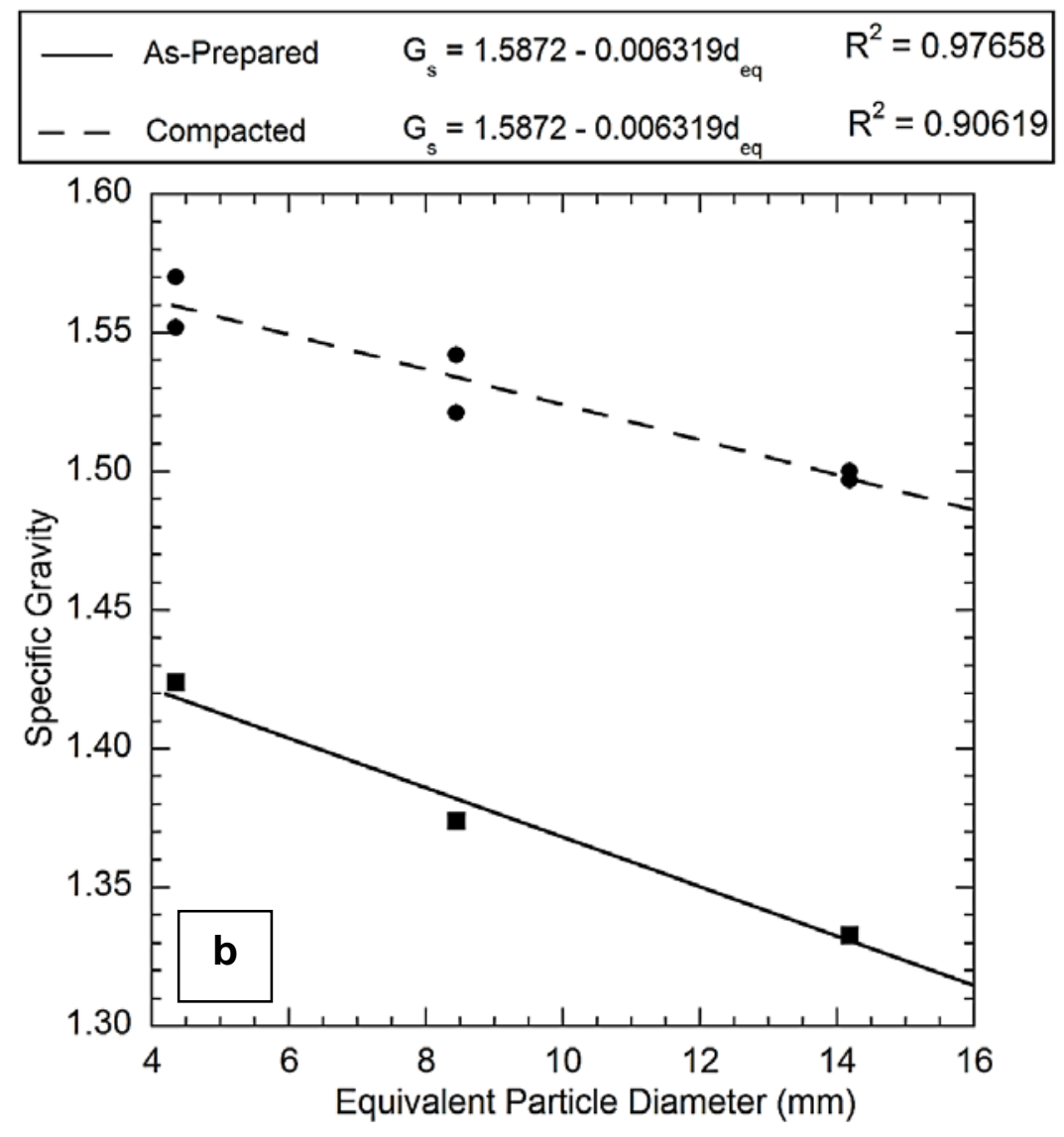

Figure 4.9. Relationship Between Specific Gravity and Equivalent Particle Diameter. 
The $G_{s}$ for the old waste (Category III) varied between 1.962 and 2.487 with an average value of 2.201 based on the measurements conducted on the specimens obtained from the four boreholes (Table 4.9). The OMSW specific gravity test results of this study are similar to specific gravity values of old wastes (obtained from landfills) reported by other researchers (Gabr and Valero 1995; Wu et al. 2012). In addition, the specific gravity values of laboratory degraded waste reported by Reddy et al. (2011) were comparable to the results of this study. The measured $G_{s}$ values were plotted as a function of depth (Figure 4.10). A strong trend between the measured specific gravity of OMSW and depth was not apparent for the tested specimens.

Table 4.9. Measured Specific Gravity of OMSW Specimens

\begin{tabular}{|c|c|c|c|c|}
\hline Borehole & Depth (m) & $\begin{array}{c}\text { Normalized } \\
\text { Depth }\end{array}$ & $\begin{array}{c}\text { Specimen } \\
\text { Mass (g) }\end{array}$ & $\begin{array}{c}\mathbf{G}_{\mathbf{s}} \\
\mathbf{( 2 0 ^ { \circ } \mathbf { C } )}\end{array}$ \\
\hline \multirow{4}{*}{ BH1 } & 1.9 & 0.1 & 224.64 & 2.487 \\
\cline { 2 - 5 } & 6.2 & 0.4 & 144.26 & 1.962 \\
\cline { 2 - 5 } & 14.2 & 0.8 & 149.97 & 2.151 \\
\hline \multirow{4}{*}{ BH2 } & 1.9 & 0.1 & 311.4 & 2.113 \\
\cline { 2 - 5 } & 6.5 & 0.3 & 243.54 & 2.274 \\
\cline { 2 - 5 } & 13.9 & 0.7 & 264.04 & 2.110 \\
\hline \multirow{4}{*}{ BH5 } & 2.5 & 0.1 & 309.64 & 2.175 \\
\cline { 2 - 5 } & 3.7 & 0.2 & 281.52 & 2.288 \\
\cline { 2 - 5 } & 5.3 & 0.3 & 335.60 & 2.251 \\
\cline { 2 - 5 } & 7.7 & 0.4 & 316.35 & 2.166 \\
\cline { 2 - 5 } & 12.1 & 0.6 & 290.88 & 2.041 \\
\hline \multirow{5}{*}{ BH6 } & 13.3 & 0.7 & 342.57 & 2.051 \\
\cline { 2 - 5 } & 1.5 & 0.1 & 283.64 & 2.247 \\
\cline { 2 - 5 } & 3.7 & 0.2 & 298.72 & 2.323 \\
\cline { 2 - 5 } & 7.1 & 0.4 & 304.78 & 2.313 \\
\cline { 2 - 5 } & 9.9 & 0.5 & 303.12 & 2.249 \\
\cline { 2 - 5 } & 12.1 & 0.6 & 305.41 & 2.208 \\
\hline & 14.6 & 0.8 & 271.44 & 2.316 \\
\hline
\end{tabular}


The specific gravity values for old wastes were significantly higher than the data obtained for the manufactured and fresh wastes. For waste depth as shallow as $1.5 \mathrm{~m}$ and waste age as low as 0.7 years, the $G_{s}$ had increased significantly to values above those for both the incoming fresh wastes and fresh wastes immediately after compaction. 

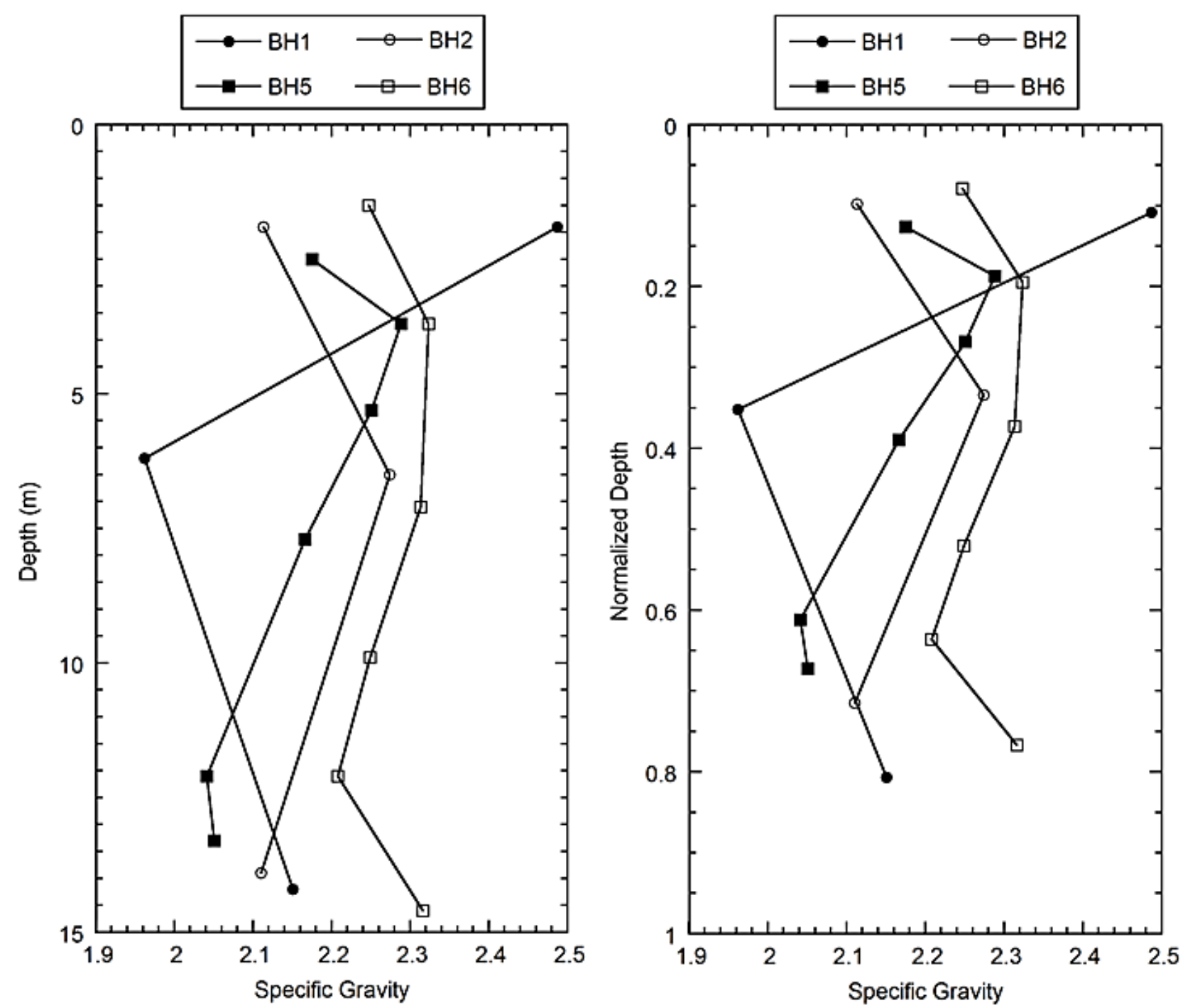

Figure 4.10. Specific Gravity of OMSW Specimens as a Function of Depth and Normalized Depths. 


\subsection{Temperature}

In general, waste temperatures at shallow, middle, and great depths increased over time and an overall warming of the waste mass occurred (Figure 4.11). The temperature increased on average $5,3,5$, and $6^{\circ} \mathrm{C}$ between the initial and final day of measurements for $\mathrm{BH} 5, \mathrm{BH} 6, \mathrm{BH}$, and $\mathrm{BH}$, respectively. The larger increases in temperature for $\mathrm{BH} 7$ and $\mathrm{BH} 8$ between the initial and final days of measurement were produced by the onset of degradation processes. Day zero corresponds to the first measurement taken after the thermocouple connectors were installed. Temperature monitoring for $\mathrm{BH} 5$ and $\mathrm{BH} 6$ was continuous from day zero onward. Temperature monitoring for $\mathrm{BH} 7$ and $\mathrm{BH} 8$ did not begin until after the placement of a fresh waste lift (Day 145). The increases in waste temperatures were attributed to the heat generated during degradation.

In addition, the top lift of waste at the location $\mathrm{BH} 6(0$ to $4.5 \mathrm{~m})$ was placed during wet conditions (i.e., wet season) and the top lift of BH5 (0 to $4.5 \mathrm{~m}$ ) was placed during dry conditions (i.e., dry season). The initial waste temperatures for the top lift of $\mathrm{BH} 6$ were slightly higher than those of $\mathrm{BH} 5$ possibly indicating that degradation processes had been enhanced due to additional moisture. A summary of the initial and final temperatures recorded at each depth within the four boreholes is provided in Table 4.10. 

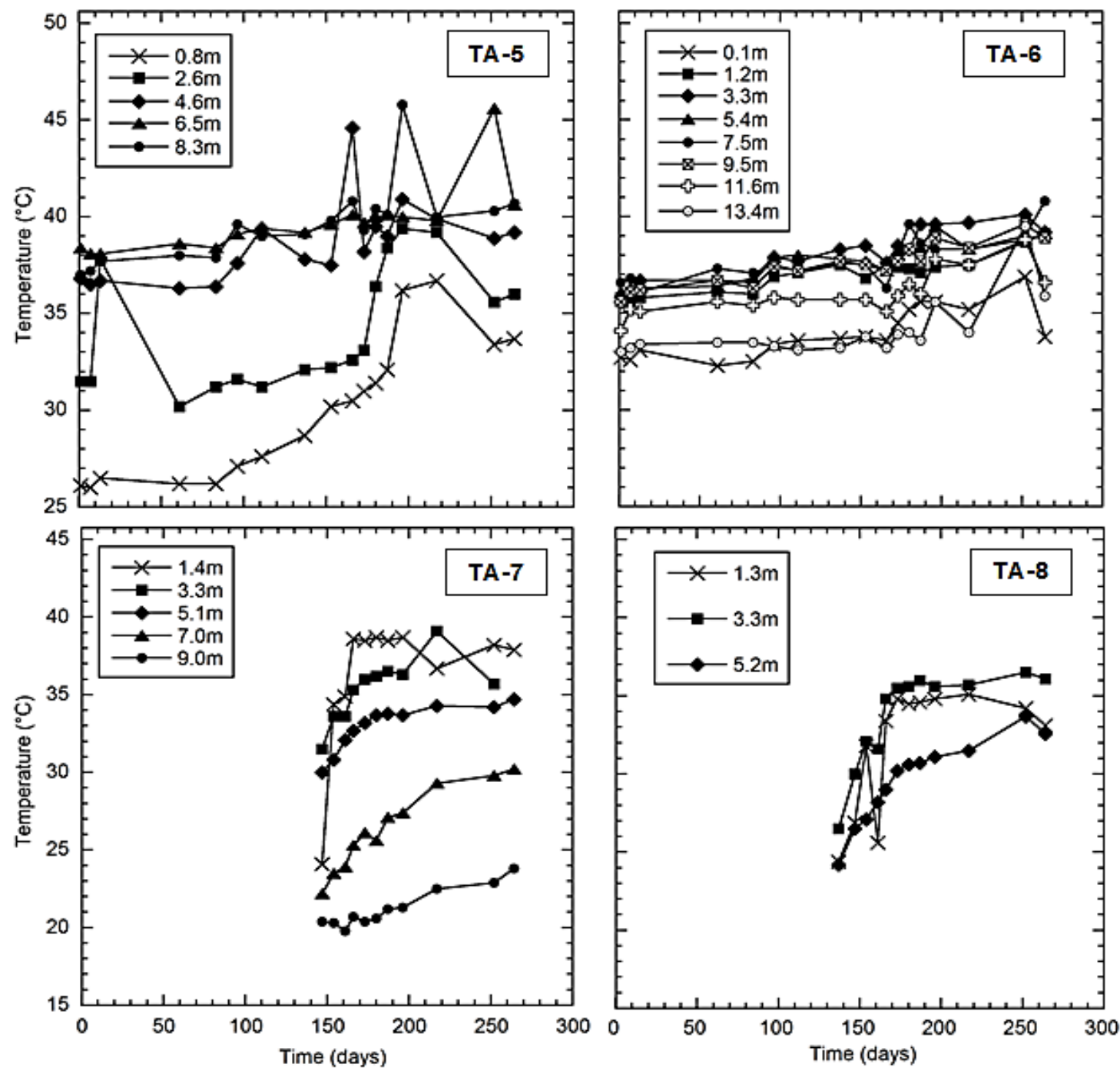

Figure 4.11. Waste Temperatures with Time.

Table 4.10. Summary of Changes in Waste Temperature Over Time.

\begin{tabular}{|c|c|c|c|c|c|}
\hline Borehole & $\begin{array}{c}\text { Depth } \\
(\mathbf{m})\end{array}$ & $\begin{array}{c}\text { Initial } \\
\text { Temperature } \\
\left({ }^{\circ} \mathbf{C}\right)\end{array}$ & $\begin{array}{c}\text { Final } \\
\text { Temperature } \\
\left({ }^{\circ} \mathbf{C}\right)\end{array}$ & $\begin{array}{c}\text { Duration } \\
\text { (Days) }\end{array}$ & $\begin{array}{c}\text { Temperature } \\
\text { Increase } \\
\left({ }^{\circ} \mathbf{C}\right)\end{array}$ \\
\hline \multirow{5}{*}{ BH5 } & 0.8 & 26.1 & 33.7 & 264 & 8.5 \\
\cline { 2 - 6 } & 2.6 & 31.5 & 36.0 & 264 & 4.7 \\
\cline { 2 - 6 } & 4.6 & 36.8 & 39.2 & 264 & 2.7 \\
\cline { 2 - 6 } & 6.5 & 38.4 & 40.6 & 264 & 3.6 \\
\cline { 2 - 6 } & 8.3 & 37.0 & 40.7 & 264 & 4.1 \\
\hline \multirow{5}{*}{$\mathrm{BH} 6$} & 0.1 & 32.7 & 33.8 & 264 & 2.4 \\
\cline { 2 - 6 } & 1.2 & 35.8 & 39.1 & 264 & 3.6 \\
\cline { 2 - 6 } & 3.3 & 35.6 & 39.2 & 246 & 2.8 \\
\cline { 2 - 6 } & 5.4 & 36.1 & 39.1 & 246 & 2.2 \\
\cline { 2 - 6 } & 7.5 & 36.6 & 40.8 & 246 & 3.5 \\
\hline
\end{tabular}


Table 4.10. Summary of Changes in Waste Temperature Over Time (Cont'd).

\begin{tabular}{|c|c|c|c|c|c|}
\hline Borehole & $\begin{array}{c}\text { Depth } \\
(\mathbf{m})\end{array}$ & $\begin{array}{c}\text { Initial } \\
\text { Temperature } \\
\left({ }^{\circ} \mathbf{C}\right)\end{array}$ & $\begin{array}{c}\text { Final } \\
\text { Temperature } \\
\left({ }^{\circ} \mathbf{C}\right)\end{array}$ & $\begin{array}{c}\text { Duration } \\
(\text { Days) }\end{array}$ & $\begin{array}{c}\text { Temperature } \\
\text { Increase } \\
\left({ }^{\circ} \mathbf{C}\right)\end{array}$ \\
\hline \multirow{3}{*}{$\mathrm{BH} 6$} & 9.5 & 35.6 & 38.6 & 246 & 2.4 \\
\cline { 2 - 6 } & 11.6 & 34.1 & 36.6 & 246 & 3.6 \\
\cline { 2 - 6 } & 13.4 & 33.0 & 35.9 & 246 & 2.8 \\
\hline \multirow{4}{*}{$\mathrm{BH} 7$} & 1.4 & 24.1 & 37.9 & 117 & 3.1 \\
\cline { 2 - 6 } & 3.3 & 31.5 & 35.7 & 117 & 5.3 \\
\cline { 2 - 6 } & 5.1 & 30.0 & 34.7 & 117 & 4.5 \\
\cline { 2 - 6 } & 7.0 & 22.2 & 30.2 & 117 & 9.1 \\
\cline { 2 - 6 } & 9.0 & 20.4 & 23.8 & 117 & 3.4 \\
\hline \multirow{3}{*}{$\mathrm{BH} 8$} & 1.3 & 24.4 & 33.1 & 127 & 4.6 \\
\cline { 2 - 6 } & 3.3 & 26.5 & 36.1 & 127 & 5.8 \\
\cline { 2 - 6 } & 5.2 & 24.2 & 32.6 & 127 & 6.4 \\
\hline
\end{tabular}

The final recorded temperatures within each borehole were plotted as a function of absolute and normalized depths (Figure 4.12). The temperature trends with depth align well with the data reported by Yesiller et al. (2005) and Hanson et al. (2010a). In general, waste temperatures were cooler toward the ground surface, increased to a maximum temperature at the middle depths of the waste mass, and then decreased as depth approached the bottom liner. Overall, measured waste temperatures were similar to those reported in the literature (Yesiller et al. 2005; Hanson et al. 2010a; Yesiller et al. 2011; Wang et al. 2012). 

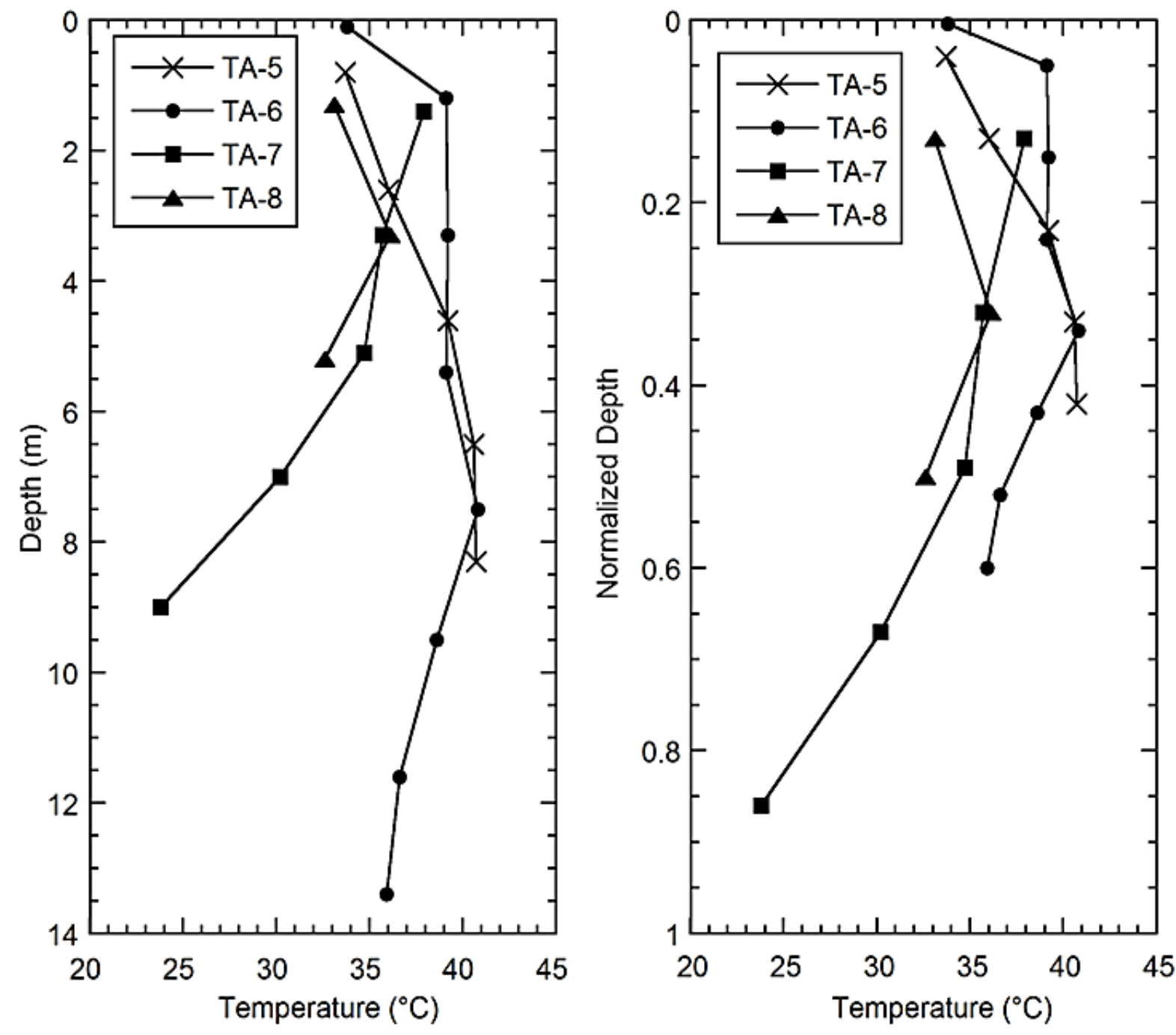

Figure 4.12. Temperature as a Function of Depth. 


\subsection{Settlement}

The settlement of MSW was analyzed based on regular measurements obtained from the settlement arrays installed at SMRL. The magnetic extensometer rings (MERs) and settlement plates were systematically placed to capture the strain of waste lifts (described in Section 3.2.4) for a given borehole. The strain of each waste lift for Boreholes 1 through 8 was measured over a period of 3 to 12 months depending on placement times and installation dates (Figures 4.13 through 4.16). Positive strain values represented the compression of a given waste lift (i.e., MERs and/or settlement plates moved closer together) and negative strain values represented the swelling of a given waste lift (i.e., MERs and/or settlement plates moved further apart)

In general, settlement data measured for this investigation represented the secondary compression stages (i.e., mechanical creep and biochemical compression) of the wastes. In most cases, settlement of preexisting waste (i.e., old MSW) was monitored and initial compression had already been completed. However, new waste lifts (i.e., fresh MSW) were placed over Boreholes 3, 7, and 8 at different times throughout the investigation. For these waste lifts, initial compression strains were obtained and characterized as recompression of fresh waste. For the bottom waste lifts (i.e., Lift I) of Boreholes 3 and 7, additional primary compression due to loading of the overlying fresh waste lift was measured and characterized as primary compression of degraded waste. In addition, the influence of an earthen embankment (i.e., stockpile) with an

approximate volume of $19,000 \mathrm{~m}^{3}$ on the settlement of waste for boreholes 1,2 , 
5, and 6 was measured and characterized as primary compression of degraded waste. In addition, unloading and reloading of the earthen embankment occurred over the duration of the test program. The bottom waste lift of borehole 6 exhibited a unique response to the unloading and reloading process and characterized as a recompression of degraded waste.

Based on the limited duration of settlement monitoring, it was difficult to differentiate between the mechanical creep and biochemical compression of the waste. Therefore, the secondary compression of the waste was characterized by a single modified secondary compression index $C_{\alpha}^{\prime}$ as opposed to dividing secondary compression into separate mechanisms of mechanical creep $\left(C_{\alpha M}^{\prime}\right)$ and biochemical compression $\left(C_{\alpha B}^{\prime}\right)$ ratios. Secondary compression ratio $\left(C_{\alpha}^{\prime}\right)$ values were determined using the set of data points from Figures 4.13 through 4.16 that exhibited a linear slope on vertical strain versus log time plot.

The start date at which the strains increased in a consistent manner such that a linear curve fit could be applied varied for each borehole. In general the trends became prominent after 150 to 200 days of monitoring. The set of data points exhibiting $C_{\alpha}^{\prime}$ trends for a given borehole were analyzed consistently such that the starting point (e.g., strain associated with 150 to 200 days) was selected first. Then a middle point along the data set was selected. Finally, the last data point was selected to complete a 3 point curve-fit for a given waste lift. The maximum $C_{\alpha}^{\prime}$ was determined to be 0.067 and whereas the minimum $C_{\alpha}^{\prime}$ was 0.013. The measured $C_{\alpha}^{\prime}$ for the waste lifts are summarized in Table 4.11. 
The maximum measured waste settlement within a single waste lift (each lift approximately $5 \mathrm{~m}$ in height) was $777 \mathrm{~mm}$, which was associated with Lift I of BH6. The minimum measured settlement was $15 \mathrm{~mm}$ and was associated with Lift III of $\mathrm{BH} 2$. The top waste lifts of $\mathrm{BH} 1$ and $\mathrm{BH} 3$ were measured to have negative settlement (i.e., swell). A negative strain was representative of an increase in the lift height and could have been a result of either the MER at the bottom of the lift moving downward at a faster rate than the settlement plate on the waste surface or the settlement moving upward with time. Swell of waste during self-weight compression is not expected and was attributed to a downward slip of the MERs. A downward slip of a magnetic extensometer ring may have been caused by the collapse of a waste constituent (e.g., cardboard box) that had inhibited the movement of the MER.

In addition, the bottom waste lift (Lift I) for all boreholes had the largest final strain (Table 4.11). The final strain values for the waste lifts within boreholes 2, 4, 6, and 8, were generally larger than those within boreholes 1, 3, 5, 7 (Table 4.12). The resulting increased final strain values were attributed to relatively enhanced degradation in boreholes $2,4,6$, and 8 due to placement of the top waste lifts in wet conditions (i.e., waste placement during rainy season). Increased amounts of moisture could have migrated downward to the underlying waste lifts, transported microbes and nutrients to less microbial active areas, and enhanced degradation processes.

It should be noted that the settlement array installed in BH5 did not reach the target depth due to refusal (i.e., collapse of borehole or blockage). 
Implications of missing the target depth by approximately $3 \mathrm{~m}$ included the following: 1) the top MER was deployed into the embankment; 2) the instrumented top waste lift (i.e., locations of MER) was not representative of the actual waste lift; and 3) the measured settlements were not necessarily comparable to the measured settlements of waste lifts of other borehole. 

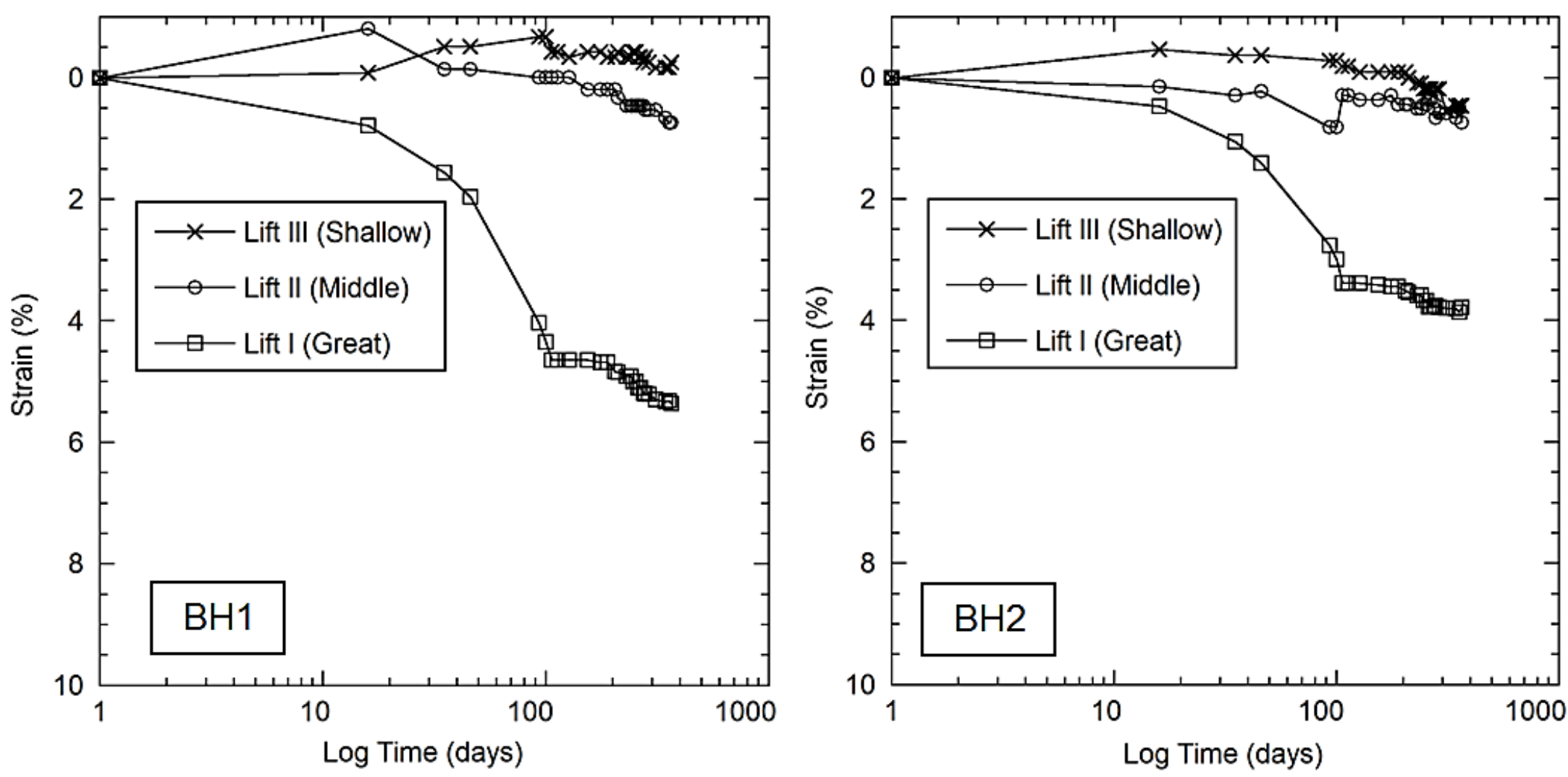

Figure 4.13. Vertical Waste Lift Strain of $\mathrm{BH} 1$ and $\mathrm{BH} 2$ as a Function of Time. 

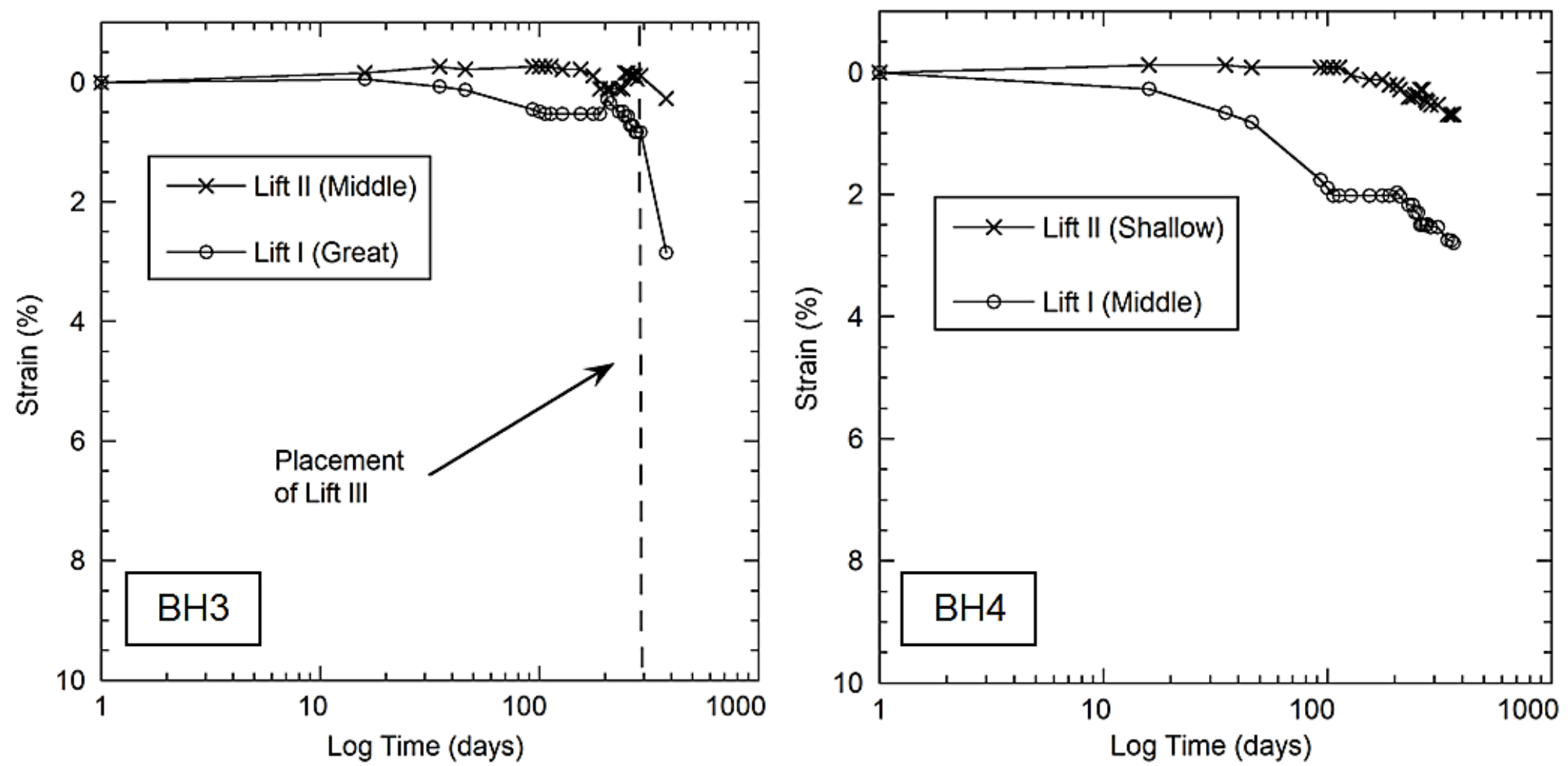

Figure 4.14. Vertical Waste Lift Strain of $\mathrm{BH} 3$ and $\mathrm{BH} 4$ as a Function of Time. 

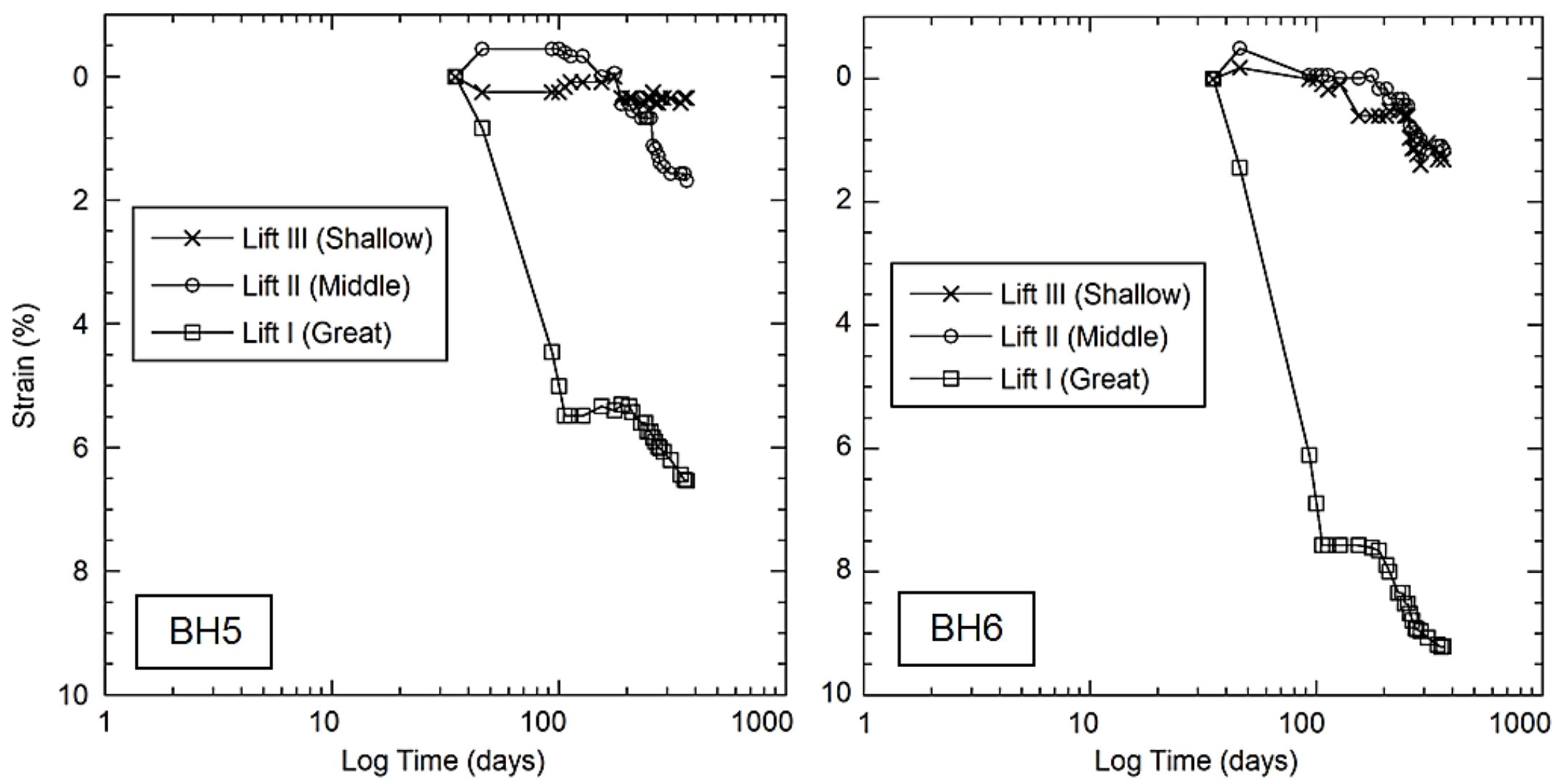

Figure 4.15. Vertical Waste Lift Strain of BH5 and BH6 as a Function of Time. 

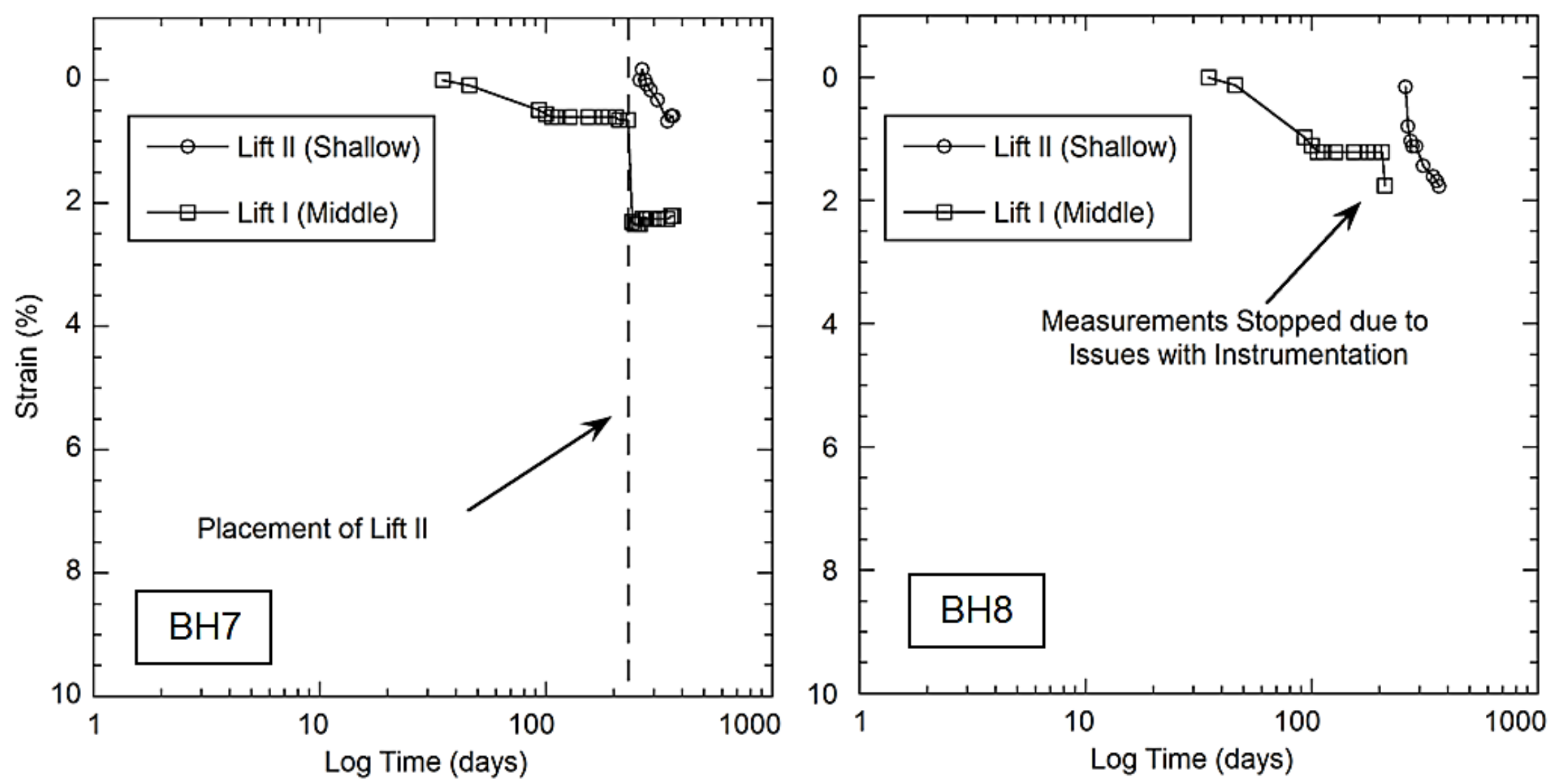

Figure 4.16. Vertical Waste Lift Strain of $\mathrm{BH} 7$ and $\mathrm{BH} 8$ as a Function of Time. 
Table 4.11. Summary of Waste Strain Parameters and Data

\begin{tabular}{|c|c|c|c|c|c|c|c|}
\hline Borehole & $\begin{array}{c}\text { Waste } \\
\text { Lift }\end{array}$ & $\begin{array}{c}\text { Approximate } \\
\text { Date of } \\
\text { Placement }\end{array}$ & $\begin{array}{c}\text { Initial } \\
\text { Lift } \\
\text { Height } \\
\text { (m) }\end{array}$ & $\begin{array}{c}\text { Duration of } \\
\text { Monitoring } \\
\text { (days) }\end{array}$ & $\begin{array}{c}\text { Final } \\
\text { Measured } \\
\text { Strain } \\
(\%) \\
\end{array}$ & $C_{\alpha}^{\prime}$ & $\begin{array}{l}\text { Total } \\
\text { Settlement } \\
(\mathrm{mm})\end{array}$ \\
\hline \multirow{3}{*}{$\mathrm{BH} 1$} & Lift III & Nov. 2010 & 3.66 & 366 & -0.3 & - & -9 \\
\hline & Lift II & Aug. 2010 & 4.61 & 366 & 0.7 & 0.014 & 34 \\
\hline & Lift I & Nov. 2006 & 9.33 & 366 & 5.4 & 0.024 & 489 \\
\hline \multirow{3}{*}{$\mathrm{BH} 2$} & Lift III & Dec. 2010 & 3.36 & 366 & 0.5 & 0.018 & 15 \\
\hline & Lift II & Jul. 2010 & 4.21 & 366 & 0.7 & 0.013 & 31 \\
\hline & Lift I & Aug. 2006 & 11.87 & 366 & 3.8 & 0.016 & 443 \\
\hline \multirow{3}{*}{$\mathrm{BH} 3$} & Lift III & Sep. 2013 & 4.91 & 30 & - & - & - \\
\hline & Lift II & Aug. 2009 & 5.79 & 366 & -0.3 & - & -6 \\
\hline & Lift I & Jun. 2004 & 6.51 & 366 & 0.8 & 0.030 & 54 \\
\hline \multirow{2}{*}{$\mathrm{BH} 4$} & Lift II & Mar. 2010 & 7.59 & 366 & 0.7 & 0.019 & 53 \\
\hline & Lift I & Jun. 2003 & 6.39 & 366 & 2.8 & 0.032 & 176 \\
\hline \multirow{3}{*}{$\mathrm{BH} 5$} & Lift III & Jan. 2012 & $\mathrm{~N} / \mathrm{A}$ & $\mathrm{N} / \mathrm{A}$ & $\mathrm{N} / \mathrm{A}$ & - & N/A \\
\hline & Lift II & Dec. 2007 & 5.85 & 331 & 1.7 & 0.045 & 93 \\
\hline & Lift I & Aug. 2006 & 11.41 & 331 & 6.5 & 0.047 & 731 \\
\hline \multirow{3}{*}{$\mathrm{BH} 6$} & Lift III & Mar. 2012 & 3.56 & 331 & 1.3 & 0.027 & 46 \\
\hline & Lift II & Sep. 2010 & 5.66 & 331 & 1.2 & 0.036 & 65 \\
\hline & Lift I & Aug. 2006 & 8.71 & 331 & 9.2 & 0.067 & 777 \\
\hline \multirow{2}{*}{$\mathrm{BH} 7$} & Lift II & Jun. 2013 & 3.72 & 112 & 0.6 & - & 22 \\
\hline & Lift I & Mar. 2004 & 6.85 & 331 & 2.2 & - & 151 \\
\hline \multirow{2}{*}{$\mathrm{BH} 8$} & Lift II & Jun. 2013 & 3.89 & 112 & 1.8 & - & 68 \\
\hline & Lift I & Feb. 2004 & 6.35 & 176 & 1.8 & - & 111 \\
\hline
\end{tabular}


Large increases in the strain of Lift I (relative to the total strain of the lift) for all boreholes occurred within the first 30 to 100 days of measurements (Figures 4.13 and 4.16). The relatively large increases in the initial strain for Boreholes 1, 2, 3, 4, 7, and 8 were possibly due to an instrumentation response after disturbance during drilling. For example, macro voids could have been created during drilling due to removal of waste particles and in turn a downward drop of the magnetic extensometer ring could have occurred upon encountering a macro void. A third potential cause for the increases in initial strain of the bottom lifts is related to the bottom MER moving downward at a given rate while the bottom of the landfill (i.e, liner) is incompressible (relative to the waste).

The initial strains of Lift I for Boreholes 5, and 6 were significantly larger than those of the other boreholes. While the mechanisms described above may have contributed to the increased initial strain, a majority of the increased strains were likely due to primary compression induced by vertical stresses generated by the overlying earthen embankment. Boreholes 5 and 6 are located directly beneath the center of the embankment and the stress generated by the embankment had significant influence on the underlying waste lifts for Boreholes 5 and 6. In addition, new waste lifts were placed on top of existing waste lifts for Boreholes 3, 7, and 8 . The resulting increase of vertical stress from the new waste lifts on the underlying waste lifts produced sharp increases in strain.

The initial dimensions of the embankment were approximated to be $7 \mathrm{~m}$ in height and a basal area of $3640 \mathrm{~m}^{2}$. The stockpile was assumed to be a trapezoidal prism for the analysis however the actual shape of the embankment 
was similar to a semi-elliptical prism (Figure 4.17a). The embankment was constructed between October $15^{\text {th }}$ and $19^{\text {th }}$ in 2012 and periodically unloaded (i.e., soil was removed) until June 18, 2013 at which point approximately 15,000 $\mathrm{m}^{3}$ of additional soil was added to the existing embankment (i.e., reloading). The dimensions of the modified embankment (i.e., addition of soil) were approximately $5 \mathrm{~m}$ in height with a basal area of approximately $6500 \mathrm{~m}^{2}$ (Figure 4.17b). The volume of the embankment was periodically determined with GPS surveys and on occasion linear interpolation between survey days (Table 4.12). 
Actual Shape of Embankment (semi-elliptical prism)

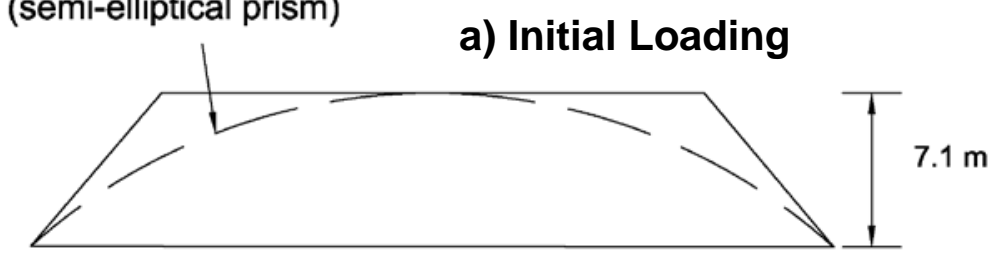

CROSS SECTION

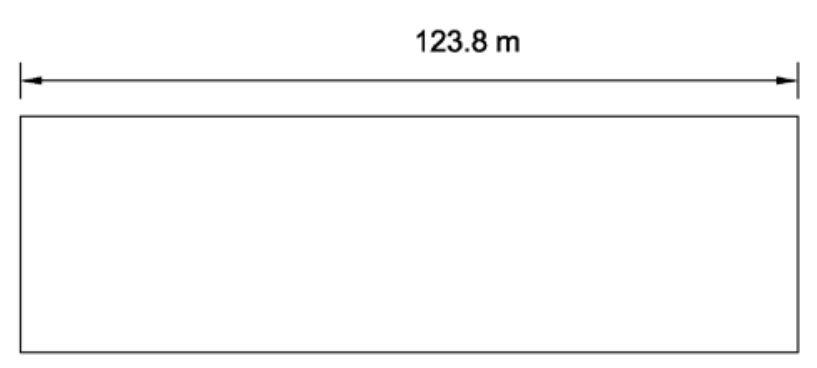

PLAN VIEW b) Reloading

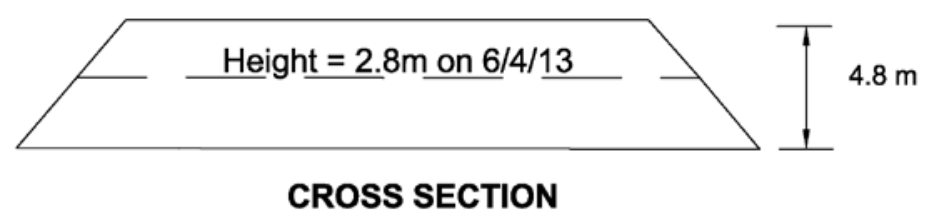

$123.8 \mathrm{~m}$

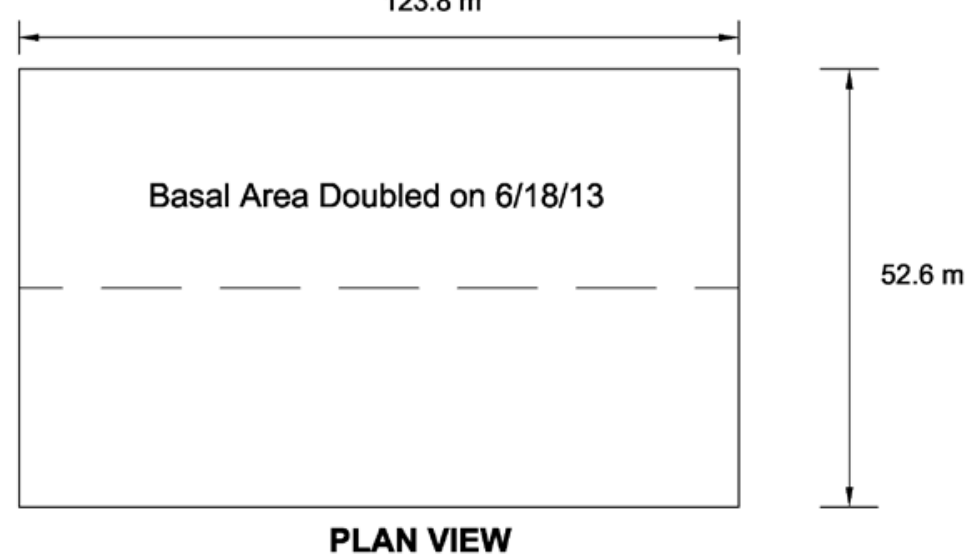

Figure 4.17. Embankment Schematic at Initial Placement and After Reloading. 
Bossiness stress distribution for an embankment load (US Navy 1986) was used to determine the induced vertical stresses on the midheight of Lift I for borehole 6 during the unloading and reloading of the embankment. Borehole 5 was not analyzed due to refusal of the settlement array system during installation. The initial induced vertical stress from the embankment $\left(\Delta \sigma_{E}\right)$ on Lift I of Borehole 6 was approximately $99 \mathrm{kPa}$. A summary of the embankment dimensions, volumes and calculated induced stress on Lift I of Boreholes 6 over the duration of the test program are provided in Table 4.12. Also included in Table 4.12 is the total stress $\left(\Delta \sigma_{T}\right)$ at the midheight of Lift I which includes the stress induced overlying Waste Lifts II and III.

Table 4.12. Embankment Unloading and Reloading Summary

\begin{tabular}{|c|c|c|c|c|c|c|}
\hline Date & Day & $\begin{array}{l}\text { Height } \\
\text { (m) }\end{array}$ & $\begin{array}{c}\text { Basal } \\
\text { Area }\left(\mathrm{m}^{2}\right)\end{array}$ & $\begin{array}{l}\text { Volume } \\
\left(\mathrm{m}^{3}\right)\end{array}$ & $\begin{array}{c}\Delta \sigma_{E} \\
(\mathrm{kPa})\end{array}$ & $\begin{array}{c}\Delta \sigma_{T} \\
(\mathrm{kPa})\end{array}$ \\
\hline 11/12/2012 & 1 & 7.1 & 3640 & 19,115 & 99.2 & 157.2 \\
\hline $11 / 30 / 2012^{a}$ & 18 & 6.4 & 3640 & 17,362 & 90.1 & 148.1 \\
\hline $12 / 31 / 2012^{a}$ & 49 & 4.6 & 3640 & 12,589 & 65.4 & 123.3 \\
\hline $1 / 29 / 2013$ & 78 & 4.2 & 3640 & 11,615 & 60.3 & 118.2 \\
\hline $2 / 15 / 2013^{a}$ & 95 & 3.8 & 3640 & 10,952 & 56.9 & 114.8 \\
\hline $3 / 5 / 2013$ & 113 & 3.4 & 3640 & 10,250 & 54.0 & 111.9 \\
\hline $3 / 27 / 2013$ & 135 & 3.0 & 3640 & 9,260 & 47.8 & 105.7 \\
\hline $4 / 15 / 2013^{\mathrm{a}}$ & 154 & 2.9 & 3640 & 9,014 & 46.8 & 104.7 \\
\hline $5 / 3 / 2013$ & 172 & 2.9 & 3640 & 8,780 & 45.5 & 103.4 \\
\hline $6 / 4 / 2013$ & 204 & 2.4 & 3640 & 7,760 & 40.2 & 98.2 \\
\hline $6 / 18 / 2013$ & 218 & 4.8 & 6520 & 23,050 & 66.8 & 124.8 \\
\hline $7 / 15 / 2013^{\mathrm{a}}$ & 245 & 4.4 & 6520 & 20,690 & 60.0 & 117.9 \\
\hline $8 / 15 / 2013^{a}$ & 276 & 3.9 & 6520 & 17,981 & 52.1 & 110.1 \\
\hline $9 / 15 / 2013^{a}$ & 307 & 3.4 & 6520 & 15,272 & 44.3 & 102.2 \\
\hline $10 / 15 / 2013$ & 337 & 2.9 & 6520 & 12,650 & 36.6 & 94.6 \\
\hline
\end{tabular}

${ }^{a}$ Linear interpolation

In addition, Boussinesq stress distribution for a uniformly loaded rectangular area (Newmark 1935) was used to calculate the induced vertical stress on Lift I of Boreholes 3 and 7 due to 1 he placement of a fresh waste lift. The applied vertical load was determined to be 69 and $59 \mathrm{kPa}$ for Borehole 3 and 
7 , respectively. The influence factors of the fresh waste lifts on the midheight of Lift I were determined to be 1 for boreholes 3 and 7, respectively.

A modified initial compression ratio was calculated for degraded waste $\left(C_{c, \text { old }}^{\prime}\right)$ for the increased strains due to the application of additional vertical stress (i.e., waste lift or earthen embankment). A $C_{c, \text { old }}^{\prime}$ was calculated for Lift I of Boreholes 3, 6, and 7. A $C_{c, \text { old }}^{\prime}$ for Lift I of Boreholes 1, 2, and 4 could not be calculated due to an inadequate amount of available information (e.g., initial lift heights from aerial surveys). A $C_{c, \text { old }}^{\prime}$ for Lift I of Boreholes 5 and 8 was not determined to due complications with the instrumentation.

For Boreholes 3 and 7, the increased vertical stress was due to the construction of an overlying fresh waste lift. For Borehole 6 , the increased vertical stress was generated from the addition of the embankment over the top of the existing waste layers. The increase in applied stress due to the addition of waste lifts and/or the embankment on Lift I of Boreholes 3, 6, and 7 was approximately, 45, 58, and $25 \mathrm{kPa}$, respectively (Table 4.13). The corresponding $C_{c, \text { old }}^{\prime}$ values for boreholes 3,6 , and 7 were determined to be $0.105,0.322$, and 0.069, respectively (Table 4.14).

Table 4.13. $C_{c, \text { old }}^{\prime}$ Values for the Bottom Lift of Boreholes 3, 6, and 7.

\begin{tabular}{|c|c|c|c|c|c|c|c|c|}
\hline Borehole & Lift & $\begin{array}{c}\mathbf{H}_{\mathbf{o}} \\
(\mathbf{m})\end{array}$ & $\begin{array}{c}\boldsymbol{\sigma}_{\boldsymbol{i}} \\
\mathbf{( k P a )}\end{array}$ & $\begin{array}{c}\boldsymbol{\sigma}_{\boldsymbol{f}} \\
\mathbf{( k P a )}\end{array}$ & $\begin{array}{c}\Delta \boldsymbol{\sigma} \\
\mathbf{( k P a )}\end{array}$ & $\begin{array}{c}\text { Initial } \\
\mathbf{S t a i n} \\
(\mathbf{\%})\end{array}$ & $\begin{array}{c}\text { Final } \\
\text { Strain } \\
(\%)\end{array}$ & $\boldsymbol{C}_{\boldsymbol{c}, \text { old }}^{\prime}$ \\
\hline $\mathrm{BH} 3$ & $\mathrm{I}$ & 6.5 & 24.6 & 69.2 & 45 & 0 & 5.1 & 0.105 \\
\hline $\mathrm{BH} 6$ & $\mathrm{I}$ & 8.9 & 60.3 & $118.3^{\mathrm{a}}$ & 58 & 0 & 9.4 & 0.332 \\
\hline $\mathrm{BH} 7$ & $\mathrm{I}$ & 3.9 & 33.9 & 59.1 & 25 & 0 & 1.7 & 0.069 \\
\hline
\end{tabular}

${ }^{\mathrm{a}}$ Final stress corresponds to the total vertical stress $\left(\Delta \sigma_{T}\right)$ at the midheight of Lift I on 1/29/2013 
Over the duration of the test program, 3 fresh layers of waste were placed on top of installed Boreholes 3, 7, and 8 and initial vertical strains of the fresh waste layers were monitored. Lift II for Boreholes 7 and 8, and Lift III for borehole 3 were analyzed to obtain a modified initial compression ratio $\left(C_{c}^{\prime}\right)$ for as-placed MSW at SMRL. An initial as-compacted height of the waste layers was determined and a total unit weight of $6.18 \mathrm{kN} / \mathrm{m}^{3}$ was assumed for waste compacted at the as-received moisture conditions based on site records (Section 4.8.2). Initial stresses of the fresh waste layers were calculated for the mid-height of each layer and were associated with an initial strain equal to zero (Table 4.14). The strain was then measured periodically over the first two months following placement of the waste to determine the total strain for the initial compression phase. The increases in strain were likely a result of self-consolidation of the waste layer and application of a $0.45 \mathrm{~m}$ layer of intermediate soil cover. A unit weight of $18.9 \mathrm{kN} / \mathrm{m}^{3}$ was used for the intermediate soil cover based on nuclear density tests performed onsite.

Based on the log stress versus strain plots for the 3 fresh waste layers (Figure 4.18), the slopes of the curve are more representative of a modified recompression index $\left(C_{r}^{\prime}\right)$ for waste than a modified initial compression index $\left(C_{c}^{\prime}\right)$ for waste. This phenomenon can be attributed to the effects of compaction on the waste layer. A waste compactor applies a vertical stress of approximately 45 $\mathrm{kPa}$ (Olivier and Gourc 2007) on a given zone of influence of a waste mass. The stress associated with compaction can be considered the preconsolidation stress 
$\left(\sigma_{p}\right)$ of the fresh waste. Therefore, the 3 layers of fresh waste analyzed for initial compression were in an overconsolidated condition due to the compaction process (Figure 4.18). A summary of the measured strains and calculated $C_{r}^{\prime}$ values for each overconsolidated waste lift are provided in Table 4.14.

Table 4.14. Modified Recompression Index Properties of Fresh Waste Lifts

\begin{tabular}{|c|c|c|c|c|c|c|c|c|c|}
\hline Borehole & Lift & $\begin{array}{c}\mathrm{H}_{\mathrm{o}} \\
(\mathrm{m})\end{array}$ & $\begin{array}{c}\gamma_{t} \\
\left(\mathrm{kN} / \mathrm{m}^{3}\right)\end{array}$ & $\begin{array}{c}\sigma_{i} \\
(\mathrm{kPa})\end{array}$ & $\begin{array}{c}\sigma_{f} \\
(\mathrm{kPa})\end{array}$ & $\begin{array}{c}\sigma_{p} \\
(\mathrm{kPa})^{\mathrm{a}}\end{array}$ & $\begin{array}{c}\text { Initial } \\
\text { Stain } \\
(\%)\end{array}$ & $\begin{array}{c}\text { Final } \\
\text { Strain } \\
(\%)\end{array}$ & $C_{r}^{\prime}$ \\
\hline $\mathrm{BH} 3$ & III & 4.9 & 6.18 & 16.5 & 23.9 & 45 & 0 & 1.8 & 0.112 \\
\hline $\mathrm{BH} 7$ & II & 3.7 & 6.18 & 12.5 & 20.3 & 45 & 0 & 0.8 & 0.038 \\
\hline BH8 & 1 & 3.9 & 6.18 & 13.1 & 21.8 & 45 & 0 & 1.7 & 0.077 \\
\hline
\end{tabular}

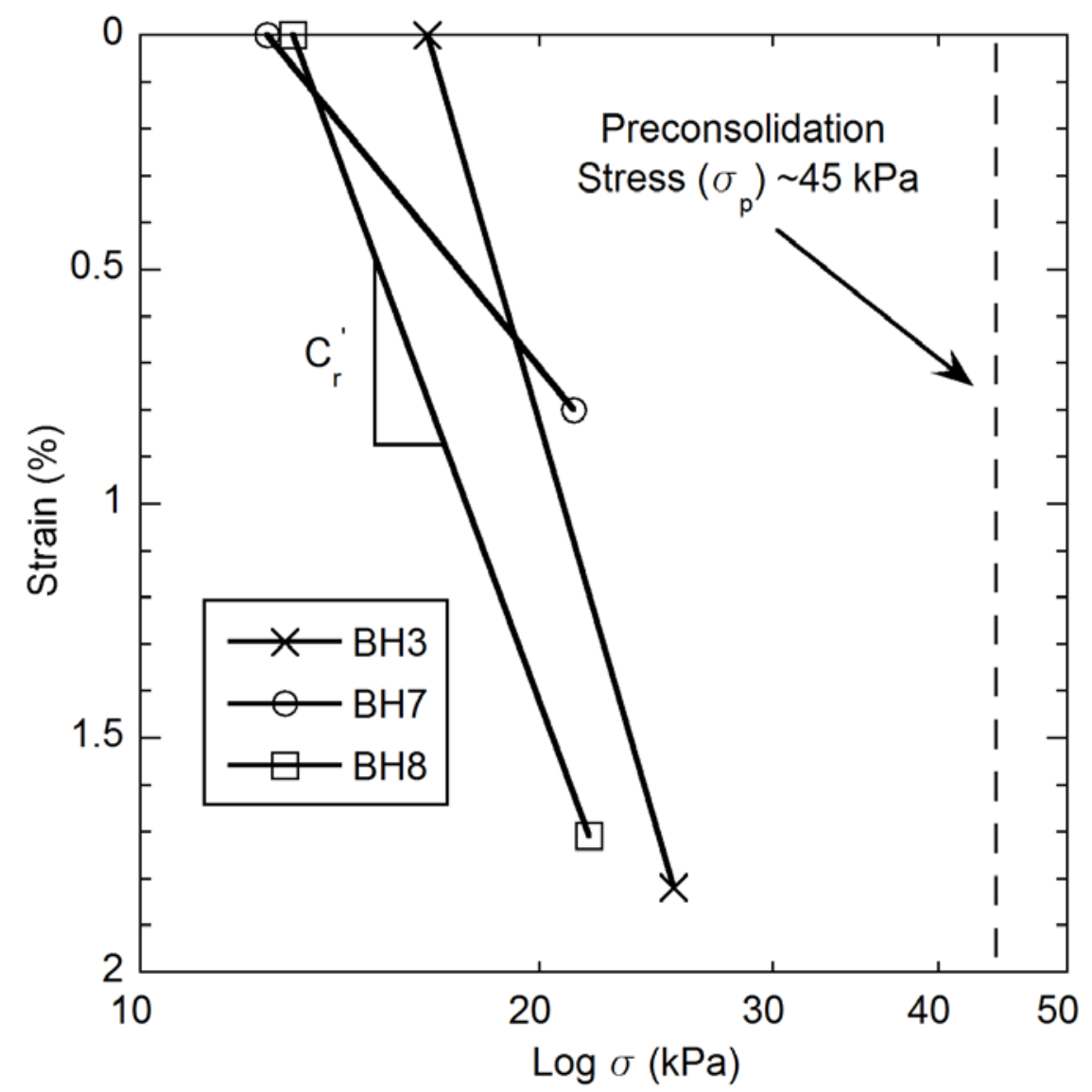

Figure 4.18. Modified Recompression Index for Fresh MSW at SMRL. 
In addition, the effects of unloading and reloading the embankment (i.e., removal and addition of soil) were analyzed using measurements obtained from Borehole 6. The initial vertical stress for the midheight of Lift I was determined for the condition immediately prior to placement of the embankment. The initial stress acting at the midpoint of Lift I was approximately $60 \mathrm{kPa}$ was caused by the overburden stresses associated with 2 existing overlying waste lifts (Lift II and III). From the Boussinesq stress distribution calculation for an embankment (US Navy 1986), the initial induced vertical stress at midheight of Lift I from the placement of the embankment on top of the waste mass was determined to be approximately $99 \mathrm{kPa}$. The stresses associated with the embankment decreased during the unloading phase and then increased during the reloading phase (Table 4.13).

During the unloading phase, the strain of Lift I leveled off (Figure 4.19). The leveling off of the strain is likely due to a net change of zero strain between swell (resulting from unloading) and continued secondary compression of the waste. As the soil is removed, the waste was attempting to swell because the compression from the original load had not yet completed (analogous to complete dissipation of pore pressures not being completed for continued soil consolidation). However, the continued time-dependent deformation of the waste (i.e., mechanical creep) was counteracting the swelling tendencies, thus resulting in a net change in vertical strain of zero for a given period of time (Figure 4.20).

A modified recompression index $\left(C_{r, \text { old }}^{\prime}\right)$ for the degraded waste of Lift I was estimated using the assumed secondary compression line in Figure 4.18. 
The net change in vertical strain was zero for three data points due to the unloading of the embankment. The assumed creep line is an estimate based on engineering judgment of the creep strain that would have occurred had the embankment not been unloaded. The difference between the flat portion (i.e., zero change in vertical strain) of the measured strain versus log time and the assumed creep line at those 3 data points represents a good estimate of the creep strain. The estimated changes in vertical strain were $0.24,0.44$, and $0.67 \%$ for the 3 data points and were assumed to be equal to the changes in swell at those 3 corresponding data points. Therefore, the calculated creep for the 3 data points from Figure 4.19 were translated to the corresponding data points on Figure 4.19 as the swell of the waste lift. Using the newly estimated swell values, an estimated recompression curve and $C_{r, \text { old }}^{\prime}$ was determined (Figure 4.20).

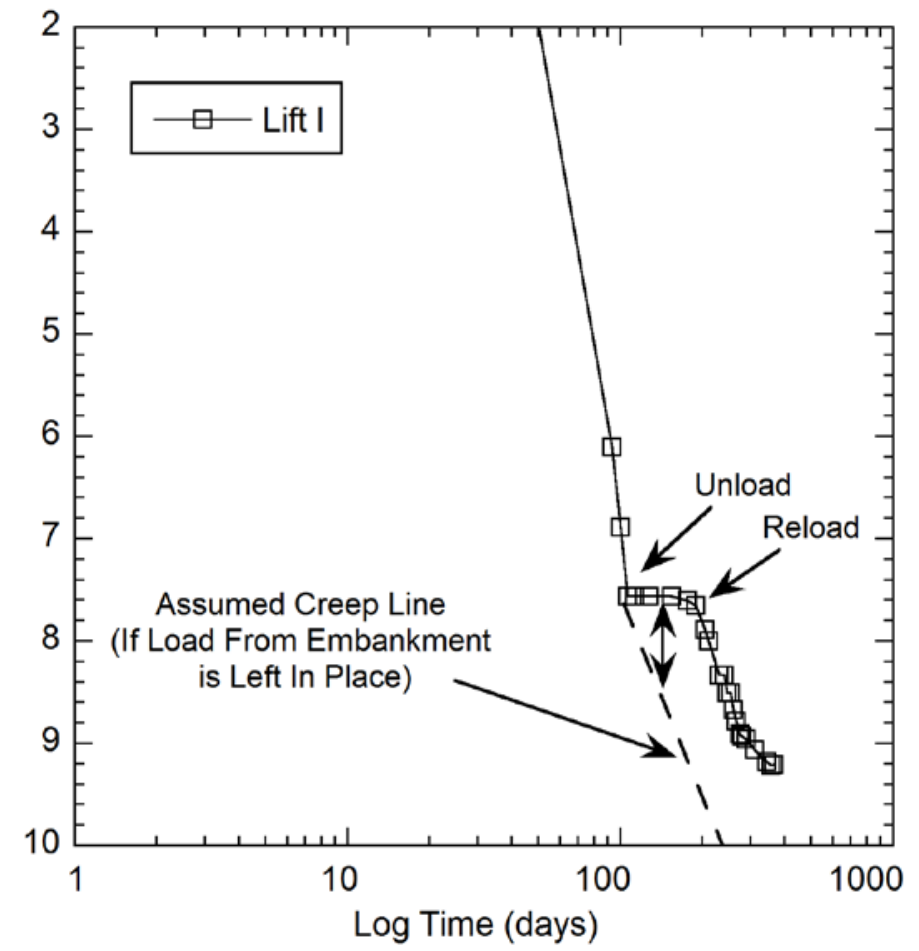

Figure 4.19. Assumed Creep Line For Lift I of BH6. 
Upon reloading of the embankment, the vertical strain versus log stress relationship returned to the virgin compression curve (Figure 4.20) for a short period of time until another unloading sequence. This occurrence demonstrates that the waste returned to an overconsolidated state for a short period of time and had the load been left untouched then the path would have continued along the virgin compression curve. 


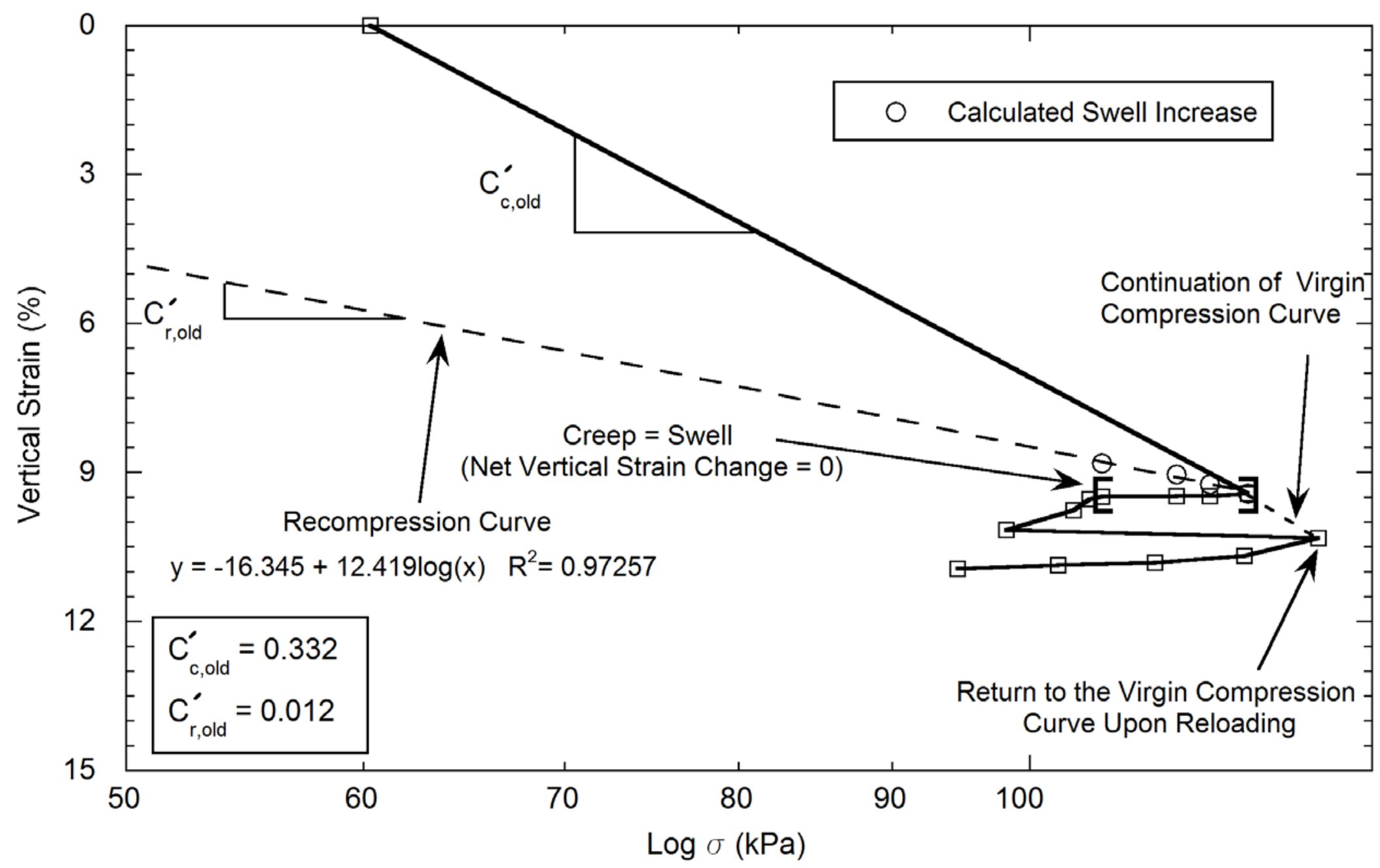

Figure 4.20. Estimated Recompression Curve and $C_{r, \text { old }}^{\prime}$ for Lift I of BH6. 


\subsection{Field Compaction Investigation}

The results of the meso- and field-scale compaction studies of municipal solid waste were used to evaluate the systematic moisture addition during waste placement on waste compaction and placement efficiency at MSW landfills. In addition, moisture distribution within the wastes due to added water was investigated. The detailed results of the compaction investigation are described in the following sections.

\subsubsection{Meso-Scale Compaction Study}

As-placed unit weights (i.e., dry and operational unit weights) of residential MSW improved significantly with the addition of intermediate amounts of moisture. When large amounts of moisture were added to the waste, as-placed unit weights decreased below the unit weight for wastes compacted at asreceived (i.e., baseline) conditions. The average dry unit weight of RMSW compacted and placed at moisture contents $\left(w_{d}\right)$ of 65,80 , and $95 \%$ increased by approximately 31,65 , and $39 \%$, respectively, as compared to the average dry unit weight of the waste compacted at the as-received moisture content (i.e., $55 \%)$. The average operational unit weight of RMSW compacted and placed at moisture contents of 65,80 , and $95 \%$ increased by 33,66 , and $37 \%$, respectively, as compared to the unit weights of the waste compacted at the asreceived moisture content. The average dry and operational unit weights of MSW compacted at $120 \%$ decreased by approximately 23 and $17 \%$, respectively, compared to the dry and as-received unit weights of waste compacted at $55 \%$. 
The data and results for the three phases of the meso-scale compaction study are provided in Table 4.15 .

The compaction curves generated for meso-scale compaction study (Figure 4.21) resulted in maximum dry unit weight $\left(\gamma_{d \max }\right)$ and operational unit weight $\left(\gamma_{\text {oper-max }}\right)$ of 8.5 and $13.3 \mathrm{kN} / \mathrm{m}^{3}$, respectively. These maximum unit weights correspond to optimum moisture contents, $w_{\text {opt-dmax }}$ and $w_{\text {opt-oper }}$, of 78.5 and $79.5 \%$, respectively (Figure 4.21). The calculated compaction characteristics (i.e., $\gamma_{\text {dmax }}, \gamma_{\text {oper-max }}, w_{\text {opt-dmax }}$, and $w_{\text {opt-oper }}$ ) for this test program were similar to the reported maximum unit weights for high effort field compaction tests performed by Von Stockhausen (2007). Von Stockhausen (2007) reported $\gamma_{d \max }$ of $8.2 \mathrm{kN} / \mathrm{m}^{3}$ at an optimum moisture content of $78 \%$ and $\gamma_{\text {oper-max }}$ of $10.7 \mathrm{kN} / \mathrm{m}^{3}$ at an optimum moisture content of approximately $75 \%$.

For the measured as-received average moisture content of $55 \%$, dry unit weights ranged between 3.01 and $10.71 \mathrm{kN} / \mathrm{m}^{3}$. At $65 \%$ moisture content the dry unit weights ranged between 4.64 and $11.17 \mathrm{kN} / \mathrm{m}^{3}$ and at $80 \%$ moisture content, $\gamma_{d}$ ranged between 5.85 and $13.33 \mathrm{kN} / \mathrm{m}^{3}$. Values of $\gamma_{d}$ for $95 \%$ moisture content varied between 4.49 and $10.98 \mathrm{kN} / \mathrm{m}^{3}$ and for $120 \%$ moisture content the $\gamma_{d}$ ranged between 3.79 and $4.12 \mathrm{kN} / \mathrm{m}^{3}$. Upper and lower bound limits of dry unit weight at given moisture contents for residential MSW are presented in Figure 4.22 along with the dry unit weight compaction curve generated for the mesoscale compaction study. The upper and lower limits represent the bound of the compaction data from the meso-scale tests. 


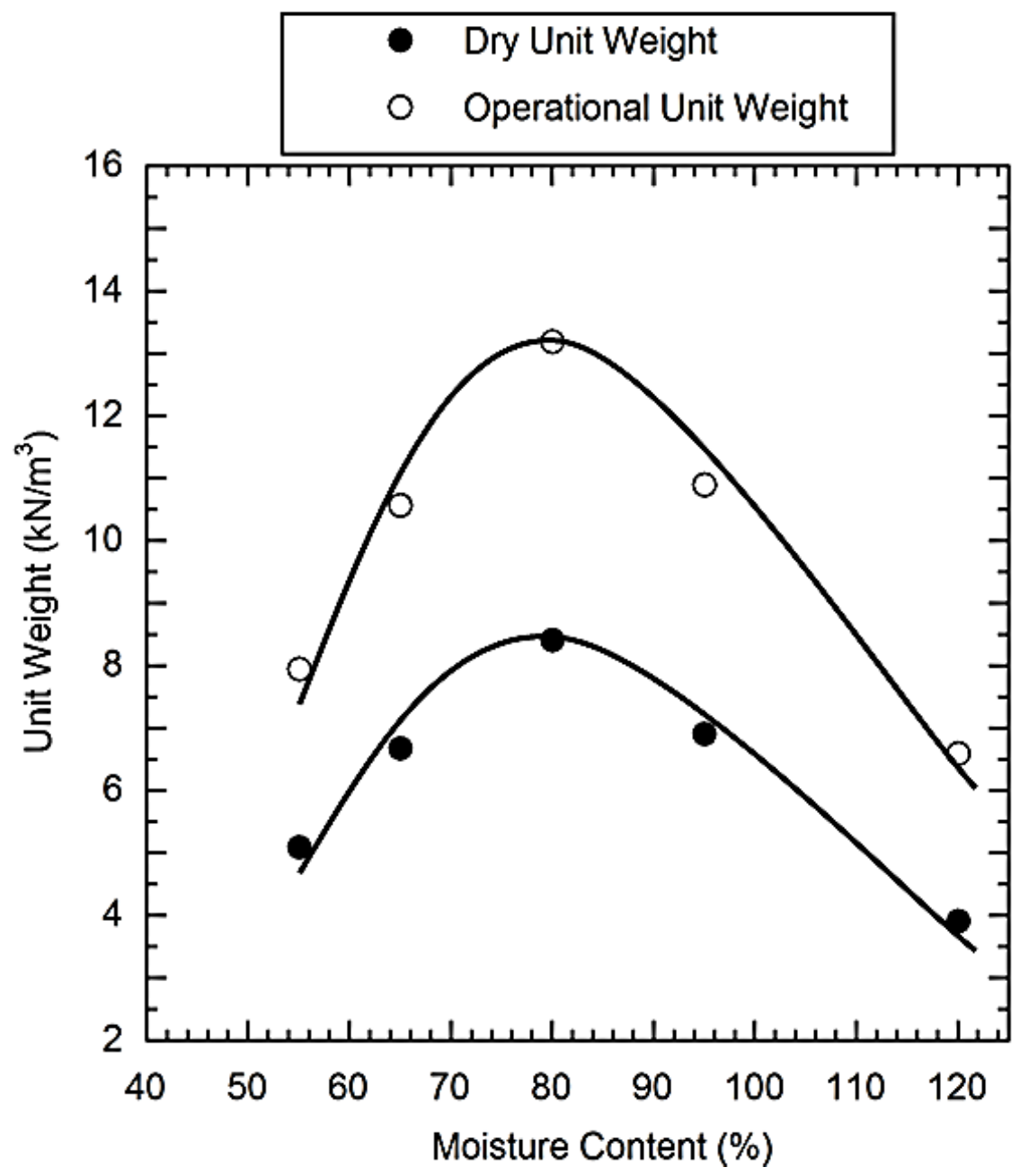

Figure 4.21. Compaction Curves from Meso-Scale Compaction Study. 


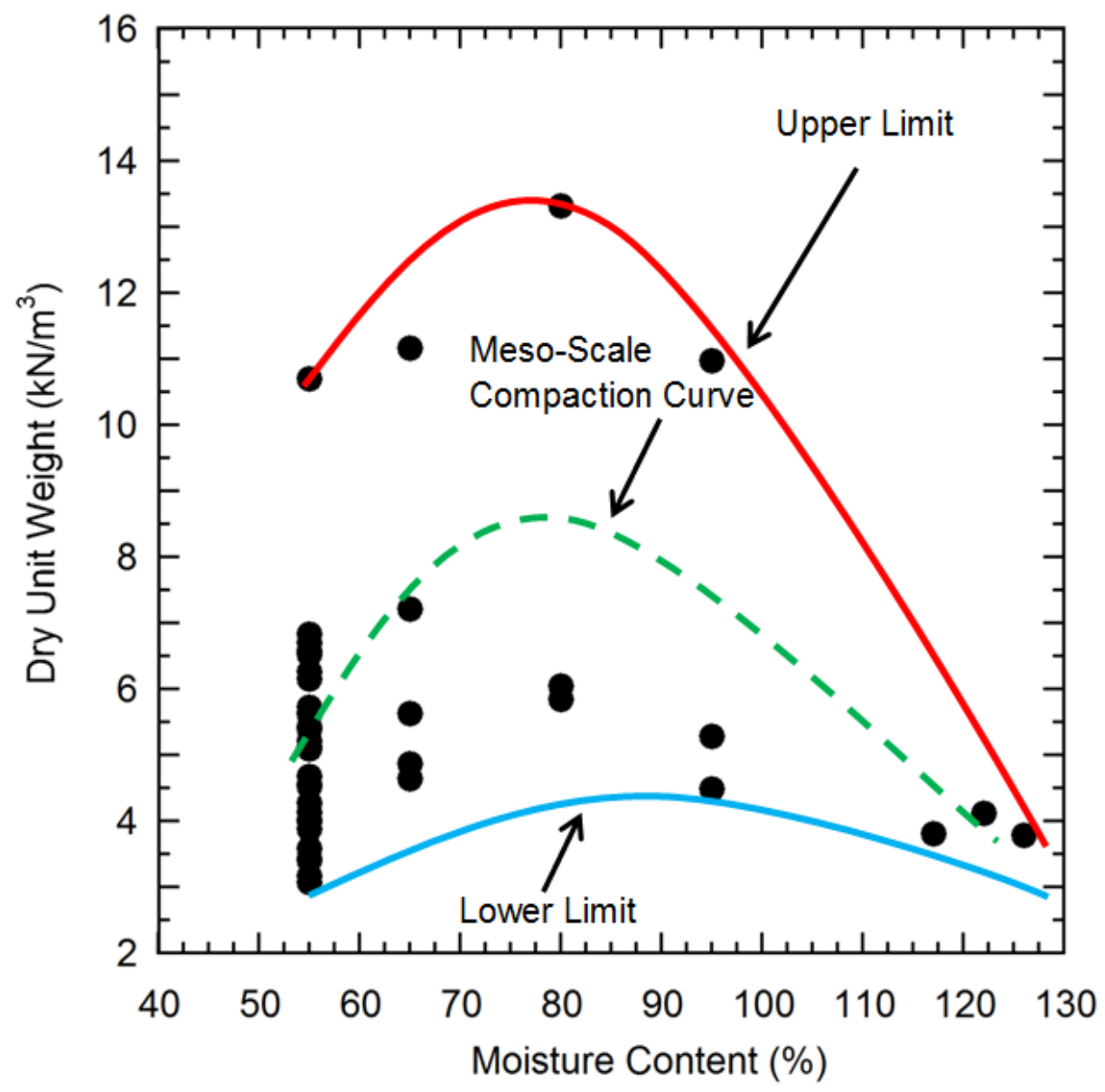

Figure 4.22. Upper and Lower Limits of Dry Unit Weight for RMSW. 
Table 4.15. Compaction Data for Meso-scale Study.

\begin{tabular}{|c|c|c|c|c|c|c|c|c|c|c|}
\hline Phase & Day & $\begin{array}{l}\text { Test } \\
\text { Pad }\end{array}$ & $\begin{array}{l}\text { Weight of } \\
\text { Incoming } \\
\text { MSW } \\
\text { (kN) }\end{array}$ & $\begin{array}{l}\text { Compacted } \\
\text { Volume } \\
\qquad\left(\mathrm{m}^{3}\right)\end{array}$ & $\begin{array}{c}\text { Target } \\
\text { Moisture } \\
\text { Content } \\
(\%)\end{array}$ & $\begin{array}{c}\text { Measured } \\
\text { Moisture } \\
\text { Content } \\
(\%)\end{array}$ & $\begin{array}{l}\text { Total } \\
\text { Weight } \\
\text { (kN) }\end{array}$ & $\underset{\left(\mathrm{kN} / \mathrm{m}^{3}\right)}{\gamma_{t}}$ & $\underset{\left(\mathrm{kN} / \mathrm{m}^{3}\right)}{\gamma_{d}}$ & $\begin{array}{c}\gamma_{\text {oper }} \\
\left(\mathrm{kN} / \mathrm{m}^{3}\right)\end{array}$ \\
\hline \multirow{12}{*}{ 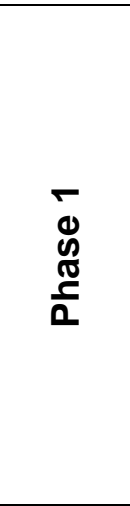 } & \multirow{2}{*}{1} & A & 420 & 76.3 & 65 & - & 447 & 7.66 & 4.64 & 7.19 \\
\hline & & $B$ & 455 & 124.6 & 55 & - & 455 & 4.77 & 3.07 & 4.77 \\
\hline & \multirow{2}{*}{2} & $\mathrm{~A}$ & 413 & 31.2 & 65 & - & 440 & $18.43^{\mathrm{a}}$ & $11.17^{\mathrm{a}}$ & $17.28^{\mathrm{a}}$ \\
\hline & & $\mathrm{B}$ & 380 & 55.9 & 55 & - & 380 & 8.89 & 5.73 & 8.89 \\
\hline & \multirow{2}{*}{3} & $A$ & 374 & 56.7 & 65 & - & 402 & 9.26 & 4.87 & 8.62 \\
\hline & & $\mathrm{B}$ & 349 & 85.6 & 55 & - & 349 & 5.32 & 3.43 & 5.32 \\
\hline & \multirow{2}{*}{4} & $\mathrm{~A}$ & 472 & 66.8 & 80 & - & 569 & 11.12 & 5.85 & 9.23 \\
\hline & & $B$ & 395 & 71.1 & 55 & - & 395 & 7.26 & 4.68 & 7.26 \\
\hline & \multirow{2}{*}{5} & $\mathrm{~A}$ & 308 & 54.2 & 80 & - & 363 & 8.76 & 4.49 & 7.43 \\
\hline & & $B$ & 313 & 58.2 & 55 & - & 313 & 7.03 & 4.53 & 7.03 \\
\hline & \multirow{2}{*}{6} & A & 361 & 67.9 & 80 & 117 & 430 & 8.27 & 3.81 & 6.95 \\
\hline & & $\mathrm{B}$ & 412 & 84.1 & 55 & - & 412 & 6.40 & 4.13 & 6.40 \\
\hline \multirow{14}{*}{ 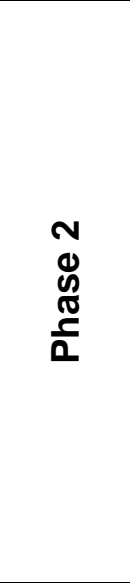 } & \multirow{2}{*}{1} & $A$ & 318 & 67.1 & 55 & - & 318 & 6.19 & 3.99 & 6.19 \\
\hline & & $B$ & 341 & 84.3 & 55 & - & 341 & 5.28 & 3.40 & 5.28 \\
\hline & \multirow{2}{*}{2} & A & 447 & 61.2 & 55 & - & 447 & 9.54 & 6.15 & 9.54 \\
\hline & & $B$ & 455 & 71.2 & 55 & - & 455 & 8.35 & 5.39 & 8.35 \\
\hline & \multirow{2}{*}{3} & $A$ & 385 & 45.3 & 65 & - & 413 & 11.90 & 7.21 & 11.10 \\
\hline & & $B$ & 431 & 64.3 & 55 & - & 431 & 8.76 & 5.65 & 8.76 \\
\hline & \multirow{2}{*}{4} & $A$ & 380 & 89.4 & 55 & - & 380 & 5.56 & 3.58 & 5.56 \\
\hline & & $B$ & 464 & 59.9 & 55 & - & 464 & 10.11 & 6.53 & 10.11 \\
\hline & \multirow{2}{*}{5} & $A$ & 530 & 115.1 & 55 & - & 530 & 6.02 & 3.88 & 6.02 \\
\hline & & $B$ & 408 & 108.4 & 55 & - & 408 & 4.92 & 3.17 & 4.92 \\
\hline & \multirow{2}{*}{6} & $A$ & 343 & 51.4 & 65 & 67 & 365 & 9.29 & 5.63 & 8.72 \\
\hline & & $B$ & 332 & 61.3 & 55 & - & 332 & 7.07 & 4.56 & 7.07 \\
\hline & \multirow{2}{*}{7} & $A$ & 461 & 58 & 55 & - & 461 & 10.39 & 6.71 & 10.39 \\
\hline & & $B$ & 448 & 60.4 & 55 & - & 448 & 9.70 & 6.26 & 9.70 \\
\hline
\end{tabular}


Table 4.15. Compaction Data for Meso-scale Study (Cont'd).

\begin{tabular}{|c|c|c|c|c|c|c|c|c|c|c|}
\hline Phase & Day & $\begin{array}{l}\text { Test } \\
\text { Pad }\end{array}$ & $\begin{array}{l}\text { Weight of } \\
\text { Incoming } \\
\text { MSW (kN) }\end{array}$ & $\begin{array}{c}\text { Compacted } \\
\text { Volume } \\
\left(\mathrm{m}^{3}\right)\end{array}$ & $\begin{array}{c}\text { Target } \\
\text { Moisture } \\
\text { Content } \\
(\%)\end{array}$ & $\begin{array}{c}\text { Measured } \\
\text { Moisture } \\
\text { Content } \\
(\%) \\
\end{array}$ & $\begin{array}{c}\text { Total } \\
\text { Weight } \\
\text { (kN) }\end{array}$ & $\begin{array}{c}\gamma_{t} \\
\left(\mathrm{kN} / \mathrm{m}^{3}\right)\end{array}$ & $\begin{array}{c}\gamma_{d} \\
\left(\mathrm{kN} / \mathrm{m}^{3}\right)\end{array}$ & $\begin{array}{c}\gamma_{\text {oper }} \\
\left(\mathrm{kN} / \mathrm{m}^{3}\right)\end{array}$ \\
\hline \multirow{18}{*}{ 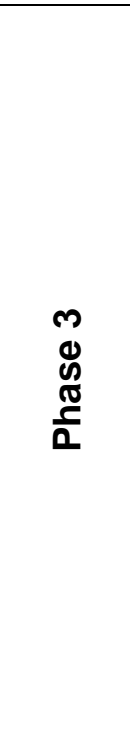 } & \multirow{2}{*}{1} & $\mathrm{C}$ & 353 & 83.1 & 55 & - & 353 & 5.55 & 3.58 & 5.55 \\
\hline & & $\mathrm{D}$ & 356 & 74.5 & 55 & - & 356 & 6.24 & 4.03 & 6.24 \\
\hline & \multirow{2}{*}{2} & C & 496 & 39 & 55 & - & 496 & $16.61^{a}$ & $10.71^{a}$ & $16.61^{a}$ \\
\hline & & $\mathrm{D}$ & 480 & 59.1 & 55 & - & 480 & 10.60 & 6.84 & 10.60 \\
\hline & \multirow{2}{*}{3} & $\mathrm{C}$ & 518 & 39.7 & 95 & - & 651 & $21.42^{a}$ & $10.98^{\mathrm{a}}$ & $17.06^{\mathrm{a}}$ \\
\hline & & $\mathrm{D}$ & 389 & 24.2 & 80 & - & 444 & $23.99^{\mathrm{a}}$ & $13.33^{\mathrm{a}}$ & $21.01^{\mathrm{a}}$ \\
\hline & \multirow{2}{*}{4} & $\mathrm{C}$ & 488 & 73.2 & 55 & - & 488 & 8.70 & 5.62 & 8.70 \\
\hline & & D & 410 & 66.2 & 55 & - & 410 & 8.09 & 5.22 & 8.09 \\
\hline & \multirow{2}{*}{5} & $\mathrm{C}$ & 459 & 90.6 & 55 & - & 459 & 6.61 & 4.27 & 6.61 \\
\hline & & $\mathrm{D}$ & 472 & 60.8 & 55 & - & 472 & 10.14 & 6.54 & 10.14 \\
\hline & \multirow{2}{*}{6} & C & 350 & 55.5 & 95 & - & 438 & 10.31 & 5.29 & 8.23 \\
\hline & & $\mathrm{D}$ & 332 & 46.5 & 80 & - & 388 & 10.89 & 6.05 & 9.34 \\
\hline & \multirow{2}{*}{7} & $\mathrm{C}$ & 459 & 75.40 & 55 & - & 459 & 7.95 & 5.13 & 7.95 \\
\hline & & D & 475 & 73.70 & 55 & - & 475 & 8.41 & 5.43 & 8.41 \\
\hline & \multirow{2}{*}{8} & C & 353 & 58.30 & 55 & - & 353 & 7.91 & 5.10 & 7.91 \\
\hline & & $\mathrm{D}$ & 517 & 66.20 & 55 & - & 517 & 10.21 & 6.59 & 10.21 \\
\hline & \multirow{2}{*}{9} & C & 445 & 85.40 & 110 & 122 & 597 & 9.14 & 4.12 & 6.82 \\
\hline & & $\mathrm{D}$ & 435 & 94.00 & 110 & 126 & 617 & 8.57 & 3.79 & 6.04 \\
\hline
\end{tabular}

${ }^{a}$ Possible penetration of waste into underlying waste layer resulted in higher unit weights

Note: Bold and Italicized numbers represent days of moisture addition. The days when no surface measurement was taken after compaction are represented by the "-" symbol. 
A penetration of waste from the top layer into the underlying waste layer was observed during the meso-scale compaction study. The penetration of waste into the underlying layer resulted in higher unit weights due to lower measured volumes for a given weight of waste. The penetration effects were observed to occur on 4 days (see note $a$ in Table 4.13) during the meso-scale study. A corrected total volume $\left(V_{t c}\right)$ was provided by assuming a degree of saturation equal to $100 \%$ and a specific gravity equal to 1.208 . Assuming a degree of saturation equal to $100 \%$ yields a more conservative value of the compacted volume of waste. The conservative $V_{t c}$ represented the volume of waste that would have been measured for that given day if some of the waste had not penetrated into the underlying layer and also if the waste was fully saturated (i.e., volume of voids is equal to the volume of water). The actual degrees of saturation of the MSW for the 4 days of observed penetration are not known. However, the assumption that the waste was fully saturated provided a reasonable estimate for the amount of volume gained due to penetration of the waste $\left(\Delta V_{\text {gain }}\right)$. A summary of the corrected volumes and estimated volumetric gains for the 4 days of observed waste penetration are provided in Table 4.16.

Table 4.16. Volume Gain Due to Waste Penetration Effects

\begin{tabular}{|c|c|c|c|c|c|c|}
\hline Phase & Day & $\begin{array}{l}\text { Test } \\
\text { Pad }\end{array}$ & $\begin{array}{c}\text { Target } \\
\text { Moisture } \\
\text { Content } \\
(\%)^{\mathrm{a}}\end{array}$ & $\begin{array}{c}\text { Measured } \\
\text { Volume, } \\
V_{t}\left(\mathrm{~m}^{3}\right)\end{array}$ & $\begin{array}{l}\text { Corrected } \\
\text { Volume, } \\
V_{t c}\left(\mathrm{~m}^{3}\right)\end{array}$ & $\begin{array}{c}\Delta V_{\text {gain }} \\
\left(\mathrm{m}^{3}\right)\end{array}$ \\
\hline 1 & 2 & A & 65 & 31.2 & 40.2 & 9.0 \\
\hline 3 & 2 & $C$ & 55 & 39.0 & 44.9 & 5.9 \\
\hline 3 & 3 & C & 95 & 39.7 & 60.5 & 20.8 \\
\hline 3 & 3 & $\mathrm{D}$ & 80 & 24.2 & 41.0 & 16.8 \\
\hline
\end{tabular}

${ }^{a}$ The target and measured moisture contents were assumed to be the same 
An operational waste placement factor (OWPF) was determined, to evaluate the additional weight of RMSW that could be placed into a given volume of airspace due to the addition of moisture prior to compaction. The OWPF is defined as the as-compacted operational unit weight of waste at a given moisture content divided by the as-compacted operational unit weight of waste at the asreceived moisture content (Equation 4.1). Therefore, the OWPF for waste compacted at $55 \%$ during the meso-scale compaction study was equal to 1 .

$$
O W P F=\frac{\gamma_{o p e r, M C}}{\gamma_{o p e r, A R}}
$$

Where:

$O W P F=$ operational waste placement factor

$\gamma_{o p e r, M C}=$ operational unit weight at a given moisture content

$\gamma_{o p e r, A R}=$ operational unit weight at the as-received moisture content

The maximum OWPF was calculated for waste compacted near $80 \%$ which naturally aligns with the measured $w_{\text {opt,oper }}$ of $79.7 \%$ for the meso-scale study. Approximately 1.66 times the amount of residential MSW can be placed into a given volume when compacted at or near $80 \%$ moisture content as compared to baseline moisture conditions (i.e., 55\% moisture content). A summary of the measured unit weights and OWPF for the combined target and measured moisture contents is proved in Table 4.17. 
Table 4.17. Summary of Meso-Scale Compaction Study

\begin{tabular}{|c|c|c|c|c|}
\hline $\begin{array}{c}\text { Combined } \\
\text { Target and } \\
\text { Measured } \\
\text { Moisture } \\
\text { Content (\%) }\end{array}$ & $\boldsymbol{\gamma}_{\boldsymbol{t}}\left(\mathbf{k N / \mathbf { m } ^ { 3 } )}\right.$ & $\begin{array}{c}\boldsymbol{\gamma}_{\boldsymbol{d}} \\
\left(\mathbf{k N} / \mathbf{m}^{\mathbf{3}}\right)\end{array}$ & $\begin{array}{c}\gamma_{\boldsymbol{o p e r}} \\
\left(\mathbf{k N} / \mathbf{m}^{\mathbf{3}}\right)\end{array}$ & $\begin{array}{c}\text { Operational Waste } \\
\text { Placement Factor } \\
\text { (OWPF) }\end{array}$ \\
\hline 55 & 7.95 & 5.10 & 7.95 & 1 \\
\hline 65 & 11.31 & 6.68 & 10.58 & 1.33 \\
\hline 80 & 15.33 & 8.41 & 13.20 & 1.66 \\
\hline 95 & 13.49 & 6.92 & 10.91 & 1.37 \\
\hline 120 & 8.66 & 3.91 & 6.60 & 0.83 \\
\hline
\end{tabular}

The spatial variability associated with moisture addition also was determined for the meso-scale compaction study. The excavated tests pits (Figure 3.21) were used to determine the resulting moisture contents with depth and analyze the absorptive tendencies of the waste (i.e., degree of saturation and field capacity). The results of the test pit measurements (Table 4.18) indicated that the measured moisture contents were on average, within $17 \%$ of the target moisture contents. However, the surface measurement during Phase 1 was determined to be $117 \%$ compared to the target moisture content of $80 \%$ (a difference of 37\%). The significant difference between the two moisture contents may be attributed to a pumping effect (i.e., moisture was pumped to the surface) that likely occurred during Phase 1 of the meso-scale tests. Alternatively, the waste could have arrived at higher moisture content than originally assumed and the addition of moisture resulted in significantly higher moisture content measurements. If this data point is omitted, the resulting difference between target and measured moisture contents is on average $10 \%$. 
Table 4.18. Test Pit Measurements for Meso-Scale Compaction Study.

\begin{tabular}{|c|c|c|c|}
\hline \multirow{3}{*}{ Test Pit } & $\begin{array}{c}\text { Depth of } \\
\text { Measurement (m) }\end{array}$ & $\begin{array}{c}\text { Target Moisture } \\
\text { Content (\%) }\end{array}$ & $\begin{array}{c}\text { Measured } \\
\text { Moisture Content } \\
(\%)\end{array}$ \\
\hline \multirow{4}{*}{1} & 0 (Surface) & 80 & 117.4 \\
\cline { 2 - 4 } & 0.5 & 80 & 95.1 \\
\cline { 2 - 4 } & 0.9 & 80 & 89.1 \\
\cline { 2 - 4 } & 1.3 & 65 & 89.9 \\
\hline \multirow{4}{*}{2} & $0($ Surface) & 65 & 67.4 \\
\cline { 2 - 4 } & 0.5 & 55 & 69.9 \\
\cline { 2 - 4 } & 0.9 & 55 & 79.0 \\
\cline { 2 - 4 } & 1.3 & 65 & 66.0 \\
\hline \multirow{3}{*}{3} & 0 (Surface) & 110 & 122.9 \\
\cline { 2 - 4 } & 0.5 & 55 & 126.9 \\
\cline { 2 - 4 } & 0 (Surface) & 110 & 99. \\
\cline { 2 - 4 } & 0.5 & 55 & \\
\hline
\end{tabular}

The degree of saturation $(S)$ and volumetric moisture content $(\theta)$ were calculated for each day of the compaction study (Table 4.19). The degree of saturation was calculated using a specific gravity value of 1.208 which was experimentally determined for fresh compacted MSW (Section 4.5). The degrees of saturation ranged between 16.5 and $68.8 \%$ and the volumetric moisture contents ranged between 13.2 and $83.2 \%$.

In addition, the varied degree of saturation and volumetric moisture content were measured on the waste specimens obtained from the test pit excavation (Table 4.19). A total of 12 waste layers at various as-placed moisture contents were analyzed. For all 12 waste layers, the degree of saturation and volumetric moisture content of the waste layers increased after the addition of moisture. The increases in $S$ and $\theta$ in the surface layers were attributed to pumping of moisture to the surface or residential MSW arriving at higher moisture contents than the assumed as-received moisture content of $55 \%$. For the 
underlying waste layers (i.e., 0.45 to $1.3 \mathrm{~m}$ ), increases in degree of saturation of and volumetric moisture contents were likely a direct result of downward movement of moisture from the overlying waste layer. For waste compacted at target moisture contents of $55,65,80$, and $110 \%, S$ increased by $19,4.5,4.4$, and $4.3 \%$, respectively while $\theta$ increased by $28,7.7,8.1$, and 5.7 , respectively. Test pit excavations did not include a day of $95 \%$ target moisture content and therefore changes in $S$ and $\theta$ for waste compacted at target moisture content of $95 \%$ were not determined. On average, the degree of saturation and volumetric moisture content were determined to increase by $10 \%$ and $15 \%$, respectively. 
Table 4.19. Moisture Characteristics of the Meso-Scale Compaction Study.

\begin{tabular}{|c|c|c|c|c|c|c|c|c|c|c|c|}
\hline Phase & Day & $\begin{array}{l}\text { Test } \\
\text { Pad }\end{array}$ & $\begin{array}{c}\text { Target } \\
w_{d} \\
(\%)\end{array}$ & $\begin{array}{c}\text { Measured } \\
w_{d} \\
(\%)^{\mathrm{b}}\end{array}$ & $\begin{array}{c}\text { Target } \\
w_{w} \\
(\%)\end{array}$ & $\begin{array}{c}\text { Measured } \\
w_{w} \\
(\%)^{b}\end{array}$ & $\begin{array}{c}\text { Moisture } \\
\text { Added } \\
\left(\mathrm{kN} / \mathrm{m}^{3}\right)\end{array}$ & $\begin{array}{c}\text { Degree of } \\
\text { Saturation } \\
\text { for Target } \\
w_{d}(\%)\end{array}$ & $\begin{array}{c}\text { Degree of } \\
\text { Saturation } \\
\text { for } \\
\text { Measured } \\
w_{d}(\%)\end{array}$ & $\begin{array}{c}\boldsymbol{\theta} \text { for } \\
\text { Target } \\
w_{d} \\
(\%)\end{array}$ & $\begin{array}{c}\theta \text { for } \\
\text { Measured } \\
w_{d}(\%)\end{array}$ \\
\hline \multirow{12}{*}{ 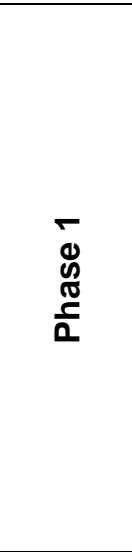 } & \multirow{2}{*}{1} & $A$ & 65 & - & 39 & - & 0.4 & 33.6 & - & 23.5 & - \\
\hline & & $\mathrm{B}$ & 55 & - & 35 & - & 0 & 16.5 & - & 13.2 & - \\
\hline & \multirow{2}{*}{2} & $A$ & 65 & - & 39 & - & 0.9 & $100^{c}$ & - & 56.6 & - \\
\hline & & $B$ & 55 & - & 35 & - & 0 & 39.1 & - & 24.6 & - \\
\hline & \multirow{2}{*}{3} & A & 65 & $89^{a}$ & 39 & 47 & 0.5 & 44.6 & 49.9 & 28.5 & 34.2 \\
\hline & & $B$ & 55 & - & 35 & - & 0 & 18.9 & - & 14.7 & - \\
\hline & \multirow{2}{*}{4} & $A$ & 80 & $89^{a}$ & 44 & 47 & 1.4 & 64.2 & 66.1 & 38.6 & 41.1 \\
\hline & & $\mathrm{B}$ & 55 & - & 35 & - & 0 & 28.8 & - & 20.1 & - \\
\hline & \multirow{2}{*}{5} & $\mathrm{~A}$ & 80 & $95^{a}$ & 44 & 49 & 1.0 & 44.3 & 46.9 & 30.4 & 33.3 \\
\hline & & $\mathrm{B}$ & 55 & - & 35 & - & 0 & 27.5 & - & 19.5 & - \\
\hline & \multirow{2}{*}{6} & $A$ & 80 & $117^{a}$ & 44 & 54 & 1.0 & 40.8 & 46.2 & 28.7 & 34.8 \\
\hline & & $\mathrm{B}$ & 55 & - & 35 & - & 0 & 24.2 & - & 17.7 & - \\
\hline \multirow{14}{*}{ 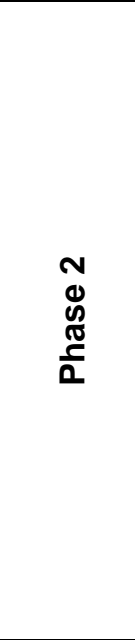 } & \multirow{2}{*}{1} & $\mathrm{~A}$ & 55 & - & 35 & - & 0 & 23.1 & - & 17.1 & - \\
\hline & & $\mathrm{B}$ & 55 & - & 35 & - & 0 & 18.7 & - & 14.6 & - \\
\hline & \multirow{2}{*}{2} & $A$ & 55 & - & 35 & - & 0 & 43.8 & - & 26.4 & - \\
\hline & & $B$ & 55 & - & 35 & - & 0 & 35.5 & - & 23.1 & - \\
\hline & \multirow{2}{*}{3} & $\mathrm{~A}$ & 65 & $66^{a}$ & 39 & 40 & 0.6 & 68.5 & 68.8 & 36.6 & 36.9 \\
\hline & & $B$ & 55 & - & 35 & - & 0 & 38.2 & - & 24.2 & - \\
\hline & \multirow{2}{*}{4} & A & 55 & $79^{a}$ & 35 & 44 & 0 & 20.0 & 23.9 & 15.4 & 19.1 \\
\hline & & $B$ & 55 & - & 35 & - & 0 & 48.4 & - & 28.0 & - \\
\hline & \multirow{2}{*}{5} & $\mathrm{~A}$ & 55 & $70^{a}$ & 35 & 41 & 0 & 22.2 & 25.1 & 16.7 & 19.3 \\
\hline & & $B$ & 55 & - & 35 & - & 0 & 17.1 & - & 13.6 & - \\
\hline & \multirow{2}{*}{6} & $\mathrm{~A}$ & 65 & $67^{a}$ & 39 & 40 & 0.4 & 44.8 & 45.3 & 28.5 & 29.1 \\
\hline & & $B$ & 55 & - & 35 & - & 0 & 27.7 & - & 19.6 & - \\
\hline & \multirow{2}{*}{7} & A & 55 & - & 35 & - & 0 & 50.8 & - & 28.8 & - \\
\hline & & $B$ & 55 & - & 35 & - & 0 & 45.1 & - & 26.9 & - \\
\hline
\end{tabular}


Table 4.19. Moisture Characteristics of the Meso-Scale Compaction Study (Cont'd).

\begin{tabular}{|c|c|c|c|c|c|c|c|c|c|c|c|}
\hline Phase & Day & $\begin{array}{l}\text { Test } \\
\text { Pad }\end{array}$ & $\begin{array}{c}\text { Target } \\
w_{d} \\
(\%)\end{array}$ & $\begin{array}{l}\text { Measured } \\
\qquad \begin{array}{c}w_{d} \\
(\%)\end{array}\end{array}$ & $\begin{array}{c}\text { Target } \\
w_{w_{b}} \\
(\%)^{b}\end{array}$ & $\begin{array}{l}\text { Measured } \\
\qquad w_{w} \\
(\%)^{b}\end{array}$ & $\begin{array}{c}\text { Moisture } \\
\text { Added } \\
\left(\mathrm{kN} / \mathrm{m}^{3}\right)\end{array}$ & $\begin{array}{c}\text { Degree of } \\
\text { Saturation } \\
\text { for Target } \\
w_{d}(\%)\end{array}$ & $\begin{array}{c}\text { Degree of } \\
\text { Saturation } \\
\text { for } \\
\text { Measured } \\
w_{d}(\%) \\
\end{array}$ & $\begin{array}{c}\theta \text { for } \\
\text { Target } \\
w_{d}(\%)\end{array}$ & $\begin{array}{c}\theta \text { for } \\
\text { Measured } \\
w_{d}(\%)\end{array}$ \\
\hline \multirow{18}{*}{ 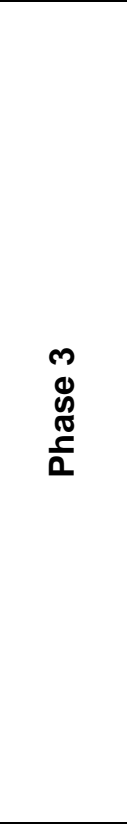 } & \multirow{2}{*}{1} & C & 55 & - & 35 & - & 0 & 20.0 & - & 15.4 & - \\
\hline & & $\mathrm{D}$ & 55 & - & 35 & - & 0 & 23.3 & - & 17.3 & - \\
\hline & \multirow{2}{*}{2} & $\mathrm{C}$ & 55 & - & 35 & - & 0 & $100^{c}$ & - & 46.0 & - \\
\hline & & $\mathrm{D}$ & 55 & - & 35 & - & 0 & 52.6 & - & 29.4 & - \\
\hline & \multirow{2}{*}{3} & $\mathrm{C}$ & 95 & - & 49 & - & 3.3 & $100^{c}$ & - & 81.4 & - \\
\hline & & $\mathrm{D}$ & 80 & - & 44 & - & 2.3 & $100^{c}$ & - & 83.2 & - \\
\hline & \multirow{2}{*}{4} & C & 55 & - & 35 & - & 0 & 37.8 & - & 24.1 & - \\
\hline & & D & 55 & - & 35 & - & 0 & 33.8 & - & 22.4 & - \\
\hline & \multirow{2}{*}{5} & C & 55 & - & 35 & - & 0 & 25.3 & - & 18.3 & - \\
\hline & & D & 55 & - & 35 & - & 0 & 48.6 & - & 28.1 & - \\
\hline & \multirow{2}{*}{6} & $\mathrm{C}$ & 95 & - & 49 & - & 1.6 & 59.5 & - & 39.2 & - \\
\hline & & $\mathrm{D}$ & 80 & - & 44 & - & 1.2 & 62.0 & - & 37.8 & - \\
\hline & \multirow{2}{*}{7} & C & 55 & - & 35 & - & 0 & 32.9 & - & 22.0 & - \\
\hline & & $D$ & 55 & - & 35 & - & 0 & 35.9 & - & 23.3 & - \\
\hline & \multirow{2}{*}{8} & C & 55 & - & 35 & - & 0 & 32.7 & 39.8 & 21.9 & 29.0 \\
\hline & & D & 55 & - & 35 & - & 0 & 49.2 & 59.4 & 28.3 & 39.8 \\
\hline & \multirow{2}{*}{9} & C & 110 & $122^{a}$ & 52 & 55 & 1.8 & 51.9 & 53.4 & 37.3 & 39.2 \\
\hline & & D & 110 & $126^{a}$ & 52 & 56 & 1.9 & 47.6 & 49.4 & 35.0 & 37.3 \\
\hline
\end{tabular}

${ }^{a}$ Moisture contents measured from the test pit excavations. These values were used to calculate degrees of saturation and volumetric moisture contents

${ }^{\mathrm{b}}$ Wet-basis moisture content (See Section 2.8.2)

${ }^{c}$ Assumed $\mathrm{S}=1$ due to possible penetration of waste into the underlying layer

Note: Bold numbers represent days of moisture addition. The "-" symbol represents the days when no surface measurement was taken after compaction and moisture contents were assumed to be the same as the target moisture contents 


\subsubsection{Full-Scale Compaction Study}

The full-scale compaction study yielded similar results to the meso-scale compaction study. Namely, intermediate amounts of moisture improved the compaction of MSW and larger amounts of moisture hindered the compaction of MSW. In addition, moisture addition and distribution characteristics (i.e., surface gravimetric moisture content, degree of saturation, and volumetric moisture content) of the full-scale compaction study were comparable to the meso-scale study.

In general, the dry and operational unit weights were lower for the fullscale compaction study as compared to the meso-scale study and this was attributed to the presence of bulkier items such as furniture and appliances. The constituents of the RMSW at SMRL (e.g., paper, cardboard, plastic bags, food containers, food and yard wastes) are favorable for a tighter packing arrangement of waste particles after moisture addition and compaction. On the contrary, the entire waste stream at SMRL, composed of residential, commercial, and self-delivered wastes, contains constituents such as furniture, appliances, and large quantities of plastic packaging that could potentially decrease the effectiveness of compaction. The average dry unit weight for waste compacted at 65 and $85 \%$ moisture content, increased by approximately 22.5 and 50\%, respectively, compared to the dry unit weight compacted at $45 \%$ moisture content. In addition, the average operational unit weight for waste compacted at 65 and $85 \%$ increased by 18 and 43\%, respectively. For MSW compacted at 
$105 \%$ moisture content, the $\gamma_{d}$ and $\gamma_{o p e r}$ decreased by approximately 15 and $26 \%$, respectively, compared to MSW compacted at $45 \%$ moisture content.

The compaction curves generated for the full-scale compaction study resulted in maximum dry unit weight $\left(\gamma_{d \max }\right)$ and maximum operational unit weight $\left(\gamma_{\text {oper-max }}\right)$ of 7.0 and $9.8 \mathrm{kN} / \mathrm{m}^{3}$, respectively (Figure 4.23). These maximum unit weights corresponded to optimum moisture contents, $w_{\text {opt-dmax }}$ and $w_{\text {opt-oper }}$, of 76 and $75.5 \%$, respectively (Figure 4.23 ). The calculated $\gamma_{d \max }$ and $w_{\text {opt-dmax }}$ for the full-scale compaction tests were in good agreement with the reported maximum dry unit weight and optimum moisture content for high effort field compaction tests performed by Von Stockhausen (2007). Von Stockhausen (2007) reported $\gamma_{d \max }$ of $8.2 \mathrm{kN} / \mathrm{m}^{3}$ at optimum moisture content of $78 \%$ and $\gamma_{\text {oper-max }}$ of $10.7 \mathrm{kN} / \mathrm{m}^{3}$ at optimum moisture content of approximately $75 \%$.

At $45 \%$ moisture content (i.e., as-received moisture condition), the minimum $\gamma_{d}$ and $\gamma_{\text {oper }}$ values were 3.19 and $4.63 \mathrm{kN} / \mathrm{m}^{3}$, respectively. The maximum measured $\gamma_{d}$ and $\gamma_{\text {oper }}$ values for MSW compacted at $45 \%$ were 9.71 and $14.09 \mathrm{kN} / \mathrm{m}^{3}$, respectively. The maximum dry unit weights at 65 and $85 \%$ moisture content were determined to be 6.81 and $7.47 \mathrm{kN} / \mathrm{m}^{3}$, respectively. In addition, the maximum measured operational unit weights for MSW compacted 65 and $85 \%$ moisture content were 9.41 and $9.80 \mathrm{kN} / \mathrm{m}^{3}$, respectively. The measured operational and dry unit weight values for MSW compacted at $105 \%$ were 3.92 and $4.93 \mathrm{kN} / \mathrm{m}^{3}$, respectively. A summary of the compaction data from 
the full-scale compaction tests is provided in Table 4.20 and estimated upper and lower bound limits for dry unit weight at given moisture contents for MSW are provided in Figure 4.24 . 
Table 4.20. Full-Scale Compaction Study Data

\begin{tabular}{|c|c|c|c|c|c|c|c|c|}
\hline Day & $\begin{array}{l}\text { Weight of } \\
\text { Incoming } \\
\text { MSW } \\
\text { (kN) }\end{array}$ & $\begin{array}{c}\text { Compacted } \\
\text { Volume } \\
\left(\mathrm{m}^{3}\right)\end{array}$ & $\begin{array}{c}\text { Target } \\
\text { Moisture } \\
\text { Content } \\
(\%)^{a}\end{array}$ & $\begin{array}{l}\text { Weight of } \\
\text { Additional } \\
\text { Moisture } \\
\text { (kN) }\end{array}$ & $\begin{array}{l}\text { Total } \\
\text { Weight } \\
\text { (kN) }\end{array}$ & $\underset{\left(\mathrm{kN} / \mathrm{m}^{3}\right)}{\gamma_{t}}$ & $\underset{\left(k N / m^{3}\right)}{\gamma_{d}}$ & $\begin{array}{c}\gamma_{\text {oper }} \\
\left(\mathrm{kN} / \mathrm{m}^{3}\right)\end{array}$ \\
\hline 1 & 2724 & 588.0 & 45 & 0 & 2724 & 4.63 & 3.19 & 4.63 \\
\hline 2 & 3042 & 471.1 & 65 & 481 & 3522 & 7.48 & 4.53 & 6.46 \\
\hline $3^{b}$ & $2859^{b}$ & $203.0^{b}$ & $45^{b}$ & 0 & $2859^{b}$ & $14.09^{b}$ & $9.71^{b}$ & $14.09^{b}$ \\
\hline 4 & 2216 & 359.5 & 45 & 0 & 2216 & 6.16 & 4.25 & 6.16 \\
\hline 5 & 2477 & 263.1 & 65 & 481 & 2957 & 11.24 & 6.81 & 9.41 \\
\hline 6 & 3566 & 526.8 & 45 & 0 & 3566 & 6.77 & 4.67 & 6.77 \\
\hline 7 & 980 & 165.0 & 45 & 0 & 980 & 5.94 & 4.09 & 5.94 \\
\hline 8 & 2962 & 308.7 & 85 & 917 & 3877 & 12.56 & 6.79 & 9.59 \\
\hline 9 & 2847 & 502.8 & 45 & 0 & 2847 & 5.66 & 3.90 & 5.66 \\
\hline 10 & 1926 & 350.8 & 45 & 0 & 1926 & 5.49 & 3.79 & 5.49 \\
\hline 11 & 2533 & 258.5 & 85 & 917 & 3449 & 13.34 & 7.21 & 9.80 \\
\hline 12 & 3108 & 379.4 & 45 & 0 & 3108 & 8.19 & 5.65 & 8.19 \\
\hline 13 & 1291 & 228.6 & 45 & 0 & 1291 & 5.65 & 3.90 & 5.65 \\
\hline 14 & 3256 & 353.1 & 85 & 917 & 4171 & 11.81 & 6.39 & 9.22 \\
\hline 15 & 2594 & 262.9 & 45 & 0 & 2594 & 9.87 & 6.81 & 9.87 \\
\hline 16 & 2927 & 537.3 & 45 & 0 & 2927 & 5.45 & 3.76 & 5.45 \\
\hline 17 & 2211 & 226.2 & 85 & 917 & 3127 & 13.82 & 7.47 & 9.77 \\
\hline 18 & 3028 & 625.7 & 45 & 0 & 3028 & 6.82 & 4.70 & 6.82 \\
\hline 19 & 1241 & 349.0 & 45 & 0 & 1241 & 8.33 & 5.74 & 8.33 \\
\hline 20 & 2907 & 385.8 & 45 & 0 & 2907 & 7.56 & 5.21 & 7.56 \\
\hline 21 & 2916 & 438.6 & 105 & 1362 & 2916 & 8.03 & 3.92 & 4.93 \\
\hline
\end{tabular}

${ }^{a}$ The target and measured moisture contents were assumed to be identical because test pits were not excavated during the full-scale study.

${ }^{\mathrm{b}}$ Outlier data point not included in analysis (see Figure 4.16). 
The maximum and minimum OWPFs for the full-scale compaction study were 1.55 at a moisture content of $85 \%$ and 0.80 at a moisture content of $105 \%$ (Table 4.21). In addition, the OWPF for waste compacted at $65 \%$ was determined to be 1.28. The OWPFs calculated for the full-scale study are reasonably similar to the OPWPFs calculated for the meso-scale study. However, the OWPFs for the meso-scale tests were generally larger than those for the full-scale test. The OWPFs for the meso-scale compaction study were larger due to a tighter packing arrangement of the waste, potential penetration into underlying waste layers, and absence of bulky items such as furniture. All three mechanisms led to an increase in the amount of waste placed into a given volume. In both studies, the OWPF displayed the same general trend of increasing and decreasing values as a function of moisture content. The OWPF initially increased with increasing moisture content to a maximum value at or near the optimum moisture content and then decreased with increasing moisture content (Tables 4.17 and 4.21). 


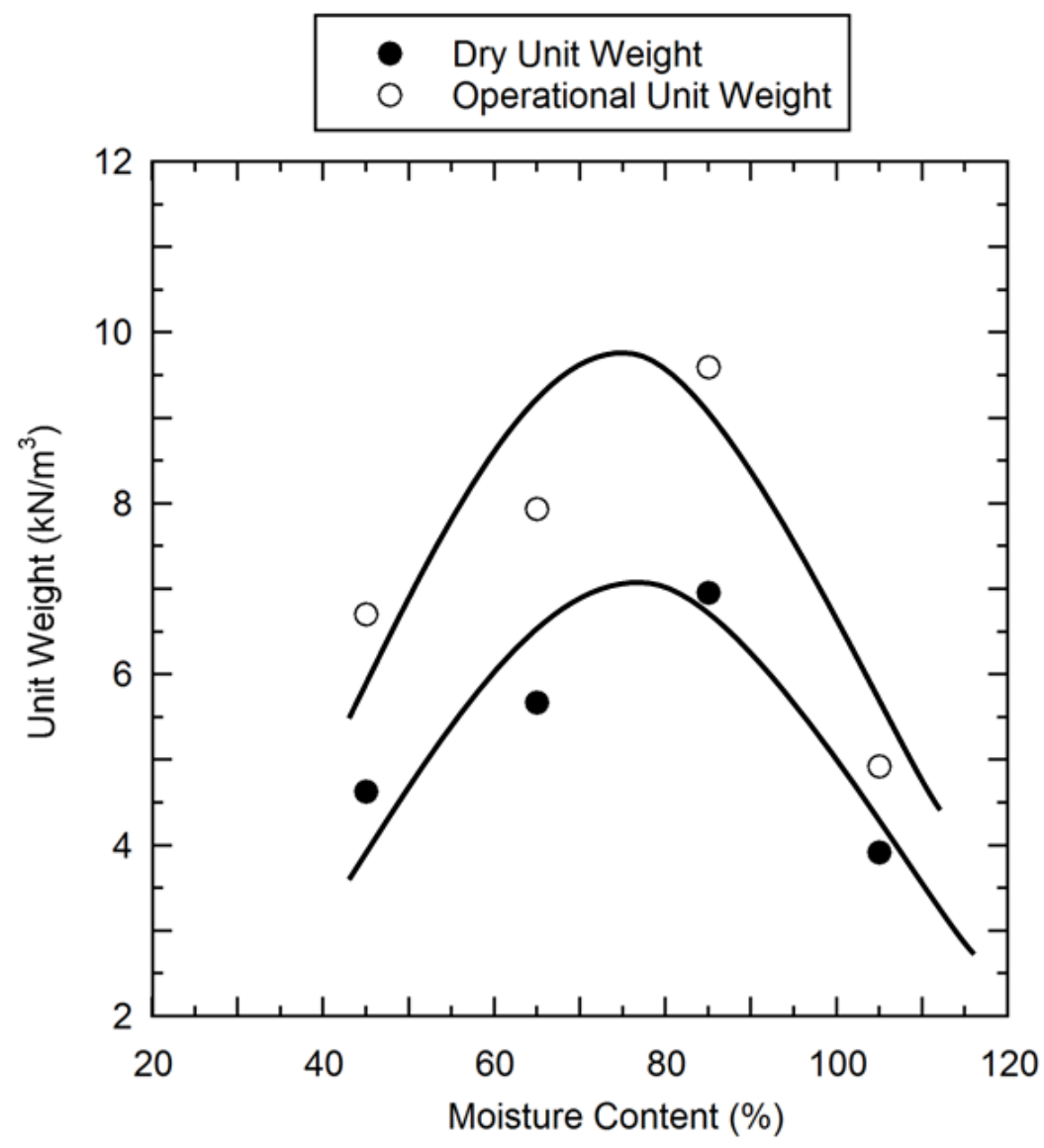

Figure 4.23. Compaction Curves for the Full-Scale Compaction Study.

The decrease in full-scale dry and operational unit weights from $85 \%$ moisture content to $105 \%$ moisture content were 44 and $49 \%$, respectively. Conversely, The decrease in meso-scale dry and operational unit weights at $95 \%$ moisture content to $120 \%$ moisture content were 43 and $40 \%$, respectively. The larger decrease in unit weights for the full-scale compaction study corresponded to a steeper slope on the wet of optimum portion (i.e., right side) of the full-scale compaction curve (Figure 4.23) as compared to the meso-scale compaction curve (Figure 4.21). 


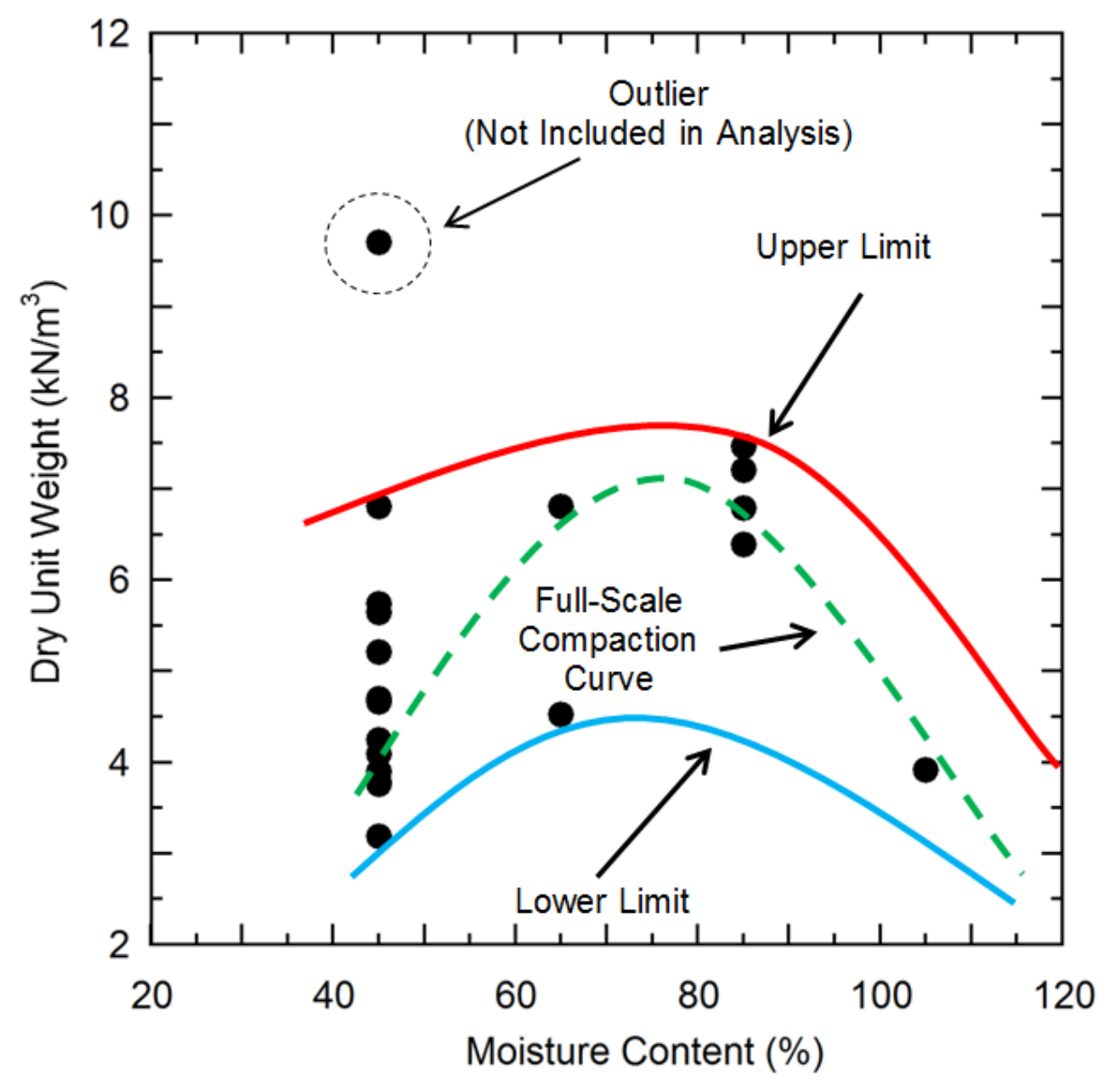

Figure 4.24. Upper and Lower Limits of Dry Unit Weight for MSW.

Table 4.21. Summary of Field-Compaction Study

\begin{tabular}{|c|c|c|c|c|}
\hline $\begin{array}{c}\text { Moisture } \\
\text { Content (\%) }\end{array}$ & $\begin{array}{c}\gamma_{t} \\
\left(\mathrm{kN} / \mathrm{m}^{3}\right)\end{array}$ & $\gamma_{d}\left(\mathrm{kN} / \mathrm{m}^{3}\right)$ & $\begin{array}{c}\gamma_{\text {oper }} \\
\left(\mathrm{kN} / \mathrm{m}^{3}\right)\end{array}$ & $\begin{array}{c}\text { Operational Waste } \\
\text { Placement Factor } \\
\text { (OWPF) }\end{array}$ \\
\hline 45 & 6.18 & 4.26 & 6.18 & 1.00 \\
\hline 65 & 9.36 & 5.67 & 7.94 & 1.28 \\
\hline 85 & 12.88 & 6.96 & 9.60 & 1.55 \\
\hline 105 & 8.03 & 3.92 & 4.93 & 0.80 \\
\hline
\end{tabular}

A total of 2 test pits were excavated for the full-scale compaction study several days subsequent to completion of the structured test program. The tests pits were excavated following a day of waste compaction at $85 \%$ (i.e., near 
optimum moisture content). The average weight of incoming waste during the full-scale compaction study and the average compacted volumes of waste placed at 45 and $85 \%$ during the structured full-scale compaction study were used for the degree of saturation calculation. The average weight of incoming waste during the compaction study was approximately $2553 \mathrm{kN} /$ day and the average compacted volumes for the waste compacted at 45 and $85 \%$ moisture content were 390 and $335 \mathrm{~m}^{3}$, respectively. In addition, an experimentally determined specific gravity value (Section 4.5) of 1.208 was used.

The target degrees of saturation (i.e., before test pit measurements) were determined to be $33.4 \%$ for waste compacted at $45 \%$ and $53.7 \%$ for waste compacted at $85 \%$ (Table 4.22). The average target volumetric moisture contents were determined to be 20.7 and $35.3 \%$, respectively (Table 4.22). For the MSW compacted at the as-received moisture content, the degree of saturation increased by an average of $43 \%$ and the volumetric moisture contents increased by an average of $78 \%$ (Table 4.22). The target degree of saturation and volumetric moisture content for waste compacted at the $85 \%$ moisture content were based on the assumption that the target moisture content was achieved. However, the samples obtained from the surface (i.e., $85 \%$ target moisture content) during the test pit excavations indicate that the waste was compacted at higher moisture content then the targeted moisture content of $85 \%$. Therefore, the measured $S$ and $\theta$ for the surface samples represented the actual as-placed moisture conditions and were higher than the estimated values. On the contrary, the difference between target and measured $S$ and $\theta$ for the underlying layers 
(i.e., $45 \%$ target moisture content) represented the change in $S$ and $\theta$ due to the addition of moisture on the top layer.

Table 4.22. Moisture Characteristics of the Full-Scale Compaction Study

\begin{tabular}{|c|c|c|c|c|c|c|c|}
\hline $\begin{array}{c}\text { Test } \\
\text { Pit }\end{array}$ & $\begin{array}{c}\text { Depth } \\
(\mathbf{m})\end{array}$ & $\begin{array}{c}\text { Target } \\
\boldsymbol{w}_{\boldsymbol{d}} \\
\mathbf{( \% )}\end{array}$ & $\begin{array}{c}\text { Measured } \\
\boldsymbol{w}_{\boldsymbol{d}} \mathbf{( \% )}\end{array}$ & $\begin{array}{c}\text { S for } \\
\text { Target } \\
\boldsymbol{w}_{\boldsymbol{d}} \mathbf{( \% )}\end{array}$ & $\begin{array}{c}\text { S for } \\
\text { Measured } \\
\boldsymbol{w}_{\boldsymbol{d}} \mathbf{( \% )}\end{array}$ & $\begin{array}{c}\boldsymbol{\theta} \text { for } \\
\text { Target } \\
\boldsymbol{w}_{\boldsymbol{d}}(\mathbf{\%})\end{array}$ & $\begin{array}{c}\boldsymbol{\theta} \text { for } \\
\text { Measure } \\
\mathbf{d} \boldsymbol{w}_{\boldsymbol{d}}(\%)\end{array}$ \\
\hline \multirow{3}{*}{1} & 0 & 85 & 119.0 & 53.7 & 58.8 & 35.3 & 41.7 \\
\cline { 2 - 8 } & 0.6 & 45 & 108.9 & 53.7 & 57.5 & 35.3 & 40.0 \\
\cline { 2 - 8 } & 1.2 & 45 & 112.4 & 33.4 & 47.7 & 20.7 & 35.3 \\
\hline \multirow{3}{*}{2} & 0 & 85 & 128.8 & 33.4 & 49.5 & 20.7 & 37.5 \\
\cline { 2 - 8 } & 0.6 & 45 & 97.0 & 33.4 & 45.6 & 20.7 & 32.8 \\
\cline { 2 - 8 } & 1.2 & 45 & 123.3 & 33.4 & 48.9 & 20.7 & 36.8 \\
\hline
\end{tabular}

The spatial distribution of moisture on the waste surface after compaction was determined for the as-received (45\%) and optimum (85\%) moisture content conditions. The measured moisture contents of the 100 samples (50 as-received and 50 optimum) obtained from the active face are summarized in Table 4.23. In addition, a spatial moisture distribution index map for the as-received and optimum conditions was developed (Figure 4.25).

In general, moisture was effectively distributed across the entire active face during days of moisture addition. A majority of the measured surface moisture contents after compaction of waste at the as-received moisture content were at or near 45\% (Figure 4.25 and Table 4.23). The spatial moisture content analysis for as-received wastes yielded an average moisture content of $34.0 \%$. The surface measurements for waste compacted at $85 \%$ yielded an average moisture content of $145.3 \%$ which is higher than the target moisture content. Ponding of moisture on the waste surface was visible and prominent at low points along the active face caused by the wheels of the compactor. The darker 
shades of blue on Figure 4.25 represent areas of high measured moisture contents which coincide with the lowest measured elevations on the active face. Although the average measured moisture content (145\%) was well above the target moisture content (85\%), the moisture distribution over the active face was relatively consistent as is presented in Figure 4.25. A majority of the map is green to light blue corresponding to relatively consistent moisture content values. If the areas of significantly higher moisture contents (i.e., samples $6,13.23,26$, $37,39,41,43,45$, and 46 ) are withheld from the analysis, the measured surface moisture content ranged between 81 and 179\% and averaged 133\%.

Table 4.23. Spatial Moisture Content Results

\begin{tabular}{|c|c|c|c|c|}
\hline \multirow{2}{*}{ Sample } & \multicolumn{2}{|c|}{ Sample Size (kg) } & \multicolumn{2}{c|}{ Moisture Content (\%) } \\
\cline { 2 - 5 } & As-Received & Optimum & As-Received & Optimum \\
\hline 1 & 1.535 & 2.142 & 22.4 & 152.3 \\
\hline 2 & 0.964 & 1.407 & 64.2 & 149.5 \\
\hline 3 & 0.764 & 2.281 & 20.3 & 169.6 \\
\hline 4 & 1.176 & 1.486 & 28.7 & 162.5 \\
\hline 5 & 1.508 & 1.855 & 35.4 & 178.5 \\
\hline 6 & 1.06 & 2.075 & 48.7 & 197.7 \\
\hline 7 & 0.958 & 1.686 & 25.7 & 117.3 \\
\hline 8 & 1.284 & 1.617 & 50.9 & 174.5 \\
\hline 9 & 1.838 & 1.722 & 37.7 & 143.6 \\
\hline 10 & 1.114 & 2.04 & 69.6 & 80.9 \\
\hline 11 & 0.721 & 1.264 & 39.7 & 98.1 \\
\hline 12 & 0.871 & 1.387 & 44.7 & 145.1 \\
\hline 13 & 0.99 & 1.579 & 20.0 & 180.5 \\
\hline 14 & 1.064 & 2.153 & 19.7 & 93.1 \\
\hline 15 & 1.001 & 1.504 & 32.4 & 99.5 \\
\hline 16 & 1.605 & 1.561 & 34.0 & 174.8 \\
\hline 17 & 1.305 & 1.316 & 20.5 & 164.3 \\
\hline 18 & 1.395 & 1.503 & 27.6 & 149.7 \\
\hline 19 & 1.453 & 1.861 & 51.5 & 105.2 \\
\hline 20 & 0.834 & 1.837 & 19.1 & 147.2 \\
\hline 21 & 1.014 & 1.8 & 32.0 & 102.3 \\
\hline 22 & 1.187 & 2.774 & 27.0 & 148.8 \\
\hline 23 & 1.209 & 1.93 & 44.4 & 244.0 \\
\hline 24 & 0.934 & 2.01 & 27.8 & 155.1 \\
\hline
\end{tabular}


Table 4.23. Spatial Moisture Content Results (Cont'd)

\begin{tabular}{|c|c|c|c|c|}
\hline \multirow{2}{*}{ Sample } & \multicolumn{2}{|c|}{ Sample Size (kg) } & \multicolumn{2}{c|}{ Moisture Content (\%) } \\
\cline { 2 - 5 } & As-Received & Optimum & As-Received & Optimum \\
\hline 25 & 0.971 & 2.52 & 37.0 & 122.4 \\
\hline 26 & 1.288 & 1.658 & 29.3 & 183.9 \\
\hline 27 & 1.216 & 1.975 & 21.5 & 159.9 \\
\hline 28 & 1.381 & 2.309 & 20.6 & 124.6 \\
\hline 29 & 1.038 & 1.662 & 27.8 & 106.7 \\
\hline 30 & 0.855 & 1.266 & 54.3 & 135.8 \\
\hline 31 & 0.866 & 1.717 & 9.2 & 134.6 \\
\hline 32 & 1.188 & 1.821 & 23.8 & 84.1 \\
\hline 33 & 1.224 & 1.674 & 8.2 & 157.1 \\
\hline 34 & 1.21 & 1.735 & 32.5 & 110.1 \\
\hline 35 & 1.351 & 1.93 & 66.0 & 97.3 \\
\hline 36 & 1.446 & 2.024 & 71.9 & 179.2 \\
\hline 37 & 1.092 & 2.499 & 42.2 & 225.8 \\
\hline 38 & 1.285 & 1.677 & 42.5 & 167.9 \\
\hline 39 & 1.335 & 1.606 & 27.9 & 204.7 \\
\hline 40 & 0.892 & 1.343 & 15.7 & 133.6 \\
\hline 41 & 0.968 & 1.781 & 28.7 & 187.3 \\
\hline 42 & 1.072 & 2.078 & 22.1 & 126.6 \\
\hline 43 & 1.269 & 1.497 & 22.4 & 195.9 \\
\hline 44 & 1.394 & 1.698 & 18.8 & 143.3 \\
\hline 45 & 1.27 & 1.844 & 24.0 & 188.1 \\
\hline 46 & 1.268 & 3.052 & 35.6 & 204.6 \\
\hline 47 & 0.811 & 2.156 & 45.1 & 119.1 \\
\hline 48 & 0.958 & 2.436 & 24.9 & 168.3 \\
\hline 49 & 1.156 & 1.273 & 23.5 & 131.5 \\
\hline 50 & 1.433 & 1.627 & 82.1 & 97.9 \\
\hline
\end{tabular}



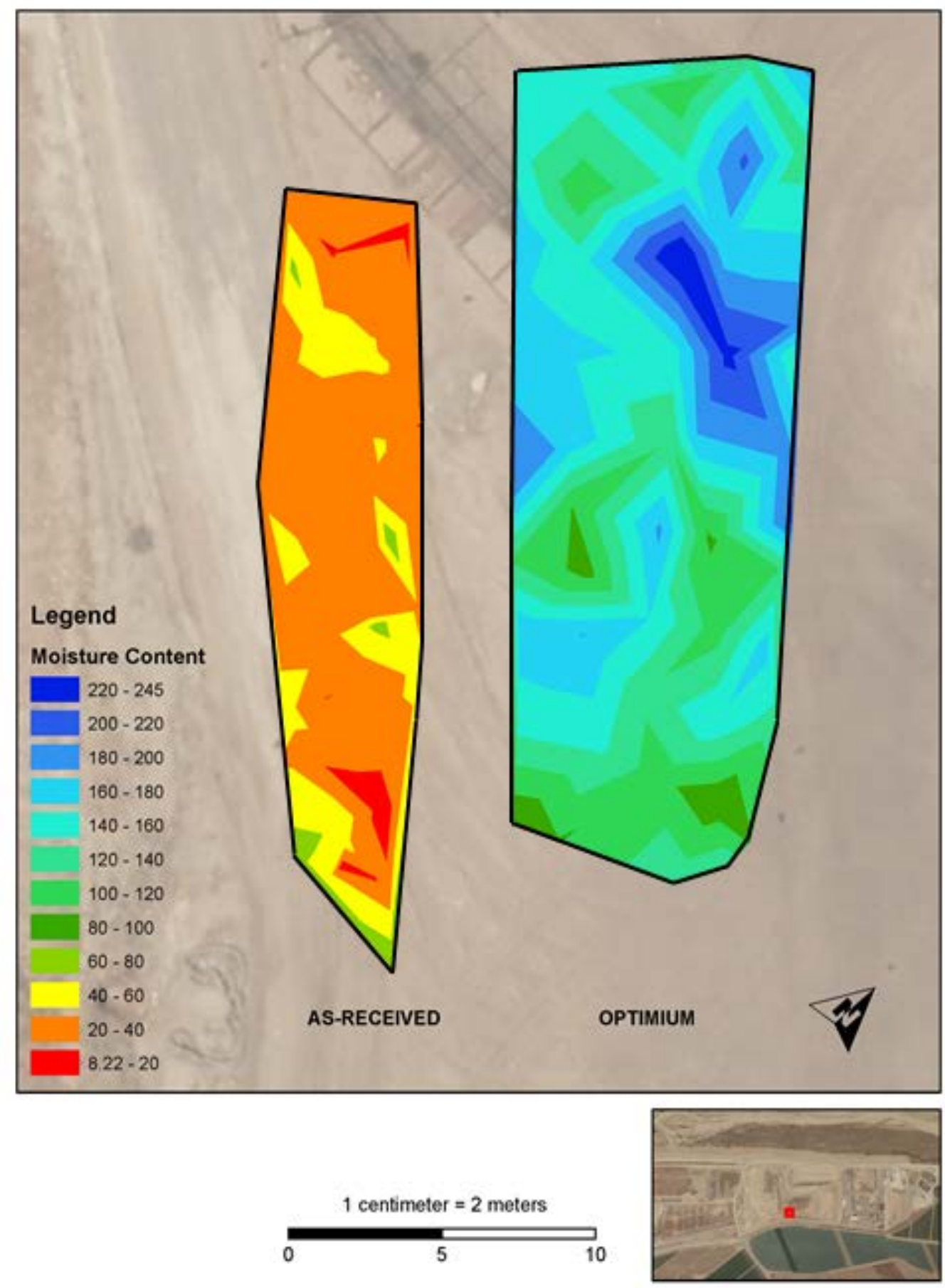

Figure 4.25. Spatial Moisture Distribution Index Map.

\subsection{Composite Plot}

Figures 4.26 to 4.32 summarize the measured physical and engineering of waste as a function of depth for each borehole. No definitive trends were 
observed between the waste properties for a given borehole. However, the specific gravity and organic content seem to mirror each other in some of the boreholes. For example, the specific gravity of $\mathrm{BH} 2$ increases to a mid-depth and then decreases at a great depth while the organic content behaves in an opposite manner. In addition, the vertical strain in all boreholes increases with increasing depth.

Due to complications with settlement array installation, the vertical strain of the bottom 2 waste lifts were measured for BH5 (Figure 4.29). In addition, one of the MERs in $\mathrm{BH} 8$ is not functioning properly and therefore, the settlement readings for the bottom waste layer were terminated after 176 days (Figure 4.32). 

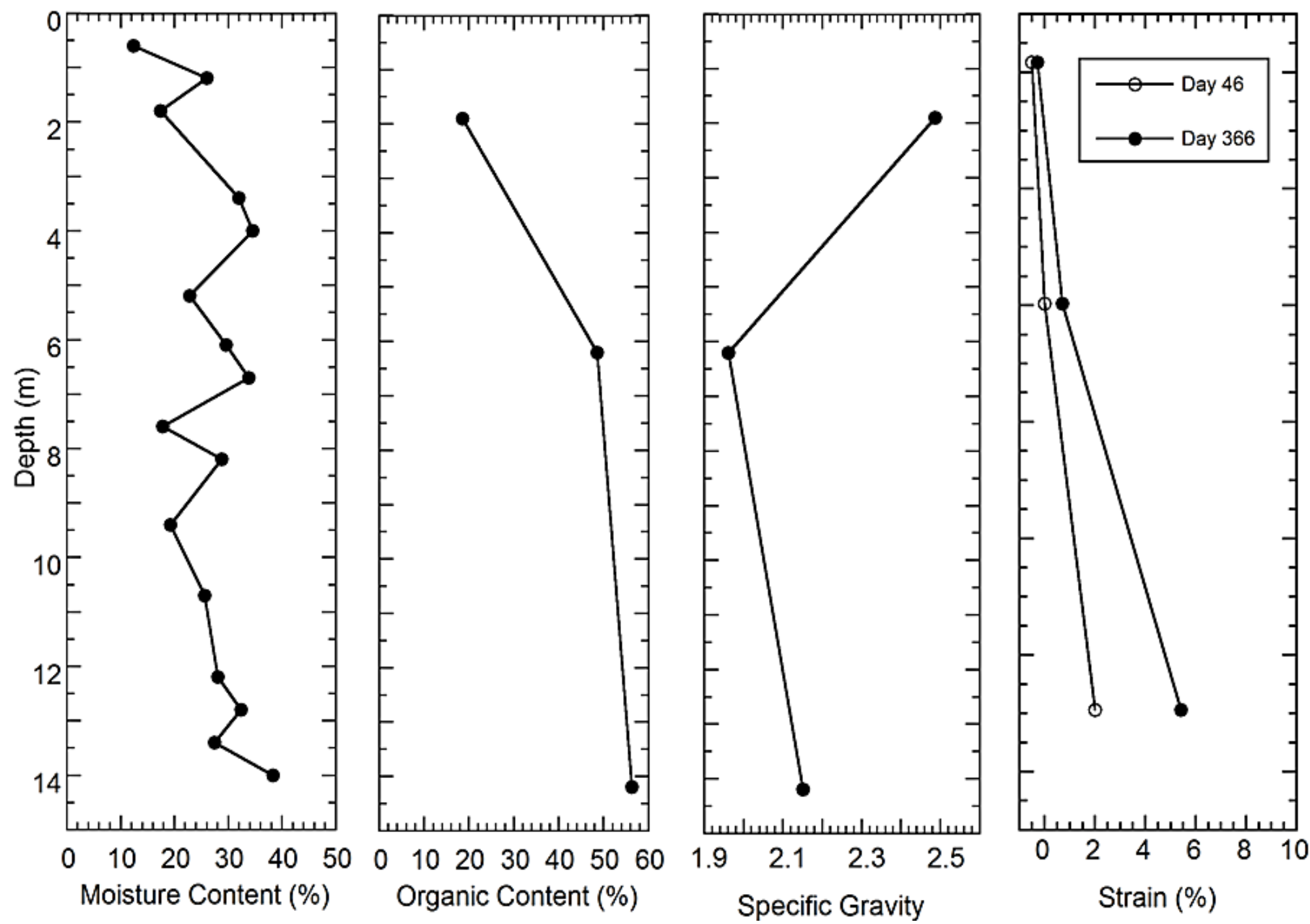

Figure 4.26. Physical and Engineering Properties of MSW as a Function of Depth for BH1. 

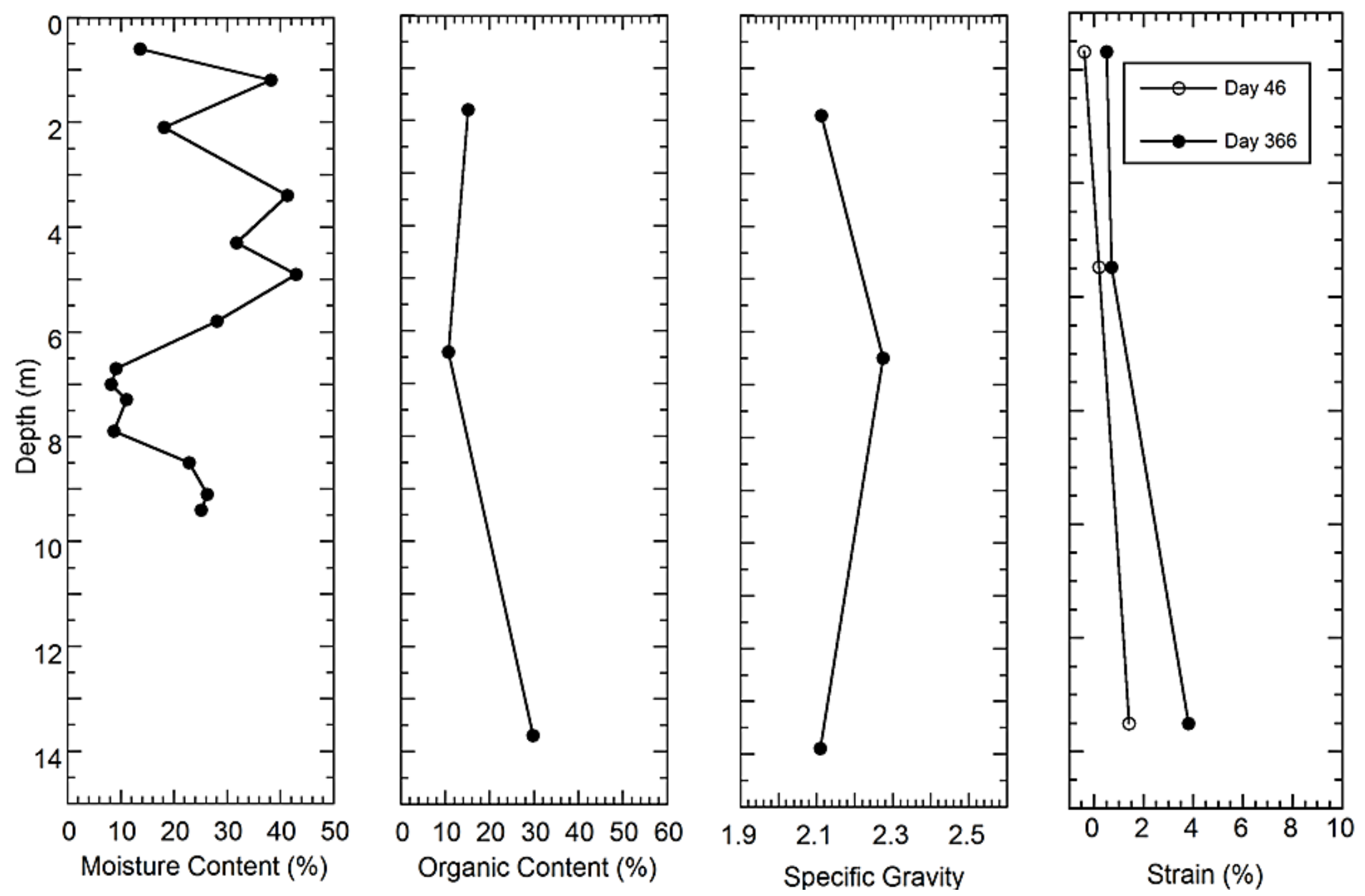

Figure 4.27. Physical and Engineering Properties of MSW as a Function of Depth for $\mathrm{BH} 2$. 

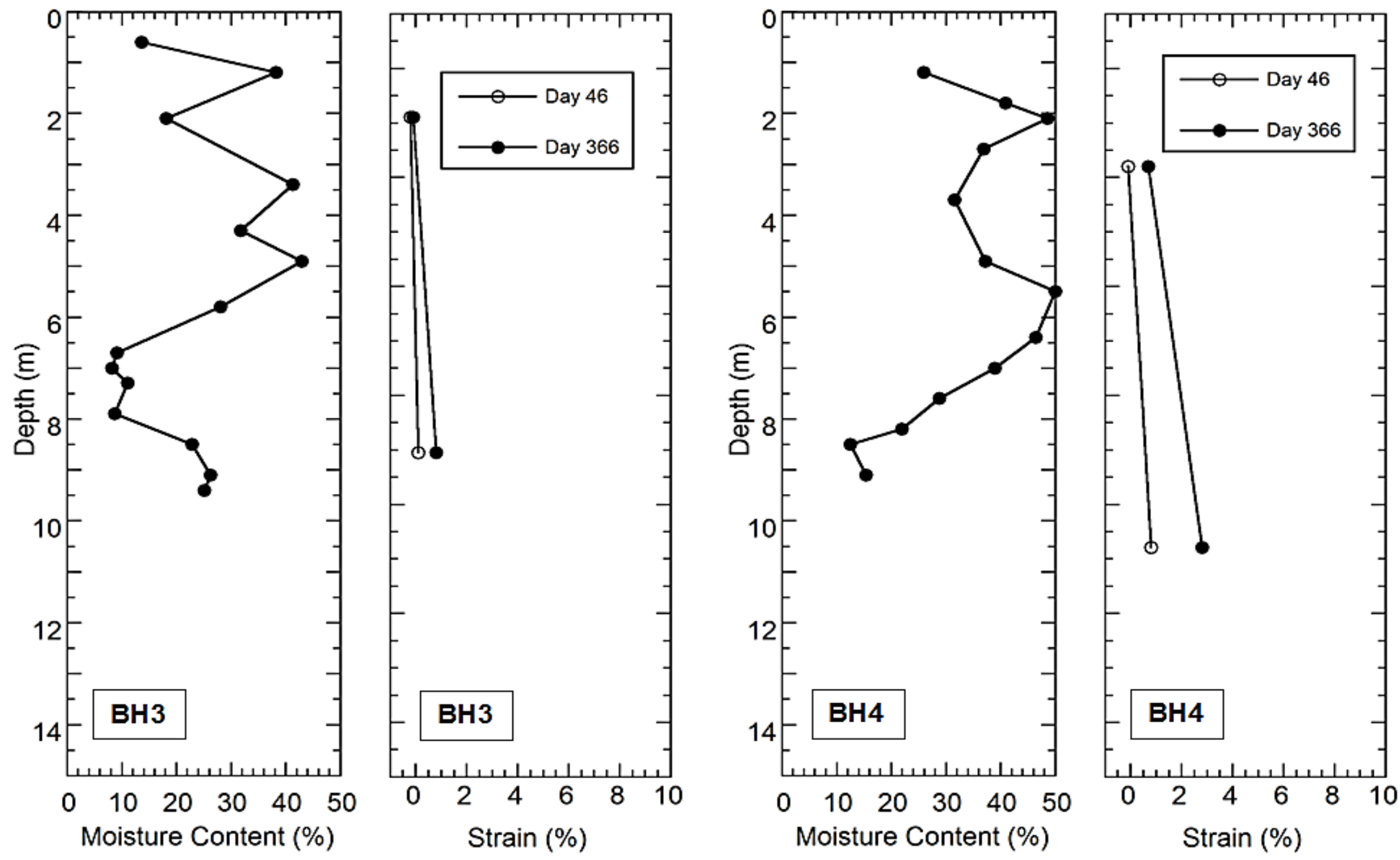

Figure 4.28. Physical and Engineering Properties of MSW as a Function of Depth for $\mathrm{BH} 3$ and $\mathrm{BH} 4$. 

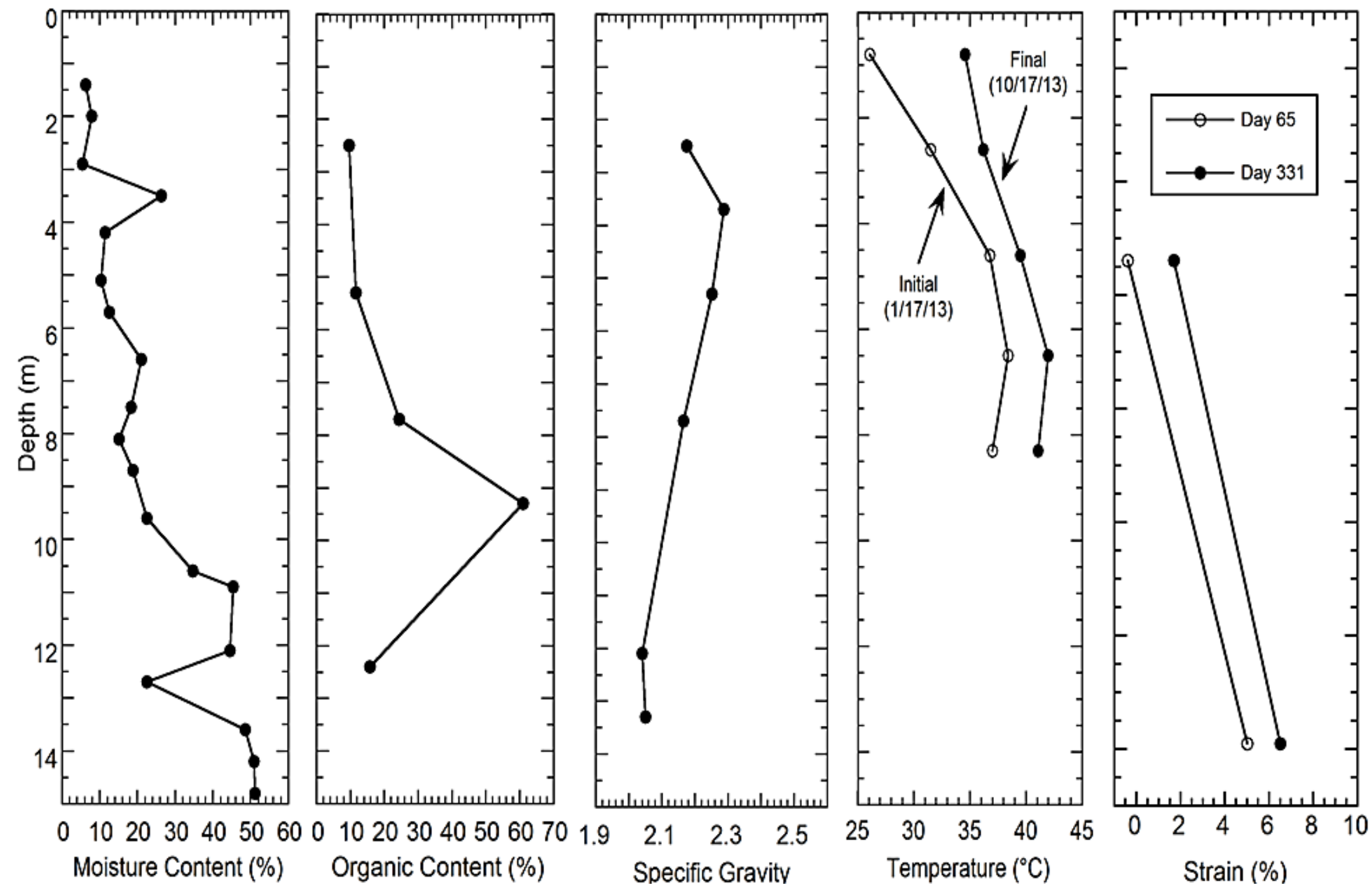

Figure 4.29. Physical and Engineering Properties of MSW as a Function of Depth for BH5. 

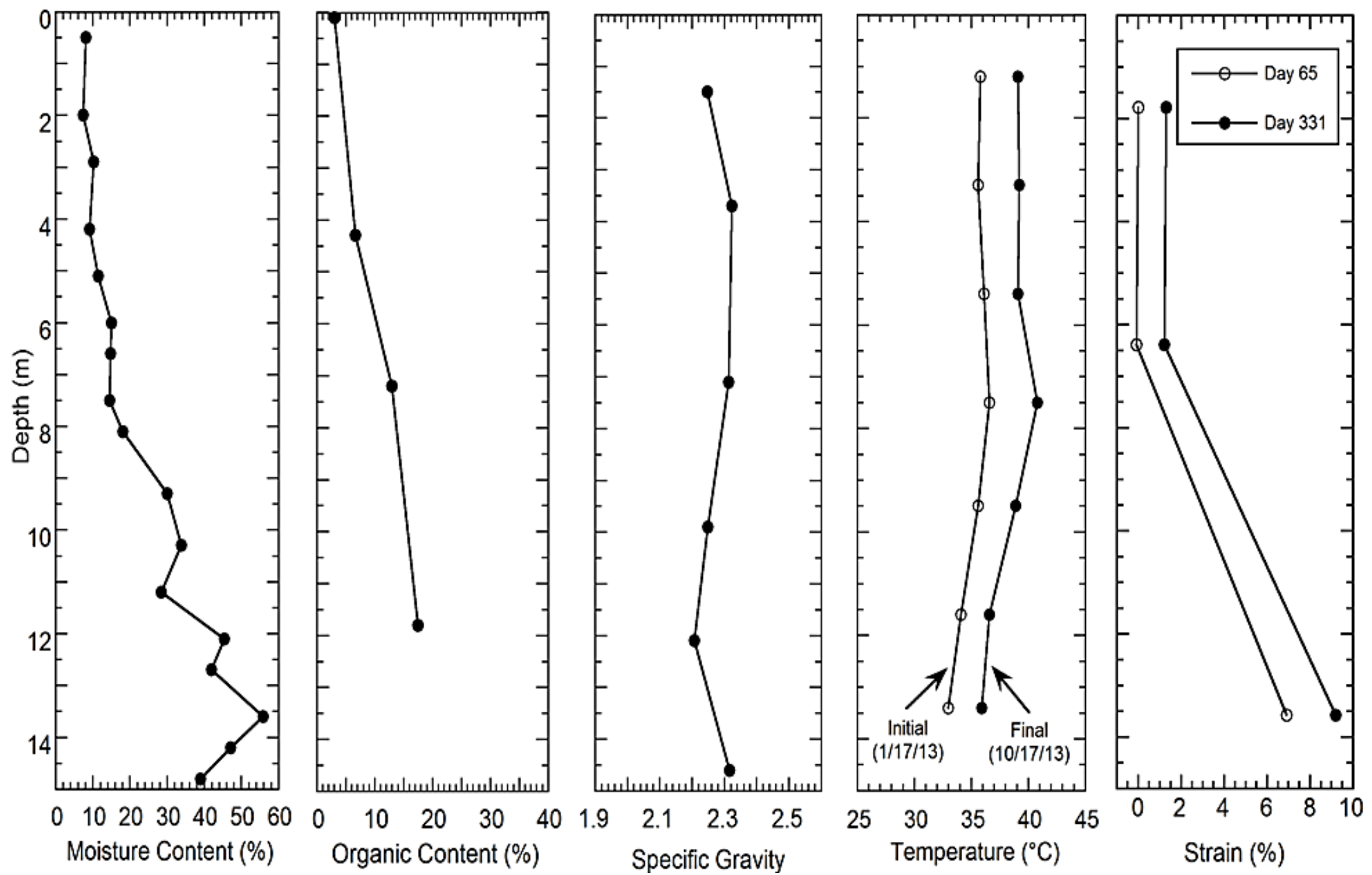

Figure 4.30. Physical and Engineering Properties of MSW as a Function of Depth for BH6. 

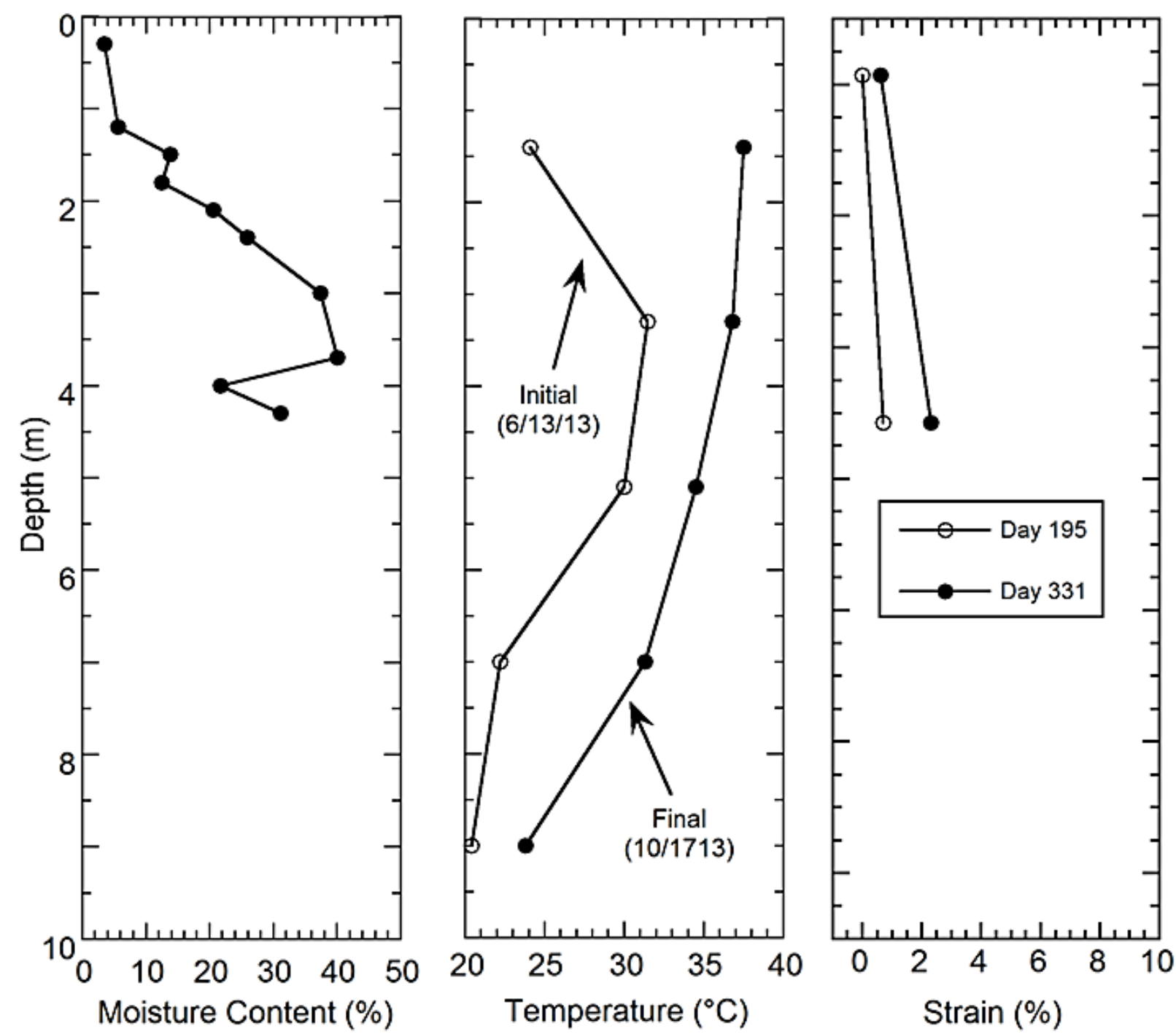

Figure 4.31. Physical and Engineering Properties of MSW as a Function of Depth for $\mathrm{BH} 7$. 

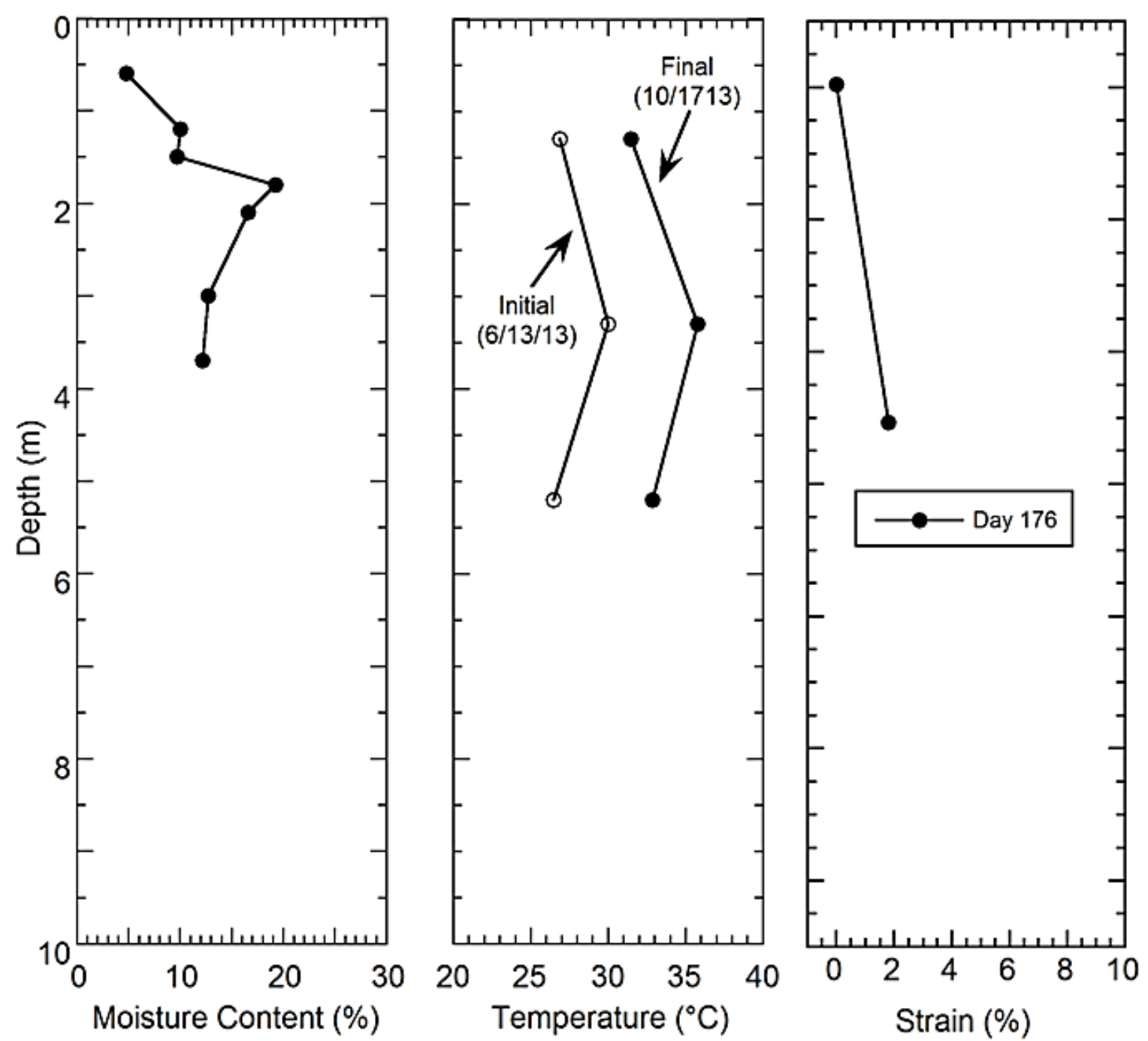

Figure 4.32. Physical and Engineering Properties of MSW as a Function of Depth for BH8. 


\section{Chapter 5: Engineering Significance and Future Research}

\subsection{Introduction}

Systematic moisture addition during waste placement affects the shortand long-term physical and mechanical responses of MSW (i.e., compaction, degradation, moisture, and compressibility). In addition, the addition of moisture during waste placement offers significant financial and environmental benefits.

\subsection{Specific Gravity of MSW}

The specific gravity of MSW is an important physical property that can be used for basic phase (i.e., weight-volume) relationship calculations. Unlike soils, the $G_{s}$ for MSW was not unique, but varied in a landfill environment. Characteristics of the constituent materials and the processes that occur within landfills resulted in the variable $G_{s}$. Variations were observed between uncompacted and compacted conditions and between fresh and old wastes. In addition, changes in intraparticle voids due to compaction and processing (i.e., cutting and shredding) were observed for manufactured waste specimens.

Changes in $G_{s}$ due to compaction, degradation, and compression are a result of transformations in the waste fabric and structure (Figure 5.1). The bending, crushing, shredding, and rearrangement of waste particles during compaction contribute to reductions of interparticle and intraparticle voids present within the waste mass. For increasing levels of degradation, removal of solids from individual waste constituents result in the exposure of previously occluded intraparticle voids within that waste constituent. For example, as a piece of wood 
degrades, solid particles are consumed by bacteria thus exposing previously occluded intraparticle voids that existed in the form of gas bubbles (Figure 5.1). The mechanisms associated with reduction of interparticle and intraparticle voids due to increased overburden stress include residual collapse of interparticle voids between waste constituents and continuous compression of intraparticle voids within deformable materials such as wood, food, and closed plastic and metal containers (i.e., lid is closed).

Waste constituents can be classified into four distinct categories each of which exhibit unique behavior during compaction, degradation, and compression processes (Table 5.1). The four categories include: 1. Deformable and highly degradable (DHD); 2. Deformable and slightly degradable (DSD); 3. Deformable and non-degradable (DND); and 4. Inert Solids (IS). 
Table 5.1. The Four Categories of Waste Constituents at MSW Landfills.

\begin{tabular}{|c|c|c|c|}
\hline Category & $\begin{array}{l}\text { Waste Constituent } \\
\text { Examples }\end{array}$ & $\begin{array}{l}\text { Mechanisms } \\
\text { Influencing } \\
\text { Changes to } \\
\text { Waste } \\
\text { Constituents }\end{array}$ & Response of Individual Waste Constituents \\
\hline $\begin{array}{l}\text { Deformable } \\
\text { and Highly } \\
\text { Degradable } \\
\text { (DHD) }\end{array}$ & Food; yard waste & $\begin{array}{l}\text { Compaction } \\
\text { Degradation } \\
\text { Compression }\end{array}$ & $\begin{array}{l}\text { - Exposure and reduction of intraparticle voids during } \\
\text { compaction } \\
\text { - Removal of solids at a high rate due to degradation } \\
\text { processes } \\
\text { - Further reduction of remaining intraparticle voids due to } \\
\text { increased vertical stresses }\end{array}$ \\
\hline $\begin{array}{l}\text { Deformable } \\
\text { and Slightly } \\
\text { Degradable } \\
\quad \text { (DSD) }\end{array}$ & $\begin{array}{l}\text { Plastic bottles and } \\
\text { containers; wood; } \\
\text { paper; cardboard; } \\
\text { textiles }\end{array}$ & $\begin{array}{l}\text { Compaction } \\
\text { Degradation } \\
\text { Compression }\end{array}$ & $\begin{array}{l}\text { - Exposure and reduction of intraparticle voids during } \\
\text { compaction } \\
\text { - Removal of solids at low rates due to degradation processes } \\
\text { - Further reduction of remaining intraparticle voids due to } \\
\text { increased vertical stresses }\end{array}$ \\
\hline $\begin{array}{l}\text { Deformable } \\
\text { and Non- } \\
\text { Degradable } \\
\text { (DND) }\end{array}$ & $\begin{array}{l}\text { Metal containers; } \\
\text { appliances; } \\
\text { concrete, glass } \\
\text { containers } \\
\end{array}$ & $\begin{array}{l}\text { Compaction } \\
\text { Compression }\end{array}$ & $\begin{array}{l}\text { - Exposure and reduction of intraparticle voids during } \\
\text { compaction } \\
\text { - Further reduction of remaining intraparticle voids due to } \\
\text { increased vertical stresses }\end{array}$ \\
\hline $\begin{array}{l}\text { Inert Solids } \\
\text { (IS) }\end{array}$ & Metal scraps; soils & $\begin{array}{l}\text { No Direct } \\
\text { Mechanistic } \\
\text { Influence }\end{array}$ & $\begin{array}{l}\text { - No changes in the structure of the inert materials } \\
\text { - Potential movement of inert materials into open interparticle } \\
\text { voids or exposed intraparticle voids. }\end{array}$ \\
\hline
\end{tabular}


The reduction of both the interparticle (i.e., voids between individual waste particles) and intraparticle voids (i.e., occluded voids within an individual waste particle) due to compaction and due to the coupled effects of degradation and overburden stress were quantified for this investigation. Phase diagrams were developed for fresh uncompacted MSW, fresh compacted MSW, and old MSW. Using an assumed mass of solids of $100 \mathrm{~g}$ and $G_{s}$ values of 1.072, 1.208, and 2.201 for fresh uncompacted MSW, fresh compacted MSW, and old MSW, respectively, a volume of MSW solids $\left(V_{s}\right)$ was calculated for each case. The change in solids volume between uncompacted and compacted fresh MSW (Equation 5.2) was a result of exposure and reduction of intraparticle voids and calculated to be $10.5 \mathrm{~cm}^{3}$ (Table 5.2). In addition, the change in volume of solids between fresh compacted MSW and old MSW (Equation 5.3) was determined to be $37.5 \mathrm{~cm}^{3}$ (Table 5.2) and was attributed to both compression and degradation processes. Increased vertical stresses compress and expose occluded intraparticle voids and removal of solids coupled with exposure of occluded intraparticle voids during degradation processes contribute to the reduction of solids volume.

$$
\begin{aligned}
& \Delta V_{s, F M S W}=V_{s, U C}-V_{S, C} \\
& \Delta V_{S, O M S W}=V_{S, C}-V_{S, O M S W}
\end{aligned}
$$

Where:

$\Delta V_{S, F M S W}=$ change in solids volume of fresh MSW after compaction

$\Delta V_{S, O M S W}=$ change in solids volume of after degradation and compression 


$$
\begin{aligned}
V_{S, C} & =\text { volume of solids of compacted fresh MSW } \\
V_{S, U C} & =\text { volume of solids of uncompacted fresh MSW } \\
V_{S, O M S W} & =\text { volume of solids of old MSW }
\end{aligned}
$$

Table 5.2. Reduction of Solids Volume due to Intraparticle Void Loss

\begin{tabular}{|c|c|c|c|c|c|}
\hline $\begin{array}{c}\text { Waste } \\
\text { Condition }\end{array}$ & $\begin{array}{c}\boldsymbol{M}_{\boldsymbol{s}} \\
\mathbf{( g )}\end{array}$ & $\mathbf{G}_{\boldsymbol{s}}$ & $\begin{array}{c}\boldsymbol{V}_{\boldsymbol{s}_{\mathbf{3}}} \\
\left(\mathbf{c m}^{\mathbf{3}}\right)\end{array}$ & $\begin{array}{c}\boldsymbol{\Delta} \boldsymbol{V}_{\boldsymbol{s}} \\
\mathbf{( c m}^{\mathbf{3}} \mathbf{)}\end{array}$ & $\begin{array}{c}\text { Percent } \\
\text { Change }\end{array}$ \\
\hline $\begin{array}{c}\text { Fresh } \\
\text { Uncompacted }\end{array}$ & 100 & 1.072 & 93.3 & - & - \\
\hline $\begin{array}{c}\text { Fresh } \\
\text { Compacted }\end{array}$ & 100 & 1.208 & 82.8 & 10.5 & 11.3 \\
\hline Old & 100 & 2.201 & 45.3 & 37.5 & 45.3 \\
\hline
\end{tabular}

A similar analysis was conducted for manufactured waste samples to determine the effects of compaction and processing (i.e., cutting and shredding) on the intraparticle voids of the waste particles. Four phase diagrams were developed for manufactured waste and included: 1) uncompacted coarse-grained waste $\left(d_{e q}=14.2 \mathrm{~mm}\right)$; 2) compacted coarse-grained waste; 3) uncompacted fine-grained waste $\left(d_{e q}=4.4 \mathrm{~mm}\right)$; and 4$)$ compacted fine-grained waste. A mass of solids was again assumed for the phase diagram and specific gravity values of $1.333,1.424,1.499$, and 1.561 were used for phases 1 to 4 , respectively. The effects of processing and compaction were compared as decoupled mechanisms and as a coupled mechanism by evaluating the changes in solids volume between different phases. A total of 4 cases were investigated and include: 1) difference between uncompacted coarse- and fine-grained; 2) difference between uncompacted and compacted coarse-grained; 3) difference between uncompacted and compacted fine-grained; and 4) difference between 
uncompacted coarse-grained and compacted fine-grained. A summary of the changes in solids volume due to the decoupled effects of processing (Case 1) and compaction (Cases 2-3) and the coupled effects of processing and compaction (Case 4) are presented in Table 5.3.

Processing of the waste (Case 1) resulted in a reduction of solids volume by $4.8 \mathrm{~cm}^{3}$ and compaction of waste (Cases 2-3) resulted in an average reduction of solids volume of $5.45 \mathrm{~cm}^{3}$. For Cases 2 and 3 , the discrepancy between the volume change due to compaction for coarse- and fine-grained waste is explained by a greater reduction of intraparticle voids. Coarse-grained waste was observed to crush and break into smaller particle sizes after compaction whereas, the fine-grained waste particles were already smaller and compaction induced a smaller change in the particle size. 
Table 5.3. Reduction of Solids Volume of MMSW due to Intraparticle Void Loss.

\begin{tabular}{|c|c|c|c|c|c|c|c|c|c|c|}
\hline \multirow[b]{2}{*}{ Case } & \multicolumn{4}{|c|}{ Begin } & \multicolumn{4}{|c|}{ End } & \multirow[b]{2}{*}{$\begin{array}{c}\Delta V_{s} \\
\left(\mathrm{~cm}^{3}\right)\end{array}$} & \multirow[b]{2}{*}{$\begin{array}{l}\text { Percent } \\
\text { Change }\end{array}$} \\
\hline & $\begin{array}{c}\text { Waste } \\
\text { Condition }\end{array}$ & $\begin{array}{l}M_{s} \\
(\mathrm{~g})\end{array}$ & $\boldsymbol{G}_{s}$ & $\begin{array}{c}V_{s} \\
\left(\mathrm{~cm}^{3}\right)\end{array}$ & $\begin{array}{c}\text { Waste } \\
\text { Condition }\end{array}$ & $\begin{array}{l}M_{s} \\
(g)\end{array}$ & $\boldsymbol{G}_{s}$ & $\begin{array}{c}V_{s} \\
\left(\mathrm{~cm}^{3}\right)\end{array}$ & & \\
\hline 1 & $\begin{array}{c}\text { Uncompacted } \\
\text { (Coarse) }\end{array}$ & 100 & 1.333 & 75.0 & $\begin{array}{l}\text { Uncompacted } \\
\text { (Fine) }\end{array}$ & 100 & 1.499 & 70.2 & 4.8 & 6.4 \\
\hline 2 & $\begin{array}{c}\text { Uncompacted } \\
\text { (Coarse) }\end{array}$ & 100 & 1.333 & 75.0 & $\begin{array}{c}\text { Compacted } \\
\text { (Coarse) }\end{array}$ & 100 & 1.424 & 66.7 & 8.3 & 11.0 \\
\hline 3 & $\begin{array}{l}\text { Uncompacted } \\
\text { (Fine) }\end{array}$ & 100 & 1.499 & 70.2 & $\begin{array}{l}\text { Compacted } \\
\text { (Fine) }\end{array}$ & 100 & 1.561 & 64.1 & 2.6 & 3.7 \\
\hline 4 & $\begin{array}{c}\text { Uncompacted } \\
\text { (Coarse) }\end{array}$ & 100 & 1.333 & 75.0 & $\begin{array}{c}\text { Compacted } \\
\text { (Fine) }\end{array}$ & 100 & 1.561 & 64.1 & 10.9 & 14.5 \\
\hline
\end{tabular}


The degree of decomposition (DOD) and specific gravity of waste were determined to be strongly correlated. The DOD relates the percent organic fraction degraded with respect to the inorganic fraction present at the time of sampling and provides an indication of the biochemical methane potential (BMP) of wastes (Reddy et al. 2011). At initial waste condition (i.e., as-placed) the DOD is $0 \%$ and varies over time as the waste degrades. The degree of decomposition was calculated using the formulation provided by Andersland et al. (1981) presented in Equation 5.5. The DOD calculated for the MSW obtained from SMRL was based on the averages of measured organic content values at the surface, shallow, medium, and great depths (Table 5.4). The average age and measured moisture contents and temperatures at the given depths are provided in Table 5.4 as well.

$$
D O D=\left(1-\frac{X_{f i}}{X_{f o}}\right) \frac{1}{1-X_{f i}} \times 100 \%
$$

Where:

$$
\begin{aligned}
D O D & =\text { degree of decomposition } \\
X_{f o} & =\text { initial organic fraction } \\
X_{f i} & =\text { organic fraction at a given stage of degradation }
\end{aligned}
$$


Table 5.4. Summary of Degree of Degradation and Gs of MSW.

\begin{tabular}{|c|c|c|c|c|c|c|}
\hline $\begin{array}{c}\text { Average } \\
\text { Depth } \\
(\mathbf{m})\end{array}$ & $\mathbf{G}_{\boldsymbol{s}}$ & $\begin{array}{c}\text { Organic } \\
\text { Content }\end{array}$ & $\begin{array}{c}\text { DOD } \\
\mathbf{( \% )}\end{array}$ & $\begin{array}{c}\text { Average } \\
\text { Temperature } \\
\left.\mathbf{(}{ }^{\circ} \mathbf{C}\right)\end{array}$ & $\begin{array}{c}\text { Average } \\
\text { Moisture } \\
\text { Content (\%) }\end{array}$ & $\begin{array}{c}\text { Average } \\
\text { Age } \\
\text { (Months) }\end{array}$ \\
\hline Surface & 1.162 & 0.772 & 0 & 18.2 & - & 0 \\
\hline 3.4 & 2.237 & 0.157 & 95 & 32.3 & 21.98 & 31 \\
\hline 5.6 & 2.235 & 0.180 & 94 & 37.4 & 18.91 & 70 \\
\hline 12.4 & 2.161 & 0.361 & 83 & 34.2 & 31.86 & 85 \\
\hline
\end{tabular}

The strong correlation between DOD and $G_{s}$ is presented in Figure 5.1 alongside the results reported by Reddy et al. (2011) for manufactured wastes. The strong linear trend is evidence that the removal of solid waste particles and exposure of occluded intraparticle voids due to degradation are responsible for increases in $G_{s}$ over time. The relationship between DOD and $G_{s}$ for this study can be used estimate the $G_{s}$ for real MSW (as opposed to manufactured MSW). If organic content of waste is known (or experimentally calculated) a DOD can be determined and in turn a $G_{s}$ can be calculated. The effects of vertical stress on the reduction intraparticle voids (i.e., increase in $G_{s}$ ) have not been evaluated. Further testing is needed to decouple the effects compression and degradation have on the specific gravity of waste. 


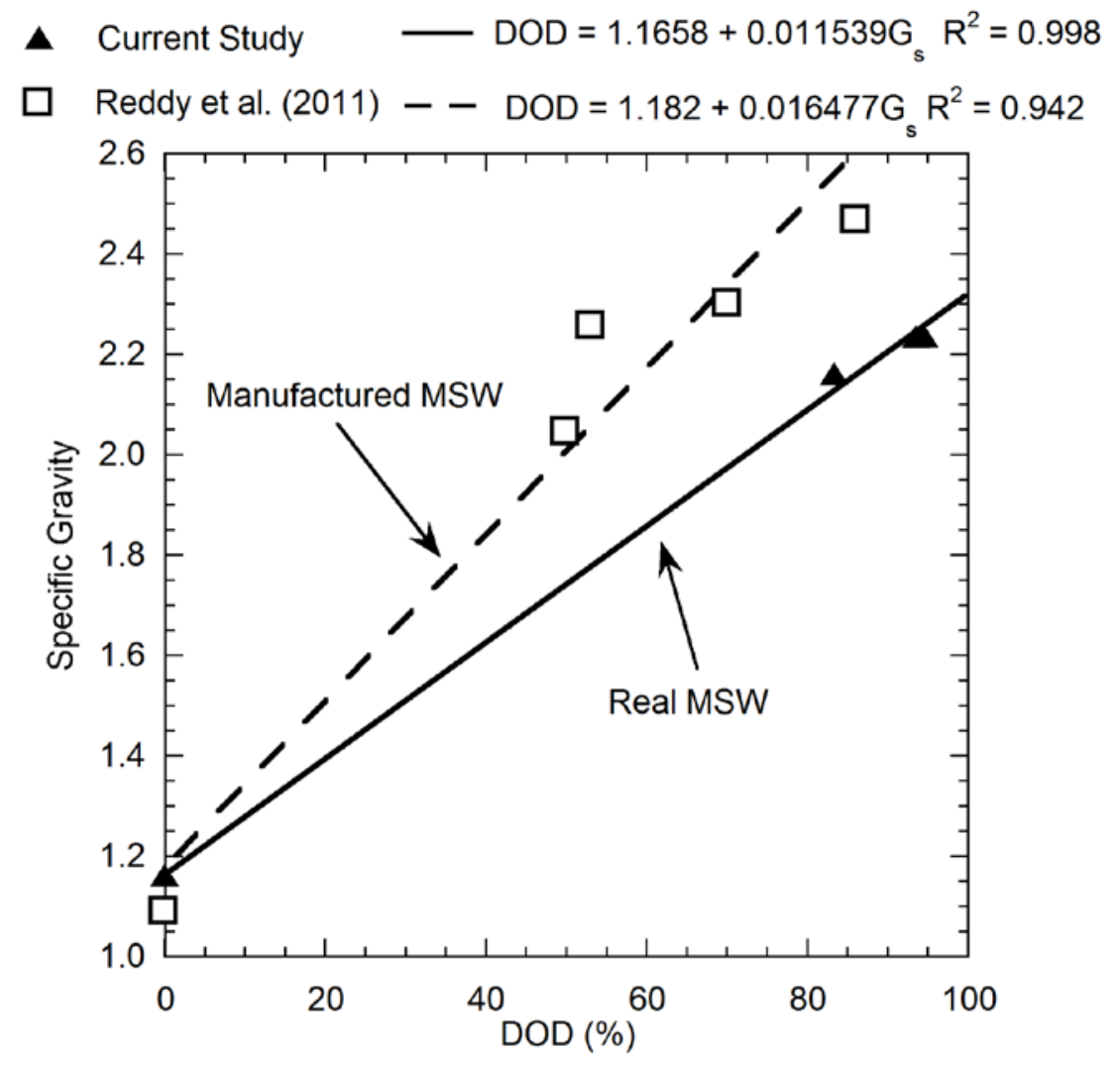

Figure 5.1. Relationship between DOD and Specific Gravity of MSW.

Implications of changes in Gs are significant and should be considered in analysis of micro and macrostructure and constitutive relationships of MSW through determination of phase relations and characteristic physical parameters. For example, settlement calculations and models that utilize void ratio (e.g., Sowers 1973, Bjarngard and Edgers 1990, Landva and Clark 1990, Hudson et al. 2004, Durmusoglu et al. 2006, Oweis 2006, Babu et al. 2010, Bareither et al. 2012) require detailed weight-volume relationships. Accurate knowledge of $G_{s}$ is needed to evaluate and determine the void ratio associated with given waste densities and moisture contents. This in turn provides ability to convert between strain based and void-ratio-based settlement calculations. In addition, accurate knowledge of $G_{s}$ provides ability to determine quantities of solid, liquid, and gas 
phases per unit volume, which is required for accurate assessment of leachate, gas, and heat production and transfer for wastes (e.g., Zornberg et al. 1999, Hanson et al. 2000, Jain et al. 2006, Reddy et al. 2009b, Stoltz et al. 2010b, Breitmeyer 2011).

Specific gravity testing is recommended to be conducted not only using representative waste composition, but also using representative stress state and history and degradation conditions. Tests can be repeated in time to provide representative values for long-term studies and analyses. When data are not available, $G_{s}$ values of 1.1 and 1.2 may be used for as- delivered/uncompacted and compacted fresh wastes, respectively for conditions similar to the landfill site presented herein. A higher $G_{s}$ of 2.2 may be used for older wastes at depth subjected to decomposition and mechanical stress in the landfill environment.

\subsection{Compressibility}

The short- and long-term compressibility of MSW is directly affected by the placement procedures at a landfill. In particular, systematic moisture addition prior to compaction of waste increases the as-placed density of the waste and enhance the long-term biochemical degradation processes.

The initial compression of MSW (Equation 5.6) was estimated using the waste compressibility index (WCI) developed by Bareither et al. (2012a). The WCI can be used to predict $C_{c}^{\prime}$ for MSW based on moisture content, dry unit weight, and organic content (Equations 5.7 and 5.8).

$$
S_{i}=H \cdot C_{c}^{\prime} \cdot \log \frac{\sigma_{v o}^{\prime}+\Delta \sigma_{v}^{\prime}}{\sigma_{v o}^{\prime}}
$$




$$
\begin{aligned}
W C I & =w_{d} \cdot\left(\frac{\gamma_{w}}{\gamma_{d}}\right) \cdot\left(\frac{O C}{100-O C}\right) \\
C_{c}^{\prime} & =0.26+0.058 \cdot \log (W C I)
\end{aligned}
$$

Where:

$$
\begin{aligned}
H & =\text { thickness of a given waste lift } \\
C_{c}^{\prime} & =\text { compression ratio } \\
\sigma_{v o}^{\prime} & =\text { initial vertical effective stress at midpoint of layer } \\
\Delta \sigma_{v}^{\prime} & =\text { induced change in vertical effective stress at midpoint of layer } \\
W C I & =\text { waste compressibility index } \\
W_{d} & =\text { moisture content } \\
\gamma_{w} & =\text { unit weight of water } \\
\gamma_{d} & =\text { dry unit weight of waste } \\
O C & =\text { organic content of waste }
\end{aligned}
$$

The initial compression was analyzed for 3 placement conditions: 1) waste compacted at as-received moisture conditions (i.e., $w_{d}=45 \%$ ); 2) waste compacted at optimum moisture conditions (i.e., $w_{d}=76 \%$ ); and 3) waste compacted at wet of optimum $\left(w_{d}=105 \%\right)$. The dry unit weights associated with the 3 cases were determined from the field-scale compaction study and were used for computation of $\mathrm{WCl}$. In addition, the measured organic content for fresh MSW $(77.2 \%)$ was used in the analysis. A summary of the calculated $W C I$ and $C_{c}^{\prime}$ 
values for each case and the respective parameters used for the calculations are provided in Table 5.5 .

Table 5.5. $W C I$ and $C_{c}^{\prime}$ Values for Different Waste Placement Conditions

\begin{tabular}{|c|c|c|c|c|c|}
\hline Case & $\begin{array}{c}\boldsymbol{O C} \\
\mathbf{( \% )}\end{array}$ & $\begin{array}{c}\boldsymbol{w}_{\boldsymbol{d}} \\
\mathbf{( \% )}\end{array}$ & $\begin{array}{c}\boldsymbol{\gamma}_{\boldsymbol{d}} \\
\left(\mathbf{k N / \mathbf { m } ^ { \mathbf { 3 } } )}\right.\end{array}$ & $\boldsymbol{W C I}$ & $\boldsymbol{C}_{\boldsymbol{c}}^{\prime}$ \\
\hline $\begin{array}{c}\text { As-Received } \\
\text { (Dry of Optimum) }\end{array}$ & 77.2 & 45 & 4.6 & 3.24 & 0.290 \\
\hline Optimum & 77.2 & 76 & 7.0 & 3.82 & 0.294 \\
\hline Wet of Optimum & 77.2 & 105 & 3.9 & 8.92 & 0.315 \\
\hline
\end{tabular}

The settlement was calculated for a 10-m-height waste lift and it was assumed the waste was placed and then immediately loaded with an overlying $10 \mathrm{~m}$ waste lift and $0.5 \mathrm{~m}$ of intermediate soil cover. The soil was assumed to have a unit weight of $18.9 \mathrm{kN} / \mathrm{m}^{3}$ (based on nuclear density meter testing) and the overlying waste lift was assumed to have a the same unit weight as the underlying waste lift. Initial compression is reduced by approximately $2.0 \%$ when waste is placed and compacted at optimum moisture content as compared to the as-received conditions. If waste is compacted at wet of optimum conditions the initial compression is increased by approximately $8.8 \%$. The reduction of initial compression for waste compacted at optimum moisture content is likely due to the increase in the as-placed unit weight of the waste. At the optimum moisture conditions, waste compaction is most efficient and dry and operational unit weight is at a maximum $\left(\gamma_{d \max }\right.$ and $\left.\gamma_{o p e r-\max }\right)$. The amount of interparticle voids reduced due to increased vertical loading (i.e., initial compression) when the waste mass is at $\gamma_{d \max }$ and $\gamma_{\text {oper-max }}$ is significantly less than the interparticle 
voids compressed at the as-received dry and operational unit weight. The total initial compression of the $10 \mathrm{~m}$ waste mass for each case of waste placement is presented in Table 5.6

Table 5.6. Total Initial Compression with Varying Waste Placement Conditions

\begin{tabular}{|c|c|c|c|c|c|c|}
\hline Case & $\begin{array}{l}\text { Height } \\
\text { (m) }\end{array}$ & $\begin{array}{c}\gamma_{t} \\
\left(\mathrm{kN} / \mathrm{m}^{3}\right)\end{array}$ & $\begin{array}{c}\sigma_{v o}^{\prime} \\
(\mathrm{kPa})\end{array}$ & $\begin{array}{c}\Delta \sigma_{v}^{\prime} \\
(\mathrm{kPa})\end{array}$ & $C_{c}^{\prime}$ & $\begin{array}{c}S_{i} \\
(\mathrm{~m})\end{array}$ \\
\hline $\begin{array}{c}\text { As-Received } \\
\text { (Dry of Optimum) }\end{array}$ & 10 & 6.7 & 33.6 & 76.5 & 0.290 & 1.49 \\
\hline Optimum & 10 & 12.3 & 61.6 & 132.5 & 0.292 & 1.46 \\
\hline Wet of Optimum & 10 & 8.0 & 40.2 & 89.5 & 0.315 & 1.60 \\
\hline
\end{tabular}

In addition, the long-term secondary compression due to mechanical creep and biochemical degradation is affected by the 3 different placement conditions. Further research is needed to identify the independent effects of placement conditions on mechanical creep and biochemical degradation compression. For this analysis, the mechanical creep and biochemical compression are simplified and combined into a long-term compression component, which is defined using Sowers (1973) model for secondary compression of waste (Equation 5.9)

$$
S_{S}=H_{i} \cdot C_{\alpha}^{\prime} \cdot \log \left(\frac{t_{f}}{t_{i}}\right)
$$

Where:

$$
\begin{aligned}
& H_{i}=\text { thickness of the waste lift after initial compression } \\
& C_{\alpha}^{\prime}=\text { modified secondary compression ratio } \\
& t_{f}=\text { duration of the secondary compression phase }
\end{aligned}
$$


$t_{i}=$ duration of the initial compression phase

For the waste compacted at as-received moisture content, the average $C_{\alpha}^{\prime}$ determined for this test program (Section 4.7) was used for the long-term compression analysis. For the optimum and wet of optimum conditions, a weighted average of mechanical creep compression ratio $\left(C_{\alpha M}^{\prime}\right)$ and biochemical compression ratio $\left(C_{\alpha B}^{\prime}\right)$ provided in the literature was used. An assumption was made that waste placed with the addition of moisture would induce long-term settlement behavior similar to a bioreactor landfill. Therefore, at optimum moisture content, the secondary compression ratio was estimated using the average $C_{\alpha M}^{\prime}(0.036)$ and $C_{\alpha B}^{\prime}(0.215)$ reported in the literature for bioreactor landfills (e.g., Lamothe and Edgers 1994; Hossain et al. 2003; Benson et al. 2007; Bareither et al. 2010; Gourc et al. 2010; Bareither et al. 2012b). An average value for $C_{\alpha B}^{\prime}$ was used to represent that a moderate increase in degradation would occur over time due to optimum moisture addition.

Using the estimated $C_{\alpha M}^{\prime}$ and $C_{\alpha B}^{\prime}$ values and the reported distribution of long-term compression of $30 \%$ mechanical creep and $70 \%$ biochemical compression, a weighted average $C_{\alpha}^{\prime}$ value of 0.161 was calculated. The same process was repeated for wet of optimum moisture conditions however, an average $C_{\alpha M}^{\prime}(0.036)$ and $C_{\alpha B}^{\prime}(0.360)$ were used to account for the likely possibility of enhanced degradation due to large amounts of moisture addition. $C_{\alpha B}^{\prime}$ equal to 0.360 is representative of the reported upper limit for bioreactor landfills. The same weighted average method was used and $C_{\alpha}^{\prime}$ was equal to 0.263 . 
The long-term compression of waste was analyzed for a duration of 5 years (1825 days). The wet of optimum placement conditions resulted in the highest long-term settlement $(3.3 \mathrm{~m})$ followed by the optimum $(2 \mathrm{~m})$ and asreceived conditions $(0.5 \mathrm{~m})$. In addition, the total overall settlement (summation of initial and secondary) for as-received, optimum, and wet of optimum placement conditions was determined to be $2.0,3.5$, and $4.9 \mathrm{~m}$, respectively. The long-term secondary compression and total settlement of the waste placed at the three conditions is summarized in Table 5.7.

Table 5.7. Long-Term Compression for Various Waste Placement Conditions

\begin{tabular}{|c|c|c|c|c|c|c|}
\hline $\begin{array}{c}\text { Placement } \\
\text { Condition }\end{array}$ & $\begin{array}{c}H_{i} \\
\mathbf{( m )}\end{array}$ & $\begin{array}{c}t_{i} \\
\text { (days) }\end{array}$ & $\begin{array}{c}t_{f} \\
\text { (days) }\end{array}$ & $C_{\alpha}^{\prime}$ & $\begin{array}{c}\boldsymbol{S}_{\boldsymbol{s}} \\
\mathbf{( m )}\end{array}$ & $\begin{array}{c}\text { Total } \\
\text { Settlement } \\
(\mathbf{m})\end{array}$ \\
\hline $\begin{array}{c}\text { As-Received } \\
\text { (Dry of Optimum) }\end{array}$ & 8.51 & 60 & 1825 & 0.036 & 0.5 & 2.0 \\
\hline Optimum & 8.54 & 60 & 1825 & 0.161 & 2.0 & 3.5 \\
\hline Wet of Optimum & 8.40 & 60 & 1825 & 0.263 & 3.3 & 4.9 \\
\hline
\end{tabular}

A unique compressibility characteristic of waste was observed during the investigation. The both fresh and old wastes exhibited a stress history response during loading and unloading processes. Analogous to the normal and over consolidation of soils, the waste can be characterized as normally consolidated, overconsolidated, or underconsolidated. Fresh waste lifts were determined to be slightly overconsolidated such that the self-weight of the fresh waste did not reach the preconsolidation stess $\left(\sigma_{p}\right)$ exhibited on the waste lift during compaction $(\sim 45 \mathrm{kPa})$. The slight overconsolidation of the fresh waste lifts should be considered when determining the waste filling location (i.e., location of active 
face). For example, fresh waste lifts should be constructed, covered, and then loaded with either another waste lift or an earthen embankment shortly (i.e., within the first few months) after placement to maximize the compression of that waste lift.

In addition, waste lifts were loaded with an earthen embankment and then periodically unloaded and reloaded over the duration of the test program. The bottom waste lift (Lift I) of Borehole 6 exhibited unique recompression behavior as the earthen embankment was reloaded and then returned to the virgin compression curve upon reloading (Figure 4.20). The recompression behavior of the waste is important for a landfill similar to SMRL in which earthen embankments are placed periodically at various locations of the active cell in order to induce settlement. The recompression behavior of the waste indicates that there is potential for the waste to swell toward the original lift height negating a portion of the induced settlement. The recompression index estimated for the bottom lift of Borehole 6 is only applicable to old waste, whereas the recompression index calculated for the fresh waste lifts is only applicable to fresh waste.

Using the average modified recompression index determined in this investigation for fresh wastes (Table 4.14), the swell of a fresh waste lift due to unloading can be quantified. The average modified compression index for fresh wastes was 0.076 and can described by Equation 5.10:

$$
C_{r}^{\prime}=\frac{\varepsilon}{\Delta \log \sigma}
$$


Where:

$C_{r}^{\prime}=$ modified recompression index for fresh waste

$\varepsilon=$ vertical strain of at midheight of a given waste lift

$\Delta \log \sigma=$ vertical stress at midheight of a given waste lift

For the recompression analysis a waste lift with an initial height of $10 \mathrm{~m}$ and a preconsolidation stress $\left(\sigma_{p}\right)$ equal to $45 \mathrm{kPa}$ was assumed. In addition, the physical as-placed waste characteristics (i.e., moisture content, dry unit weight, and organic content) were assumed to be the same as the waste compacted at as-received moisture conditions (Table 5.4). At the initial condition the vertical strain was assumed to be zero. Immediately after placement of the waste lift, a 5 m embankment is placed over the top of the lift inducing a vertical stress of 100 $\mathrm{kPa}$ at the midheight of the lift. The embankment was assumed to remain over the waste lift for the duration of initial compression (i.e., 30 days). The $C_{c}^{\prime}$ was determined to be 0.290 and was calculated using Equation 5.8.

The vertical strain of the waste lift due to initial compression was calculated to be $14.7 \%$ and was determined using Equation 5.6. An initial compression strain of $14.7 \%$ corresponds to a new lift height equal to approximately $8.5 \mathrm{~m}$ (i.e., $1.47 \mathrm{~m}$ of initial compression). Upon completion of initial compression of the fresh waste lift, the embankment was assumed to be immediately and entirely removed (i.e., unloaded to preconsolidation stress). The vertical strain $(\varepsilon)$ due to the removal of the embankment was estimated, using Equation 5.10, to be $7.6 \%$. The difference between the initial compression strain 
$(14.7 \%)$ and the strain after removal of the embankment (7.6\%) is representative of the recompression strain (i.e., swell) of the fresh waste lift. The recompression strain of $7.1 \%$ corresponds to a swell of $0.6 \mathrm{~m}$. The relatively large swell should be taken into consideration when loading and unloading procedures are implemented at a landfill.

\subsection{Compaction}

Systematic moisture addition prior to compaction of waste resulted in both environmental and financial benefits. The waste compaction methods provided in the investigation can be considered a straightforward to implement alternative to bioreactor landfill systems with similar positive financial and environmental effects. In addition, a waste compaction theory has been developed based on the results and observations from this investigation.

\subsubsection{Moisture Distribution}

Systematic moisture addition prior to compaction of waste affects the moisture distribution and retention characteristics of the waste mass. In particular, the volumetric field capacity $\left(\theta_{F C}\right)$ is greatly influenced by the amount of moisture added to the waste mass. A great majority of the data reported in literature for volumetric field capacity of MSW ranged between 30 and 55\% (Qian et al. 2002). Experimental testing was not conducted for this investigation to determine the volumetric field capacity of the waste at SMRL. However, the assumption was made that the range of data provided by Qian et al. (2002) is representative of at or near field capacity conditions at SMRL. 
For the meso-scale compaction study, the volumetric moisture contents associated with the target and measured (i.e., test pit measurements) moisture contents of the residential MSW were compared and evaluated with respect to the data provided in Qian et al. (2002). For the as-placed conditions (i.e., target moisture conditions), the residential MSW was at or near the volumetric field capacity five days out of the twelve days measured during the test pit excavations. After the test pit measurements it was determined that the waste was at or near volumetric field capacity eight out of the twelve days (Table 5.8 and Figure 5.2).

Table 5.8. Effects of Moisture Addition on Field Capacity for Meso-scale.

\begin{tabular}{|c|c|c|c|c|c|}
\hline \multirow{3}{*}{ Test Pit } & Depth & $\begin{array}{c}\text { Target } \\
\boldsymbol{w}_{\boldsymbol{d}} \\
(\boldsymbol{\%})\end{array}$ & $\begin{array}{c}\text { Measured } \\
\boldsymbol{w}_{\boldsymbol{d}} \\
(\mathbf{\%})\end{array}$ & $\begin{array}{c}\text { Target } \\
\boldsymbol{\theta}(\%)\end{array}$ & $\begin{array}{c}\text { Measured } \\
\boldsymbol{\theta}(\%)\end{array}$ \\
\hline \multirow{4}{*}{1} & Surface & 80 & 117 & $\mathbf{2 8 . 7}$ & $\mathbf{3 4 . 8}$ \\
\cline { 2 - 6 } & $0.5 \mathrm{~m}$ & 80 & 95 & 30.4 & 33.3 \\
\cline { 2 - 6 } & $0.9 \mathrm{~m}$ & 80 & 89 & 38.6 & 41.1 \\
\cline { 2 - 6 } & $1.3 \mathrm{~m}$ & 65 & 89 & $\mathbf{2 8 . 5}$ & $\mathbf{3 4 . 2}$ \\
\hline \multirow{4}{*}{2} & Surface & 65 & 67 & 28.5 & 29.1 \\
\cline { 2 - 6 } & $0.5 \mathrm{~m}$ & 55 & 70 & 16.7 & 19.3 \\
\cline { 2 - 6 } & $0.9 \mathrm{~m}$ & 55 & 79 & 15.4 & 19.1 \\
\cline { 2 - 6 } & $1.3 \mathrm{~m}$ & 65 & 66 & 36.6 & 36.9 \\
\hline \multirow{3}{*}{3} & Surface & 110 & 122 & 37.3 & 39.2 \\
\cline { 2 - 6 } & $0.5 \mathrm{~m}$ & 55 & 89 & 21.9 & 29.0 \\
\cline { 2 - 6 } & Surface & 110 & 126 & 35.0 & 37.3 \\
\cline { 2 - 6 } & $0.5 \mathrm{~m}$ & 55 & 100 & $\mathbf{2 8 . 3}$ & $\mathbf{3 9 . 8}$ \\
\hline
\end{tabular}




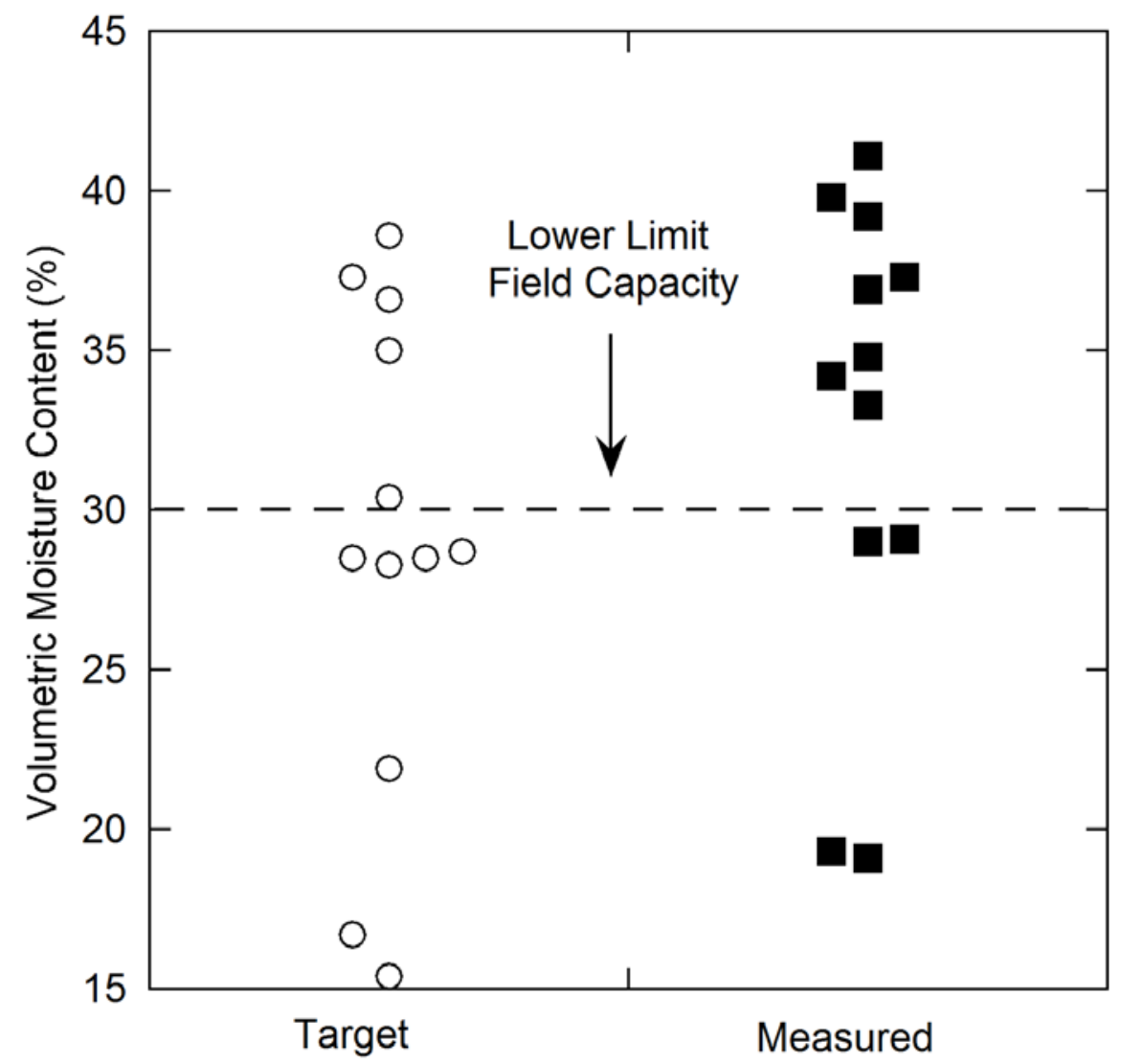

Figure 5.2. Dot Plot of Target and Measured $\theta$ for Meso-scale Compaction Tests.

The increase in volumetric moisture contents to field capacity for the 3 waste layers was likely attributed to the systematic moisture addition prior to compaction. Two of the waste layers that increased to $\theta_{F C}$ were surface and bottom layers of a single test pit (i.e., same vertical profile). The surface waste layer had a target $\theta$ of $28.7 \%$ and a measured $\theta$ of $34.8 \%$. The increase at the surface is likely due to the waste being near field capacity prior to moisture addition. Field capacity would have then been reached before the allotted amount of moisture was added. Therefore, moisture could have either infiltrated downward into the underlying waste layers or been pumped up (i.e., squeezed out interparticle and intraparticle void space) from the vertical stress of the 
compactor wheel. The most likely scenario involves a combination of both mechanisms. The middle waste layers were determined to already be at field capacity prior to moisture addition while the bottom waste layer was under volumetric field capacity. Once moisture was added, some of the excess moisture not retained by the top and middle layers could have flowed freely to the bottom layer. On the contrary, once the compactor began to pass over the waste surface, moisture was likely pumped (i.e., squeezed) from pores within layers that are influenced by the compactor wheels. For the bottom waste layer that increased to field capacity after moisture addition and compaction, the movement of moisture downward was likely the only cause for reaching field capacity (i.e., no pumping effects).

Increases in $\theta_{F C}$ for the field scale compaction study were more difficult to evaluate due to a lack of knowledge of the weight and volume of as-placed waste for the layers measured from the test pits. The field capacity was evaluated for 2 sets of 3 waste layers of identical placement conditions. A waste layer placed at $85 \%$ moisture content and two underlying waste layers placed at $45 \%$ moisture content were estimated to have volumetric moisture contents of 35.3 and $20.7 \%$ (dry-basis), respectively. The underlying waste layers (i.e., $45 \%$ moisture content) reached field capacity after moisture addition to the overlying waste layer (i.e. $85 \%$ moisture content) (Table 5.9). Similar to the meso-scale compaction study, the surface layers reached field capacity at some point during the moisture addition process and the excess moisture migrated to the underlying layers resulting in an increase of $\theta$ to field capacity. The movement of 
moisture into the underlying waste layers was confirmed and observed in the field during the test pit excavation. The concept of top layers reaching field capacity during moisture addition and excess moisture migrating downward bringing the underlying layers to field capacity is a reasonable assessment of the moisture distribution through the waste mass for the full-scale study.

Table 5.9. Effects of Moisture Addition on Field Capacity for Full-scale.

\begin{tabular}{|c|c|c|c|c|c|}
\hline \multirow{3}{*}{ Test Pit } & Depth & $\begin{array}{c}\text { Target } \\
\boldsymbol{w}_{\boldsymbol{d}} \\
(\mathbf{\%})\end{array}$ & $\begin{array}{c}\text { Measured } \\
\boldsymbol{w}_{\boldsymbol{d}} \\
\mathbf{( \% )}\end{array}$ & $\begin{array}{c}\text { Target } \\
\boldsymbol{\theta}(\%)\end{array}$ & $\begin{array}{c}\text { Measured } \\
\boldsymbol{\theta}(\%)\end{array}$ \\
\hline \multirow{3}{*}{1} & Surface & 85 & 119 & $\mathbf{2 8 . 7}$ & $\mathbf{3 4 . 8}$ \\
\cline { 2 - 6 } & $0.45 \mathrm{~m}$ & 45 & 109 & 30.4 & 33.3 \\
\cline { 2 - 6 } & $0.90 \mathrm{~m}$ & 45 & 112 & 38.6 & 41.1 \\
\hline \multirow{3}{*}{2} & Surface & 85 & 129 & 28.5 & 29.1 \\
\cline { 2 - 6 } & $0.45 \mathrm{~m}$ & 45 & 97 & 16.7 & 19.3 \\
\cline { 2 - 6 } & $0.90 \mathrm{~m}$ & 45 & 123 & 15.4 & 19.1 \\
\hline
\end{tabular}

$\theta_{F C}$ is significant because it represents the amount of water likely to be retained by MSW prior to the production of leachate (Orta de Velasquez et al. 2003). In relation to the current investigation, moisture addition prior to compaction could potentially result in an increase of leachate production and create a need to upgrade the leachate collection system. In addition, pumping effects due to compaction of multiple layers at or above field capacity could become problematic for waste compaction equipment and hinder operations. However, most importantly, the systematic addition of moisture prior to compaction has provided evidence that moisture will migrate downward into the underlying waste layers. The possible environmental benefits associated with the moisture addition are described in the following section. 


\subsubsection{Waste Compaction Theory}

The general shape of the waste compaction curves generated for the meso- and full-scale compaction studies was consistent with the shape of the typical compaction curve for soils. The dry and operational unit weight of waste increased with increasing moisture content to an optimum condition (i.e., peak of the compaction curve) at which point the effectiveness of moisture addition was reduced and unit weights decreased with increasing moisture content.

The additional waste solids material per unit volume at moisture conditions near optimum, characterized by the OWPF, was attributed to a combination of two mechanisms. First, waste particles were lubricated, softened, and became more deformable during moisture addition resulting in less rebound of the waste mass in response to compaction. Next, similar to soils, the lubricated waste particles resulted in a denser packing arrangement as waste particles were able to easily slide past one another into interparticle voids. In addition, the increased amount of moisture resulted in waste particles molding (i.e., sticking and binding) together into macro waste clods. The macro waste clods were observed in both the meso- and full-scale compaction tests however, the clods were more prominent during the meso-scale tests where little to no bulky items were present.

The macro waste clods typically consisted of soft compressible materials (e.g., paper, cardboard, food, yard wastes, plastic bags). The molding of waste constituents into macro waste clods was attributed to a combination of interlocking between the waste particles and the development of an adhesive 
bonding strength between waste particles. The effectiveness of the moisture addition diminished at wet of optimum conditions as indicated by the decreasing dry and operational unit weights due to the replacement of solids with water. In addition, at wet of optimum conditions, waste particles began to slip due to breaking of the surface tension and then roll over one another.

Additional waste compaction phenomena include an increase in specific gravity solids, with increasing compactive effort, a composite zero air voids curve (ZAV $\left.V_{\text {composite }}\right)$ corresponding to a progressively increasing $G_{s}$, and penetration of waste into underlying waste layers. Bending, crushing, shredding, reorganization of the structure of waste particles during compaction led to a reduction and exposure of intraparticle voids resulting in increased $G_{s}$ as compared to uncompacted MSW. The increased specific gravity of the compacted waste indicated that more solids were present in a unit of volume due entirely to the reduction and exposure of intraparticle voids.

Unlike soils, the zero air voids (ZAV) curve (i.e., 100\% saturation line) for wastes was not unique and was not associated with a single $G_{s}$ value. The $Z A V$ curve provides a theoretical upper limit for paired dry unit weight/moisture content data points in the compaction domain. Hanson et al. (2010a) proposed a new composite zero air voids curve ( $\left.Z A V_{\text {composite }}\right)$ for MSW corresponding to progressively increasing $G_{s}$ (Fig. 2.13) to ensure similar alignment between the singular $Z A V$ curve and the steep line of optimums. The $Z A V_{\text {composite }}$ was positioned parallel to the line of optimums established using equivalent degrees 
of saturation at the peak of the compaction curves associated with the different compactive efforts.

The results of the specific gravity tests were used to ascertain the location of the $Z A V_{\text {composite }}$ curve in Figure 5.3. The $Z A V_{\text {composite }}$ presented on the original figure provided in Hanson et al. (2010a) (Figure 2.13) was positioned approximately as $G_{s}$ testing was not conducted and $G_{s}$ data were not available. The authors had provided conceptual discussion of the $Z A V_{\text {composite }}$ curve. The precise location of the $Z A V_{\text {composite }}$ was established using data from the specific gravity tests. The measured $G_{s}(1.538)$ was used with the waste dry unit of 5.3 $\mathrm{kN} / \mathrm{m}^{3}$ and moisture content of $90 \%$ to determine the corresponding degree of saturation (S) as $75.0 \%$ for the wet of optimum moisture content test. Using the degree of saturation along the line of optimums (55.5\%, provided in Hanson et al. 2010a) and the calculated degree of saturation (75\%) for the dry unit weight/moisture content pair of $5.3 \mathrm{kN} / \mathrm{m} 3 / 90 \%$, the location of the $100 \%$ degree of saturation was scaled (point marked with star in Fig. 5.3). The $Z A V_{\text {composite }}$ curve was then drawn parallel to the line of optimums on Fig. 5.3 passing through the newly marked point. The $G_{s}$ was backcalculated at this point to be 1.640 using the dry unit weight of $5.3 \mathrm{kN} / \mathrm{m}^{3}$, the degree of saturation of $100 \%$, and the water content of $124 \%$ (obtained from the figure). The backcalculated $G_{s}$ agreed with the variable $G_{s}$ trends presented on the figure (i.e., the backcalculated $G_{s}$ of 1.640 fell between the ZAV curves for $G_{s} 1.6$ and 1.8 , close to 1.64 graphically). 

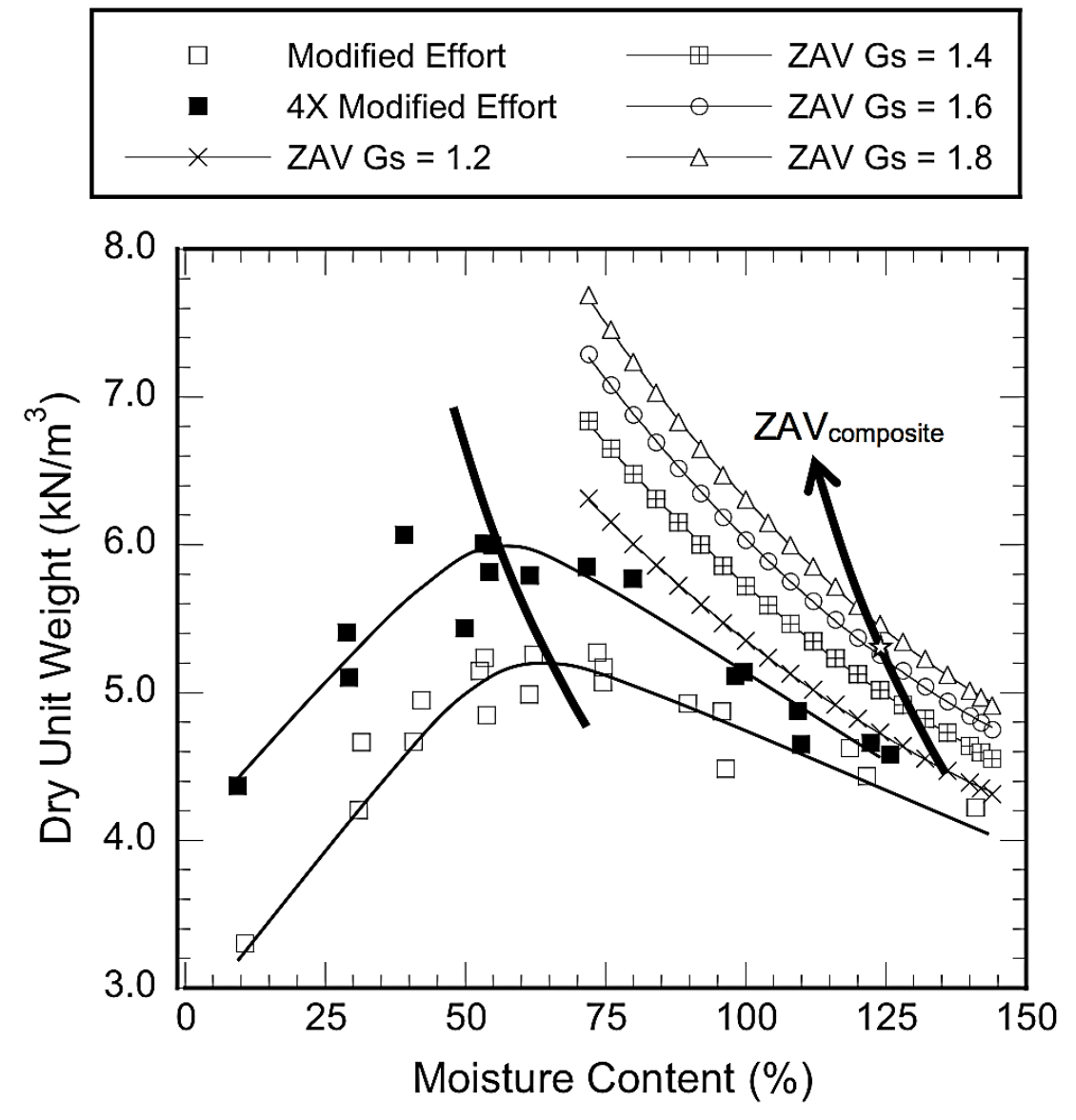

Figure 5.3. Compaction Plot with Variable ZAV (modified from Hanson et al. 2010a).

The penetration of waste into an underlying waste layer was observed on during the meso-scale compaction study. This phenomenon is unique to waste compaction procedures and resulted in significantly higher dry and operational unit weights. The penetration of the waste into underlying waste layer may have been attributed to a combination of softened waste particles and small lift heights (approximately $0.5 \mathrm{~m}$ ). The softened waste particles for a given day, either due to moisture addition or arrival at high moisture content, allowed for the compactor teeth to penetrate into the underlying layer and remove a portion of the underlying waste. As the compactor passed over the top waste layer and 
removed a portion of the underlying waste, the top and bottom waste mixed and remolded together allowing for penetration back into the newly created interparticle void space. The penetration of waste was not observed during the full-scale compaction tests due to the presence of bulkier items (i.e., furniture and appliances) that inhibited the mixing and remolding of two waste layers.

\subsubsection{Practical Implications}

Systematic moisture addition prior to compaction of waste has environmental, operational, and financial implications that are relevant to any MSW landfill that implements a similar placement procedure. A majority of the practical implications associated with waste placement procedures presented herein are beneficial for the environment and economy. However, careful consideration is needed when determining the exact methodology for moisture addition (i.e., quantity of moisture, compaction procedures, etc.).

\section{Environmental Benefits}

Environmental and financial benefits of systematic moisture addition prior to compaction are evident from the results of the meso-scale and full-scale compaction studies. The operational waste placement factor (OWPF) was calculated to determine the additional amount (i.e., weight) of waste that could be placed into a given volume as compared to the as-received conditions (i.e., no moisture addition). At optimum moisture conditions, approximately 55\% more waste can be placed into a given volume. Consequently, the life of a landfill will be extended and more waste can be disposed of into an operating landfill. Under the current regulatory requirements, final cover must be placed once the 
permitted capacity of a landfill is reached (USEPA 2013b). Therefore, compaction of waste at optimum moisture conditions will maximize the amount of waste placed into the permitted volume. Furthermore, extending the life of a landfill will prevent the need for siting and permitting of a new landfill, vertical expansion, or transporting waste to another landfill site.

Moisture addition also improved the moisture distribution within the waste mass. Specifically, field capacity was achieved in $75 \%$ of the waste layers including increasing volumetric moisture content of waste layers to field capacity that were placed under field capacity. The long-term effects of the systematic moisture addition prior to compaction were not investigated. However, moisture is considered to be the key factor for the degradation processes of MSW (e.g., Barlaz et al. 1989; El-Fadel and Al-Rashed 1998; Warith et al. 2005; Benson et al. 2007; Reddy et al. 2009a,b; Staub et al. 2010a). Furthermore, increased moisture addition through leachate recirculation (i.e., bioreactor landfill) was determined to enhance methane production, increase settlement, and reduce leachate treatment costs and post closure monitoring (e.g., Reinhart and Townsend 1998; Barlaz et al. 2002, 2010; Mehta et al. 2002; Reinhart et al. 2002; Benson et al. 2007; Bareither et al. 2010). Based on the assumption that the methods employed in the current study result in moisture conditions similar to those present in bioreactor landfills, it can be deduced that moisture addition prior to compaction will result in similar environmental and long-term operational (i.e., post-closure monitoring) benefits. 


\section{Operational Implications}

Adjustment to the standard operational procedures at a landfill should be considered if systematic moisture addition prior to compaction is implemented. First, an increase in leachate generation can be expected due to moisture addition and therefore the in-place leachate collection system should be evaluated. Adding moisture to the waste prior to compaction could potentially slow down waste placement operations if landfill staff members are not well prepared. Therefore, effective communication and coordination between landfill staff members are required for effective implementation of the proposed waste placement procedures.

Compaction of waste at extremely high moisture contents could potentially become problematic for landfill equipment such as waste compactors and bulldozers. Overheating of the waste compactor was encountered at SMRL during the meso-scale compaction study and operational procedures were adjusted to resolve the issue. In addition, the shear strength of the wetted waste should be considered during waste placement operations especially when waste is placed along a slope. Increased amounts of moisture could reduce the shear strength of waste and facilitate particle slippage by wetting the interface between waste particles. Furthermore, the reduced shear strength coupled with the stresses applied by the waste compactor could potentially result in slope failures.

\section{Financial Analysis}

The additional costs and revenues of systematic moisture addition prior to compaction were analyzed and compared to the as-received, baseline waste 
placement procedures used at SMRL. The additional costs associated with moisture addition include: water truck operator costs, operation and maintenance costs associated with additional usage of the water truck, and water pumping costs associate with filling up the water storage tank.

It was determined that it takes approximately $35 \mathrm{~min}$ ( 0.58 hours) to unload the water truck, refill, and then return to the active face to unload once again. In addition, Clarin (2013) provided the hourly operator rates, hourly operation and maintenance rates and yearly water pumping costs (i.e., cost to fill up the water storage tank). The total additional daily costs associated with adding moisture to achieve target moisture contents of 65,76 (optimum), 85, and 105\% were calculated based on the water pumping costs, number of additional trips, additional maintenance and operator hours utilized to achieve target moisture content (Table 5.10).

Water is essentially free at SMRL and water costs are only associated with pumping the groundwater into the onsite storage tank. However, water may not be free at other landfills and a hypothetical scenario such that water consumption costs exist, was considered for this analysis. The City of Santa Maria charges a flat rate of $\$ 0.633$ for every $1000 \mathrm{~L}$ of water used. That rate was applied to the amount water used on a daily and yearly basis, at each target moisture content, to account for a situation in which water is not free (Table 5.10). The additional water consumption costs were determined to be minimal and the therefore are neglected for the remainder of the analysis. 
A "2-to-1" placement method (Section 3.2.6) was implemented for the fullscale field compaction study. The "2-to-1" method represents a total of 83 days of moisture addition in a given year or $1 / 3$ of the total number of days SMRL is open (250). Annual costs of moisture addition were determined by multiplying the daily costs by 83 (Table 5.10).

Table 5.10 Additional Costs Associated with Systematic Moisture Addition.

\begin{tabular}{|c|c|c|c|c|}
\hline Category & $w_{d}=65 \%$ & $\begin{array}{c}w_{d}=76 \% \\
\text { (Optimum) }^{\mathrm{a}}\end{array}$ & $w_{d}=85 \%$ & $w_{d}=105 \%$ \\
\hline Trips per Day & 3 & 4.5 & 6 & 9 \\
\hline $\begin{array}{l}\text { Operation and Maintenance } \\
\text { (O\&M) Hours per Day }\end{array}$ & 1.75 & 2.8 & 3.5 & 5.25 \\
\hline $\begin{array}{l}\text { Water Truck Operator Hours } \\
\text { per Day }\end{array}$ & 1.75 & 2.8 & 3.5 & 5.25 \\
\hline $\begin{array}{l}\text { Operation and Maintenance } \\
\text { Costs }(\$ / \text { day })^{\mathrm{a}}\end{array}$ & 87 & 139 & 174 & 261 \\
\hline $\begin{array}{l}\text { Water Truck Operator Costs } \\
(\$ / \text { day })^{\mathrm{a}}\end{array}$ & 70 & 112 & 140 & 210 \\
\hline Well Pumping Costs (\$/day) & 0.56 & 0.81 & 1.12 & 1.68 \\
\hline Total Daily Costs & 158 & 252 & 315 & 472 \\
\hline Water Consumption (L/day) & 3400 & 5100 & 6500 & 9650 \\
\hline $\begin{array}{l}\text { Water Consumption Fee } \\
(\$ / 1000 L)^{b}\end{array}$ & 0.63 & 0.63 & 0.63 & 0.63 \\
\hline $\begin{array}{l}\text { Water Consumption Costs } \\
\text { (\$/day) }\end{array}$ & 2.15 & 3.20 & 4.10 & 6.10 \\
\hline $\begin{array}{l}\text { Total Annual Costs (With } \\
\text { Free Water) }^{\mathrm{C}}\end{array}$ & $\$ 13,140$ & $\$ 21,015$ & $\$ 26,250$ & $\$ 39,370$ \\
\hline $\begin{array}{l}\text { Total Annual Costs (With } \\
\text { Water Consumption Costs) }\end{array}$ & $\$ 13,320$ & $\$ 21,280$ & $\$ 26,590$ & $\$ 39,880$ \\
\hline Total Cost (\$/ha) & $\$ 8,725$ & $\$ 14,000$ & $\$ 17,400$ & $\$ 26,100$ \\
\hline
\end{tabular}

${ }^{a}$ Hourly rates of $\$ 49.80$ and $\$ 40.00$ apply O\&M and water truck operator wages, respectively

${ }^{\mathrm{b}}$ Water consumption rate for the City of Santa Maria, CA

${ }^{c}$ Representative of 83 days of moisture addition in a given year (250 days) at SMRL.

The financial benefits for the proposed waste placement procedures are provided in Table 5.10. An operational unit weight was determined for each 
moisture content (Section 4.8.2) and the average daily weight of incoming waste was assumed to be $2940 \mathrm{kN}$. The daily airspace consumption (i.e. weight of waste multiplied by operational unit weight) at a given moisture condition was subtracted from the airspace consumed for a day of waste placement at asreceived conditions yielding an airspace savings. In addition, every 12th day approximately $30 \mathrm{~m}^{3}$ of intermediate soil cover is placed and the airspace savings dedicated to waste placement is lost.

The baseline airspace consumption was determined to be $476 \mathrm{~m}^{3}$ at the as-received unit weight of $6.18 \mathrm{kN} / \mathrm{m}^{3}$. The airspace net gain (or loss) that occurred due to moisture addition was converted into a weight of waste that could be placed into that airspace. The additional weight of waste was calculated using the as-received operational unit weight $\left(6.18 \mathrm{kN} / \mathrm{m}^{3}\right)$ due to the placement procedure of the "2-to-1" method (i.e., as-received placement always follows a day of moisture addition). The daily revenue from moisture addition was calculated using the tipping fee at SMRL of $\$ 7.1 / \mathrm{kN}$ ( $\$ 71 /$ ton). The annual revenue was determined by multiplying the daily revenue by 83 . The revenue per hectare (ha) was determined based on the assumption that approximately 1.5 hectares of footprint are covered in a given year at SMRL and the net revenue per hectare incorporates the costs (Table. 5.11) associated with each placement condition. The net revenue incorporates the costs associated with each placement condition and can be considered the additional revenue potential for a given hectare of footprint. 
Table 5.11. Additional Revenue Associated with Systematic Moisture Addition.

\begin{tabular}{|l|c|c|c|c|}
\hline \multicolumn{1}{|c|}{ Category } & $\boldsymbol{w}_{\boldsymbol{d}}=\mathbf{6 5 \%}$ & $\begin{array}{c}\boldsymbol{w}_{\boldsymbol{d}}=\mathbf{7 6 \%} \\
\text { (Optimum) }\end{array}$ & $\boldsymbol{w}_{\boldsymbol{d}}=\mathbf{8 5 \%}$ & $\boldsymbol{w}_{\boldsymbol{d}}=\mathbf{1 0 5 \%}$ \\
\hline $\begin{array}{l}\text { Operational Unit Weight } \\
\left(\mathrm{kN} / \mathrm{m}^{3}\right)\end{array}$ & 7.94 & 9.80 & 9.60 & 4.93 \\
\hline Daily Weight of Waste (kN) & 2940 & 2940 & 2940 & 2940 \\
\hline $\begin{array}{l}\text { Airspace Consumption } \\
(\mathrm{m} 3 / \text { day) }\end{array}$ & 370 & 300 & 306 & 596 \\
\hline $\begin{array}{l}\text { Net Airspace Gain } \\
\text { (m3/day) }^{\mathrm{a}}\end{array}$ & 75 & 146 & 139 & -151 \\
\hline $\begin{array}{l}\text { Additional Daily Weight of } \\
\text { Waste (kN) }\end{array}$ & 466 & 1,428 & 1,339 & -743 \\
\hline Tipping Fee (\$/kN) & 7.1 & 7.1 & 7.1 & 7.1 \\
\hline Daily Revenue & $\$ 3,300$ & $\$ 10,100$ & $\$ 9,500$ & $\$-5,250$ \\
\hline Annual Revenue & $\$ 275,000$ & $\$ 841,600$ & $\$ 789,000$ & $\$-437,600$ \\
\hline Net Revenue (\$/ha) $)^{\mathrm{c,d}}$ & $\$ 175,000$ & $\$ 547,000$ & $\$ 508,500$ & $\$-318,000$ \\
\hline
\end{tabular}

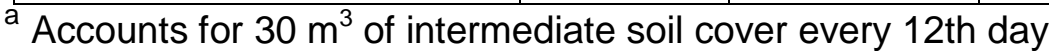

${ }^{\mathrm{b}}$ Calculated using operational unit weight for as-received conditions $\left(6.18 \mathrm{kN} / \mathrm{m}^{3}\right)$

${ }^{\mathrm{c}}$ Approximately 1.5 hectares of footprint are covered per year

${ }^{d}$ Costs associated with the moisture addition placement procedures are subtracted out

Settlement induced revenue gain can also be expected for the placement procedures presented herein. A similar methodology to the one used in Section 5.3 to determine the total settlement was used for this portion of the analysis as well. However, it was assumed that $735,000 \mathrm{kN}$ of waste were placed on average within one hectare of footprint. The total volume of and height of waste at each placement condition within the given hectare were calculated. Using the calculated waste heights, the assumption that the waste lift placed on top had identical features (i.e., same height and unit weight), and the assumption that the overlying waste layer did not self-consolidate, the total settlement over a 5 year period for a given hectare was calculated (Table 5.12). The airspace gain associated with the calculated settlements was used to determine an additional amount of waste that could be filled into that airspace. A tipping fee of $\$ 7.1 / \mathrm{kN}$ 
was applied and the settlement induced revenue gain per hectare-year was calculated (Table 5.12).

Table 5.12. Settlement Induced Revenue Gain.

\begin{tabular}{|c|c|c|c|}
\hline \multirow[b]{2}{*}{$\begin{array}{c}\text { Financial Analysis } \\
\text { Parameters }\end{array}$} & \multicolumn{3}{|c|}{ Placement Conditions } \\
\hline & $\begin{array}{c}\text { As-Received } \\
\left(w_{d}=45 \%\right)\end{array}$ & $\begin{array}{c}\text { Optimum } \\
\left(w_{d}=76 \%\right)\end{array}$ & $\begin{array}{l}\text { Wet of Optimum } \\
\left(w_{d}=105 \%\right)\end{array}$ \\
\hline $\begin{array}{l}\text { Operational Unit Weight } \\
\left(\mathrm{kN} / \mathrm{m}^{3}\right)\end{array}$ & 6.18 & 9.80 & 4.93 \\
\hline Waste Height (m/ha) & 11.9 & 7.5 & 14.9 \\
\hline Initial Settlement (m/ha) & 1.5 & 1.5 & 1.6 \\
\hline Secondary Settlement (m/ha) & 0.5 & 2.0 & 3.3 \\
\hline Total Settlement (m/ha) & 1.9 & 3.5 & 4.9 \\
\hline Airspace Gain ( $\left.\mathrm{m}^{3} / \mathrm{ha}\right)$ & 19,470 & 34,970 & 48,780 \\
\hline $\begin{array}{l}\text { Additional Weight of Waste } \\
(\mathrm{kN} / \mathrm{ha})\end{array}$ & 120,300 & 342,700 & 240,500 \\
\hline Tipping Fee $(\$ / k N)$ & 7.1 & 7.1 & 7.1 \\
\hline $\begin{array}{l}\text { Settlement Induced Revenue } \\
\text { (\$/ha-year) }\end{array}$ & $\$ 170,900$ & $\$ 486,600$ & $\$ 341,500$ \\
\hline
\end{tabular}

Significant revenue gain will occur due to settlement for a given hectare footprint within a landfill if optimum placement conditions are implemented. An $84 \%$ increase in revenue could potentially occur in a given hectare if optimum waste placement procedures are implemented in place of baseline as-received placement conditions. Although settlement and airspace gain were the highest for wet of optimum conditions, lower unit weights associated with the wet of optimum conditions limit the amount of additional waste that can be placed in the gained airspace.

A hypothetical financial comparison between SMRL and an anaerobic bioreactor landfill of the same size also was conducted. The costs and revenues associated with waste placement procedures implemented in the current study were compared to the costs and benefits of a typical bioreactor landfill. Asreceived, optimum, and wet of optimum placement conditions were analyzed for 
the comparison. Berge et al. (2009) provided a financial analysis for several different bioreactor landfill applications. The typical anaerobic bioreactor landfill is analyzed for this investigation.

The following assumptions and parameters were incorporated into the financial comparison: 1) Both SMRL and the bioreactor landfill have a cell footprint of 15 hectares; 2) Active filling was evaluated for a 5 year period; 3) $735,000 \mathrm{kN}$ of waste was placed in each hectare; 4) The costs and revenues associated with as-received conditions are considered baseline; 5) The tipping fee is $\$ 7.1 / \mathrm{kN} ; 6$ ) the operational unit weight of the as-received condition was applied to the bioreactor landfill; 7) the bioreactor landfill induced a total settlement of $20 \%$ of the original height within the 5 year period; 8 ) leachate treatment costs provided by Berge et al. (2009) were $\$ 0.024 / \mathrm{L}$ and used for both cases; and 9) the amount of leachate generated and the associated treatment costs at SMRL for as-received conditions were assumed to be $10 \%$ and $20 \%$ higher for optimum and wet of optimum conditions, conditions. The costs and revenues associated with the various waste placement conditions and the bioreactor landfill are presented in Table 5.13. 
Table 5.13. Comparison of Additional Costs and Revenues between Different Waste Placement Procedures and a Bioreactor Landfill.

\begin{tabular}{|c|c|c|c|c|}
\hline \multirow[b]{2}{*}{$\begin{array}{l}\text { Financial } \\
\text { Parameters }\end{array}$} & \multicolumn{3}{|c|}{ Santa Maria Regional Landfill } & \multirow[b]{2}{*}{$\begin{array}{l}\text { Bioreactor } \\
\text { Landfill }\end{array}$} \\
\hline & $\begin{array}{c}\text { As- } \\
\text { Received } \\
\left(w_{d}=45 \%\right)\end{array}$ & $\begin{array}{c}\text { Optimum } \\
\left(w_{d}=76 \%\right)\end{array}$ & $\begin{array}{c}\text { Wet of } \\
\text { Optimum } \\
\left(w_{d}=105 \%\right)\end{array}$ & \\
\hline Cell Footprint (ha) & 7.5 & 7.5 & 7.5 & 7.5 \\
\hline Total Weight of Waste $(\mathrm{kN})$ & $6.5 \times 10^{6}$ & $6.5 \times 10^{6}$ & $6.5 \times 10^{6}$ & $6.5 \times 10^{6}$ \\
\hline $\begin{array}{l}\text { Systematic Moisture } \\
\text { Addition Costs (\$/ha) }\end{array}$ & 0 & 14,000 & 26,100 & 0 \\
\hline $\begin{array}{l}\text { Leachate Treatment Costs } \\
\text { (\$/ha) }\end{array}$ & 115,700 & 127,270 & 138,840 & 561,000 \\
\hline Total Additional Costs & $\$ 867,750$ & $\$ 1,059,525$ & $\$ 1,237,050$ & $\$ 4,207,500$ \\
\hline $\begin{array}{l}\text { Settlement Induced } \\
\text { Revenue }(\$ / 5 \text {-year period) }\end{array}$ & 854,300 & $2,433,100$ & $1,707,500$ & $1,053,000$ \\
\hline $\begin{array}{l}\text { Systematic Moisture } \\
\text { Induced Revenue (\$/ha) }\end{array}$ & 0 & 561,000 & $-291,700$ & 0 \\
\hline $\begin{array}{l}\text { Gas Recovery Revenue } \\
(\$ / \mathrm{ha})\end{array}$ & - & - & - & 845,600 \\
\hline Total Additional Revenue & $\$ 854,300$ & $\$ 6,640,600$ & $\$-480,250$ & $\$ 7,395,000$ \\
\hline Net Revenue & $\$-13,450$ & $\$ 5,581,100$ & $\$-1,737,300$ & $\$ 3,187,500$ \\
\hline
\end{tabular}

The financial comparison between a bioreactor landfill and the waste placement procedures implemented for this test program indicates that compaction at optimum moisture conditions is more beneficial. However, this may not be the case as long-term testing has not been conducted on the waste placement procedures described in this investigation. While the financial comparison yields promising results, a recommendation and justification for implementing the waste placement procedures from this investigation over a bioreactor system cannot be made until further research is conducted. 


\section{Chapter 6: Summary and Conclusions}

The laboratory and field investigation highlighted the importance of waste placement procedures on the engineering response of waste. The physical and mechanical characteristics of MSW were affected by waste placement conditions and procedures at SMRL and were evaluated in this investigation.

An adapted version of ASTM Standard D854 (ASTM 2010b) was used to determine specific gravity for manufactured waste prepared in the laboratory, fresh waste obtained from the active face at SMRL, and old waste obtained from depth at SMRL. Manufactured MSW (MMSW) samples were prepared in accordance with the waste constituent fractionation provided by United States EPA. In addition, the manufactured waste samples were processed (i.e., shredded, and cut) to three particle size fractions (coarse, medium, and fine). Specific gravity was evaluated for uncompacted waste samples at each particle size and after compaction at dry and wet of optimum conditions. The manufactured waste mixture was representative, consistent, reproducible, and allowed for determination of specific gravity without variations in material composition. Fresh waste samples were representative of the entire incoming waste stream at SMRL and obtained from the active face before and after compaction. Incoming waste at SMRL was composed of residential, commercial, and self-delivered wastes. Old waste samples were obtained from different depths during drilling operations for installation of settlement and temperature monitoring equipment. 
Based on the results obtained from the experimental determination of specific gravity of MSW, the following conclusions were drawn:

1. Determination of specific gravity for MSW is important for weight-volume phase calculations.

2. Changes in $G_{s}$ are significant and should be considered in analysis of micro and macrostructure as well as constitutive relationships of MSW through determination of phase relations and characteristic physical parameters.

3. Specific gravity of manufactured waste samples increased with decreasing particle size and with compaction.

4. The average specific gravity of coarse, medium, and fine uncompacted manufactured MSW samples was 1.333, 1.374, and 1.424, respectively.

5. The average specific gravity of coarse, medium, and fine MMSW samples compacted at dry of optimum (i.e, wd $=30 \%$ ) was determined to be 1.497 , 1.521, and 1.552, respectively.

6. Specific gravity of coarse, medium and fine MMSW samples compacted at wet of optimum (i.e., wd $=90 \%$ ) were determined to be $1.500,1.542$, and 1.570 , respectively.

7. A strong linear trend exists between $G_{s}$ and equivalent diameter of uncompacted and compacted manufactured waste specimens.

8. Compacted and uncompacted specific gravity of fresh MSW was lower than manufactured and old MSW.

9. The average specific gravity of uncompacted and compacted fresh MSW was 1.072 and 1.208 , respectively. 
10. Old MSW had a significantly higher average specific gravity as compared to manufactured and fresh MSW and was determined to be on average 2.201.

11. A strong linear trend exists between degree of degradation (DOD) and $G_{s}$, which can be used to predict the $G_{S}$ of MSW at any level of degradation.

12. Compaction, degradation, and compression effects increased the specific gravity of MSW.

13. $G_{s}$ values of 1.1 and 1.2 may be used for as-delivered/uncompacted and compacted fresh wastes. Higher $G_{s}$ of 2.2 may be used for older wastes at depth subjected to decomposition and mechanical stress in the landfill environment. Recommended values would apply for sites with conditions similar to the Santa Maria Regional Landfill site.

The physical and engineering properties of fresh and old MSW from SMRL were experimentally determined during the investigation. Settlement and thermocouple arrays were placed into a total of eight boreholes (BH1-BH8) installed at various locations at SMRL. Settlement and temperature were monitored for the duration of the study. In addition, organic and moisture content of fresh waste samples obtained from the active face and old waste samples obtained from different depths were measured.

Based on the data obtained from settlement and temperature monitoring and laboratory testing of waste samples, the following conclusions were drawn:

1. The particle size distribution of OMSW is similar to a uniformly graded soil. The average coefficient of uniformity $\left(C_{u}\right)$ was 11 and the average coefficient of curvature $\left(C_{c}\right)$ was approximately 0.5 . 
2. The baseline weighted-average moisture content of fresh incoming waste at SMRL was $42.7 \%$.

3. The moisture content of incoming waste during the wet and dry seasons was relatively consistent with a slight peak of moisture content in June due to increased disposal of fruits.

4. The moisture content of OMSW slightly increased with increasing depth for each of the eight boreholes (approximately 1.75 percentage points $/ \mathrm{m}$ ) and was attributed to downward movement of moisture due to gravity and due to lower hydraulic conductivity of the waste $\left(k_{M S W}\right)$ at greater depths caused by consolidation.

5. The average moisture content of OMSW at shallow, middle, and great depths were $19.4,25.6$, and $30.8 \%$, respectively.

6. The organic contents of FMSW ranged between 68.1 and $86.2 \%$ with an average of $77.2 \%$. The organic contents of OMSW ranged between 3.0 and $66.1 \%$ with an average of $23.5 \%$.

7. A strong trend did not exist between organic content and depth and was attributed to the variability of MSW sampled.

8. In general, waste temperatures at shallow, middle, and great depths increased over time and an overall warming of the waste mass occurred. The temperature increased on average $5,3,5$, and $6^{\circ} \mathrm{C}$ between the initial and final day of measurements for $\mathrm{BH} 5, \mathrm{BH} 6, \mathrm{BH}$, and $\mathrm{BH}$, respectively. Temperatures were highest at mid-depths of the waste mass. 
9. In general, settlement data obtained in this investigation represented the secondary compression stages (i.e., mechanical creep and biochemical compression) of the wastes. The bottom waste lift (Lift I) for all boreholes demonstrated the largest final strain.

10. The maximum measured waste settlement within a single waste lift (each lift approximately $5 \mathrm{~m}$ in height) was $780 \mathrm{~mm}$, which was associated with Lift I (deepest waste materials) of $\mathrm{BH} 6$. The minimum measured settlement was $15 \mathrm{~mm}$ and was associated with Lift III (shallowest waste materials) of $\mathrm{BH} 2$.

11. The maximum $C_{\alpha}^{\prime}$ was determined to be 0.067 and the minimum $C_{\alpha}^{\prime}$ was 0.013. The average $C_{\alpha}^{\prime}$ was determined to be 0.025 .

12. A modified initial compression ratio for old waste $\left(C_{c, \text { old }}^{\prime}\right)$ was determined to be 0.332 for old waste loaded with an earthen embankment and 0.067 to 0.105 for old waste loaded with a fresh waste lift.

13. Based assumed preconsolidation stress for MSW of $45 \mathrm{kPa}$ (Olivier and Gourc 2007), fresh MSW was determined to be slightly overconsolidated. The modified recompression indices for fresh waste lifts ranged between 0.038 and 0.112 with an average of 0.076 .

14. Loading and unloading of an earthen embankment placed over the waste mass resulted in unique compression behavior of old waste. During unloading of the earthen embankment the bottom waste lift (Lift I) exhibited a net change in vertical strain of zero. Based on projected calculations net change in vertical strain equal to zero corresponded to equivalent amount of secondary compression and swell of the bottom waste lift. Based on this 
analysis, a modified recompression index for old waste was estimated to be 0.012. When reloaded, the vertical strain versus log stress relationship returned to the virgin compression curve.

15. Compaction of waste at or near optimum moisture conditions reduced the amount of initial compression approximately $2 \%$ compared to waste compacted at as-received moisture conditions.

16. Long-term secondary compression was the highest for waste compacted at wet of optimum moisture contents due to enhanced degradation conditions.

17. Loading and unloading of a fresh waste lift with an earthen embankment induced recompression behavior of the waste. Upon unloading (after completion of initial compression), the waste lift could potentially swell up to $7.1 \%$ of the waste lift height after initial compression.

Meso- and full-scale compaction studies also were conducted at SMRL. Test plots were constructed for the meso-scale compaction study and filled with residential MSW. Approximately $900 \mathrm{kN}$ of residential waste was placed into the test plots. The residential waste was compacted using controlled compaction effort at 5 different moisture contents and compaction curves were generated. Maximum dry and operational unit weights and dry and operational optimum moisture contents were determined for the meso-scale study. The meso-scale compaction study provided a baseline procedural approach that was used for the full-scale compaction study and allowed for any operational constraints to be mitigated prior to the commencement of the full-scale compaction study. 
The full-scale compaction study incorporated the entire waste stream at SMRL (i.e., $2500 \mathrm{kN}$ of waste per day). The incoming MSW was placed and compacted at 4 different target moisture contents and compaction curves were generated for different compaction parameters. Maximum dry and operational unit weights and dry and operational optimum moisture contents were determined for the full-scale compaction study. The results of both the meso- and full-scale compaction studies were compared and guidelines for systematic moisture addition prior to waste compaction in the field were developed.

Based on the results obtained from the meso- and full-scale compaction test program, the following conclusions were drawn:

1. As-placed unit weights (i.e., dry and operational unit weights) of MSW improved significantly with the addition of intermediate amounts of moisture.

2. Compaction was improved for wastes compacted at or near optimum moisture conditions as compared to wastes compacted at baseline asreceived moisture conditions.

3. The dry and operational unit weight of waste increased with increasing moisture content to an optimum condition (i.e., peak of the compaction curve) at which point the effectiveness of moisture addition was reduced and unit weights decreased with increasing moisture content.

4. The maximum dry unit weight $\left(\gamma_{d \max }\right)$ and operational unit weight $\left(\gamma_{o p e r-\max }\right)$ for the meso-scale compaction study were 8.5 and $13.3 \mathrm{kN} / \mathrm{m}^{3}$, respectively. These maximum unit weights corresponded to optimum moisture contents, $w_{\text {opt-dmax }}$ and $w_{\text {opt-oper }}$, of 78.5 and $79.5 \%$, respectively. 
5. The penetration of waste into underlying waste layers during the meso-scale tests resulted in higher unit weights due to lower measured volumes for a given weight of waste.

6. The maximum OWPF determined during the meso-scale tests corresponded to waste compacted at or near optimum and was 1.66 . This indicated that $66 \%$ more waste could be placed into a given unit volume.

7. The spatial variability associated with moisture addition indicated that degree of saturation $(S)$ and volumetric moisture content $(\theta)$ of underlying waste layer increased due to moisture addition.

8. For waste compacted at target moisture contents of $55,65,80$, and $110 \%$ during the meso-scale tests, $S$ increased by $19,4.5,4.4$, and $4.3 \%$, respectively while $\theta$ increased by $28,7.7,8.1$, and $5.7 \%$, respectively.

9. Based on the waste layers measured during test pit excavation, field capacity was reached in $75 \%$ of the waste layers due to moisture addition for the waste layers that were placed under field capacity.

10. The maximum dry unit weight $\left(\gamma_{d \max }\right)$ and maximum operational unit weight $\left(\gamma_{\text {oper-max }}\right)$ for the full-scale compaction study were 7.0 and $9.8 \mathrm{kN} / \mathrm{m}^{3}$, respectively. These maximum unit weights corresponded to optimum moisture contents, $w_{\text {opt-dmax }}$ and $w_{\text {opt-oper }}$, of 76 and $75.5 \%$, respectively.

11. In general, the dry and operational unit weights were lower for the full-scale compaction study as compared to the meso-scale study and this was attributed to the presence of bulkier items such as furniture and appliances. 
12. The maximum OWPF determined during the full-scale tests corresponded to waste compacted at or near optimum and was 1.55 . This indicated that $55 \%$ more waste could be placed into a given unit of volume as compared to the amount of waste that could be placed into a given volume when compacted at as-received moisture conditions. The maximum amount of waste can be disposed of in the permitted volume of a landfill when compacted at optimum moisture conditions.

13. Test pit excavations indicated that the degree of saturation increased by an average of $43 \%$ and the volumetric moisture contents increased by an average of $78 \%$ due to moisture addition in the waste layer immediately below the waste layer compacted with moisture addition.

14. Moisture was effectively distributed across the entire active face during days of moisture addition.

15. The addition of moisture to optimum conditions resulted in waste particles molding together into macro waste clods. At high moisture contents, waste particles began to slip due to breaking of the surface tension and then roll over one another.

16. The zero air voids (ZAV) curve (i.e., 100\% saturation line) for wastes was not unique and was not associated with a single $G_{s}$ value.

17. Compaction of waste at or near optimum conditions resulted in significant net revenue. At optimum moisture conditions, the net revenue due to combined waste placement procedures and settlement over a 5-year period was estimated to be $\$ 5.6$ million. 
18. Systematic moisture addition prior to compaction of waste may be financially and environmentally more beneficial than a bioreactor landfill system.

19. The life of a landfill can be extended when waste is compacted at optimum moisture conditions minimizing the need for vertical expansion, additional siting/permitting, or diversion of waste to another landfill site.

It is recommended that a "2-to-1" placement method be used if similar placement procedures described herein are implemented at a landfill site. Baseline physical and engineering properties should be established prior to implementation. It is recommended that wastes be compacted at an optimum moisture content of $75 \%$ to achieve maximum waste placement efficiency.

\subsection{Future Research}

The decoupled effects of degradation and compression on the interparticle and intraparticle voids and on the specific gravity of MSW need to be evaluated. In addition, the waste moisture distribution characteristics (i.e., field capacity) of systematic moisture addition prior to compaction need to be thoroughly evaluated. The effect of compactive effort (i.e., number of passes) and lift height on the waste compaction procedures implemented in this study should be determined in the future. In addition, shear strength and hydraulic conductivity of MSW after moisture addition and compaction should also be investigated. Most importantly, the long-term effects (i.e., compressibility, degradation, leachate and methane generation, etc.) on the systematic moisture addition to waste prior to compaction need to be evaluated. 


\section{References}

Andersland, O. B., Khattak, A. S., Al-Khafaji, A. W. N. (1981). "Effect of Organic Material on Soil Shear Strength," Laboratory Shear Strength of Soil, ASTM STP 740, Eds. R. N. Yong and F. C. Townsend, ASTM, West Conshohocken, PA, 226-242.

ASTM D2974, (2007). Standard Test Methods for Moisture, Ash, and Organic Matter of Peat and Other Organic Soils, Annual Book of ASTM Standards. American Society For Testing and Materials, West Conshohocken, PA.

ASTM D6913, (2009). Standard Test Methods for Particle-Size Distribution (Gradation) of Soils Using Sieve Analysis, Annual Book of ASTM Standards. American Society For Testing and Materials, West Conshohocken, PA.

ASTM D2216, (2010a). Standard Test Methods for Laboratory Determination of Water (Moisture) Content of Soil and Rock by Mass, Annual Book of ASTM Standards. American Society For Testing and Materials, West Conshohocken, PA.

ASTM D854, (2010b). Standard Test Methods for Specific Gravity of Soil Solids by Water Pycnometer. Annual Book of ASTM Standards. American Society For Testing and Materials, West Conshohocken, PA.

ASTM D5057, (2010c). Screening Apparent Specific Gravity and Bulk Density of Waste. Annual Book of ASTM Standards. American Society For Testing and Materials, West Conshohocken, PA.

ASTM D0698, (2012a). Standard Test methods for Laboratory Compaction Characteristics of Soil Using Standard Effort $\left(12400 \mathrm{ft}-\mathrm{lbf} / \mathrm{ft}^{3}\left(600 \mathrm{kN}-\mathrm{m} / \mathrm{m}^{3}\right)\right)$. Annual Book of ASTM Standards. American Society For Testing and Materials, West Conshohocken, PA

ASTM D1557, (2012b). Standard Test methods for Laboratory Compaction Characteristics of Soil Using Modified Effort $\left(56,000 \mathrm{ft}-\mathrm{lbf} / \mathrm{ft}^{3}\left(2,700 \mathrm{kN}-\mathrm{m} / \mathrm{m}^{3}\right)\right)$. Annual Book of ASTM Standards. American Society For Testing and Materials, West Conshohocken, PA

Babu, G. L., Reddy, K. R., and Chouskey, S. K. (2010a). "Constitutive Model for Municipal Solid Waste Incorporating Mechancial Creep and BiodegradationInduced Comprssion," Waste Management, Elsevier, 30(1), 11-22.

Babu, G. L., Reddy, K. R., Chouskey, S. K., Kulkarni, H. S. (2010b). "Prediction of Long-Term Municipal Solid Waste Landfill Settlement Using Constitutive Model," Practice Periodical of Hazardous, Toxics, and Radioactive Waste Management, ASCE, 14(2), 139-150. 
Bareither, C. A., Breitmeyer, R., Erses, A., Benson, C., Edil, T., and Barlaz, M. (2008). "Relative Contributions of Moisture and Biological Activity on Compression of Municipal Solid Waste in Bioreactor Landfills," Proceedings of the Global Waste Management Symposium, Penton Media, Orlando, FL, 1-9.

Bareither, C. A. (2010). Compression Behavior of Solid Waste, Ph.D. dissertation, University of Wisconsin-Madison, Madison, WI.

Bareither, C. A., Benson, C. H., Barlaz, M. A., Edil, T. B., and Tolaymat, T. M. (2010). "Performance of North American bioreactor landfills: I. Leachate hydrology and waste settlement," Journal of Environmental Engineering, ASCE, 136(8), 824-838.

Bareither, C. A., Benson, C. H., and Edil, T. B. (2012a). "Compression Behavior of Municipal Solid Waste: Immediate Compression," Journal of Geotechnical and Geoenvironmental Engineering, ASCE, 138(9), 1047-1062.

Bareither, C. A., Benson, C. H., Edil, T. B., and Barlaz, M. A. (2012b). "Abiotic and Biotic Compression of Municipal Solid Waste," Journal of Geotechnical and Geoenvironmental Engineering, ASCE, 138(8), 877-888.

Bareither, C. A., Breitmeyer, R. J., Benson, C. H., Barlaz, M. A., and Edil, T. B. (2012c). "Deer Track Bioreactor Experiment: Field-Scale Evaluation of Municipal Solid Waste Bioreactor Performance," Journal of Geotechnical and Geoenvironmental Engineering, ASCE, 138(6), 658-670.

Bareither, C. A., Benson, C. H., and Edil, T. B. (2013). "Compression of Municipal Solid Waste in Bioreactor Landfills: Mechanical Creep and Biocompression," Journal of Geotechnical and Geoenvironmental Engineering, ASCE, 139(7), 1007-1021

Barlaz, M. A., Ham, R. K., Schaefer, D. M. (1989). "Mass-Balance Analysis of Anaerobically Decomposed Refuse," Journal of Environmental Engineering, ASCE, 115(6), 1088-1102.

Beaven, R. P., 2000. The Hydrogeological and Geotechnical Properties of Household Waste in Relation to Sustainable Landfilling. Ph.D. Dissertation, Queen Mary and Westfield College, University of London.

Beaven and Powrie (1996). "Determination of the Hydrogeological and Geotechnical Properties of Refuse in Relation to Sustainable Landfilling," Proceedings of the 19th International Madison Waste Conference. University of Wisconsin-Madison, Madison, WI, 435-454. 
Benson, C. H., Barlaz, M. A., Lane, D. T., Rawe, J. W. (2007). "Practice Review of Five Bioreactor/recirculation Landfills," Waste Management, Elsevier, 27(1), 13-21.

Berge, N. D., Reinhart, D. R., and Batarseh, E. S. (2009). "An Assessment of Bioreactor Landfill Costs and Benefits," Waste Management, Elsevier, 29, 11581567.

Bjarngard, A., and Edgers, L. (1990). "Settlement of Municipal Solid Waste Landfills," Proceedings of the 13th Annual Madison Waste Conference, D. S. Ermer, Ed., University of Wisconsin-Madison, Madison, WI, 192-205.

Blakey, N. C., Bradshaw, K., and Reynolds, P. (1997). "Bioreactor Landfill-A Field Trial of Accelerated Waste Stabilization," Proceedings of the 6th International Landfill Symposium, Eds. T.H. Christensen, R. Cossu and R. Stegmann, CISA, S. Margherita di Pula, Cagliari, Italy, 375-386.

Breitmeyer, R. J. (2011). Hydraulic Characterization of Municipal Solid Waste, Ph.D. Dissertation, University of Wisconsin-Madison, Madison, WI.

Bray J. D., Zekkos, D., Kavazanjian, E., Athanasopoulos, G. A., and Riemer, M. F. (2009). 'Shear Strength of Municipal Solid Waste," Journal of Geotechnical and Geoenvironmental Engineering, ASCE, 135(6), 709-722.

Buisman, A. S. K. (1936). "Results of Long Duration Settlement Tests." Proceedings of the 1st International Conference on Soil Mechanics and Foundation Engineering, ISSMGE, Cambridge, MA, 103-107.

Burmister, D. M. (1963). "Physical Stress-Strain and Stength Responses of Granular Soils," ASTM Special Technical Publication, No. 322, Field Testing of Soils, American Society For Testing and Materials, Philadelphia, PA, 67-97.

Burmister, D. M. (1964). "Environmental Factors in Soil Compaction," ASTM Special Technical Publication, No. 377, Compaction of Soils, American Society For Testing and Materials, Chicago, IL, 47-66.

Cal Recycle. (2013). "2011 Landfill Summary Tonnage Report." <http://www.calrecycle.ca.gov/SWFacilities/Landfills/tonnages> (August 12, 2013).

Capelo, J., and de Castro, M. A. H. (2007). "Measuring Transient Water Flow in Unsaturated Municipal Solid Waste-A New Experimental Approach," Waste Management, Elsevier, 27(6), 811-819.

Carpenter, P. J., Grellier, S., Reddy, K. R., Adib, R., Peters, C., and Gangtahulasi, J. (2008). "Investigating the Interior of a Landfill Cell With 
Leachate Injection Using Electromagnetic Conductivity and Ground-Penetrating Radar Surveys," Proceedings of the 21st Symposium on the Application of Geophysics to Engineering and Environmental Problems, EEGE, Philadelphia, PA, 1017-1027.

Catley, A. J., Samson, C., and Van Geel, P. J., (2008). "Seismic Velocity Analysis to Determine Moisture Distribution in a Bioreactor Landfill," Journal of Solid Waste Technology and Management, Widener University School of Engineering , 34(2), 81-90.

Chen, K. S., Chen, R. H., and Liu, C. N. (2012). "Modeling Municipal Solid Waste Landfill Settlement." Environmental Earth Science, Springer, 66, 2301-2309.

Chen, R. H., Chen, K. S., and Liu, C. N. (2010b). "Study of the Mechanical Compression Behavior of Municipal Solid Waste by Temperature-controlled Compression Tests," Environmental Earth Science, Springer, 61, 1677-1690.

Chen, T., Chynoweth, D. P. (1995). "Hydraulic Conductivity of Compacted Municipal Solid Waste," Bioresource Technology, Elsevier, 51, 205-212.

Chen, Y. M., Zhan, L. T., Wei, H. Y., Ke, H. (2009). "Aging and Compressibility of Municipal Solid Wastes," Waste Management, Elsevier, 29(1), 86-95.

Chen, Y. M., Ke, H., Delwyn, G., Fredlund, M., Liangtong, Z., and Xie, Y. (2010a). "Secondary Compression of Municipal Solid Wastes and a Compression Model for Predicting Settlement of Municipal Solid Waste Landfills." Journal of Geotechnical and Geoenvironmental Engineering, ASCE, 136(5), 706-717.

Clarin, J. (2013, August 2). Solid Waste Manager at Santa Maria Regional Landfill. (J. Cox, Interviewer).

Collins, H. J. (2001). "Compaction of Municipal Solid Waste After Mechanical and Biological Treatment," Proceedings of the 8th International Landfill Symposium, Eds. T.H. Christensen, R. Cossu and R. Stegmann, CISA, S. Margherita di Pula, Cagliari, Italy, 455-464.

Coduto, D. P., and Huitric, R. (1990). "Monitoring Landfill Movements Using Precise Instruments," Geotechnics of Waste Fills - Theory and Practice, ASTM STP 1070, A. O. Landva, and D. G. Knowles, Eds., American Society for Testing and Materials, Philadelphia, PA, 358-370.

Coduto, D. P., Yeung, M.-C. R., and Kitch, W. A. (2010). Geotechnical Engineering: Principles \& Practices, 2nd Ed., Prentice Hall, India. 
D' Appolonia, D. J., Whitman, R. V., and D' Appolonia, E. D. (1969). " Sand Compaction with Vibratory Rollers," Journal of Soil Mechanics and Foundations Divisions, ASCE, Vol. 95, No. SM1, 263-284.

Demirbas, A. (2006). "Biogas Production From the Organic Content Fraction of Municipal Solid," Energy Sources, Taylor and Francis, 28(9-12), 1127-1134.

Dixon, N., and Jones, D. R. V. (2005). "Engineering Properties of Municipal Solid Waste," Geotextiles and Geomembranes, Elsevier, 23, 205-233.

Dixon, N., and Langer, U. (2006). "Development of a MSW Classification System For the Evaluation of Mechanical Properties," Waste Management, Elsevier, 26, 220-232.

Durmusoglu, E., Corapcioglu, M. Y., and Tuncay, K. (2005). "Landfill Settlement with Decomposition and Gas Generation," Journal of Environmental Engineering, ASCE, 131(9), 1311-1321.

Durmusoglu, E., Sanchez, I. M., and Corapcioglu, M. Y., (2006). "Permeability and Compression Characteristics of Municipal Solid Waste Samples," Environmental Geology, Springer-Verlag, 50, 773-786.

Edgers, L., Noble, J., and Williams, E. (1992). "A Biologic Model for Long Term Settlement in Landfills," Proceedings of the Mediterranean Conference on Environmental Geotechnology, Eds. M. A. Usmen, and Y. B. Acar, Environmental Technology, Cesme, Turkey, 177-184.

Edil, T., den Haan, Evert J. (1994). "Settlement of Peats and Organic Soils," Proceedings of the Conference on Vertical and Horizontal Deformations of Foundations and Embankments, Eds. A. K. W. Yeung, and G. Feaalio, ASCE, College Station, TX, Volume 2, 1543-1572.

Edil, T., Ranguette, V., and Wuellner, W. (1990). "Settlement of Municipal Refuse," Geotechnics of Waste Fills - Theory and Practice, ASTM STP 1070, Eds. A. O. Landva, and D. G. Knowles, American Society for Testing and Materials, Philadelphia, PA, 225-239.

El-Fadel, M., and Al-Rashed, H. (1998). "Settlement in Municipal Solid Waste Landfills, Field Scale Experiments," The Journal of Solid Waste Technology and Management, Widener University School of Engineering, 25(2), 89-98.

El-Fadel, M., and Khoury, R. (2000). Modeling Settlement in MSW Landfills: A Critical Review, CRC Press LLC, Boca-Raton, FL. 
Eleazer, W. E., Odle, W. III, Shengwang, Y., Barlaz, M. A. (1997). "Biodegradability of Municipal Solid Waste Components in Laboratory-Scale Landfills," Environmental Science and Technology, ACS, 31, 911-917.

Entenmann, W. and Wendt, P., 2007. "Placement and Compaction of Treated Municipal Solid Waste in Modern Landfills, Results of Geotechnical and Hydraulic Tests and Monitoring," Proceedings of the 11th International Waste Management and Landfill Symposium, CD-ROM.

Fahker, A. 2006). "Experimental Study on the Compaction of Waste," Proceedings of the 5th International Conference of Environmental Geotechnics, ISSMGE, London, UK, 445-452.

Fassett, J., Leonardo, G., and Repetto, P. (1994). "Geotechnical Properties of Municipal Solid Waste and Their Use in Landfill Design," Waste Technology '94 Landfill Technology Technical Proceedings. Charleston, SC.

Fungaroli, A., and Steiner, R. (1979). "Investigation of Sanitary Landfill BehaviorVolume I." Final Report EPA-600-2-79-053a, Environmental Protection Agency, Washington, D.C.

Gabr, M. A., and Valero, S. N. (1995). "Geotechnical Properties of Municipal Solid Waste," Geotechnical Testing Journal, ASTM International, West Conshohocken, PA, 18(2), 241-251.

Gabr, M. A., Hossain, M. S., and Barlaz, M. A. (2007). "Shear Strength Parameters of Municipal Solid Waste with Leachate Recirculation." Journal of Geotechnical and Geoenvironmental Engineering, ASCE, 133(4), 478-484.

Gawande, N. A., Reinhart, D. R., Thomas, P. A., McCreanor, P. T., and Townsend, T. G. (2003). "Municipal Solid Waste In Situ Moisture Content Measurement Using an Electrical Resistance Sensor," Waste Management, Elsevier, 23(7), 667-674.

Grellier, S., Reddy, K. R., Gangathulasi, J., Adib, R., Peters, C. C. (2007). "Correlation Between Electrical Resistivity and Moisture Content of Municipal Solid Waste in Bioreactor Landfill," Geotechnical Special Publication, No. 163, Proceedings of the Geo-Denver Conference - Geoevironmental Engineering, ASCE, Denver, CO, 1-14.

Google Earth (2013). "Santa Maria Regional Landfill," 34 $56^{\circ} 43.2 " \mathrm{~N}$ and 120²2'25.2”W, April 14, 2013, July 1, 2013.

Grisolia, M. \& Napoleoni, Q. (1995). "Deformability of Waste and Settlements of Sanitary Landfills," ISWA'95 World Congress on Waste Management Wien. 1995 
Grisolia, M., Napoleoni, Q., and Tancredi, G. (1995). "Contribution to a Technical Classification of MSW," Proceedings of the 5th International Landfill Symposium, Eds. T.H. Christensen, R. Cossu and R. Stegmann, CISA, S. Margherita di Pula, Cagliari, Italy, 703-710.

Gomes, C. C., and Lopes, M. L. (2012). "Characterisation of Municipal Solid waste Physical Properties and Their Evolution with Age," Geotechnical Engineering, Institution of Civil Engineers, 165(GE1), 23-34.

Gomes, C. C., Lopes, M. L., and Oliveira, P. J. V. (2013). "Municipal Solid Waste Shear Strength Parameters Defined Through Laboratorial and In-situ Tests," Journal of The Air and Waste Management Association, Taylor and Francis, 63(11), 1352-1368.

Gourc, J. P., Staub, M. J., Conte, M. (2010). "Decoupling MSW Settlement Into Mechanical and Biochemical Process-Modeling and Validation on Large-scale Setups," Waste Management, Elsevier, 30(9), 1556-1568.

Guerin, R., Munoz, M. L., Aran, C., Laperrelle, C., Hidra, M., Drouart, E., and Grellier, S. (2004). "Leachate Recirculation: Moisture Content Assessment by Means of a Geophysical Technique," Waste Management, Elsevier, 24(8), 785794.

Ham, R. K., Reinhardt, J. J., and Sevick, G. W. (1978). "Density of Milled and Unprocessed Refuse," Journal of Environmental Engineering Division, ASCE, 104(EE1), 109-125.

Hanson, J. L., Yesiller, N., Von Stockhausen, S. A., and Wong, W. W., (2010a). "Compaction Characteristics of Municipal Solid Waste," Journal of Geotechnical and Geoenvironmental Engineering, ASCE, 136(8), 1095-1102.

Hanson, J. L., Yesiller, N., Oettle, N. K. (2010b). "Spatial and Temporal Temperature Distributions in Municipal Solid Waste Landfills," Journal of Environmental Engineering, ASCE, 136(8), 804-814.

Harker, R. J., and Juds, M. A. (1976). " A Laboratory Investigation of Compaction of Solid Waste by Roller Crushing," Proceedings of the National Waste Processing Conference, American Society of Mechanical Engineers, 7, 513-527.

Harris, M. R. R. (1979). "Geotechnical Characteristics of Landfilled Domestic Refuse," The Engineering Behaviour of Industrial and Urban Fill: Proc. of the Symposium held at the University of Birmingham, Midland Geotechnical Society, University of Birmingham, Birmingham, England, B1-B10. 
Hartz, K. E., Klink, R. E., and Ham, R. K. (1982). "Temperature Effects: Methane Generation from Landfill Samples," Journal of Environmental Engineering Division, ASCE, 108(4), 629-638.

Haydar, M. M., and Khire, M. V. (2005). "Leachate Recirculation Using Horizontal Trenches in Bioreactor Landfills," Journal of Geotechnical and Geoenvironmental Engineering, ASCE, 131(7), 837-847.

Haydar, M. M., and Khire, M. V. (2007). "Leachate Recirculation Using Permeable Blankets in Engineered Landfills," Journal of Geotechnical and Geoenvironmental Engineering, ASCE, 133(4), 360-371.

Hentrich, R. L., Swartzbaugh, J. T., and Thomas, J. M. (1979). "Influence of MSW Processing on Gas and Leachate Production," Municipal Solid Waste: Proceedings of the Fifth Annual Research Symposium at Orlando, Florida, Eds. Martin P. W., and James S. T., Municipal Environmental Research Laboratory, Office of Research and Development, US Environmental Protection Agency, Orlando, FL, Volume 79.

Hettiarachchi, C. H., (2005). Mechanics of Biocell Landfill Settlements, Ph.D. Dissertation, New Jersey Institute of Technology, Newark, NJ.

Hettiarachchi, C. H., Meegoda, J., and Hettiaratchi, P. (2009). "Effects of Gas and Moisture on Modeling of Bioreactor Landfill Settlement." Waste Management, Elsevier, 29(3), 1018-1025.

Holmes, R. (1983). "The Absorptive Capacity of Domestic Refuse From a Full Scale Active Landfill," Wastes Management, 73(11), 581-593.

Holtz, R., Kovacs, W., and Sheahan, T. (2011). An Introduction to Geotechnical Engineering, 2nd Ed., Pearson Education Inc., Upper Saddle River, NJ.

Hossain, M. S., Gabr, M. A., and Barlaz, M. A. (2003). "Relationship of Compressibility Parameters to Municipal Solid Waste Decomposition," Journal of Geotechnical and Geoenvironmental Engineering, ASCE, 129(12), 1151-1158.

Hossain, M. S. and Gabr, M. A. (2005). "Prediction of Municipal Solid Waste Landfill Settlement with Leachate Recirculation," Geotechnical Special Publication, No. 142, Proceedings of the Geo-Frontiers Conference - Waste Containment and Remediation, ASCE, Austin, TX,

Hossain, M. S., Gabr, M. A., Asce, F. (2009). "The Effect of Shredding and Test Apparatus Size on Compressibility and Strength Parameters of Degraded Municipal Solid Waste," Waste Management, Elsevier, 29(9), 2417-2424. 
Hudson, A. P., White, A. K., Beaven, R. P., and Powrie, W., (2004). "Modeling the Compression Behaviour of Landfilled Domestic Waste," Waste Management, Elsevier, 24, 259-269.

Imhoff, P. T., Jakubowitch, A., Briening, M. L., and Chiu, P. C. (2003). "Partitioning Gas Tracer Tests for Measurement of Water in Municipal Solid Waste," Journal of the Air and Waste Management Association, Taylor and Francis, 53(1), 1-10.

Imhoff, P. T., Reinhart, D. R., Englund, M., Guerin, R., Gawande, N., Han, B., Jonnalagadda, S., Townsend, T. G., and Yazdari, R. (2007). "Review of State of the Art Methods for Measuring Water in Landfills," Waste Management, Elsevier, 27(6), 729-745.

Itoh, T., Towhata, I., Kawano, Y., Kameda, M., Fukui, S., Koelsch, F., and Yonai, Y. (2005). "Mechanical Properties of Municipal Waste Deposits and Ground Improvement," Proceedings of the Sixteenth International Conference on Soil Mechanics and Geotechnical Engineering, Volume 4, Millpress Science Publishers, Rotterdam, the Netherlands, 2273-2276.

Ivanova, L. K., Richards, D. J., and Smallman, D. J. (2008). "The Long-term Settlement of Landfill Waste," Proceedings of the Institution of Civil Engineers Waste and Resource Management, Institution of Civil Engineers, 161(3), 121133.

Jain, P., Powell, J., Townsend, T. G., and Reinhart, D. R. (2006). "Estimating the Hydraulic Conductivity of Landfilled Municipal Solid Waste Using the Borehole Permeameter Test," Journal of Environmental Engineering, ASCE, 132(6), 645652.

Jessberger, H., Syllwasschy, O., and Kockel, R. (1995). "Investigation of Waste Body Behaviour and Waste-Structure Interaction," Proceedings of the 5th International Landfill Symposium, Eds. T.H. Christensen, R. Cossu and R. Stegmann, CISA, S. Margherita di Pula, Cagliari, Italy, 731-743.

Johnson, A. W., and Sallberg, J. R. (1960). Factors that Influence Field Compaction of Soils, Bulletin 272, Highway Research Board.

Kadambala, R., Townsend, T. G., Jain, P., and Singh, K. (2011). "Temporal and Spatial Pore Water Pressure Distribution Surrounding a Vertical Landfill Leachate Recirculation Well," International Journal of Environmental Research and Public Health, MDPI, 8, 1692-1706.

Kavazanjian, E., Jr., Matasovic, N., and Bachus, R. C. (1999). "Large Diameter Static and Cyclic Laboratory Testing of Municipal Solid Waste," Proceedings of the 7th International Waste Management and Landfill Symposium, T. H. 
Christensen, R. Cossu, and R. Stegmann, Eds., CISA, Environmental Sanitary Engineering Centre, Cagliari, Italy, 437-444.

Kavazanjian, E. Jr. (2001). "Mechanical Properties of Municipal Solid Waste," Proceedings of the 8th International Waste Management and Landfill Symposium, T. H. Christensen, R. Cossu, and R. Stegmann, Eds., CISA, Environmental Sanitary Engineering Center, Cagliari, Italy, 415-424.

Kavazanjian, E., Jr. (2006). "Waste Mechanics: Recent Findings and Unanswered Questions," Geotechnical Special Publication, No. 148, Proceedings of the Geo-Shanghai 2006 - Advances in Unsaturated Soil, Seepage, and Environmental Geotechnics, N. Lu, L. R. Hoyos, and L. Reddi, Eds., ASCE, Shanghai, China, 34-54.

Kavazanjian, N., Matasovic, R., Bonaparte, G. R., and Schmertmazin, E. (1995). "Evaluation of MSW Properties for Seismic Analysis" Geotechnical Special Publication, No.46, Proceedings of Geoenvironment 2000 - Characterization Containment Remediation, and Performance in Environmental Geotechnics, ASCE, New Orleans, LA, 1126-1141.

Kazimoglu, Y. K., McDougall, J. R., and Pyrah, I. C. (2005). "Moisture Retention Curve in Landfilled Waste," Proceedings of the International Conference - From Experimental Evidence towards Numerical Modeling of Unsaturated Soils, T. Schanz, Ed., Springer, Weimar, Germany, 59-67.

Kelly, R. J., Shearer, B. D., Kim, J., Goldsmith, C. D., Hater, G. R., and Novak, J. T. (2006). "Relationships Between Analytical Methods Utilized as Tools in the Evaluation of Landfill Waste Stability," Waste Management, Elsevier, 26, 13491356.

Khire, M. V., and Haydar, M. M. (2003). "Numerical Evaluation of Granular Blankets for Leachate Recirculation in MSW Landfills," Proceedings of the 9th International Waste Management and Landfill Symposium, CISA, Environmental Sanitary Engineering Centre, Cagliari, Italy.

Khire, M. V., and Haydar, M. M. (2007). "Leachate Recirculation in Bioreactor Landfills Using Geocomposite Drainage Material," Journal of Geotechnical and Geoenvironmental Engineering, ASCE, 133(2),166-174.

Khire, M. V., and Mukherjee, M. (2007). "Leachate Injection Using Vertical Wells in Bioreactor Landfills," Waste Management, Elsevier, 27(9), 1233-1247.

Krase, V., Bente, S., Kowalsky, U., and Dinkler, D. (2011). "Modeling the StressDeformation Behaviour of Municipal Solid Waste." Geotechnique, Institution of Civil Engineers, 61(8), 665-675. 
Kreith, F., Tchobanoglous, G. (2002). Handbook of Solid Waste Management, $2^{\text {nd }}$ Ed, McGraw-Hill, New York.

Kulkarni, H. S., and Reddy, K. R. (2012). "Moisture Distribution in Bioreactor Landfills: A Review," Indian Geotechnical Journal, Springer, 42(3), 125-149.

Lambe, T. (1958a). "The Engineering Behavior of Compacted Clay," Journal of the Soil Mechanics and Foundations Division, ASCE, 84, SM2, 1655-1 - 1655-35.

Lambe, T. (1958b). "The Structure of Compacted Clay," Journal of the Soil Mechanics and Foundations Division, ASCE, 125, 1654-1 - 1654-34.

Lambe, T., and Whitman, R. (1969). Soil Mechanics, John Wiley and Sons, New York, NY.

Lamothe, D., and Edgers, L. (1994). "The Effects of Environmental Parameters on the Laboratory Compression of Refuse," Proceedings of the Seventeenth International Madison Waste Conference, Department of Engineering Professional Development, University of Wisconsin-Madison, Madison, WI.

Landva, A. O., and Clark, J. I. (1990). "Geotechnics of Waste Fill," Geotechnics of Waste Fill - Theory and Practice, ASTM STP 1070, American Society of Testing and Materials, Philadelphia, PA, 86-106.

Landva, A. O., Valsangkar, A. J., and Pelkey, S. C. (2000). "Lateral earth Pressure at Rest and Compressibility of Municipal Solid Waste," Canadian Geotechnical Journal, NRC Research Press, 37(6), 1157-1165.

Lee, K. L., and Singh, A. (1971). "Compaction of Granular Soils," Proceedings of the Ninth Annual Symposium on Engineering Geology and Soils Engineering, Boise, ID, 161-174.

Li, R. S., and Zeiss, C. (2001). "In Situ Moisture Content Measurement in MSW Landfill with TDR," Environmental Engineering Science, Mary Ann Liebert, Inc., 18(1), 53-66.

Ling, I., Leshchinsky, D., Yoshiyuki, M., and Toshinori, K. (1998). "Estimation of Municipal Solid Waste Landfill Settlement," Journal of Geotechnical and Geoenvironmental Engineering, 124(1), 21-28.

Liu, C. N., Chen, R. H., and Chen, K. S. (2006). "Unsaturated Consolidation Theory for the Prediction of Long-Term Municipal Solid Waste Landfill Settlement," Waste Management and Research, SAGE, 24, 80-91. 
Machado, S.L., Vilar, O. M., Carvalho, M. F. (2008). "Constitutive Model for Long Term Municipal Solid Waste Mechanical Behavior," Computers and Geotechnics, Elsevier, 35, 775-790.

Machado, S. L., Karmipour-Fard, M., Shariatmadari N., Carvalho M. F., and Nascimento, J. C. F. (2010). "Evaluation of the Geotechnical Properties of MSW in Two Brazilian Landfills," Waste Management, Elsevier, 30, 2579-2591.

Marcoux, M. A., Laiger, T., and Gourc, J.-P. (2007). "Monitoring of Leachate Recirculation in a Bioreactor Landfill: Comparison of Lysimeter and Resistivity Measurements," Proceedings of the 11th International Waste Management and Landfill Symposium, CISA, Environmental Sanitary Engineering Centre, Cagliari, Italy, 1-5.

Marques, A. C., Vilar, O. M., and Kaimoto, L. S. A. (2002). "Compaction of Urban Waste," Solos e Roches: Revista Brasileira de Geotecnia, 25(1), 37-50.

Marques, A. C., Filz, G. M., and Vilar, O. M. (2003). "Composite Compressibility Model for Municipal Solid Waste," Journal of Geotechnical and Geoenvironmental Engineering, ASCE, 129(4), 372-378.

Mata-Alvarez, J., and Martinez-Viturtia, A. (1986). "Laboratory Simulation of Municipal Solid Waste Fermentation with Leachate Recycle," Journal of Chemical Technology Biotechnology, Society of Chemical Industry, 36(12), 547556.

McDougall, J. (2007). "A Hydro-Bio-Mechanical Model for Settlement and Other Behaviour in Landfilled Waste," Computers and Geotechnics, Elsevier, 34(4), 229-246.

McDougall, J. R. and Pyrah, I. C., (2004). "Phase Relations for Decomposable Soils," Geotechnique, Institution of Civil Engineers, 54(7), 487-494.

Means, R. E., and Parcher, J. V. (1951). Physical Properties of Soils, Charles E. Merrill Books, Inc., Columbus, OH.

Mehta, R., Barlaz, M. A., Yazdani, R., Augenstein, D., Bryars, M., and Sinderson, L. (2002). "Refuse Decomposition in the Presence and Absence of Leachate Recirculation," Journal of Environmental Engineering, ASCE, 128(3), 228-236.

Mesri, G., Stark, T., Ajlouni, M, Chen, C. (1997). "Secondary Compression of Peat with or without Surcharging," Journal of Geotechnical and Geoenvironmental Engineering, ASCE, 123(4), 411-421. 
Millspaugh, A. M., Tinjum, J. M., and Boecher, T. A. (2010). "Specific Gravity of Expansive Chromium Ore Processing Residue with Complex Microstructure," Geotechnical Testing Journal, ASTM, 33(4), 322-328.

Mitchell, J., and Soga, K. (2005). Fundamentals of Soil Behavior, $3^{\text {rd }}$ Ed, John Wiley and Sons, Hoboken, NJ.

Morris, D. V, and Woods, C. E. (1990). "Settlement and Engineering Considerations in Landfill Final Cover Design." Geotechnics of Waste Fill Theory and Practice, ASTM STP 1070, American Society of Testing and Materials, Philadelphia, PA, 9-21.

Newmark, N. M. (1935). "Simplified Computation of Vertical Pressures in Elastic Foundations," University of Illinois Engineering Experiment Station Circular 24, Urbana, IL, 19.

Olivier, F., and Gourc, J.-P., (2007). "Hydro-Mechanical Behavior of Municipal Solid Waste Subject to Leachate Recirculation in a Large-Scale Compression Reactor Cell," Waste Management, Elsevier, 27, 44-58.

Olsen, H. (1962). "Hydraulic Flow through Saturated Clay," Proceedings of the Ninth National Conference on Clays and Clay Minerals, Pergamon Press, West Lafayette, IN, 131-161.

Orta de Velasquez, M. T., Rojas-Valencia, N., Monje-Ramirez, I., and SanchezGomez, J. (2003). "Determination of Field Capacity of Municipal Solid Waste Under Surcharge Simulation," Waste Management and Research, SAGE, 21, 137-144.

Oweis, I. S., (2006). "Estimating Landfill Settlements Due to Mechanical and Decomposition Processes," Journal of Geotechnical and Environmental Engineering, ASCE, 132(5), 644-650.

Oweis, I. S., and Khera, R. (1986). "Criteria for Geotechnical Construction on Sanitary Landfills," Proceedings of the International Symposium on Environmental Geotechnology, H.-Y. Fang, Ed., Allentown, PA, 205-223.

Oweis, I. S., and Khera, R., (1998). Geotechnology of Waste Management, PWS Publishing Co., New York, NY.

Park, H. I., and Lee, S. R. (1997). "Long-Term Settlement Behavior of Landfills with Refuse Decomposition," Journal of Solid Waste Technology and Management, Widener University School of Engineering, 20, 159-165. 
Park, H. I., Lee, S. R., and Do, N. Y. (2002). "Evaluation of Decomposition Effect on Long-Term Settlement Prediction for Fresh Municipal Solid Waste," Journal of Geotechnical and Geoenvironmental Engineering, ASCE, 128(2), 107-118.

Penmenthsa, K. K. (2007). Permeability of Municipal Solid Waste in Bioreactor Landfill with Degradation. M.S. Thesis, University of Texas at Arlington, Arlington, Texas.

Pohland, F. G., and Kim, J. C. (1999). "In Situ Anaerobic Treatment of Leachate in Landfill Bioreactors," Water Science and Technology, Elsevier, 40(8), 203-210.

Powrie W., and Beaven R. P., (1999). "Hydraulic Properties of Household Waste and Implications for Liquid Flow in Landfills," Proceedings of the Institution of Civil Engineers, Geotechnical Engineering, 137, 235-247.

Proctor, R. (1933). "Fundamental Principles of Soil Compaction," Engineering News Record, 111, 245-248.

Qian, X., Koerner, R. M., and Gray, D. H., (2002). Geotechnical Aspects of Landfill Design and Construction, Prentice-Hall, Inc., Upper Saddle River, New Jersey.

Rao, S., Moulton, L., and Seals, R. (1977). "Settlement of Refuse Landfills," Proceedings of the Conference on Geotechnical Practice for Disposal of Solid Waste Materials, ASCE, 574-598.

Reddy, K. R., Gangathulasi, J., Parakalla, N. S., Hettiarachichi, H., Bogner, J., and Lagier, T. (2009a). "Compressibility and Shear Strength of Municipal Solid Waste Under Short-term Leachate Recirculation Operations." Waste Management and Research, SAGE, 27(6), 578-587.

Reddy, K. R., Hettiarachchi, H., Parakalla, N. S., Gangathulasi, J., and Bogner, J. E. (2009b). "Geotechnical Properties of Fresh Municipal Solid Waste at Orchard Hills Landfill, USA," Waste Management, Elsevier, 29(2), 952-959.

Reddy, K. R., Hettiarachchi, H., Gangathulasi, J., Bogner, J. E., and Lagier, T. (2009c). "Geotechnical Properties of Synthetic Municipal Solid waste." International Journal of Geotechnical Engineering, Maney Publishing, 3(3), 429438.

Reddy, K. R., Hettiarachchi, H., Parakalla, N., Gangathulasi, J., Bogner, J., and Lagier, T., (2009d). "Hydraulic Conductivity of MSW in Landfills," Journal of Environmental Engineering, ASCE, 135(8), 677-683. 
Reddy, K. R., Hettiarachchi, H., Gangathulasi, J., and Bogner, J., 2011. "Geotechnical Properties of Municipal Solid Waste at Different Phases of Biodegradation," Waste Management, Elsevier, 31, 2275-2286.

Rees, J. F. (1980). "Optimisation of Methane Production and Refuse Decomposition in Landfills by Temperature Control," Journal of Chemical Technology and Biotechnology, Society of Chemical Industry, 30(8), 458-465.

Reinhart, D. R., and Townsend, T. G. (1998) Landfill Bioreactor Design and Operation, Lewis Publishers, Boca Raton, FL.

Reinhart, D. R., McCreanor, P. T., and Townsend, T. G. (2002). "The Bioreactor Landfill: Its Status and Future," Waste Management and Research, SAGE, 20, 172-186.

Rowe, R. K. (1998). "Geosynthetics and the Minimization of Contaminant Migration Through Barrier Systems Beneath Solid Waste," Proceedings of the 6th International Conference on Geosynthetics, Ed. R. K. Rowe, Vol. I, IFAI, Atlanta, GA, 27-102.

Salgado, R. (2006). The Engineering of Foundations, McGraw Hill, New York, NY.

Seed, H., and Chan, C. (1959). "Structure and Strength Characteristics of Compacted Clays," Journal of the Soil Mechanics and Foundations Division, ASCE, 85, SM5, 87-128.

Sethi, S., Kothiyal, N. C., and Nema, A. K. (2013). "Stabilisation of Municipal Solid Waste in Bioreactor Landfills- An Overview," International Journal of Environment and Pollution, ASCE, 51(1-2), 57-78.

Sharma, H. D., and De, A. (2007). "Municipal Solid Waste Landfill Settlement: Postclosure Perspectives," Journal of Geotechnical and Geoenvironmental Engineering, ASCE, 133(6), 619-625.

Shihada, H., Hossain, M. S., Kemler, V., and Dugger, D., (2013). "Estimating Moisture Content of Landfilled Municipal Solid Waste without Drilling: Innovative Approach," Journal of Hazardous, Toxic, and Radioactive Waste, ASCE, 17(4), 317-330.

Singh, S., and Murphy, B. (1990). "Evaluation of the Stability of Sanitary Landfills," Geotechnics of Waste Fills - Theory and Practice," ASTM STP 1070, American Society for Testing and Materials, Philadelphia, PA, 240-258. 
Sowers, G. F. (1973). "Settlement of Waste Disposal Fills." Proceedings of the 8th International Conference on Soil Mechanics and Foundation Engineering, Moscow, Russia, 207-210.

Staub, M. J., Galietti, B., Oxarango, L., Khire, M. V., and Gourc, J.-P. (2009). "Porosity and Hydraulic Conductivity of MSW Using Laboratory Scale Tests," Proceedings of the 3rd International Workshop - Hydro-physico-mechanics of Landfills, Braunschweig, Germany.

Staub, M. J., Laurent, J.-P., Gourc, J.-P., and Morra, C. (2010a). "Applicability of Time Domain Reflectometry Water Content Measurements in Municipal Solid Waste," Vadose Zone Journal, SSSA, 9(1), 160-171.

Staub, M. J., Gourc, J.-P., Laurent, J.-P., Kintzuger, C., Oxarango, L., Benbelkacem, H., Bayard, R., and Morra, C. (2010b). "Long-term Moisture Measurements in Large-Scale Bioreactor Cells Using TDR and Neutron Probes," Journal of Hazardous Materials, Elsevier, 180, 165-172.

Stoltz, G., Gourc, J.-P., and Oxarango, L. (2010). "Characterisation of the Physico-Mechanical Parameters of MSW," Waste Management, Elsevier, 30(89), 1439-1449.

Stoltz, G., Tinet, A. J., Staub, M. J., Oxarango, L., and Gourc, J. P. (2012). "Moisture Retention Properties of Municipal Solid Waste in Relation to Compression," Journal of Geotechnical and Geoenvironmental Engineering, ASCE, 138(4), 535-543.

Surprenant, G. and Lemke, J. (1994). "Landfill Compaction: Setting a Density Standard," Waste Age, 25(8), 42-52.

Swati, M., Joseph, K. (2008). "Settlement Analysis of Fresh and Partially Stabilised Municipal Solid Waste in Simulated Controlled Dumps and Bioreactor Landfills," Waste Management, Elsevier, 138(8), 1355-1363.

SWT Engineering (2012a). Waste Capacity Utilization For the Santa Maria Regional Landfill.

Tamari, S., Samaniego-Martinez, D., Bonola, I., Bandala, E. R., and OrdazChaparro, V., (2005). "Particle Density of Volcanic Scoria Determined by Water Pycnometry," Geotechnical Testing Journal, ASTM, 28(4), 321-327.

Tchobanoglous, G., and Kreith, F. (2002). Handbook of Solid Waste Management, 2nd Ed., McGraw-Hill, New York, NY. 
Tchobanoglous, G., Theisen, H., and Vigil, S. (1993). Integrated Solid Waste Management: Engineering Principles and Management Issues, McGraw-Hill, New York.

Terzaghi, K., and Peck, R. (1948). Soil Mechanics in Engineering Practice, John Wiley and Sons, New York, NY.

Tinjum, J. M., Benson, C. H., and Edil, T. B., (2008). "Mobilization of $\mathrm{Cr}(\mathrm{VI})$ from Chromite Ore Processing Residue Through Acid Treatment," Science of the Total Environment, Elsevier, 391, 13-25.

USEPA. (2004). "Survey of Technologies for Monitoring Containment Liners and Covers." EPA 542-R-04-013.

USEPA. (2005). "Introduction to Municipal Solid Waste Disposal Facility Criteria." EPA530-K-05-015.

USEPA. (2010). "Municipal Solid Waste Generation, Recycling, and Disposal in the United States: Facts and Figures for 2009: Full Report," EPA530-R-10-012.

USEPA. (2013a). "Municipal Solid Waste Generation, Recycling, and Disposal in the United States: Facts and Figures for 2011: Full Report," EPA530-R-13-001.

USEPA. (2013b). "Title 40: Protection of Environment." <http://www.ecfr.gov/cgibin/textidx?SID=7124bdb5bb05721f4a88ec9e5b1cf417\&tpl=/ecfrbrowse/Title40/ 40tab_02.tpl> (August 24, 2013).

USEPA. (2013c). "Landfill Methane Outreach Program."

<http://www.epa.gov/lmop/index.htm> (November 12,2013).

USEPA. (2013d). "Closure and Post-Closure Care Requirements for Municipal Solid Waste Landfills." <http://www.epa.gov/epaoswer/non-

hw/muncpl/landfill/financial/mswclose.htm> (November 12, 2013).

US Navy (1986). "Soil Mechanics, Foundations, and Earth Structures," NAVFAC Design Manual DM-7.2, Washington, D.C.

Veihmeyer, F. J., and Hendrickson, A. H. (1931). "The Moisture Equivalent as a Measure of the Field Capacity of Soils." Soil Science, LWW, 32(3), 181-194.

Vilar, O. M., Carvalho, M. F. (2004). "Mechanical Properties of Municipal Solid Waste," Journal of Testing and Evaluation, ASCE, 32(6), 438-449.

Von Stockhausen, S. (2007). Optimization of Waste Compaction Practices for Landfills, M.S. Thesis, California Polytechnic State University, San Luis Obispo, San Luis Obispo, CA. 
Wall, D. K., Zeiss, C. (1995). "Municipal Landfill Biodegradation and Settlement," Journal of Environmental Engineering, ASCE, 121(3), 214-224.

Wang, Y., Pelkonen, M., and Kaila, J. (2012). "Effects of Temperature on the Long-Term Behaviour of Waste Degradation, Emissions and Post-Closure Management Based on Landfill Simulators," The Open Waste Management Journal, Bentham, 5, 19-27.

Warith, M., Li, X., and Jin, H. (2005). "Bioreactor Landfills: State-of-the-Art Review," Emirates Journal for Engineering Research, UAEU, 10(1), 1-14.

Wesley, L. D., 2001. "Determination of Specific Gravity and Void Ratio of Pumice Materials," Geotechnical Testing Journal, ASTM, 24(4), 418-422.

Wong, W. W., 2009. Investigation of Geotechnical Properties of Municipal Solid Waste, M.S. Thesis, California Polytechnic State University, San Luis Obispo, California.

Wu, H., Wang, H., Zhao, Y., Chen, T., and Lu, W. (2012). "Evolution of Unsaturated Hydraulic Properties of Municipal Solid Waste with Landfill Depth and Age," Waste Management, Elsevier, 32(3), 463-470.

Yen, B. C., and Scanlon, B. (1975). "Sanitary Landfill Settlement Rates," Journal of Geotechnical Engineering Division, ASCE, 101(5), 475-487.

Yesiller, N., Hanson, J. L., and Liu, W.-L. (2005). "Heat Generation in Municipal Solid Waste Landfills," Journal of Geotechnical and Geoenvironmental Engineering, ASCE, 131(11), 1330-1344.

Yesiller, N., Hanson, J. L., and Yoshida, H. (2011). "Landfill Temperatures Under Variable Decomposition Conditions," Proceeding of Geo-Frontiers 2011: Advances in Geotechnical Engineering, Han, J., and Alzamora, D. A., Eds., ASCE, Dallas, TX, 1055-1065.

Yesiller, N., Hanson, J. L., Cox, J. T., and Noce, D., (2013).

Zhao, Y., Yang, C., and Lui, L. (2012). "Experimental Study on the Effect of Organic Content on the Compression Properties of Municipal Solid Waste," The Electronic Journal of Geotechnical Engineers, W3G, 17, 2335-2342.

Zekkos, D., Bray, J. D., Kavazanjian, E., Matasovic, N., Rathje, E., Riemer, M., and Stokoe, K. H. (2005). "Framework for the Estimation of MSW Unit Weight Profile," Proceedings of 10th International Waste Management and Landfill Symposium, CISA, Environmental Sanitary Engineering Centre, Cagliari, Italy. 
Zekkos, D., Bray, J. D., Kavazanjian, E., Matasovic, N., Rathje, E. M., Riemer, M. F., and Stokoe, K. H. (2006). "Unit Weight of Municipal Solid Waste," Journal of Geotechnical and Geoenvironmental Engineering, ASCE, 132(10), 1250-1261.

Zekkos, D. M., Kavazanjian, E., Jr., Bray, J. D., Matasovic, N., and Riemer, M. F. (2010). "Physical Characterization of Municipal Solid Waste for Geotechnical Purposes," Journal of Geotechnical and Geoenvironmental Engineering, ASCE, 136(9), 1231-1241.

Zhang, B., Dixon, N., and El-Hamalawi, A. (2010). "Development and Evaluation of a Phase Relationship for MSW," Waste and Resource Management, Institution of Civil Engineers, 163(WR2), 67-75.

Zornberg, J. G., Jernigan, B. L., Sanglerat, T. R., and Cooley, B. H. (1999). "Retention of Free Liquids in Landfills Undergoing Vertical Expansion," Journal of Geotechnical and Geoenvironmental Engineering, ASCE, 125(7), 583-594. 


\section{Appendix}

\section{Unit Conversions}

\begin{tabular}{|c|c|}
\hline U.S./Imperial & Metric \\
\hline 1 inch (in) & 25.40 millimeters $(\mathrm{mm})$ \\
\hline $1 \mathrm{foot}(\mathrm{ft})$ & 0.3048 meter $(\mathrm{m})$ \\
\hline 1 mile $(\mathrm{mi})$ & 1.6093 kilometer $(\mathrm{km})$ \\
\hline $1 \mathrm{ft}^{2}$ & $0.0929 \mathrm{~m}^{2}$ \\
\hline $1 \mathrm{acre}$ & $4046.9 \mathrm{~m}^{2}$ \\
\hline $1 \mathrm{acre}$ & $0.40469 \mathrm{hectare}^{2}$ \\
\hline $1 \mathrm{mi}^{2}$ & $2.59 \mathrm{~km}^{2}$ \\
\hline $1 \mathrm{in}^{3}$ & $16,387.1 \mathrm{~mm}^{3}$ \\
\hline $1 \mathrm{ft}^{3}$ & $0.02832 \mathrm{~m}^{3}$ \\
\hline $1 \mathrm{gallon}$ & 3.7854 liters $(\mathrm{L})$ \\
\hline 1 pound $(\mathrm{lb})$ & $0.4536 \mathrm{~kg}$ \\
\hline $1 \mathrm{U} . \mathrm{S}$. ton & $8.89 \mathrm{kN}$ \\
\hline $1 \mathrm{lb} / \mathrm{ft}^{2}$ & $0.04788 \mathrm{kPa}$ \\
\hline $1 \mathrm{lb} / \mathrm{ft}^{3}$ & $0.1571 \mathrm{kN} / \mathrm{m}^{3}$ \\
\hline
\end{tabular}

